INSTITUTO DE PESQUISAS ENERGÉTICAS E NUCLEARES Autarquia associada à Universidade de São Paulo

\title{
DESENVOLVIMENTO DE UM COMBUSTÍVEL DE ALTA DENSIDADE À BASE DA LIGA URÂNIO-MOLIBDÊNIO COM ALTA COMPATIBILIDADE EM ALTAS TEMPERATURAS
}

\section{FÁBIO BRANCO VAZ DE OLIVEIRA}

Tese apresentada como parte dos requisitos para a obtenção do Grau de Doutor em Ciências na Área de Tecnologia Nuclear - Materiais.

Orientador:

Dr. Ing. Humberto Gracher Riella

SÃO PAULO 
Aos meus pais, Ana Maria e Darlove.

Ás minhas filhas, Daniela (Nani) e Deborah (Dépulah). 


\section{AGRADECIMENTOS}

Ao Dr. Ing. Humberto Gracher Riella, por mais uma vez me dar a oportunidade de contar com a sua valiosa orientação. Só tenho a lhe agradecer por todo o apoio, serenidade e demonstração de confiança que depositou em mim durante todos estes anos de convívio.

À Agência Internacional de Energia Atômica - AIEA, pelo fornecimento de condições para a compra de equipamentos, realização de treinamento externo e participação em eventos, sempre ligados aos combustíveis de alta densidade. $O$ projeto de pesquisa Brasil / AIEA número BRA/4/053 foi essencial para a realização desta tese, para aumento de experiência pessoal e do Centro do Combustível Nuclear na área de combustíveis nucleares de alta densidade $\gamma$ UMo.

Ao IPEN-CNEN/SP, por fornecer a infraestrutura necessária à realização desta tese.

Aos doutores Elita Fontenelle Urano de Carvalho, Luis Filipe C. P. de Lima, Sônia Regina H. M. Castanho, por se tornarem conselheiros e facilitadores neste meu caminho.

Ao pessoal do Laboratório de Materiais Magnéticos LMM do IPEN-CNEN / SP, por proporcionarem a realização de boa parte dos experimentos desta tese.

Aos amigos do Centro do Combustível Nuclear, pelo apoio na realização da parte experimental deste trabalho, em especial ao grupo do Urânio Metálico, Ilson Carlos Martins, José Vicente Pereira e Enéas Tavares de Oliveira.

Aos analistas e técnicos do IPEN-CNEN/SP, por caracterizarem as minhas amostras, mesmo em período de greve, e ao pessoal da pós-graduação, pela presteza na resolução de problemas que surgiram ao longo do período de realização desta tese. 
Aos meus pais Ana Maria e Darlove, minha irmã Cláudia e minhas filhas Daniela e Deborah, por todo o apoio demonstrado num momento muito difícil de minha vida pessoal.

Enfim, a todos aqueles que estiveram ao meu lado durante todo este período, os meus mais sinceros agradecimentos. 


\title{
DESENVOLVIMENTO DE UM COMBUSTÍVEL DE ALTA DENSIDADE À BASE DA LIGAS URÂNIO-MOLIBDÊNIO COM ALTA COMPATIBILIDADE EM ALTAS TEMPERATURAS
}

\author{
FÁBIO BRANCO VAZ DE OLIVEIRA
}

\begin{abstract}
RESUMO
Este trabalho tem como objetivo o desenvolvimento de um combustível nuclear de alta densidade e baixo enriquecimento com base na liga $\gamma$-UMo, para aplicações nas quais seja necessário desempenho satisfatório a altas temperaturas, considerando-se a sua utilização na forma de dispersão.

Para tanto, partiu-se da análise dos resultados dos testes RERTR (sigla em inglês para "Reduced Enrichment of Research and Test Reactors") e de alguns trabalhos teóricos envolvendo a elaboração de ligas metaestáveis de $\gamma$-urânio. Uma adição ternária é proposta, com base em propriedades de ligas binárias e ternárias de urânio-molibdênio estudadas, e que teve como objetivos um aumento na estabilidade da fase gama do urânio e a facilidade na obtenção dos pós.

Assim, as ligas de urânio-molibdênio foram preparadas com adições de Mo de 5 a $10 \%$ em peso, e adição de 1 e $3 \%$ de elemento ternário (o silício), sobre uma liga base binária de U7Mo. Em todas as fases do processo de preparação, as ligas foram caracterizadas pelas técnicas tradicionais, para determinação de suas propriedades estruturais e mecânicas. Para a elaboração de um processo para a obtenção de pós destas ligas, o seu comportamento sob atmosfera de hidrogênio foi estudado em equipamento de análise térmica e gravimétrica diferencial. Temperaturas variaram da ambiente a $1000^{\circ} \mathrm{C}$, por tempos de 15 minutos a 16 horas. A validação destes resultados foi feita em escala semi-piloto, na qual quantidades de 10 a $50 \mathrm{~g}$ de pós de algumas das ligas foram preparados, sob atmosfera estática de hidrogênio. Os estudos de compatibilidade foram conduzidos expondo-se as ligas à atmosfera de oxigênio e ao contato com alumínio, para a verificação de possíveis reações por meio de análise térmica diferencial. As ligas foram submetidas a aquecimento constante até temperatura de $1000^{\circ} \mathrm{C}$, e seu desempenho foi avaliado quanto a maior resistência à reação.
\end{abstract}


Com base nestes resultados, observou-se que as adições ternárias aumentam as temperaturas para a oxidação das ligas e reação com alumínio frente aos binários $\gamma$ UMo. Um conjunto de condições para hidretação das ligas e fabricação dos pós foi estabelecido, tanto mais restritivos em termos de tempo, temperatura e necessidade de pré-tratamentos quanto mais estável a estrutura $\gamma$. Com a adição de ternário em pequeno excesso e formação de fase intergranular, mostrou-se que um aumento na estabilidade não prejudica a formação dos pós. 


\title{
DEVELOPMENT OF A HIGH DENSITY FUEL BASED ON URANIUM-MOLIBDENUM ALLOYS WITH HIGH COMPATIBILITY IN HIGH TEMPERATURES
}

\author{
FÁBIO BRANCO VAZ DE OLIVEIRA
}

\begin{abstract}
This work has as its objective the development of a high density and low enriched nuclear fuel based on the $\gamma$-UMo alloys, for utilization where it is necessary satisfactory behavior in high temperatures, considering its utilization as dispersion.

For its accomplishment, it was started from the analysis of the RERTR ("Reduced Enrichment for Research and Test Reactors") results and some theoretical works involving the fabrication of $\gamma$-uranium metastable alloys. A ternary addition is proposed, supported by the properties of binary and ternary uranium alloys studied, having the objectives of the gamma stability enhancement and an ease to its powder fabrication.

Alloys of uranium-molybdenum were prepared with 5 to $10 \%$ Mo addition, and 1 and $3 \%$ of ternary, over a $\gamma \mathrm{U} 7 \mathrm{Mo}$ binary base alloy. In all the steps of its preparation, the alloys were characterized with the traditional techniques, to the determination of its mechanical and structural properties. To provide a process for the alloys powder obtention, its behavior under hydrogen atmosphere were studied, in thermoanalyserthermogravimeter equipment. Temperatures varied from the ambient up to $1000^{\circ} \mathrm{C}$, and times from 15 minutes to 16 hours. The results validation were made in a semi-pilot scale, where 10 to $50 \mathrm{~g}$ of powders of some of the alloys studied were prepared, under static hydrogen atmosphere. Compatibility studies were conducted by the exposure of the alloys under oxygen and aluminum, to the verification of possible reactions by means of differential thermal analysis. The alloys were exposed to a constant heat up to $1000^{\circ} \mathrm{C}$, and their performances were evaluated in terms of their reaction resistance.

On the basis of the results, it was observed that ternary additions increases the temperatures of the reaction with aluminum and oxydation, in comparision with the $\gamma \mathrm{UMo}$ binaries. A set of conditions to the hydration of the alloys were defined, more restrictive in terms of temperature, time and pre-treatment to stabilize the gamma structure. The addition
\end{abstract}


of a bit low ternary excess and formation of an intergranular phase, the increase in stability, it was demonstrated that there is not a damage in the formation of their powders. 


\section{SUMÁRIO}

Página

JUSTIFICATIVAS, OBJETIVOS E PLANO GERAL DA TESE Xxi

Primeira Parte - ESTABILIZAÇÃO DA FASE $\gamma$-URÂNIO 01

1. ESTADO DA ARTE E MOTIVAÇÕES 02

1.1 Breve situação do problema $\quad 02$

1.2 Considerações sobre a tecnologia de fabricação $\quad 02$

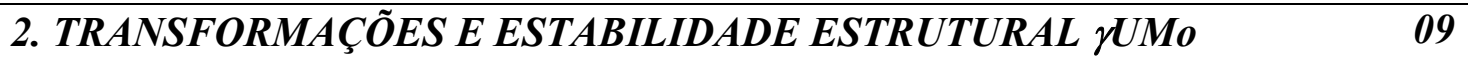

2.1 Estabilidade e fabricação 09

2.2 Estabilidade da fase y em sistemas binários UMo 10

3. REAÇÕES E COMPORTAMENTO SOB IRRADIAÇÃO 26

3.1 Problemas de compatibilidade 26

3.2 Estudos de adições ao combustivel e a matriz de alumínio 29

3.3 Qualificação e desempenho sob irradiação $\mathbf{3 6}$

3.4. Simulação de propriedades dos combustíveis UMo sob irradiação

4. PROCESSOS DE FABRICAÇÃO

4.1 Desempenho sob irradiação x técnicas de fabricação 54

4.2 Processos tradicionais para a fabricação de pós $\gamma U M o$

4.3 O processo HMDH 59

Segunda Parte - DESENVOLVIMENTO EXPERIMENTAL 61

5. PROCEDIMENTOS DE FUSÃO E TRATAMENTOS TÉRMICOS 62

5.1 Preparo das ligas binárias UMo via fusão a arco

5.2 Preparo das ligas binárias UMo via fusão por indução $\quad \mathbf{6 8}$

\begin{tabular}{ll}
\hline 5.3 Tratamentos térmicos & $\mathbf{7 3}$
\end{tabular}

6. ENSAIOS DE HIDROGENAÇÃO E COMPATIBILIDADE

6.1 Procedimento experimental / ensaios de hidrogenação 79

6.1 .1 ensaios do primeiro ciclo

\begin{tabular}{lc}
\hline 6.1 .2 ensaios do segundo ciclo & 87
\end{tabular}

6.1 .3 ensaios do terceiro ciclo 90 
6.2 Procedimento experimental / ensaios de compatibilidade

$\begin{array}{lc}6.2 .1 \text { ensaios de oxidação } & 97\end{array}$

6.2.2 ensaios de compatibilidade combustivel matriz $\mathbf{9 8}$

6.3 Procedimento experimental / hidrogenação em escala semi-piloto 99

Terceira Parte - DESENVOLVIMENTO TEÓRICO 101

7. TEORIA DA NUCLEAÇÃO DA FASE $\alpha U$ A PARTIR DA FASE $\gamma U$

7.1 Evidências experimentais 102

$\begin{array}{ll}7.2 \text { Teoria simplificada } & 104\end{array}$

7.3 Comentários finais 111

8. INTERAÇÃO HIDROGÊENIO-URÂAIO 114

8.1 Termodinâmica e cinética da interação $H-U \quad 114$

8.2 Transporte do hidrogênio para a matriz de $\gamma$ Uo 122

8.3 Solubilidade do hidrogênio em urânio 122

$\begin{array}{lr}8.4 \text { Dehidretação e histerese } & \mathbf{1 2 5}\end{array}$

8.5 Difusão do H através da matriz e do hidreto 126

8.6 Efeitos do H nas propriedades mecânicas do urânio gama 126

9 FORMULAÇÃO DO PROBLEMA

\begin{tabular}{lr}
\hline 9.1 Fenomenologia & 129
\end{tabular}

9.2 Enunciado do problema e modelos 134

Quarta Parte - RESULTADOS E DISCUSSÕES 137

10. SÍNTESE E CARACTERIZAÇÃO 138

$\begin{array}{ll}\text { 10.1 Ligas produzidas por fusão a arco } & 138\end{array}$

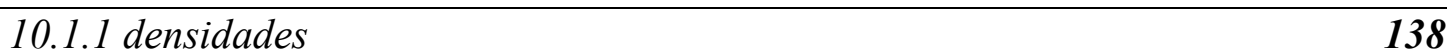

$\begin{array}{lc}10.1 .2 \text { caracterização microestrutural } & 144\end{array}$

10.2 Ligas produzidas por fusão via indução 173

$\begin{array}{ll}10.2 .1 \text { densidades } & 173\end{array}$

10.2.2 caracterização microestrutural 174

10.2.3 difração de raios- $X \quad 192$

10.3 Microdureza Vickers 196

10.3 Comparação arco x indução 200

11. INFLU ÊECIA DO OXIGÊNIO NA ESTABILIDADE DAS LIGAS 206

11.1 Comportamento frente ao oxigênio 206 
11.2 Análise 215

12. ESTABILIDADE DAS LIGAS FRENTE AO ALUMÍNIO 223

12.1 Comportamento frente ao alumínio 223

12.2. Análise 226

13 HIDROGENAÇÃO E EQUILÍBRIO $\gamma \rightarrow \alpha$

13.1. Hidretação fase alfa- $U \quad \mathbf{2 3 6}$

\begin{tabular}{ll}
\hline 13.2. Tratamento de sensibilização & $\mathbf{2 3 9}$
\end{tabular}

13.3 Evidências da relação entre hidrogenação e decomposição $\gamma \rightarrow \alpha \quad 250$

\begin{tabular}{|c|c|}
\hline 13.3.1 ensaios do primeiro ciclo & 250 \\
\hline 13.3.2 choque térmico e equilibrio em ligas $\gamma U 8 M o$ & 261 \\
\hline 13.4 Características dos pós & 268 \\
\hline 13.4.1 ligas $\gamma U 5 M o$ e $\gamma U 6 M o$ & 268 \\
\hline 13.4.2 ligas $\gamma U 7 M o$ & 269 \\
\hline 13.4.3 ligas $\gamma U 8 M o$ & 270 \\
\hline 13.4.4 ligas $\gamma U 9 M o$ e $\gamma U 10 M o$ & 271 \\
\hline 13.5 Processo sugerido para obtenção de pós via HDH & 272 \\
\hline 13.6 Validação & 276 \\
\hline 13.7 Modelagem matemática & 279 \\
\hline CONCLUSÕES & 289 \\
\hline REFERÊ NCIAS BIBLIOGRÁFICAS & 296 \\
\hline
\end{tabular}




\section{ÍNDICE DE TABELAS}

Tabela

pág.

$01 \quad$ Valores de densidade de algumas ligas de gama-urânio.

06

02 Ciclos de potência, experimentos de fusão por indução, cargas 01 a 04.69

03 Ciclos de potência, experimentos de fusão por indução, cargas 05 a 08.69

04 Ciclos de potência, experimentos de fusão por indução, cargas 09 e 10.69

05 Parâmetros de interesse na seleção de elementos estabilizadores de $\gamma$ - 110 $U$.

06 Solubilidade máxima antes da formação do hidreto.

07 Solubilidade máxima antes da formação do hidreto, metalografia. $\quad 124$

08 Valores de densidade hidrostática determinadas, ligas $\gamma U M o$, forno a 139 arco.

$09 \quad$ Valores calculados de densidade de algumas ligas UMo, base alfa-U. $\quad 140$

10 Microdureza Vickers, ligas brutas de fusão, indução. 196

11 Microdureza Vickers, ligas de indução, tratadas termicamente, $1038^{\circ} \mathrm{C}, 196$ 24 horas.

12 Microdureza Vickers, ligas de indução, tratadas termicamente, $1038^{\circ} \mathrm{C}, 197$ 48 horas.

13 Microdureza Vickers, ligas de indução e ternárias tratadas 197 termicamente, $900^{\circ} \mathrm{C} / 6$ horas $(C)$ e $920^{\circ} \mathrm{C} / 3$ horas (D).

14 Microdureza Vickers, ligas brutas de fusão, arco.

15 Microdureza Vickers, ligas de arco, tratadas termicamente, $1038^{\circ} \mathrm{C}, 48197$ horas.

16 Valores de ganho de massa, ligas-base e ternária.

17 Resultados de temperatura de oxidação, ligas-base e ternária, indução.

18 Eventos principais nas curvas de análise térmica diferencial.

19 Temperaturas $\left({ }^{\circ} \mathrm{C}\right)$ associadas aos eventos da Tabela 18. 
(cont.)

pág.

20 Fluxos de calor $(\mu V)$ asssociados aos eventos da Tabela 18.

21 Resultados de Integração (mV.s).

22 Resultados de Integração ( $m V . s)$, normalizados ( $\mathrm{mV} . \mathrm{s} / \mathrm{g})$.

23 Resultados de Integração (mV.s), normalizados ( $m V . s / g)$.

24 Tratamentos Isotérmicos de Ligas $\gamma$-U8Mo e Respectivos Rendimentos.

25 Dados Térmicos a Partir das Curvas de Resfriamento.

26 Dados de Absorção de Hidrogênio, Isotermas.

27 Parâmetros de rede médios das ligas $\gamma U_{x}$ Mo e estimativas de cs.

28 Coeficientes da equação de correlação de segundo grau $Y=A+B . H V$ $+C$. $H V^{2}$, tensão de ruptura Y e dureza $H V$, segundo Waldron et al..

29 Tensões de ruptura e elongação na ruptura, ligas de indução, brutas de fusão.

30 Tensões de ruptura e elongação na ruptura, ligas de indução, tratadas termicamente: $1038^{\circ} \mathrm{C}, 24$ horas (binários). Liga C conforme cap. 10.

31 Parâmetros das curvas de resfriamento, liga $\gamma U 8 M o$, liberação até 287 mudança.

32 Parâmetros das curvas de resfriamento, liga $\gamma U 8 M o$, após mudança. 


\section{ÍNDICE DE FIGURAS}

Figura

pág.

no $n^{o}$ Diagrama de fases $U-M^{4}$.

07

$02 \quad$ Diagrama de fases $U-N b^{4}$. 07

03 Forno a arco. Em vermelho a unidade de tensão, contornado em azul o 67 painel de controle de gases, acima do qual está situada a câmara de fusão. A chamada tocha aparece como um prolongamento da câmara.

04 Carga e geometria de carregamento, experimentos de fusão via 71 indução.

05 Forno de indução, centro: câmara de fusão, à esquerda: painel de controle de potência, à direita: painel de controle de válvulas de vácuo e de introdução de gases.

06 Estados da carga em cada um dos patamares de potência, a) 35\%, b) $55 \%$, c) $75 \%$ e d) $90 \%$.

07 Esquerda: visualização dos dados coletados em um experimento TG, 76 direita: unidade de controle de gases e balança.

08 Vista do cabeçote com os sensores da balança.

09 Diagrama TTT para a decomposição detectável dada

pela reação $\gamma \rightarrow \alpha$, em ligas $U-M o^{14}$.

10 Efeito da adição de $\mathrm{Pt}^{14}$.

11 Tempo de nucleação para a decomposição metaestável $\gamma$ em função do calor de mistura para ligas de U-Mo ${ }^{14}$.

12 Entalpia de mistura de metais de transição em $\gamma-U$ (esquerda), e o efeito de alguns metais de transição sobre os tempos de decomposição ti em U16\%at.Mo (direita) ${ }^{14}$.

13 Densidades em função da \% em peso de Mo, base alfa- $U^{03}$

14 Densidades em função da \% em peso de Mo, ligas de fusão a arco.

15 Densidades, carga de Mo em tabletes.

16 Densidades, 8\% Mo, cargas variadas.

17 Densidades, amostras sem refusão.

18 Densidades, amostras refundidas. 
(cont.)

pág.

19 Espectro de difração de raios-X, amostra UA1.

20 Espectro de difração de raios-X, amostra UA6.

148

21 Micrografias, liga UA6, esquerda (400X), direita (800X). 148

22 Espectro de difração de raios-X, amostra UA9. 150

23 Micrografias, liga UA9 400X (esquerda) e 800X (direita). 150

24 Micrografias, liga UA8 (400X), esquerda: bruta de fusão, direita: 151 tratada termicamente $(100 X)$.

25 Espectro de difração, amostra UA8.

26 Espectro de difração de raios-X, amostra U7Mo2R.

27 Amostra U7Mo2R, superior esquerda: borda (800X), superior direita: entre borda e centro (800X), inferior esquerda: centro (800X), inferior direita: topo (400X).

28 Espectro de difração de raios-X, amostra UA10.

29 Estrutura típica de fases dendríticas do composto $\mathrm{U}_{3} \mathrm{Si}_{2}(200 X)$.

30 Micrografias da liga UA10, esquerda: bruta de fusão (400X), direita: 157 tratada termicamente $(800 X)$.

31 Micrografias da liga UMo3A, esquerda: detalhes dos grãos (400X), 158 direita (200X).

32 Espectro de difração de raios-X, amostra UMo3A.

33 Espectro de difração de raios-X, amostra UMo4.

34 Espectro de difração de raios- $X$, liga UA5.

35 Regiões distintas da liga UA5, aumento (200X), borda (esquerda) e centro (direita).

36 Espectro de difração de raios-X, liga UA3.

37 Micrografia liga U6Mo (200X).

38 Micrografia com detalhe, solidificação eutetóide, liga U6Mo (800X).

39 Detalhe das dendritas e início de formação de contornos de grão, liga U6Mo (800X).

40 Detalhe das dendritas da liga U6Mo (1200X).

41 Espectro de difração de raios-X, liga U10Mo, bruta de fusão. 167

42 Espectro de difração de raios-X, liga U10Mo, tratada termicamente. 168

43 Micrografia de liga bruta de fusão, microscópio óptico com analisador 168 de imagens (400X). 
44 Micrografia da liga tratada termicamente, microscópio óptico com 169 analisador de imagens (1200X).

$45 \quad$ Imagem de varredura de superficie da liga U10Mo (600X).

46 Mesma imagem, por elétrons retro-espalhados (600X). 170

47 Delineamento dos grãos por poros, liga U10Mo, micrografia anterior. 170

48 Análise de imagens realizada sobre superficie da amostra U10Mo. 171

49 Resultados de área de superfície por fase, Figura 48.

50 Densidades das ligas produzidas por indução. 173

51 Micrografia de liga U5Mo, 200X, bruta de fusão. 174

52 Micrografia de liga $\gamma\left(\mathrm{SMo}, 200 X\right.$, tratada termicamente, $1038^{\circ} \mathrm{C} / 24 \quad 175$ horas.

53 Micrografia liga $\gamma$ U5Mo, 200X, tratada termicamente, 72 horas, 175 $1000^{\circ} \mathrm{C}$.

54 Micrografia da liga $\gamma U 6 M o, 400 X$, bruta de fusão. 176

55 Micrografia da liga $\gamma U 6 M o, 200 X$, tratada termicamente, $1038^{\circ} \mathrm{C} / 24 \quad 177$ horas.

56 Micrografia da liga $\gamma U 7 M o, 200 X$, bruta de fusão.

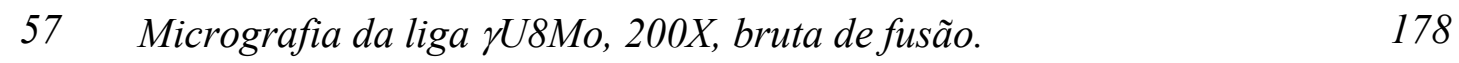

58 Micrografia da liga $\gamma U 8 M o, 200 X$, tratada termicamente, $1038^{\circ} \mathrm{C} / 24179$ horas.

59 Micrografia da liga $\gamma U 9 M o, 200 X$, bruta de fusão.

60 Micrografia da liga $\gamma U 9 M o, 200 X$, tratada termicamente, $1038^{\circ} \mathrm{C} / 72180$ horas.

61 Micrografia liga U10Mo, 200X, bruta de fusão.

62 Micrografia da liga $\gamma 10 M o, 200 X$, tratada termicamente, $1000^{\circ} \mathrm{C}, 48$ horas.

63 Liga ternária código UMo11, (200X), centro da amostra, bruta de fusão.

64 Liga ternária código UMo11, (200X), borda, bruta de fusão.

65 Liga ternária UMo11, bruta de fusão, esquerda 700X, direita 200X. 184

66 EDS, liga ternária UMo11, bruta de fusão, concentrações na região 01184 da amostra. 
(cont.)

pág.

67 EDS, liga ternária UMo11, bruta de fusão, concentrações nas regiões 185 02 a 04 da amostra.

68 EDS, liga ternária UMo11, bruta de fusão, concentrações na região 05186 da amostra.

69 Liga ternária UMo11, $900^{\circ} \mathrm{C} / 8$ horas, esquerda $700 X$, direita $250 X$.

70 EDS, liga ternária UMo11, 900 C / 8horas, concentrações na região 01186 da amostra.

71 EDS, liga ternária UMo11, 900 C / 8 horas, regiões 02 a 04 da 187 amostra.

72 Liga ternária UMo11, $950^{\circ} \mathrm{C} / 8$ horas, esquerda $700 X$, direita $250 X$.

$73 E D S$, liga ternária UMo11, 950 C / 8 horas, concentrações nas regiões 188 01 e 02 da amostra.

74 EDS, liga ternária UMo11, 950 C / 8 horas, concentrações nas regiões 189 03 e 05 da amostra.

75 Liga ternária UMo12, bruta de fusão, esquerda 700X, direita $250 X$.

76 EDS, liga ternária UMo12, bruta de fusão, concentrações nas regiões 01 e 02 da amostra

77 EDS, liga ternária UMo12, bruta de fusão, concentrações nas regiões 03 e 04 da amostra.

78 Difratograma de raios- $X$, liga base U5Mo.

79 Difratograma de raios- $X$, liga base U6Mo.

80 Difratograma de raios-X, liga base $\gamma$ U7Mo bruta de fusão (esquerda) $e$ após tratamento térmico (direita).

81 Difratograma de raios-X, liga base $\chi U 8 M o$ bruta de fusão (esquerda) e após tratamento térmico (direita).

82 Difratograma de raios- $X$, liga base U9Mo.

83 Difratograma de raios- $X$, liga base $\chi 10 M o$.

84 Difratograma de raios-X, liga base $Z M M o 11$.

85 Microdureza Vickers, ligas de indução.

86 Microdureza Vickers, ligas produzidas via de arco.

87 Microdureza Vickers, tratamento a $1038^{\circ}$ C, ligas $\gamma U 6 M o$ e $\gamma U 10 M o, 199$ ligas produzidas via forno de indução.

88 Densidades de UMo em função da porcentagem de soluto. 
(cont.)

pág.

89 Imagem de MEV e espectro de difração de raios-X de uma liga $\gamma$-U8Mo 203 alloy, fundida via indução.

90 Imagem de MEV e espectro de difração de raios-X de liga $\gamma-U 8 M o$, fundida via arco, tratada termicamente, mesma composição que a amostra de indução.

91 Comparação entre as adsorções de hidrogênio entre as amostras de arco e indução, mesmas condições de análise.

92 Partículas de liga $\gamma$-U8Mo.

93 Liga-base $\gamma U 5 M$ o, tratada termicamente, enfatizando TG.

94 Liga-base $\gamma U 5 M$ o, tratada termicamente, temperaturas de oxidação.

95 Liga-base $\gamma U 5 \mathrm{Mo}$, bruta de fusão, enfatizando TG.

96 Liga-base $\gamma$ U5Mo, bruta de fusão, temperaturas de oxidação.

97 Liga-base $\gamma U 6 M o$, tratada termicamente, enfatizando TG.

98 Liga-base $\gamma U 6 M o$, tratada termicamente, temperaturas de oxidação.

99 Liga-base $\gamma U 6 M o$, bruta de fusão, enfatizando TG.

100 Liga-base $\gamma U 6 M o$, bruta de fusão, temperaturas de oxidação.

101 Liga-base $\gamma U 7 M o$, tratada termicamente, enfatizando TG.

102 Liga-base $\gamma U 7 M o$, tratada termicamente, temperaturas de oxidação.

103 Liga-base $\gamma U 7 M o$, bruta de fusão, enfatizando TG.

104 Liga-base $\gamma$ U7Mo, bruta de fusão, temperaturas de oxidação.

105 Liga-base $\gamma U 8 M o$, tratada termicamente, enfatizando TG.

106 Liga-base $\gamma U 8 M o$, tratada termicamente, temperaturas de oxidação.

107 Liga-base $\gamma U 8 M o$, bruta de fusão, enfatizando $T G$.

108 Liga-base $\gamma U 8 M o$, bruta de fusão, temperaturas de oxidação.

109 Liga-base $\gamma U 9 M o$, tratada termicamente, enfatizando TG.

110 Liga-base $\gamma$ U9Mo, tratada termicamente, temperaturas de oxidação.

111 Liga-base $\gamma U 9 M o$, bruta de fusão, enfatizando TG.

112 Liga-base $\gamma U 9 M o$, bruta de fusão, temperaturas de oxidação.

113 Liga-base $\gamma U 10 M o$, tratada termicamente, enfatizando TG.

114 Liga-base $\gamma U 10 M o$, tratada termicamente, temperaturas de oxidação. 
(cont.)

pág.

117 Liga-base $\gamma U M o S i$, bruta de fusão, enfatizando TG. 214

118 Liga-base $\gamma U M o S i$, bruta de fusão, temperaturas de oxidação. 214

119 Curvas de ganho de massa absoluta, ligas-base $\gamma$ UMo. 216

120 Razão O/U, ligas-base. 218

121 Temperaturas de oxidação, primeiros picos ATD, ligas base $\gamma$-UMo. 220

122 Diferenças de temperatura de oxidação, ligas-base, diferentes 221 condições.

123 Liga-base $\gamma U 5 M$ o, tratada termicamente.

124 Liga-base $\gamma U 6 M o$, tratada termicamente. 224

125 Liga-base $\gamma U 6 M o$, bruta de fusão. 224

126 Liga-base $\gamma U 7 M o$, tratada termicamente. 224

127 Liga-base $\gamma U 8 M$ o, tratada termicamente. 225

128 Liga-base $\gamma U 9 M o$, tratada termicamente. 225

129 Liga-base $\gamma U 10 M o$, tratada termicamente. 225

130 Liga-base $\gamma U M o S i$, bruta de fusão, amostra 111.

131 Pontos de fusão e solidificação do alumínio. 226

132 Liga-base $\gamma U M o S i$, bruta de fusão, amostra 113.

133 Liga-base $\gamma U M o S i$, bruta de fusão, amostra 115.

134 Energia de reação x \% Mo, comparada a UMoSi. 234

135 Hidretação de urânio metálico. 236

136 Dehidretação de urânio metálico. 237

137 Taxa de variação da massa com relação ao tempo, hidretação. 238

138 Taxa de variação da massa com relação ao tempo, hidretação a $100^{\circ} \mathrm{C} 240$ por 4 horas, liga $\gamma U 6 M o$.

139 Taxa de variação da massa com relação ao tempo, hidretação a $75^{\circ} \mathrm{C} 241$ por 4 horas, liga $\gamma U 6 M o$.

140 Taxa de variação da massa com relação ao tempo, hidretação a $50^{\circ} \mathrm{C} 242$ por 4 horas, liga $\gamma U 6 M o$.

141 Taxa de variação da massa com relação ao tempo, hidretação a $120^{\circ} \mathrm{C} \quad 243$ por 2 horas, liga $\gamma U 5 M o$.

142 Taxa de variação da massa com relação ao tempo, hidretação a $130^{\circ} \mathrm{C} \quad 244$ por 1 hora, liga $\gamma U 7 M o$. 
143 Taxa de variação da massa com relação ao tempo, hidretação a $100^{\circ} \mathrm{C} 244$ por 4 horas, liga $\gamma$ U10Mo, massa igual a 106mg.

144 Taxa de variação da massa com relação ao tempo, hidretação a $100^{\circ} \mathrm{C} \quad 245$ por 4 horas, liga $\gamma$ U10Mo, massa igual a $77 \mathrm{mg}$.

145 Taxa de variação da massa com relação ao tempo, hidretação a $250^{\circ} \mathrm{C} 246$ por 1 hora, liga $\gamma$ U9Mo.

146 Taxa de variação da massa com relação ao tempo, hidretação a $250^{\circ} \mathrm{C} 246$ $/ 1 h+562^{\circ} \mathrm{C} / 4 h$, liga $\gamma U 9 M o$.

147 Taxa de variação da massa com relação ao tempo, hidretação a $250^{\circ} \mathrm{C}$ $/ 2 \mathrm{~h}+562^{\circ} \mathrm{C} / 4 \mathrm{~h}$, liga $\gamma U 9 \mathrm{Mo}$.

148 Taxa de variação da massa com relação ao tempo, hidretação a $250^{\circ} \mathrm{C} \quad 247$ $/ 3 h+562^{\circ} \mathrm{C} / 4 h$, liga $\gamma U 9 M o$.

149 Taxa de variação da massa com relação ao tempo, hidretação a $562^{\circ} \mathrm{C} 248$ / 4h, liga $\gamma U 9 M o$.

150 Taxa de variação da massa com relação ao tempo, hidretação a $250^{\circ} \mathrm{C}$ / Ih, liga $\gamma U 6 M o$.

151 Taxa de variação da massa com relação ao tempo, hidretação a $300^{\circ} \mathrm{C}$ / 4h, liga $\gamma U 6 M o$.

152 Rendimentos na produção dos pós em função da temperatura, ensaios TG/DTA.

153 Curva típica de um ensaio termogravimétrico, amostra 201 (U7Mo).

154 Curvas dos ensaios de termogravimetria, liga $\gamma U 5 \mathrm{Mo}, T \leq 600^{\circ} \mathrm{C}$.

155 Curvas dos ensaios de termogravimetria, liga $\gamma \mathrm{UMO}, \mathrm{T} \geq 850^{\circ} \mathrm{C}$.

156 Mudança nos mecanismos de incorporação de $\mathrm{H}_{2}$.

157 Dehidretação, ensaio 606.

158 Hidretação, ensaio 606.

159 Dehidretação, ensaio 602.

160 Hidretação, ensaio 602, liga భU6Mo. 261

161 Curvas de ganho de hidrogênio para as amostras das ligas $\gamma$-U8Mo. 262

162 Correlação entre rendimento e $\Delta T$. 265

163 Curvas típicas de variação de massa (esquerda) e respectiva estrutura 268 do pó (direita), liga $\gamma$-U5Mo. 
164 Curvas típicas de dehidretação (esquerda) e respectiva estrutura do pó 269 formado (direita), liga $\gamma-U 5 M o$.

165 Curvas típicas de variação de massa (esquerda) e respectiva estrutura 270 do pó (direita), liga $\gamma$-U7Mo.

166 Curvas típicas de variação de massa (esquerda) e respectiva estrutura 271 do pó (direita), liga $\gamma$-U8Mo.

167 Curvas típicas de variação de massa (esquerda) e respectiva estrutura 272 do pó (direita), liga $\gamma$-U9Mo.

168 Processos comparados, (a) tradicional, (b) o oferecido por esta tese. 275

169 Hidretação liga X7Mo, pré-tratamento. 277

170 Dehidretação liga $\gamma$ UMo, pré-tratamento. 277

171 Absorção de hidrogênio, liga భU7Mo. 278

172 Dessorção de hidrogênio, liga భU7Mo. 278

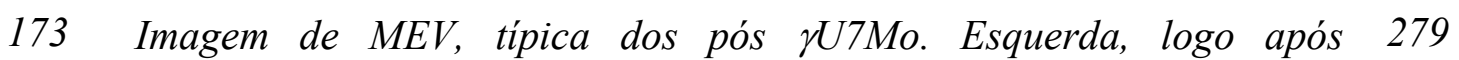
hidretação, direita, após dehidretação.

174 Comparação das energias de ativação obtidas para o início da 286 decomposição e interdifusão, ligas $\gamma \mathrm{UMo}^{14}$.

175 Início da decomposição da fase $\gamma$-UMo como função da temperatura ${ }^{14}$. 


\section{JUSTIFICATIVAS, OBJETIVOS E PLANO GERAL DA TESE}

A tese de doutoramento tem como principal objetivo o desenvolvimento de um novo combustível, alternativo aos já existentes, à base da liga urânio-molibdênio, com alto desempenho a altas temperaturas. Este desenvolvimento iniciou-se com o projeto BRA/4/053 ${ }^{01}$, um contrato internacional de pesquisas entre Brasil e a Agência Internacional de Energia Atômica (AIEA), cujo título é "Development of na Alternative

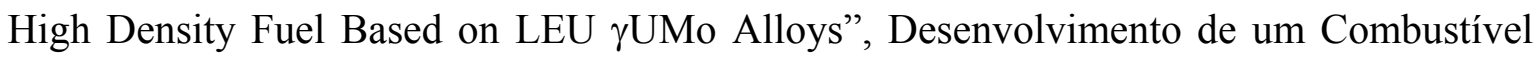
Alternativo de Alta Densidade à Base das Ligas $\gamma$ UMo de Baixo Enriquecimento.

Como atualmente se procura diminuir o enriquecimento dos combustíveis para evitar a geração de Pu e conseqüente procura por este elemento para a fabricação de armas, vê-se nas ligas de $\gamma \mathrm{UMo}$ as melhores candidatas como combustíveis de alta densidade. Além de apresentarem a vantagem da alta capacidade de carga, até densidades calculadas de $9,0 \mathrm{gU} / \mathrm{cm}^{3}$ na placa, possuem propriedades químicas e sob irradiação semelhantes às dos silicetos, permitem que o urânio dos combustíveis gastos seja recuperado mais facilmente, pelos processos usuais de separação. Os silicetos, por serem mais duros, estão limitados a densidades de $6,0 \mathrm{gU} / \mathrm{cm}^{3}$, por problemas tecnológicos na etapa de laminação. Por serem compostos estáveis, com estequiometria bem definida e formados por ligações covalentes, processos químicos são utilizados para a recuperação do urânio.

O que os resultados dos testes RERTR (sigla em inglês para "Reduced Enrichment of Research and Test Reactors") mostraram até o momento é que as adições de molibdênio ao urânio atuam em dois sentidos, concorrentes e opostos em termos de desempenho. Possuindo caráter metaestável, é de se esperar que sua reatividade seja maior que a de combustíveis com estrutura e composição química bem definidas, como o óxido de urânio $\mathrm{U}_{3} \mathrm{O}_{8}$ e o siliceto de urânio $\mathrm{U}_{3} \mathrm{Si}_{2}$. Assim, enquanto estes apresentam baixa tendência à formação de camada de interação, que é o resultado da reação das fases combustível e matriz, e cuja instabilidade é a responsável pelos problemas de inchamento, a crescente adição de molibdênio aumenta sua velocidade de formação.

Por outro lado, é nesta direção que há o aumento da estabilidade da fase gama, responsável pela elevação da capacidade de carga e, portanto, pela diminuição do enriquecimento dos combustíveis nucleares. Obviamente que, em ciclos de queima baixos e em reatores com baixa potência, estes problemas são minimizados. Entretanto, ao pensarmos em reatores com potência mais alta e no fornecimento de combustíveis para 
reatores a nível mundial, os problemas de compatibilidade devem ser solucionados. Assim, fica claro que deve haver um compromisso entre estabilidade da fase gama e a formação de camada de reação. Portanto, deve-se procurar desenvolver um material no qual este equilíbrio seja obedecido. Este é um dos objetivos desta tese.

O desenvolvimento de um material é um processo longo e compreende, além do estudo de suas propriedades, o estabelecimento de parâmetros para sua fabricação, em um nível preliminar, e para a sua utilização, em um nível posterior. Visto que a fase $\gamma \mathrm{UMo}$ é metaestável nas condições usuais de operação em reatores de pesquisa (o reator IEAR1 do IPEN-CNEN/SP tem capacidade para operar à potência de $5 \mathrm{MW}$, temperatura do combustível de $120^{\circ} \mathrm{C}$ ), e em dispositivos de mais alta potência, como reatores de submarinos nucleares (usualmente operam a $45 \mathrm{MW}$ ), é necessário o entendimento dos processos de estabilização desta fase.

Assim, o desenvolvimento foi iniciado com a fabricação das ligas à base de urânio-molibdênio, com adições de Mo entre 5 e 10\% em peso, por meio das técnicas de fusão a arco e indução. Para garantia da homogeneidade da composição, amostras das ligas foram tratadas termicamente, seguindo condições estabelecidas em literatura. As propriedades microestruturais das ligas brutas de fusão e tratadas termicamente, produzidas por ambas as técnicas de fusão, foram avaliadas pelas técnicas usuais de caracterização. Com base na comparação entre os resultados, optou-se por uma delas, para a eventual produção em larga escala.

Com vistas a se levantar parâmetros de equilíbrio, foi proposta uma técnica que, ao mesmo tempo, serviu de base para o desenvolvimento de um processo de fabricação de pós das ligas $\gamma \mathrm{UMoX}$, com X sendo um possível elemento ternário (no caso o silício). A técnica tomou por base a maior afinidade do hidrogênio pela fase $\alpha U$. Com base em diversos trabalhos sobre equilíbrio em sistemas binários e ternários UMoX, optouse pela exposição das amostras a temperaturas próximas à da decomposição eutetóide, sob atmosfera de hidrogênio, que foi a principal condição escolhida, para a realização dos ensaios em analisador termogravimétrico.

Assim, acompanhou-se a adsorção de hidrogênio pelas ligas, para se determinar o efeito do teor de soluto em sua fragilização, relacionando-o ao fenômeno de decomposição $\gamma \rightarrow \alpha$, pelo qual curvas semelhantes aos já conhecidos diagramas tempotemperatura-transformação para o sistema foram obtidas. Além disso, ao longo destes experimentos, descobriu-se que as condições de resfriamento das ligas são essenciais para 
a obtenção de alta taxa de fragmentação. Com base em modelo teórico proposto, que tomou por base a teoria da nucleação e crescimento, foram obtidos alguns resultados interessantes sobre o fenômeno de nucleação da fase alfa, proeutetóide, quando comparados com os de literatura, obtidos por meio de outras técnicas.

A validação destes resultados foi efetuada numa etapa seguinte, em escala semi-piloto. A hidrogenação de maiores quantidades de material, de 10 a 60 g, foi realizada em unidade já existente neste Instituto, encerrando-se assim o desenvolvimento do processo de fabricação dos pós.

$\mathrm{Na}$ fase seguinte do desenvolvimento, foi estudada a compatibilidade das ligas brutas de fusão e tratadas termicamente frente a alguns materiais presentes no ambiente mais próximo ao combustível, importante para a fabricação das placas e utilização em um reator nuclear. Assim, novamente em analisador termogravimétrico, a ação do oxigênio e do alumínio metálico sobre as ligas base foi estudada, para fins de comparação de desempenho com as adições ternárias propostas. Nesta fase em particular, alguns comentários são extremamente importantes. Os mais recentes resultados dos testes RERTR indicaram que a adição de silício à matriz, no caso de combustíveis dispersos, quando combinada com adições de silício ao combustível, reduz significativamente a formação da camada de interação. Não foram feitas adições de silício ao alumínio nos experimentos de compatibilidade, por considerar-se que a compatibilidade frente ao alumínio puro seja uma medida efetiva da estabilidade do novo combustível ou das ligas base. Ou seja, se o material comporta-se bem frente ao alumínio puro, comportar-se-á melhor frente a uma matriz mais estável. Na verdade, descobriu-se que um pequeno excesso de elemento ternário, com formação de matriz estável metálica e composto intergranular com características intermediárias entre metal e composto intermetálico, apresenta propriedades satisfatórias, ao contrário do que se observou recentemente em testes RERTR, quando da proposta de novas ligas metálicas.

Concluir-se-ía este trabalho por meio da fabricação de miniplacas de ligas base e das ligas propostas, para avaliação de seu desempenho na etapa de fabricação e irradiação. Como não houve, até a presente data, condições para a fabricação das miniplacas e testes de irradiação destes materiais, é oferecida aqui a possibilidade de realização deste trabalho futuramente.

Assim, descobriu-se aqui que a combinação de propriedades de ambos os combustíveis é a mais adequada para a obtenção de pós e de uma estrutura gama estável. Espera-se com isso um bom desempenho na etapa de laminação e, possivelmente, durante 
a irradiação em reatores nucleares, dada a sua melhor estabilidade frente às ligas base $\gamma$ UMo. Ou seja, a alta resistência à corrosão da fase intermetálica é combinada à maior estabilização da fase gama, existente em ligas urânio-molibdênio. Assim, mesmo que haja alguma perda de densidade, evitar-se-íam problemas de inchamento, existentes quando da formação de camadas de interação entre o combustível e a matriz. Isto concluiu o desenvolvimento do material.

Seguindo uma seqüência lógica de apresentação, o primeiro capítulo, que abre a parte I - Estabilidade da Fase $\gamma-\mathrm{U}$, situa este trabalho no contexto histórico e mundial, em um nível mais amplo, e no contexto institucional, num nível mais específico. A verdadeira necessidade é a da utilização de combustíveis de alta densidade e baixo enriquecimento em substituição aos tradicionalmente enriquecidos, mas com baixa densidade em urânio nas placas. Uma breve introdução aos resultados dos testes RERTR será oferecida.

Sob um ponto de vista mais técnico, no capítulo 2 será discutido o problema da estabilidade da fase $\gamma-U$ e o papel das adições binárias e ternárias, ou elementos estabilizantes, na manutenção da fase. Entende-se por estabilizante como o composto adicionado ao urânio e que permite, por meio da formação de compostos ou ligas, a retenção da estabilidade desta estrutura às temperaturas utilizadas para a operação de reatores de pesquisa e de processamento metalúrgico. Por qual motivo se prefere o uso da fase $\gamma-U$ ao invés de $\alpha$ ou $\beta$, estáveis a temperaturas mais baixas? Por que a escolha de ligas binárias de urânio com molibdênio, ao invés de outros elementos ou de sistemas ternários? Os trabalhos aqui apresentados são os clássicos, mostrando o esforço de vários autores para a compreensão dos mecanismos de decomposição da fase gama no proeutetóide alfa e na fase delta, o único composto de urânio do sistema binário U-Mo. Eles servirão de base de comparação para os dados de equilíbrio que serão utilizados nesta tese, em capítulo apropriado.

No capítulo 3 serão apresentados os fatos e experimentos básicos sobre os problemas da camada de interação e desempenho sob irradiação dos combustíveis de alta densidade. Quais ligas apresentaram melhor desempenho sob irradiação e processamento metalúrgico, tornando-se então as melhores candidatas? Todos os principais resultados dos trabalhos RERTR serão tratados aqui, com base em trabalhos de diversos autores, que forneceram a base para a escolha do material estudado, e cujos resultados até o momento serão introduzidos nesta tese. 
O capítulo 4 trata dos principais trabalhos na área de processamento e técnicas de obtenção de pós das ligas $\gamma$-UMo. Neste caso, procura-se aqui justificar a utilização da técnica da hidretação-dehidretação $(\mathrm{HDH})$ ou da hidretação-moagem-dehidretação (HMDH), utilizada também para o estudo da estabilidade da fase gama-UMo, comparando-a com as técnicas tradicionais, mostrando-se quais as suas vantagens e desvantagens em relação às demais.

A parte II - Desenvolvimento Experimental será destinada a apresentação e discussão do método utilizado para a resolução do nosso problema, e compreende os capítulos 5 e 6 . Dada a extensão de cada conjunto de experimentos, a divisão em capítulos foi considerada conveniente. Assim, no capítulo 5 descrevem-se os métodos de obtenção das ligas e dos novos combustíveis, via fusão a arco e indução, tratamentos térmicos, justificando-os. Os ensaios de análise térmica diferencial relacionados a ganho ou perda de massa por hidrogenação, dehidretação, oxidação e reações com alumínio, produção de ligas e estabilidade térmica, validação, serão descritos no capítulo 6.

Julgou-se conveniente dedicar uma das partes da tese ao modelo teórico, dada a sua extensão, o que será feito na parte III - Desenvolvimento Teórico. No capítulo 7 a teoria da nucleação e crescimento da fase $\alpha$ a partir da fase $\gamma$ será apresentada da maneira tradicional e conforme a abordagem dada na tese, que parte da obtenção da solução de uma equação diferencial parcial para a modelagem do sistema. No capítulo 8 , dada a importância da reação entre hidrogênio e fase $\alpha$-U para a formação dos pós e a oxidação das ligas, será brevemente apresentada a teoria da difusão gasosa, especialmente a do hidrogênio, pelas ligas UMo e subseqüentes formação de solução sólida intersticial e reações. Também serão analisados fenômenos de difusão em estado sólido, para compreensão da interação entre alumínio e fases combustíveis.

Estes capítulos formam a base para a elaboração do modelo, enunciado no capítulo 9 como o problema físico-matemático cuja solução está sendo proposta ao final da tese. Deve-se ter em mente que estamos considerando como principais fenômenos as transformações de fase $\gamma \rightarrow \alpha+\gamma$ e $\gamma \rightarrow \alpha+\delta$, os que se referem a incorporação de hidrogênio por reação e intersticialmente, e em termos de compatibilidade, os de incorporação do oxigênio e alumínio pelas ligas base e novos combustíveis, e as alterações nas suas propriedades mecânicas.

Na parte IV - Resultados e Discussões, são apresentados e discutidos todos os resultados. No capítulo 10 são fornecidos os resultados de caracterização das ligas 
produzidas via forno a arco e indução, brutas de fusão e tratadas termicamente, discutindoos em termos comparativos. As características químicas, mecânicas e microestruturais das ligas serão apresentadas em conjunto com os resultados de difração de raios-X, densidade e análises de EDS, o que permite a avaliação da qualidade das ligas em termos de homogeneidade de composição, estrutura e previsões de desempenho na fabricação. No capítulo 11 serão apresentados e discutidos os resultados de oxidação, importantes para o próximo capítulo e para a verificação da estabilidade das ligas. No capítulo 12 são apresentados e discutidos os resultados de análise termogravimétrica dos experimentos de compatibilidade das ligas e da liga proposta com alumínio, para fins de comparação de desempenho. Estes dois capítulos formam a base para a adoção da liga com potencial candidata à substituição dos tradicionais silicetos de urânio e binários UMo.

No capítulo 13 serão apresentados os principais resultados de hidrogenação das ligas, e a aplicação das técnicas de análise do equilíbrio acima mencionadas serão finalmente utilizadas. Como resultado tecnologicamente importante, será definida a condição ideal para a obtenção de uma maior quantidade de fragmentação e, portanto, um maior rendimento na produção de pós, em função das porcentagens de molibdênio adicionadas às ligas. Os resultados de caracterização dos pós serão apresentados, e analisados em termos da porcentagem de adição e dureza das ligas. As condições de estabilidade química da fase combustível frente aos materiais de teste serão também apresentadas e discutidas aqui.

Finalmente, conclusões serão tomadas com base nos resultados acima, em especial quanto ao método de obtenção das ligas, processo de fabricação dos pós via hidretação-dehidretação, e também quanto à utilização de ternário para a resolução de problemas de estabilidade e fabricação dos pós. 


\section{PRIMEIRA PARTE}

\section{ESTABILIZAÇÃO DA FASE $\gamma$-U}




\section{ESTADO DA ARTE E MOTIVAÇÕES - DIMINUIÇÃO NO ENRIQUECIMENTO DOS COMBUSTÍVEIS DE REATORES DE PESQUISA}

\subsection{Breve situação do problema no contexto do programa RERTR}

Ao final dos anos 70, a comunidade internacional despertou para o fato de que os combustíveis utilizados nos reatores de pesquisa, muitos deles com grau de enriquecimento maior do que $20 \%$ em peso de urânio no isótopo físsil $\mathrm{U}^{235}$, seriam muito visados por nações ou organizações vinculadas a atividades terroristas, pois é por meio do reprocessamento destes combustíveis gastos que se extrai o $\mathrm{Pu}^{239}$, matéria prima para a fabricação de armas nucleares.

Sugeriu-se então, para contornar este problema, a criação de um programa internacional, cuja finalidade seria a de se evitar o uso de combustíveis nucleares em reatores de pesquisa com grau de enriquecimento elevado, bem como solucionar os problemas advindos desta nova condição. Assim, em 1978, foi criado o programa RERTR ("Reduced Enrichment for Research and Test Reactors" - Redução de Enriquecimento para Reatores de Teste e Pesquisa). Limitou-se então o enriquecimento a $20 \%$ no isótopo físsil $U^{235}$, mas, como conseqüência, novas classes de combustíveis nucleares tiveram que ser pesquisadas, para possibilitar um aumento na carga em urânio nos reatores de pesquisa, mantendo-se os mesmos níveis de potência e fluxo de nêutrons. É neste contexto que esta tese se encontra.

Como objetivo mundial, o programa RERTR pretende converter todos os reatores que utilizam HEU (HEU - "High Enriched Uranium” ou Urânio de Alto Enriquecimento) a LEU (LEU - "Low Enriched Uranium", Urânio de Baixo Enriquecimento) o que reduziria drasticamente a quantidade de $\mathrm{Pu}^{239}$ disponível. Portanto, para que o requisito de redução no enriquecimento seja obedecido, a quantidade do isótopo físsil $\mathrm{U}^{235}$ por placa deve aumentar. Visto que todos os reatores de pesquisa possuem projetos fechados e com pouca flexibilidade quanto à alteração no arranjo e características geométricas e de criticalidade dos elementos combustíveis, a única maneira é o aumento na densidade das fases combustíveis, que pode ser feita durante a fabricação dos elementos 
combustíveis. Estima-se como valor ideal o de $9 \mathrm{~g} \mathrm{U} / \mathrm{cm}^{3}$ na placa, o que hoje é 1,5 vezes maior do que o obtido com os silicetos de urânio $\mathrm{U}_{3} \mathrm{Si}_{2}$, atualmente utilizado no reator IEA-R1 do IPEN-CNEN/SP. Assim, para um volume fixo do núcleo da placa (restrição de projeto), o aumento na densidade da fase combustível permite a redução no enriquecimento em $\mathrm{U}^{235}$, mantendo-se fixa a quantidade de nêutrons necessária à geração da potência especificada para o reator.

Outras vantagens no uso de combustíveis com enriquecimento baixo e alta densidade são a utilização de um maior ciclo de queima e, portanto, um maior tempo de operação dos reatores, a compactação do núcleo, permitindo maior homogeneidade no fluxo de nêutrons, e um menor número de combustíveis irradiados, minimizando problemas de armazenagem em repositórios.

\subsection{Considerações sobre tecnologias de fabricação de combustíveis de alta densidade}

Os isótopos $\mathrm{U}^{235}$ e $\mathrm{Th}^{232}$ são os únicos físseis encontrados na natureza, todos possuindo, portanto, alta seção de choque para a fissão. Dentre estes é o urânio, dada a forma em que se encontra concentrado em minérios e a disponibilidade de reservas naturais, o mais utilizado para a geração de energia em reatores nucleares. Esta energia, entretanto, só é liberada quando o material físsil é disposto no reator em forma física e geometria adequadas, para que se atinja a condição de criticalidade.

Como exemplo, os elementos combustíveis de reatores de alta potência como os PWR (“Pressurized Water Reactors"- Reatores a Água Pressurizada) de Angra dos Reis apresentam a fase combustível contendo o isótopo físsil $\mathrm{U}^{235}$ em pastilhas cilíndricas do composto $\mathrm{UO}_{2}$, dispostas em varetas com geometria cilíndrica. Em um reator de pesquisa, o arranjo geométrico usual é o de placas planas, com a fase combustível dispersa em uma matriz de baixa seção de choque para absorção de nêutrons. Nesta tese não será estudado o comportamento dos combustíveis sob irradiação, mas sim a influência de suas propriedades nas etapas de fabricação dos elementos combustíveis. Entretanto, é importante a avaliação de quais fases combustíveis apresentam melhores propriedades sob irradiação, visto que é para esta aplicação que são projetadas.

Dentre as variedades alotrópicas do urânio, a fase estável à temperatura ambiente é a alfa, de estrutura cristalina ortorrômbica, com densidade de $19,12 \mathrm{~g} / \mathrm{cm}^{3}$. A partir de $662^{\circ} \mathrm{C}$, urânio alfa transforma-se em beta, que apresenta estrutura cristalina tetragonal e densidade de $18,11 \mathrm{~g} / \mathrm{cm}^{3}$. A fase gama é estável de $772^{\circ} \mathrm{C}$ até o ponto de fusão, $1129^{\circ} \mathrm{C}$, e possui estrutura cúbica de corpo centrado e densidade de $18,06 \mathrm{~g} / \mathrm{cm}^{3}$, a 
$805^{\circ} \mathrm{C}$. Para o uso específico em reatores de pesquisa, testes experimentais demonstraram que melhores desempenhos sob irradiação e durante o processamento metalúrgico foram obtidos com as ligas de urânio na estrutura cristalina cúbica de corpo centrado, a fase $\gamma-U$ (gama-Urânio), daí a necessidade de torná-la estável às temperaturas usuais de fabricação e operação dos reatores.

Levando-se em conta que, em termos de processamento físico-químico, em etapas de obtenção de pós via hidretação-dehidretação as temperaturas variam de $100^{\circ} \mathrm{C}$ a $575^{\circ} \mathrm{C}$, na dehidretação de $250^{\circ} \mathrm{C}$ a $400^{\circ} \mathrm{C}$, na laminação de $450^{\circ} \mathrm{C}$ a $550^{\circ} \mathrm{C}$, e sob condições de irradiação (ao menos no reator do IPEN, baixa potência) ao redor de $100^{\circ} \mathrm{C}$ (reatores tipo placa de alta potência, temperaturas são de 2 a 3 vezes maiores) todas abaixo da temperatura de transformação eutetóide, região abaixo da qual a fase gama não existe, torna-se importante a sua estabilização. Assim, devemos procurar por elementos que, formando ligas ou compostos com urânio, apresentem alto poder de estabilização da fase gama nestas condições. Deve-se cuidar, entretanto, para que os elementos de adição possuam propriedades nucleares convenientes, como baixa seção de choque para absorção de nêutrons, estabilidade sob irradiação e inércia química frente ao combustível e à matriz.

Após a escolha do elemento, devemos determinar a forma física pela qual ele será utilizado nas placas do elemento combustível. A mais difundida e utilizada, inclusive no IPEN, é a de se dispersar a fase combustível, na forma de pó, em mistura com pó de alumínio, zircaloy ou com outro material inerte e de baixa seção de choque de absorção de nêutrons. A mistura é homogeneizada e prensada para a formação do chamado briquete, que por sua vez é colocado no centro de uma moldura de alumínio. O conjunto moldura mais briquete forma o núcleo da placa de elemento combustível, por sua vez envolta por 2 placas de alumínio. Após soldagem das 3 placas para a formação do estojo, o mesmo é laminado até a espessura especificada, e juntamente com outras 17 (no caso do reator do IPEN) e 2 externas, estruturais, irão formar o elemento combustível do tipo placa, à base de dispersão. Outro tipo de elemento, que utiliza como núcleo uma placa de combustível puro, chama-se elemento combustível do tipo placa monolítico ${ }^{02}$, atualmente considerado como a melhor alternativa para a resolução dos problemas de compatibilidade, discutidos no capítulo 3.

O reator IEAR1 do Instituto de Pesquisas Energéticas e Nucleares (IPEN/CNEN - São Paulo) utilizou por muitos anos combustível à base de óxido de urânio $\mathrm{U}_{3} \mathrm{O}_{8}$ disperso em matriz de alumínio, com densidades em urânio na placa da ordem de 1,9, 3,1 e $3,8 \mathrm{gU} / \mathrm{cm}^{3}$ (limite tecnológico). Recentemente, com o projeto de cooperação Brasil- 
IAEA BRA/4/047, o uso de combustíveis à base de siliceto de urânio, no caso o $\mathrm{U}_{3} \mathrm{Si}_{2}$, (que tem densidade teórica de $12,2 \mathrm{~g} / \mathrm{cm}^{3}$, com densidade em urânio no composto igual a $11,3 \mathrm{~g} / \mathrm{cm}^{3}$ ) começou a ser estudado, e hoje alguns elementos combustíveis já foram produzidos com tecnologia totalmente nacional. A densidade de urânio na placa é de 3,1 $\mathrm{gU} / \mathrm{cm}^{3}$ com enriquecimento em $\mathrm{U}^{235}$ de 19,75\%. Apesar de possuir excelente comportamento sob irradiação, conforme atestam vários trabalhos existentes em literatura, o que os silicetos permitem em termos de carregamento de urânio por placa ainda é considerado muito baixo. Além disso, como os silicetos são compostos com estequiometria bem definida, o preparo das cargas e o uso de condições de fusão e solidificação devem ser bem controlados para a manutenção da homogeneidade da composição pela amostra, para evitar o aparecimento de outras fases. Outra desvantagem dos silicetos aparece na recuperação do urânio das placas, muito mais fácil quando se trabalha com ligas metálicas de urânio ${ }^{3}$.

Em elementos combustíveis à base de siliceto são utilizadas densidades de 4,8 $\mathrm{gU} / \mathrm{cm}^{3}$, as mais usuais, com um máximo de $6,0 \mathrm{gU} / \mathrm{cm}^{3}$, em alguns elementos combustíveis franceses. Este valor corresponde a uma carga em volume de $43 \%$ na placa (briquete), já no limite tecnológico imposto pela etapa de laminação. Embora represente um avanço na capacidade de carga, este valor é ainda 1,5 vezes menor que o objetivo de 9 $\mathrm{gU} / \mathrm{cm}^{3}$. Com ligas metálicas de urânio este valor sobe a $7 \mathrm{ou} 8 \mathrm{gU} / \mathrm{cm}^{3}$, e assim, elas são as preferidas, embora os elementos compostos por silicetos sejam os únicos comissionados até o momento, para utilização comercial ${ }^{3}$.

Outros compostos de urânio foram testados, além dos silicetos, e todos apresentaram problemas. Apesar de serem os mais densos, $\mathrm{U}_{3} \mathrm{Si}, \mathrm{U}_{6} \mathrm{Ni}, \mathrm{U}_{6} \mathrm{Fe}, \mathrm{U}_{6} \mathrm{Mn}$ sofrem transformação peritética já em temperaturas da ordem de 930, 790, 815 e $725^{\circ} \mathrm{C}$, respectivamente. Além disso, todos eles são materiais instáveis e apresentam inchamento insatisfatório sob irradiação. Assim, sua aplicabilidade torna-se restrita a condições suaves de irradiação (baixas queimas ou fluxo de nêutrons) e baixas temperaturas de fabricação.

Todos estes problemas podem ser minimizados pela utilização da classe de combustíveis baseados nas ligas gama-U. Com o projeto BRA/4/053 ${ }^{1}$ e com a finalização desta tese, a tecnologia para a fabricação de combustíveis com base nas ligas metálicas de urânio será oferecida, o que permitirá a sua utilização futura no reator IEAR1. Entretanto, há ainda a necessidade de comissioná-los, algo que até a presente data não foi efetuado, dados alguns problemas apresentados durante os testes de irradiação RERTR, que serão discutidos adiante. Como exemplo, testes foram conduzidos com elementos de baixa seção 
de choque para absorção de nêutrons, tais como $\mathrm{Zr}, \mathrm{Nb}$, Ti, e Mo os quais, pelos diagramas de fases, possuem os maiores campos de estabilidade da fase gama, exemplificado nas Figuras 1 e 2. Observou-se que combinações de $\mathrm{Zr}-\mathrm{Nb}$ e Mo foram as mais efetivas na estabilização da fase gama, mas os primeiros apresentaram baixo desempenho sob irradiação em ciclos de alta queima.

$\mathrm{Na}$ Tabela 1 estão apresentados os valores de densidade de alguns dos compostos e ligas de urânio, e nas figuras 1 e 2, a extensão dos campos de estabilidade da fase gama para os binários U-Mo e U-Nb.

Tabela 1- Valores de densidade de algumas ligas de gama-urânio ${ }^{3}$.

\begin{tabular}{cccc}
\hline Liga (\% peso $)$ & $\begin{array}{r}\text { Densidade } \\
\left(\mathrm{g} / \mathrm{cm}^{3}\right)\end{array}$ & $\begin{array}{c}\text { Densidade } \mathrm{PF}\left({ }^{\circ} \mathrm{C}\right) \\
\left(\mathrm{g} / \mathrm{cm}^{3}\right)\end{array}$ \\
\hline $\mathrm{U}$ & 19,0 & 19,0 & 1135 \\
$\mathrm{U} 2 \mathrm{Mo}$ & 18,5 & 18,1 & 1147 \\
$\mathrm{U} 5 \mathrm{Mo}$ & 17,9 & 17,0 & 1169 \\
$\mathrm{U} 6,5 \mathrm{Mo}$ & 17,5 & 16,4 & 1190 \\
$\mathrm{U} 8 \mathrm{Mo}$ & 17,3 & 15,9 & 1215 \\
$\mathrm{U} 9 \mathrm{Mo}$ & 17,0 & 15,5 & 1245 \\
$\mathrm{U} 4 \mathrm{Zr} 2 \mathrm{Nb}$ & 17,3 & 16,2 & $\sim 1160$ \\
$\mathrm{U} 6 \mathrm{Zr} 4 \mathrm{Nb}$ & 16,4 & 15,8 & $\sim 1170$ \\
$\mathrm{U} 7 \mathrm{Nb}$ & 17,0 & 15,0 & 1240 \\
$\mathrm{U} 10 \mathrm{Zr}$ & 16,0 & 14,4 & 1245 \\
\hline
\end{tabular}

Além das dispersões, o uso de ligas metálicas leva a uma segunda forma de utilização de combustíveis, os chamados combustíveis monolíticos. Aqui, o núcleo das placas é formado por uma chapa metálica da própria liga, não havendo obviamente interação combustível-matriz (abandona-se o conceito de dispersão). Portanto, a densidade de urânio no núcleo será dada pela porcentagem de adição de molibdênio na liga, valor médio entre 16 e $17 \mathrm{gU} / \mathrm{cm}^{3}$, o valor de densidade de urânio no núcleo ${ }^{02}$.

Esta é uma tecnologia que já está sendo otimizada, foi patenteada ${ }^{2}$ e utilizada em países como a Argentina, Coréia, França e Estados Unidos. No Brasil, está sendo desenvolvida como um projeto de pesquisa no Centro do Combustível Nuclear do IPENCNEN/SP. Algumas seções planas de combustíveis das ligas binárias $\gamma$ U10Mo já foram 
produzidas, e o processo de montagem de um núcleo para posterior laminação está em fase de estudos de engenharia.

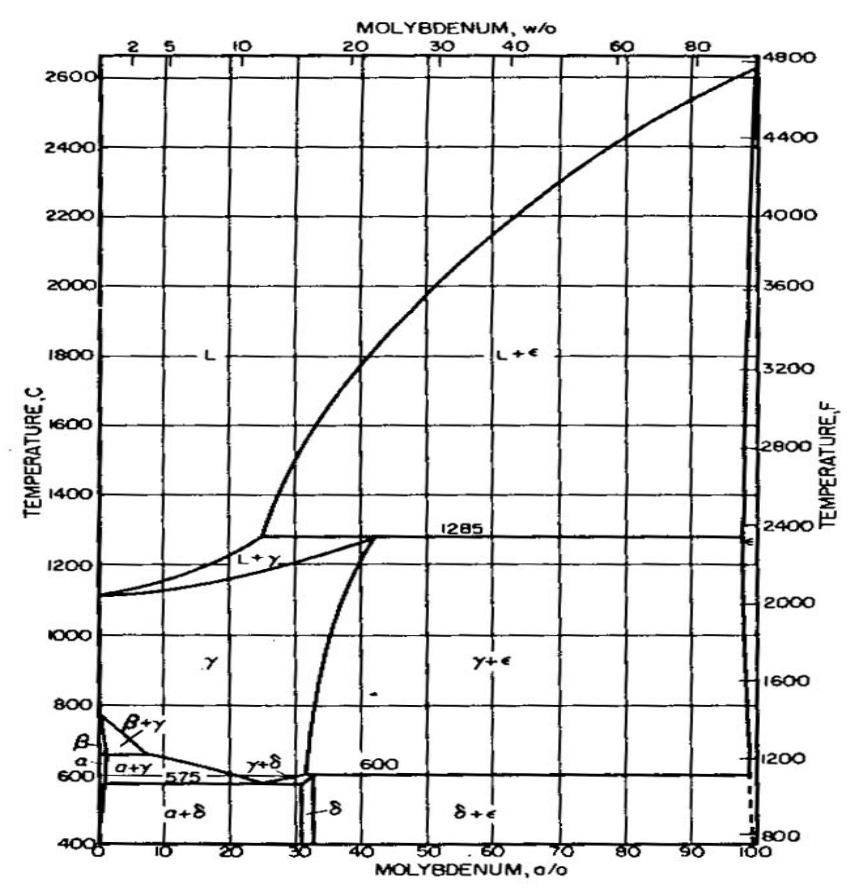

FIGURA 1 - Diagrama de fases $U-M o^{4}$.

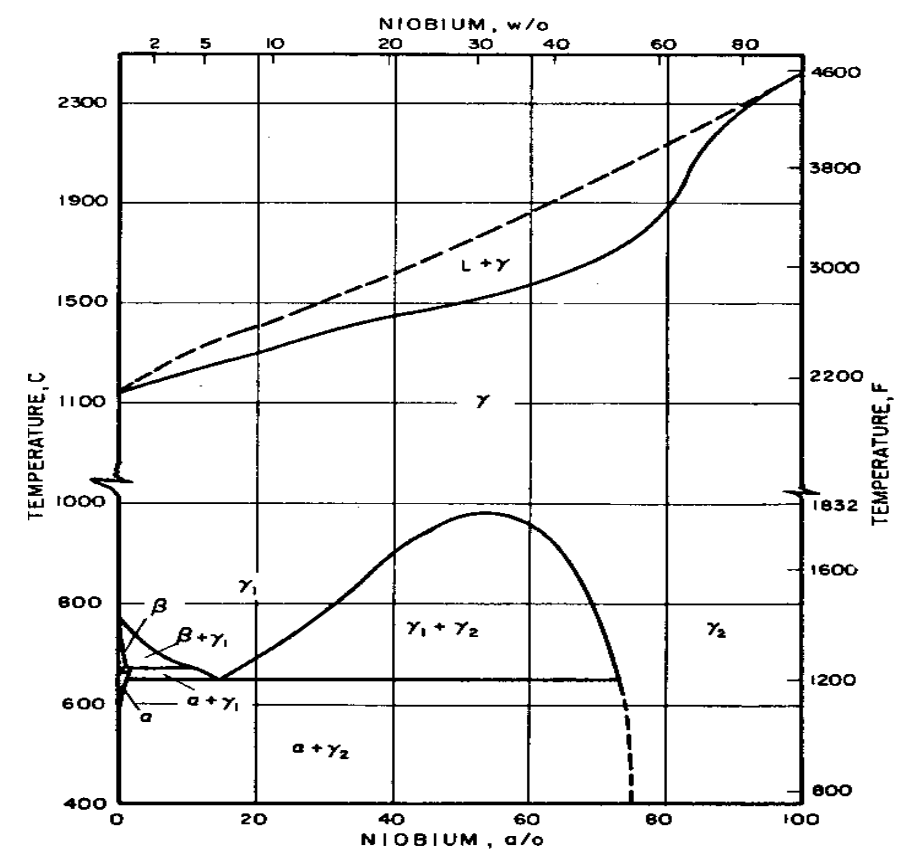

FIGURA 2 - Diagrama de fases $U-N b^{4}$.

Nas Figuras 1 e 2, as escalas superiores referem-se as porcentagens em peso, e as inferiores as porcentagens atômicas. A produção das ligas, os estudos de estabilidade e outras de suas propriedades, estão sendo conduzidos no IPEN regularmente, conforme será 
mostrado ao longo desta tese. Este programa foi muito auxiliado pelo projeto de cooperação Brasil-Agência Internacional de Energia Atômica AIEA de número $\mathrm{BRA} / 4 / 053^{1}$. 


\section{TRANSFORMAÇÕES E ESTABILIDADE NO SISTEMA U-Mo}

\subsection{Estabilidade e fabricação}

Para classes de combustíveis que tomam por base a estabilidade da fase gama do urânio, a exposição a quaisquer das temperaturas de processamento e irradiação, por tempos prolongados, pode acelerar a sua decomposição nas fases estáveis alfa, principalmente, por se tratar da fase proeutetóide em composições hipoeutetóides, na fase delta (também chamada de épsilon, $\varepsilon$, ou gama linha, $\gamma^{\prime}$ ), que é o composto $\mathrm{U}_{2} \mathrm{Mo}$, de estrutura tetragonal, rico em molibdênio. Como se sabe que a fase gama do urânio, cúbica de corpo centrado, apresenta maior estabilidade química e sob irradiação que as demais formas alotrópicas do urânio, é de se esperar uma queda significativa no desempenho de combustíveis que as contenham. Daí ser necessário o conhecimento da velocidade de decomposição da fase gama, dada pela reação:

$$
\gamma \rightarrow \alpha+\delta
$$

em função da temperatura e do tempo.

Uma comparação interessante pode ser feita entre os diagramas de fases Fe-C e U-Mo, pois alguns termos relativos ao primeiro poderão ser usados ao longo deste trabalho. A fase gama do $\mathrm{Fe}$ (austenita) sofre transformação eutetóide a $723^{\circ} \mathrm{C}$ e $2,5 \% \mathrm{C}$, com produtos de reação identificados como fases alfa (ferrita) e beta (cementita, ou o composto $\mathrm{Fe}_{3} \mathrm{C}$ ). Ferrita solubiliza uma quantidade máxima de carbono igual a $0,025 \% \mathrm{em}$ átomos, enquanto a cementita pode solubilizar até $25 \%$ em átomos. No sistema U-Mo, a fase gama do $\mathrm{U}$ sofre transformação eutetóide a $565^{\circ} \mathrm{C}$ com aproximadamente $10,5 \% \mathrm{Mo}$ em peso, dando como produtos as fases alfa-U, ortorrômbica e que dissolve até $0,6 \% \mathrm{Mo}$ em peso, e o composto $\mathrm{U}_{2} \mathrm{Mo}$, também identificado como fase delta, que contém $33 \%$ em átomos de Mo, com estrutura cristalina tetragonal de corpo centrado.

Assim, espera-se que o eutetóide do sistema binário urânio-molibdênio tenha características perlíticas, ou seja, quando da reação, lamelas contendo alternadamente fases rica e pobre em Mo formando-se preferencialmente nos contornos de grão ou em pontos de encontro de 3 ou mais grãos, se o resfriamento for suficientemente rápido (o que minimiza 
a decomposição intragranular), por meio de nucleação heterogênea. Este fenômeno também é responsável pela nucleação e crescimento de aglomerados pequenos no interior dos grãos, em condições de tratamento que serão vistas nos parágrafos seguintes, ou em amostras submetidas a resfriamento lento.

Como nesta tese estamos tratando das ligas UMo hipoeutetóides, com composições entre 5 e $10 \%$ em peso de Mo, espera-se que durante o resfriamento a partir do estado líquido e após a passagem da amostra pela isoterma do eutetóide gama, a tendência seja a formação de fase primária alfa, seguida pela posterior decomposição da fase gama remanescente em alfa e delta. Para as ligas em estudo, a porcentagem de Mo utilizada é suficiente para que gama seja retida mesmo sob resfriamento lento, e as análises de difração de raios-X confirmam este fato, principalmente nas amostras fundidas por indução.

\subsection{Estabilidade da fase $\gamma$ em sistemas binários de urânio-molibdênio}

O interesse pelo estudo da estabilidade da fase gama urânio surgiu logo após a Segunda Guerra Mundial, e foi conduzido por poucos mas importantes autores. Pode-se considerar como um grande avanço no estudo da estabilidade destas ligas o trabalho de Saller, Rough e Vaughan ${ }^{5}$, de 1951, no qual foram determinadas as fronteiras de fases do sistema binário U-Mo, não muito bem estabelecidas até então por trabalhos anteriores, como os apresentados na compilação de Ahman, Snow e Wilson ${ }^{6}$, de 1945.

As transformações e compostos formados foram determinados até uma porcentagem de $50 \%$ em átomos ( $28 \%$ em peso) de Mo, com a finalidade de se estabelecer a constituição correta dos campos do sistema binário. As ligas com baixo teor de Mo, com massas de 10 a $25 \mathrm{~g}$, foram preparadas via forno a arco, e para correta homogeneização, de 3 a 5 refusões foram realizadas. Será visto adiante que esta foi a ordem de grandeza das massas das ligas preparadas via fusão a arco neste trabalho. Ligas contendo quantidade de molibdênio maior do que $25 \%$ em átomos foram fundidas via indução, em cadinhos de berílio, sob vácuo e somente quando houve algum tipo de segregação elas foram refundidas. Este foi, basicamente, o procedimento experimental adotado nesta tese para preparo das ligas.

Uma observação interessante sobre processos de fabricação é dada neste artigo, a saber, que para que se quebre a estrutura bruta de fusão e se aumente o grau de homogeneização, forjamento e laminação foram utilizados. Assim, tratamentos mecânicos adicionais podem ser aplicados nas ligas obtidas, para aumentar a sua qualidade. As ligas 
contendo até 2,5\% em átomos de Mo foram laminadas a quente ("hot alpha rolling") a temperaturas de $550^{\circ} \mathrm{C}$ a $600^{\circ} \mathrm{C}$, com 2 a 5 minutos entre os passes. Ligas contendo de 5 a $50 \%$ em átomos foram laminadas na região de gama a temperaturas entre $800^{\circ} \mathrm{C}$ a $1100^{\circ} \mathrm{C}$, com 2 minutos entre cada passe. Para acompanhar as transformações, os autores utilizaram as técnicas da difração de raios-X e microscopia óptica, e a decomposição foi acompanhada a partir de tratamento térmico de homogeneização realizado por 100 horas a $1000^{\circ} \mathrm{C}$.

Os autores verificaram que a reação peritética:

$$
\mathrm{L}+\delta \rightarrow \gamma
$$

ocorre a $1285^{\circ} \mathrm{C}$, com $42 \%$ em átomos, L representando a fase líquida, e $\delta$ sendo hoje identificada como a fase $\varepsilon$ (Mo) em diagramas mais recentes, com alto teor de Mo. Observaram que ao redor de 28 a $30 \%$ em átomos, em temperatura entre $575^{\circ} \mathrm{C}$ e $600^{\circ} \mathrm{C}$, a fase gama se decompõe completamente em fase $\varepsilon$ (hoje delta), como resultado do decréscimo em solubilidade do Mo na fase gama com a redução na temperatura. Assim, sendo esta uma composição hipereutetóide, este trabalho foi um dos primeiros a confirmar a existência deste intermetálico no sistema. Uma observação importante feita pelos autores e de interesse em estudos cinéticos é a de que a transformação de gama a $\varepsilon$ (hoje delta) é muito vagarosa, ocorrendo apenas após sujeitar-se a amostra a um tempo longo de tratamento térmico abaixo da temperatura eutetóide, de aproximadamente $565^{\circ} \mathrm{C}$. Ao observarmos mais atenciosamente o diagrama de fases, notamos que nesta temperatura e composição estamos num campo bifásico de gama mais épsilon (hoje delta). Esta lentidão na transformação de gama decresce com o decréscimo na quantidade de Mo, e para ligas com $12 \%$ em átomos ou menos, houve transformação em alfa e épsilon (hoje delta) durante seu resfriamento em forno, portanto lento. Esta observação é importante, pois nos leva ao exame dos espectros de difração de raios- $\mathrm{X}$ das ligas base produzidas nesta tese, pois foram resfriadas em forno.

Pelo exame metalográfico das amostras resfriadas a partir da condição de tratamento térmico, obtiveram, para adições de $0,8 \%$ em átomos, que toda a estrutura gama transformou-se em alfa durante o resfriamento. Assim, adições desta ordem não são suficientes para a estabilização da fase gama. Uma fase tetragonal de transição foi identificada em amostras com 12\% em átomos (aproximadamente $6 \%$ em peso), diferente 
da fase épsilon (hoje delta), e que desapareceu prontamente durante recozimentos a $450^{\circ} \mathrm{C}$, $500^{\circ} \mathrm{C}$ e $600^{\circ} \mathrm{C}$. Confirmaram que gama já pode ser retida nestas porcentagens (aproximadamente $6 \%$ em peso Mo), e como este valor é próximo ao nosso limite inferior, problemas quanto à decomposição da fase gama em alfa e formação desta estrutura de transição não podem ocorrer.

Para ligas contendo $20 \%$ em átomos e, portanto, altamente estabilizadas, gama foi retida durante têmpera (resfriamento rápido) e também durante resfriamento em forno (resfriamento lento), correspondendo ao que foi obtido neste trabalho em termos de estabilidade. Como esta corresponde ao limite superior de composições, confirma-se que a estrutura gama proveniente de ligas altamente estabilizadas pode ser retida nestas porcentagens mesmo sem têmpera.

Um resultado de interesse direto para esta tese foi o apresentado na figura 25 desta publicação, na qual é apresentada uma micrografia de liga contendo $12 \%$ em átomos de molibdênio, com grãos contornados por precipitados de fase alfa, que é uma das condições necessárias para altos rendimentos nos tratamentos térmicos de hidrogenação. Estas ligas foram trabalhadas a frio e tratadas para homogeneização por 2 horas a $830^{\circ} \mathrm{C}$, resfriadas em forno até $640^{\circ} \mathrm{C}$, e mantidas nesta temperatura por 20 horas e posteriormente temperadas. Como esta foi feita a partir de uma região bifásica alfa mais gama, a matriz de gama ficou contornada por precipitação de fase alfa. Ao contrário do que ocorre em amostras com teores menores de Mo, não foi observada a precipitação de alfa intragranular.

Com os tratamentos realizados próximos à temperatura de transformação eutetóide, os autores observaram que alguma precipitação intragranular pode ocorrer, conforme exame de amostras tratadas por 40 horas a $600^{\circ} \mathrm{C}$, aquecidas e mantidas a $620^{\circ} \mathrm{C}$ (todas as temperaturas do campo de $\gamma+\alpha$ ) por 70 horas e depois temperadas. Este fenômeno tornou-se ainda mais evidente quando as amostras foram tratadas a $580^{\circ} \mathrm{C}$ por 100 horas, e depois temperadas. Observou-se que, além dos precipitados intragranulares, uma estrutura lamelar eutetóide fez-se também presente, indicando o avanço da decomposição da matriz da fase gama nestas condições.

Em ligas contendo $20 \%$ em átomos de soluto, trabalhadas a frio até $75 \%$ de deformação, e posteriormente tratadas por 24 horas a $600^{\circ} \mathrm{C}$ e temperadas, manteve-se a estrutura gama. $\mathrm{O}$ mesmo tipo de tratamento, mas quando realizado em temperaturas de $500^{\circ} \mathrm{C}$ a $550^{\circ} \mathrm{C}$, entretanto, levou à decomposição progressiva da fase gama em alfa mais épsilon (hoje delta), sendo que a $500^{\circ} \mathrm{C}$ a matriz transformou-se rapidamente. Ou seja, 
como as temperaturas de laminação são desta ordem, mesmo com ligas altamente estabilizadas como as de $20 \%$ de adição, em átomos, é grande a tendência à ocorrência da reação de decomposição (01).

Se estas estruturas de decomposição são formadas após os tratamentos das ligas, então é correta a hipótese de que a facilidade na hidretação aumenta com os tratamentos térmicos de hidretação realizados no campo bifásico de alfa e gama, e mais ainda, quando as mesmas são tratadas preferencialmente nos campos de alfa e delta. A facilidade na hidretação, conforme fato conhecido, depende da quantidade de fase alfa presente em contornos de grão. Portanto deve-se também tomar o cuidado para que não haja decomposição excessiva e perda de estrutura, mesmo em tempos muito menores do que os utilizados por estes autores. Daí ser estudado nesta tese a determinação do tempo real em que há o início da decomposição eutetóide da fase $\gamma$-UMo.

No trabalho de Van Thyne e McPherson ${ }^{7}$ foram utilizadas três técnicas para a determinação das velocidades e do início das transformações no sistema binário U-Mo, a saber, a da variação na resistividade, a da variação da microestrutura (metalografia), acompanhada da microscopia óptica associada à difração de raios-X, e a da medida de variação na dureza. Os autores prepararam as ligas UMo nas composições de 5,4\%, 8\%, $10 \%$ e $12 \%$ em peso de Mo. A liga contendo 5,4\% Mo foi preparada via fusão a arco, após aplicação de "vácuo" até $20 \mathrm{mmHg}$ e atmosfera de gás He, com a carga sendo composta por molibdênio na forma de folhas e urânio em pedaços, ambos com pureza nominal de 99,9\%. Para garantir a homogeneidade da liga, algo que será discutido em capítulo apropriado, a amostra foi refundida 4 vezes. As ligas nas demais composições foram fundidas inicialmente em forno a arco, sem refusões, e posteriormente levadas a forno de indução. Os autores confirmaram a elevada homogeneidade das amostras fundidas em forno de indução, o que também vem ao encontro dos resultados obtidos nesta tese.

Todas as ligas foram tratadas termicamente para homogeneização em campo de fase $\gamma$-UMo, por 65 horas a $1000^{\circ} \mathrm{C}$, e para estudo das transformações, as temperaturas de tratamento situaram-se entre 200 e $570^{\circ} \mathrm{C}$. Exames metalográficos indicaram que a liga contendo 5,4\% Mo, quando tratada a $550^{\circ} \mathrm{C}$, apresentou produtos de decomposição detectáveis após $0,1 \mathrm{~h}$, e este ponto foi identificado pelos autores como o "nariz" da curva tempo-temperatura-transformação (chamada TTT), para esta composição. A $400^{\circ} \mathrm{C}$ detecta-se a decomposição da fase gama após 2 horas, a $300^{\circ} \mathrm{C}$ somente após 100 horas, e a $200^{\circ} \mathrm{C}$ não se observa a decomposição, mesmo após 700 horas. Ou seja, a estrutura gama pode ser mantida estável quanto mais afastados forem os tratamentos ou temperaturas de 
processamento da temperatura de transformação. Os autores observaram que o início da transformação ocorreu sempre nos contornos de grão, não havendo nucleação e crescimento de fase alfa nem mesmo a partir de impurezas situadas no interior dos grãos.

Os precipitados apresentaram forma lamelar, característico de decomposições perlíticas, no caso eutetóides, e com o prolongamento dos tratamentos por 5 horas transformou a matriz quase que totalmente, pois apesar de $\gamma$-UMo não ter sido evidenciadao nas micrografias, por difração de raios-X detectou-se a sua presença. Estes resultados confirmaram os de Saller, Rough e Vaughan ${ }^{5}$. Se esta última estrutura foi a verdadeira, então, segundo os autores, seria correto associar-se a estrutura lamelar observada após pequenos tempos de tratamento como sendo composta pelas fases $\alpha-U$ e $\gamma^{\prime}$-UMo, esta última empobrecida em Mo com relação à matriz, constituindo-se na fase de transição referida anteriormente ${ }^{5}$. Com o aumento nos tempos de tratamento, a fase $\gamma^{\prime}$ UMo vai progressivamente tornando-se rica em Mo, precipitando-se como delta-U, levando à estrutura final observada, após 600 horas, nas micrografias. Novamente, confirma-se a decomposição em delta após tempos muito maiores do que os aqui utilizados, onde preferencialmente a fase alfa é o produto majoritário de decomposição.

Observando o diagrama de fases binário UMo (pág. 07), $550^{\circ} \mathrm{C}$ é uma temperatura que se encontra próxima à da transformação eutetóide $\left(565^{\circ} \mathrm{C}\right)$, mas ainda pertence ao campo de fases $\alpha-U+\delta$ (ou $\varepsilon$ ) UMo, para 5,4\% em peso de molibdênio. As equações de transformação que governam os fenômenos observados pelos autores são as seguintes:

$$
\gamma \mathrm{U} \rightarrow \alpha \mathrm{U}+\gamma^{\prime} \mathrm{U}
$$

quando tempos pequenos de tratamento térmico são utilizados, com:

$$
\gamma^{\prime} U \rightarrow \delta U
$$

quando do aumento nos tempos de tratamento térmico ou "annealing".

Estrutura de precipitação semelhante à eutetóide foi obtida quando amostras a $5,4 \%$ foram tratadas à temperatura de $590^{\circ} \mathrm{C}$, portanto no campo de $\gamma+\alpha$, por 244 horas. Novamente observou-se a presença das lamelas, os resultados de difração de raios-X confirmaram a presença somente das fases $\gamma-U$ e $\alpha-U$. Ou seja, os mecanismos de 
decomposição da fase $\gamma$-UMo nos campos de $\gamma+\alpha$ e $\alpha+\delta$ são semelhantes. Já na temperatura de $400^{\circ} \mathrm{C}$ por tempo de 672 horas, um precipitado fino cobrindo toda a matriz foi obtido, indicando elevada decomposição da matriz nas fases $\alpha$ e $\delta$. Também observaram, em ligas com 8 a 12\% em peso, sinais de decomposição logo a $500^{\circ} \mathrm{C}$, mais evidentes após um tempo de tratamento de 10 horas, com a precipitação cobrindo toda a amostra após 400 horas.

Creio que o importante de se citar estes resultados é o fato de que a metaestabilidade pode levar a alguns problemas nas condições de operação nos reatores. Como exemplo, após um tempo de queima da ordem dos tratamentos utilizados por estes autores, pode haver transformação de grandes quantidades de liga UMo, com conseqüente agravamento de problemas de interação química com a matriz, inchamento e alteração no perfil de temperatura das placas.

Os autores observaram que as ligas contendo $8 \%, 10 \%$ e $12 \%$ de $\mathrm{Mo}$ apresentaram estruturas e prováveis mecanismos de decomposição com características diferentes das ligas anteriores, o que pode estar diretamente relacionado com alguns dos resultados de hidretação obtidos nesta tese, quanto à diferença nas características das partículas em função da estabilidade da estrutura gama. Em geral, para estes 3 casos, os depósitos formaram-se principalmente ao longo dos contornos de subgrãos, sendo muito finos, após tratamento por 1000 horas a $400^{\circ} \mathrm{C}$, abaixo das temperaturas de laminação. Entretanto, por metalografia notaram que pouca decomposição ocorreu, mesmo com a amostra em um campo onde claramente a fase gama não é a estável. Estes resultados indicam a grande capacidade de retenção metaestável e, portanto, o alto poder estabilizador, quando adicionamos quantidades hipoeutetóides maiores do que $8 \%$ de Mo ao urânio. Para a liga hipereutetóide a $12 \%$ Mo, com um tratamento a uma temperatura de $500^{\circ} \mathrm{C}$, mais próxima da temperatura eutetóide, e pelo mesmo intervalo de tempo de 1000 horas, cobriu-se toda a amostra com os produtos de decomposição, constituído principalmente pelo proeutetóide deste hipereutetóide, a fase $\delta$ (ou $\varepsilon$ ) ou $\mathrm{U}_{2} \mathrm{Mo}$.

Portanto, ficou comprovado que composições ao redor de $10 \%$ Mo, mas ainda hipoeutetóides, são as que garantem uma maior estabilidade da fase gama-U. Ou seja, para uma suposta composição $\gamma$ hipereutetóide, sua tendência a se decompor em $\delta$ (pró) e pouco $\alpha$ é maior do que a de uma composição $\gamma$ hipoeutetóide em $\alpha$ (pró) e $\delta$.

Os espectros de difração de raios-X indicaram a presença de fase $\alpha$ em amostras tratadas a $550^{\circ} \mathrm{C}$ de ligas $5,4 \%$ Mo somente após 5 horas de tratamento, picos de $\delta$ 
(ع) tornaram-se também bem visíveis nas amostras tratadas por 16 horas, enquanto que nos espectros tomados após 64 horas as intensidades dos picos de $\alpha$ sobrepujaram as de $\gamma$, o mais intenso desta fase igualando-se ao da fase $\delta$. Os autores não identificaram picos de fases $\delta$ e transformação em amostras tratadas por 1 hora, e não foram identificados picos isolados de fase $\gamma$ após 168 horas, indicando, obviamente que, respeitando o limite de detecção do equipamento de difração de raios-X, que a maior parte desta fase tenha sido consumida. A indicação de transformação total na amostra foi dada quando não houve alterações nos espectros, após a aplicação de tratamentos mais prolongados.

Assim, concluem os autores que, quanto mais próximo do campo de alfa, a tendência apresentada pela fase gama em se decompor em alfa é maior, a fase delta vai aparecendo com a saturação de gama em molibdênio. Esta tendência vai diminuindo com o aumento da porcentagem de Mo, pois estamos nos aproximando do campo de delta puro, a precipitação de ambas ocorre simultaneamente. Para a liga hipereutetóide $12 \% \mathrm{Mo}$, não foi observada a presença de fase alfa como produto de decomposição. Produtos de decomposição não foram encontrados em quaisquer das ligas após 1000 horas a $350^{\circ} \mathrm{C}$ ou $300^{\circ} \mathrm{C}$.

A resistividade de amostras com 5,4\% em peso de adição de soluto decresceu com o aumento nos tempos de tratamento, pois gama-U tem maior resistividade elétrica que suas fases de decomposição. Como transformações significativas ocorrem somente em temperaturas próximas à do nariz da curva TTT, é de se esperar que variações significativas de resistividade também ocorram nestas regiões. A $400^{\circ} \mathrm{C}$, por exemplo, mesmo por tempos elevados, não houve praticamente variação na resistividade, significando que tempos extremamente elevados seriam necessários para a transformação total, a esta temperatura.

Um resultado interessante destas curvas e que se assemelha em muito ao fenômeno que foi observado nas curvas de hidrogenação de amostras de $\gamma$-UMo é um pequeno aumento nos valores de resistividade no início dos experimentos, que os autores relacionam a tensões de pré-precipitação induzidas nas amostras. Um pequeno aumento na absorção de hidrogênio, seguido de queda, ocorreu nos experimentos desta tese. Entretanto, o fenômeno não foi observado nos patamares de temperatura, mas sim nas rampas de aquecimento, antes das isotermas.

Os autores ainda observaram que, em geral, o "nariz" ou ponto de inflexão das curvas de resistividade ocorreu em temperaturas entre $550^{\circ} \mathrm{C}$ a $480^{\circ} \mathrm{C}$, decrescendo 
conforme cresce a \%Mo. Os tempos para a decomposição detectável são aproximadamente de $0,3 \mathrm{~h}(5,4 \%), 1,3 \mathrm{~h}(8 \%), 10,2 \mathrm{~h}(10 \%)$ e 10,8h (12\%), crescente com a \% de Mo nas ligas. Ainda, em temperaturas próximas às utilizadas em processos de laminação $\left(550^{\circ} \mathrm{C}\right)$, o aumento na porcentagem de Mo das ligas eleva o tempo para a decomposição. Entretanto, em temperaturas próximas a $450^{\circ} \mathrm{C}$, há um ponto onde as curvas se cruzam para as porcentagens de $8 \% \mathrm{Mo}$ e $10 \% \mathrm{Mo}$, sendo um indicativo de que há, para cada temperatura, um valor ótimo de adição de soluto que produz a máxima estabilização da fase $\gamma$.

Os ensaios de dureza também confirmam os anteriores. Para as ligas $\gamma \mathrm{U} 5,4 \mathrm{Mo}$, obteve-se um aumento de dureza, em todas as temperaturas, com o aumento na conversão de $\gamma$-UMo. Portanto, ligas mais duras são as de menor teor de Mo, as menos estabilizadas, e este fenômeno será estudado adiante, no capítulo sobre caracterização. A máxima diferença em dureza ocorreu quando a amostra foi tratada a temperatura de $400^{\circ} \mathrm{C}$, a partir daí decrescendo até a temperatura de $550^{\circ} \mathrm{C}$. Este comportamento não deixa de ser interessante, pois quanto menor a temperatura, menor a energia fornecida ao sistema para que o mesmo se transforme. Como os autores estão trabalhando no campo de fases $\alpha+\delta$, seria de se esperar comportamento semelhante ao obtido nos gráficos de resistividade. Entretanto, há um máximo em dureza a $400^{\circ} \mathrm{C}$, e crescimento detectável somente a $300^{\circ} \mathrm{C}$, que os autores associam, sem muita discussão, ao mecanismo de endurecimento por préprecipitação, que normalmente ocorre em temperaturas baixas. Presume-se então que este endurecimento atinja um máximo a $400^{\circ} \mathrm{C}$, e tenda a diminuir novamente com o aumento da temperatura. Estes resultados não foram discutidos extensivamente.

Os resultados de início de alteração em dureza foram utilizados para a elaboração de um diagrama TTT. Ligas com 12\% de adição apresentaram tendência à estabilização após longos tempos de tratamento, devido à ausência de fase $\alpha$ como produto de transformação. Comportamento interessante é o da liga a $8 \% \mathrm{Mo}$, que apresenta um ponto de descontinuidade a aproximadamente $400^{\circ} \mathrm{C}$, novamente fazendo referência ao fenômeno descrito no parágrafo anterior, relacionada a alguma alteração na velocidade de transformação. Começa a se evidenciar que, ao contrário do que se acredita, o poder de estabilização da fase $\gamma$ não é uma função estritamente crescente do aumento na porcentagem de Mo, dado que as curvas mostram que, a $450^{\circ} \mathrm{C}$, os tempos para início de decomposição (alteração na dureza) crescem conforme as porcentagens de 5,4\%, 12\%, $10 \%$ e $8 \%$ Mo. Nesta tese um comportamento descontínuo também foi observado, referente 
à adição de 6\%, muito menos estável que todas as demais, inclusive com relação à liga $\gamma \mathrm{U} 5 \mathrm{Mo}$.

Finalizando, este trabalho ${ }^{7}$ é extremamente importante, por ter muita relação com o estudo e o método aqui utilizados para análise da estabilidade da fase gama, além de mostrar que as técnicas utilizadas para estudo do equilíbrio produzem resultados diferentes. Aqui será apresentada mais uma técnica para estudo de estabilidade, a da hidrogenação das amostras, dada a diferença de comportamento das fases alfa e gama à presença do gás hidrogênio.

No trabalho de Goldstein e Bar-Or ${ }^{8}$ os autores estudaram a decomposição da fase gama em ligas UMo contendo $8 \%, 10,8 \%$ e 14,3 \% em peso de Mo, por difração de raios-X em amostras na forma de pó, e determinaram experimentalmente as energias de ativação para o crescimento das fases alfa e gama linha (delta). Mencionam, assim como em Van Thyne e McPherson ${ }^{7}$ que a obtenção de pós traz a complicação de que a fase delta reverte sob trabalho a frio a gama, o que pode mascarar os resultados de cinética, além da introdução de elevada oxidação das amostras.

A fusão das amostras foi realizada em forno a arco, com eletrodo nãoconsumível de tungstênio, sob atmosfera de argônio, obtendo-se botões com massas da ordem de $50 \mathrm{~g}$, procedimento semelhante ao utilizado para a fusão a arco das ligas base. Refusões foram utilizadas para assegurar boa homogeneização e, em seguida, as amostras foram fundidas em forno de indução, sob vácuo e cadinhos de magnésia, com resfriamento no próprio forno. Para assegurar a homogeneização, efetuou-se tratamento térmico por 120 horas a $1000^{\circ} \mathrm{C}$. Após homogeneização, as amostras foram aquecidas por 1 hora a $950^{\circ} \mathrm{C} \mathrm{e}$ temperadas em água, para que se assegurasse a presença de fase gama, e em seguida foram moídas sob vácuo, não apresentando nenhum sinal de oxidação, segundo os autores. Para a realização do estudo propriamente dito, os pós das amostras, inseridos em tubos de sílica, foram tratados em temperaturas entre $300^{\circ} \mathrm{C}$ a $550^{\circ} \mathrm{C}$ por tempos variando de 10 minutos a 100 horas. A intenção foi a de se determinar os diagramas TTT para as transformações seguintes:

$$
\begin{gathered}
\gamma \rightarrow \alpha+\gamma \\
\gamma \rightarrow \alpha+\gamma+\delta
\end{gathered}
$$


Face às condições usuais em que as ligas são processadas, observa-se que transformações diretas a $550^{\circ} \mathrm{C}$ em $\alpha+\gamma+\delta$ nas ligas eutetóides ocorreram após 10 horas, mas a $500^{\circ} \mathrm{C}$ e temperaturas menores, e também para a liga com $8 \%$ em peso de molibdênio, ocorre uma transformação gradual, primeiro a $\alpha+\gamma$ e depois a $\alpha+\gamma+\delta$. Para a liga a $14,3 \%$ em peso, velocidades bem diferentes foram observadas acima e abaixo de $550^{\circ} \mathrm{C}$, nesta última a transformação foi muito lenta. Os autores observaram que a presença de fase alfa nas ligas alarga as linhas espectrais da fase gama, pelo fato de os picos serem muito próximos, o que é importante no exame dos espectros de difração adiante.

A decomposição em alfa mais gama seguida por alfa mais gama mais delta se dá em temperaturas entre $530^{\circ} \mathrm{C}$ e $420^{\circ} \mathrm{C}$, nos tempos estudados pelos autores, para as amostras eutetóides. Abaixo de $420^{\circ} \mathrm{C}$, gama decompõe-se somente em alfa mais gama até $300^{\circ} \mathrm{C}$, mesmo após 120 horas de tratamento, tempo a partir do qual indica-se algum comportamento assintótico.

Observou-se na liga a $8 \% \mathrm{Mo}$ em peso primeiramente uma rápida decomposição no campo alfa mais gama, a transformação a delta ocorrendo a $550^{\circ} \mathrm{C}$, após somente 2 horas de tratamento. De $420^{\circ} \mathrm{C}$ a $380^{\circ} \mathrm{C}$, a transformação em alfa mais gama ainda é muito rápida. Abaixo de $380^{\circ} \mathrm{C}$, entretanto, o ritmo da transformação começa a diminuir, e após 100 horas a $300^{\circ} \mathrm{C}$ não é observada transformação. Com a liga a $14,3 \%$ Mo, observa-se a passagem direta ao campo alfa mais gama mais delta em temperatura próxima à da transformação eutetóide. Abaixo deste valor e até $480^{\circ} \mathrm{C}$, a transformação ocorre pela passagem em ambos os campos, embora a transformação a alfa mais gama se dê mais rapidamente. De $480^{\circ} \mathrm{C}$ a $300^{\circ} \mathrm{C}$, os ritmos de transformação diminuíram. Aqui, o comportamento assintótico não é característico, indicando que dados em tempos de transformação maiores poderiam ter sido tomados, ou seja, a velocidade de decomposição do hipereutetóide em delta é muito lenta.

A partir destas curvas, os autores examinaram quais os tempos em que as primeiras linhas de fase alfa e delta apareceram nos difratogramas de raios-X, e construíram gráficos que relacionam o logaritmo dos tempos e o inverso das temperaturas, para cada uma das ligas. Com a inclinação destas retas, obtiveram as energias de ativação para a formação das fases alfa e delta, para cada uma das composições, concluindo que o máximo de energia de ativação para a formação da fase alfa $(77 \mathrm{kcal} / \mathrm{mol})$ se dá com $10,8 \%$ em peso, e a da fase delta $(75 \mathrm{kcal} / \mathrm{mol})$ com $8 \%$ Mo. Assim, concluíram que ligas hipereutetóides decompõe-se mais facilmente, e que tanto com relação à formação de alfa ou delta, composições com aproximadamente 10\% de molibdênio são as mais estáveis. 
Seguindo a linha de Saller et al. ${ }^{5}$, no trabalho de Lehmann ${ }^{09}$ estudaram-se as transformações no sistema UMo com adições de soluto de 0,5 a $4 \%$ em peso, campo no qual a fase beta do urânio pode ser um produto de decomposição, com o objetivo de determinar a faixa de estabilidades dos campos $\beta$ e $\beta+\gamma$. A autora observou que precipitação lamelar de fase alfa ocorre na matriz de gama, e que o limite de solubilidade do molibdênio na fase beta é igual a $0,9 \%$ em peso. É interessante observar que o limite de solubilidade de molibdênio na fase alfa é igual a $0,6 \%$ em peso, ou seja, tratamentos térmicos de reconversão em processos de hidretação não conseguem, se é alta a taxa de precipitação de fase alfa, recuperar totalmente a estrutura gama. Por utilizar no preparo cadinhos de grafite, observou a autora a presença de inclusões cúbicas de carbeto de urânio nas ligas, o que deve ser evitado, pois o teor de carbono é um item importante nas especificações de combustíveis para o reator do IPEN, não devendo ultrapassar o valor de 500 ppm.

Tratamentos térmicos de homogeneização foram realizados sob vácuo de $10^{-5}$ $\mathrm{mmHg}$, de 24 a 250 horas em temperaturas de 900 a $950^{\circ} \mathrm{C}$, seguidos por têmpera em óleo. Para estudo das transformações, as amostras foram aquecidas e mantidas nas isotermas por 20 horas, e em seguida um novo aquecimento foi feito por 0,5 hora a $950^{\circ} \mathrm{C}$, seguido de têmpera em óleo, para retenção da fase gama. O exame dos produtos de reação foi realizado por meio de microscopia óptica, difração de raios-X e de dureza Vickers.

Para a solubilidade de molibdênio na fase gama do urânio, obteve-se um limite de $22,6 \%$ em peso no ponto peritético do diagrama a $1285^{\circ} \mathrm{C}$. Para a transformação eutetóide dada pela reação $(01)$, chegou-se às seguintes coordenadas $(T, x), T$ sendo a temperatura e $\mathrm{x}$ a composição, para este ponto invariante: $\left(575^{\circ} \mathrm{C}, 11,3 \% \mathrm{em}\right.$ peso), quando em alguns diagramas, por exemplo, em Rough e Bauer ${ }^{4}$ a composição eutetóide se dá em $10,6 \%$ em peso, em Beghi ${ }^{10}$, em 10,9\%, e em Konobevsky ${ }^{11}$, a 9,8\% em peso.

Para as transformações de interesse para esta tese, têmperas a partir de $950^{\circ} \mathrm{C}$ nas temperaturas de 630, 602 e $600^{\circ} \mathrm{C}$, campos onde há a transformação $\gamma \rightarrow \alpha+\gamma$ produziram precipitado de fase alfa lamelar sobre a matriz gama, formada por sua vez por grãos poligonais, após 20 horas de tratamento. As medidas de dureza para as ligas a 3 e 4 $\%$ de Mo acompanharam os resultados de Van Thyne e McPherson ${ }^{7}$ e os desta tese para hidrogenação, com máximos em temperaturas e tempos onde a decomposição foi máxima. Para 3\% de Mo, o máximo em dureza Vickers, igual a 360 , ocorreu a $600^{\circ} \mathrm{C}$ após 15 minutos de tratamento, e para $4 \%$ de Mo, um máximo de 320 a $600^{\circ} \mathrm{C}$ foi obtido após 1 
hora. No campo de $\alpha+\delta$, em temperaturas de $500^{\circ} \mathrm{C}$ a $560^{\circ} \mathrm{C}$, observou para a liga a $3 \%$ de Mo o aparecimento da fase alfa intragranular, precipitados muito finos, também identificados em algumas das ligas base estudadas nesta tese. A dureza máxima igual a 580 foi obtida a $450^{\circ} \mathrm{C}$, tempos de tratamento de 2 horas, e para a liga a $4 \%$, obteve-se dureza máxima igual a 610 a $400^{\circ} \mathrm{C}$, após 16 horas de tratamento. Estes dados de dureza serão utilizados adiante, para determinação das melhores condições de fabricação dos pós. Observou a autora que estes valores são todos superiores aos de dureza da fase alfa com $0,5 \%$ de Mo, com grãos da ordem de $60 \mu \mathrm{m}$, que é de 275 , e também aos valores das ligas de estrutura gama, tipicamente iguais a 180. Um estudo da dureza das ligas será efetuado nesta tese. Assim, o máximo de dureza de 610 se deve, segundo ela, à formação de precipitação fina da fase alfa sobre a matriz de gama, e com a evolução da decomposição perlítica, a dureza cai rapidamente. A determinação dos valores para os cotovelos das curvas TTT levou aos seguintes resultados, para a liga a $2 \%, 525^{\circ} \mathrm{C}$, para as ligas a 3 e $4 \%$, $500^{\circ} \mathrm{C}$. Ainda, determinam suas temperaturas de transformação martensítica, respectivamente iguais a $487^{\circ} \mathrm{C}, 437^{\circ} \mathrm{C}$ e $387^{\circ} \mathrm{C}$, respectivamente. Em outro trabalho da mesma autora $^{12}$, há a preocupação em se identificar as fases oriundas das transformações martensíticas sofridas pelas ligas, nesta mesma faixa de composições. Todas estas fases intermediárias apresentaram estrutura monoclínica.

Suas conclusões foram de extrema importância para esta tese. Relacionadas às transformações, observou-se que a solução sólida gama nunca poderá ser retida à temperatura ambiente, com teores de adição entre o limite de solubilidade do Mo em alfa, 0,5\%, e 4\%, justificando-se assim o uso de 5\% de Mo como limite inferior de adição para as ligas base. A transformação $\gamma \rightarrow \alpha+\gamma$ é uma precipitação clássica, ocorrendo entre $640^{\circ} \mathrm{C}$ e $570^{\circ} \mathrm{C}$, para amostras resfriadas a $100^{\circ} \mathrm{C} / \mathrm{min}$., temperadas. Determinou-se que a transformação $\gamma \rightarrow \alpha+\delta$ é uma decomposição eutetóide da fase gama que se efetua pela precipitação rápida da fase alfa e reação de ordem-desordem a delta muito lenta, que não se completou mesmo após 100 horas de tratamento. Para ligas com Mo de 14 a $15 \%$ em peso, esta decomposição ocorre com velocidades mais altas. Para composições de 7\% em peso, alfa e delta precipitam-se na forma de um eutetóide lamelar. Observa-se aqui que os tempos de tratamento foram bem maiores que os utilizados nesta tese, a formação de lamelas foi observada em casos restritos, nos contornos de grão.

Com relação às condições de resfriamento, observou-se que elas influenciam as velocidades de transformação, especialmente nas ligas com baixos teores de Mo, pois não 
há muito poder para a estabilização da fase gama, manutenção da solução sólida à temperatura ambiente. Portanto, a posição das curvas TTT também é função das condições de resfriamento. Assim, observou-se que entre 20 e $100^{\circ} \mathrm{C} / \mathrm{min}$. o tamanho médio de grão das ligas é de $150 \mu \mathrm{m}$, grãos regulares, de 2,5 a $20^{\circ} \mathrm{C} / \mathrm{min}$ os grãos são irregulares e muito largos, com dimensões típicas entre 400 a $600 \mu \mathrm{m}$ para a liga U0,5Mo, e de 160 a $180^{\circ} \mathrm{C} / \mathrm{min}$. a estrutura é composta por grãos muito pequenos e muito irregulares. Portanto, o estudo das condições de resfriamento e o controle da solidificação são importantes para a definição da dimensão e estrutura de grãos das ligas. No caso do IPEN, partículas para uso como dispersões devem ter dimensões entre 44 a $53 \mu \mathrm{m}$, tolerando-se a presença de $20 \%$ de finos.

Esta série de trabalhos foram os mais importantes sobre a estabilização do binário UMo. Em termos de adições ternárias e, portanto, de obtenção de maior estabilidade da fase gama, o trabalho de Cabané e Donzé ${ }^{13}$ é um dos mais completos, e que complementa o trabalho teórico mais recente de Hofman et al. ${ }^{14}$, que será discutido mais tarde. A análise da alteração no equilíbrio com adições ternárias aos binários UMo foi efetuada tendo como objetivo a aplicação como combustíveis nucleares, assim como nesta tese.

Os autores verificaram que adições de cromo, nióbio e rutênio retardaram a decomposição da fase gama a $500^{\circ} \mathrm{C}$. Assim, procederam à substituição gradual de Mo por elementos de adição ternários, determinando os respectivos diagramas TTT. Enfatizaram o fato de que o retardo na decomposição da fase gama a alfa, na temperatura de transformação eutetóide, tida por eles igual a $575^{\circ} \mathrm{C}$, pode ser conseguida a partir de um teor de molibdênio adicionado de $10 \%$ em átomos, ou aproximadamente $5 \%$ de Mo, por têmpera, e que com $20 \%$ de adição, a estrutura metaestável pode ser retida mesmo sem têmpera por um longo tempo. Daí a necessidade de, operacionalmente, proceder-se a resfriamentos rápidos nas amostras com teores de Mo baixos. Ainda operacionalmente, observaram que as velocidades de resfriamento nos processos de têmpera alteram as curvas TTT, portanto, fusões a arco ou indução, por serem técnicas bem diferentes quanto ao resfriamento, podem levar a estruturas diferentes. Nas micrografias da parte II veremos que as ligas obtidas por fusão a arco apresentam estrutura muito mais refinada que as de indução, de resfriamento mais lento. No primeiro caso, o resfriamento foi feito sobre base de cobre refrigerada, e no segundo caso, em molde cerâmico, não refrigerado, portanto com baixa velocidade de transferência de calor. 
Adições de $2 \%$ em átomos de $\mathrm{Zr}$ substituindo átomos de Mo em ligas $\gamma \mathrm{U} 18 \mathrm{Mo}$ (aqui, nesta publicação, 16 refere-se à porcentagem em átomos, equivalendo aproximadamente a uma liga $\mathrm{U} 9 \mathrm{Mo}$ ) foram as que produziram os piores resultados quando comparados aos de estabilização da liga base. Observou-se assim que o Zr, conforme será visto em trabalho de Park et al. ${ }^{15}$, embora reduza a camada de interação combustívelmatriz, diminui a estabilidade da fase gama. Adições de 2 e $4 \%$ de nióbio também não produziram bons resultados, o "cotovelo" dos diagramas deslocou-se para a direita somente com adições de rutênio, rênio e cromo. Para ligas U16Mo (U8Mo em peso), ou seja, com menor estabilidade, todas as adições deslocaram as curvas TTT para a direita, em ordem crescente de estabilidade, nióbio, cromo, rutênio e rênio. Para ligas U14Mo (U7Mo em peso), os resultados foram os mesmos, mas as várias adições de cromo foram menos efetivas em estabilização que as adições de nióbio.

Assim, nas ligas-base altamente estabilizadas, com teores de Mo de 9 a $10 \%$ em peso, as substituições de átomos de Mo por elementos de adição ternários deve ser muito bem estudada, pois não houve em nenhum dos casos, mesmo com aumento de estabilidade, um ganho efetivo nos tempos de decomposição. Exemplificando, a velocidade máxima de decomposição da liga-base U9Mo ocorreu a $525^{\circ} \mathrm{C}$ após $1,5 \mathrm{~h}$, a substituição por $1,0 \%$ de Ru elevou o tempo para $2 \mathrm{~h}$. Com $2 \%$ em átomos de Ru é que o tempo chegou próximo de 5 horas. Ao contrário, estes elementos provocam grande efeito em ligas com teores de $8 \%$ ou inferiores.

Entretanto, assim como o fizeram, posteriormente, Hofman et al. ${ }^{14}$, para aplicação como combustível nuclear deve ser analisado, também, o que as adições acarretam em termos de perda de reatividade. Conforme mencionado na apresentação desta tese, este é o primeiro fator a ser considerado na escolha de um estabilizante. Os autores observaram que um aumento na porcentagem de Mo aumenta a perda de reatividade. Para todas as ligas-base verificou-se diminuição na perda de reatividade com a adição dos ternários, a minimização se dá, em todos os casos, com adições de $4 \%$ em átomos de $\mathrm{Nb}$, mas a estabilização também é a mais baixa. Devemos lembrar que a perda de reatividade deve ser a menor possível. Observa-se em geral que as adições que estabilizam a fase gama são as que provocam maior perda de reatividade e então, novamente, um compromisso entre ambos os parâmetros deve ser levado em conta na escolha deste elemento. Como os melhores estabilizantes são aqueles que contraem mais a rede cúbica de corpo centrado da estrutura gama, então deve haver também um compromisso entre a queda no parâmetro e a perda de reatividade. 
Em Van Thyne e McPherson ${ }^{16}$ também se estudou a adição de elementos ternários em ligas-base de UMo, combinações de U-Mo-Nb e U-Mo-Pt. Para o estudo das decomposições utilizaram as mesmas técnicas descritas em seu trabalho anterior ${ }^{07}$, tratamentos térmicos de homogeneização a $1000^{\circ} \mathrm{C}$ e $1050^{\circ} \mathrm{C}$, a partir desta temperatura estudaram as transformações entre $300^{\circ} \mathrm{C}$ e $600^{\circ} \mathrm{C}$. Este trabalho é interessante, pois poucos dados existem, até hoje, em literatura, sobre a decomposição e estabilidade da fase gama em sistemas $\mathrm{U}-\mathrm{Nb}$.

Os autores determinaram, por metalografia, que o tempo para a decomposição detectável da liga $\mathrm{U} 10 \mathrm{Nb}$ se dá a $550^{\circ} \mathrm{C}$ após 12 minutos, os produtos de reação sendo alfa e fase contendo $60 \%$ de $\mathrm{Nb}$, denominada épsilon. Este produto de decomposição cobriu toda a matriz gama estável após somente 10 horas de tratamento térmico entre $500^{\circ} \mathrm{C}$ e $600^{\circ} \mathrm{C}$. A $400^{\circ} \mathrm{C}$, após 10 horas, somente traços dos produtos de decomposição foram observados, mesmo após 1000 horas. Queda na resistividade das ligas foi obtida após 2 horas em temperatura de $350^{\circ} \mathrm{C}$, mais acentuada quanto mais próximas de $500^{\circ} \mathrm{C}$, o que confirmou os resultados de análise metalográfica.

Verificaram também que o poder de estabilização da fase gama de UNb aumentou com a porcentagem de adição. Medidas de resistividade indicaram que ligas U20 Nb sofrem decomposição detectável somente após 10 horas a $550^{\circ} \mathrm{C}$, e U10Nb após 0,7 horas, nesta mesma temperatura. Estes resultados, com pequenas diferenças nos valores dos tempos, foram confirmados pelas técnicas de difração de raios-X e dureza.

Para os sistemas UMoPt e UMoNb não foi observada metalograficamente a presença de fase alfa proeutetóide. Para a liga U8MoPt, o tempo de transformação detectável chegou a 40 horas, aproximadamente o mesmo para a liga U8Mo1,5Pt. Não observaram transformação da fase gama em temperaturas abaixo de $350^{\circ} \mathrm{C}$. Em ligas U8Mo3 $\mathrm{Nb}$, o efeito da adição de ternário foi o contrário, o tempo de decomposição diminuiu para 10 horas. Este resultado foi confirmado posteriormente ${ }^{13}$, sendo sugerido que os efeitos das adições de $\mathrm{Nb}$ têm um limite, acima do qual a estabilidade cai. O mesmo foi observado com outros elementos de adição.

Entretanto, ao contrário do observado mais recentemente por Hofman et al. ${ }^{14}$, técnicas diferentes conduziram a resultados diferentes quanto à estabilidade devida às adições de Pt e Nb à liga-base $\gamma$ U8Mo. Segundo Hofman et al. ${ }^{14}$, Pt, Ru e Re são os mais fortes estabilizadores da fase gama, conforme cálculos teóricos. Aqui, observou-se pela técnica de medida na dureza, que $1 \%$ de Pt tem maior poder de estabilidade que 1,5\% de $\mathrm{Nb}$, embora os valores para os tempos de transformação não sejam muito diferentes (100 
horas para Pt e algo ao redor de 150 horas para $\mathrm{Nb}$ ). Mas, pela medida de resistividade, inverte-se o poder, verifica-se a decomposição em $\mathrm{Nb}$ ternário após 40 horas, e com a Pt, somente após 90 horas. Será discutido adiante, no capítulo que trata sobre a hidrogenação das ligas, a influência das técnicas nos resultados de equilíbrio.

Em Repas et al. ${ }^{17}$, adições de Ti em ligas base de UMo foram estudadas, e alguns de seus resultados são interessantes, face aos obtidos mais recentemente por Park et al ${ }^{18}$. As composições foram as seguintes: U8Mo, U10Mo, U8MoTi e U8Mo0,5Ti, dada a baixa solubilidade na fase gama do elemento $\mathrm{Ti}$, conforme pode ser visto nos diagramas binários $\mathrm{UTi}^{4}$. Várias foram as condições de tratamento térmico aplicados às ligas, que foram encapsuladas em folhas de Mo, introduzidas em sistemas selados com vácuo a $10^{-3}$ mbar. Utilizaram a técnica da dilatometria para acompanhamento das transformações, determinando temperaturas críticas e acompanhando as transformações isotérmicas.

Os autores observaram, também pelas técnicas utilizadas por Van Thyne e McPherson ${ }^{7,16}$, que a estrutura gama pode ser retida nos binários U8Mo e U10Mo mesmo com resfriamento lento. Temperaturas críticas de transformação foram, respectivamente, de $574^{\circ} \mathrm{C}(\mathrm{U} 8 \mathrm{Mo})$ e $573^{\circ} \mathrm{C}(\mathrm{U} 10 \mathrm{Mo}), 577^{\circ} \mathrm{C}$ para $\mathrm{U} 8 \mathrm{Mo} 0,5 \mathrm{Ti}$, e $583^{\circ} \mathrm{C}$ para U8MoTi. Medidas de dureza indicaram início de transformação após 200 horas e 70 horas a $500^{\circ} \mathrm{C}$, em ligas U10Mo e U8Mo, respectivamente, e observaram aumento na temperatura de precipitação da fase alfa pelas adições de Ti aos binários U8Mo, havendo também o aparecimento em contornos de grão da fase $\mathrm{U}_{2} \mathrm{Mo}$, em temperaturas acima da temperatura de transformação eutetóide, o que não ocorre nos binários. Conforme será visto adiante ${ }^{18}$, tanto $\mathrm{Zr}$ quanto Ti podem ter efeito de acelerar a decomposição da fase gama.

Dentre outros, creio que estes sejam os mais importantes trabalhos tratando da estabilização da fase gama por adições de Mo, $\mathrm{Nb}$ e ternários combinados a eles. Uma extensa compilação de resultados é dada em Beghi ${ }^{10}$, que trata somente de estudos realizados sobre a estabilização da fase gama em ligas de UMo.

No Capítulo 7 será apresentada, discutida e adaptada a este trabalho a teoria proposta por Hofman et al. ${ }^{14}$, para determinação do poder de estabilização da fase gama do urânio por adições binárias de $\mathrm{Mo} \mathrm{e} \mathrm{Nb}$ e ternárias combinadas ao Mo. Este é um trabalho mais recente, e que orientou a pesquisa pela estabilização, principalmente quando relacionada aos combustíveis dispersos. Ver-se-á adiante que não somente a fase gama estabilizada, mas também a compatibilidade química com a matriz, é essencial para o bom desempenho de um combustível nuclear, para este tipo de aplicação. 


\section{REAÇÕES E COMPORTAMENTO SOB IRRADIAÇÃO DOS COMBUSTÍVEIS $\gamma$-UMo}

\subsection{Problema de compatibilidade UMo / Al}

Um dos maiores problemas apresentados por combustíveis dispersos é a possibilidade de interação entre a fase combustível e a matriz. Como são formadas por elementos químicos diferentes, presume-se sempre que, até onde a termodinâmica permitir, alguma reação possa ocorrer. A formação de novos compostos reflete no desempenho das placas, pois altera propriedades como condutividade térmica e, portanto, perfis de temperatura ao longo das mesmas, acúmulo e formação de bolhas de gases de fissão, etc., tudo isto sendo dado como função das propriedades físicas dos novos materiais presentes. Assim, é importante a obtenção de pós quimicamente estáveis ou pouco ativos, para que estes problemas não ocorram. A validação dos testes ou confirmação das hipóteses são efetuadas por meio dos testes RERTR, pelos quais se avaliam as propriedades das dispersões sob irradiação. Os resultados destes testes serão discutidos a seguir.

Sabemos que, para a qualificação de um combustível nuclear, o seu comportamento sob irradiação deve ser estudado e levado em conta como a sua propriedade mais importante. Muitos testes foram conduzidos para a qualificação dos combustíveis a base de UMo e de alta densidade, os chamados testes RERTR. Dos 8 grandes programas de testes de combustíveis de alta densidade, os primeiros 7 já foram concluídos, e o último deles, o RERTR-8, ainda está em andamento. A partir de seus resultados, Pasqualini ${ }^{19}$ apresenta um resumo dos mais recentes avanços na área de fabricação e desenvolvimento de combustíveis de alta densidade na forma de partículas e monolítica, e que podem servir de orientação para futuras pesquisas na área. Esta tese de doutoramento apóia algumas das linhas sugeridas pelo autor.

Com relação aos combustíveis particulados, muitos foram os problemas apresentados quando da irradiação das ligas em ciclos de queima elevados. Assim, considera-se a sua aplicabilidade como estritamente relacionada a algumas das seguintes inovações. A adição de germânio à matriz de alumínio está sendo estudada no sentido de se melhorar o desempenho, em termos de formação de camada de reação, relativamente às adições de silício. Conforme mencionado à p. xiii, a adição de silício à matriz reduz em 
muito a formação da camada, embora em certas condições não apresente vantagem significativa. Como a porosidade aumenta do lado do alumínio com relação à camada de reação, é de se supor que a maior difusão de elementos se dê do alumínio para o combustível, daí o uso de inibidores misturados à matriz. O germânio é uma boa alternativa ao silício por não formar compostos com o alumínio. Entretanto, há o problema da formação de eutético no sistema $\mathrm{Al}-\mathrm{Ge}$ a $420^{\circ} \mathrm{C}$, limitando-se as temperaturas de laminação a valores inferiores.

A formação de barreiras de difusão diretamente sobre as partículas de combustível, como deposições de silício, níquel e nióbio também podem ser viáveis tecnologicamente, desde que estes depósitos sejam dúcteis, não frágeis. Ainda, revestimentos com ligas de Al também estão sendo estudados, os mais promissores sendo as ligas binárias de alumínio-níquel Al-Ni. As ligas Al-Si e Al-Ge são também candidatas, embora menos estáveis, dada a incompatibilidade de suas estruturas cristalinas com relação à da fase $\gamma$ UMo. Estes revestimentos devem prevenir também a oxidação das partículas de UMo, que, se continuamente expostas ao ar, podem ter redução de até $1 \%$ na densidade. Isto é o que ocorre nas partículas de $\mathrm{HMDH}$, após 1 ano de fabricação.

A incorporação de alumina porosa à matriz, com o objetivo de aumentar a absorção e retenção de produtos de físsão sem alteração nas dimensões das partículas e placas, o que evita inchamento excessivo e formação de trincas, e a introdução de moderador junto à fase combustível, como por exemplo um material com alta seção de choque para a absorção de nêutrons como o hidreto de zircônio $\mathrm{ZrH}_{2}$, são outras propostas para a resolução do problema de inchamento. Faz-se aqui uma analogia aos combustíveis de reatores $\mathrm{PWR}$, nos quais, juntamente ao $\mathrm{UO}_{2}$, incorpora-se alguma quantidade de óxido de gadolínio $\mathrm{Gd}_{2} \mathrm{O}_{3}$, com altíssima seção de choque para absorção de nêutrons, o que praticamente dobra o tempo de vida dos combustíveis nos reatores nucleares de potência.

Assim, observou-se que em combustíveis de liga-base $\gamma$ U7Mo com densidade de $8 \mathrm{gU} / \mathrm{cm}^{3}$, partículas de alumina com 80 micra e a $50 \%$ de queima, foi medido um volume de gás na matriz equivalente a duas vezes o volume do próprio núcleo da placa. $\mathrm{Ou}$ seja, levando-se em conta que este volume é extremamente danoso ao bom desempenho sob irradiação das placas, a adição de um material à matriz com alta área de superfície específica poderia resolver este problema. Assim, o uso de materiais como alumina, na forma de pó, poderia diminuir o problema do inchamento. Estima-se, conforme testes realizados com pós oriundos do processo $\mathrm{HMDH}$, que para se evitar problemas de processamento, um volume de até $10 \%$ de alumina no núcleo pode ser utilizado. 
No caso dos combustíveis monolíticos, resultados satisfatórios foram obtidos com chapas da liga $\gamma \mathrm{U} 7 \mathrm{Mo}$, encapsuladas em zircaloy 4, conforme resultados dos testes RERTR-7A. As miniplacas RERTR-7A foram divididas em duas categorias, apresentando espessura total de $1 \mathrm{~mm}$ de espessura e de núcleos com 0,25mm (MZ25) e 0,50mm (MZ50), densidades em urânio de $16 \mathrm{~g} / \mathrm{cm}^{3}$ (o teórico aproximadamente igual a $18 \mathrm{~g} / \mathrm{cm}^{3}$, para a fase gama a $805^{\circ} \mathrm{C}$ ). A porcentagem de queima chegou a $38 \%$ nas MZ25 e $33 \%$ nas MZ50, o que levou a um fluxo de nêutrons menor em MZ50, mas a um fluxo de calor, dada a maior quantidade de urânio, maior em MZ50 ( $217 \mathrm{~W} / \mathrm{cm}^{2}$ contra $\left.135 \mathrm{~W} / \mathrm{cm}^{2}\right)$.

Aqui entra em discussão um outro aspecto tecnológico, que pode melhorar o desempenho dos combustíveis, que é o da redução na espessura da placa de revestimento. Conforme demonstram alguns cálculos, pode-se com isso também diminuir o enriquecimento dos combustíveis, mas deve-se aumentar as dimensões dos canais de água dos elementos combustíveis para a remoção de maior quantidade de calor. Além disso, a redução na espessura do revestimento é uma variável que pode ser alterada facilmente no projeto quando da conversão de HEU para LEU. Para aumentar a razão de moderação de modo a compensar a queda no enriquecimento, a redução no revestimento permite o aumento na espessura do canal de água e, portanto, o número de átomos de hidrogênio disponíveis à moderação dos nêutrons gerados pelo $\mathrm{U}^{235}$. Mas isto só é possível tecnologicamente até que se atinja o valor 0,5 na relação entre as espessuras do revestimento e do núcleo, com o zircaloy e o aço inox, no caso de combustíveis monolíticos.

No trabalho de Dubois et al. ${ }^{20}$, foi mencionado que em vários experimentos as dispersões de UMo em alumínio não se mantém estáveis em operações a alta potência, produzindo graves problemas devido ao inchamento excessivo. A instabilidade desta camada de interação é a principal responsável por este comportamento indesejado, o que justifica a grande maioria de trabalhos nesta área. Como propriedades desta camada de óxido, devemos ter: espessura de alguns micra, estrutura cúbica como a do $\mathrm{UO}_{2}$ e a do UMo, e boa aderência.

Sugerem os autores que um combustível avançado à base de dispersão UMo em Al deve atender a dois objetivos, o primeiro o de diminuir a velocidade de formação da camada de interação, e o segundo o de aumentar a retenção de gases de fissão. Para que isso seja alcançado, são três as principais abordagens adotadas. A primeira delas refere-se à modificação das partículas de UMo, na maioria das vezes por adições ternárias. Neste caso, foram testadas as adições de $\mathrm{Ti}, \mathrm{Zr}, \mathrm{Nb}$ e $\mathrm{Si}$, com o objetivo de diminuir a reatividade entre 
UMo e $\mathrm{Al}$ ou a estabilização da fase $\mathrm{UAl}_{3}$ que tem bom desempenho sob irradiação. A segunda maneira consiste em se modificar a matriz de alumínio, também por adição de íons tetravalentes (SiIV+ e GeIV+), pela dispersão de materiais altamente porosos em seu interior, ou pela substituição de alumínio por magnésio, embora mais difícil por haver a formação de eutético. A terceira maneira é a modificação da interface UMo/Al pelo uso de barreiras de difusão ou materiais de recobrimento, e materiais como $\mathrm{Si}, \mathrm{Nb}, \mathrm{Zr}-\mathrm{Nb}, \mathrm{Ni}$ foram estudados, bem como a oxidação parcial das partículas de UMo. Foi esta a via estudada pelos autores, e justificada a seguir. A que adotarei nesta tese é a abordagem que leva em conta a elaboração dos chamados combustíveis inteligentes, a ser explicada adiante, em capítulo apropriado.

As razões pelas quais se justifica a utilização das barreiras de óxido são várias. A primeira delas é a de que, durante os tratamentos térmicos de laminação e fabricação dos pós, a camada de óxido minimiza o crescimento da interface de reação danosa ao bom desempenho dos combustíveis. Esta camada é de $\mathrm{UO}_{2}$, e com o prolongamento dos tratamentos, observaram que a mesma progride para o interior da partícula de UMo.

A comparação entre micrografias de pós moídos e atomizados U7Mo mostra, em ambos os casos, grande consumo de UMo pelo Al. Para os pós moídos observou-se que a oxidação pode ter sido induzida pelo processo de moagem mas, de qualquer forma, o problema da camada de interação foi reduzido. Entretanto, pós moídos não se comportaram bem em condições de temperatura acima de $75^{\circ} \mathrm{C}$ e fluxos de calor de no máximo $140 \mathrm{~W} / \mathrm{cm}^{2}$, inviabilizando o seu uso em reatores de alta potência. Ainda, o aumento na estabilidade por adição de Mo, formação da liga-base U8Mo, um fluxo de calor de $300 \mathrm{~W} / \mathrm{cm}^{2}$ pode ser utilizado sem comportamento anormal sob inchamento, independente de a matriz apresentar-se pura em Al ou com Si adicionado.

\subsection{Estudos de adições ao combustível e à matriz de alumínio}

No mais recente trabalho para identificação das fases no sistema UMoZrAl, o de Varela et al. ${ }^{21}$ utilizaram-se as instalações do Laboratório Nacional de Luz Síncrotron, da Unicamp, para a identificação de fases presentes nesta camada de interação. Utilizaram como pares de difusão lâminas contendo as combinações U7Mo1Zr / Al A356 (7,1\%Si) e $\mathrm{U} 7 \mathrm{Mo} 1 \mathrm{Zr} / \mathrm{Al}$ tratado a $550^{\circ} \mathrm{C}$ por 1,5 horas, temperaturas usuais de laminação. Os resultados foram comparados com os usuais de difração de raios-X, microscopia óptica e de varredura. As ligas foram preparadas via forno a arco, e tratadas termicamente a $1000^{\circ} \mathrm{C}$ por 2 horas, para homogeneização da composição e retenção da fase gama. 
A camada de interação da liga estabilizada com zircônio, apresentou dimensão variando de 25 a $150 \mu \mathrm{m}$ e, além dos já presentes gama-U, alfa-U e alumínio, as fases que se formaram foram $\mathrm{UAl}_{3}, \mathrm{UAl}_{4}, \mathrm{Al}_{20} \mathrm{Mo}_{2} \mathrm{U}$ e $\mathrm{Al}_{43} \mathrm{Mo}_{4} \mathrm{U}_{6}$. No caso da matriz estabilizada com silício, a camada de reação variou de 3 a $12 \mu \mathrm{m}$, indicando que a adição de composto à matriz é a maior responsável pela inibição de seu crescimento. As fases sugeridas são o $\mathrm{U}(\mathrm{Al}, \mathrm{Si})_{3}$, com concentração de silício da ordem de $25 \%$, e as outras fases, identificadas com a luz síncrotron, sendo gama-U, alfa-U, e $\mathrm{U}_{5} \mathrm{Si}_{3}$. Não são mencionadas as quantidades de cada fase presente, o que é importante na estimativa de propriedades físicas das placas de elemento combustível e também em medidas de velocidades de reação. Presume-se assim que, se o silício na matriz reduz em 92\% (comparando-se as espessuras das camadas de interação) o tamanho da camada de reação, a velocidade de reação também seja reduzida nesta mesma porcentagem, considerando-se mecanismos de reação de primeira ordem.

O estudo da liga ternária UMoZr, tomou por base os resultados de Park et al. ${ }^{15}$, sobre a estabilidade da fase gama e interdifusão no sistema UMoZr / AlSi. Nesta publicação, os autores analisaram pós atomizados das ligas de U7MoxZr, x =1, 2 e 4\%, e sua interação com matriz de alumínio estabilizada com adições de 0,4, 2 e $5 \%$ de silício em peso. Observaram que adições de silício à matriz reduziram as taxas de reação combustível matriz, mas a justificativa para o uso do zircônio, entretanto, foi com base em resultados de simulações atomísticas, mas restritas às condições de processamento préirradiação.

Para os experimentos de estabilidade térmica, as ligas combustíveis foram preparadas via indução e tratadas termicamente por 24 horas a $950^{\circ} \mathrm{C}$ e temperadas em água para estabilização da fase gama. Para os testes de dispersão, utilizaram os pós atomizados, na faixa de composições acima, com partículas da ordem de 150 a $200 \mu \mathrm{m}$. Conforme a configuração de seu elemento combustível, procederam então à mistura e extrusão da fase combustível com a matriz de alumínio-silício, a $400^{\circ} \mathrm{C}$, para fabricar dispersões contendo $10 \%$ de fração volumétrica.

Em termos de estabilidade da fase gama-U, obtiveram que as ligas tratadas a $500^{\circ} \mathrm{C}$ transformam-se em uma mistura de alfa e delta, por que abaixo de $600^{\circ} \mathrm{C}$ para uma liga de U7Mo a fase gama é instável, conforme mostra o diagrama de fases binário UMo. Entretanto, as fases de decomposição aparecem, nos mesmos diagramas, somente em temperaturas menores do que $565^{\circ} \mathrm{C}$. Observaram também que é nulo o efeito das adições 
de zircônio na estabilização da fase gama, pois os espectros de difração de raios-X não se alteram. Sugere-se assim que, a $500^{\circ} \mathrm{C}$, a decomposição é tão rápida que não há influência da adição de zircônio na redução da velocidade de decomposição. Tratando-se termicamente as ligas por mais tempo, observaram que as velocidades de transformação, medidas pelo surgimento e crescimento de picos em DRX das fases de decomposição, aumentam com o aumento das adições de zircônio. Ou seja, o zircônio tem efeito desestabilizador, o que prejudica o desempenho dos combustíveis em longos ciclos de queima.

Estudando-se as camadas de interação, a primeira importante observação é sobre a não homogeneidade da estrutura do pó atomizado. Assim, possuindo estrutura celular metaestável dada a alta velocidade de resfriamento característica do processo de atomização, sabe-se que as concentrações de Mo nas bordas das partículas são de 2 a 3\% menores que a concentração média. Assim, é de se esperar que, como são regiões onde a fase gama tem menor estabilidade, produtos de reação se difundam por elas mais facilmente, o que foi confirmado por exame em microscópio de varredura. Partículas de UMo puro comportaram-se melhor em termos de reação com matriz de Al puro, sob tratamentos térmicos a $600^{\circ} \mathrm{C}$ por 1 hora, que partículas contendo zircônio adicionado, dado o efeito desestabilizador do zircônio. Quando se trabalhou com adições de silício à matriz e se aumentou o tempo de tratamento para 3 horas, observou-se que o tamanho das células face às condições anteriores diminuiu mas não o suficiente para que se concluísse favoravelmente ao efeito da adição de zircônio, pois a redução na camada de interação esteve dentro dos erros experimentais.

Combinações de U7Mo2Zr / A15Si seguidas de tratamento térmico das amostras por $600^{\circ} \mathrm{C}$ a 3 horas, a análise de distribuição dos elementos pelas partículas indicou que a camada de reação encontrou-se regularmente distribuída ao redor das partículas atomizadas. Em termos da distribuição dos elementos, observou-se que zircônio e molibdênio distribuíram-se homogeneamente, alumínio permaneceu concentrado na própria camada, e o silício difundiu-se até a partícula de combustível, indicando que um possível efeito estabilizador se dê por formação de interação silício-combustível. Aqui observo que isto pode justificar a adição de silício, ao menos até o limite de solubilidade, ao combustível. Quando se diminuiu a quantidade de silício na matriz, a camada de reação apresentou-se de maneira irregular, devido ao aumento na irregularidade de sua distribuição ao redor da partícula combustível. 
Por meio dos estudos de crescimento da camada de reação em função do teor de zircônio sob tratamentos térmicos de pares $\mathrm{UMoxZr} / \mathrm{Al}$ a $580^{\circ} \mathrm{C}$ por 5 horas, obtiveram uma redução em espessura com o aumento da porcentagem de $\mathrm{Zr}$, em matrizes contendo alumínio puro. Entretanto, para uma mesma porcentagem de Zr, a variação da quantidade de silício apresentou efeito desprezível na redução da camada, quando do tratamento das amostras a $600^{\circ} \mathrm{C}$ por 3 horas. Assim, é o efeito combinado, e não isolado, das adições à matriz e ao combustível que torna a camada de reação mínima. Destacam a importância do uso da combinação entre ambos os elementos, pois quando utilizados separadamente promovem a reação de UMo pelo silício e de alumínio pelo zircônio.

Assim, a possível formação de barreira de difusão, promovida pela formação de supostos compostos como $\mathrm{U}(\mathrm{Al}, \mathrm{Si})_{2}$ ou $\mathrm{U}(\mathrm{Al}, \mathrm{Si})_{3}$, é o que minimiza a movimentação de silício pelo combustível e de zircônio para a matriz. Em termos de combustíveis, observa-se que o silício, ao se movimentar pelas zonas celulares do combustível mais facilmente que o zircônio, tem melhor desempenho como estabilizador.

Finalmente, a análise do perfil de composições na camada de interação com a matriz composta por alumínio puro mostrou que molibdênio e zircônio distribuem-se de maneira uniforme. Para o alumínio, sua concentração é praticamente a mesma que a da matriz, caindo bruscamente na fase combustível, indicando maior difusividade do alumínio pela camada de reação. O perfil de concentração do urânio segue de perto os de zircônio e molibdênio, mas a sua concentração é maior.

O silício reduz a camada de reação quando se trabalha com o par U7Mo / AlySi. O perfil de concentrações de alumínio se altera, possuindo um mínimo no centro da camada, enquanto neste ponto temos um máximo em concentração de silício, o que mostra a maior difusividade do silício. Quando se adiciona zircônio, os perfis de concentração de urânio, molibdênio e zircônio são os mesmos, seguem o padrão acima. Entretanto, fica evidenciada a presença de dois tipos de camadas de reação, a mais próxima à matriz rica em alumínio e pobre em silício, e a mais próxima à fase combustível mais rica em silício, pobre em alumínio, ambas possuindo regiões de extremos de concentração.

Apesar da combinação Zr-Si produzir efeito na minimização da camada, a estabilidade da fase gama diminui com adições de zircônio. Como a estabilidade da fase gama é uma condição necessária para a sua aplicação como fase combustível, os autores refizeram o estudo, mantendo a adição de silício, mas alterando a adição ternária ao combustível de zircônio para titânio. 
Isto foi feito em Park et al. ${ }^{18}$, seguindo os mesmos passos do artigo anterior, determinaram maior redução na camada de reação com a adição de titânio ao combustível. Entretanto, o comportamento das ligas em termos de estabilidade da fase gama é semelhante ao do zircônio, havendo ainda o complicador de que, com o aumento na porcentagem de adição, houve a formação de precipitado rico em titânio. Assim, os autores sugerem que o limite de solubilidade do Ti no binário U-Mo seja de 1\%. Adições isoladas de Ti reduzem a camada de interação U-Mo-Ti / Al, mas adições superiores a 1\% desestabilizam a fase gama. Da mesma forma, concluíram favoravelmente pela adição combinada $\mathrm{Ti}$ - Si, observando ainda que as adições de titânio foram mais efetivas que a de zircônio.

O importante a ser notado é que deve haver, então, um compromisso em termos de estabilidade da fase gama e crescimento da camada de interação. Conforme estes dois resultados demonstram, perde-se em estabilidade e ganha-se em redução na camada de interação quando da adição de ternários ao combustível. Como estamos falando em fração em peso de até $10 \%$ de elemento de liga ao urânio, e como se sabe que o Mo é formador de camada, seriam convenientes adições de 10\% em peso no total. Entretanto, a porcentagem de Mo deve ser suficiente para que o compromisso estabilidade química $\mathrm{x}$ estabilidade estrutural seja obedecido. Justifica-se assim a escolha, nesta tese, do valor máximo de 7\% em Mo, com adições ternárias e quaternárias da ordem de 3\%.

A utilização de modelos para o crescimento da camada de interação em combustíveis de U-Mo, com e sem adições de silício à matriz, é importante no estudo do efeito de outras possíveis adições. No trabalho de Kim et al. ${ }^{22}$ foi proposto modelo para os casos de crescimento sob irradiação, em temperaturas de operação nos reatores da ordem de $150^{\circ} \mathrm{C}$. Como a extrapolação dos resultados clássicos de crescimento em temperaturas de $550^{\circ} \mathrm{C}$ não produziram resultados condizentes com as medidas pós-irradiação nos testes RERTR, os efeitos de danos de irradiação foram introduzidos. Assim, a correlação para o crescimento sob irradiação foi estabelecida com base em 4 parâmetros: tempo, temperatura, taxa de fissões e taxa de danos de irradiação.

No caso do crescimento sob laminação, considerou-se satisfatório o ajuste dos dados a uma expressão parabólica, com constante de velocidade dada por um termo exponencial, dependente da energia de ativação para o crescimento da camada e da temperatura de irradiação. Estas equações foram previamente descritas no trabalho de Kim et al. $^{23}$, que calcularam as energias de ativação para crescimento da camada com combustíveis à base de siliceto de urânio e U-Mo, trabalho este examinado adiante. 
Para o caso de crescimento da camada sob irradiação, considerou-se a influência de vários fatores sobre o processo de interdifusão. Foi sugerida uma expressão que considera a média geométrica entre as taxas de fissão Fr, usualmente obtidas em cálculos de física de reatores, e de danos de irradiação Fd, produzidas na fase combustível, que necessitam ser estimadas. Além disso, considerou-se uma energia de ativação média $Q^{i}$ para cada classe de efeitos sobre o crescimento da camada de reação. A expressão foi a seguinte:

$$
k^{i}=A(F r F d)^{0,5} \exp \frac{-Q^{i}}{R T}
$$

e o efeito da difusão sob irradiação na camada de interação é o de amorfizá-la, gerando cada vez mais defeitos em seu interior, na chamada de amorfização induzida por irradiação.

Com base nos ajustes de suas expressões aos dados das medidas dos testes RERTR6, as energias de ativação médias para o crescimento da camada de reação sob irradiação encontraram-se na faixa de 46 a $76 \mathrm{~kJ} / \mathrm{mol}$, com constante de velocidade variando entre $1,46 \times 10^{-14}$ a $1,94 \times 10^{-10} \mathrm{~cm}^{3.5} \mathrm{~s}^{-0.5}$, enquanto que, para o caso de interação não induzida por irradiação, a energia de ativação ficou ao redor de $300 \mathrm{~kJ} / \mathrm{mol}$, e a constante de velocidade ao redor de $3,94 \times 10^{-16} \mu \mathrm{m} \mathrm{s}^{-2}$. Isto significa que a camada de interação cresce mais rapidamente durante a irradiação, conforme esperado. Entretanto, adições progressivas de silício, conforme mencionam os autores, reduzem exponencialmente este crescimento, demonstrando-se assim a efetividade das adições de silício à matriz.

Kim et al. ${ }^{23}$ estabeleceram as energias de ativação para crescimento da camada de reação em dispersões de $\mathrm{U}_{3} \mathrm{Si}_{2}$ e U7Mo em alumínio, apenas para o regime de temperaturas de laminação. Explicaram o aparecimento de poros na fase matriz das placas e sua conseqüente expansão volumétrica como resultado da maior difusividade do alumínio para o interior das partículas de combustível. O movimento no sentido contrário não se processa na mesma velocidade, pois o urânio, por ter menor difusividade, não tem tempo para ocupar os espaços vazios deixados pelo alumínio. Verificaram ainda que, em temperaturas da ordem de $500^{\circ} \mathrm{C}$, o crescimento da camada de reação é acentuado, e propuseram a seguinte equação para o crescimento da interface: 


$$
\mathrm{Y}^{2}=\mathrm{kt}
$$

onde Y mede a espessura da camada de reação. A constante da reação foi estimada utilizando-se dependência exponencial com a temperatura, característica dos processos difusivos de primeira ordem. Em termos da energia de ativação Q para a reação, temos:

$$
\mathrm{k}=\mathrm{ko} \exp (-\mathrm{Q} / \mathrm{BT})
$$

e fazendo as curvas de Y ao quadrado, medido experimentalmente, em função do tempo para diversas temperaturas, e colocando em gráfico os valores do logaritmo das inclinações obtidas em função do inverso da temperatura, obtiveram a energia de ativação para crescimento da camada de interação U-Mo / Al como sendo Q $=316 \mathrm{~kJ} / \mathrm{mol}$.

Segundo o mesmo trabalho, este valor é maior do que a observado no sistema $\mathrm{U}_{3} \mathrm{Si}-\mathrm{Al}(\mathrm{Q}=220 \mathrm{~kJ} / \mathrm{mol})$, e portanto, neste caso, o processo de difusão pode ocorrer em temperaturas mais baixas. Assim, o sistema U-Mo/Al, por ser menos susceptível a estas reações (maior energia de ativação), possui esta vantagem adicional: a de não apresentar reação, ou baixa taxa de reação mesmo em altas temperaturas, comparadas com o sistema U-Si-Al.

Outros resultados interessantes, e confirmados por esta tese, foram os relacionados à temperatura de início e calor de reação para reação espontânea entre U6Mo e Al. Por exemplo, para a fração volumétrica de U6Mo nas miniplacas de $10 \%$, por Calorimetria Diferencial de Varredura (DSC, "Differential Scanning Calorimetry", em inglês), observou-se pico endotérmico a $645^{\circ} \mathrm{C}$ correspondente à reação U6Mo e $\mathrm{Al}$, confirmados nesta tese pela técnica de Análise Térmica Diferencial (DTA, "Differential Thermal Analysis", em inglês), conforme será visto adiante. Ao contrário de $\mathrm{KIM}^{23}$, achei interessante efetuar as análises para todas as ligas-base e ligas propostas nesta tese, com o objetivo de se verificar se há alteração no valor de temperatura, ou até mesmo, se estas reações ocorrem. Estes resultados são importantes também para a previsão do desempenho das placas, estudado no trabalho de LEE et al. ${ }^{24}$.

Os trabalhos apresentados neste item são os mais indicados para a discussão ou suporte do trabalho proposto nesta tese, e enfatizaram o problema da interação combustível-matriz. Obviamente que a qualificação do combustível se dá no seu uso final, ou seja, em condições de operação nos reatores de pesquisa. Alguns resultados serão apresentados no próximo item. 


\subsection{Qualificação e desempenho sob irradiação / testes RERTR}

Para que um material seja utilizado como combustível nuclear, é necessário que passe por uma série de testes sob irradiação. O seu desempenho nestes testes, usualmente conduzidos em condições variadas de ciclos de queima, temperatura, etc., permite a avaliação de seu comportamento, principalmente sob a formação e crescimento de camadas de interação combustível-matriz, no caso de combustíveis dispersos, e formação e crescimento de bolhas, que levam ao inchamento e falha nos elementos.

Para isso, em 1996 foi elaborado um programa de avaliação de desempenho de combustíveis dispersos e monolíticos, sob irradiação, denominado RERTR-x, x = 1 a 9 (até a presente data), que se iniciou em 1997. Todos estes testes estão relacionados à qualificação de combustíveis à base da liga U-Mo disperso em matriz de Al.

Relativos ao desempenho dos binários $\gamma$-UMo nos dois primeiros testes, RERTR-1 e 2, em Meyer et al. ${ }^{25}$ foram examinados os inchamentos das placas a 40 e $70 \%$ de queima, o crescimento da camada de interação combustível-matriz, e também a microestrutura dos combustíveis à base de ligas $\gamma$ UMo antes e após a irradiação. No teste RERTR-1, a descarga do reator ATR foi feita após 94 dias de irradiação a potência máxima, com queima calculada em torno de 39 a $45 \%$ de $U^{235}$. No RERTR-2, descarregouse após 232 dias a plena potência, com queimas calculadas de 65 a $71 \%$. A temperatura média na linha central da placa foi calculada em $65^{\circ} \mathrm{C}$. A composição em termos de elementos de liga foi de 6,8 e 10\% em peso, todas atomizadas (10\% também de limagem), e alguns ternários com Ru. As densidades de fissão e queimas foram calculadas para cada uma delas. No caso das ligas a 6 e 10\% em peso de molibdênio, $\gamma$ U6Mo e $\gamma$ U10Mo, prepararam cargas com pó atomizado e com pó limado, para comparação dos efeitos do processo de fabricação no desempenho. Os carregamentos em $\mathrm{U}$ foram da ordem de $4 \mathrm{gU}$ $/ \mathrm{cm}^{3}$, e juntamente com os valores de temperatura, muito abaixo dos valores necessários para reatores de pesquisa de alta potência, embora as exposições e ciclos de queima tenham sido altos.

Como as principais contribuições para o inchamento de um combustível são dadas pela formação e crescimento da camada de interação combustível-matriz, os autores conduziram medidas pós-irradiação de espessura da camada, e de variação de volume do combustível e de bolhas, considerando a referente à formação de produtos sólidos de fissão desprezível, conforme dados de literatura. Sabe-se que é a camada de interação a maior 
responsável pela variação em área da fase combustível, pela formação de produtos de fissão sólidos e pela nucleação e crescimento de bolhas de gases de fissão.

Comparando-se as técnicas de processamento, para as ligas U10Mo, observaram que a camada de interação cresce da mesma forma, uniformemente ao redor das partículas, mas a taxas diferentes. Assim, para as limalhas, o crescimento em área observado nas provas metalográficas foi sempre maior. A $40 \%$ de queima, limalhas produziram aumento em área $7 \%$ e, a $70 \%$ de queima, $25 \%$. No caso dos gases de físsão, este acréscimo foi de aproximadamente $65 \%$, a $70 \%$ de queima. Isto indica que, mesmo em queimas baixas (40\% é o que o reator do IPEN tem como limite), partículas atomizadas apresentam melhor desempenho, e as de limagem devem ser consideradas com maior atenção.

Comparando-se o desempenho a 6,8 e 10\% em peso para pós atomizados, em termos de camada de interação observou-se queda com o aumento no teor de molibdênio, nos dois ciclos de queima utilizados. Para a variação em área de fase combustível, o mesmo efeito foi observado. Entretanto o fenômeno não foi linear, caindo mais rapidamente quando a liga continha $10 \%$ de adição. Em termos do volume das bolhas de fissão, houve novamente queda com a porcentagem de adição. Ainda, a adição de $0,6 \%$ em peso de rutênio à liga U6Mo reduziu fração em área da fase combustível, a 70\% de queima, e também a espessura média da camada de interação. Conforme trabalho de Hofman et al. ${ }^{14}$, este elemento, assim como platina, paládio e ósmio, atua no sentido da estabilização da fase gama, minimizando problemas de interação. Devemos, entretanto, levar em conta também a perda neutrônica quando de sua presença na fase combustível.

Além das frações em área mencionadas, no caso das bolhas de gases devemos levar em conta a sua solubilidade na camada de interação, na fase matriz e na combustível. Assim, o tamanho das bolhas é importante para sabermos se há a possibilidade de acomodação das mesmas na placa, em caso afirmativo não haveria contribuição ao inchamento. Observou-se que a área das bolhas decresce também com o aumento na porcentagem de molibdênio, e que também, para o caso dos pós atomizados, obteve-se o valor mínimo.

Um estudo da segregação de molibdênio em partículas atomizadas pode ser encontrado no trabalho de Kim et al. ${ }^{26}$. Este trabalho e o anterior indicaram, conforme mencionei anteriormente, o importante papel do molibdênio na estabilização da fase gama e, conseqüentemente, na minimização do crescimento da camada de reação. Assim, o aumento no Mo diminui a velocidade de crescimento, pois gama é menos reativa que alfa. 
Entenda-se bem que a diminuição na velocidade não implica em minimização do crescimento. Conforme foi observado nos trabalhos do item anterior, Mo é formador de camada.

Além disso, observam os autores que, durante a etapa de fabricação, a fase gama de U6Mo decompõe-se significativamente, mas lembram que, a conteúdos suficientemente grandes de estabilizante, sob irradiação pode-se reverter $\alpha+\delta$ em $\gamma$ em temperaturas menores que $200^{\circ} \mathrm{C}$, já em queimas da ordem de $0,1 \%$. Devemos levar em conta, entretanto, que a região em que ocorre a decomposição na partícula de combustível deve permitir a difusão de molibdênio, ou seja, a decomposição deve ser intergranular. Ou seja, visto que os resultados de desempenho sob irradiação foram satisfatórios para todas as composições, há clara indicação para a utilização de porcentagens de adição ao redor de $10 \%$ em peso de molibdênio ou, melhor ainda, $10 \%$ em peso total de elementos de adição. Entretanto, há o compromisso, mencionado anteriormente, entre estabilidade química e estrutural, que deve sempre ser levado em conta.

Em termos de contribuição total para o inchamento do combustível, a formação do alumineto (U, Mo) $\mathrm{Al}_{3}$ durante a irradiação, a formação de UAlx na fabricação, e o volume total de gases de fissão, todos eles caem com o aumento da porcentagem de Mo, sendo minimizada com a atomização. Os resultados de desempenho dos combustíveis em termos das técnicas de processamento serão descritos no capítulo 4.

Nestes dois programas de testes, outras ligas de urânio foram testadas, e os resultados examinados com mais detalhes no trabalho de HOFMAN et al ${ }^{27}$. As composições principais foram as seguintes: U10Mo, U8Mo, U6Mo, U4Mo, U6Mo1Pt, U6Mo0,6Ru, U10Mo0,05Sn, U9Nb4Zr, U5Nb3Zr, $\mathrm{U}_{2} \mathrm{Mo}$ e $\mathrm{U}_{3} \mathrm{Si}_{2}$, e as dispersões foram feitas, para U10Mo e $\mathrm{U}_{3} \mathrm{Si}_{2}$, com pós mecanizados, moídos e atomizados. As frações volumétricas de combustível ficaram entre 26 e $41 \%$, com média aproximada de 30\%, o enriquecimento ficou entre 19,1 e $19,8 \%$ e as placas continham tipicamente $0,11 \mathrm{~g} \mathrm{U}^{235}$. O fluxo de nêutrons aproximado foi de $1,3 \times 10^{18} \mathrm{n} \mathrm{m}^{-2} \mathrm{~s}^{-1}$, potência de $500 \mathrm{~kW}$, densidade de potência de $5,5 \times 10^{5} \mathrm{~kW} \mathrm{~m}^{-2}$ e temperatura no BOL ("beginning of life" ou início de atividade) de $70^{\circ} \mathrm{C}$.

Relativamente aos testes RERTR-1, suas principais conclusões foram as seguintes. $\mathrm{Na}$ fabricação, após tratamento térmico a $485^{\circ} \mathrm{C}$, um significativo aumento na espessura das placas foi observado na liga $\gamma \mathrm{U} 4 \mathrm{Mo}$ e em todas as ligas de $\gamma \mathrm{UZrNb}$, e ainda, quando a porcentagem de adição diminuiu, diminuindo-se a estabilidade da fase gama. 
Assim, pode-se descartar o uso destas ligas, posto que os testes foram realizados em temperaturas muito baixas.

Para as ligas binárias de UMo contendo $\mathrm{U}(\mathrm{x} \geq 6)$ Mo e ternárias, praticamente não houve aumento de espessura. Comparando-se, por exemplo, as estruturas de bolhas de $\gamma \mathrm{U} 10 \mathrm{Mo}, \gamma \mathrm{U} 6 \mathrm{Mo0} .6 \mathrm{Ru}$ e $\gamma \mathrm{U} 6 \mathrm{Mo1Pt}$, não foi possível a sua observação até um aumento de 500 vezes. Entretanto, a adição de Ru e Pt alterou a estrutura de grãos em relação a $\gamma$ U6Mo e demais binários de $\gamma \mathrm{UxMo}$, tornando-a mais fina, presumindo-se daí que pode haver maior formação de bolhas nestes ternários. Este refinamento foi atribuído como sendo devido também à recristalização induzida por irradiação, fenômeno este recorrente em todos os binários $\gamma \mathrm{UxMo}$. Entretanto, a fase gama manteve-se relativamente estável, ao contrário do que ocorreu, por exemplo, nas ligas de $\gamma \mathrm{UxZ}$ ryNb, nas quais houve altas taxas de inchamento devido à formação de grande quantidade de camada de interação.

Para o teste RERTR-2, 70\% de queima, observaram bolhas em todas as ligas já em 500 vezes de aumento, compostas por duas populações distintas, a primeira principalmente com diâmetro médio de $1 \mu \mathrm{m}$, e a outra, muito densa, com diâmetro da ordem de $0,1 \mu \mathrm{m}$. O número de bolhas da primeira população cresceu com a diminuição do teor de Mo, sendo dominante na liga $\gamma \mathrm{U} 4 \mathrm{Mo}$, o que reforça a idéia de que estas ligas são instáveis. Neste caso, criou-se a possibilidade de coalescência de bolhas e, portanto, de inchamento catastrófico, ao contrário das ligas com $\gamma \mathrm{U}(\mathrm{x} \geq 6) \mathrm{Mo}$, e U6Mo com adição de ternário, nas quais as bolhas pertenciam principalmente à classe 2. Bolhas pequenas indicam a possibilidade de solubilização, e também a impossibilidade de coalescimento, e observaram haver uma transição, em alguma porcentagem entre 4 e $6 \%$ de adição $\gamma$ UxMo, para a qual o comportamento passa de aceitável para inaceitável. Ligas de $\gamma$ U4Mo e $\gamma \mathrm{UZrNb}$ comportaram-se de maneira semelhante.

Em termos microestruturais, observou-se para todas as composições, exceto $\gamma$ U4Mo, um refinamento dos grãos durante a irradiação, que foi incompleto no caso dos pós $\gamma \mathrm{U} 10 \mathrm{Mo}$ atomizados, devido ao pequeno trabalho a frio e à segregação composicional. $\gamma \mathrm{U} 8 \mathrm{Mo}$ e $\gamma \mathrm{UZrNb}$, durante fabricação a $500^{\circ} \mathrm{C}$, sofrem também decomposição a alfa e delta, reagindo significativamente com a matriz de alumínio. Estas duas fases ficam presentes na partícula de combustível, mesmo na parte não reagida, possibilitando a nucleação e crescimento de bolhas. Assim, novamente, reforça-se a idéia da utilização de porcentagens de adição equivalentes a $10 \%$ em peso de Mo, para maior estabilidade da 
estrutura gama, embora, durante a irradiação, as fases de decomposição revertem-se a gama, especialmente nas ligas termodinamicamente mais estáveis.

Finalmente, em termos das camadas de interação, observaram que a interdifusão de $\mathrm{U}$ em $\mathrm{Al}$ é rápida já a $300^{\circ} \mathrm{C}$, o que leva à excessiva interação nas ligas $\gamma \mathrm{U} 4 \mathrm{Mo}$ e $\gamma \mathrm{UZrNb}$, a $500^{\circ} \mathrm{C}$. Sob irradiação, interação pode ocorrer já a $100^{\circ} \mathrm{C}$, e se a fração volumétrica for alta, a $250^{\circ} \mathrm{C}$ pode ocorrer consumo total da matriz de alumínio, acompanhada de inchamento excessivo. Comparando-se com os dados de $\mathrm{U}_{3} \mathrm{Si}_{2}$ e $\mathrm{U}_{3} \mathrm{Si}$, entretanto, observou-se que todos os binários $\gamma \mathrm{UxMo}$ comportaram-se melhor, a espessura da camada de interação foi menor em todos os casos, e decresceu com o aumento no teor de Mo, para uma fixa taxa de fissões. Entretanto, este consumo de alumínio da matriz foi mais alta para estes sistemas.

Para testar condições mais severas, foi programado o teste RERTR-3, no qual altas cargas de urânio e temperatura foram utilizadas. Serão citados em seguida as análises dos resultados feitas por Meyer et al. ${ }^{28}$. As condições deste grupo de testes foram as seguintes: mesmas composições binárias $\gamma \mathrm{UMo}$, densidades de 8 a $9 \mathrm{gU}^{235} / \mathrm{cm}^{3}$, temperaturas de $200^{\circ} \mathrm{C}$, mas exposições moderadas, $40 \%$ de queima, $3 \times 10^{21}$ fissões $/ \mathrm{cm}^{3}$, ao contrário dos testes RERTR 2.

Os autores enfatizam que, com base nos resultados dos testes anteriores, nos testes RERTR-3 trabalhou-se exclusivamente com ligas de U-Mo, procurando-se diferenciar efeitos de composição em termos da reatividade combustível-matriz, mas em maiores temperaturas, densidades na placa e ciclos de queima. A adição de ósmio foi feita em algumas placas, para tentar se confirmar o predito por Hofman et al. ${ }^{14}$. O que observaram foi um aumento na interação combustível-matriz em relação aos testes anteriores, primeira evidência de que a reação é função tanto da taxa de fissões quanto da temperatura. Observou-se também que, ao contrário de Hofman et al. ${ }^{14}$, houve consumo de alumínio da matriz por difusão deste ao interior das partículas de combustível e, portanto, o ósmio não conseguiu diminuir este fenômeno, apesar de teoricamente aumentar a estabilidade. Conforme visto anteriormente, $\mathrm{Zr}$ e Ti diminuem a espessura da camada de reação, mas também a estabilidade da fase gama.

Para explicar o mecanismo de interação combustível-matriz, os autores fizeram o balanço de massa e volume, equações de conservação ou de continuidade, e os aplicaram à possível reação U-Mo / Al: 


$$
\mathrm{A}(\mathrm{U}-\mathrm{Mo})+\mathrm{B} \mathrm{Al} \rightarrow \mathrm{Y}(\mathrm{U}-\mathrm{Mo}) \mathrm{Al}_{\mathrm{x}}+\mathrm{W} \mathrm{Al}+\mathrm{Z}(\mathrm{U}-\mathrm{Mo})
$$

ou

$$
(\mathrm{A}-\mathrm{Z})(\mathrm{U}-\mathrm{Mo})+(\mathrm{B}-\mathrm{W}) \mathrm{Al} \rightarrow \mathrm{Y}(\mathrm{U}-\mathrm{Mo}) \mathrm{Al}_{\mathrm{x}}
$$

onde A, B, W, Y e Z são as quantidades molares, e x determina a quantidade de alumínio na fase $(\mathrm{U}-\mathrm{Mo}) \mathrm{Al}_{\mathrm{x}}$ de interação. Como primeira hipótese, foi assumida a solubilidade sólida do molibdênio no $\mathrm{UAl}_{\mathrm{x}}$. Os coeficientes $\mathrm{A}$ e $\mathrm{B}$ podem ser obtidos dos dados de fabricação das placas, W de medidas metalográficas pós-irradiação. Ainda, ao assumirem que o alumínio não sofre alteração significativa de volume, então a quantidade de alumínio consumida para formar a fase $(\mathrm{U}-\mathrm{Mo}) \mathrm{Al}_{\mathrm{x}}$ pode ser dada pela diferença $\mathrm{B}-\mathrm{W}$, ou seja, $\mathrm{xY}=$ B-W. O coeficiente $\mathrm{Z}$ foi usado para dar conta do inchamento da liga. Como estamos falando em equações de continuidade, as densidades são importantes, daí considerar-se também a variação em volume.

Resultados dos testes indicaram que o aumento na adição de Mo reduz a formação da camada de $\mathrm{UMoAl}_{\mathrm{x}}$, embora ainda haja grande interação nas condições destes testes, mais drásticas. Observaram que, além da solubilização do Al na camada, houve boa presença do mesmo na partícula de combustível. Ou seja, mesmo que se atinja saturação em uma das fases, a outra ainda acomoda o alumínio da matriz. Propuseram então uma equação mais geral:

$$
\mathrm{A}(\mathrm{U}-\mathrm{Mo})+\mathrm{B} \mathrm{Al} \rightarrow \mathrm{Y}(\mathrm{U}-\mathrm{Mo}) \mathrm{Al}_{\mathrm{x}}+\mathrm{W} \mathrm{Al}+\mathrm{Z}\left[(\mathrm{U}-\mathrm{Mo})+\mathrm{Al}_{\mathrm{q}}\right]
$$

no qual $\left[(\mathrm{U}-\mathrm{Mo})+\mathrm{Al}_{\mathrm{q}}\right]$ representa a solução sólida de $\mathrm{Al}$ na fase $\gamma \mathrm{UMo}$.

Neste ponto os autores inserem no modelo as equações de conservação de massa e volume, para obtenção de solução para Y, Z, x e q. São elas:

- conservação de volume do núcleo da placa de combustível:

$$
\mathrm{V}_{\mathrm{m}}=\mathrm{V}(\mathrm{U}-\mathrm{Mo}) \mathrm{Al}_{\mathrm{q}}+\mathrm{V}(\mathrm{U}-\mathrm{Mo}) \mathrm{Al}_{\mathrm{x}}+\mathrm{VAl}
$$

- equação para o volume total da solução sólida (U-Mo)+Al $\mathrm{q}_{\mathrm{q}}$ : 


$$
\mathrm{V}(\mathrm{U}-\mathrm{Mo}) \mathrm{Al}_{\mathrm{q}}=\mathrm{Z} \mathrm{G}(\mathrm{q})\left(1+\mathrm{S}_{1}\right) / \mathrm{J}(\mathrm{q})
$$

- equação para o intermetálico $(\mathrm{U}-\mathrm{Mo}) \mathrm{Al}_{\mathrm{x}}$ :

$$
\mathrm{V}(\mathrm{U}-\mathrm{Mo}) \mathrm{Alx}=\mathrm{Y} \mathrm{L}(\mathrm{x})\left(1+\mathrm{S}_{2}\right) / \mathrm{H}(\mathrm{x})
$$

nas quais Vm é o volume do combustível irradiado relativo ao volume original, $\mathrm{S}_{1}$ e $\mathrm{S}_{2}$ os inchamentos da fase $\left[(\mathrm{U}-\mathrm{Mo})+\mathrm{Al}_{\mathrm{q}}\right]$, solução sólida, e intermetálica (U-Mo) $\mathrm{Al}_{\mathrm{x}}$, respectivamente, $\mathrm{G}(\mathrm{q})$ e $\mathrm{L}(\mathrm{x})$ os pesos moleculares da solução sólida e da fase intermetálica, J(q) a densidade da solução sólida, calculada utilizando-se da regra da mistura, $\mathrm{H}(\mathrm{x})$ a densidade da fase intermetálica. Esta última foi determinada por meio de regressão linear sobre valores conhecidos de densidades de 3 fases aluminetos de urânio, UAlx, como função de $\mathrm{x}$ :

$$
H(x)=9,38-0,98 x
$$

$\mathrm{O}$ aumento no volume devido ao inchamento foi definido da maneira usual, $\mathrm{S}=\Delta \mathrm{V} / \mathrm{Vo}$. O aumento de volume devido ao inchamento da solução sólida foi determinado por diferença, conforme equação seguinte.

$$
\Delta \mathrm{V}(\text { sol.sól,fissão })=\Delta \mathrm{V}_{\mathrm{m}}-\Delta \mathrm{V}(\mathrm{UMo}) \mathrm{Al}_{\mathrm{x}}-\Delta \mathrm{V}\left((\mathrm{U}-\mathrm{Mo}) \mathrm{Al}_{\mathrm{x}}, \text { fissão }\right)-\Delta \mathrm{VUMoAl} \mathrm{q}_{\mathrm{q}}
$$

$\mathrm{O}$ inchamento da fase alumineto foi baseado em dados do $\mathrm{UAl}_{3}$ :

$$
\mathrm{S} 2=0,033 * \mathrm{Fd}
$$

Fd é a densidade de fissão da fase alumineto em unidades de $10^{21} / \mathrm{cm}^{3}$. Considerações de conservação da massa do Al levam a:

$$
\begin{gathered}
Z=A-Y \\
q=(B-W-x Y) / Z
\end{gathered}
$$


A resolução simultânea das equações de (12) a (20), aliadas a medida de alguns parâmetros por metalografia e análise dimensional das placas, para obtenção dos valores de $\mathrm{x}, \mathrm{q}$ e $\mathrm{S}_{1}$, apresentam as seguintes limitações. A primeira delas é a de que são empíricas, não havia dados (ao menos na época) para ternários UMoAl. Ainda, a alteração de volume na placa é aproximada por uma medida de espessura média da placa na zona do combustível, e também, medidas de fração volumétrica foram feitas em apenas uma seção transversal simples da placa do combustível, assumida como representativa de toda a amostra. Após estimativa dos erros, chegou-se a valores para os parâmetros q entre 2,5 e $4,8 \%$ em peso, portanto estas seriam as quantidades de alumínio dissolvidos na fase gama, e para $\mathrm{x}$, obteve-se porcentagem em átomos de 81 a $84 \%$. Transformando para porcentagens em peso, chega-se a $\mathrm{x}=4$. Assim, nesta primeira análise, os autores concluíram que a camada de interação tem a composição (UMo) $\mathrm{Al}_{4}$. Entretanto, mesmo sendo este um material indesejado, nas condições deste experimento não houve alteração drástica na performance dos combustíveis, o seu comportamento sob irradiação foi muito estável.

Em termos de complexidade, o único fato que perdura, até o momento, é o da previsão da distribuição de temperaturas ao longo das placas em presença da camada de interação, que ainda permanece de difícil resolução. Segundo observou Hofman et al. ${ }^{29}$, e tomando por base os resultados de perfis de condutividade obtidos por Lee et al. ${ }^{30}$, a condutividade térmica reduzida do material na região da interface tem o efeito de aumentar globalmente a temperatura das demais regiões do combustível. Esta elevação na temperatura aumenta a interdifusão e, portanto, a taxa de depleção de $\mathrm{Al}$ da matriz, embora ela possa ser inibida pelas adições de Mo.

Além disso, os processos relativos à dinâmica de formação e crescimento das bolhas também são funções do perfil de temperaturas na placa e no combustível. Observou-se que, a partir do momento em que se atingiu uma quantidade de Al suficiente para a formação da camada de interação de composição estável, o processo de formação de bolhas é outro. Daí a realização, até o momento, dos estudos de compatibilidade. À época desta publicação, como pouco se conhecia sobre a interação combustível-matriz, já se sabia que, embora de mais fácil formação, a interface em combustíveis à base de U-Si é mais fina.

Nos testes RERTR-4 e 5 irradiaram-se as mesmas ligas, nas condições nominais de operação de reatores de alta potência: temperatura do combustível de $180^{\circ} \mathrm{C}$, e carregamentos em volume de $\mathrm{U}^{235}$ de 6 e $8 \mathrm{~g} / \mathrm{cm}^{3}$. No RERTR-4, a queima foi de $50 \%$ em 
átomos, e no RERTR-5, de 80\%. As dispersões, em sua maioria, foram fabricadas com pós atomizados, mas algumas miniplacas foram feitas com pós usinados.

Núcleos monolíticos também foram testados e, em geral, observou-se que, mesmo nestas condições mais drásticas, as ligas-base $\gamma \mathrm{UMo}$ comportaram-se bem. Assim, até cargas em volume de $8 \mathrm{gU}^{235} / \mathrm{cm}^{3}$ e temperaturas de $300^{\circ} \mathrm{C}$, observou-se inchamento das ligas estável e independente da temperatura, conforme discussão dos resultados apresentada no trabalho de Hofman e Meyer. ${ }^{31}$. Bom comportamento também foi obtido para os monolíticos.

Entretanto, para a camada de interação, observou-se consumo de praticamente toda a matriz de alumínio nestas condições, ocupando volume maior que o da fase combustível remanescente.

Os testes RERTR 6 confirmaram o bom desempenho sob irradiação dos combustíveis à base da liga $\gamma \mathrm{UMo}$, tanto na forma dispersa quanto na monolítica, mas em condições de baixa potência e queima, conforme discutido em WACHS et al, ${ }^{32}$. O grande problema continua sendo, ainda, a sua reação com a matriz, formando camada de interação com composição não muito bem definida e comportamento instável sob irradiação. Indicam estes autores que as possibilidades mais plausíveis para a minimização da camada sejam as adições de Ti, $\mathrm{Zr}$ ou outro material refratário, a adição de silício à matriz ou a eliminação da matriz, pela utilização de combustíveis monolíticos. Verificou-se que as adições de silício à matriz e os combustíveis monolíticos comportaram-se bem, não havendo falhas que os impeçam, nestas condições, de serem utilizados. Devemos salientar que o problema com os combustíveis monolíticos é a sua fabricação, embora métodos já tenham sido patenteados ${ }^{02}$. Todas estas modificações à liga base de $\gamma \mathrm{UMo}$ foram propostas no sentido de minimizar o inchamento e a formação de camada de interação combustível / matriz.

Nos testes RERTR-7 A e 7 B, foram analisados o desempenho dos mesmos materiais, mas em condições de queima e potência mais severas, como no teste RERTR 7 A conduzido com os mesmos materiais do teste RERTR 6, ligas de $\gamma$ UMo com composições de 7, 10 e 12\% de soluto, na forma dispersa ou monolítica. No teste RERTR $7 \mathrm{~B}$, ligas ternárias foram novamente testadas, a saber U7Mo2Zr e U7Mo1Ti, na forma dispersa, assim como foi feito nos testes iniciais, RERTR 2 e 3. Como principais resultados dos testes RERTR 7 A e 7 B, citam que as adições de Si à matriz reduziram a espessura da camada de reação e o inchamento das placas, a adição dos ternários em baixas quantidades, 
$2 \%$ de $\mathrm{Zr}$ e $1 \%$ de $\mathrm{Ti}$, ao combustível, e conseqüente exposição a altas potências $\left(200 \mathrm{~W} / \mathrm{cm}^{2}\right)$ e altas temperaturas $\left(110-125^{\circ} \mathrm{C}\right)$, a queimas moderadas $(30 \%)$. Será visto a seguir que, para que não ocorra queda no desempenho dos combustíveis, perda de estabilidade da fase gama, a porcentagem de adição não deve ser muito alta, mas baixas adições indicam excessiva formação de camada, decorrente da adição destes ternários. Sugere-se, conforme mencionado, as adições de Nióbio, Tungstênio e Silício.

Para os monolíticos, placas de $\gamma \mathrm{U} 7 \mathrm{Mo}$ e $\gamma \mathrm{U} 10 \mathrm{Mo}$ foram irradiadas a queimas e potências moderadas $\left(45 \%\right.$ e 165 a $\left.225 \mathrm{~W} / \mathrm{cm}^{2}\right)$, mas temperaturas altas $\left(125\right.$ a $\left.205^{\circ} \mathrm{C}\right)$, enquanto $\gamma \mathrm{U} 10 \mathrm{Mo}$ e $\gamma \mathrm{U} 12 \mathrm{Mo}$ foram irradiadas em condições mais severas, queima de $50 \mathrm{a}$ $83 \%$, temperaturas entre 100 a $146^{\circ} \mathrm{C}$ na linha central, e fluxo de potência de 165 a $300 \mathrm{~W} / \mathrm{cm}^{2}$ na superfície. Observou-se bom desempenho em todos os testes, tanto melhor em termos de inchamento das placas quanto maior a adição de molibdênio. Um exame mais detalhado foi feito no trabalho de Finlay et al. ${ }^{33}$.

Observa-se ainda que os testes RERTR-8 estão sendo programados para examinar e entender a interação combustível / matriz, avaliar comportamento sob irradiação de várias composições de combustíveis, e explorar técnicas mais avançadas de fabricação de monolíticos. Além do desempenho sob irradiação, outro foco será dado aos monolíticos nos testes RERTR 8, o dos processos para a sua fabricação, e de sua avaliação sob irradiação. Os resultados, segundo o autor, serão utilizados para a seleção das melhores composições, com o objetivo de realização de testes com placas "full-size", e em seguida, para a elaboração de documentação para a qualificação destes combustíveis.

Vejamos agora alguns resultados dos testes RERTR 6 e 7, discutidos nos encontros RERTR de 2006 e 2007.

Em Hofman et al. ${ }^{34}$ analisou-se o efeito do silício adicionado à matriz de alumínio na formação da camada de reação. Os resultados mostraram que adições de $\mathrm{Si}$ reduzem a interdifusão no sistema UMo / Al e eliminam a formação de porosidade, aliada à adição de Ti ou Zr à matriz. Entretanto, como foi visto anteriormente, Ti e Zr quando adicionados acima de uma determinada porcentagem diminuem a estabilidade da fase gama, com seria de se esperar no caso do Ti, dada a baixa solubilidade deste em fase gama. A queima dos combustíveis no teste RERTR-6 foi de 39 a 45\%, temperaturas no início da operação menores do que $200^{\circ} \mathrm{C}$, e picos de fluxo de calor iguais a $140 \mathrm{~W} / \mathrm{cm}^{2}$. Foram testadas ligas de U10Mo e UMo dispersas e monolíticas, com matrizes contendo 0,2 a $4,8 \%$ de $\mathrm{Si}$. 
Os resultados indicaram também que há um limite acima do qual adições de Si não produzem efeito importante, e este limite é o de $2 \%$. Adições superiores não produziram efeito considerável na redução da camada de reação. Outra observação interessante foi a de que adições de até $0,9 \%$ Si comportaram-se da mesma maneira, portanto pequenas adições produzem o mesmo efeito. Em regiões de alto fluxo de irradiação a espessura da camada de reação foi de $7 \mu \mathrm{m}$, e em regiões de baixo fluxo da ordem de 2,5 $\mu \mathrm{m}$. As miniplacas foram produzidas com Al6061, $6 \mathrm{gU} / \mathrm{cm}^{3}$ de densidade. Este trabalho é muito importante, pois mostrou que pequenas adições de Si à matriz podem reduzir os efeitos da formação de porosidade, e a extensão da camada de reação foi em muito reduzida.

Em adição a estes resultados, e conforme previamente mencionado, citemos novamente o trabalho de Kim et al. $^{22}$, que procuraram identificar as possíveis energias necessárias para a formação e crescimento da camada de reação devida à irradiação. Chegaram à conclusão de que elas são muito diferentes das obtidas até a etapa do processamento metalúrgico posto que a cinética é favorecida pela aparecimento de danos de irradiação na camada de interação. Assim, em altas temperaturas de tratamento térmico, $550^{\circ} \mathrm{C}, 3$ zonas são identificadas nas camadas de interação, cada uma com diferente composição, enquanto que, após irradiação, apenas uma é identificada. Entretanto, a composição desta monocamada após irradiação varia conforme a condição de reação, por exemplo, em baixas temperaturas $\left(65^{\circ} \mathrm{C}\right)$ a razão molar $(\mathrm{Al} / \mathrm{UMo})$ tende a ser alta, indicando alta difusão do Al para o interior da partícula de combustível, o que indica que o teor de alumínio nesta camada depende da temperatura de irradiação, carregamento do combustível na placa e densidade de fissões.

Avaliando-se as adições de Si à matriz, e com base em vários trabalhos que tratam do assunto, observam que, em todos os casos, Si diminui a taxa de crescimento da camada com a temperatura, a partir de $0,9 \%$ de adição. A $0,2 \%$ de adição, o valor para a espessura da camada de reação chegou a $11,3 \mu \mathrm{m}$, caindo abruptamente a $1,9 \mu$ com $0,9 \%$, e daí a $1,5 \mu \mathrm{m}$ para $4,8 \%$ de adição.

Dadas as inconsistências entre os resultados de caracterização da camada de reação para os testes fora e dentro do reator, Ryu et al. ${ }^{35}$ tratam de estudar o sistema UMo-Al, identificando possíveis fases no ternário na região com baixos teores de $\mathrm{U}$ e Mo. Amorfização do produto de reação foi suposta devido aos mecanismos de formação de porosidade ser semelhante ao de materiais amorfos, mas a verdadeira natureza e estrutura deste material ainda não foram confirmadas. Sabe-se que materiais como $\mathrm{U}_{6} \mathrm{Fe}, \mathrm{U}_{3} \mathrm{Si}$ e 
$\mathrm{U}_{3} \mathrm{Si}_{2}$ são amorfizados durante a irradiação, e que este fenômeno é um dos principais responsáveis pela formação de bolhas.

Foram observadas diferentes composições para a camada de interação, conforme a temperatura e o tempo de tratamento nos experimentos realizados por Keyser et $\mathrm{al}^{36}$, mais ricas em alumínio quanto maiores a temperatura e o tempo de tratamento, que variaram de 550 a $625^{\circ} \mathrm{C}$, por tempos de 30 minutos e 50 horas. Observou-se que a camada em todos os testes consistia de várias subcamadas com composição diferente, e que, sob irradiação, com temperaturas máximas dos testes de $200^{\circ} \mathrm{C}$, esta camada era composta por uma única fase, mas com composição variando entre (U,Mo) $\mathrm{Al}_{6}$ e $(\mathrm{U}, \mathrm{Mo}) \mathrm{Al}_{7}$, para os testes realizados nos reatores IRIS- 1 , (U,Mo)Al $\mathrm{Al}_{4,4}$ e $(\mathrm{U}, \mathrm{Mo}) \mathrm{Al}_{5,8}$ para os testes IRIS-2, e $(\mathrm{U}, \mathrm{Mo})_{3,3}$ e $(\mathrm{U}, \mathrm{Mo})_{4,7}$ para os testes denominados FUTURE.

Concluem os autores, dado que foi observada a possibilidade de restauração da cristalinidade em combustíveis $\mathrm{U}_{3} \mathrm{Si}_{2} / \mathrm{Al}$ em altas temperaturas de tratamento térmico, que a camada de interação é amorfa, pois a variação na composição dos produtos de interação, mostrada acima, não apresenta claras fronteiras entre as fases, o que indica que a mesma não é cristalina. Ainda, fases ternárias no sistema UMoAl após tratamentos térmicos, com composição complicada como $\mathrm{U}_{6} \mathrm{Mo}_{4} \mathrm{Al}_{43}$, etc., reportadas em outros trabalhos, não foram identificadas em amostras irradiadas, uma outra diferença de resultados que caracterizam a fase como um material amorfo.

Confirma-se também que há uma temperatura de transição, durante a irradiação, na qual a cristalinidade deixa de existir. Os autores então propõem o conceito de temperatura crítica do combustível, aquela para a qual o produto de reação deixa de ser cristalino para tornar-se amorfo. Esta temperatura é função da taxa de fissões e da composição da camada.

Resumindo, a camada de reação $\gamma \mathrm{UMo} / \mathrm{Al}$ ainda é o principal problema, não resolvido, que impede até o momento a qualificação dos combustíveis de alta densidade dispersos. Daí ser forte a tendência na utilização de fases monolíticas. Maiores detalhes sobre as técnicas para a sua fabricação, bem como as de combustíveis dispersos, será dada no capítulo 4.

\subsection{Simulação de propriedades dos combustíveis sob irradiação}

Como exemplo de equacionamento dos fenômenos envolvidos durante a irradiação de combustíveis, analisemos o trabalho de REST et al. ${ }^{37}$, que trata do comportamento sob irradiação das ligas urânio-molibdênio com relação ao inchamento. 
Dois são os mecanismos de inchamento considerados: o intragranular e o intergranular ou no contorno de grão. As equações para cinética de crescimento e aniquilação de defeitos foram tomadas do trabalho de Szimann $^{38}$ e Blailsford e Bullough ${ }^{39}$. Visto que o mecanismo de crescimento das cavidades resulta em maior inchamento que o comportamento devido à formação de bolhas, é importante o conhecimento da cinética de crescimento das discordâncias nestes materiais.

O modelo utilizado consistiu num conjunto de 15 equações acopladas, dadas a seguir, no qual procura-se o estabelecimento da variação com o tempo (1) da concentração de vacâncias e intersticiais (cv e ci), (2) do diâmetro do loop intersticial, Dl, e de sua densidade (NI), (3) da densidade das discordâncias forest, fd, (4) do raio da cavidade e de sua densidade, rc e cc, (5) do número médio de átomos de gás em cada cavidade, (Ng), (6) e da concentração de átomos de gás em solução no combustível (cg). Temos:

$$
\begin{aligned}
& \mathrm{d} / \mathrm{dt}(\mathrm{cv}(\mathrm{t}))=\mathrm{K}-\alpha \mathrm{r} \operatorname{ci} \mathrm{cv}-\mathrm{kv}(\rho \mathrm{l}) \mathrm{Dv} \mathrm{cv} \\
& \mathrm{d} / \mathrm{dt}(\mathrm{ci}(\mathrm{t}))=\mathrm{K}-\alpha \mathrm{r} \text { cv ci }-\mathrm{ki}(\rho \mathrm{l}) \text { Di ci }-16 \pi \mathrm{Di} \text { ci ci } / \mathrm{a}^{2} \\
& \mathrm{~d} / \mathrm{dt}(\mathrm{Nl})=16 \pi \text { Di ci ci } /\left(\Omega \mathrm{a}^{2}\right)-\pi \mathrm{vl}(\mathrm{t}) \mathrm{Nl} / \mathrm{Dd} \\
& \mathrm{d} / \mathrm{dt}(\operatorname{Dd}(\mathrm{t}))=2 \mathrm{vl}(\mathrm{t}) / \mathrm{a} \\
& \mathrm{d} / \mathrm{dt}(\mathrm{fd})=\pi \mathrm{vl}(\mathrm{t}) \mathrm{Nl}-4 \mathrm{vl}(\mathrm{t}) \mathrm{fd} / \mathrm{dg} \\
& \mathrm{d} / \mathrm{dt}(\mathrm{rc})=\mathrm{kv} \text { Dv }\left(\mathrm{cv}-\mathrm{cv}^{*}\right)-\mathrm{ki} \text { Di ci } \\
& \mathrm{d} / \mathrm{dt}(\mathrm{cg})=\mathrm{G}-16 \pi \mathrm{fn} \operatorname{rg} \mathrm{Dg} \operatorname{cg} \mathrm{cg}-4 \pi \mathrm{rc} \mathrm{Dg} \mathrm{cc} \mathrm{cg}+\mathrm{b} \mathrm{Ng} \mathrm{cc} \\
& \mathrm{d} / \mathrm{dt}(\mathrm{cc})=16 \pi \text { fn rg Dg cg cg } / \mathrm{Ng}-16 \pi \mathrm{Dc} \text { cc cc } \\
& \mathrm{d} / \mathrm{dt}(\mathrm{Ng})=4 \pi \mathrm{rc} \mathrm{Dg} \mathrm{cg}-\mathrm{b} \mathrm{Ng}+16 \pi \mathrm{Ng} \mathrm{rc} \mathrm{Dc} \mathrm{cc}
\end{aligned}
$$

nas quais:

$$
\mathrm{cv}^{\mathrm{o}}=\mathrm{cv}^{\mathrm{t}} \exp [-(\mathrm{Pg}-(2 \gamma / \mathrm{rc})-\sigma) /(\Omega \mathrm{kT})]
$$




$$
\begin{gathered}
\operatorname{vl}(\mathrm{t})=\mathrm{zi} \rho \mathrm{l}(\mathrm{t}) \text { Di ci }- \text { zo } \rho \mathrm{l}(\mathrm{t}) \mathrm{Dv} \mathrm{cv} \\
\rho \mathrm{l}(\mathrm{t})=\pi \mathrm{Nl} \text { Dl }
\end{gathered}
$$

Os parâmetros são definidos como segue: $\mathrm{K}$ : taxa de danos em dpa/s, $\alpha$ : coeficiente usual de recombinação, a: parâmetro de rede, $\Omega$ : volume atômico, Dv, Di e Dd: difusividades das vacâncias, intersticiais e de átomos de gás, respectivamente, kv ( $\rho)$ e ki ( $\rho 1)$ : resistências (ao deslocamento ou à formação?) de vacâncias e intersticiais, fn: fator de nucleação das bolhas de gás, zV e zi: fatores parciais de (formação?) de vacâncias e intersticiais, $\mathrm{cv}^{\mathrm{t}}$ : concentração de vacâncias em equilíbrio térmico, Pg: pressão interna do gás na cavidade, $\sigma$ : tensão externa sobre a cavidade, dg: diâmetro do grão, $\gamma$ : é a energia de superfície, rg: raio dos átomos de gás, G: taxa de geração de átomos de gás em át $/\left(\mathrm{cm}^{3} \mathrm{~s}\right)$, e as difusividades de vacâncias e de átomos de gás dadas por:

$$
\begin{gathered}
\mathrm{Dv}=0.0458 \exp \left[-\left(\varepsilon_{\mathrm{vm}} / \mathrm{kT}\right)+\mathrm{f}^{*} \mathrm{~V}^{5 / 3} / 15\right. \\
\mathrm{e} \\
\mathrm{Dg}=\mathrm{Dg}^{\mathrm{T}}+\mathrm{f}^{*} \mathrm{~V}^{5 / 3} / 15
\end{gathered}
$$

onde: $\mathrm{f}^{*}$ : taxa de fissões em fiss $/\left(\mathrm{cm}^{3} \mathrm{~s}\right), \mathrm{Dg}^{\mathrm{T}}$ : componente térmica da difusividade dos átomos de gás ( $<<$ que o termo $\mathrm{f}^{*} \mathrm{~V}^{5 / 3} / 15$ nas temperaturas ATR), Dg e Dv: obtido com base nas mudanças estruturais nas ligas bifásicas de U-Mo sob ação da radiação com nêutrons (portanto experimental), V: volume das faíscas térmicas para difusão de vacâncias, baseado em cálculos de curvas T-T, estimada com o valor de $8,2 \times 10^{-13} \mathrm{~cm}^{3}$ a $373 \mathrm{~K}, \varepsilon_{\mathrm{vm}}$ : energia para a imigração de vacâncias, Dv: a componente de irradiação (o segundo termo da equação) foi introduzido para obtenção de resultados físicos reais em baixas temperaturas para concentração de defeitos pontuais e de densidades de saturação de discordâncias. Assumindo que a evolução de anéis de discordâncias ocorre até que o espaçamento entre os mesmos atinja alguma distância característica, a nucleação do anel e seu crescimento (de acordo com as equações 33 e 34) continua até que os anéis colidam, ou até que:

$$
\operatorname{Dl}(\mathrm{t}) \rho 1(\mathrm{t})=1
$$


Dois são os processos para a formação de cavidades no interior do combustível. Sendo crítica a energia para a formação dos defeitos nas condições de operação dos reatores, temos o valor de $1,1 \mathrm{eV}$ indicando processos dominados por radiação, e o valor de $0,75 \mathrm{eV}$ indicando processo dominado por difusão. Após análise das expressões anteriores, e levando em conta que o mecanismo de inchamento é dependente da razão entre os fluxos de vacâncias e dos átomos de gás para o interior das cavidades, as equações 31 e 32 podem ser simplificadas e a razão entre o fluxo de vacâncias e o de átomos de gás para as cavidades é:

$$
\varepsilon=\rho d(\mathrm{zi}-\mathrm{zr})[(\mathrm{K} \text { Dv Di }) / \alpha r] / \mathrm{K}_{\mathrm{xe}}
$$

no qual $\mathrm{K}_{\mathrm{xe}}=$ taxa de produção de átomos de Xe, em fração atômica/seg.. Assim, para os dois valores acima determinados pela teoria, obtiveram $\varepsilon=4$ para $\varepsilon_{\mathrm{vm}}=1,1 \mathrm{eV}$ e $\varepsilon=2,5$ para $\varepsilon_{\mathrm{vm}}=0,75 \mathrm{eV}$.

Usando o fato de que há relação de linearidade entre a energia de ativação da auto-difusão do U em metais ccc e o ponto de fusão de metais em consideração:

$$
\text { Qself }=\mathrm{k} \text { Tmelt }
$$

onde $\mathrm{k}=1,453 \times 10-3 \mathrm{eV} /($ át.K), Qself é a energia para auto-difusão, relacionada com a energia de migração de vacâncias $\varepsilon_{\mathrm{vm}} \mathrm{e}$ formação, $\varepsilon_{\mathrm{vf}}$, por:

$$
\varepsilon_{\mathrm{vm}}+\varepsilon_{\mathrm{vf}}=\text { Qself }
$$

e como em geral $\varepsilon_{\mathrm{vm}}=0,5 \mathrm{Q}$ self, então:

$$
\mathrm{e}_{\mathrm{vm}}=7,265 \times 10^{-4} \text { Tmelt }(\mathrm{eV} / \mathrm{K})
$$

Para ligas metaestáveis como U-10wt\%Mo, o ponto solidus representa o ponto de fusão, portanto para U-10Mo, o solidus ocorre a $1520 \mathrm{~K}\left(1247^{\circ} \mathrm{C}\right)$, Assim, concluem que qualquer cavidade na rede do U-10Mo é devida a bolhas de gás e não à formação de vazios. Ainda, na análise acima, a energia para migração de vacâncias no U-10Mo é de $1,1 \mathrm{eV}$. Isto indica que a fragilização do material via formação e propagação de discordâncias intragranularmente são fenômenos que não ocorrem, não sendo 
preocupantes. Então, presume-se que as falhas ou o mau comportamento do combustível se dê por algum mecanismo que ocorre intergranularmente.

Propõe-se aqui que a recristalização induzida por radiação promova o crescimento de bolhas nos novos contornos formados, comportamento este semelhante ao apresentado pelos combustíveis à base de siliceto $\mathrm{U}_{3} \mathrm{Si}_{2}-\mathrm{Al}$ e $\mathrm{U}_{3} \mathrm{O}_{8}$. Este foi confirmado pelo uso dos códigos computacionais aplicados ao urânio-molibdênio, pela mudança na inclinação da curva de crescimento em volume x taxa de fissão (v. Rest e Hofman ${ }^{40}$ ). Assim, as bolhas observadas podem estar associadas a esta estrutura de subgrãos.

Em trabalho semelhante, Konovalov ${ }^{41}$ procura determinar quais as propriedades dos combustíveis que podem ou não influenciar o seu comportamento sob inchamento. Partindo das mesmas equações anteriores e das utilizadas por Szimann ${ }^{37,38}$ para descrever a cinética de interação entre os defeitos, o autor estabelece que a temperatura de fusão dos materiais, relacionada diretamente com a energia para a produção de defeitos, pode nos servir de parâmetro para o estabelecimento da faixa de comportamento estável para os mesmos. Assim, conclui que há uma temperatura crítica, na qual há transição de um instável inchamento dominado pelos gases de fissão para um catastrófico inchamento produzido pela propagação e crescimento de defeitos. Este ponto crítico é, para as ligas de urânio com $10 \%$ em peso de molibdênio, da ordem de $220^{\circ} \mathrm{C}$, que seria o limite superior para obtenção de comportamento aceitável do inchamento sob irradiação.

A modelagem para a interdifusão nos sistemas combustíveis é detalhada no trabalho de Rest ${ }^{42}$, que trata da interdifusão de alumínio em diversas ligas de urânio. Obtém-se que o crescimento da espessura da zona de interação para a difusão de alumínio em siliceto de urânio como função linear da taxa de fissão, com dependência exponencial da temperatura. Ainda, se o mecanismo de difusão for dominado pela aniquilação de pares, então a difusão, nas temperaturas de operação, sendo função preferencialmente da radiação, haverá dependência com a raiz quadrada da taxa de fissão. Ambos os fenômenos não possuem embasamento teórico algum até o momento, e conforme mencionado na parte inicial deste trabalho são temas a serem estudados. Aqui foi demonstrado que o mecanismo que mantém os defeitos no material é o de aniquilação de pares.

Fato observado na prática é a ausência de bolhas na fase alumineto, na camada de interação entre combustível e matriz, e postula-se que isto se deva a ausência de recristalização nesta fase. Usando as equações do trabalho de Szimann ${ }^{38}$ e Blaislford e Bullough $^{39}$ e o código DART ${ }^{43}$, chega-se a uma boa concordância com os dados 
experimentais para combustíveis à base de urânio-silício em termos da variação em volume em função da taxa de fissão. Determina-se a entalpia para difusão de vacâncias e intersticiais nestes materiais, e discute-se a ausência de bolhas na fase alumineto. Postulase que elas não possam crescer nesta fase, pois estão confinadas no material, e não podem evoluir a tamanhos apreciáveis em baixas temperaturas devido a efeitos de ressolubilização. A recristalização induz a formação de novos contornos, onde as bolhas podem nuclear e crescer. Se a recristalização não ocorre em UAlx, talvez assim se explique a ausência de bolhas na camada, observáveis por MEV. Determina-se que a condição teórica para que não ocorra recristalização é a de que a entalpia para a migração de intersticiais seja maior que o dobro da entalpia para a migração de vacâncias.

Nas micrografias de partículas de $\mathrm{U}_{3} \mathrm{Si}_{2}$ foram observadas cascas de alumineto que não mostraram recristalização, um anel tipo alumineto interior que mostra evidência de recristalização por grão e uma região central que mostra inchamento que é característica de materiais amorfos. $\mathrm{O}$ código $\mathrm{DART}^{40}$, usado para a simulação do comportamento dos combustíveis, identificou os seguintes fenômenos sobre a evolução e inchamento destas estruturas: (1) formação de camada externa de alumineto atua como repressora do inchamento do material interno do combustível; (2) isto ocorre pois a camada externa de alumineto contém predominantemente pequenas bolhas intragranulares não visíveis por SEM. Assim, esta camada externa tem uma relativa baixa taxa de inchamento quando comparada com as regiões interiores (que são compostas de material amorfo ou recristalizado, e aparece dura, quando comparada com a suave, das regiões interiores). Ainda, sugere-se que se a camada externa de alumineto não se forma (para partículas combustíveis irradiadas na ausência de alumínio), partículas combustíveis incham significativamente.

$\mathrm{O}$ anel interior recristaliza antes da penetração do Al, levando a um anel de alumineto com uma estrutura de grão refinada. DART calculou taxas de inchamento no anel com esta estrutura, que possuem taxa de inchamento muito maior que as que ocorrem nas regiões com ausência de recristalização, devido ao aumento no crescimento no crescimento das bolhas sobre os contornos de grão e os nodos terminais. Após a recristalização, penetração do $\mathrm{Al}$ através deste anel ocorre, convertendo o material em uma região de $\mathrm{Al}$ reestruturada.

Rest et al. ${ }^{40}$ conclui o trabalho frisando o fato de que há similaridade na interdifusão de alumínio para combustíveis a base de siliceto e ligas de U-Mo, e que esta similaridade se deve ao fato de que a difusão de alumínio pela camada de alumineto é o 
mecanismo dominante na formação da camada de alumineto durante a irradiação. Assim, inicialmente se forma uma película entre combustível e matriz, a película de alumineto atuando como resistência principal do sistema. Ainda, esta similaridade pode ser obtida teoricamente pois tratou-se aqui a densidade de sumidouros como sendo dependente da temperatura, o que usualmente não é assumido.

No capítulo seguinte, completando a introdução sobre o que existe hoje na área de combustíveis de alta densidade, serão abordadas as técnicas de processamento utilizadas para a fabricação dos pós. Ênfase será dada, obviamente, às técnicas de hidretação. 


\section{PROCESSOS DE FABRICAÇÃO}

\subsection{Desempenho sob irradiação e técnicas de fabricação}

A influência das características dos pós e, portanto, do processo de fabricação escolhido para a produção de partículas da fase combustível, tem influência no desempenho dos combustíveis nucleares. Em Kim et al. ${ }^{23}$, além das energias de ativação e temperaturas de reação espontânea para o sistema U-Mo / Al, foram obtidas conclusões importantes relacionadas à influência dos processos de fabricação no desempenho dos combustíveis.

Observaram que, sob irradiação, os pós atomizados provocam reação que causa um aumento global no volume menor do que os pós mecanizados. Isto se deve ao fato das partículas moídas possuírem forma irregular, e portanto possuem maior área de superfície específica que as esféricas, mais regulares. A área de contato com as partículas da matriz é maior, e, portanto, maior é a quantidade de combustível disponível para reação. Para pós moídos em amostras com fração volumétrica de $30 \%$ e tratamento térmico por 20 horas a $500^{\circ} \mathrm{C}$, observaram que os produtos de reação se estenderam até a metade da partícula, aumentando o volume das mesmas em 15\%. Por 300 horas a reação foi completa, com o produto de reação sendo aquele para o qual $x=3$ (ver equação (12)), havendo um aumento no volume das amostras de 25\%. No caso dos pós atomizados, por 20 horas as partículas apresentaram uma camada superficial regular e suave, camada de reação bem definida face ao moído, e menor extensão da camada de reação, com aumento no volume aproximadamente 2 vezes menor que o dos pós mecanizados. Por 300 horas, muitas das partículas apresentaram centros não reagidos muito pequenos. A reação causou um aumento global no volume da amostra de aproximadamente $12 \%$ e, assim, pode-se concluir favoravelmente à utilização de pós atomizados face aos obtidos pelas vias mecanizadas.

Os autores encerram o trabalho propondo 2 mecanismos para a interdifusão nas partículas. O primeiro deles, ocorrendo em ambas as classes de pós, é o da difusão uniforme através da interface combustível-matriz, muito discutido anteriormente, e o segundo, presente juntamente com o primeiro nos pós mecanizados, é o da difusão através de trincas ou zonas deformadas, muito presentes nestes. 
Publicação semelhante foi a de Lee et al. $^{24}$, que destacou a influência do processo de fabricação dos pós sobre a condutividade térmica da fase combustível em placas de combustíveis dispersos. O seu principal objetivo foi o estabelecimento da melhor forma de se preparar o pó, dentre as técnicas analisadas, e de qual a porcentagem de molibdênio adicionada ao urânio que minimiza problemas de interação.

Sabe-se que cada processo produz partículas com geometrias diferentes, e assim a maior ou menor formação de camada de interação está associada à maior ou menor regularidade ou área da superfície da partícula de combustível. A estimativa do valor da condutividade térmica dos componentes do núcleo da placa em função da temperatura é importante no levantamento, ao menos teórico, do perfil de temperaturas na placa durante a irradiação, e depende da formação da camada de interação, que por sua vez é função da forma das partículas. Aqui surge um problema tecnológico importante. Sabe-se que nos combustíveis a base de siliceto de urânio, a evolução da camada de reação entre esta fase e a matriz de alumínio é menor que em combustíveis UMo. Assim, como o poder de estabilização da fase gama aumenta com o aumento na quantidade de molibdênio adicionada, até composições hipoeutetóides, é de se esperar que isto se reflita também em maior reatividade. Portanto, considera-se que o Mo é um promotor da reação, mas ao mesmo tempo, sabendo-se que ele estabiliza gama, deve ser encontrada uma composição em que ambos os fatores se equilibrem. Adota-se muitas vezes como composição padrão dos combustíveis UMo o valor de 7\% em peso de Mo.

Lee et al. ${ }^{24}$ prepararam briquetes contendo dispersões de pós da liga UMo em matriz de Al, nas composições de 6, 8 e 10\% em peso, e estudaram propriedades térmicas das placas e o avanço da camada de reação em função da temperatura, da ambiente até $500^{\circ} \mathrm{C}$. As frações volumétricas de pó de U-Mo foram de 10, 30, 40 e 50\% em volume. Sua primeira conclusão foi a de que a difusividade térmica cai com o aumento da porcentagem em volume de U-Mo no núcleo, afastando-se cada vez mais também do valor da condutividade térmica do Al. Segundo os autores, isto pode ser reflexo da menor homogeneidade no perfil de temperaturas ao longo da superfície / volume das placas, devida a uma maior quantidade de fase de interação entre as partículas de combustível com a matriz. Assume-se assim que o composto provável (U,Mo)Alx, com $2 \leq \mathrm{x} \leq 4$, formado ao redor da partícula de combustível, atue como isolante térmico, aumentando a temperatura das partículas, dificultando a dispersão do calor nela armazenado pelas fissões ao longo da matriz, o que induz à expansão volumétrica por formação de vazios, aumentando a espessura da camada de reação. 
Outros resultados interessantes foram obtidos por Meyer et al. ${ }^{25}$. Na etapa de laminação, estes autores observaram que o crescimento da fase combustível foi nulo para as ligas U10Mo, tanto de atomização quanto de mecanização, mas significativa para as ligas mecanizadas U6Mo. A variação em área para U6Mo foi medida como sendo equivalente a $17 \%$ da área total das partículas, promovida pela interação entre o combustível e a matriz. Destacaram os autores os efeitos da microestrutura na minimização, pois, em primeiro lugar, o formato das partículas é esférico e, portanto, há menor área de superfície para interação com a matriz.

A diferença nas características dos pós refletiu-se nos mecanismo de nucleação e crescimento das bolhas, visto que os pós atomizados apresentam regiões de segregação de molibdênio, portanto inomogeneidades composicionais. Ainda, e importante de se observar, além dos contornos de grão, as limalhas possuem outros sítios para crescimento das bolhas devido a sua alta densidade de discordâncias, originárias de deformação a frio quando de sua fabricação. Condições de laminação e irradiação levam estas discordâncias a formarem os chamados contornos de subgrãos, superfícies livres dentro dos grãos, que atuam como sítios de nucleação para as bolhas. Assim, em pós deformados a frio, aumenta-se estatisticamente o número destas posições, favorecendo-se o inchamento.

Em Hofman et al. ${ }^{27}$ observou-se que, exceto para o pó atomizado de U10Mo, todos os pós contiveram quantidade significativa de fase alfa, proveniente da decomposição de fase gama durante a fabricação. As camadas de interação formadas na laminação das placas foram similares em ambos os casos, tanto em tamanho quanto em aparência. No caso dos pós moídos, entretanto, populações de bolhas com maior diâmetro foram produzidas, e a maior distribuição de tamanhos de bolhas foi atribuída pelos autores à densidade de discordâncias existentes nos pós mecanizados.

Com estes trabalhos demonstra-se que a técnica de fabricação influi no desempenho sob irradiação dos combustíveis. Como a hidretação produz pós com características intermediárias (não tão esféricas quanto as atomizadas, e nem tão irregulares quanto as mecanizadas), esta foi a técnica escolhida para a produção dos pós das ligas $\gamma$ UMo nesta tese. Nos itens seguintes cada uma das técnicas será detalhada, finalizando-se o capítulo com a descrição das técnicas de hidretação.

\subsection{Processos tradicionais para a fabricação de pós da fase gama UMo}

Como pó é a forma pela qual o combustível nuclear é disperso na placa, iremos apresentar três das principais técnicas utilizadas para a fabricação do pó da liga urânio- 
molibdênio. São elas a moagem, a atomização e a hidretação-dehidretação, cada uma produzindo partículas com características diferentes. Discutiremos a seguir cada uma delas, mostrando vantagens e desvantagens.

No trabalho de Clark et al. $^{44}$ compararam-se as 3 rotas utilizadas para a fabricação dos pós HD-LEU. Mencionam que as características mais importantes dos pós são as relacionadas ao valor médio e distribuição do tamanho de partícula, forma e a maleabilidade. A primeira delas refere-se à capacidade do pó em ser pressionado para a obtenção das altas densidades. A forma afeta a resistência do material verde e o grau de segregação, e a ductilidade ou maleabilidade refere-se à facilidade em se conformar o pó. Façamos um pequeno resumo deste trabalho.

Segundo os autores, a mecanização, sendo o mais simples dos métodos, foi o mais utilizado devido aos baixos custos operacionais envolvidos e à fácil disponibilidade de equipamentos. Consiste no uso de um dispositivo para triturar a liga até a obtenção do pó, que apresenta a forma de agulhas com dimensões maiores do que as apresentadas pelos produzidos pelos demais métodos, levando a altas taxas de rejeição. Outras desvantagens são o alto poder de contaminação, a baixa taxa de produção do pó e a grande taxa de deformação introduzida no pó resultante. Pelo fato da partícula sofrer muitas deformações durante o processo, a densidade de discordâncias é alta, aumentando o número de regiões em potencial para a nucleação e crescimento de bolhas de gás durante a irradiação.

Os autores também fabricaram pós atomizados com dimensões de 40 a 180 micra, mas não conseguiram evitar a presença de satélites, partículas aderidas a outras de diâmetro maior. A técnica da atomização consiste na introdução de uma corrente líquida do metal ou liga no interior de uma câmara e sobre um disco rotativo, que a espalha pela câmara. As gotas formadas, durante o seu trajeto no interior da câmara, solidificam-se na forma esférica, formando a carga do pó. Utiliza-se comercialmente também a atomização com 2 fluidos, na qual uma corrente em queda do metal fundido é forçada sobre uma corrente de gás ou água em alta pressão. As câmaras devem apresentar dimensões que permitam que o pó se solidifique antes de entrar em contato com as suas paredes. Apresenta como desvantagem, dada pela regularidade na forma, uma maior escoabilidade e, portanto, problemas de segregação são freqüentes. Observou-se que, ao contrário dos processos tradicionais, a distribuição e o valor médio do tamanho das partículas obedeceu aos requisitos de especificação. Além disso, é um processo que não introduz impurezas nos pós. 
No trabalho de Wiencek e Prokofiev ${ }^{45}$, estudou-se a trabalhabilidade de pós moídos e atomizados centrifugamente, durante a fabricação das placas. Trabalhando com os seguintes materiais: pó de Al 6061, e pós atomizados e moídos de U-10Mo em diversas distribuições de tamanho de partícula, produziram placas com $87 \%$ de redução, 7,7 x de aumento no comprimento, e com espessura final de 1,5 $\mathrm{mm}$. Observaram que os pós moídos dispersaram-se no núcleo da placa mais heterogeneamente que os pós atomizados (34\% contra $15 \%$ em termos de desvio máximo do valor médio de densidade de urânio na placa) embora ainda dentro do valor especificado. Isto pode ser explicado pelo fato de que partículas moídas em geral apresentam forma irregular, e que assim apresentam maior resistência ao escoamento durante a etapa de mistura (segregação, etc.). Entretanto, esta maior fluidez apresenta o inconveniente de levar as partículas atomizadas a espalharem-se para fora da região do núcleo, especialmente quando carregados com densidades maiores do que $8 \mathrm{gU} / \mathrm{cm}^{3}$. Este é um problema durante a etapa de laminação de placas de pós atomizados.

Placas com pós mecanizados apresentaram bom comportamento na laminação, mas a variação de espessura da placa na região do "dog-bone" foi muito maior que a apresentada no resto da placa. Comparativamente, chegou-se a $10 \%$ de variação na espessura no "dog-bone" para pós atomizados, contra 30\% para os pós mecanizados. Nas demais regiões, houve variação de $5 \%$ para atomizados, contra $10 \%$ para os mecanizados. Assim, concluíram os autores que o trabalho com placas com partículas atomizadas de U10Mo apresentaram as melhores propriedades, mas recomendaram o uso de densidades menores que $8 \mathrm{gU} / \mathrm{cm}^{3}$ para evitar o problema de dispersão das partículas esféricas para fora da zona do combustível.

\subsection{O processo H (M) DH}

Embora a atomização seja o mais indicado dos três processos, foi veiculada a possibilidade de se produzir pó de urânio-molibdênio nas dependências do IPENCNEN/SP via hidretação-dehidretação, a mesma linha adotada pela Argentina e Rússia. Passemos à descrição da técnica, inicialmente como fornecida por Balart et al. ${ }^{46}$.

O processo de hidretação-dehidretação é usado freqüentemente como um bom método para produção de pós metálicos finos. Na hidretação do urânio, por exemplo, inicia-se o processo aquecendo-se o lingote em atmosfera de $\mathrm{H}_{2}$. A temperaturas moderadas $\left(\sim 300^{\circ} \mathrm{C}\right)$, o $\mathrm{U}$ reage com $\mathrm{H}_{2}$ formando $\mathrm{UH}_{3}$, que tem menor densidade que $\mathrm{U}$ metálico $\left(10,9\right.$ contra $\left.19 \mathrm{~g} / \mathrm{cm}^{3}\right)$ que "descasca" da superfície do lingote, como um hidreto 


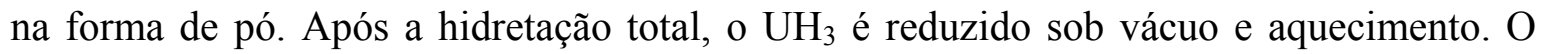
hidrogênio vagarosamente dissocia-se do hidreto, deixando somente o urânio metálico na forma de pó. A reação de formação do hidreto é:

$$
3 \mathrm{H}_{2}+2 \mathrm{U}=2 \mathrm{UH}_{3}
$$

Procede-se a uma conversão inicial da mistura U-7\%Mo, com urânio inicialmente na fase alfa à temperatura ambiente, em um forno a $1000^{\circ} \mathrm{C}$ para a obtenção da fase gama. Esta conversão não é total, e a análise do lingote formado mostra uma estrutura composta por uma região central formada predominantemente por gama, sendo contornada pela fase alfa. O material assim obtido é levado ao forno de hidretação, onde gás hidrogênio inicialmente a 1 atmosfera de pressão é posto para circular sobre a amostra da liga sólida. Aproveita-se agora a grande afinidade pelo gás apresentada pela fase alfa, que se hidreta a $\mathrm{UH}_{3}$, deixando o núcleo gama inalterado. Este hidreto é frágil e, na operação subseqüente de dehidretação, a fase alfa torna-se quebradiça. O pó de gama formado por este processo é usualmente mais fino que o produzido pelos demais processos, apresentando dimensões de 10 a 40 micra. O monitoramento do andamento da reação de hidretação se dá pela variação de pressão. Assim, enquanto há reação, a pressão no interior da câmara permanece abaixo do valor de 1 atmosfera. Quando a reação termina, não há mais absorção do gás pelo sólido, a pressão volta ao valor normal. Toda reação de hidretação ocorre a $250^{\circ} \mathrm{C}$. Recomenda-se a utilização deste processo quando se desejar trabalhar com quantidades de material pequenas, próximo do que se precisa em termos de produção no IPEN-CNEN/SP. Seguindo a mesma linha, no trabalho de Solonin et al. ${ }^{47}$, tratando ligas $\gamma$-U6,5Mo fabricadas por indução, menciona-se que a formação de microestrutura contendo fases frágeis facilita a fragmentação das ligas, embora haja perda de densidade na etapa de conversão.

O desenvolvimento posterior de Pasqualini $^{48}$ e Pasqualini et al. ${ }^{49}$ levou à técnica HMDH. Os autores utilizaram tratamento térmico pré-hidretação de ligas $\gamma$-U7Mo produzidas a arco em temperaturas entre $500^{\circ} \mathrm{C}$ e $700^{\circ} \mathrm{C}$. Na fase de hidretação, diferentemente de Balart ${ }^{50}$, utilizaram para a liga U7Mo temperaturas entre 50 e $190^{\circ} \mathrm{C}$, com absorção máxima obtida a $120^{\circ} \mathrm{C}$, sob 1 atmosfera de hidrogênio por 36 horas. Utilizaram $1 \mathrm{~kg}$ de material, dividido em peças de 50g. Os hidretos formados levam a obtenção de fragmentos com aproximadamente $5 \mathrm{~mm}$, com pequenas partículas formadas por fratura transgranular, com 30 microns. A partir deste ponto introduziram a moagem, 
em moinho de bolas, seguida de posterior dehidretação à uma temperatura máxima de $700^{\circ} \mathrm{C}$ por 5 horas. Recuperação e moagem foram por fim utilizados para obtenção dos pós conforme especificações.

Portanto, a linha tradicional estabelecida para obtenção de pós a partir de ligas $\gamma$-U $\leq 7 \mathrm{Mo}$, via hidrogênio, compreende as seguintes operações: fusão a arco da carga de molibdênio mais $\alpha U$, tratamento térmico de homogeneização, hidretação, seguida de moagem, dehidretação (daí o nome $\mathrm{H}(\mathrm{M}) \mathrm{DH}$ ), novo tratamento térmico para recuperação de parte da estrutura da matriz. Entretanto, como esta é uma linha desenvolvida para adições de até 7\% de Mo, e como os melhores resultados em termos de comportamento sob irradiação e interação combustível-matriz foram obtidos com a liga a 10\% de Mo, deve-se procurar também uma maneira de obter pós de ligas com esta porcentagem de adição.

Um refinamento da técnica de $\mathrm{HMDH}$ pode ser encontrado no trabalho de Balart et al. ${ }^{51}$. Este toma por base a variação no tamanho de grão da fase gama, após tratamento térmico de homogeneização em temperaturas entre 900 e $950^{\circ} \mathrm{C}$, por tempos de 1 a 4 horas, seguido de tratamento de decomposição a $565^{\circ} \mathrm{C}$ por 24 horas.

Conforme será visto em capítulo apropriado, tratamentos térmicos de homogeneização em temperaturas próximas a $1000^{\circ} \mathrm{C}$, em intervalo de tempo de 24 a 48 horas, promovem um grande aumento nas dimensões dos grãos. Assim, os autores pretendem controlar as dimensões das partículas nos tratamentos de homogeneização. Observa-se que as micrografias apresentadas no trabalho são semelhantes às nossas, apresentadas adiante. 
SEGUNDA PARTE DESENVOLVIMENTO EXPERIMENTAL 


\section{PROCEDIMENTOS DE FUSÃO E TRATAMENTO TÉRMICO}

Este capítulo trata das técnicas de fabricação das ligas utilizadas nesta tese. Serão descritos os procedimentos de fusão e solidificação via forno a arco e indução e as técnicas utilizadas para tratamento térmico.

A justificativa para a adoção de fusão via indução seguida de tratamento térmico, para estudos de equilíbrio e preparo das amostras, será brevemente discutida. Em capítulo apropriado, uma série de resultados será apresentada com este objetivo.

\subsection{Preparo das ligas binárias de UMo, fusão a arco.}

Para as fusões via forno a arco foram utilizados como carga discos de urânio metálico natural, obtidos em equipamento do tipo "cut-off", que utiliza discos rotativos diamantados ou com materiais abrasivos para corte. Estes discos foram obtidos a partir de cilindros de urânio natural, e foram cortados em duas ou quatro partes, para melhor preenchimento das coquilhas.

Após o corte, os discos de urânio metálico foram previamente decapados em solução aquosa de ácido nítrico concentrado a $65 \%$ em volume. O tempo de exposição ao ataque não foi superior a 1 minuto. Em seguida, efetuou-se sua lavagem com água destilada corrente, e posterior imersão em acetona ou etanol P.A., para auxílio na secagem em condições ambientes, e só então foi efetuada a pesagem dos discos.

As cargas de Mo foram adicionadas em porcentagens em peso variando de 4 a $10 \%$, calculada em cada preparo com base na massa dos discos de urânio. Inicialmente algumas ligas foram preparadas com o soluto na forma de pó. Como foi observada alguma perda durante a fusão, prepararam-se algumas ligas por compactação dos pós em prensa e depois fragmentação dos tabletes assim obtidos, adicionando-os às coquilhas.

A grande dificuldade no trabalho com a configuração particulada reside no fato de que há sempre a tendência de que o arco, ao ser aplicado sobre a carga, espalhe as partículas de pó, impregnando internamente a campânula do forno, e com isso se perde controle sobre a composição da liga. Com o material em tabletes não houve perdas, mas a homogeneidade das ligas não foi muito boa, e então operações de rebatimentos (refusões) foram realizadas.

Melhores resultados foram obtidos com cargas compostas por pequenos 
cilindros de Mo, e aqui utilizou-se dois tipos, um deles fornecido pela Comissão Chilena de Energia Nuclear (CChEN), com dimensões aproximadas (altura x diâmetro), em milímetros, de 8 x 5, e o outro adquiridos pelo próprio IPEN, com dimensões de $3 \times 3$. Com os maiores as ligas apresentaram melhor homogeneização em termos de composição, mas mesmo assim efetuaram-se novas refusões, pois o tamanho da peça de Mo e o seu alto ponto de fusão do Mo tenham levado a liga, na primeira fusão, a apresentar-se bem segregado. No segundo caso, com os cilindros menores, não houve dificuldade em se homogeneizar a carga logo na primeira tentativa. Entretanto, para se assegurar que toda a peça apresentasse elevado grau de homogeneização, as ligas foram refundidas uma ou mais vezes.

Os cilindros de molibdênio apresentaram-se sem cobertura de óxido, portanto não foi necessária a realização de tratamento superficial. Para as cargas em pó e tabletes, apesar de haver maior chance de oxidação (materiais bem particulados), também não se utilizou nenhum preparo da superfície, dadas as dificuldades em se remover camadas de óxidos de partículas muito pequenas.

Após a disposição da carga sobre a base de cobre do forno nas coquilhas sobre ela usinadas, a campânula do forno foi fechada e acionado o sistema de refrigeração simultâneo da base de cobre e da campânula. Vácuo mecânico foi aplicado com bomba de estágio único. Na pressão de $-90 \mathrm{mmHg}$, efetuou-se o fechamento da válvula de passagem de gás para a campânula, e por meio de outra válvula gás Ar foi inserido em seu interior. A abertura do arco foi feita quando a pressão chegou à zero ou menor, indicando campânula preenchida com gás igualando a pressão externa.

Arco voltaico foi feito por pressionamento do pedal para abertura de arco, aproximando-se vagarosamente a tocha, com eletrodo não consumível de tungstênio em sua extremidade, do chamado "iniciador de arco" ou "arc-starter", localizado na base de cobre refrigerada. $\mathrm{O}$ controle de intensidade foi feito pelo pressionamento do pedal, menor pressão quando do transporte do arco para as coquilhas, maior pressão quando de sua chegada sobre a amostra. O controle da fusão foi feito através de visor instalado na parte superior da campânula, devidamente protegido com material plástico para a filtragem do excesso de luz. Observou-se a facilidade com a qual os discos de urânio se fundem, e a dificuldade na fusão e homogeneização do Mo com o U, em fase líquida. Somente após alguns segundos de aplicação do arco sobre a amostra é que não foi mais possível distinguir Mo de U, indicando que houve mistura. Foi bem visível também a influência que o movimento do gás (convectivo) no interior da câmara exerce sobre a integridade do arco, 
daí ser mais difícil a sua manutenção quando a pressão durante o processo de fusão está no nível zero no marcador (ou seja, igual a $1 \mathrm{~atm}$ ).

Quando da aplicação de arco sobre a amostra, inicialmente há a fusão do urânio (temperatura de fusão menor que a do Mo), com a formação de uma bolha no interior da coquilha. A utilização de pós de Mo não permite que observemos o seu comportamento durante a fusão, o que pode indicar que o mesmo se homogeneíze melhor dentro da fase líquida, mas que não necessariamente haja solubilização total entre $U$ e Mo para a formação da composição de liga desejada, durante o resfriamento. A dificuldade nesta fase do preparo é notória com os tabletes, embora o trabalho com esta geometria evite as perdas acima mencionadas.

Para evitar danos na campânula, limitou-se a aplicação do arco sobre a amostra em um tempo de 30 segundos. A propagação do calor é muito rápida no interior do forno, da coquilha até as paredes, dadas as suas dimensões reduzidas, o que gera também elevadas temperaturas em sua parede externa. Após a realização das fusões, e para minimizar o risco de geração de chama pela oxidação violenta da liga formada, o resfriamento foi feito no interior do forno, com a refrigeração da base de cobre ligada, mantida a $20^{\circ} \mathrm{C}$. A abertura foi feita após temperatura da parede externa da campânula ao redor de $40^{\circ} \mathrm{C}$, ou seja, até que pudesse ser tocada com as mãos. Nestas condições, o tempo de resfriamento das amostras até a temperatura ambiente variou de 20 a 30 minutos.

Como há grande diferença de temperaturas entre a base e a parte superior da amostra, durante o seu resfriamento elas destacam-se facilmente da coquilha. Como foi utilizado molde metálico refrigerado, a velocidade de remoção de calor é muito alta, os gradientes de temperatura na amostra são elevados. Em muitas das ligas, observou-se a presença de dendritas, persistentes mesmo após vários rebatimentos. Daí ser necessário, neste processo, a realização de tratamentos térmicos prolongados de homogeneização. Discute-se mais detalhadamente este assunto em publicação apresentada na "European Nuclear Conference ENC-2007" 52 . Isto foi confirmando pela observação, após retirada das amostras das coquilhas, de estruturas diferentes ao longo do eixo menor das amostras, pois os botões apresentaram usualmente geometria elipsoidal ou de um setor esférico.

Após inspeção visual das ligas, verificou-se a necessidade ou não da aplicação de refusões, principalmente quando sinais de segregação foram observados. Quando foi este o caso, as amostras foram posicionadas com a parte superior da primeira fusão em contato com a base. Todo o procedimento de preparo para a fusão foi repetido, em cada operação de refusão. Entretanto, foi observado que o aumento no número de fusões 
aumentou a camada de óxido sobre as peças, e este foi o limite adotado para o número de refusões.

Para a retirada de amostras das ligas utilizou-se cortadeira com disco diamantado, com velocidade igual a $80 \%$ da máxima permitida pelo equipamento, sob lubrificação feita com óleo próprio para corte. As amostras foram coletadas para os ensaios de caracterização, tratamentos térmicos e testes em analisador termogravimétrico. Após o corte as amostras foram limpas com álcool, para a remoção do lubrificante, lavadas com água destilada corrente e novamente com etanol e, em seguida, dispostas em dessecadores.

A seguir relaciona-se os dados de produção das amostras preparadas por arco, porcentagens nominais de molibdênio:

U6Mo: 6\% em peso de Mo, massa final de 40,54g, carga de urânio metálico em discos, pó como carga de molibdênio. Massa inicial $\mathrm{U}\left(\mathrm{M}_{\mathrm{U}}\right)=50,00 \mathrm{~g}$, massa inicial Mo $\left(\mathrm{M}_{\mathrm{Mo}}\right)=$ $3,19 \mathrm{~g}$.

UA1: 8\% em peso de Mo, massa final de 27,02g, após ser submetida a 3 refusões, carga de urânio metálico em discos, carga de molibdênio em cilindros de $8 \mathrm{~mm}$ x $5 \mathrm{~mm}$. $\left(\mathrm{M}_{\mathrm{U}}\right)=$ $29,28 \mathrm{~g},\left(\mathrm{M}_{\mathrm{Mo}}\right)=2,55 \mathrm{~g}$. Após primeira fusão, massa $=31,40 \mathrm{~g}$, e após segunda, massa $=$ $27,11 \mathrm{~g}$.

UA6: de 1 a 7\% em peso de Mo, massa final de 30,47g, carga de urânio metálico em discos, carga de molibdênio pó. A incerteza na porcentagem deveu-se ao problema da passagem do arco sobre a carga em forma de pó. Após abertura da campânula, notou-se grande quantidade de molibdênio sobre a base, que impregnava sua parede interna. $\left(\mathrm{M}_{\mathrm{U}}\right)=$ $30,15 \mathrm{~g},\left(\mathrm{M}_{\mathrm{Mo}}\right)=2,13 \mathrm{~g}$.

UA9: 9\% em peso de Mo, massa final de 37,87g, submetida a 5 refusões, discos como carga de urânio metálico, pedaços de tabletes como carga de molibdênio. $\left(\mathrm{M}_{\mathrm{U}}\right)=37,47 \mathrm{~g}$, $\left(\mathrm{M}_{\mathrm{Mo}}\right)=3,75 \mathrm{~g}$. Após primeira refusão, massa $=42,37 \mathrm{~g}$, indicando alguma incorporação de material da base de cobre ou oxidação acentuada na liga.

UA8: 8\% em peso de Mo, massa final de 34,72g, submetida a 2 refusões, discos como carga de urânio metálico, pedaços de tabletes como carga de molibdênio. $\left(\mathrm{M}_{\mathrm{U}}\right)=31,97 \mathrm{~g}$, $\left(\mathrm{M}_{\mathrm{Mo}}\right)=3,05 \mathrm{~g}$. 
U7Mo (também identificada como U7Mo2R): 7\% em peso de Mo, massa final de 35,33g, submetida a 2 refusões, discos como carga de urânio metálico, pedaços de tabletes como carga de molibdênio. $\left(\mathrm{M}_{\mathrm{U}}\right)=31,54 \mathrm{~g},\left(\mathrm{M}_{\mathrm{Mo}}\right)=2,40 \mathrm{~g}$. Diferenças nas massas antes e depois da fusão indicaram perdas de processo.

UA10: 7\% em peso de mistura Mo e Si (Mo:Si = 1:1 em peso), massa final de 30,84g, submetida a 2 refusões, discos como carga de urânio metálico, pedaços de tabletes como carga de molibdênio, pedaços com geometria irregular como carga de silício. $\left(\mathrm{M}_{\mathrm{U}}\right)=$ $29,31 \mathrm{~g},\left(\mathrm{M}_{\mathrm{Mo}}\right)=1,00 \mathrm{~g},\left(\mathrm{M}_{\mathrm{Si}}\right)=1,01 \mathrm{~g}$.

UA7: 5\% em peso de Mo, massa final de 26,68g, submetida a duas refusões, discos como carga de urânio metálico, pedaços de tabletes como carga de molibdênio. $\left(\mathrm{M}_{\mathrm{U}}\right)=26,11 \mathrm{~g}$, $\left(\mathrm{M}_{\mathrm{Mo}}\right)=1,39 \mathrm{~g}$.

U4Mo: 4\% em peso de Mo, massa final de 39,62g, 2 refusões, $\left(\mathrm{M}_{\mathrm{U}}\right)=38,34 \mathrm{~g},\left(\mathrm{M}_{\mathrm{Mo}}\right)=$ $1,61 \mathrm{~g}$.

UMo3A: 7\% em peso de Mo, massa final de 45,35g, discos como carga de urânio metálico, cilindros $3 \times 3$ como carga de molibdênio. $\left(\mathrm{M}_{\mathrm{U}}\right)=41,86 \mathrm{~g},\left(\mathrm{M}_{\mathrm{Mo}}\right)=3,33 \mathrm{~g}$.

UMo4: 10\% em peso de Mo, massa final de 32,69g, submetida a 2 refusões, discos como carga de urânio metálico, cilindros $3 \mathrm{~mm} \times 3 \mathrm{~mm}$ como carga de molibdênio. $\left(\mathrm{M}_{U}\right)=29,31 \mathrm{~g}$, $\left(\mathrm{M}_{\mathrm{Mo}}\right)=3,75 \mathrm{~g}$.

U10Mo: $10 \%$ em peso de Mo, massa final de 50,80g, discos como carga de urânio metálico, pó como carga de molibdênio. $\left(\mathrm{M}_{\mathrm{U}}\right)=45,99 \mathrm{~g},\left(\mathrm{M}_{\mathrm{Mo}}\right)=4,81 \mathrm{~g}$.

UA3: 8,5\% em peso de Mo, massa final de 31,10g, discos como carga de urânio metálico, pó como carga de molibdênio. $\left(\mathrm{M}_{\mathrm{U}}\right)=28,78 \mathrm{~g},\left(\mathrm{M}_{\mathrm{Mo}}\right)=2,78 \mathrm{~g}$.

UA5: 4\% em peso de Mo, massa final de 39,62g, discos como carga de urânio metálico, pedaços de tabletes como carga de molibdênio. $\left(\mathrm{M}_{\mathrm{U}}\right)=38,34 \mathrm{~g},\left(\mathrm{M}_{\mathrm{Mo}}\right)=1,61 \mathrm{~g}, 2$ refusões.

USi: composto $\mathrm{U}_{3} \mathrm{Si}_{2}$, massa igual a $17,01 \mathrm{~g}$, discos como carga de urânio metálico, 
pedaços de silício como carga de silício.

Na figura 3 está apresentado o forno de fusão a arco utilizado para a realização destes experimentos. Foto obviamente tomada com o forno ainda não operacional. Hoje o forno encontra-se totalmente instalado e operacional.

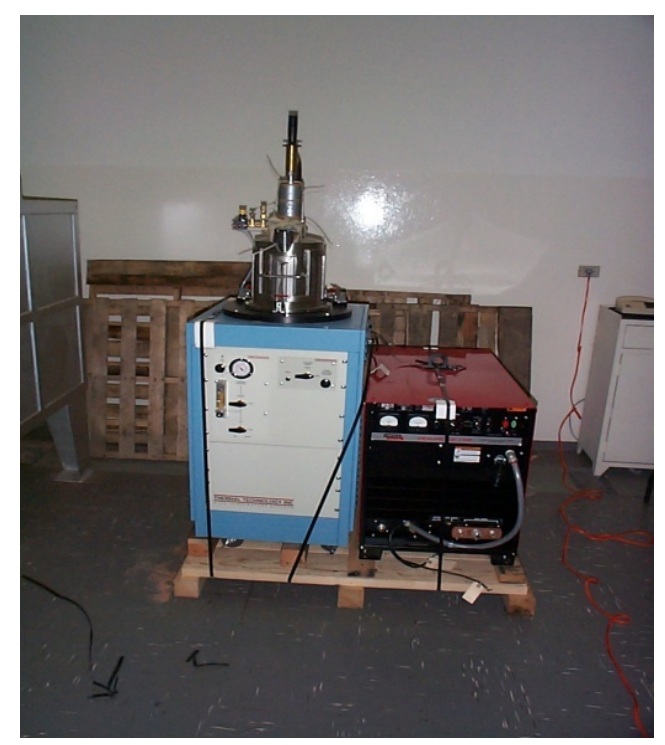

FIGURA 03 - Forno a arco. Em vermelho a unidade de tensão, contornado em azul o painel de controle de gases, acima do qual está situada a câmara de fusão. A chamada tocha aparece como um prolongamento da câmara.

Análises químicas dos materiais de partida são as constantes em certificado de análises fornecidos pelo fabricante, nos casos dos materiais molibdênio e silício. Molibdênio, sob todas as formas, foi adquirido com 99,95\% de pureza, e silício com $99,9 \%$, todos com pureza suficiente para o preparo de ligas sem contaminação. No caso dos discos de urânio metálico, análises químicas foram realizadas em laboratório no IPEN, indicando como principais impurezas o carbono $(0,067 \%$ em peso, provavelmente oriundo de cadinhos de redução, feitos em grafite), e ainda magnésio, alumínio, estanho e outras, presentes em quantidades da ordem de ppm. A confirmação destes resultados, infelizmente, não foi possível, dado o estado da técnica das análises de amostras das ligas $\gamma$ UMo. A técnica utilizada foi a da fluorescência de raios-X, mas, conforme atestado no certificado de análises, os resultados não podem ser considerados conclusivos.

Este problema pode ser contornado ao considerarmos que, visto que as pesagens das cargas foram realizadas em balanças com precisão de até 3 casas decimais, a precisão nos valores é alta e dada pela precisão nos equipamentos de medida, atendendo ao 
que se pretende como objetivos neste trabalho. Corroborando esta afirmação, apresentarei em capítulo apropriado os dados de densidade.

\subsection{Preparo das ligas binárias de U-Mo, fusão via indução.}

Para o preparo das ligas via fusão por indução foram utilizadas como cargas cilindros de urânio metálico produzidos no IPEN, com aproximadamente $7 \mathrm{~cm}$ de altura por $2 \mathrm{~cm}$ de diâmetro, e cargas de Mo compostas pelos tabletes de pós compactados, cilindros $8 \mathrm{~mm} \times 5 \mathrm{~mm}$ e cilindros $3 \mathrm{~mm} \times 3 \mathrm{~mm}$. Tabletes e os cilindros $8 \mathrm{~mm} \times 5 \mathrm{~mm}$ foram utilizados em conjunto, quando do preparo da primeira fusão de uma liga UMo no IPEN, nunca tendo sido, ao contrário das fusões a arco, utilizados isoladamente. As cargas de Mo $3 \mathrm{~mm} \times 3 \mathrm{~mm}$ foram utilizadas no preparo das demais ligas. Cilindros $8 \mathrm{~mm}$ x $5 \mathrm{~mm}$ foram os recomendados pela missão chilena ao Brasil, e constituem o tipo de carga utilizado para indução nas instalações nucleares da Comissão Chilena de Energia Nuclear. Por considerações de homogeneidade, optou-se pela compra de cilindros menores.

A carga foi preparada da seguinte maneira. Após limpeza de sua superfície com ácido nítrico, os cilindros de urânio mais os de Mo foram inseridos no interior de cadinho de zircônia. Antes da colocação do conjunto no interior da bobina de indução, procurou-se dispor o cilindro de $\mathrm{U}$ de modo a haver coincidência entre seu eixo central e o do cadinho e, portanto, entre o eixo do cilindro de urânio e o da bobina.

Em seguida realizou-se um ciclo de purga e vácuo da câmara interna, num total de 3 operações. Com um vácuo estável de $4 \times 10^{-2} \mathrm{mbar}$, acionou-se a bomba difusora, e procedeu-se à operação de fusão propriamente dita, com aumentos graduais da potência fornecida à bobina, após estabilização em patamares de potência por não mais do que 4 minutos, conforme tabela 02 . Após observação da fusão do cilindro de urânio e da carga de molibdênio, manteve-se o sistema sob agitação por 2 a 3 minutos, para garantia da homogeneização, e desligou-se o forno.

Nas tabelas 02 a 04, a \% pot. refere-se ao patamar de potência, dado pela porcentagem da máxima potência capaz de ser atingida pelo forno, $15 \mathrm{~kW}$, e t é o tempo da amostra no patamar. Em todos os casos, o tempo para a estabilização do forno (para a entrada do forno em regime de operação), foi de 5 minutos. A descrição mais detalhada de cada um dos experimentos é dada a seguir. Valores de porcentagem são nominais.

Carga 01: 7\% Mo em peso, massa final bruta aproximada de $623,81 \mathrm{~g}$, foi preparada com tabletes de pós compactados mais os cilindros de Mo $8 \mathrm{~mm}$ x $5 \mathrm{~mm}$. Para a completa 
solubilização dos tabletes houve a necessidade de se efetuar 3 operações, e assim, sabendose que a massa de material carregada no forno no primeiro ciclo foi de $654,42 \mathrm{~g}$, houve uma perda de 30,61g por problemas de homogeneização e simetria no carregamento. Chegou-se ao final do terceiro ciclo com uma potência de $90 \%$, após a qual o forno foi desligado, aumento de potência subseqüente o desarmaria, conforme constatou-se nos 2 ciclos anteriores. Massa de urânio antes da decapagem igual a 608,46g, massa de molibdênio igual a $45,8 \mathrm{~g}$.

TABELA 02 - Ciclos de potência, experimentos de fusão por indução, cargas 01 a 04.

\begin{tabular}{|c|c|c|c|c|c|c|c|}
\hline \multicolumn{2}{|c|}{ carga 01(U7Mo) } & \multicolumn{2}{c|}{ carga 02(U7Mo) } & \multicolumn{2}{c|}{ carga 03 (U8Mo) } & \multicolumn{2}{c|}{ carga 04 (U6Mo) } \\
\hline$\%$ pot & $\mathrm{t}(\mathrm{min})$. & $\%$ pot & $\mathrm{t}$ (min.) & $\%$ pot & $\mathrm{t}(\mathrm{min})$. & $\%$ pot & $\mathrm{t}(\mathrm{min})$. \\
\hline 30 & 3 & 30 & 3 & 35 & 3 & 35 & 4 \\
\hline 55 & 4 & 55 & 4 & 55 & 4 & 55 & 5 \\
\hline 75 & 5 & 75 & 5 & 75 & 3 & 75 & 3 \\
\hline 90 & 4 & 90 & 1 & 90 & 1 & 88 & 1 \\
\hline & & & & 100 & 2 & & \\
\hline
\end{tabular}

TABELA 03 - Ciclos de potência, experimentos de fusão por indução, cargas 05 a 08.

\begin{tabular}{|c|c|c|c|c|c|c|c|}
\hline \multicolumn{2}{|c|}{ carga 05 (U5Mo) } & \multicolumn{2}{c|}{ carga 06 (U9Mo) } & \multicolumn{2}{c|}{ carga 07 (U10Mo) } & \multicolumn{2}{c|}{ carga 08 (U10Mo) } \\
\hline$\%$ pot & $\mathrm{t}$ (min.) & $\%$ pot & $\mathrm{t}($ min.) & $\%$ pot & $\mathrm{t}(\mathrm{min})$. & $\%$ pot & $\mathrm{t}(\mathrm{min})$. \\
\hline 35 & 3 & 35 & 3 & 25 & 3 & 25 & 3 \\
\hline 55 & 4 & 55 & 4 & 50 & 4 & 50 & 4 \\
\hline 75 & 4 & 75 & 4 & 75 & 4 & 75 & 4 \\
\hline 85 & 3 & 85 & 2 & 90 & 3 & 90 & 2 \\
\hline
\end{tabular}

TABELA 04 - Ciclos de potência, experimentos de fusão por indução, cargas 09 e 10.

\begin{tabular}{|c|c|c|c|}
\hline \multicolumn{2}{|c|}{ carga 09 (UMo11) } & \multicolumn{2}{c|}{ carga 10 (UMo12) } \\
\hline$\%$ pot & $\mathrm{t}$ (min.) & $\%$ pot & $\mathrm{t}$ (min.) \\
\hline 35 & 3 & 35 & 3 \\
\hline 50 & 5 & 50 & 4,5 \\
\hline 75 & 5 & 75 & 6 \\
\hline 90 & 2 & 90 & 2 \\
\hline
\end{tabular}


Carga 02: 7\% Mo em peso, massa final bruta aproximada de 1004,29 g, primeiro experimento conduzido com carga cilíndrica $3 \mathrm{~mm}$ x $3 \mathrm{~mm}$. Não houve necessidade de refusões, pois a amostra apresentou-se bem homogênea. Massa de urânio antes da decapagem igual a 935,60g, massa de molibdênio igual a 70,69g.

Carga 03: 8\% Mo em peso, massa final bruta aproximada de 795,22 g. Massa de urânio após decapagem igual a 734,25g, massa de molibdênio igual a 63,79g. Não foi observada agitação na carga em $90 \%$ da potência, problema este resolvido quando da subida para $100 \%$. Isto foi devido a uma provável irregularidade na disposição das cargas no interior do cadinho de zircônia, não foi possível alinhar o eixo central do cilindro de urânio com o eixo central da bobina, o que dificultou a fusão.

Carga 04: 6\% Mo em peso, massa final bruta aproximada de 786,48 g. Massa de urânio após decapagem do cilindro igual a 739,49g, massa de molibdênio igual a 47,26g. Ao contrário do experimento anterior, houve boa agitação da carga já na potência de $88 \%$. Experimento também conduzido com carga de molibdênio $3 \mathrm{~mm}$ x $3 \mathrm{~mm}$.

Carga 05: 5\% Mo em peso, massa final bruta aproximada de 776,05 g. Massa de urânio após decapagem do cilindro igual a 737,18g, massa de molibdênio de 38,87g. Muita agitação já a $85 \%$ de potência. Mesmo assim, forçou-se a permanência da liga por 3 minutos, após os quais desligou-se o forno.

Carga 06: 9\% Mo em peso, massa final bruta aproximada de 765,31 g. Massa de urânio após decapagem igual a 697,41g, massa de molibdênio adicionada igual a 68,80g. Aqui se observou agitação violenta após 2 minutos. Com receio de comprometer-se a integridade do cadinho, diminuiu-se a potência antes de completar 3 minutos.

Carga 07: 10\% Mo em peso, massa final bruta aproximada de 803,69 g. Massa de urânio após decapagem igual a 723,32g, massa de molibdênio igual a 80,37g. Como foi observada boa agitação a 90\% optou-se pela utilização de 3 minutos de homogeneização, dada a maior quantidade de molibdênio relativamente aos outros experimentos.

Carga 08: 10\% Mo em peso, massa final bruta aproximada de 803,03 g. Massa de urânio após decapagem igual a 722,74g, massa de molibdênio adicionada igual a 80,29g. Dada a 
boa homogeneidade da carga e para fins de riscos quanto à integridade do cadinho, diminui-se o tempo no patamar superior em 1 minuto. Uma liga também homogênea foi obtida.

Cargas 09 e 10: massa final bruta aproximada de 800,26g. Massa de urânio igual a $720,49 \mathrm{~g}$, masssa total de elementos de adição igual a 80,39g.

Foram retiradas algumas amostras destas ligas para tratamento térmico, para comparação de desempenho com as amostras brutas de fusão. Com o resfriamento da carga completo, procedeu-se então às medidas de densidade e outros parâmetros de interesse da peça bruta de fusão, e à retirada de amostras para os demais ensaios desta tese.

É interessante fornecer-se o detalhamento do procedimento de carregamento do forno e fusão das cargas. As fotografias apresentadas na Figura 04 referem-se à fusão realizada na Comissão Chilena de Energia Nuclear, para a produção de uma liga $\gamma$-UMo a $7 \%$ em peso de molibdênio. Nesta figura são mostrados os materiais que compõem a carga do forno de indução, a saber: cadinho de zircônia, cilindro de urânio metálico natural e peças de molibdênio, no caso as de $8 \mathrm{~mm}$ x $5 \mathrm{~mm}$.

Na Figura 04(b) é mostrada a geometria do carregamento, onde se manteve o cilindro de urânio o mais alinhado possível com o eixo central do cadinho e bobina de indução, dispondo-se os cilindros de molibdênio simetricamente ao seu redor. Na Figura 05 é mostrada uma vista externa do forno de indução e painel de controle, por onde foi possível a realização das alterações de potência.
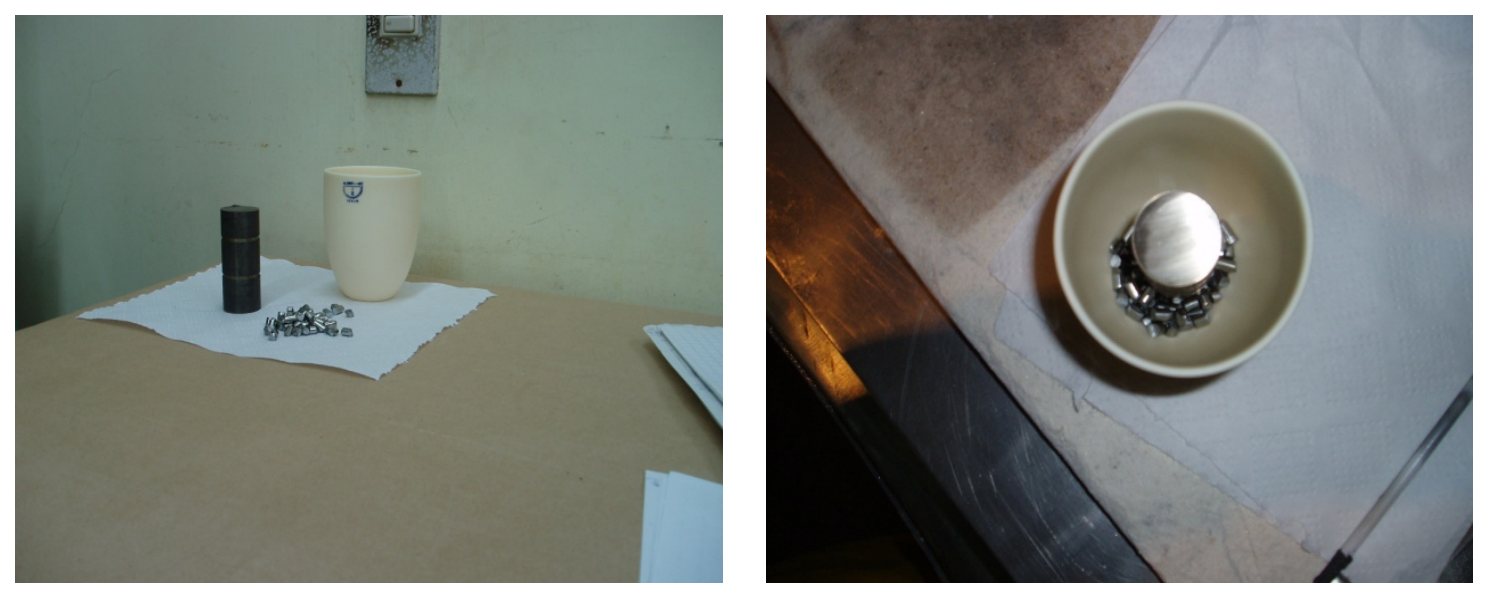

FIGURA 04 - Carga e geometria de carregamento, experimentos de fusão via indução. 


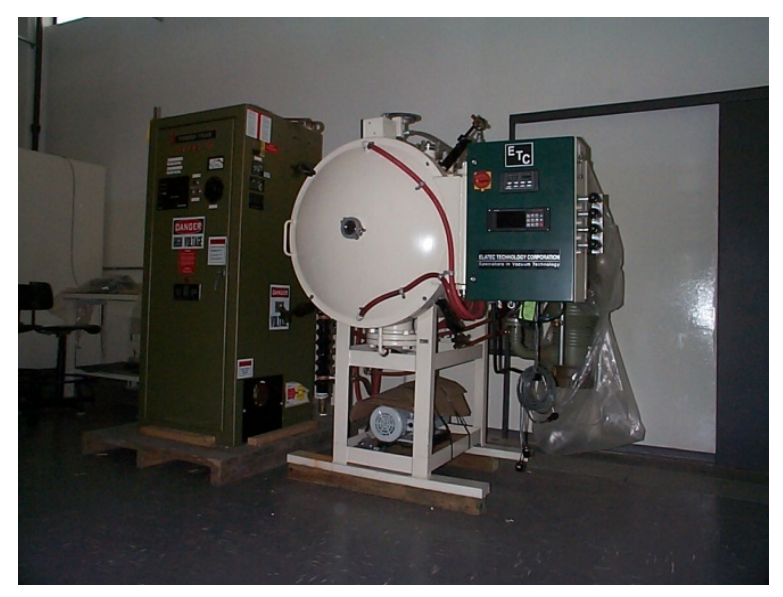

FIGURA 05 - Forno de indução, centro: câmara de fusão, à esquerda: painel de controle de potência, à direita: painel de controle de válvulas de vácuo e de introdução de gases.

Após o carregamento do forno, realização dos procedimentos de vácuo e purga, e subida de potência, a visualização do andamento do processo de fusão pode ser feito por meio de visor existente na parte lateral da câmara. Na figura 06 é mostrada uma seqüência de fotografias correspondentes ao estado da carga em cada um dos patamares de potência.

$\mathrm{Na}$ Figura 6(a) observamos o instante em que o cadinho começa a tornar-se rubro, o que ocorre ao final do primeiro patamar de potência. A carga começa a tomar a mesma coloração do cadinho a partir da segunda fase, ao final do segundo patamar de potência, Figura 6(b). Com a passagem ao terceiro patamar, Figura 6(c), o cilindro de urânio começa a derreter, indicando que a temperatura no sistema deva ter atingido a do ponto de fusão do urânio puro, de $1129^{\circ} \mathrm{C}$. Esta foi tomada instantes antes da fusão total do cilindro de urânio metálico. A última das imagens foi tomada a partir de visor frontal da câmara, antes da interrupção da potência do forno, Figura 6(d). Ela mostra, portanto, a radiação emitida pela superfície externa do isolamento refratário da bobina de indução.

Após o aquecimento, a carga volta à temperatura ambiente por resfriamento no interior do próprio forno. Como o resfriamento é feito sobre molde cerâmico, no caso zircônia, a taxa de remoção de calor da amostra é baixa comparada com a das amostras de forno a arco. Portanto, sendo um resfriamento mais lento, espera-se maior homogeneidade em termos de composição e tamanho de grãos, relativamente às amostras de forno a arco.

Como em sistemas binários há sempre o problema da microssegregação ${ }^{53}$, tratamentos térmicos também foram aplicados sobre as amostras, para sua melhor homogeneização. No item seguinte serão apresentados os procedimentos de tratamentos térmicos, em ambos os conjuntos de ligas. 

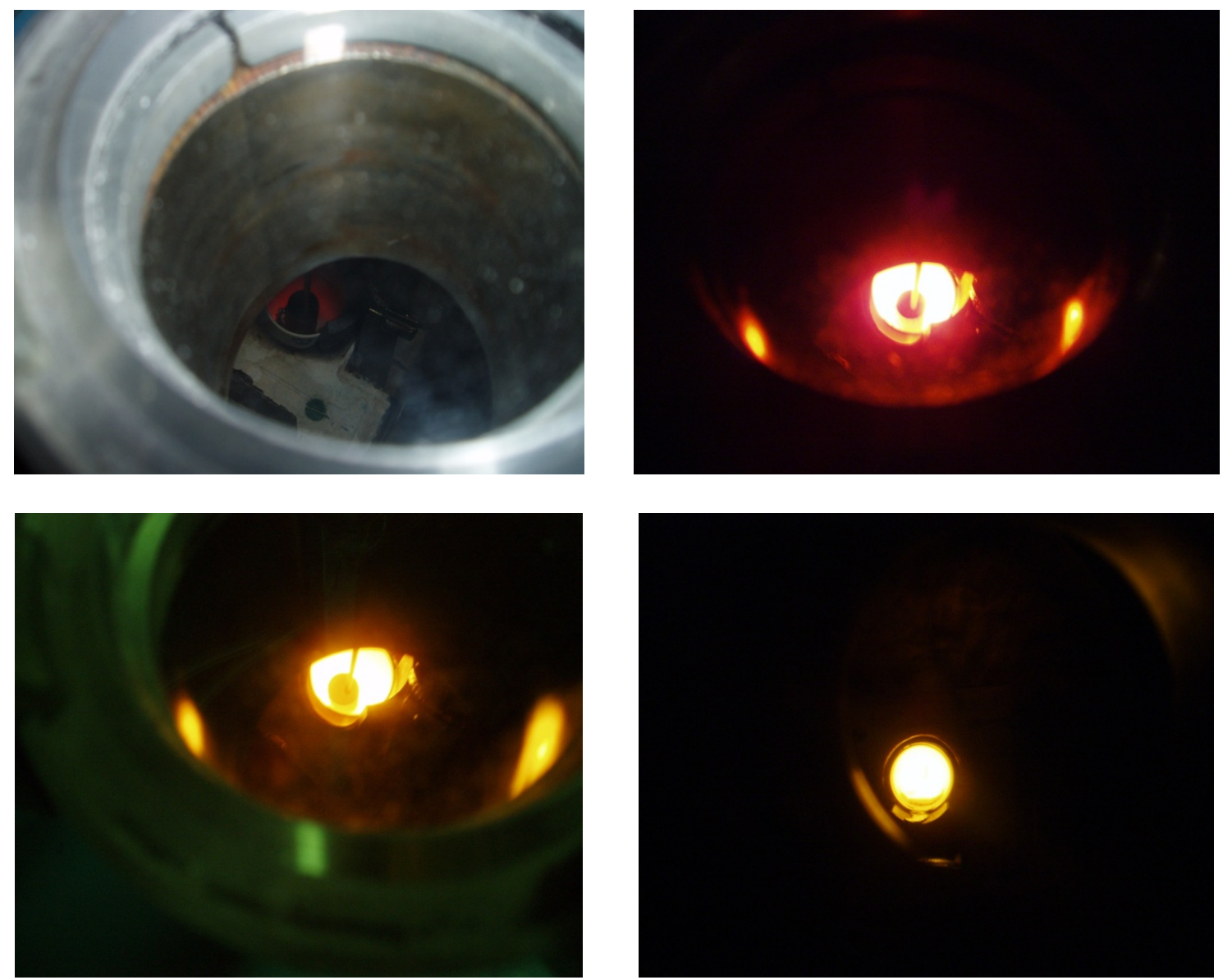

FIGURA 06 - Estados da carga em cada um dos patamares de potência, superior esquerda $=35 \%$, superior direita $=55 \%$, inferior esquerda $=75 \%$ e inferior direita $=90 \%$.

\subsection{Tratamentos térmicos}

As ligas produzidas em forno a arco apresentaram, conforme será visto adiante, dendritas e, portanto, indícios de não homogeneidade na distribuição de soluto. Por outro lado, as amostras de indução apresentaram-se bem mais homogêneas, mas as micrografias das amostras brutas de fusão mostraram indícios de microssegregação, diferenças de composição no interior dos grãos devida à segregação de soluto durante a solidificação.

Para assegurar a homogeneidade na composição e, portanto, melhor precisão nos testes de hidretação, oxidação e compatibilidade, algumas amostras de forno a arco e todas as amostras de ligas de forno de indução foram tratadas termicamente para homogeneização. Utilizou-se, para tanto, os mesmos sistemas existentes no IPEN para a hidrogenação das ligas de urânio, um deles pertencente ao Laboratório de Materiais Magnéticos, e o outro em equipamento de análise termogravimétrica, cujas imagens encontram-se nas Figuras 07 e 08 do capítulo 06. 
Os tratamentos térmicos de homogeneização são conduzidos usualmente em temperaturas próximas à da linha solidus. Para a faixa de composições $\gamma$ UMo estudadas nesta tese, a temperatura de $1000^{\circ} \mathrm{C}$ já pode ser considerada suficiente, e também de acordo com alguns trabalhos existentes na literatura, conforme visto no Capítulo 2 da Introdução. Entretanto, para verificar a influência do tempo na obtenção de grãos com dimensões próximas às especificadas para tamanhos de partículas dos combustíveis de óxido de urânio e de siliceto de urânio, as amostras foram tratadas nesta temperatura, por tempos de 24, 48 e 72 horas. Como os estudos foram realizados em amostras de indução, somente algumas de arco sofreram o tratamento. A seguir descreve-se o procedimento utilizado e os dados de amostras para os tratamentos térmicos de homogeneização.

Pelas características dos equipamentos, pode-se dizer que a estrutura final da amostra foi obtida após "annealing" a $1000^{\circ} \mathrm{C}$, por tempos variando de 24 a 72 horas, após resfriamento ao ar, velocidade de resfriamento média de $40^{\circ} \mathrm{C}$ por minuto, portanto não foi produzida estrutura de têmpera.

U10Mo: arco, temperatura média de $980^{\circ} \mathrm{C}$, tempo de 72 horas, $10^{-2} \mathrm{mbar}$, forno tubular.

UA9: arco, temperatura média de $1038^{\circ} \mathrm{C}, 48$ horas, $4 \times 10^{-2} \mathrm{mbar}$, forno tubular.

UA10: arco, temperatura média de $1038^{\circ} \mathrm{C}, 48$ horas, $4 \times 10^{-2} \mathrm{mbar}$, forno tubular.

UMo2: indução, temperatura média de $1038^{\circ} \mathrm{C}, 24$ horas, $4 \times 10^{-2} \mathrm{mbar}$, forno tubular.

UMo6: indução, 2 condições de tratamento: $1^{\mathrm{a}}$. temperatura média de $1038^{\circ} \mathrm{C}, 24$ horas, $4 \times 10^{-2}$ mbar; $2^{\mathrm{a}}$. temperatura média de $1038^{\circ} \mathrm{C}, 48$ horas, $4 \times 10^{-2} \mathrm{mbar}$, forno tubular.

UMo5: indução, temperatura média de $1038^{\circ} \mathrm{C}, 24$ horas, $4 \times 10^{-2} \mathrm{mbar}$, forno tubular.

UMo7: indução, temperatura média de $1038^{\circ} \mathrm{C}, 24$ horas, $4 \times 10^{-2} \mathrm{mbar}$, forno tubular.

UMo8: indução, temperatura média de $1038^{\circ} \mathrm{C}, 24$ horas, $4 \times 10^{-2} \mathrm{mbar}$, forno tubular.

UMo9: indução, temperatura média de $1038^{\circ} \mathrm{C}, 24$ horas, $4 \times 10^{-2} \mathrm{mbar}$, forno tubular. 
UMo10: indução, temperatura média de $1038^{\circ} \mathrm{C}, 48$ horas, $4 \times 10^{-2} \mathrm{mbar}$, forno tubular.

UMo11: indução, temperatura de $900^{\circ} \mathrm{C}, 6$ horas, $\mathrm{Ar} ; 920^{\circ} \mathrm{C}, 3$ horas, Ar, analisador térmico. 


\section{ENSAIOS DE HIDROGENAÇÃO E COMPATIBILIDADE}

Todos os ensaios foram realizados em equipamento fornecido pela Agência Internacional de Energia Atômica, projeto BRA/4/053 de cooperação internacional Brasil / AIEA $^{01}$. Este conjunto de experimentos teve como objetivo principal a verificação de condições pelas quais é possível a obtenção de pós de urânio em fase gama, de compatibilidade entre as ligas e o alumínio, e de estabilidade frente ao oxigênio.

Em seguida, com base nestes resultados, efetuou-se a validação em escala semi-piloto dos ensaios de hidrogenação, para algumas das ligas produzidas, em instalação existente no Laboratório de Materiais Magnéticos do IPEN-CNEN/SP. Por problemas de radioproteção, trabalhou-se com um máximo de $50 \mathrm{~g}$ de ligas $\gamma \mathrm{UMo}$.
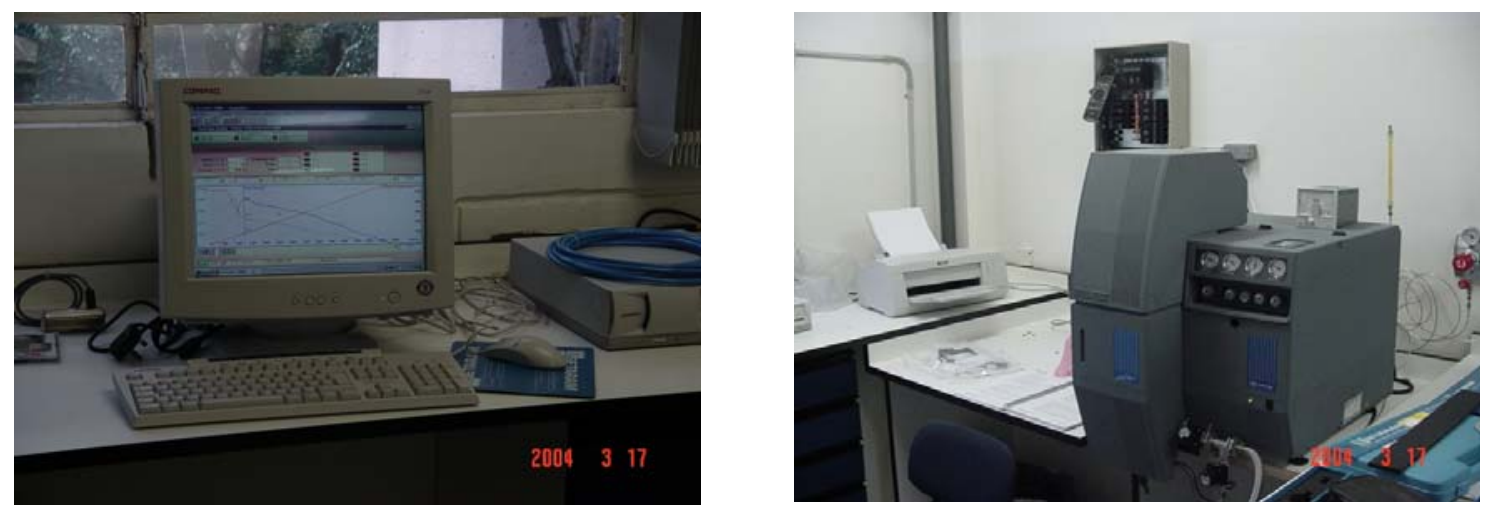

FIGURA 07 - Esquerda: visualização dos dados coletados em um experimento TG, direita: unidade de controle de gases e balança.

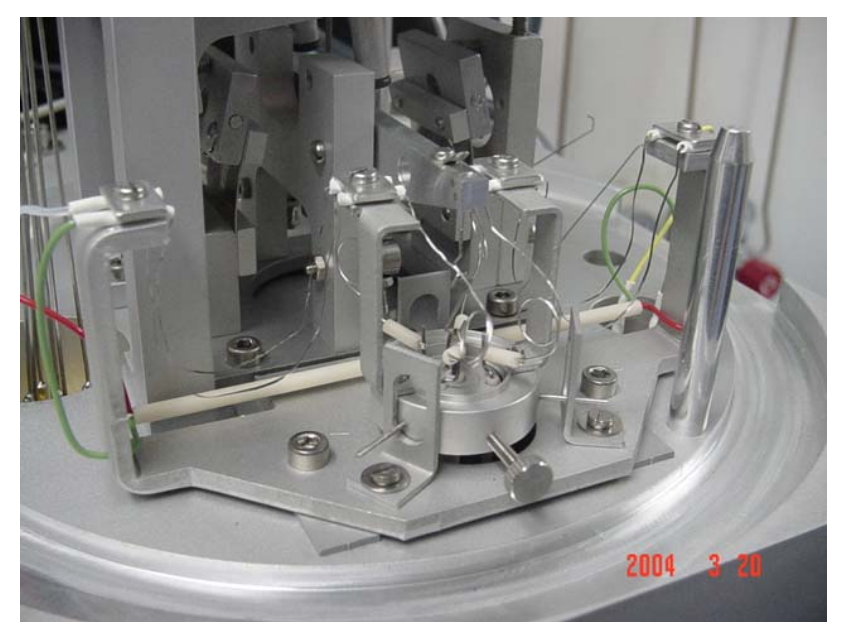

FIGURA 08 - Vista do cabeçote com os sensores da balança. 
Foram tomadas amostras de cada uma das cargas de urânio, com massas variando entre 200 e $300 \mathrm{mg}$, conforme o objetivo do experimento. Para tanto, procedeu-se ao corte de fatias das amostras brutas de fusão e tratadas termicamente em equipamento de corte com disco diamantado, para obtenção de algumas fatias. Em equipamento de corte de laboratório, as ligas foram obtidas em pequenas amostras com altura, largura e espessura tais que pudessem ser acondicionadas nos cadinhos.

Os cadinhos utilizados foram os apropriados para os ensaios de TG / DTA com hidrogênio, para os ensaios de hidrogenação, e TG / DTA com oxigênio e gás inerte, para os ensaios de compatibilidade e estabilidade térmica. Todos foram fornecidos com o próprio equipamento. Após cada experimento, sua limpeza foi efetuada com água destilada e etanol, secos em mufla a $200^{\circ} \mathrm{C}$, e dispostos em dessecador para remoção da umidade, até o ensaio no dia seguinte. Quando resíduos sólidos se acumularam nos cadinhos, a remoção dos mesmos foi feita com ataque por ácido nítrico seguido de ataque por ácido fluorídrico concentrado, por tempo suficiente até sua remoção. Quando necessário, efetuou-se o tratamento subseqüente dos mesmos em mufla até $1000^{\circ} \mathrm{C}$. As condições dos cadinhos foram constantemente monitoradas, efetuando-se a substituição quando a limpeza não conseguiu remover os resíduos.

O sistema cadinho mais amostra foi então inserido no interior da câmara do forno do equipamento. Após fechamento das câmaras e válvulas do sistema de vácuo, acionou-se o programa que controla a balança, para a determinação das massas de amostras, taras, etc.. A partir desta condição, a válvula da câmara interna do forno foi aberta para a realização de vácuo, inicialmente aplicado à linha e, em seguida, na câmara interna do forno. Procurou-se em todos os experimentos manter o isolamento entre a parede externa do forno e a interna da câmara preenchida com Ar, para evitar deterioração do isolamento e demais componentes do forno. Depois de atingido um vácuo da ordem de 2 a $3 \times 10^{-2}$ mbar, após tempo aproximado de 20 minutos, o máximo permitido pelo sistema, procedeu-se ao isolamento da câmara interna fechando-se as conexões à linha de vácuo. Em seguida, introduziu-se gás hidrogênio, argônio ou ar sintético até que o valor de pressão no sistema atingisse zero no manômetro. Após preenchimento da câmara com o gás, verificado pela movimentação da esfera em tubo de Brooks, e estabilização do valor de vazão na linha, acionou-se o programa para a realização do controle do experimento. Valores de tempos e temperaturas foram inseridos neste programa, conforme objetivos dos ensaios. O valor da massa das amostras considerado nas análises sempre foi o medido após a estabilização na vazão e preenchimento total da câmara com o gás. Neste ponto dos 
experimentos, o DTG era da ordem de $\pm 0,001 \mathrm{mg} / \mathrm{min}$, indicando balança bem estável.

Taxas de aquecimento e resfriamento, em todos os experimentos, bem como cadinhos e demais condições externas, foram mantidos constantes para os experimentos de hidretação e compatibilidade. O volume interno aproximado do cadinho é de $47 \mathrm{~mm}^{3}$, um cilindro com diâmetro interno de $3 \mathrm{~mm}$ e altura de $7 \mathrm{~mm}$. O termopar e a haste utilizados para as análises com hidrogênio foi sempre o de W-Re (Tungstênio - Rênio), que permite trabalhos da temperatura ambiente até $2150^{\circ} \mathrm{C}$. Termopar e haste tipo $\mathrm{S}$, com $1620^{\circ} \mathrm{C}$ de máximo, e de $\mathrm{Pt} / \mathrm{Rh}$, foram utilizados para os ensaios de compatibilidade. Entretanto, conforme recomendação do fabricante, temperaturas maiores que $1750^{\circ} \mathrm{C}$ não foram utilizadas, para evitar danos aos elementos do forno.

Após o encerramento dos experimentos, aguardou-se o sistema resfriar até a temperatura ambiente, conforme valor registrado pelo programa. A abertura da câmara se deu de maneira cuidadosa, o sistema cadinho mais amostra retirado do forno e esta analisada quanto ao seu estado final. Procedeu-se então à determinação da quantidade de pó formado, nos ensaios de $\mathrm{HDH}$, e algumas destas amostras foram levadas para determinação de fases em difratômetro de raios-X, microscópio eletrônico de varredura e microscópio óptico com analisador de imagens.

Os ensaios foram programados com base nos resultados de equilíbrio entre gama e alfa, existentes em literatura, mas novas condições também foram testadas. Ao invés de procurar por seqüências de experimentos estatisticamente pré-determinadas, dadas por teorias ou considerações sobre programação e análise de experimentos, cada um dos resultados aqui obtidos orientou a realização dos demais ensaios. Adotou-se aqui, portanto, um comportamento dinâmico, não minimizando de maneira alguma o valor destas técnicas. Creio que sua maior importância relaciona-se a regimes de produção em escala industrial, avaliando-se eventuais melhorias que devam ser implementadas na qualidade do produto, no controle de variáveis de processo, etc. Em escala de laboratório e em nível acadêmico, a investigação deve preceder qualquer conjunto de experimentos elaborados em termos estatísticos, pois a aleatoriedade pode eliminar experimentos essenciais à compreensão dos fenômenos aqui estudados.

Alguns experimentos foram classificados como "neutros" ou "brancos". Ou seja, para as mesmas condições de tempo, temperatura, material de cadinho, vazão de gás, etc., que seriam utilizadas nos experimentos normais, efetuou-se os ensaios sem a presença de amostra, para a verificação da influência do material do cadinho nas curvas de ganho ou perda de massa e estabilidade do sistema de análise termogravimétrica. Nestes ensaios o 
procedimento adotado foi o mesmo, exceto que o cadinho não foi carregado com amostra nenhuma. A intenção foi a obtenção de um ajuste que fornecesse os valores de ganho de massa em função da temperatura, para dados valores de tempo. Estes ensaios também tiveram a finalidade da verificação da estabilidade do equipamento, pela permanência do sistema por tempos e temperaturas convenientes e análise da estabilidade do sinal mostrado na tela. Em todos os casos, nada que exigisse uma correção significativa foi observado.

Abaixo segue uma breve descrição dos experimentos, citando a sua relação em termos das investigações propostas, quando houver, com os anteriores.

\subsection{Procedimento experimental / ensaios de hidrogenação}

Deve ser destacado que os principais objetivos destes experimentos foram dois. O primeiro deles, de natureza tecnológica, tem a intenção de obter dados para o processamento das ligas via hidrogenação, para fragmentação e obtenção de pós, visando a obtenção de bons rendimentos. Assim, as variações nas condições experimentais foram realizadas para se obter resultados conclusivos sobre valores de parâmetros como tempo e temperatura, e como podem ser fixados para obtenção de bons rendimentos. Como segundo objetivo, pretende-se estudar propriedades das ligas-base de $\gamma$ UMo e suas derivadas, para compreensão de dados de equilíbrio e estabilidade sob atmosfera de hidrogênio, de natureza acadêmica. Três ciclos de experimentos foram realizados, e em seguida, apresentam-se suas condições e seus objetivos.

\subsection{1 ensaios do primeiro ciclo}

A primeira série de experimentos foi programada para verificar o comportamento de ligas sob hidrogênio já estudadas em literatura, comparando os resultados em termos de técnicas de fusão e rendimentos na obtenção dos pós. Trabalhouse com porcentagens em peso de 6, 7 e 10\% de soluto, para as amostras de indução, e com ligas de forno a arco contendo $5 \%$ de Mo e tratadas termicamente. Para este caso em particular, os dados serviram para a melhor visualização dos efeitos da temperatura e tempo de exposição ao hidrogênio na forma dos gráficos de rendimento e também nas perturbações das curvas de ganho de massa. Alguns ensaios de dehidretação foram também realizados.

\section{a. Liga Base $\gamma \mathrm{U} 6 \mathrm{Mo}$ (6\% Mo em peso)}

(001) massa de amostra igual a $122,012 \mathrm{mg}$, ciclo utilizado: $900^{\circ} \mathrm{C}$ por $0,5 \mathrm{~h}$, taxa de 
aquecimento a $10^{\circ} \mathrm{C} / \mathrm{min}$., com o objetivo de se verificar comportamento da amostra sob hidrogênio na região de $\gamma$ puro do diagrama binário U-Mo. Este ensaio também teve a finalidade de se testar, pela primeira vez, o comportamento do equipamento termogravimétrico frente ao hidrogênio.

(002) massa de $120,016 \mathrm{mg}$, ciclo utilizado: estabilização por 1 minuto a $40^{\circ} \mathrm{C}$, seguida por aquecimento até o patamar de $500^{\circ} \mathrm{C}$, a uma taxa de $20^{\circ} \mathrm{C}$ por minuto, 2 horas neste patamar, derrubada de 500 a $40^{\circ} \mathrm{C}$ em taxa de resfriamento de $20^{\circ} \mathrm{C}$ por minuto, estabilização em $40^{\circ} \mathrm{C}$ por 30 minutos. Sobre a mesma amostra, agora com massa igual a $118,560 \mathrm{mg}$, indicando que foi gerado $(120,016-118,560)=1,456 \mathrm{mg}$ de pó no primeiro tratamento, foi aplicado novo ciclo: estabilização do sistema por 1 minuto a $40^{\circ} \mathrm{C}$, subida ao valor de $1100^{\circ} \mathrm{C}$ com velocidade de $30^{\circ} \mathrm{C}$ por minuto, e derrubada da potência novamente a $40^{\circ} \mathrm{C}$, numa taxa de resfriamento de $30^{\circ} \mathrm{C}$ por minuto, e manutenção do sistema em $40^{\circ} \mathrm{C}$ por 1 hora.

$\mathrm{O}$ primeiro objetivo aqui foi verificar se um tratamento a $500^{\circ} \mathrm{C}$, que corresponde a uma isoterma do diagrama de equilíbrio pertencente, para a composição dada, à região de $\alpha+\gamma^{\prime}$, teria influencia no resultado final. Como foi produzido pouco pó, resolveu-se estudar, sobre a mesma amostra, supostamente já atacada pelo hidrogênio, a facilidade na obtenção dos pós. Observa-se que, na não foi efetuado tratamento em patamar a $1100^{\circ} \mathrm{C}$, a temperatura foi elevada até este valor. Algum pó foi obtido, e analisado quanto à forma em microscópio óptico.

\section{b. Liga Base $\gamma \mathrm{UA} 7$}

(701) massa de 125,863 mg, ciclo utilizado: estabilização do sistema por 1 minuto a $30^{\circ} \mathrm{C}$, seguido de subida a $900^{\circ} \mathrm{C}$ na velocidade de $20^{\circ} \mathrm{C}$ por minuto, permanência neste patamar por 4 horas, descida ao patamar de $400^{\circ} \mathrm{C}$ à velocidade de $20^{\circ} \mathrm{C}$ por minuto, permanência neste patamar por 0,5 hora, e derrubada. O objetivo aqui foi verificar se exposição do material a uma temperatura onde $\gamma$ é a fase de equilíbrio, seguida de tratamento a uma temperatura bem abaixo da transformação eutetóide, onde $\alpha+\gamma$ ' são as fases de equilíbrio, produziria algum resultado em termos de rendimento na produção dos pós.

(702) massa de 156,032 mg, ciclo utilizado: estabilização do sistema por 1 minuto a $30^{\circ} \mathrm{C}$, subida de 30 a $450^{\circ} \mathrm{C}$ em velocidade de $30^{\circ} \mathrm{C}$ por minuto, permanência neste patamar por 4 
horas, e derrubada. Aqui verificou-se diretamente a ação da temperatura de tratamento, inferior à isoterma de transformação eutetóide e pertencente ao campo do diagrama de fases binário U-Mo onde $\alpha+\gamma^{\prime}$ são as fases estáveis, novamente sobre o rendimento na produção de pós.

(703) massa de 109,475 mg, ciclo utilizado: estabilização do sistema por 1 minuto a $30^{\circ} \mathrm{C}$, subida a $30^{\circ} \mathrm{C}$ por minuto ao patamar de $1000^{\circ} \mathrm{C}$, no qual a amostra foi exposta à ação do hidrogênio por 4 horas. Simples verificação do comportamento da mesma liga, numa outra isoterma da região onde a fase $\gamma$ é a estável.

(704) massa total de $141,352 \mathrm{mg}$, ciclo utilizado: estabilização por 1 minuto a $30^{\circ} \mathrm{C}$, subida ao patamar de $900^{\circ} \mathrm{C}$ a uma velocidade de $30^{\circ} \mathrm{C}$ por minuto e manutenção por 5 horas, derrubada a $20^{\circ} \mathrm{C}$ por minuto até temperatura de $20^{\circ} \mathrm{C}$. Verificou-se se o tempo em temperatura alta tem influência no resultado, por ampliação da faixa de verificação temporal para a amostra UA7.

(705) massa de 76,293 mg, ciclo utilizado: estabilização por 1 minuto a $30^{\circ} \mathrm{C}$, subida ao patamar de $1000^{\circ} \mathrm{C}$ com velocidade de $30^{\circ} \mathrm{C}$ por minuto, manutenção no patamar por 4 horas, descida a $20^{\circ} \mathrm{C}$ por minuto a $400^{\circ} \mathrm{C}$ e manutenção neste patamar por 1 hora, seguida de derrubada do forno. Como o primeiro patamar situou-se no campo de $\gamma$ estável, uma comparação direta entre os experimentos (703) e (704) pode ser realizada, verificando-se simultaneamente, em relação ao experimento (703), o efeito da temperatura no primeiro patamar, e também o efeito do tempo no segundo patamar. Com relação ao experimento (704), verificou-se o efeito de um posterior tratamento térmico em temperatura de $400^{\circ} \mathrm{C}$.

(707) massa de $110,108 \mathrm{mg}$, ciclo utilizado: estabilização do sistema por 1 minuto a $30^{\circ} \mathrm{C}$, subida ao patamar de $600^{\circ} \mathrm{C}$ a uma velocidade de $30^{\circ} \mathrm{C}$ por minuto, manutenção por 4 horas no patamar de $600^{\circ} \mathrm{C}$, descida ao patamar de $300^{\circ} \mathrm{C}$ a $20^{\circ} \mathrm{C}$ por minuto, manutenção neste patamar por 0,5 hora e derrubada. Como houve sucesso na produção de pós para a liga UMo2 nestas condições, procurou-se repetir aqui o mesmo ensaio.

(709) massa de $151,050 \mathrm{mg}$, ciclo utilizado: estabilização do sistema por 1 minuto a $30^{\circ} \mathrm{C}$, aquecimento até o patamar de $850^{\circ} \mathrm{C}$ a uma velocidade de $30^{\circ} \mathrm{C}$ por minuto e manutenção 
neste patamar por 4 horas, descida ao patamar de $400^{\circ} \mathrm{C}$ a uma velocidade de $20^{\circ} \mathrm{C}$ por minuto e manutenção por 0,5 hora. Como o resultados a $450^{\circ} \mathrm{C}$ foi promissor, procurou-se manter o segundo patamar num valor de temperatura próximo, entre 300 e $450^{\circ} \mathrm{C}$, além de ampliar a faixa de verificações no primeiro patamar à região onde gama é estável, para esta amostra.

(710) massa de 137,695 mg, mesma amostra, já previamente tratada, do experimento anterior. Ciclo utilizado: estabilização do sistema por 1 minuto a $30^{\circ} \mathrm{C}$, subida a $30^{\circ} \mathrm{C}$ por minuto ao patamar de $580^{\circ} \mathrm{C}$ e manutenção por 2 horas, neste patamar, subida novamente a $30^{\circ} \mathrm{C}$ por minuto ao patamar de $850^{\circ} \mathrm{C}$ e manutenção por 2 horas, seguida de derrubada. Objetivo: verificar se tratamento prévio em isoterma de campo bifásico pode produzir algum alfa, que, por elevação posterior de temperatura mesmo em campo de gama, possa fragilizar a amostra.

(711) massa de $127,862 \mathrm{mg}$, ciclo utilizado: estabilização do sistema por 1 minuto a $30^{\circ} \mathrm{C}$, subida ao patamar de $560^{\circ} \mathrm{C}$ a velocidade de $30^{\circ} \mathrm{C}$ por minuto e manutenção neste patamar por 1 hora, derrubada. Objetivo foi verificar se, próximo a temperatura de transformação eutetóide, se obtém mais alto rendimento.

(DH01I) massa de 137,255 mg, dehidretação de amostra do experimento (702), verificação se há, ainda, algum hidreto de urânio presente na amostra na forma de pó, ciclo utilizado: estabilização do sistema por 1 minuto a $30^{\circ} \mathrm{C}$, elevação da temperatura até $350^{\circ} \mathrm{C}$ a uma velocidade de $30^{\circ} \mathrm{C}$ por minuto e manutenção por 1 hora neste patamar.

(DH02I) massa de 108,321 mg, dehidretação de amostra do experimento (711), ciclo utilizado: estabilização do sistema por 1 minuto a $30^{\circ} \mathrm{C}$, elevação da temperatura a $300^{\circ} \mathrm{C}$ a $30^{\circ} \mathrm{C}$ por minuto e manutenção neste patamar a 40 minutos, elevação da temperatura a $350^{\circ} \mathrm{C}$ a $30^{\circ} \mathrm{C}$ por minuto e manutenção neste patamar por 40 minutos.

\section{c. Liga Base $\gamma \mathrm{UMo} 2$}

(201) massa de $143,240 \mathrm{mg}$, ciclo utilizado: estabilização por 1 minuto a $30^{\circ} \mathrm{C}$, subida ao patamar de $700^{\circ} \mathrm{C}$ à velocidade de $30^{\circ} \mathrm{C}$ por minuto, manutenção a $700^{\circ} \mathrm{C}$ por 5 horas, e derrubada da potência do forno. A 7\% de Mo, estamos na região onde $\gamma$ é a fase estável, 
mas em grande proximidade com o campo bifásico de $\gamma+\alpha$. Início dos tratamentos das ligas de indução.

(202) massa de $146,077 \mathrm{mg}$, ciclo utilizado: estabilização por 1 minuto a $30^{\circ} \mathrm{C}$, subida ao patamar de $800^{\circ} \mathrm{C}$ a uma velocidade de $30^{\circ} \mathrm{C}$ por minuto, manutenção no patamar de $800^{\circ} \mathrm{C}$ por 4 horas, resfriamento a $20^{\circ} \mathrm{C}$ por minuto até o patamar de $400^{\circ} \mathrm{C}$, manutenção neste patamar por 0,5 hora. Segundo experimento com amostra produzida por indução, verificação se há diferenças no rendimento quando se aumenta a temperatura de tratamento térmico, ou quando se aumenta a diferença entre as temperaturas dos dois patamares. Também conduzido em temperatura onde a fase $\gamma$ é a estável.

(203) massa de $142,799 \mathrm{mg}$, ciclo utilizado: estabilização do sistema a $30^{\circ} \mathrm{C}$ por 1 minuto, subida de 30 a $600^{\circ} \mathrm{C}$ na velocidade de $30^{\circ} \mathrm{C}$ por minuto, manutenção no patamar de $600^{\circ} \mathrm{C}$ por 4 horas, descida ao patamar de $300^{\circ} \mathrm{C}$ a $20^{\circ} \mathrm{C}$ por minuto, manutenção no patamar por 0,5 hora e derrubada. Aqui já se está dentro do campo onde as fases $\gamma+\alpha$ são as estáveis, e o objetivo é verificar se, tratando a liga neste campo, se acelera a decomposição de parte da fase gama em alfa, conforme reações descritas na introdução. Também desejou-se comparar os valores com os dos experimentos (201) e (202), verificando no primeiro caso a influência do tratamento da liga em região de $\gamma+\alpha$ e no segundo caso, além disso, se a temperatura no segundo patamar tem influência no resultado.

(204) massa de 149,845 mg, ciclo utilizado: estabilização do sistema a $30^{\circ} \mathrm{C}$ por 1 minuto, subida ao patamar de $600^{\circ} \mathrm{C}$ à velocidade de $30^{\circ} \mathrm{C}$ por minuto, estabilização no patamar de $600^{\circ} \mathrm{C}$ por 2 horas, descida ao patamar de $300^{\circ} \mathrm{C}$ a uma velocidade de $20^{\circ} \mathrm{C}$ por minuto e manutenção aí por 0,5 hora. O objetivo foi verificar o comportamento da liga a $600^{\circ} \mathrm{C}$ por um tempo menor (está-se buscando um limite inferior para o tempo de tratamento no primeiro patamar), e avaliar se o efeito da dehidretação pode compensar a diminuição no tempo.

(205) massa de 140,611 mg, ciclo utilizado: estabilização do sistema por 1 minuto a $30^{\circ} \mathrm{C}$, subida até o patamar de $900^{\circ} \mathrm{C}$ com velocidade de $30^{\circ} \mathrm{C}$ por minuto, manutenção no patamar de $900^{\circ} \mathrm{C}$ por 4 horas, descida ao patamar de $400^{\circ} \mathrm{C}$ a velocidade de $20^{\circ} \mathrm{C}$ por minuto, manutenção em $400^{\circ} \mathrm{C}$ por 0,5 hora e derrubada. Este experimento foi conduzido para se ampliar a faixa de verificação de temperaturas no campo onde a fase $\gamma$ é a estável, 
para a liga UMo2, e verificar se tratamentos em temperaturas inferiores a da transformação eutetóide podem, mesmo após um tratamento prévio na região de $\gamma$, favorecer a formação de pó.

(207) massa de $141,852 \mathrm{mg}$, ciclo utilizado: estabilização do sistema por 1 minuto a $30^{\circ} \mathrm{C}$, subida ao patamar de $600^{\circ} \mathrm{C}$ a uma velocidade de $30^{\circ} \mathrm{C}$ por minuto, manutenção a $600^{\circ} \mathrm{C}$ por 15 minutos, descida a $20^{\circ} \mathrm{C}$ por minuto ao patamar de $300^{\circ} \mathrm{C}$, onde a amostra foi mantida também por 0,5 hora. Mantendo-se o tempo em 15minutos, o objetivo foi verificar, novamente, se o tratamento a $600^{\circ} \mathrm{C}$ inibe o rendimento na etapa de dehidretação.

\section{d. Liga Base $\gamma \mathrm{UMo6}$}

(601) massa de 284,441 mg, ciclo utilizado: estabilização do sistema por 1 minuto a $30^{\circ} \mathrm{C}$, subida ao patamar de temperatura de $600^{\circ} \mathrm{C}$ e manutenção por 4 horas, descida a $20^{\circ} \mathrm{C}$ por minuto ao patamar de $300^{\circ} \mathrm{C}$, manutenção por 0,5 hora e derrubada. Como os resultados para as ligas UMo2 foram bons nesta faixa de temperatura, o que se quis aqui foi repetir as condições, esperando-se por melhores resultados pois a liga contém quantidade menor de Mo, menos estável, e portanto mais alfa.

(602) massa de $287,668 \mathrm{mg}$, mesmo ciclo anterior, somente tempo no patamar a $600^{\circ} \mathrm{C}$ de 2 horas, com o objetivo de se otimizar o tempo.

(603) massa de $318,042 \mathrm{mg}$, ciclo utilizado: estabilização em $30^{\circ} \mathrm{C}$ por 1 minuto, subida ao patamar de $900^{\circ} \mathrm{C}$ e manutenção por 4 horas, descida ao patamar de $300^{\circ} \mathrm{C}$ a $20^{\circ} \mathrm{C}$ por minuto e manutenção por 0,5 hora, seguida de derrubada. Verificação do comportamento da curva em temperatura mais alta com as mesmas condições para o segundo patamar, e também verificar se este tratamento sofre influência de pré-tratamento em baixa temperatura, mesmo em campo onde fase gama é a estável.

(604) massa de $297,512 \mathrm{mg}$, ciclo utilizado: estabilização do sistema por 1 minuto a $30^{\circ} \mathrm{C}$, subida ao patamar de $660^{\circ} \mathrm{C}$ a uma velocidade de $30^{\circ} \mathrm{C}$ por minuto e manutenção neste patamar por 4 horas, descida ao patamar de $300^{\circ} \mathrm{C}$ a $20^{\circ} \mathrm{C}$ por minuto e manutenção neste patamar por 0,5 h. O objetivo foi verificar se há transformação nesta região, onde temos o bifásico $\gamma+\alpha$. 
(605) massa de 316,129 mg, ciclo utilizado: estabilização do sistema por 1 minuto a $30^{\circ} \mathrm{C}$, subida ao patamar de $650^{\circ} \mathrm{C}$ a uma velocidade de $30^{\circ} \mathrm{C}$ por minuto e manutenção neste patamar por 2 horas, descida ao patamar de $300^{\circ} \mathrm{C}$ a $20^{\circ} \mathrm{C}$ por minuto e manutenção neste patamar por 0,5 h.. Objetivo foi o de se aproximar mais da temperatura de transição gama para gama + alfa, e verificar o que ocorre.

(606) massa de $185,853 \mathrm{mg}$, ciclo utilizado: estabilização do sistema por 1 minuto a $30^{\circ} \mathrm{C}$, subida ao patamar de $660^{\circ} \mathrm{C}$ a uma velocidade de $30^{\circ} \mathrm{C}$ por minuto e manutenção neste patamar por 4 horas, descida ao patamar de $250^{\circ} \mathrm{C}$ a $20^{\circ} \mathrm{C}$ por minuto e manutenção neste patamar por $0,5 \mathrm{~h}$. Objetivo foi a verificação da influência do segundo patamar no rendimento, frente aos experimentos anteriores.

(607) massa de 293,085 mg, ciclo utilizado: estabilização do sistema por 1 minuto a $30^{\circ} \mathrm{C}$, subida ao patamar de $660^{\circ} \mathrm{C}$ a uma velocidade de $30^{\circ} \mathrm{C}$ por minuto e manutenção neste patamar por 7 horas, seguida de derrubada do forno. Objetivo foi verificar se o tempo tem influência no rendimento, quando do tratamento isotérmico em campo monofásico.

(608) massa de 194,216 mg, ciclo utilizado: estabilização do sistema por 1 minuto a $30^{\circ} \mathrm{C}$, subida ao patamar de $655^{\circ} \mathrm{C}$ a uma velocidade de $30^{\circ} \mathrm{C}$ por minuto e manutenção neste patamar por 5 horas, descida ao patamar de $350^{\circ} \mathrm{C}$ a $20^{\circ} \mathrm{C}$ por minuto e manutenção neste patamar por 40 minutos. Objetivo também é verificar comportamento do sistema em região monofásica, porém próxima à linha de transição gama to gama + alfa.

(609) massa de 26,634 mg, ciclo utilizado: estabilização do sistema por 1 minuto a $30^{\circ} \mathrm{C}$, subida ao patamar de $655^{\circ} \mathrm{C}$ a uma velocidade de $30^{\circ} \mathrm{C}$ por minuto e manutenção neste patamar por 3 horas. Objetivo: diminuindo a massa de amostra, aumenta-se a razão vazão de gás / massa, tentar verificar se há influência nos rendimentos.

(609A) massa de 17,2 $\mathrm{mg}$, remanescente do experimento anterior, ciclo utilizado: estabilização do sistema por 1 minuto a $30^{\circ} \mathrm{C}$, subida ao patamar de $655^{\circ} \mathrm{C}$ a uma velocidade de $30^{\circ} \mathrm{C}$ por minuto e manutenção neste patamar por 3 horas. Verificação da influência de se pré-tratar a amostra no rendimento na obtenção de pó.

(DH01A) massa de 174,453 mg, amostra proveniente do experimento (606), pó mais núcleo não reagido, ciclo utilizado: estabilização do sistema por 1 minuto a $30^{\circ} \mathrm{C}$, subida ao patamar de $350^{\circ} \mathrm{C}$ a uma velocidade de $30^{\circ} \mathrm{C}$ por minuto e manutenção neste patamar 
por 1 hora, nova subida ao patamar de $400^{\circ} \mathrm{C}$ a velocidade de $30^{\circ} \mathrm{C}$ por minuto e manutenção por 1 hora, subida ao patamar de $450^{\circ} \mathrm{C}$ a $30^{\circ} \mathrm{C}$ por minuto e manutenção neste patamar por 1 hora. Experimento de dehidretação, pois foi aventada a hipótese de que o pó talvez fique passivado com pequena camada de oxigênio, deve-se tentar efetuar tentativa de eliminação por meio de tratamento que, além disso, libere hidrogênio.

(DH02A) ensaio de dehidretação experimento (602), massa de pó igual a 256,028 mg, ciclo utilizado: estabilização do sistema por 1 minuto a $30^{\circ} \mathrm{C}$, subida à temperatura de $300^{\circ} \mathrm{C}$ e manutenção por 30 minutos, nova subida a $350^{\circ} \mathrm{C}$ a velocidade de $30^{\circ} \mathrm{C}$ por minuto e manutenção por 30 minutos, seguida de derrubada.

\section{e. Liga Base $\gamma \mathrm{UMo10}$}

(1001) massa de 63,005 mg, ciclo utilizado: estabilização do sistema por 1 minuto a $30^{\circ} \mathrm{C}$, elevação da temperatura a $670^{\circ} \mathrm{C}$ a velocidade de $30^{\circ} \mathrm{C}$ por minuto, e manutenção por 6 horas, seguida de derrubada. Objetivo: início dos estudos com ligas altamente estabilizadas, $10 \%$ Mo.

(1002) massa de 48,8 mg, oriunda do experimento anterior, ciclo utilizado: estabilização do sistema por 1 minuto a $30^{\circ} \mathrm{C}$, elevação da temperatura a $670^{\circ} \mathrm{C}$ a velocidade de $30^{\circ} \mathrm{C}$ por minuto, e manutenção por 3,5 horas, seguida de derrubada. Objetivo: verificar se o prétratamento, assim como nos últimos experimentos UMo6, influenciam no rendimento.

(1003) massa de $111,129 \mathrm{mg}$, ciclo utilizado: estabilização do sistema por 1 minuto a $30^{\circ} \mathrm{C}$, elevação da temperatura a $600^{\circ} \mathrm{C}$ a velocidade de $30^{\circ} \mathrm{C}$ por minuto, e manutenção por 6 horas, seguida de derrubada. Objetivo: tratamento do material em temperatura próxima à da transformação eutetóide, verificar se o campo é bifásico ou monofásico.

(1004) massa de $169,844 \mathrm{mg}$, ciclo utilizado: estabilização do sistema por 1 minuto a $30^{\circ} \mathrm{C}$, elevação da temperatura a $577^{\circ} \mathrm{C}$ a velocidade de $30^{\circ} \mathrm{C}$ por minuto, e manutenção por 5 horas, seguida de derrubada. Objetivo: estudar comportamento da liga com 10\% Mo sob tratamento isotérmico próximo à temperatura de transformação eutetóide.

(1005) massa de 216,974 mg, ciclo utilizado: estabilização do sistema por 1 minuto a $30^{\circ} \mathrm{C}$, elevação da temperatura a $550^{\circ} \mathrm{C}$ a velocidade de $30^{\circ} \mathrm{C}$ por minuto, e manutenção por 7 horas, seguida de derrubada. Objetivo: verificar comportamento do sistema em temperatura abaixo da isoterma de transformação eutetóide, campo bifásico alfa mais delta (gama 
linha).

(1006) massa de 69,334 mg, ciclo utilizado: estabilização do sistema por 1 minuto a $30^{\circ} \mathrm{C}$, elevação da temperatura a $900^{\circ} \mathrm{C}$ a velocidade de $30^{\circ} \mathrm{C}$ por minuto, e manutenção por 4 horas, seguida de derrubada. Objetivo: levantar comportamento do sistema em temperatura de campo monofásico gama, bem acima de linhas de transformação no diagrama de fases binário UMo.

\subsection{2 ensaios do segundo ciclo}

Numa segunda fase foram realizados experimentos adicionais de hidretação nas demais porcentagens, e complementares aos anteriores, trabalhando-se exclusivamente com ligas de indução. Alguns ensaios em branco adicionais foram realizados. Os códigos das amostras correspondem ao da seqüência das análises.

\section{a. Liga Base $\gamma \mathrm{UMo6}$}

(II.N602) massa de $211,582 \mathrm{mg}$, ciclo utilizado: patamar de $20^{\circ} \mathrm{C}$ por 10 minutos, subida a $500 \mathrm{oC}$ a taxa de $20^{\circ} \mathrm{C} / \mathrm{min}$, patamar de $500^{\circ} \mathrm{C}$ por 4 horas, descida à temperatura ambiente a taxa de $20^{\circ} \mathrm{C} / \mathrm{min}$. Objetivo: iniciar a verificação do comportamento de liga com $6 \% \mathrm{Mo}$ para a determinação da temperatura e tempo ótimo de hidretação. Na primeira série de experimentos trabalhou-se com esta liga no campo binário alfa mais gama e gama, em regiões mais afastadas da linha de equilíbrio $\gamma+\alpha \leftrightarrow \alpha+\delta$. Aqui estaremos sempre próximos a esta linha.

(II.611) massa de 176,520mg, patamar de $562^{\circ} \mathrm{C}$, tempo de 4 horas. Objetivo: determinar a melhor temperatura de hidretação para a liga U6Mo.

(II.612) massa de $179,120 \mathrm{mg}$, patamar de $400^{\circ} \mathrm{C}$ por 4 horas. Como as amostras com baixo Mo hidretam mais facilmente, o objetivo aqui é o de se verificar o quão baixo se pode ir em termos de temperatura, para obter um bom rendimento.

(II.613) massa de $196,968 \mathrm{mg}$, patamar de $250^{\circ} \mathrm{C}$ por 1 hora. Objetivo: reproduzir resultados dos experimentos realizados na CNEA / Argentina, que obtém bons resultados por estes pré-tratamentos, em porcentagens de 7\%Mo. Também acompanha os objetivos do experimento anterior. 
(II.624) ensaio de dehidretação amostra UMo6, 6\% Mo, N02, massa de pó igual a $203,339 \mathrm{mg}$, rampa até $450^{\circ} \mathrm{C}$ à velocidade de $5^{\circ} \mathrm{C} / \mathrm{min}$., e descida a $20^{\circ} \mathrm{C} / \mathrm{min}$. até a temperatura ambiente. Objetivo é verificar a influência da taxa de aquecimento na eliminação de hidrogênio pela amostra, e se até $450^{\circ} \mathrm{C}$ aparecem picos de eliminação.

(II.625) idem anterior, mas velocidade de subida a $450^{\circ} \mathrm{C}$ de $20^{\circ} \mathrm{C} / \mathrm{min}$., mesmo objetivo anterior. Massa de pó igual a 173,500mg.

\section{b. Liga-Base $\gamma \mathrm{UMo5}$}

(II.503) massa de $175,019 \mathrm{mg}$, ciclo utilizado: patamar de $20^{\circ} \mathrm{C}$ por 10 minutos, subida a $500^{\circ} \mathrm{C}$ a taxa de $20^{\circ} \mathrm{C} / \mathrm{min}$., permanência neste patamar por 4 horas, e descida até temperatura ambiente à mesma taxa.

(II.504) massa de $166,752 \mathrm{mg}$, ciclo utilizado: patamar de $20^{\circ} \mathrm{C}$ por 10 minutos, subida a $20^{\circ} \mathrm{C} / \mathrm{min}$. até patamar de $560^{\circ} \mathrm{C}$ e permanência por 2 horas, com descida a mesma taxa até a temperatura ambiente. O objetivo é, além da verificação anterior, observar se consegue hidretar em temperatura que sabidamente apresenta resultado positivo nas ligas até 7\%Mo, por um tempo de 2 horas.

(II.505) massa de 162,289mg, mesmo ciclo anterior, temperatura e tempo no patamar de $570^{\circ} \mathrm{C}$ e 4 horas, respectivamente. Como foi verificado que o tempo do experimento anterior foi insuficiente, procurou-se então aumentar a temperatura e o tempo de tratamento.

(II.506) massa de $178,915 \mathrm{mg}$, mesmo ciclo anterior, temperatura de $565^{\circ} \mathrm{C}$. Verificou-se que a subida de temperatura do experimento anterior dificultou a quebra, assim trabalhouse aqui em temperatura mais próxima à eutetóide.

(II.507) massa de $189,401 \mathrm{mg}$, mesmo ciclo, temperatura de patamar igual a $562^{\circ} \mathrm{C}$. Mesmo objetivo do experimento anterior.

(II.508) massa de $138,140 \mathrm{mg}$, patamar de $1000^{\circ} \mathrm{C}$, com o objetivo de verificar se mesmo sob baixa pressão a amostra sofre alguma oxidação. 
(II.509) massa de 186,397mg, mesmo ciclo, patamar em $522^{\circ} \mathrm{C}$, tempo de 3 horas. Objetivo é verificar se em alguma isoterma no campo de alfa mais gama há um aumento no rendimento.

(II.510) massa de $179,083 \mathrm{mg}$, mesmo ciclo, patamar de $600^{\circ} \mathrm{C}$, tempo de 2 horas. Objetivo idêntico, só que em temperatura do campo de gama.

\section{c. Liga Base $\gamma \mathrm{UMO}$ Mo (9\% Mo em peso)}

(II.814) massa de 169,143mg, patamar de $562^{\circ} \mathrm{C}$, tempo de 4 horas. Início dos experimentos com $9 \%$ Mo, amostras teoricamente de mais difícil hidrogenação. O primeiro teste deve ser obviamente realizado em temperatura próxima a da transformação eutetóide, na qual presume-se que haja maior rendimento.

(II.815) massa de $163,901 \mathrm{mg}$ derivada do experimento anterior, patamar de $250^{\circ} \mathrm{C}$ por 1 hora. Objetivo é testar a validade das afirmações dos experimentos da CNEA de que um pré-tratamento a $500-700^{\circ} \mathrm{C}$ seguido de tratamento a $250^{\circ} \mathrm{C}$ hidreta massivamente a liga. Como verificaram isto para $7 \% \mathrm{Mo}$, está-se aqui testando para $9 \% \mathrm{Mo}$.

(II.816) massa de $163,812 \mathrm{mg}$ derivada do experimento anterior, patamar de $500^{\circ} \mathrm{C}$ por 4 horas. Objetivo é tratar a amostra em temperatura abaixo da eutetóide, em campo de alfa mais delta, verificando os resultados.

(II.817) massa de $173,572 \mathrm{mg}$, patamar de $420^{\circ} \mathrm{C}$ por 1 hora. Conforme resultados dos ensaios de dureza de VanThyne e McPherson ${ }^{7}$, a $420^{\circ} \mathrm{C}$ produz-se a primeira detecção de decomposição da fase gama em alfa. O objetivo é verificar se o mesmo aqui ocorre.

(II.818) massa de 172,947mg derivada do experimento anterior, mesmo patamar, tempo de 3 horas. Objetivo: complementar o experimento anterior.

(II.826) massa de amostra igual a $179,797 \mathrm{mg}$, patamar de $522^{\circ} \mathrm{C}$ e tempo de 4 horas. Mesmo objetivo dos experimentos anteriores.

(II.827) massa de $176,419 \mathrm{mg}$, ciclo: 2 patamares, um a $250^{\circ} \mathrm{C}$ por 1 hora, e outro a $562^{\circ} \mathrm{C}$ por 4 horas, velocidades de aquecimento e resfriamento de $20^{\circ} \mathrm{C} / \mathrm{min}$.. Objetivo é 
novamente verificar se se produz mais pó por meio de pré-tratamento a temperaturas bem abaixo da isoterma da transformação eutetóide.

(II.828) massa de 158,051mg, mesmo ciclo anterior, apenas se aumentou o tempo no primeiro patamar para 2 horas. O objetivo aqui foi verificar a ação do tempo de prétratamento no rendimento de fragmentação.

\section{d. Liga-Base $\gamma \mathrm{UMo2}$}

(II.219) massa de $184,855 \mathrm{mg}$, patamar de $560^{\circ} \mathrm{C}$ por 1 hora. Objetivo é a verificação das melhores condições de hidretação para ligas contendo 7\%Mo, e repetir as análises para $7 \%$ Mo realizadas no primeiro ciclo.

(II.220) massa de 122,607mg derivada do experimento anterior, mesmo patamar, tempo de 3 horas.

(II.221) massa de $158,231 \mathrm{mg}$, patamar de $500^{\circ} \mathrm{C}$ por 3 horas. Objetivo é verificar o efeito sobre o rendimento quando da diminuição do tempo e da temperatura de tratamento.

(II.222) massa de $147,661 \mathrm{mg}$, patamar de $522^{\circ} \mathrm{C}$ por 3 horas. Objetivo é verificar, dado o rendimento não muito satisfatório a $500^{\circ} \mathrm{C}$, se um pequeno aumento de temperatura produz um bom resultado.

(II.223) massa de $150,424 \mathrm{mg}$, patamar de $540^{\circ} \mathrm{C}$ por 4 horas, mesmo objetivo anterior.

\subsection{3 ensaios do terceiro ciclo}

Finalmente, numa terceira etapa, ensaios complementares foram realizados com o objetivo de se levantar mais pontos para elaboração de curvas de equilíbrio e de mudanças de mecanismos de adsorção de hidrogênio das amostras, salvo menção adicional. Conforme mencionado em Oliveira ${ }^{52}$ os resultados para as curvas da liga $\gamma$ U8Mo foram muito elucidativos, e assim concluiu-se pela complementação para as demais ligas. Abaixo segue uma breve descrição destes experimentos.

\section{a. Liga Base $\gamma \mathrm{UMo} 7$}

(III.01) massa de $250,529 \mathrm{mg}$, ciclo: $120^{\circ} \mathrm{C}$ por 2 horas, velocidades de aquecimento e 
resfriamento de $20^{\circ} \mathrm{C} / \mathrm{min}$.. Objetivo é verificar se a amostra reage com hidrogênio mesmo em temperaturas bem abaixo das tradicionalmente utilizadas nos processos de hidretação das ligas $\gamma$-UMo.

(III.02+DH) massa de $255,593 \mathrm{mg}$, temperatura de $565^{\circ} \mathrm{C}$ por 4 horas, velocidades de aquecimento e resfriamento iguais a $20^{\circ} \mathrm{C} / \mathrm{min}$.. Objetivo é a verificação do comportamento destas ligas novamente em temperaturas próximas à da transformação eutetóide.

O pó obtido foi dehidretado em outro experimento, sob velocidade de aquecimento e resfriamento de $20^{\circ} \mathrm{C} / \mathrm{min}$, temperatura máxima de $400^{\circ} \mathrm{C}$. Objetivo é verificar se há algum hidreto remanescente, mesmo após fase de mudança de mecanismos de absorção de hidrogênio. Seguiu-se então análise por microscopia eletrônica de varredura com EDS e difração de raios-X.

(III.03+DH) massa de 254,685mg, temperatura de $600^{\circ} \mathrm{C}$ por 4 horas, velocidade de aquecimento e resfriamento de $20^{\circ} \mathrm{C} / \mathrm{min}$., objetivo é a continuação da obtenção de pontos de mudança de mecanismos, para esta liga. O pó obtido foi dehidretado nas mesmas condições do experimento anterior.

(III.04) massa de $256,618 \mathrm{mg}$, temperatura de $500^{\circ} \mathrm{C}$ por 4 horas, mesmas velocidades de aquecimento e resfriamento, mesmos objetivos. Pó obtido submetido a ensaio de dehidretação, seguido de análise em microscópio eletrônico de varredura com EDS.

(III.04a) massa de $178,783 \mathrm{mg}, 500^{\circ} \mathrm{C}$ por 2 horas, complemento ao experimento anterior, visto que, por queda de energia, o mesmo foi interrompido após 1,5 hora.

(III.05) massa de $258,854 \mathrm{mg}$, temperatura de $500^{\circ} \mathrm{C}$ por 4 horas, mesmos objetivos.

(III.06) massa de $204,154 \mathrm{mg}$, temperatura de $480^{\circ} \mathrm{C}$ por 2 horas. Pó obtido submetido a ensaios para dehidretação.

(III.07) massa de 280,068mg, temperatura de $490^{\circ} \mathrm{C}$, tempo de 2 horas. Pó obtido submetido a ensaio para dehidretação. 
(III.08) massa de $182,676 \mathrm{mg}$, temperatura de $510^{\circ} \mathrm{C}$, por 2 horas. Pó obtido submetido a ensaio para dehidretação.

(III.09) massa de $277,814 \mathrm{mg}$, temperatura de $520^{\circ} \mathrm{C}$ por 2 horas. Pó obtido submetido a ensaio para dehidretação.

(III.10) massa de $290,202 \mathrm{mg}$, temperatura de $530^{\circ} \mathrm{C}$, por 2 horas. Pó obtido submetido a ensaio para dehidretação.

(III.12) massa de $255,051 \mathrm{mg}$, temperatura de $540^{\circ} \mathrm{C}$ por 1 hora.

(III.13) massa de $286,285 \mathrm{mg}$, temperatura de $580^{\circ} \mathrm{C}$ por 1 hora. Pó obtido submetido a ensaio para dehidretação, seguida de análise em microscópio eletrônico de varredura com EDS e difração de raios-X.

(III.15) massa de $280,870 \mathrm{mg}$, temperatura de $540^{\circ} \mathrm{C}$ por 2 horas. Pó obtido submetido a ensaio para dehidretação, seguida de análise em microscópio eletrônico de varredura com EDS.

(III.16) massa de $294,610 \mathrm{mg}$, temperatura de $565^{\circ} \mathrm{C}$ por 2 horas.

(III.18) massa de $297,526 \mathrm{mg}$, temperatura de $550^{\circ} \mathrm{C}$ por 2 horas.

(III.19b) massa de $287,639 \mathrm{mg}$, temperatura de $600^{\circ} \mathrm{C}$ por 2 horas.

(III.20) massa de $231,897 \mathrm{mg}$, temperatura de $590^{\circ} \mathrm{C}$ por 2 horas. Pó resultante analisado por difração de raios-X.

\section{b. Liga Base $\gamma \mathrm{UMo8}$}

(III.21) massa de $274,398 \mathrm{mg}$, ciclo de temperaturas: $250^{\circ} \mathrm{C}$ por 3 horas, seguido de tratamento a $562^{\circ} \mathrm{C}$ por 4 horas, taxa de aquecimento igual a $30^{\circ} \mathrm{C} / \mathrm{min}$. e de resfriamento igual a $20^{\circ} \mathrm{C} / \mathrm{min}$.

(III.22) massa de 283,452 , temperatura de $700^{\circ} \mathrm{C}$ por 4 horas. 
(III.N41) massa de $286,5 \mathrm{mg}$, temperatura de $600^{\circ} \mathrm{C}$ por 1 hora. Pó resultante analisado por microscopia eletrônica de varredura com EDS.

(III.42) massa de $277,624 \mathrm{mg}$, temperatura de $600^{\circ} \mathrm{C}$ por 8 horas. Pó resultante analisado por microscopia eletrônica de varredura com EDS.

(III.43) massa de $262,678 \mathrm{mg}$, temperatura de $600^{\circ} \mathrm{C}$ por 5 horas.

(III.44) massa de $240,650 \mathrm{mg}$, temperatura de $700^{\circ} \mathrm{C}$ por 7 horas.

\section{c. Liga Base $\gamma \mathrm{UMo2}$}

(III.23) massa de $256,473 \mathrm{mg}, 630^{\circ} \mathrm{C}$ de temperatura máxima.

(III.24) massa de $248,278 \mathrm{mg}$, temperatura de $565^{\circ} \mathrm{C}$ por 1 hora.

(III.25) massa de $175,978 \mathrm{mg}$, temperatura de $560^{\circ} \mathrm{C}$ por 1 hora.

(III.26) massa de $279,940 \mathrm{mg}$, temperatura de $520^{\circ} \mathrm{C}$ por 1 hora. Pó resultante analisado por microscopia eletrônica de varredura com EDS e difração de raios-X.

(III.27) massa de $313,028 \mathrm{mg}$, temperatura de $520^{\circ} \mathrm{C}$ por 2 horas.

(III.28) massa de $243,608 \mathrm{mg}$, temperatura de $530^{\circ} \mathrm{C}$ por 1 hora. Pó resultante analisado por microscopia eletrônica de varredura com EDS.

(III.29) massa de $350,460 \mathrm{mg}$, temperatura de $525^{\circ} \mathrm{C}$ por 2 horas. Pó resultante analisado por microscopia eletrônica de varredura com EDS.

(III.30) massa de $222,789 \mathrm{mg}$, temperatura de $600^{\circ} \mathrm{C}$ por 2 horas, material resultante submetido a ensaio de dehidretação.

(III.31) massa de $290,378 \mathrm{mg}$, temperatura de $600^{\circ} \mathrm{C}$ por 1 hora. 
(III.45) massa de $211,181 \mathrm{mg}$, temperatura de $565^{\circ} \mathrm{C}$ por 1 hora. Pó resultante submetido à ensaio de dehidretação, experimento número (III.65DH).

(III.46) massa de $210,444 \mathrm{mg}$, temperatura de $565^{\circ} \mathrm{C}$ por 8 horas.

(III.47) massa de $173,203 \mathrm{mg}$, temperatura de $540^{\circ} \mathrm{C}$ por 4 horas. Pó resultante submetido à ensaio de dehidretação, experimento (III.52), seguido de análise por difração de raios-X.

(III.48) massa de $312,605 \mathrm{mg}$, temperatura de $560^{\circ} \mathrm{C}$ por 4 horas.

(III.49) massa de $297,264 \mathrm{mg}$, temperatura de $500^{\circ} \mathrm{C}$ por 4 horas. Pó resultante submetido à ensaio de dehidretação.

(III.50) massa de $297,044 \mathrm{mg}$, temperatura de $480^{\circ} \mathrm{C}$ por 4 horas.

(III.65HDH) massa de 129,575mg, tratamento inicial a $565^{\circ} \mathrm{C}$ por 2 horas, seguido de exposição a $400^{\circ} \mathrm{C}$ por 0,5 hora.

(III.68) massa de $104,876 \mathrm{mg}$, temperatura de $130^{\circ} \mathrm{C}$ por 1 hora, com o objetivo de se verificar a susceptibilidade do pó à hidrogenação.

(III.69) massa de 96,318mg, pó do experimento (III.65HDH), simulação de tratamento térmico de reconversão.

\section{c. Liga Base $\gamma \mathrm{UMO6}$}

(III.33) massa de $325,087 \mathrm{mg}$, temperatura de $480^{\circ} \mathrm{C}$ por 2 horas.

(III.34) massa de $312,803 \mathrm{mg}$, temperatura de $480^{\circ} \mathrm{C}$ por 1 hora. Pó resultante analisado por microscopia eletrônica de varredura com EDS e difração de raios-X.

(III.35) massa de $253,915 \mathrm{mg}$, temperatura de $600^{\circ} \mathrm{C}$ por 2 horas. Pó resultante analisado por difração de raios-X. 
(III.54) massa de 369,346mg, temperatura de $350^{\circ} \mathrm{C}$ por 4 horas. Pó resultante analisado por difração de raios-X.

(III.59) massa de $88,107 \mathrm{mg}$, temperatura de $100^{\circ} \mathrm{C}$ por 4 horas, com o objetivo de se verificar, conforme mencionado em alguns trabalhos RERTR, a predisposição de ligas com baixo teor em Mo ao hidrogênio.

(III.60) massa de $133,882 \mathrm{mg}$, temperatura de $75^{\circ} \mathrm{C}$ por 4 horas, com o mesmo objetivo anterior, verificar qual a temperatura mínima para a qual há hidrogenação massiva do material. Pó resultante analisado por difração de raios-X.

(III.63) massa de $76,086 \mathrm{mg}$, temperatura de $50^{\circ} \mathrm{C}$ por 4 horas, com o mesmo objetivo do experimento acima.

\section{d. Liga Base $\gamma \mathrm{UMo5}$}

(III.36) massa de $347,120 \mathrm{mg}$, temperatura de $560^{\circ} \mathrm{C}$ por 1 hora.

(III.37) massa de $282,738 \mathrm{mg}$, temperatura de $570^{\circ} \mathrm{C}$ por 2 horas.

(III.38) massa de $311,209 \mathrm{mg}$, temperatura de $565^{\circ} \mathrm{C}$ por 2 horas.

(III.39) massa de $304,433 \mathrm{mg}$, temperatura de $565^{\circ} \mathrm{C}$ por 1 hora.

(III.40) massa de $297,263 \mathrm{mg}$, temperatura de $600^{\circ} \mathrm{C}$ por 4 horas.

\section{e. Liga Base $\gamma \mathrm{UMo10}$}

(III.55) massa de $172,920 \mathrm{mg}$, temperatura de $562^{\circ} \mathrm{C}$ por 2 horas.

(III.58) massa de $125,305 \mathrm{mg}$, temperatura de $500^{\circ} \mathrm{C}$ por 4 horas, com o objetivo de, ao aumentar a razão vazão de $\mathrm{H}_{2}$ / massa da amostra, verificar se há aumento no rendimento.

(III.N61) massa de $106,041 \mathrm{mg}$, temperatura de $100^{\circ} \mathrm{C}$ por 4 horas, para verificar se uma pré-exposição ao hidrogênio aumenta a produção de pós. 
(III.64) massa de 51,616mg, temperatura de $555^{\circ} \mathrm{C}$ por 40 minutos, com o objetivo de, ao aumentar a razão vazão de $\mathrm{H}_{2}$ / massa da amostra, verificar se há aumento no rendimento.

(III.66) massa de $126,036 \mathrm{mg}$, temperatura de $565^{\circ} \mathrm{C}$ por 2 horas, com o objetivo de, ao aumentar a razão vazão de $\mathrm{H}_{2}$ / massa da amostra, verificar se há aumento no rendimento.

(III.67) massa de $68,837 \mathrm{mg}$, temperatura de $530^{\circ} \mathrm{C}$ por 2 horas, com o objetivo de, ao aumentar a razão vazão de $\mathrm{H}_{2}$ / massa da amostra, verificar se há aumento no rendimento.

\section{f. Liga Base $\gamma \mathrm{UMo9}$}

(III.70) massa de $89,509 \mathrm{mg}$, temperatura de $565^{\circ} \mathrm{C}$ por 20 horas.

(III.72) massa de $125,630 \mathrm{mg}$, temperatura de $565^{\circ} \mathrm{C}$ por 10 horas. Pó resultante submetido a ensaio de dehidretação, sob gás inerte de argônio.

\subsection{Procedimento experimental / ensaios de compatibilidade}

O primeiro objetivo destes ensaios foi a verificação da compatibilidade das ligas-base e derivadas frente aos materiais encontrados em seu ambiente mais próximo. Assim, as ligas, brutas de fusão e tratadas termicamente, foram expostas ao contato com o alumínio e oxigênio.

Numa outra seqüência, procurou-se efetuar ensaios de tratamento térmico e processamento de ligas com o objetivo de se determinar as possíveis reações entre seus elementos constituintes. Em ambos os casos foi utilizado termopar e haste compatíveis com ensaios de variação de massa e análise térmica diferencial simultânea, como nos experimentos de hidrogenação.

Em seguida, conforme vem sendo feito neste item, segue uma breve descrição dos experimentos e seus objetivos individuais.

\subsection{1 ensaios de oxidação}

Para verificar a sensibilidade ao oxigênio das ligas-base e derivadas, efetuou-se ensaios de análise térmica diferencial sob atmosfera de ar sintético 5.0, cuja composição é: $99.999 \% \mathrm{O}_{2}+\mathrm{N}_{2}, \mathrm{O}_{2}=20,0(5) \%$, com impurezas como água em quantidade inferior a 3 ppm, $\mathrm{CO}_{2}$ menor que 2ppm, $\mathrm{CO}$ menor que $1 \mathrm{ppm}$, e hidrocarbonetos em quantidade menor do que 0,1ppm. No capítulo 11 veremos a influência destes elementos nos 
resultados de ganhos de massa.

Vejamos agora o resumo dos experimentos. Todos foram realizados com o ciclo seguinte: estabilização à temperatura ambiente por 10 minutos, seguido de rampa de aquecimento até $1000^{\circ} \mathrm{C}$, na velocidade de $5^{\circ} \mathrm{C} / \mathrm{min}$., finalizando com rampa de resfriamento até temperatura ambiente a $5^{\circ} \mathrm{C} / \mathrm{min}$. Para o ensaio (IV.120), utilizou-se taxa de aquecimento 3 vezes maior.

(IV.76) үUMo9 bruta de fusão, massa igual a 169,676mg.

(IV.77) $\gamma \mathrm{UMo8}$ bruta de fusão, massa igual a 170,654mg.

(IV.78) $\gamma \mathrm{UMo} 2$ bruta de fusão, massa igual a 169,205mg.

(IV.79) $\gamma \mathrm{UMo} 2$ bruta de fusão, massa igual a 115,260mg, verificar a influência na diminuição da massa.

(IV.80) $\gamma$ UMo6 bruta de fusão, massa igual a 112,316mg.

(IV.82) $\gamma$ UMo5 bruta de fusão, massa igual a 112,131mg.

(IV.83) $\gamma$ UMo7 bruta de fusão, massa igual a 119,143mg.

(IV.84) $\gamma \mathrm{UMo} 7$ tratada termicamente, massa igual a 130,659mg.

(IV.86) $\gamma \mathrm{UMo} 8$ tratada termicamente, massa igual a 132,473mg.

(IV.89) $\gamma \mathrm{UMo} 5$ tratada termicamente, massa igual a 113,153mg.

(IV.93) $\gamma \mathrm{UMo}$, tratada termicamente, massa igual a 146,297mg.

(IV.97) $\gamma \mathrm{UMo} 2$, tratada termicamente, massa igual a 155,596mg.

(IV.99) $\gamma \mathrm{UMo6}$, tratada termicamente, massa total igual a $122,530 \mathrm{mg}$. 
(IV.120) $\gamma \mathrm{UMo11}$, bruta de fusão, massa total igual a 131,420mg.

\subsection{2 ensaios de compatibilidade combustível / matriz}

A seguir, descrevem-se os ensaios de compatibilidade do quarto ciclo. $\mathrm{O}$ material utilizado foi o alumínio 6061, utilizado no processo de fabricação das dispersões no IPEN. A velocidade de aquecimento utilizada foi a de $15^{\circ} \mathrm{C}$ por minuto. Como não foi observada influência nos resultados, manteve-se a velocidade de $15^{\circ} \mathrm{C}$ por minuto para todos os experimentos. O ciclo utilizado: estabilização por 10 minutos à temperatura ambiente, subida até a temperatura de $1000^{\circ} \mathrm{C}$, na velocidade indicada, e descida até a temperatura ambiente, na mesma velocidade de subida.

(IV.87) $\gamma \mathrm{UMo} 8$, tratada termicamente, massa total de $148,447 \mathrm{mg}$, massa de liga igual a $74,127 \mathrm{mg}$, massa de alumínio igual a 74,320mg.

(IV.90) $\gamma$ UMo6, tratada termicamente, massa total de $168,991 \mathrm{mg}$, massa de liga igual a $89,5 \mathrm{mg}$, massa de alumínio igual a 79,491mg.

(IV.92) determinação dos pontos de fusão e solidificação do alumínio, com massa de amostra igual a $82,010 \mathrm{mg}$.

(IV.94) $\gamma \mathrm{UMo} 9$, tratada termicamente, massa total igual a $155,642 \mathrm{mg}$, massa de liga igual a 77,095mg, massa de alumínio igual a 78,546mg.

(IV.96) $\gamma \mathrm{UMo} 2$, tratada termicamente, massa total igual a $173,298 \mathrm{mg}$, massa de liga igual a 97,437mg, massa de alumínio igual a 75,86mg.

(IV.98) $\gamma \mathrm{UMo5}$, tratada termicamente, massa total igual a $175,507 \mathrm{mg}$, massa de liga igual a $91,654 \mathrm{mg}$, massa de alumínio igual a $83,853 \mathrm{mg}$.

(IV.114) $\gamma \mathrm{UMo6}$, bruta de fusão, massa total igual a 148,909mg, massa de liga igual a $73,947 \mathrm{mg}$, massa de alumínio igual a 74,962mg. 
(IV.100) $\gamma U M o 6$, tratada termicamente, massa total igual a $143,934 \mathrm{mg}$, massa de liga igual a 67,699mg, massa de alumínio igual a 76,235mg.

(IV.111) $\gamma \mathrm{UMo11}$, bruta de fusão, massa total igual a 133,136mg, massa de liga base igual a $65,468 \mathrm{mg}$, massa de alumínio igual a $67,668 \mathrm{mg}$.

(IV.112) $\gamma \mathrm{UMo} 7$, tratada termicamente, massa total igual a $149,144 \mathrm{mg}$, massa de liga igual a 75,836mg, massa de alumínio igual a 73,308mg.

(IV.113) $\gamma \mathrm{UMo11}$, bruta de fusão, massa total igual a 156,581mg, massa de liga base igual a $73,222 \mathrm{mg}$, massa de alumínio igual a $83,359 \mathrm{mg}$.

(IV.115) $\gamma \mathrm{UMo11}$, bruta de fusão, massa total igual a 146,617mg, massa de liga base igual a $64,468 \mathrm{mg}$, massa de alumínio igual a $82,149 \mathrm{mg}$.

(IV.116) $\gamma U M o 11$, bruta de fusão, massa total igual a $86,517 \mathrm{mg}$, ciclo de temperaturas: estabilização por 10 minutos à temperatura ambiente, subida a $10^{\circ} \mathrm{C}$ por minuto até $1200^{\circ} \mathrm{C}$, descida à temperatura ambiente na mesma velocidade.

(IV.121) $\gamma \mathrm{UMo11}$, bruta de fusão, massa total igual a $126,570 \mathrm{mg}$, ciclo de tratamento: estabilização à temperatura ambiente por 10 minutos, subida a $900^{\circ} \mathrm{C}$ a $30^{\circ} \mathrm{C}$ por minuto, manutenção por 6 horas, descida à mesma velocidade até temperatura ambiente.

(IV.115) $\gamma$ UMo11, bruta de fusão, massa total igual a 169,519mg, ciclo de tratamento: estabilização à temperatura ambiente por 10 minutos, subida a $920^{\circ} \mathrm{C}$ a $30^{\circ} \mathrm{C}$ por minuto, manutenção por 3 horas, descida à mesma velocidade até temperatura ambiente.

\subsection{Procedimento experimental / ensaios de hidrogenação em escala semi-piloto}

Para confirmação dos resultados de hidrogenação, alguns ensaios foram realizados com quantidades maiores de amostra e gás hidrogênio. Procurou-se, nesta série de experimentos analisar o comportamento das ligas nas melhores condições de hidretação, obtidas nos ensaios realizados no analisador termogravimétrico. Pelas características do arranjo experimental, trabalhou-se com quantidade fixa de gás no interior da câmara de 
reação e com valores diferentes de pressões iniciais, efetuando-se as medidas de queda de pressão em função do tempo em cada um dos experimentos.

A liga foi carregada no forno sobre uma "barquinha" de alumina calcinada, após ter sua superfície limpa para a remoção de camada de óxido superficial, que sabidamente interfere nos resultados. Antes de cada experimento, efetuou-se a remoção de gases do interior da câmara de reação por meio de ciclo de purga e vácuo, semelhante ao adotado na etapa de fusão por indução. Após vácuo estável de $4 \times 10^{-2} \mathrm{mbar}$, efetuou-se o preenchimento da câmara com hidrogênio, até valor desejado de pressão. Atingido este valor, programou-se o controlador do forno com o ciclo desejado de temperaturas e tempos. Com o início do experimento, procurou-se anotar o mais fielmente possível os valores de queda de pressão em função do tempo, por meio dos quais foram construídas várias curvas, para cada uma das isotermas programadas.

Em todos os experimentos, a velocidade de subida aos patamares programados foi de $20^{\circ} \mathrm{C} / \mathrm{min}$. $\mathrm{O}$ volume de gás na câmara foi assumido como sendo igual ao volume interno da câmara, e igual a aproximadamente $216 \mathrm{~mL}$. O resfriamento do sistema foi feito por retirada da retorta do forno, à temperatura ambiente.

A liga escolhida para estudo foi a contendo $7 \%$ de Mo. Com a obtenção de maior quantidade de pó, permitiu-se um envio de maior quantidade de amostras para caracterização em difração de raios-X e microscopia de varredura. Obteve-se assim alguma noção sobre a composição e qualidade dos pós. 
TERCEIRA PARTE

\section{DESENVOLVIMENTO TEÓRICO}

\section{NUCLEAÇÃO DA FASE $\alpha$-U A PARTIR DA MATRIZ DE $\gamma$-UMo}

\subsection{Evidências experimentais}

A discussão seguinte toma por base o trabalho de Hofman et al. ${ }^{14}$, que oferece uma técnica para a previsão do comportamento de ligas de urânio, por meio da teoria clássica da nucleação e de projeto das ligas metálicas. Por este motivo considera-se como o mais importante e diretamente ligado aos trabalhos realizados nesta tese de doutoramento. 
A menos de algumas simplificações com respeito à fenomenologia da nucleação em estado sólido, creio que sua simplicidade disponibiliza ferramentas de fácil acesso não só a pesquisadores da área nuclear, mas a todos aqueles que se dedicam ao estudo e projeto de ligas metálicas. Obviamente que, dado o seu interesse e aplicação direta neste trabalho, o mesmo será analisado em detalhes, com ênfase ao completo desenvolvimento das equações.

Deve-se tomar como ponto de partida para o estudo de estabilização de fases em sistemas metálicos o exame de seus diagramas binários e dos TTT já existentes. No caso da fase gama do urânio, a maior parte deles pode ser encontrada na publicação de Rough e Bauer ${ }^{04}$. De todos os elementos de adição, observa-se que o molibdênio é o mais promissor candidato a estabilizador da fase $\gamma$-U, pois dentre os elementos que estabilizam gama em uma faixa maior de composições, como $\mathrm{Zr}$, $\mathrm{Ti}$ e $\mathrm{Nb}$, o Mo apresenta solubilidade intermediária, máxima de $42 \%$ a $1300^{\circ} \mathrm{C}, 32 \%$ a $600^{\circ} \mathrm{C}$. Ainda, a tendência à formação de compostos é pequena quando comparada à de sistemas nos quais a solubilidade em gama é pequena, como em $\mathrm{Pt}, \mathrm{Pd}$, Si.

Pelo exame dos diagramas TTT existentes para o equilíbrio alfa-gama U, já discutido extensivamente no capítulo 2, com adições de Mo, verifica-se que a decomposição gama $\rightarrow$ alfa é lenta nas temperaturas de operação de reatores, usualmente inferiores a $250^{\circ} \mathrm{C}$. Entretanto, nas temperaturas de laminação, usualmente de $500^{\circ} \mathrm{C}$, uma liga $\gamma \mathrm{U} 9 \mathrm{Mo}$ (aproximadamente 18\% em átomos) transforma-se após 3 horas, e para uma liga $\gamma \mathrm{U} 6 \mathrm{Mo}$ (aproximadamente $12 \%$ em átomos) esta ocorre em menos de 1 hora. Assim, se desejarmos anular a nucleação de alfa nestas ligas, operações de laminação deverão ser conduzidas em tempos inferiores a estes. Todos estes resultados levam em conta que todas estas ligas estejam homogêneas em termos de composição. 


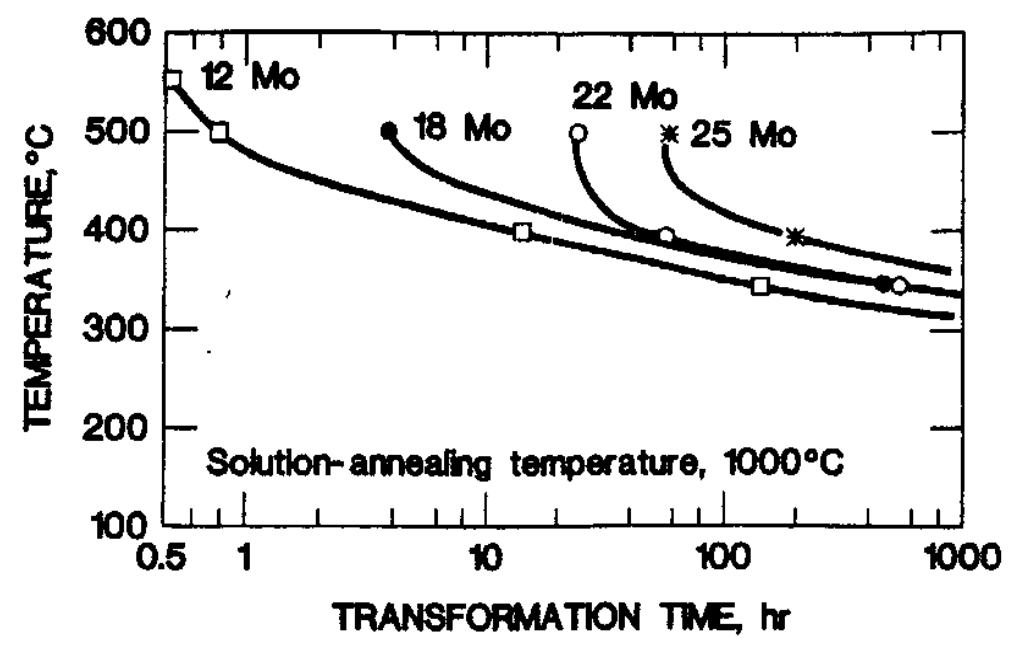

FIGURA 09 - Diagrama TTT para a decomposição detectável dada pela reação $\gamma \rightarrow \alpha$, em ligas U-Mo ${ }^{14}$.

Em termos de adição ternária ao binário UMo, exemplifica-se o poder de estabilização com o elemento Pt. A adição de 1,1\% em átomos de Pt (tem-se então 18\%Mo $+1,1 \% \mathrm{Pt}+80,9 \% \mathrm{U})$, representa o mesmo efeito estabilizante que a adição de um teor de $7 \%$ de Mo a uma liga U-18\% em átomos de Mo. Assim, tomando como exemplo a temperatura de $400^{\circ} \mathrm{C}$, o início da decomposição detectável da fase gama se dá em uma liga de U-18\% at. Mo após aproximadamente 35 horas, mas ao adicionarmos 1,1\% at. de Pt, esta decomposição ocorre somente após 200 horas.

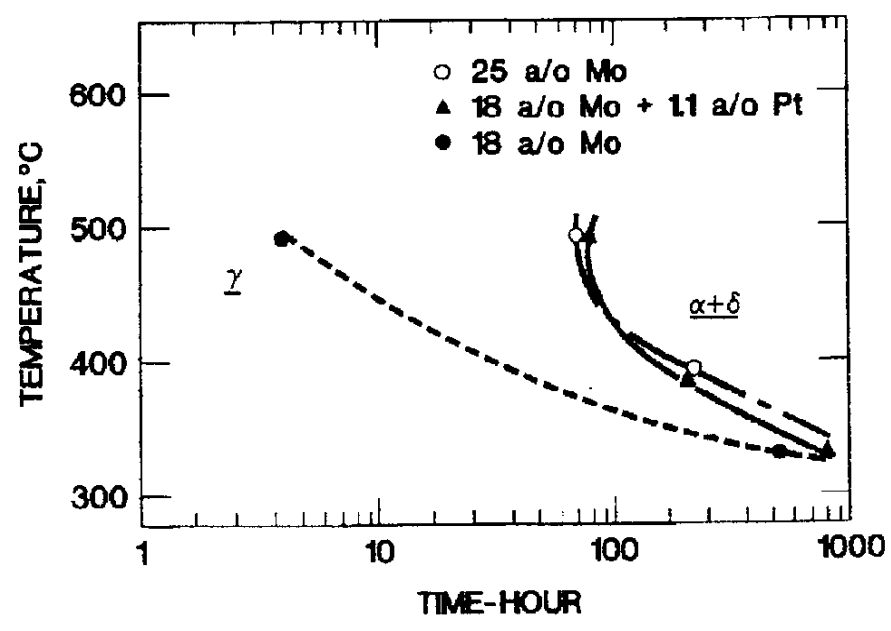

FIGURA 10 - Efeito da adição de $\mathrm{Pt}^{14}$.

Assim, com estes resultados podemos iniciar uma revisão das idéias utilizadas para a elaboração do modelo, onde o ponto de partida é a teoria clássica da nucleação e crescimento de fases. 


\subsection{Teoria simplificada}

O problema principal na fabricação de combustíveis nucleares para reatores de pesquisa à base da dispersão é a seguinte reação de decomposição da fase $\gamma$-U, no caso do binário UMo:

$$
\gamma \rightarrow \alpha+\delta
$$

Sendo gama metaestável nas temperaturas de interesse, há a necessidade da pesquisa por elementos que, quando adicionados ao urânio, estabilizem esta fase. Em outras palavras, a estabilização está diretamente relacionada à inibição da nucleação das fases de decomposição.

As combinações mais utilizadas em combustíveis nucleares são aquelas contendo teores de Mo da ordem de 5 a 10\% em peso. Sendo todas hipoeutetóides, o proeutetóide formado e que se constitui na fase cuja nucleação se quer evitar é a fase alfa, ortorrômbica, conforme os exames de amostras obtidas imediatamente após a solidificação. Como estamos tratando da nucleação de fases em ligas metálicas e não em metais puros, e da observação de que os núcleos são formados nos contornos de grão e, portanto, sobre interfaces presentes no sistema, o fenômeno é o da nucleação heterogênea. Entretanto, desprezando-se as energias de deformação da rede originadas da formação de precipitado alfa com estrutura não coerente com a da matriz, a teoria da nucleação homogênea pode ser utilizada com boa aproximação. Contornos de grão e outros defeitos são também usuais zonas de deposição (segregação) de átomos.

A nucleação é um fenômeno termodinamicamente ativado, controlado pela difusão. A movimentação aleatória dos átomos pela liga pode formar os embriões, que são grupos de átomos com composição diferente da composição média da matriz. Se a fase matriz na qual o movimento está ocorrendo for aquela que apresenta a menor energia livre, os embriões representam regiões de alta energia e, portanto, têm vida curta. Não é este o caso em estudo nesta tese, pois aqui alfa é a fase estável, e assim os embriões formados representam sítios potenciais para a nucleação.

Entretanto, para que o embrião sobreviva e se torne um núcleo de uma nova fase, deve haver uma redução na energia livre líquida do sistema para a transição embriãonúcleo. Este crescimento envolve a criação de uma nova interface entre a fase matriz e o núcleo, e no caso de reações em estado sólido, pode envolver também a introdução de tensões elásticas e de deformação na matriz, quando as novas fases formadas apresentarem 
estrutura cristalina diferente da estrutura da matriz. Este é o caso, pois gama é cúbica de corpo centrado, e alfa tem estrutura ortorrômbica. Como está-se desprezando os termos de tensão, daí o modelo simplificado, a variação de energia livre $G_{\text {net }}$ para a formação de um núcleo homogêneo esférico é escrita como:

$$
\Delta \mathrm{G}_{\mathrm{net}}=4 / 3 \pi \mathrm{r}^{3} \Delta \mathrm{G}_{\mathrm{v}}+4 \pi \mathrm{r}^{2} \gamma_{\mathrm{s}}
$$

onde $\gamma_{\mathrm{s}}$ é a energia de formação da interface, $\mathrm{G}_{\mathrm{v}}$ é a energia disponível para a formação do volume do núcleo da nova fase. Ao se examinar a contribuição individual de cada termo e a sua soma, observa-se que a um determinado valor de raio igual ao raio crítico, um pequeno aumento causa uma redução na energia livre líquida dada a forte dependência desta com o termo volumétrico, o que favorece o processo de nucleação.

Para a estimativa da taxa de nucleação $\boldsymbol{I}$, expressa em número de núcleos formados por unidade de volume e unidade de tempo, pode-se partir da expressão de Volmer-Weber ${ }^{57}$ :

$$
I=\sum_{j=0}^{i=\max } \frac{N j}{V} A j \exp -\left(\frac{U i+U j *}{R T}\right)
$$

onde $\boldsymbol{N} \boldsymbol{j} / \boldsymbol{V}$ é o número de sítios de nucleação de tamanho $\boldsymbol{j}$ por unidade de volume, $\boldsymbol{A} \boldsymbol{j}$ é um fator de freqüência, $\boldsymbol{U} \boldsymbol{i}$ é a energia de ativação para a movimentação dos átomos por difusão através da barreira (interface), $\boldsymbol{U}_{\boldsymbol{j}}$ * é a energia de ativação para a formação de núcleos de tamanho crítico $\boldsymbol{j}$ (os embriões capazes de sobreviver e crescer).

Pode-se efetuar algumas simplificações na expressão (43). Considerando ligas com tamanho de grão uniforme e sem segregação prévia nos contornos de grão, a razão $\mathbf{N j}$ $\boldsymbol{A j} / \boldsymbol{V}$ é constante, portanto sai da somatória. Podemos com isso assumir que $\boldsymbol{U} \boldsymbol{j} *$ tem valor igual a um valor médio $\boldsymbol{U} \boldsymbol{m}$. Uma forma analítica para $\boldsymbol{U}^{*} \boldsymbol{m}$ é obtida diferenciando-se $\Delta \mathrm{G}_{\text {net }}$ com respeito a $\mathrm{r}$ e fazendo o resultado igual a zero:

$$
U^{*} m=16 \frac{\pi}{3} \frac{\gamma^{3}}{\Delta G v^{2}}
$$

Sabendo que a energia livre para a formação do volume é inversamente 
proporcional ao super-resfriamento, em temperaturas abaixo do ponto de fusão, a energia média de ativação $\boldsymbol{U} \boldsymbol{j}\left(\boldsymbol{U}^{*} \boldsymbol{m}\right)$ para a formação de um núcleo crítico torna-se pequena e a nucleação é controlada por $\boldsymbol{U} \boldsymbol{i}$, ou pela movimentação de átomos através da interface. Por outro lado, em temperaturas próximas à da linha solidus, $\boldsymbol{U} \boldsymbol{j}$ é a que prepondera. Esta predominância de mecanismos em temperaturas distintas leva à forma em $\mathrm{C}$ clássica das curvas tempo-temperatura-transformação. A partir daqui, Hofman et al. ${ }^{14}$, utilizam estes diagramas para a determinação dos valores de energia do processo de nucleação. Partindo da equação (43) simplificada:

$$
I=\frac{N}{V} A \exp \left[-\left(\frac{U i+U^{*} m}{R T}\right)\right]
$$

e definindo-se ti como o tempo necessário para a realização de uma transformação, podemos relacionar a taxa de nucleação $\boldsymbol{I}$ a $\boldsymbol{t} \boldsymbol{i}$. Identificando e tomando-se o logaritmo da equação (45), obtemos:

$$
\ln t i=\ln \left\{\frac{N A}{V} \exp \left[-\left(\frac{U i+U^{*} m}{R T}\right)\right]\right.
$$

e desenvolvendo:

$$
\ln t i=\ln \frac{N A}{V}+\ln \left\{\exp \left[-\left(\frac{U i+U^{*} m}{R T}\right)\right]\right\}
$$

e portanto:

$$
\ln t i=\ln \frac{N A}{V}-\left(\frac{U i+U^{*} m}{R T}\right)
$$

A partir desta equação pode-se obter o tempo de nucleação em função da temperatura, dados os valores de energia. O termo $N \boldsymbol{A} / \boldsymbol{V}$, para ligas metálicas, identificado como o número de núcleos potencialmente existentes já em super-resfriamento nulo, é estimado em $10^{30}$ núcleos $/ \mathrm{cm}^{3} \mathrm{~s}$.

Diferenciando (48) com relação ao inverso da temperatura, obtemos: 


$$
\begin{gathered}
\frac{d \ln t i}{d(1 / T)}=\frac{d}{d(1 / T)}\left[-\ln \frac{N A}{V}\right]-\frac{d}{d(1 / T)}\left[\frac{U i+U^{*} m}{R T}\right] \\
\frac{d \ln t i}{d(1 / T)}=-\frac{d}{d(1 / T)}\left[\frac{U i}{R T}\right]-\frac{d}{d(1 / T)}\left[\frac{U^{*} m}{R T}\right]
\end{gathered}
$$

e assumindo uma condição mais genérica em que $\boldsymbol{U} \boldsymbol{i}$ e $\boldsymbol{U} \boldsymbol{*}_{\boldsymbol{m}}$ sejam funções da temperatura (o termo $\boldsymbol{U} * \boldsymbol{m}$, por exemplo, já foi dito ser dependente do super-resfriamento, sendo uma função de seu inverso) temos, por aplicação da derivada sobre $\boldsymbol{U} \boldsymbol{i}$ e (1/T):

$$
\frac{d}{d(1 / T)}\left[\frac{U i}{T}\right]+\frac{d}{d(1 / T)}\left[\frac{U^{*} m}{T}\right]=\frac{d}{d(1 / T)}[U i] \frac{1}{T}+\frac{d}{d(1 / T)}[U * m] \frac{1}{T}
$$

Assim:

$$
\frac{d \ln t i}{d(1 / T)}=\frac{U i}{R}+\frac{U^{*} m}{R}+\frac{1}{T}\left\{\frac{d}{d(1 / T)}\left[U i+U^{*} m\right]\right\}
$$

expressão final na qual os termos de energia aparecem isolados. Para a obtenção das energias $\boldsymbol{U} \boldsymbol{i}$, levamos em conta que em super-resfriamentos elevados, $\boldsymbol{U}^{*} \boldsymbol{m}$ é muito pequena, o termo que domina é $\boldsymbol{U} \boldsymbol{i}$. Assumindo que seu valor seja constante, obtemos de (52):

$$
\frac{d \ln t i}{d(1 / T)}=-\frac{U i}{R}
$$

e num gráfico de $\ln t i \mathrm{x}(1 / \mathrm{T})$ a inclinação dá energia de ativação para a difusão através da interface, dividida por R. Hofman et $\mathrm{al}^{14}$ utilizaram este procedimento para extrair, a partir de diagramas TTT pré-existentes, a energia de ativação $\boldsymbol{U} \boldsymbol{i}$ para a nucleação em temperaturas abaixo de $425^{\circ} \mathrm{C}$, na faixa de composições de 12 a $25 \%$ em átomos. Para combustíveis a base de dispersão, a mais importante faixa de temperaturas encontra-se entre $425^{\circ} \mathrm{C}$ e $500^{\circ} \mathrm{C}$, a faixa usual de temperaturas de laminação e na qual as ligas de gama-U não deveriam começar a se decompor.

Os autores verificaram experimentalmente que mesmo aumentando a energia 
de ativação para a difusão por adição de elemento de liga, o tempo de nucleação $t i$ ainda continuaria a decrescer (facilitando a decomposição), na importante faixa de temperaturas de fabricação destas duas ligas binárias. Portanto, deve ser feita uma pesquisa por elementos que, quando adicionados em pequenas quantidades como ternário, promova significativo aumento no tempo de decomposição da fase gama, como mostrado na figura 10 para o sistema U-Mo-Pt. Neste caso, os autores utilizaram os trabalhos semi-empíricos de MIEDEMA $^{58}$ e MIEDEMA et al. ${ }^{59}$, que relaciona a chamada entalpia de mistura, uma medida da força da ligação metálica em ligas, às energias $\boldsymbol{U} \boldsymbol{i}$ e $\boldsymbol{U} * \boldsymbol{m}$.

Os autores identificam a entalpia de mistura semi-empírica $-\Delta H \boldsymbol{H}$ com a soma dos termos de energia da exponencial da equação (43), $\left(\boldsymbol{U}^{*} \boldsymbol{m}+\boldsymbol{U} \boldsymbol{i}\right)$, e que, portanto, representam em conjunto o valor da força da ligação entre os elementos constituintes da liga. Com isso, forças de ligação puderam ser estimadas para ligas de urânio com elementos $4 \mathrm{~d}$ e $5 \mathrm{~d}$ da tabela periódica. Para eliminar efeitos de estrutura, os autores escolheram aquelas cuja estrutura fosse a mesma da fase $\gamma$-U. Também desconsideraram o efeito produzido pela diferença nos diâmetros dos átomos de solvente.

Como procederam para a realização das previsões? Para mistura entre dois metais de transição, a equação semi-empírica para $-\Delta \boldsymbol{H} \boldsymbol{m}$ utilizada foi ${ }^{58}$ :

$$
\Delta H m=\left\lfloor-P e\left(\Delta \phi^{*}\right)^{2}+Q\left(\Delta n_{w s}^{1 / 3}\right)^{2}\right\rfloor f\left(c^{s}\right)
$$

no qual $f\left(c^{s}\right)$ é uma função das concentrações atômicas, $\phi^{*}$ é o parâmetro de eletronegatividade, $\Delta \boldsymbol{n}_{\boldsymbol{w}}$ é a diferença de densidade eletrônica na fronteira de uma célula de Wigner-Seitz, $\boldsymbol{e}$ é a carga do elétron e $\boldsymbol{Q}$ e $\boldsymbol{P}$ são constantes empíricas, $P=14,1$ e $Q / P=$ 9,4. Alguns dos parâmetros acima se encontram tabelados abaixo, e um conjunto mais completo pode ser visto ${ }^{58}$.

Os valores de $\boldsymbol{f}\left(\boldsymbol{c}^{\boldsymbol{s}}\right)$ foram utilizados a partir dos resultados obtidos em Miedema $^{59}$. Em seguida, testaram a validade da hipótese calculando-se $\mathbf{-} \boldsymbol{\Delta H \boldsymbol { m }}$ para uma série de ligas UMo para as quais há TTT. Na figura 11 mostra-se um gráfico do tempo lnti, para nucleação de fases de decomposição em diversas composições do binário U-Mo, a $500^{\circ} \mathrm{C}$, em função dos valores calculados de $-\mathbf{\Delta H} \boldsymbol{H}$, conforme equação (54). A linearidade obtida confirma a validade da hipótese, havendo então proporcionalidade entre a entalpia de mistura e a energia total de ativação. 


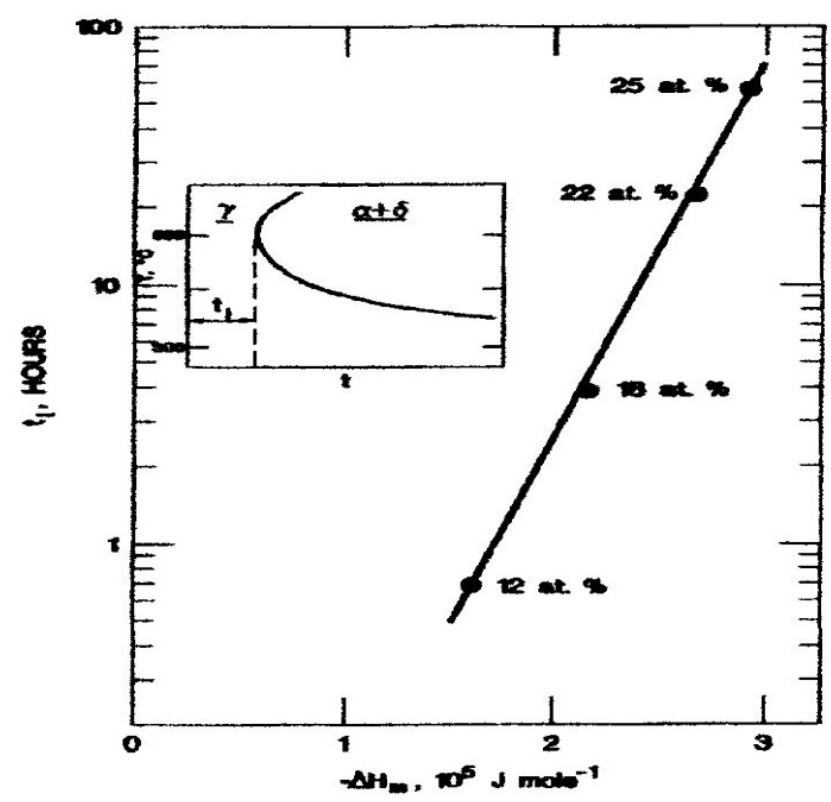

FIGURA 11 - Tempo de nucleação para a decomposição metaestável $\gamma$ em função do calor de mistura para ligas de U-Mo ${ }^{14}$.

Baseado na concordância obtida para o binário U-Mo, calculou-se $\mathbf{- \Delta H m}$ para várias ligas binárias cujos dados TTT foram publicados. Os resultados foram mostrados na Figura 12 esquerda para adições de elementos $4 \mathrm{~d}$ e $5 \mathrm{~d}$ em $\gamma$-U estabilizado com $16 \%$ átomos Mo, até os seus limites de solubilidade. Na Figura 12 direita mostra-se os efeitos de algumas destas adições ternárias no tempo ti, para uma mesma liga $\gamma$-U base contendo $16 \%$ átomos de Mo, até o limite máximo de $2 \%$ átomos de ternário.
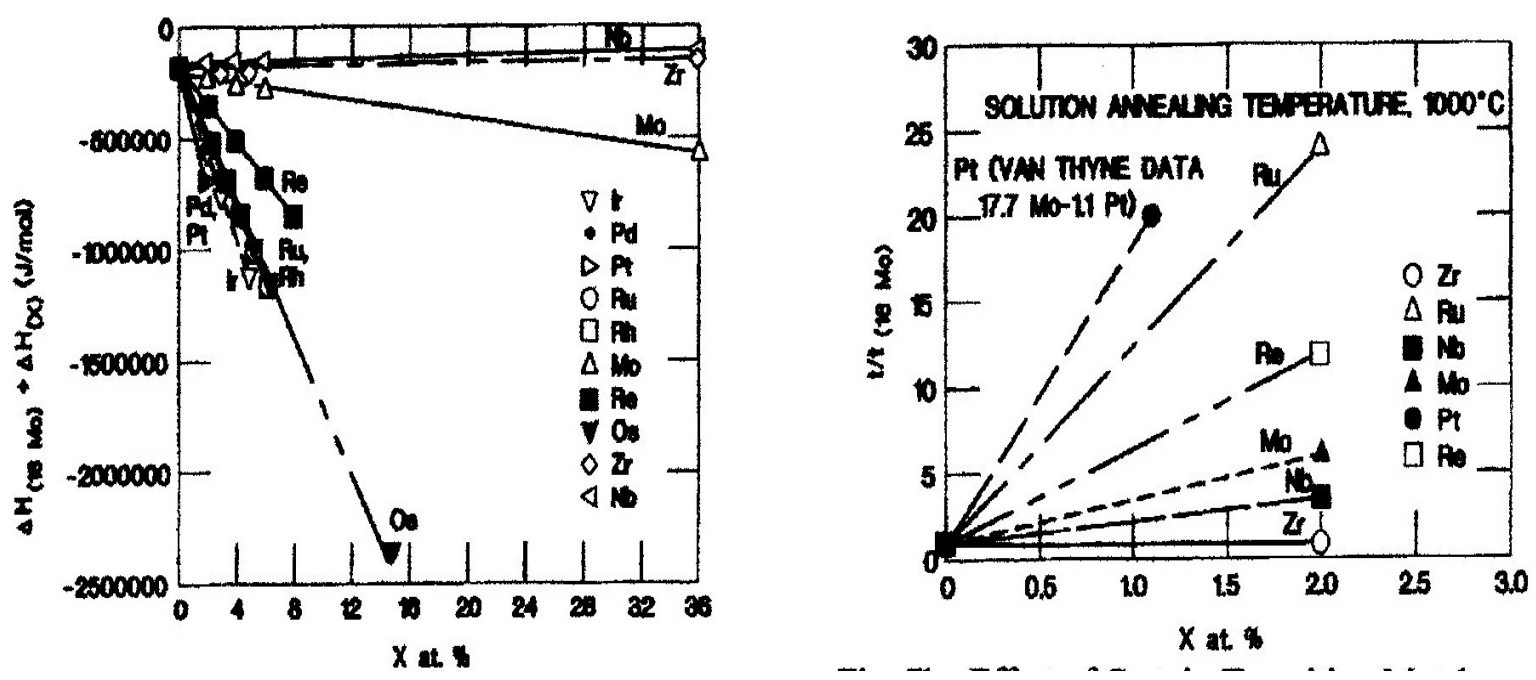

FIGURA 12 - Entalpia de mistura de metais de transição em $\gamma$-U (esquerda), e o efeito de alguns metais de transição sobre os tempos de decomposição ti em U16\%at.Mo (direita) ${ }^{14}$. 
Observa-se nestas figuras que ligas de $\gamma$-UMo são menos estabilizadas com adições ternárias de $\mathrm{Zr}$ e $\mathrm{Nb}$ que com a adição de mais Mo, pois em ambos o tempo de nucleação da fase de decomposição é menor. Adições de Mo, Re, Ru e 17,7Mo1,1Pt, em ordem crescente (Figura 12, direita), retardam em muito o início da decomposição celular dada pela reação (41), sendo portanto mais eficiente estabilizadores.

Assim, chega-se finalmente à conclusão de que o poder de estabilização da fase $\gamma$-U cresce para a direita na tabela periódica para ambos os grupos $4 \mathrm{~d}$ e $5 \mathrm{~d}$. Conforme já mencionado na introdução, isto não é suficiente na escolha de um elemento de liga para uma aplicação nuclear como esta. Outras propriedades, como a seção de choque de captura de nêutrons, e sua faixa de solubilidade, dadas pelos diagramas de equilíbrio, devem também ser consideradas. A perda neutrônica associada às adições de cada elemento, relacionadas ao decréscimo porcentual no ciclo de operação do reator, talvez seja a mais importante delas.

Com base nestes dados os autores definem um parâmetro que relaciona o tempo de nucleação $\boldsymbol{t i}$ com a porcentagem de decréscimo no comprimento do ciclo de utilização nos reatores. Verificaram assim que $\mathrm{Ru}, \mathrm{Pd}$, Os e Pt têm efeito positivo relativo ao Mo. Entretanto, o critério último que definirá a efetividade destas adições deve estar relacionado ao quanto de cada um destes elementos pode ser mantido em solução sólida com $\gamma \mathrm{U}-\mathrm{Mo}$.

Na última linha da Tabela 5 mostra-se o limite de solubilidade em $\gamma$-U a $900^{\circ} \mathrm{C}$. Levando-se todos estes fatores em consideração, somente pequenas quantidades de $\mathrm{Pd}$ e $\mathrm{Pt}$ ( 1\%át), são esperadas serem efetivas, mas estes dois elementos não devem apresentar alto poder de estabilização nestas pequenas concentrações. Os dois outros elementos, Ru e Os, por outro lado, tem um maior potencial para reposição de Mo por sua grande solubilidade.

TABELA 05 - Parâmetros de interesse na seleção de elementos estabilizadores de $\gamma-U^{14}$.

\begin{tabular}{|l|l|l|l|l|l|l|l|l|l|l|}
\hline Element 1 at\% & $\mathrm{Mo}$ & $\mathrm{Tc}$ & $\mathrm{Ru}$ & $\mathrm{Rh}$ & $\mathrm{Pd}$ & $\mathrm{W}$ & $\mathrm{Re}$ & $\mathrm{Os}$ & $\mathrm{Ir}$ & $\mathrm{Pt}$ \\
\hline$\Delta \mathrm{t}_{\mathrm{i}}$ & 1.0 & - & 4.7 & 4.7 & 11.3 & 3.3 & 3.3 & 4.0 & 5.3 & 11.7 \\
\hline$\Delta \mathrm{t}_{\mathrm{i}} / \Delta \mathrm{t}_{\mathrm{i}}(16 \mathrm{Mo})$ & 1.5 & - & 7 & 7 & 17 & 5 & 5 & 6 & 8 & 17.5 \\
\hline$\Delta \mathrm{CL},-\%$ & 2.28 & - & 2.48 & 25.71 & 3.47 & 8.23 & 19.11 & 6.00 & 67.6 & 5.48 \\
\hline $\begin{array}{l}\Delta \mathrm{CL} / \Delta \mathrm{CL}(16 \\
\mathrm{Mo})\end{array}$ & 1.0 & & 1.09 & 11.26 & 1.52 & 3.61 & 8.38 & 2.63 & 29.6 & 2.40 \\
\hline $\begin{array}{l}\Delta \mathrm{t} / \Delta \mathrm{CL} \\
\text { Relative to Mo }\end{array}$ & 1.0 & - & 4.38 & 0.42 & 7.4 & 0.9 & 0.39 & 1.5 & 0.18 & 4.8 \\
\hline $\begin{array}{l}\text { Max-Solubility in } \\
\text { Uat } 900^{\circ} \mathrm{C}\end{array}$ & 36 & - & 6 & 6 & $<2$ & $\sim 1$ & 8 & 15 & 5 & $<2$ \\
\hline
\end{tabular}




\subsection{Comentários finais}

Os autores concluem o trabalho afirmando que:

(1) extraindo-se os dados das curvas TTT experimentais disponíveis para a transformação metaestável de ligas de $\gamma$-U e aplicando-os às equações de nucleação, obteve-se que, nas temperaturas de interesse, a cinética de nucleação das fases de decomposição é primariamente controlada pela difusão.

(2) pode ser estabelecida uma boa correlação entre o calor de mistura calculado pela teoria de Miedema ${ }^{58,59}$ e a energia de ativação para a nucleação da decomposição $\gamma \rightarrow \alpha$. Esta correlação permite o acesso ao poder de estabilização relativo de fase gama para alguns elementos de transição apresentados como potenciais candidatos a elementos de adição.

(3) levando-se em conta estes poder de estabilização, determinado pelos autores, e outras propriedades como as listadas na Tabela 5, pode-se elaborar uma lista composta por elementos em ordem crescente ou decrescente quanto à efetividade na estabilização.

Cabem aqui algumas críticas e sugestões sobre o que foi feito no artigo:

(1) simplificações: como primeira hipótese simplificadora, os autores assumiram que os núcleos formados apresentam o mesmo tamanho, por suporem ligas que apresentavam uniformidade no tamanho de grão após solidificação. Espera-se então, a menos que, durante o processo de solidificação das ligas sejam utilizados tratamentos de têmpera convenientes, que alguns desvios sejam logo de início obtidos. $\mathrm{Na}$ maior parte das estruturas de solidificação obtidas logo após a fusão, o que se observa é a heterogeneidade ou um ligeiro espalhamento ao redor de um determinado valor de diâmetro de grão.

Um modelo mais realístico poderia ser estudado se fosse proposta uma função de distribuição para os tamanhos dos aglomerados atômicos, substituindo-se então o sinal de somatória pelo de integral. Como tamanhos de grão e de núcleos estão intimamente relacionados, esta distribuição poderia ser inferida a partir da determinação da distribuição de tamanho de grão em amostras brutas de fusão, para uma liga combustível produzida em particular.

Ao considerarem as energias de ativação para a difusão e para a formação de um volume de núcleo crítico como independentes da temperatura, os autores conseguiram 
obter resultados importantes e que, posteriormente, utilizaram em testes experimentais de estabilidade de ligas U-Mo com adições ternárias. Sabemos da teoria que esta hipótese não é verdadeira,os autores citam inclusive o fato de que $\boldsymbol{U}^{*} \boldsymbol{m}$ é fortemente dependente do super-resfriamento. Um modelo mais realístico poderia incluir esta dependência explicitamente, calculando cada um dos valores de $\boldsymbol{U} \boldsymbol{i}$ e $\boldsymbol{U}^{*} \boldsymbol{m}$ em definidas condições de super-resfriamento. Obviamente que o cálculo seria mais trabalhoso, mas levaria a resultados mais precisos.

Os autores também não se preocupam em tornar explícito o fato de que, em ocorrendo as reações em estado sólido, a nucleação das fases de decomposição se dá em estado sólido, o que sujeita a rede cristalina a tensões internas que devem fortemente influenciar a formação do volume de um dado núcleo. Outra equação, ao invés da equação (03), deveria ser utilizada para se levar em conta este fenômeno, os autores tentaram incorporar o termo de tensões na equação (03), mas optaram por assumir que $U^{*} \boldsymbol{m}$ dê conta deste termo. Com isso, puderam seguir adiante com a técnica.

Apesar de semi-empírica, a equação de Miedema ${ }^{58}$ para a entalpia de mistura (ou de solução) de metais em sistemas binários e ternários pode ser utilizada com sucesso. Obviamente que teorias mais complexas sobre a estrutura de compostos metálicos, como a desenvolvida no livro de Hafner et al. ${ }^{60}$, que leva em conta a mecânica quântica existente nas interações entre orbitais atômicos, podem ser utilizadas para um aumento na precisão dos resultados. Entretanto, como primeira estimativa do comportamento, entretanto, os autores mostraram que a identificação da soma $\left(\boldsymbol{U} \boldsymbol{i}+\boldsymbol{U}^{*} \boldsymbol{m}\right)$ com $-\boldsymbol{\Delta H} \boldsymbol{H}$ propiciou a obtenção de bons resultados.

(2) diagramas TTT: existem varias maneiras experimentais de se determinar o tempo para a detecção de uma transformação, ti. No caso de combustíveis nucleares, no trabalho de Van Thyne e McPherson ${ }^{7,16}$ e Repas et al. ${ }^{17}$, três destas técnicas foram utilizadas para a construção destes diagramas para ligas de $\mathrm{U}-\mathrm{Nb}$ e ternários U-Mo-X, a saber: exame metalográfico, medidas de resistividade e de dureza. O importante a ser mencionado é que, apesar da proximidade, todas elas apresentaram resultados diferentes, curvas TTT diferentes foram obtidas para a mesma liga, por meio de cada uma das técnicas.

Fica claro assim que os valores de energia e poder de estabilização aqui determinados ou inferidos dependem fortemente da técnica utilizada. Creio que isto também deveria ter sido mencionado pelos autores.

(3) tendência atuais: apesar de adições ternárias ao binário U-Mo apresentarem maior 
poder de estabilização, a tendência hoje em dia é a de se utilizar combustíveis em fase binária, conforme Hofman ${ }^{61}$. Nos diagramas de fase dos elementos da tabela 5 com urânio verifica-se a tendência para a formação de muitos compostos estáveis, o que exige um controle muito grande da homogeneidade do material nas etapas de fusão e solidificação. $O$ trabalho com binários de urânio que apresentam larga faixa de estabilidade gama e ainda o de mais fácil execução metalúrgica, é aconselhável pois exige controle menos rigoroso.

No caso de combustíveis à base de dispersão, uma outra propriedade desejada é a facilidade com a qual pode ser transformado de lingote a pó. Muitas são as técnicas utilizadas para a conversão do lingote combustível a pó, mas a que se considera atualmente no IPEN, por ser de fácil execução e relativamente barata, é a da hidretação-dehidretação. É a dificuldade na obtenção de pós U-Zr que limita o seu uso como fase combustível. No caso das ligas U-Mo um processo está sendo estudado (por este trabalho de doutoramento) de modo a se obter de maneira eficiente uma maior quantidade possível de pó estabilizado na fase gama-U.

Acredita-se então que, assim como ocorre com a solubilidade, os autores deveriam ter mencionado o fato de que a efetividade na estabilização também deve passar por algum critério que relacione o tamanho de partícula possível de ser produzido e introduzido no reator, dado que suas dimensões determinam sobre qual fluxo de calor os mesmos estarão sendo submetidos.

No entanto, a importância deste trabalho reside no fato de, além de simples, conforme mencionei na introdução, utiliza-se a teoria bem estabelecida da nucleação homogênea, por meio da equação (43), para tentar prever propriedades extremamente importantes no projeto de um combustível para reatores nucleares de pesquisa.

Evitar que a fase gama se decomponha durante a laminação e durante a operação nos reatores garante uma vida útil maior dos elementos, e minimiza o problema da produção de materiais com potencial para uso bélico. 


\section{INTERAÇÃO HIDROGÊEIO - URÂNIO}

Para que se entenda melhor os mecanismos envolvidos na fragmentação das ligas base $\gamma \mathrm{UMo}$, devemos estudar a interação do gás hidrogênio com o metal urânio. Serão destacadas agora algumas das propriedades do sistema urânio-hidrogênio, urânio considerado em suas 3 fases alotrópicas, embora a ênfase se dê na interação com as fases alfa e gama, dadas as composições com as quais se está trabalhando.

Neste item tratar-se-á o problema da interação urânio-hidrogênio inicialmente da maneira clássica. A termodinâmica e a cinética química serão utilizadas para o entendimento dos mecanismos de reação entre gás e ambas as fases do urânio, e com isso serão lançadas as bases do modelo para explicação dos resultados de hidretação, obtidos experimentalmente.

Para fins de esclarecimento, toda vez que se mencionar no texto a palavra tratamento, estes não estarão referidos aos tradicionalmente utilizados tratamentos térmicos de homogeneização, conduzidos normalmente a temperatura de 900 a $1000^{\circ} \mathrm{C}$ por tempos de 72 horas, e que têm a finalidade de diminuir a microssegregação e os efeitos de zonamento, e portanto aumentar a homogeneidade composicional das ligas. Também não aos tratamentos pré-hidretação, os que se chama ao longo do texto de tratamentos de conversão $\gamma \rightarrow \alpha$. Referir-me-ei à hidretação, que por si só já se constitui num tratamento térmico, pois é realizada sobre a amostra em atmosfera de hidrogênio e também em determinadas condições de tempo e temperatura.

\subsection{Termodinâmica e cinética da interação urânio-hidrogênio}

As interações entre gases e sólidos são geralmente estudadas dividindo-as em 3 mecanismos principais ${ }^{62}$. O primeiro deles é o transporte das moléculas de gás da fase gasosa para a superfície da partícula do metal, havendo aí as chamadas reações de interface. Ao entrarem em contato com a superfície sólida, 2 tipos de eventos podem ocorrer. Se o gás é nela presa em sua forma molecular original, dizemos que a molécula é aderida à superfície por processo de adsorção física. Neste caso, as forças que as mantém são as de van der Waals, portanto fracas, sua mobilidade na superfície do metal é alta. Caso haja a dissociação da molécula, dizemos que o processo é o da adsorção química, 
havendo então forte interação entre os átomos de gás e a superfície. Neste primeiro mecanismo, devemos considerar também que algumas moléculas podem se desprender da superfície, e o equilíbrio adsorção - dessorção deve ser estudado. Aqui o fenômeno físico que o rege é o da difusão em fase gasosa, seguida de reação.

No segundo, há a difusão do reagente gasoso ou do produto gasoso através de vazios no produto sólido da reação ou através dos vazios do sólido parcialmente reagido. Os átomos, em maior extensão, ou moléculas, começam a migrar para o interior do material, solubilizando-se ou reagindo conforme sua natureza e a do metal. No caso do hidrogênio, pelo fato experimental de que sua difusividade em metais ser 12 ordens de grandeza maior que a do oxigênio, carbono, nitrogênio, postula-se que a difusão do hidrogênio pelo interior dos metais se dê com o mesmo na forma de prótons ${ }^{63}$. Sabe-se que os espaços intersticiais, em uma rede cristalina cúbica de corpo centrado, são da ordem de $0.115 \mathrm{R}$ para sítios octaédricos e de $0.219 \mathrm{R}$ para tetraédricos, onde $\mathrm{R}$ é o raio apresentado pelo átomo de urânio na estrutura cúbica de corpo centrado, e que as dimensões das moléculas de oxigênio, nitrogênio, carbono e hidrogênio são da mesma ordem de grandeza (entre $10^{-1}$ e $10^{-2} \mathrm{~nm}$ ). Assim, esta hipótese pode ser válida, dado que um próton possui diâmetro 5 ordens de grandeza menor que a de um átomo. Um estudo aprofundado de sistemas metal-hidrogênio, que leva em conta aspectos como interações entre funções de onda metal-gás, é dado em Fukai ${ }^{64}$. Óbvio que neste caso o número de defeitos na estrutura facilita a difusão dos átomos de gás, e deve entrar na contabilidade do número de sítios disponíveis para a movimentação. Aqui, o fenômeno físico é o da difusão dos átomos por um sólido.

Finalmente, devemos considerar a possibilidade de reação química efetiva entre o gás adsorvido e o sólido. No caso da obtenção do pó de $\gamma$-UMo devemos ter em mente que, além da possível interação metal-gás, possíveis reações de decomposição $\gamma \rightarrow$ $\alpha, \gamma \rightarrow \alpha+\gamma$ ou $\gamma \rightarrow \alpha+\delta$, conforme a temperatura utilizada no tratamento e portanto, conforme os campos do diagrama binário UMo que a isoterma cruza, estão simultaneamente ocorrendo. Conforme dados disponíveis em literatura, sabe-se que a fase $\alpha-U$ é muito mais ativa quimicamente que a fase $\gamma-U$ e, portanto, a reatividade da liga como um todo aumenta progressivamente quanto maior a quantidade de alfa e, conforme discutido, quanto menor a quantidade de molibdênio utilizada na estabilização da fase gama. Por outro lado, tratamentos térmicos de homogeneização prolongados tendem a aumentar a uniformidade de composição das amostras, o que pode prejudicar o desempenho dos processos de fragmentação das ligas via hidretação-dehidretação. 
Este conjunto de mecanismos forma o chamado modelo de cinzas, havendo a formação de um produto de reação na superfície, que avança para o interior da amostra com o progresso da reação. Assim, características físicas e químicas da fase sólida vão se alterando, o que leva a mudanças progressivas na cinética de reação. Um tratamento teórico detalhado da cinética das reações gás-sólido é dado em Levenspiel ${ }^{65}$.

Assim, são vários os fatores que têm influência na construção das curvas de incorporação de hidrogênio pelas ligas $\gamma \mathrm{UMo}$ em função do tempo. Pode-se citar a título de exemplo que as velocidades de incorporação sofrem a influência dos seguintes parâmetros: temperatura, pressão, tempo, massa da amostra, \%Mo na liga, porosidade e quantidade de defeitos, solubilidade do hidrogênio na liga, conversão gama-alfa, propriedades de transporte do gás, da fase gasosa para a superfície do metal e do metal para o seu interior, difusividade das espécies químicas constituintes da amostra. Um detalhamento complementar sobre o papel de cada uma das variáveis será dado no capítulo IX.

A temperatura determina sobre qual campo do diagrama de fases binário U-Mo a amostra irá se encontrar. No caso das composições hipoeutetóides aqui utilizadas, as isopletas necessariamente atravessam três campos distintos, partindo-se da mistura fundida, a saber: o campo de $\gamma$ UMo puro, o campo de $\gamma+\alpha$ e por fim, abaixo da temperatura de reação eutetóide, tida na literatura como estando ao redor de $575^{\circ} \mathrm{C}$, o campo no qual coexistem as fases $\gamma$ e $\alpha$. Ao ser realizado um tratamento isotérmico, localizamos em quais dos campos irá se encontrar a amostra e, assim, saber-se-á qual a tendência da mesma em se decompor, principalmente em fase alfa.

A solubilidade do hidrogênio na liga é importante na obtenção de um sistema reacional homogêneo. Pelo fato de ser composta por átomos com dimensões muito menores que os dos metais, presume-se que a solubilização se dê nos interstícios, ao invés de substitucionalmente. Para tanto, é necessário inicialmente que o hidrogênio seja adsorvido fisicamente à superfície externa do metal, um primeiro estágio de incorporação de massa pela liga, que se caracteriza pela alta mobilidade das moléculas. A energia para este tipo de fenômeno, chamado adsorção física, normalmente é baixa face à do processo de adsorção química. A dissociação do hidrogênio ocorre conforme equação:

$$
1 / 2 \mathrm{H}_{2}(\mathrm{~g}) \leftrightarrow \mathrm{H}(\mathrm{s})
$$


o equilíbrio indicando que estes átomos podem se recombinar para formar novas moléculas de gás. Esta equação representa uma transição de fases, hidrogênio em fase gasosa passando para a fase metálica. A constante de equilíbrio desta reação pode ser dada pela expressão:

$$
\mathrm{Kp}=\mathrm{aH}(\mathrm{s}) / \sqrt{ } \mathrm{aH}_{2}(\mathrm{~g})
$$

e desde que a atividade do hidrogênio na fase gasosa é dada por sua pressão, então:

$$
\mathrm{Kp}=\left[\mathrm{aH}(\mathrm{s}) / \sqrt{ } \mathrm{pH}_{2}(\mathrm{~g})\right]=\exp \left(-\Delta \mathrm{G}^{\mathrm{o}} / \mathrm{RT}\right)
$$

Tomando-se o logaritmo, temos:

$$
\ln \mathrm{Kp}=\ln \left[\mathrm{aH}(\mathrm{s}) / \sqrt{ } \mathrm{pH}_{2}(\mathrm{~g})\right]=-\left(\Delta \mathrm{G}^{\mathrm{o}} / \mathrm{RT}\right)=-\left(\Delta \mathrm{H}^{\mathrm{o}} / \mathrm{RT}\right)+\left(\Delta \mathrm{S}^{\mathrm{o}} / \mathrm{R}\right)
$$

Em termos de potenciais químicos, a partir da equação (55), tem-se:

$$
1 / 2 \mu \mathrm{H}_{2}=\mu \mathrm{H} \text { (fase metálica) }
$$

no qual $\mu \mathrm{H}_{2}=\mu^{\mathrm{o}} \mathrm{H}_{2}+\mathrm{RT} \ln \mathrm{PH}_{2}$, e $\mu \mathrm{H}=\mu^{\mathrm{o}} \mathrm{H}+\mathrm{RT} \ln (\mathrm{aH})$ (s). Por substituição, rearranjo e comparação com a expressão (57), obtém-se:

$$
\ln \mathrm{Kp}=\ln \left[\mathrm{aH}(\mathrm{s}) / \bigvee_{\mathrm{pH}}(\mathrm{g})\right]=\left[1 / 2 \mu \mathrm{H}_{2}-\mu \mathrm{H}(\text { fase metal })\right] / \mathrm{RT}=-\left(\Delta \mathrm{G}^{\mathrm{o}} / \mathrm{RT}\right)
$$

Agora, levando-se em conta que a dissolução dos átomos de hidrogênio nas ligas $\gamma \mathrm{UMo}$ é intersticial, deve-se obter uma relação entre o número de posições intersticiais ocupadas e não ocupadas pelo gás, nos interstícios. A atividade do hidrogênio na fase sólida pode ser assumida como sendo igual à relação entre o número de posições intersticiais ocupadas $\theta$ e desocupadas. Da equação (60), tem-se:

$$
\ln \left[\mathrm{aH}(\mathrm{s}) / \sqrt{ } \mathrm{pH}_{2}(\mathrm{~g})\right]=\ln \left\{[\theta /(1-\theta)] / \sqrt{ }_{\mathrm{pH}}(\mathrm{g})\right\}=-\left(\Delta \mathrm{G}^{\mathrm{o}} / \mathrm{RT}\right)
$$


onde $\theta=\mathrm{N}_{\mathrm{H}} /\left(\mathrm{Z} . \mathrm{N}_{\mathrm{M}}\right), \mathrm{N}_{\mathrm{H}}$ é o número de posições ocupadas pelos átomos de hidrogênio, $\mathrm{N}_{\mathrm{M}}$ é o número de posições ocupadas por átomos de metal, e $\mathrm{Z}$ é o número de posições intersticiais disponíveis por átomo de metal, característico da rede cristalina. Expressando as atividades em termos das concentrações, temos:

$$
\mathrm{aH}(\mathrm{s})=\gamma \mathrm{H} \cdot \chi \mathrm{H}
$$

e sendo a concentração de hidrogênio em termos de átomos no metal $\mathrm{N}_{\mathrm{H}}$ dada por:

$$
\chi \mathrm{H}=\mathrm{N}_{\mathrm{H}} /\left(\mathrm{N}_{\mathrm{H}}+\mathrm{N}_{\mathrm{M}}\right)
$$

e utilizando a aproximação de que o número de átomos de hidrogênio é muito menor que o número de átomos de metal, então:

$$
\chi \mathrm{H}=\theta . \mathrm{Z}
$$

Assim, podemos escrever que, para a aproximação acima:

$$
\ln \left\{\left[\theta^{*} \mathrm{Z}\right] / \sqrt{ }_{\mathrm{pH}}(\mathrm{g})\right\}=-\left(\Delta \mathrm{G}^{\mathrm{o}} / \mathrm{RT}\right)
$$

ou:

$$
\ln \left\{\left[\theta / \sqrt{ } \mathrm{pH}_{2}(\mathrm{~g})\right]\right\}+\ln \mathrm{Z}=-\left(\Delta \mathrm{G}^{\mathrm{o}} / \mathrm{RT}\right)
$$

e daí deriva-se a relação, por identificação:

$$
\left(\Delta \mathrm{G}^{\mathrm{on}}\right)=\Delta \mathrm{G}^{\mathrm{o}}+\mathrm{RT} \ln \mathrm{Z}
$$

onde $\left(\Delta \mathrm{G}^{\mathrm{on}}\right)$ é a energia disponível para a ocupação dos sítios intersticiais por NH átomos de hidrogênio.

Em termos de velocidades de reação, devemos considerar os processos mencionados, cada qual com um mecanismo distinto. Assim, na adsorção, deveremos levar 
em conta dois mecanismos, um para a adsorção física e outro para a adsorção química ou quimissorção. No primeiro caso, considerando o equilíbrio dado pela reação:

$$
\mathrm{H}_{2}(\mathrm{~g}) \Leftrightarrow \mathrm{H}_{2} \text { (ads. física) }
$$

chegamos às equações de velocidade de consumo e reposição de hidrogênio:

$$
\begin{gathered}
\mathrm{v}_{\mathrm{Hd}}=\mathrm{K}_{\text {direto1 }} \cdot \mathrm{P}_{\mathrm{H} 2} \\
\mathrm{v}_{\mathrm{Hi}}=\mathrm{K}_{\text {inverso1 }} \cdot \theta
\end{gathered}
$$

sendo a reação global a soma de (69) e (70), K's são as constantes de reação, de primeira ordem com relação à pressão e a $\theta$, e os sufixos d e i representam reações direta e inversa, respectivamente. Deve-se lembrar que a adsorção é um fenômeno superficial, portanto $\theta$ é o número de posições superficiais ocupadas. Observa-se também que as expressões são de primeira ordem em $\mathrm{P}$ e $\theta$.

No caso da quimissorção, deve-se ter em mente que o processo se dá conforme a equação:

$$
\mathrm{H}_{2}(\mathrm{ad})+2 \mathrm{~S} \Leftrightarrow 2(\mathrm{H}-\mathrm{S})
$$

ou seja, para uma molécula diatômica, a dissociação seguida de quimissorção leva à ocupação de 2 posições ativas na superfície, denominadas S. Supõe-se então que, nas demais etapas, a difusão do gás se dê na forma atômica, o gás perde a sua identidade molecular após a quimissorção. As equações de velocidade são:

$$
\begin{gathered}
\mathrm{v}_{\mathrm{Hd}}=\mathrm{K}_{\text {direto2 }} \theta(1-\Theta) \\
\mathrm{v}_{\mathrm{Hi}}=\mathrm{K}_{\text {inverso2 }} \Theta^{2}
\end{gathered}
$$

onde $\Theta$ é a concentração de átomos do gás adsorvidos quimicamente. Observa-se que esta reação é de segunda ordem, ao contrário da reação de adsorção física. 
Finalmente, para o início da difusão do gás dissociado através da superfície, para uma posição livre intersticial I, devemos considerar a reação:

$$
(\mathrm{H}-\mathrm{S})+\mathrm{I} \Leftrightarrow(\mathrm{H}-\mathrm{I})+\mathrm{S}
$$

deixando-se uma posição $\mathrm{S}$ livre na superfície para nova combinação com os átomos de gás. A expressão de velocidade, de primeira ordem, para esta reação é:

$$
\mathrm{v}=\mathrm{K}_{\text {direta }} \cdot \Theta
$$

e

$$
\mathrm{v}=\mathrm{K}_{\text {inversa }} \cdot \mathrm{c}
$$

onde c é a concentração de átomos de gás dissolvidos no volume próximo à superfície do metal.

A partir deste ponto, devemos verificar se há transformações químicas que possam ocorrer na superfície do metal. No caso do sistema $\gamma \mathrm{UMo} / \mathrm{H}$, conforme o teor de Mo adicionado à liga e condições de realização dos tratamentos térmicos de homogeneização, pode-se favorecer a presença de fase alfa intra ou intergranular. Obviamente, como esta fase tem grande afinidade pelo hidrogênio, uma expressão de velocidade de incorporação do hidrogênio por reação com urânio em fase alfa deve ser desenvolvida. Da reação de formação do hidreto de urânio, suposta direta, sem nenhuma formação de compostos intermediários:

$$
2 \alpha \mathrm{U}(\mathrm{s})+3 \mathrm{H}_{2}(\mathrm{~g}) \rightarrow 2 \alpha\left(\mathrm{UH}_{3}\right)(\mathrm{s})
$$

reescrevendo-a em termos das reações superficiais, temos:

$$
\begin{gathered}
2 \alpha \mathrm{U}(\mathrm{s})+6(\mathrm{H}-\mathrm{S})(\mathrm{g}) \rightarrow 2 \alpha\left(\mathrm{UH}_{3}\right)(\mathrm{s})+6 \mathrm{~S} \\
\mathrm{v}_{\mathrm{H} 2}=\mathrm{k}[\mathrm{H}]^{6}=\mathrm{k}^{\prime}[\alpha \mathrm{U}]^{2}
\end{gathered}
$$


onde $[\mathrm{H}]$ é a concentração de hidrogênio adsorvido na superfície, $[\alpha \mathrm{U}]$ é a concentração de fase alfa do urânio na superfície. Como os tratamentos de hidrogenação das ligas, empregados nesta tese, tomam por base a conversão progressiva da matriz de gama a alfa, faça-se uma breve consideração sobre a sua influência nas velocidades de incorporação do hidrogênio pela amostra.

Sabemos que o teor de molibdênio pode relacionar-se à quantidade de fase alfa inicialmente presente. Como esta reage facilmente com hidrogênio, é de se prever que um menor teor de Mo, que leva a uma menor quantidade de fase gama estável e precipitação de alfa em contornos de grão ou intragranularmente, produza uma absorção de massa / redução na pressão do sistema. Deve ser mencionado, entretanto, que este parâmetro deve ser tratado nas equações de transporte como uma condição inicial, uma concentração inicial, mas levado em conta também nas equações de reação com a superfície do metal. A produção de mais quantidade de fase alfa deve ser estudada também à luz da necessidade, para tanto, de estarem desocupados de precipitados os contornos de grão. Pelos tratamentos térmicos de conversão gama-alfa sabe-se que é possível a produção de fase alfa em boa quantidade. Por meio deste estudo pode-se verificar se isto é ou não verdade. Sabe-se que pela ordem das reações temos condições de verificar esta dependência.

A massa da amostra atua no sentido do aumento na absorção do gás, pois oferece um maior número de sítios de absorção. Entretanto, seu volume atua no sentido inverso, maior o volume, maiores as distâncias a serem vencidas pelos átomos de gás no interior do material. Se associarmos volume à superfície, quanto maior e para uma mesma geometria, maior a superfície externa, portanto a adsorção ocorre a uma taxa maior.

Com isso, é claro que devemos normalizar os dados para a massa, indicando como parâmetro também a razão quantidade de gás / unidade de massa, densidade. Assumindo geometria fixa das amostras, a massa deve ser usada como normalização nos cálculos de difusão, mas os fenômenos de adsorção física e química devem ser analisados à luz da superfície livre disponível para tanto.

Após a chegada do gás à superfície externa do metal, sua adsorção física e quimissorção, e posterior passagem pela interface, deve-se prosseguir a análise estudando como o mesmo é transportado por todo o volume do metal. Para isso, deve-se estudar os processos de difusão do hidrogênio no interior da fase gama-U, cúbica de corpo centrado. Nela, o hidrogênio ainda sofre a possibilidade de reação com urânio em fase alfa, presente principalmente nas superfícies livres do metal, os contornos de grão. 
O modelo utilizado na tese lança mão da resolução das equações de difusão, primeira e segunda leis de Fick, do hidrogênio no interior da liga $\gamma \mathrm{UMo}$, considerando como geometria a de uma placa, pois os ensaios foram realizados com pequenas lâminas. Considerando uma placa infinita, com a condição inicial:

$$
\mathrm{c}=\text { co para }-\mathrm{h}<\mathrm{x}<\mathrm{h}, \mathrm{t}=0
$$

e de contorno:

$$
c=\operatorname{cs} \text { para } x=-h \text { e } x=h, \text { para } t>0
$$

onde co é a concentração inicial uniforme através da placa de espessura $2 h$, e $c s$ é a concentração imediatamente próxima à superfície da placa, constante ao longo do tempo, leva à seguinte solução, supondo o coeficiente de difusão independente da concentração:

$$
\frac{c(x, t)-c o}{c s-c o}=1-\frac{4}{\pi} \sum_{n=0}^{\infty} \frac{(-1)^{n}}{(2 n+1)} \exp \left[-(2 n+1)^{2} \frac{\pi^{2}}{4} \frac{D t}{h^{2}}\right] \cos \left[\frac{(2 n+1)}{2}\left(\pi \frac{x}{h}\right)\right]
$$

e para a concentração média $\mathrm{cm}$ na placa, temos:

$$
\frac{c m(t)-c o}{c s-c o}=1-\frac{8}{\pi^{2}} \sum_{n=0}^{\infty} \frac{(1)}{(2 n+1)^{2}} \exp \left[-(2 n+1)^{2} \frac{\pi^{2}}{4} \frac{D t}{h^{2}}\right]
$$

Em ambos os casos, supôs-se uma concentração inicial uniforme na placa, co, que no caso do presente trabalho, se suporá igual a zero. A concentração cs na superfície pode ser estimada com base nas considerações sobre adsorção, etc.

\subsection{Solubilidade do hidrogênio em urânio}

Mostra-se que a solubilidade do hidrogênio em urânio a 1 atmosfera de pressão não muda apreciavelmente com a temperatura em qualquer uma de suas fases, $\alpha, \gamma$ ou $\beta$. Em todas elas, hidrogênio solubiliza-se segundo a lei de Sievert, ou seja, com a raiz quadrada da pressão (equação 57, p.117). Empiricamente ${ }^{66}$, foram obtidas as seguintes 
relações para a razão $(\mathrm{H} / \mathrm{U})=\mathrm{r}$ do hidrogênio nas fases do urânio, puro, onde a pressão é dada em mmHg:

Fase alfa: $\log r=1 / 2 \log \mathrm{P}($ torr $)-4,315-388 / \mathrm{T}$

Fase beta: $\log r=1 / 2 \log \mathrm{P}($ torr $)-3,219-892 / \mathrm{T}$

Fase gama: $\log r=1 / 2 \log \mathrm{P}($ torr $)-3,679-227 / \mathrm{T}$

Fase líquida: $\log r=1 / 2 \log \mathrm{P}($ torr $)-3,201-587 / \mathrm{T}$

Observa-se ainda que, em fase sólida, a solubilidade (em ppm) atinge seu valores máximos na fase gama, ao redor de $17 \mathrm{ppm}$, ou equivalentemente, na razão de 0,0004 H/U. Assim, das três fases, a gama é a que mais solubiliza hidrogênio, embora quimicamente tenha pouca afinidade pelo mesmo. Outro fato interessante é o salto dado na solubilidade quando das transições de fase. Assim, em se tratando de transformações $\gamma \rightarrow$ $\alpha$, deve-se considerar então que a mesma é desfavorável à solubilização do hidrogênio, embora se saiba que a formação de hidreto de urânio se dê em fase alfa, não em fase gama. Assim, deve-se ter em mente que a fase alfa solubiliza pouco, mas reage muito, enquanto gama solubiliza muito, mas não reage.

Sabendo que a pressão de dissociação do hidreto de urânio (pressão para que $\mathrm{UH}_{3}$ se dissocie em $\mathrm{U}$ e $\mathrm{H}_{2}$ ) é maior do que 1 atm a temperaturas acima de $430^{\circ} \mathrm{C}$, as solubilidades terminais (a máxima solubilidade do hidrogênio em urânio antes da formação da fase hidreto, portanto antes da reação do hidrogênio com urânio alfa) são muito maiores que as solubilidades a 1 atmosfera. Elas estão mostradas na tabela 07.

Para os valores tabelados, está-se trabalhando com as solubilidades no limite para o qual a fase hidreto se forma, dado pelas pressões ali indicadas. Assim, consigo solubilizar $0,0014 \times 10^{4} \mathrm{H} / \mathrm{U}$ (átomos de hidrogênio por átomos de alfa urânio) até uma pressão de $1,0 \times 10^{-3}$ torr. As solubilidades máximas foram obtidas quando a pressão atingiu os valores indicados na tabela. Em termos de pressão, observa-se que a tabela fornece dados para uma curva suavemente contínua, e isto fornece também parâmetros para a determinação do andamento da reação de formação de hidreto com a pressão e temperatura, utilizadas nesta tese. 
TABELA 06 - Solubilidade máxima antes da formação do hidreto ${ }^{66}$.

\begin{tabular}{|c|c|c|c|c|c|}
\hline $\begin{array}{c}\text { Temperatura } \\
\left({ }^{\circ} \mathrm{C}\right)\end{array}$ & $\begin{array}{l}\text { Solubilidade } \\
\left(\mathrm{H} / \mathrm{U} \times 10^{4}\right)\end{array}$ & $\begin{array}{l}\text { Pressão H } \\
\text { (torr) }\end{array}$ & $\begin{array}{c}\text { Temperatura } \\
\left({ }^{\circ} \mathrm{C}\right)\end{array}$ & $\begin{array}{l}\text { Solubilidade } \\
\left(\mathrm{H} / \mathrm{U} \times 10^{4}\right)\end{array}$ & $\begin{array}{c}\text { Pressão H } \\
\text { (torr) }\end{array}$ \\
\hline & Fase Alfa & & & Fase Gama & \\
\hline 100 & 0,0014 & $1,0 \times 10^{-3}$ & 769 & 397 & $9,7 \times 10^{4}$ \\
\hline 200 & 0,05 & $4,5 \times 10^{-1}$ & 800 & 460 & $1,3 \times 10^{5}$ \\
\hline 300 & 0,5 & 2,5 & 850 & 588 & $2,0 \times 10^{5}$ \\
\hline 400 & 2,6 & $4,1 \times 10^{-2}$ & 900 & 737 & $3,0 \times 10^{5}$ \\
\hline 500 & 8,3 & $3,0 \times 10^{3}$ & 1000 & 1080 & $6,0 \times 10^{5}$ \\
\hline 550 & 13,2 & $6,5 \times 10^{3}$ & 1100 & 1520 & $1,1 \times 10^{6}$ \\
\hline 600 & 20 & $1,3 \times 10^{4}$ & 1129 & 1660 & $1,3 \times 10^{6}$ \\
\hline 662 & 32 & $3,0 \times 10^{4}$ & & & \\
\hline & Fase Beta & & & Fase Líquida & \\
\hline 662 & 116 & $3,0 \times 10^{4}$ & 1129 & 2760 & $1,3 \times 10^{6}$ \\
\hline 700 & 160 & $4,8 \times 10^{4}$ & 1200 & 3420 & $1,9 \times 10^{6}$ \\
\hline 725 & 191 & $6,1 \times 10^{4}$ & 1300 & 4580 & $3,0 \times 10^{6}$ \\
\hline 750 & 229 & $8,0 \times 10^{4}$ & 1400 & 5950 & $4,5 \times 10^{6}$ \\
\hline 769 & 262 & $9,7 \times 10^{4}$ & & & \\
\hline
\end{tabular}

a equivalência ppm H/U é de $0,0004=17 \mathrm{ppm}$.

TABELA 07 - Solubilidade máxima antes da formação do hidreto, metalografia ${ }^{66}$.

\begin{tabular}{|c|c|}
\hline Temperatura $\left({ }^{\circ} \mathrm{C}\right)$ & Solubilidade $\left(\mathrm{H} / \mathrm{U} \times 10^{4}\right)$ \\
\hline \hline 400 & 1,4 \\
\hline 500 & 6,1 \\
\hline 600 & 16 \\
\hline 640 & 24 \\
\hline
\end{tabular}

Finalmente, pelo diagrama de fases U-H, observa-se que em fase gama na qual não há hidreto presente. Para esta fase, o limite de solubilidade encontra-se a aproximadamente $0,18 \mathrm{H} / \mathrm{U}$, temperatura de $1170^{\circ} \mathrm{C}$, dados referentes ao beta-hidreto de 
urânio (não é hidreto de urânio beta). A partir daí, há coexistência entre o hidreto e gama. No caso da estrutura alfa, há coexistência em toda a faixa de composições

\subsection{Dehidretação e histerese}

Em curvas de pressão em função da composição para sistemas $U-H$, obtevese ${ }^{66}$ que $357^{\circ} \mathrm{C}$ é a temperatura onde se tem a maior velocidade de dehidretação do urânio alfa. Efeitos de histerese, como os obtidos nesta tese, foram também observados, o que pode estar relacionado à histerese obtida nos experimentos em escala maior, semi-piloto. Em Blackledge ${ }^{66}$ explica-se este efeito, o de que a pressão para a dessorção deve ser maior que a pressão para a adsorção, e que geram efeitos de histerese, pela análise de como ocorre a interação metal gás.

Para que o material se hidrete, é necessário que ele supere diversas barreiras energéticas, chegar à superfície, ser adsorvido física e quimicamente, difundir-se pelo material, reagir. No processo inverso, apenas a dissociação da molécula e seu caminho para fora do metal devem ser energeticamente vencidos. Em temperaturas, entretanto, entre $450^{\circ} \mathrm{C}$ e $650^{\circ} \mathrm{C}$, este efeito não foi observado, ao contrário do que se constatou em alguns experimentos. Uma outra explicação pode ser a de que a histerese é dada por tensões mecânicas causadas pelo alto crescimento em volume durante a hidretação, o que será utilizado como uma das condições iniciais na modelagem do processo de hidretaçãodehidretação das ligas de $\gamma \mathrm{UMo}$. Assim, isto confirma que durante a hidretação há aumento do volume, visto que o hidreto de urânio possui rede cúbica, a mesma do urânio gama, mas

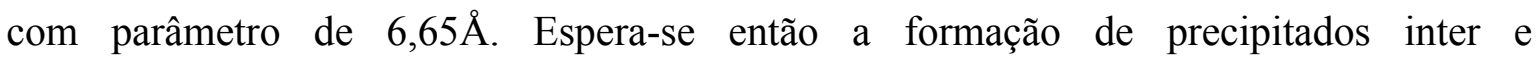
intragranulares com interface coerente à matriz de $\gamma \mathrm{UMO}$.

Explica-se também a histerese pelo fato de que o estado de subdivisão do urânio metálico desempenhe um papel importante. Ou seja, durante a hidretação, urânio é macrocristalino devido à sinterização, e durante a dehidretação ele se torna finamente subdividido. Assim, os calores de reação são diferentes em ambos os casos, levando a diferenças na pressão de equilíbrio de $\mathrm{H}$ sobre esta região de duas fases Portanto, o comportamento de histerese das ligas $\gamma \mathrm{UMo}$ pode ter uma base prévia no comportamento do urânio alfa. Ou seja, postula-se que a histerese nas curvas ocorra obtidas neste trabalho ocorra por progressiva subdivisão da amostra de urânio, que se fragmenta aos poucos, à medida que progride a reação com o tempo. Serão calculados quais os teores de hidrogênio e, portanto, tempos e temperaturas de reação, para os quais a fragmentação se inicie, 
levando-se em conta os dados de Beghi ${ }^{10}$ e as aqui determinadas propriedades mecânicas do urânio gama.

\subsection{Difusão do hidrogênio através das fases urânio metálico e hidreto:}

Resultados das medidas de difusividade de $\mathrm{H}$ em alfa, beta e gama $\mathrm{U}$ são os seguintes:

$$
\begin{aligned}
& \text { Alfa } U: D=1,95 \times 10^{-2} \exp (-11070 / \mathrm{RT}) \mathrm{cm}^{2} / \mathrm{s} \\
& \text { Beta U: } \mathrm{D}=3.3 \times 10^{-4} \exp (-3600 / \mathrm{RT}) \mathrm{cm}^{2} / \mathrm{s} \\
& \text { Gama U: } \mathrm{D}=1,5 \times 10^{-3} \exp (-11400 / \mathrm{RT}) \mathrm{cm}^{2} / \mathrm{s}
\end{aligned}
$$

As energias de ativação para a difusão do $\mathrm{H}$ pelas fases do U e pelo hidreto são as seguintes (em kcal / mol) ${ }^{66}:$ 11,1 para fase alfa, 3,6 para a fase beta, 11,4 para a fase gama, e 6,1 para o hidreto.

\subsection{Efeitos do hidrogênio nas propriedades mecânicas do U.}

Verificou-se experimentalmente que o urânio sofre uma transição dúctil-frágil a temperaturas ao redor da ambiente. O efeito do $\mathrm{H}$ nesta transição, foi a de alterar o valor de máximo em elongação sob tensão (uma medida de ductilidade), no sentido das temperaturas mais altas, quando o conteúdo de $\mathrm{H}$ cresceu de $0,3 \mathrm{ppm}\left(\mathrm{H} / \mathrm{U}=7 \times 10^{-5}\right)$ para $4,7 \mathrm{ppm}\left(\mathrm{H} / \mathrm{U}=1,1 \times 10^{-3}\right)$. Em geral, a elongação aumenta com a temperatura, tanto para a fase beta quanto para a alfa. Se a elongação aumenta, aumenta então a ductilidade do material, seria de se esperar que ocorresse o oposto, ou seja, se hidrogênio realmente tem o efeito de fragilizar, a elongação porcentual tenderia a diminuir.

Entretanto, deve-se levar em conta que está-se aumentando a temperatura, solubilizando mais $\mathrm{H}$, então o efeito da adição de $\mathrm{H}$ não suplanta o efeito da temperatura em aumentar a elasticidade dos materiais. Em termos de tensão de ruptura, obtém-se um decréscimo na tensão de ruptura com o aumento da temperatura, a partir da temperatura de transição dúctil-frágil.

Aumentando-se o conteúdo de $\mathrm{H}$ em 12 a 15 ppm (H/U = 2,9 a 3,6 x 10 $\left.0^{-3}\right)$ não produz-se efeito sobre as propriedades mecânicas. Explica-se o decréscimo na estabilidade como sendo causado pela formação de $\mathrm{H}$ molecular nas rachaduras ou discordâncias na 
rede metálica. $\mathrm{O}$ gás $\mathrm{H}$ então produz tensões triaxiais ou muda as condições de energia necessárias para a formação e propagação das discordâncias. Observa-se que os conteúdos de $\mathrm{H}$ excedem a solubilidade do $\mathrm{H}$ em $\mathrm{U}$, mesmo nas mais baixas concentrações $(0,3 \mathrm{ppm})$.

Este é um dos mecanismos que se postula para a fragilização do U gama, conforme observado nos experimentos. O hidrogênio molecular formado é acomodado em porosidades internas ou discordâncias. Com o aumento na quantidade de hidreto, que se forma por reação com alfa urânio presente inter e intragranularmente, o nível de tensão interna da matriz de gama pode chegar rapidamente a um limite, sobre o qual ela se rompe, particulando-se.

Outros estudos consideram ainda o efeito da hidretação das impurezas na fragilização do urânio, presentes também nos contornos de grão. Como evidências, as observações de que a fragilização ocorre a baixos conteúdos de $\mathrm{H}$, e que aumentos subseqüentes no conteúdo de $\mathrm{H}$ têm essencialmente nenhum efeito, visto que são as impurezas que estão completamente hidretadas; diferentes concentrações de H necessárias para a fragilização foram encontradas, presumivelmente por causa das variações no conteúdo de impurezas do $\mathrm{U}$, provenientes de diferentes fontes; e também, usualmente a concentração para a fragilização independe da temperatura, indicando que ela seja independente da solubilidade do H. Em se tratando de $\gamma \mathrm{UMo}$, este é um fato não confirmado pelos experimentos realizados aqui. A temperatura e velocidades de resfriamento têm grande influência, conforme será demonstrado no capítulo 13, na fragilização das ligas.

Como a maioria dos resultados de fragilização refere-se ao papel do hidrogênio sobre a fase alfa do urânio ${ }^{48-50}$, mesmo em ligas $\gamma \mathrm{UMo}$, nesta tese será estudada a fragilização das ligas $\gamma \mathrm{UMo}$, seu comportamento mecânico face ao hidrogênio. A partir dos resultados de hidretação em TG e DTA, e de posse de valores de propriedades mecânicas, será determinada a correlação da fragilização com os dados de propriedades mecânicas da fase gama. Isto é muito importante, pois é aqui que se encontra a fase tecnológica deste trabalho.

Finalizando, em termos de aplicações como combustíveis nucleares, observouse que a presença do Mo aumenta o tempo para falha descontínua, presumivelmente por estender a faixa de estabilidade da fase gama e, conseqüentemente, inibir a formação da fase hidreto. Portanto, em reações de hidretação, ligas contendo alto teor em Mo são menos susceptíveis à formação da fase hidreto, por decomposição de gama em alfa. Adições de 
pequenas quantidades de $\mathrm{Pt}$ à liga U-Mo reduzem a absorção de $\mathrm{H}$, lembrando dos trabalhos de adições ternárias RERTR ${ }^{14}$, pois aumentam a estabilidade da fase gama consideravelmente. Assim, é de se esperar que ligas altamente estabilizadas absorvam menos hidrogênio, por possuírem menos fase alfa em sua estrutura.

Pretendeu-se apresentar algumas informações de literatura sobre propriedades de fases do urânio sob hidrogênio, seus hidretos, dados de transporte, etc. Um conjunto de informações mais detalhadas pode ser encontrado no livro de Beghi ${ }^{10}$. A realização de alguns ensaios para a caracterização mecânica das ligas não será descartada neste trabalho, os resultados serão apresentados em capítulo pertinente. 


\subsection{Fenomenologia}

A principal aplicação para as ligas de $\gamma$-UMo aqui estudadas será como fase particulada em combustíveis na forma de dispersão, em matriz de alumínio, conforme aplicação usual em reatores de pesquisa tipo MTR. O pó será, basicamente, obtido por meio das seguintes etapas, a partir das cargas de urânio e molibdênio: fusão a arco ou por indução das cargas e solidificação, seguida de tratamento térmico de homogeneização, caso a fusão a arco seja a via considerada, e dos tratamentos térmicos sob atmosfera de hidrogênio, para a hidretação e dehidretação (HDH) das ligas e obtenção final do pó. Cada uma delas será apresentada com detalhes na parte IV, sobre resultados e discussões.

É óbvio que as condições dos ensaios como temperatura, pressão, tempo, vazão de hidrogênio, etc., bem como as propriedades das ligas, como teor de molibdênio, quantidade de defeitos, resistência mecânica, etc., exercem grande influência em sua estabilidade química, térmica e mecânica. Assim, para a elaboração de modelo que explique a fragilização das ligas, estas e outras variáveis deverão ser estudadas de maneira a se aumentar a sua precisão.

Outro aspecto importante diz respeito à abordagem. Apesar de se realizar vários experimentos, adotar-se-á uma abordagem teórica para explicação dos resultados. Ou seja, enquanto na abordagem experimental pretende-se oferecer uma base estatística para a compreensão dos fenômenos, usualmente realizadas sobre os resultados de diversos experimentos, na abordagem teórica pretende-se, por meio da resolução de um sistema de equações algébricas e / ou diferenciais, entender o fenômeno em termos de suas leis físicas mais básicas, explicando-o por meio delas.

Para tanto, faz-se necessária a visualização do processo de fragilização das ligas e obtenção de pós por meio da elaboração de uma "cadeia" de fenômenos, sobre a qual o problema poderá ser enunciado em termos físicos e / ou matemáticos. Após esta fase, o problema deverá ser formulado em termos das equações que governam cada um dos elos da cadeia fenomenológica. A solução das equações ou sistema de equações, obviamente, deverá fazer parte de um conjunto de valores ou funções que, neste trabalho, otimizem o problema da obtenção de pós da liga $\gamma$-UMo.

Um dos objetivos derivados desta tese de doutoramento é "fornecer ao IPEN uma tecnologia para a fabricação da liga metálica e dos pós do combustivel de alta densidade $\gamma$-UMo (gama-urânio-molibdênio), para uso como fase dispersa em combustíveis tipo placa de reatores MTR, e explicá-la com modelo teórico". Considerando 
as operações descritas, para a fabricação das ligas os fenômenos principais são os relacionados à fusão e solidificação da carga. No primeiro caso, temos como parâmetros principais suas características geométricas, cilíndricas, esféricas, irregulares, compactadas ou na forma de pó, etc. A geometria de carregamento, ou o grau de simetria possível quanto à disposição das cargas na coquilha ou cadinho, os tipos de dispositivos de fusão, arco voltaico ou bobina de indução, e a geometria dos sistema de fusão, velocidades de agitação do banho, são outras variáveis que exercem influência nas propriedades microestruturais das ligas. Com relação à carga não se pode deixar de falar nas propriedades físicas e químicas de cada um de seus componentes, como pontos de fusão, temperaturas de formação de eutético, etc., que podem ser extraídos dos diagramas de fases, e compatibilidade química entre carregamento e demais materiais dos fornos de fusão que podem interagir com as mesmas.

No caso da solidificação, temos como parâmetros a geometria do sistema, que influi na homogeneidade de resfriamento e velocidades de remoção de calor das ligas, relacionadas ao equipamento. Com relação aos componentes da carga, temos a composição final, os pontos de fusão da liga (solução sólida), a tendência a formação de compostos, dadas pelo diagrama de fases, e demais propriedades físicas como condutividade térmica, etc. Em escala microscópica, os fenômenos de nucleação e crescimento, determinantes das dimensões e geometria "médias" dos grãos, o zonamento e a microssegregação, no caso de ligas binárias, além de fenômenos de super-resfriamento constitucional e o efeito das impurezas, deve ser levado em conta no modelo.

O que se quer obter a partir da análise destas duas etapas são algumas das características microestruturais das ligas, que podem ser observadas e avaliadas ao microscópio óptico. Um modelo de fusão e solidificação da carga de urânio e molibdênio deve ter como entradas os parâmetros acima, e como saídas possíveis o tamanho de grão resultante, a distribuição de concentrações de molibdênio na liga, que por conseguinte determina a quantidade das fases alfa e gama presentes ao final do processo, e a concentração e os tipos de defeitos estruturais.

A próxima etapa na fabricação das ligas é o tratamento térmico de homogeneização. Verificou-se experimentalmente a sua necessidade em ligas de fusão a arco, dada a sua usualmente alta inomogeneidade, mesmo após a realização de um número de refusões em conformidade ao que a literatura recomenda para estas ligas. Aqui os parâmetros temperatura e tempo são os principais, visto que atuam na ativação do fenômeno da interdifusão entre urânio e molibdênio pela liga, o que aumenta a 
homogeneidade de composição. Outras propriedades afetadas pelos parâmetros de tratamento são o tamanho de grão da amostra, a relação entre a quantidade de fases alfa e gama, e a concentração de defeitos pontuais, de discordâncias, etc. No primeiro caso, tratamentos térmicos a temperaturas abaixo do ponto de fusão favorecem o fenômeno de sinterização, um aumento no tamanho de grão por diminuição da energia de superfície, com conseqüente diminuição da quantidade de vazios e aumento em sua densidade. No segundo caso, promovendo-se a difusão dos componentes pela liga, diferenças de composição tendem a diminuir, aumentando-se a homogeneidade. No terceiro caso, sabendo-se que a movimentação dos defeitos é um fenômeno termicamente ativado, a concentração de cada um dos tipos de defeito varia com o andamento do tratamento.

Assim, como parâmetros de entrada na etapa de tratamento térmico, pode-se utilizar o tempo e a temperatura, dadas como condições operacionais, e os tamanhos de grão e composição da matriz, dadas como resultado da modelagem aplicada à solidificação, confirmadas por medidas experimentais, por exemplo, as obtidas via microscopia óptica. Como saída, o modelo deve fornecer os tamanhos de grão e a nova composição da matriz, em termos da relação entre as concentrações de fase alfa e gama e também em termos dos defeitos.

Uma cadeia de fenômenos mais complexa é encontrada nos tratamentos térmicos sob atmosfera de hidrogênio. O primeiro deles relaciona-se à transformação de fase $\gamma \rightarrow \alpha$. Estas reações levam obviamente a uma alteração na homogeneidade de composição da amostra, função do tempo de tratamento e do campo do diagrama de fases binários em que a liga está sendo tratada, ou seja, de sua temperatura e composição iniciais. Sendo uma transformação eutetóide, com a fase alfa como proeutetóide, ocorrendo em estado sólido, deve-se considerar em qual região da amostra há a deposição preferencial do precipitado. Ou seja, dadas as características da reação, devemos determinar se a precipitação é um fenômeno preferencialmente localizado no interior dos grãos ou entre os grãos. Estes precipitados, possuindo estrutura cristalina diferente da matriz, devem provocar deformações na liga, constituindo-se então em fontes de tensões internas. Estas podem originar possíveis locais de ruptura, fragilizando-a, o que facilita o processo de obtenção dos pós.

Além disso, deve-se determinar com qual velocidade a transformação ocorre. Já se dispõe na literatura de diversos diagramas tempo-temperatura-transformação (TTT), por meio dos quais pode ser determinado o tempo para a observação de alguma transformação detectável, esta sendo definida pela técnica experimental utilizada para a 
determinação dos diagramas. Entretanto, como as ligas deste trabalho foram preparadas por técnicas diferentes em poucos aspectos das produzidas em outros trabalhos, a análise deverá ser particularizada para este caso. A velocidade tem influência na absorção do hidrogênio pela amostra, pois a fase alfa formada tem grande afinidade pelo gás, e é regulada por processos de difusão no interior da liga. A formação do precipitado deve levar em conta também o efeito da alteração do perfil de concentração dos defeitos, que influenciam a mobilidade dos elementos e portanto a sua migração para a formação de núcleos das novas fases.

Outro fenômeno desta cadeia é o da adsorção de hidrogênio pela amostra. Sabe-se que a adsorção ou incorporação de hidrogênio por um metal é função de parâmetros de processo ou macroscópicos como tempo, temperatura e pressão, e dos microscópicos como o número de sítios de incorporação na superfície do material (adsorção) e em seu interior. No primeiro caso, o estado da superfície determina a facilidade pela qual será efetuado o transporte do hidrogênio ao interior do material, portanto a presença de óxidos deve ser levada em conta, caso não seja efetuado tratamento superficial prévio às análises. No segundo caso, se se considerar a solubilidade intersticial do hidrogênio na liga, deve-se levar em conta o efeito na incorporação de hidrogênio e parâmetros como o tamanho e o número dos sítios intersticiais tetraédricos e octaédricos, a concentração de cada um dos tipos de defeitos como as lacunas, discordâncias, contornos de grão e precipitados (como a fase alfa), como os mais importantes, dentre outros. Quando se considera isoladamente a interação do hidrogênio com a amostra via reação com a fase alfa, está-se estudando o processo de hidretação.

Assim, a modelagem dos fenômenos de adsorção/dessorção de hidrogênio pelas ligas via tratamento térmico sob atmosfera de hidrogênio deverá receber como entradas em termos de processo ou macroscópicos a composição média da liga, após solidificação ou tratamento térmico, tempo, temperatura, relação entre fases alfa e gama, quantidade de hidrogênio presente no sistema e pressão inicial de tratamento. Em termos microscópicos, concentração de defeitos e dimensões médias, tamanhos de intersticiais, perfis de concentração de molibdênio nos grãos, concentração de fase alfa nos contornos e dentro dos grãos, concentração e difusividades de hidrogênio e demais espécies químicas envolvidas. Como saídas, deveremos obter a quantidade de hidreto de fase alfa, um novo perfil de concentrações de molibdênio na liga, e também valores de propriedades mecânicas. Entretanto, como estamos estudando a fragmentação da liga, estes dados de saída deverão ser utilizados em conjunto com outros dados de entrada, relativos à etapa de 
formação do pó propriamente dita.

Ainda nos tratamentos sob hidrogênio, a etapa de dehidretação será levada em conta não somente como formadora de pós, mas como um indicativo de sua quantidade e características. Assim, as entradas seriam as temperaturas e tempos de dehidretação e quantidades de hidreto formado na hidretação, e como saídas ter-se-ía as quantidades de hidrogênio liberadas, e as dimensões finais das partículas. Como se deu ênfase ao fenômeno da incorporação do hidrogênio pelas ligas na fragmentação ou na obtenção de uma estrutura frágil, a modelagem da etapa de dehidretação será conduzida para fins de complementação do trabalho.

Para a formação do pó, o limite de ruptura das ligas durante e ao final do tratamento sob atmosfera de hidrogênio, dadas em função da quantidade de molibdênio, deverão ser comparadas com os limites de ruptura determinados experimentalmente ou constantes em literatura. Serão considerados como mecanismos de fragilização das ligas os chamados de fragilização interna por hidrogênio ("IHE - Internal Hydrogen Embrittlement") e o de decrepitação por hidretação e/ou dehidretação da fase alfa em contorno de grão, (HDH). Como entradas teremos as dimensões iniciais da rede, concentrações da fase alfa nos contornos e nos grãos, possível estado de tensões, e como saída a evolução do limite de ruptura em termos das condições de tratamento. Aqui será considerado também como entrada o valor da velocidade de resfriamento aplicado sobre as ligas ao final dos experimentos. Também será interessante a informação sobre os rendimentos teóricos na fragmentação, mais um dado de saída dependente das variáveis de processo, e que será equacionado adiante.

Obviamente que em todas as etapas as propriedades físicas das fases envolvidas estarão sendo continuamente monitoradas. Condições de equilíbrio termodinâmico serão dadas pelas equações de equilíbrio químico, importantes no caso em que reações químicas estejam envolvidas, térmico e mecânico, serão estabelecidas como condições de contorno para a resolução das equações. Nesta tese, não será considerada a estabilidade das partículas de pó sob irradiação, algo que será estudado em outra oportunidade.

\subsection{Enunciado do problema e modelos}

Assim, com base nos objetivos da tese e nas considerações anteriores, o problema a se resolvido pode ser enunciado da seguinte maneira: 
"Considere-se uma esfera de raio $r \gamma$, composta inteiramente por $\gamma$-UMo com porcentagem em peso $X$ de molibdênio, rodeada por casca esférica de raio ra composta por somente por $\alpha-U$, que por sua vez está envolta por casca esférica mais externa também de $\gamma$-UMo de raio R $\mathrm{\gamma}$ e de mesma composição que a região central. Sabendo que este sistema está imerso em atmosfera de hidrogênio a uma pressão inicial $P_{0}$, e sendo submetido a tratamentos isotérmicos a dados tempos te temperaturas $T$, após os quais é refrigerado a uma velocidade de resfriamento $V$, pede-se determinar, em função destes parâmetros, quais as condições em que a estabilidade mecânica das ligas é quebrada", ou seja, "quais as condições necessárias para a obtenção de uma estrutura $\gamma$-UMo frágil a partir de uma inicialmente dúctil".

Para a resolução do problema deve-se definir a geometria sobre a qual as equações serão resolvidas. Em escala microscópica de análise dos fenômenos, que será adotada como primeira e mais elementar abordagem, será determinada a evolução da resistência mecânica da liga com as condições de tratamento. Aqui será adotada como geometria a circular ou esférica para a resolução, dada a sua simetria. Geometria semelhante foi amplamente utilizada no estudo da estabilidade de ligas de $\gamma$-UMo sob irradiação $^{37,40,41,42}$. Se se considerar os grãos com formato hexagonal, é de se esperar, na situação mais simétrica possível, que cada um deles seja rodeado por 6 outros grãos. Assim, pode-se considerar, pelas características estruturais dos materiais metálicos, que um dado grão está rodeado por grãos que se distribuem ao seu redor circularmente, se analisarmos o fenômeno no plano, ou esfericamente, se no espaço. Este grão tornar-se-á, após o final do processo, uma partícula de pó. A superfície que separa a partícula central das que estão ao seu redor será considerada como a região de precipitação (intergranular), e portanto deve-se considerar o crescimento desta camada como originário do fluxo de material proveniente do grão central e dos adjacentes, fluxo este medido com respeito à direção radial.

Deve-se frisar que serão considerados dois como os mecanismos principais de fragilização da estrutura, a saber a IHE e HDH, ambos sendo analisados simultaneamente. A estratégia básica utilizada será a de se resolver, em cada uma das 3 regiões consideradas, a equação da continuidade, na busca por gradientes de tensão provocados por distorções volumétricas no modelo da esfera. Estes gradientes serão determinados como função de condições iniciais como a pressão inicial de hidrogênio, temperatura, e porcentagem de molibdênio na liga, concentração de defeitos em equilíbrio, diâmetro dos grãos antes dos 
tratamentos térmicos, parâmetros de fusão, etc. Por meio da construção de curvas teóricas de absorção ou "pick-up" de hidrogênio em função do tempo pretende-se validar os resultados experimentais por meio de comparação. Deseja-se assim obter a evolução do comportamento mecânico da amostra ao longo do tempo, o que interessa em termos de processamento das ligas.

Está-se interessado, principalmente, na obtenção das taxas de nucleação da fase alfa, pois ela nos fornece um indicativo de como se processa a incorporação. Partindo-se do fato de que ela tem grande afinidade pelo hidrogênio, é de se esperar que nas temperaturas próximas à eutetóide, na qual a taxa de decomposição $\gamma \rightarrow \alpha$ é máxima e a precipitação ocorre predominantemente nos contornos de grão, haja alguma mudança nos mecanismos de incorporação de hidrogênio pela amostra.

Em escala maior, para a obtenção dos rendimentos em fragmentação, será adotada a geometria de uma placa plana, semelhante à das amostras estudadas. Perfis de concentração de hidrogênio e sua evolução temporal nas placas deverão ser determinados, bem como os perfis de temperatura. No caso dos ensaios sob pressão, as curvas de queda de pressão em função do tempo deverão ser transformadas em curvas de ganho de massa, com conseqüente determinação dos perfis de concentração. Aqui, pode ser necessária a construção de um perfil de tensões ou deformações como condição inicial do problema, cuja evolução determina a maior ou menor quantidade de fragmentação. As hipóteses básicas de construção de ambos os modelos serão dadas na parte IV, bem como as definições e justificativas de uso de condições iniciais e de fronteira, etc.

Resumidamente teremos, para a construção do modelo, que os parâmetros principais a serem analisados serão:

composição inicial da liga: indicativo da quantidade inicial de fase alfa presente na amostra, é uma das condições iniciais do problema;

velocidade de decomposição $\gamma \rightarrow \alpha$ : será utilizada de duas maneiras. Na primeira, dados existentes na literatura serão obtidos diretamente dos diagramas TTT e inseridos no programa, como condição de contorno. Para melhor ajuste das curvas teóricas aos dados, serão testados diversos valores ou mecanismos;

pressão inicial: como a concentração de um gás em um sólido é proporcional à raiz quadrada da pressão, é de se esperar que uma maior quantidade esteja presente dissolvida 
na liga, tanto intersticialmente quanto nos precipitados, com o aumento da pressão. Assim, ela será levada em conta como condição inicial do problema;

temperatura e tempo: duas das condições iniciais. A primeira, juntamente com a composição, nos dá a localização do experimento no diagrama de fases, e a segunda, juntamente com a temperatura, nos diagramas TTT.

concentração de defeitos: tem grande influência na difusividade do hidrogênio pela liga, pois sabe-se que os defeitos atuam como zonas de potencial armazenamento de hidrogênio molecular, inibindo o processo de transporte de massa pelo interior do metal;

taxa de crescimento dos grãos: sabe-se que, quanto menor o diâmetro dos grãos, maior é a área de superfície interna na amostra disponível para a formação de precipitados de fase alfa. Assim, tratamentos térmicos prolongados a altas temperaturas podem atuar na inibição da incorporação de hidrogênio pela amostra por hidretação;

condições de fusão e tratamentos térmicos: serão utilizadas as teorias de nucleação e crescimento para a previsão das microestruturas, que serão utilizadas também como condições iniciais em nosso modelo.

As equações de equilíbrio mecânico para a amostra deverão ser resolvidas, tendo-se estes como parâmetros mínimos. Como saída, o programa deverá oferecer os valores de tempo, temperatura, pressão, para cada uma das composições, para que haja ruptura das ligas. 
QUARTA PARTE

RESULTADOS E DISCUSSÕES 


\section{SÍNTESE E CARACTERIZAÇÃO}

\subsection{Ligas produzidas por fusão a arco}

Serão apresentados os resultados dos ensaios de caracterização das ligas produzidas por forno a arco. Inicialmente será feito um comparativo entre os resultados de densidades das ligas produzidas com as diversas cargas de molibdênio, e discutidos os problemas de homogeneidade, refusões, e outros relacionados.

Em seguida, os espectros de difração de raios-X, juntamente com a análise por microscopias óptica e eletrônica de varredura com EDS, serão apresentados, quando realizados, para cada uma das ligas. As variações nas dimensões dos grãos quando da realização dos tratamentos térmicos serão discutidas para cada liga individualmente. Ao final do capítulo será destacada sua importância na obtenção de partículas com tamanho próximo ao especificado, caso se deseje partir para a produção de pós via hidretação.

\subsubsection{Densidades}

Uma das maneiras encontradas para a verificação da qualidade das ligas foi pela determinação de suas densidades. É de se esperar que um teor maior de molibdênio adicionado às amostras diminua progressivamente o valor de densidade, relativamente ao apresentado pela fase gama, aqui considerado como o teórico, de $18,06 \mathrm{~g} / \mathrm{cm}^{3}$, conforme Rough e Bauer ${ }^{4}$. Este foi tomado sobre uma amostra de gama-U puro, a $805^{\circ} \mathrm{C}$. Densidades específicas de molibdênio e silício são, respectivamente, $10,2 \mathrm{~g} / \mathrm{cm}^{3}$ e $2 \mathrm{~g} / \mathrm{cm}^{3}$, conforme Perry e Green ${ }^{55}$.

O método utilizado para a determinação das densidades foi o hidrostático. Das 13 amostras preparadas, foram tomadas as densidades de 9 delas. A amostra U6Mo foi enviada diretamente para corte e hidretação, a amostra U7Mo para embutimento e análise por microscopia óptica, a amostra U10Mo foi cortada para tratamentos térmicos e exame em microscópio óptico e de varredura. Em todas as situações, limitações de tempo de uso dos microscópios dentro e fora das instalações do CCN-IPEN levaram ao preparo urgente das mesmas. O problema com a amostra UMo4 foi a sua alta irregularidade e elevado grau de aderência à matriz de cobre (vide p. 160). Mesmo assim, medidas de densidade foram tomadas, bem como os exames metalográfico e de difração de raios-X. 
Entretanto, os valores apresentados na Tabela 08 contêm também o destas amostras (em itálico), como estimativas baseadas em sua geometria, integridade (ausência de irregularidades, como porosidades fechadas, etc. e nos valores apresentados por amostras com composição equivalente.

TABELA 08 - Valores de densidade hidrostática determinadas, ligas $\gamma \mathrm{UMo}$, forno a arco.

\begin{tabular}{|c|c|c|c|}
\hline código liga & \% Mo & $\begin{array}{c}\text { densidade } \\
\text { hidrostática } \\
\left(\mathrm{g} / \mathrm{cm}^{3}\right)\end{array}$ & $\begin{array}{c}\text { \% densidade } \\
\text { teórica } \\
(\gamma \mathrm{U})\end{array}$ \\
\hline U6Mo & 6 & 16 & 84,9 \\
\hline UA1 & 4 & 13,13 & 69,7 \\
\hline UA6 & 9 & 17,32 & 91,9 \\
\hline UA9 & 8 & 15,24 & 80,9 \\
\hline UA8 & 7 & 17,06 & 90,6 \\
\hline U7Mo & 5 & 17,67 & 92,9 \\
\hline UA7 & 10 & 18,00 & 92,8 \\
\hline UMo3A & 10 & 16,45 & 86,8 \\
\hline UMo4 & 8,5 & 15 & 79,6 \\
\hline U10Mo & 4 & 17,39 & 60,5 \\
\hline UA3 & $7(3,5 \mathrm{Si}: 3,5 \mathrm{Mo})$ & 14,33 & 76,1 \\
\hline UA5 & & & 92,3 \\
\hline UA10 & & 15 & \\
\hline
\end{tabular}

Aqui não se está calculando o valor de densidade teórica considerando as respectivas porcentagens de Mo. Ou seja, átomos substitucionais em posições da rede cúbica de corpo centrado alteram o parâmetro de rede cristalina da estrutura gama, conforme veremos nos difratogramas de raios-X adiante. Isto altera o volume da célula unitária e, portanto, a sua densidade, face à de gama-U puro. $\mathrm{O}$ valor tomado como base é o da densidade do gama-U à $25^{\circ} \mathrm{C}$, igual a $18,84 \mathrm{~g} / \mathrm{cm}^{3}$.

Para fins de comparação, os valores calculados de densidade de algumas ligas de UMo foram relacionados na Tabela 09, extraídos da Tabela 01 da introdução. Estes foram também colocados em gráfico, na Figura 17. Serão assumidos como valores teóricos de densidade da fase gama-U. 
TABELA 09- Valores calculados de densidade de algumas ligas UMo, base alfa-U ${ }^{56}$.

\begin{tabular}{|c|c|c|}
\hline Liga \% & Densidade $\left(\mathrm{g} / \mathrm{cm}^{3}\right)$ & Densidade $\mathrm{U}\left(\mathrm{g} / \mathrm{cm}^{3}\right)$ \\
\hline \hline $\mathrm{U}$ & 19,0 & 19,0 \\
\hline $\mathrm{U}-2 \mathrm{Mo}$ & 18,5 & 18,1 \\
\hline $\mathrm{U}-5 \mathrm{Mo}$ & 17,9 & 17,0 \\
\hline $\mathrm{U}-6,5 \mathrm{Mo}$ & 17,5 & 16,4 \\
\hline $\mathrm{U}-8 \mathrm{Mo}$ & 17,3 & 15,9 \\
\hline $\mathrm{U}-9 \mathrm{Mo}$ & 17,0 & 15,5 \\
\hline
\end{tabular}

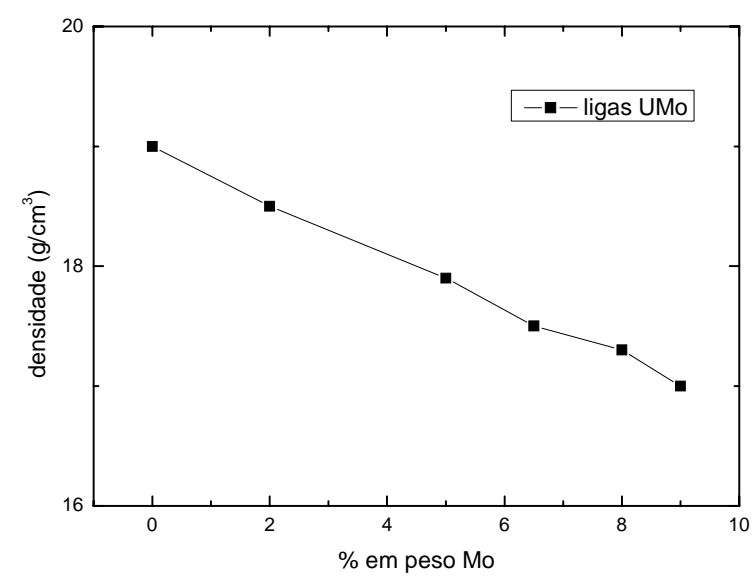

FIGURA 13 - Densidades em função da \% em peso de Mo, base alfa-U $\mathrm{U}^{03}$.

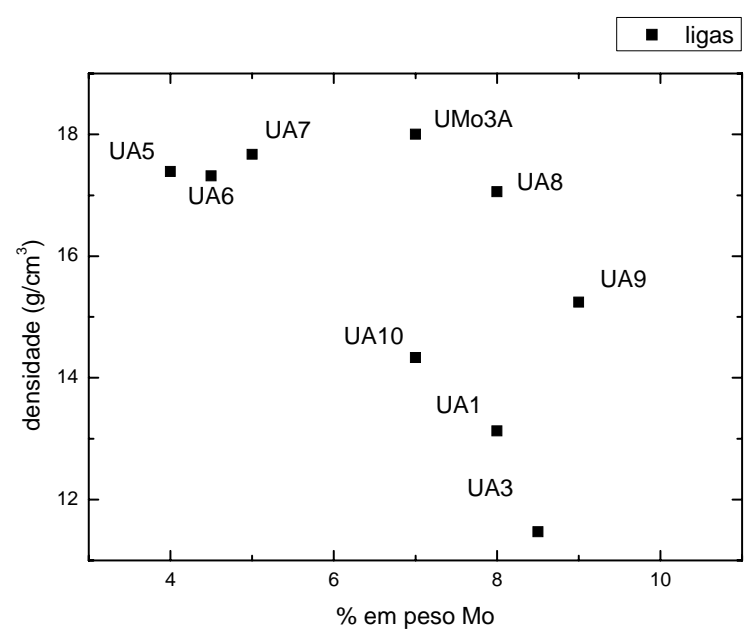

FIGURA 14 - Densidades em função da \% em peso de Mo, ligas de fusão a arco. 
Da Figura 13 e Tabela 8, conclui-se que a tendência é a de que a densidade das ligas decresça com o aumento da quantidade de molibdênio em sua composição, o que é óbvio, pois está-se substituindo átomos de urânio, mais pesados, por átomos de molibdênio, mais leves. Portanto, o comportamento das ligas quanto à densidade é coerente, conforme pode ser observado na Figura 14.

Numa primeira análise, esta queda experimental não obedece à linearidade apresentada pela curva da Figura 13, com os valores caindo bruscamente com o aumento do teor de molibdênio. Como os experimentos de fusão foram realizados em diferentes condições, analisemos os mesmos conforme os efeitos das principais variáveis consideradas. Os valores entre parênteses ao lado do código da liga indicam a sua composição em Mo.

Ligas produzidas sem refusão, a saber, UA5 (U4Mo), UA6 (U4.5Mo), UMo3A (U7Mo) e UA3 (U8.5Mo), apresentaram comportamento irregular. Uma queda comparável à apresentada na Figura 13 ocorre somente nas 2 primeiras composições. A densidade aumenta no valor de 7\%, para depois cair bruscamente quando a composição é de 8,5\%. Notando que ambas as composições de 4 e 4,5\% foram formuladas com diferentes tipos de carga, tabletes e pós, enquanto que a de 7\% utilizou-se de cilindros 3x3 de Mo, e a composição de $8,5 \%$, pó, a diferença nas características da carga de Mo pode explicar esta irregularidade.

Assim, foi observado anteriormente que ligas preparadas com cilindros $3 \times 3$ fundiram mais facilmente, não havendo, ao menos visualmente, indícios de segregação. Amostras contendo pó compactado de Mo tendem a se comportar melhor sob fusão que amostras preparadas com Mo em pó. É de se esperar, portanto, que a liga com composição de $8,5 \%$ se apresente mais segregada e, portanto, menos homogênea, com valores de densidade se afastando muito dos previstos teoricamente. Obviamente que a presença de cavidades internas às amostras pode ter influência nestas determinações.

Quantidades de pó diferentes (UA6 e UA3) de Mo homogeneízam-se em urânio líquido da mesma maneira. Entretanto, o tempo para que haja total difusão dos átomos das partículas na rede de urânio é limitado ao tempo pelo qual o arco é aplicado à amostra, que por sua vez é limitado pela necessidade de manutenção da integridade física do equipamento e operador durante a operação. Assim, há a necessidade de refusões, quando do trabalho com o pó, a partir de uma determinada \% de Mo na carga, que estimo deva se encontrar ao redor de $5 \%$. 
Conforme será visto adiante, o valor de densidade da amostra UMo3A foi o que mais se aproximou dos valores de densidade de amostras na mesma composição, fundidas por indução. Além disso, das amostras produzidas a arco, foi a que apresentou também o maior valor de densidade, o que indica que o uso deste tipo de carga torne desnecessária a realização de refusões.

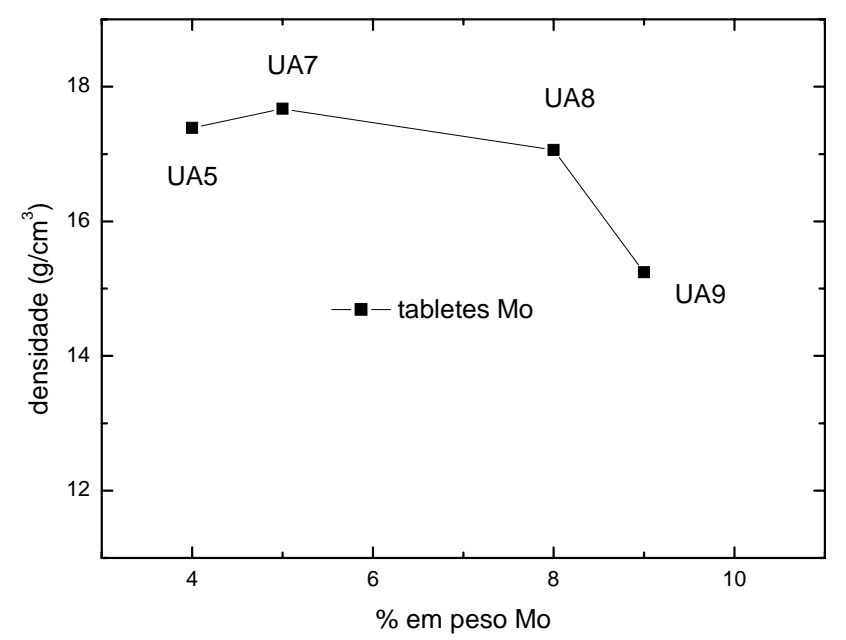

FIGURA 15 - Densidades, carga de Mo em tabletes.

Ao considerarmos cargas preparadas com os tabletes, a saber, UA5 (U4Mo), UA7 (U5Mo), UA8 (U8Mo) e UA9 (U9Mo), verificou-se, independentemente do número de refusões, um comportamento semelhante ao observado pelas amostras de indução (vide p. 173). Com boa aproximação, e talvez devido à diferença de homogeneidades das ligas UA5 e UA7, pode-se considerar ambos os valores iguais, caindo levemente em UA8 e bruscamente em UA9. Era de se esperar também uma queda entre UA5 e UA7, mas devese notar que a primeira não foi refundida, enquanto a segunda foi refundida duas vezes. Ainda, a queda brusca em densidade de UA8 para UA9 pode ser devida à formação de fases oriundas de inomogeneidades na composição desta última, pelas mesmas razões expostas quando dos comentários sobre homogeneidade de pós e tempos de difusão. Assim, localmente em UA9, pode-se ter a ocorrência de composições hipereutetóides, com a formação de $\mathrm{U}_{2} \mathrm{Mo}$, composto com densidade de $16,63 \mathrm{~g} / \mathrm{cm}^{3}$, mais baixa que a dos compostos de urânio aqui estudados. Entretanto, o número elevado de vezes que esta amostra foi fundida minimiza este problema. Verificar-se-á estes fatos nas análises por microscopia e pelos espectros de difração de raios-X. 
A influência da carga também é percebida quando da análise de amostras com aproximadamente a mesma composição, UA8 (U8Mo), UA1 (U8Mo) e UA3 (U8.5Mo), Figura 16. O trabalho com pós compactados e 2 refusões (UA8) apresentou melhores resultados do que o trabalho com cilindros $8 \times 5$ (UA1), onde houve a necessidade de 3 refusões para homogeneização, ao menos visual, completa. Ambos os resultados foram melhores com relação a UA3.

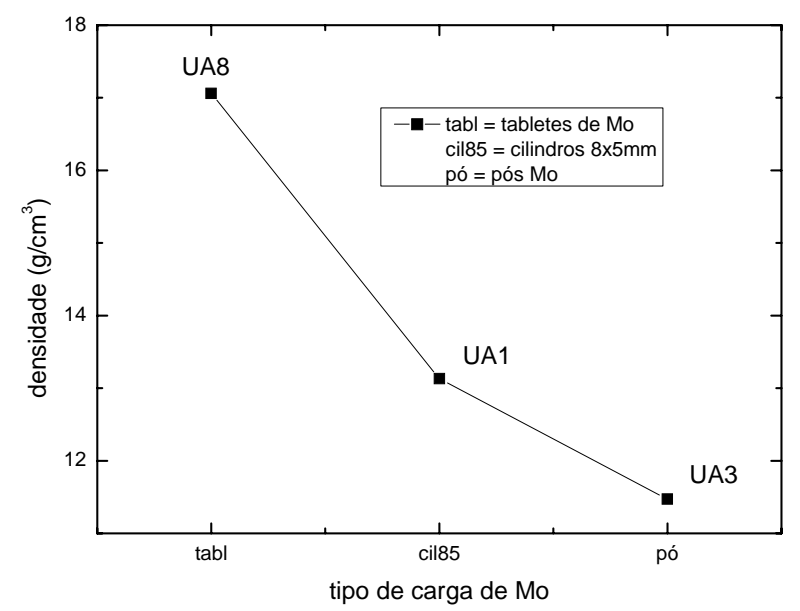

FIGURA 16 - Densidades, $8 \%$ Mo, cargas variadas.

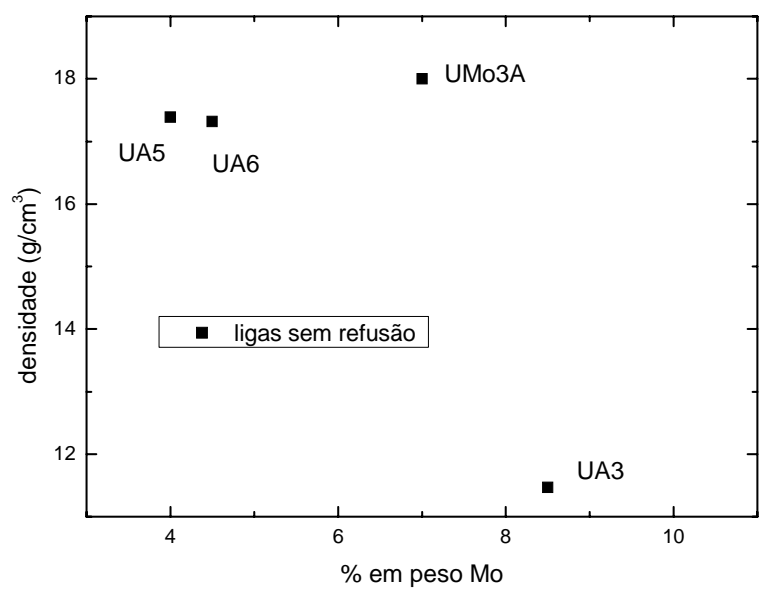

FIGURA 17 - Densidades, amostras sem refusão.

Não foram efetuadas refusões em amostras carregadas com pó de Mo. Os dados da Figura 17 reforçam a necessidade de se adotar este procedimento, quando do trabalho com este tipo de carga. 
Finalmente, em termos de refusões, mostra-se que o comportamento da densidade foi o esperado, à exceção do que ocorreu com o material UA1, preparado com cargas cilíndricas $8 \mathrm{~mm} \times 5 \mathrm{~mm}$ de Mo.

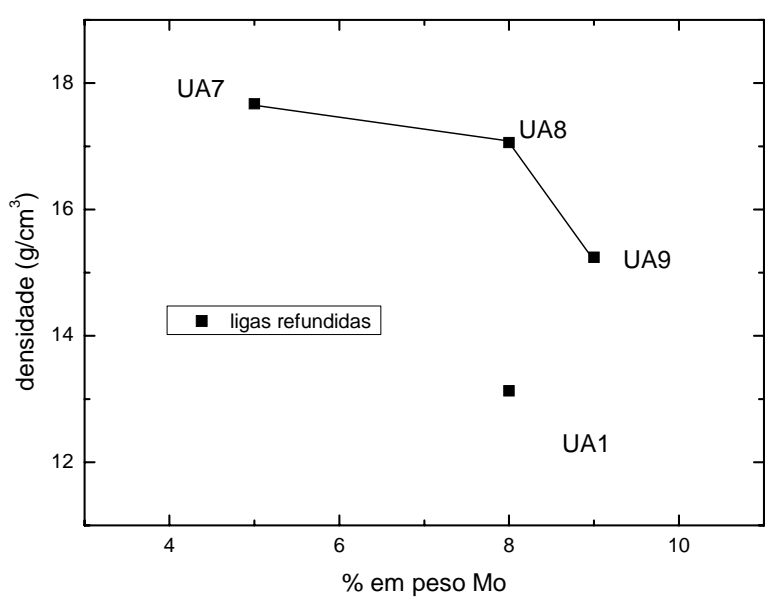

FIGURA 18 - Densidades, amostras refundidas.

Deve-se analisar a amostra UA10 em separado como caso especial, pois é uma liga $\mathrm{U} 7(\mathrm{Mo}+\mathrm{Si})$. A densidade da liga UA10 foi menor que o de uma liga contendo $7 \% \mathrm{Mo}$ total, o que pode indicar, conforme será visto adiante, a formação de compostos de U-Si, como o $\mathrm{U}_{3} \mathrm{Si}_{2}$, de densidade igual a $12,2 \mathrm{~g} / \mathrm{cm}^{3}$, em uma matriz contendo gama-U, com densidade da ordem de 16 a $18 \mathrm{~g} / \mathrm{cm}^{3}$, valores esperados para as composições estudadas, conforme visto na Tabela 9, p.141.

\subsubsection{Caracterização microestrutural}

Análises de difração de raios- $\mathrm{X}$ foram feitas em equipamento do IPEN, escolhendo-se uma faixa angular de $0^{\circ}$ a $90^{\circ}$, velocidade angular da varredura de $2^{\circ} / \mathrm{min}$., com feixe de raios- $\mathrm{X}$ de $40 \mathrm{kV}$, corrente de $20 \mathrm{~mA}$, comprimento de onda do cobre $\mathrm{K} \alpha=$ 1,54Å. As análises em microscópio eletrônico de varredura foram efetuadas conforme condições apresentadas nas micrografias, e as de microscopia óptica foram utilizadas, quando foi o caso, com analisador de imagens para a determinação, principalmente, de distribuição de tamanho de grão e porcentagem de fases. 


\subsubsection{1 liga código UA1}

Produzida com $8 \% \mathrm{Mo}$, é de se esperar boa retenção de fase gama, mesmo com resfriamento em forno. O trabalho de Bar-Or e Goldstein ${ }^{8}$ mostra que, nesta porcentagem de molibdênio, a energia de ativação para a formação da fase alfa-U é menor que a da fase delta-U, o que é de se esperar dado que estamos trabalhando com composições hipoeutetóides. Assim, espera-se a presença de precipitação de alfa primária, ao invés de co-precipitação, conforme Van Thyne et al. ${ }^{7}$. Obviamente que estes estudos de decomposição são realizados em patamares de temperatura, por tempos prolongados, havendo então condições favoráveis à decomposição de gama.

Nos experimentos de fusão a arco, os resfriamentos foram realizados no próprio forno, submetendo-se as amostras a fluxo de Ar em sua parte superior, e na parte inferior, em contato com a base de cobre, a fluxo constante de água a $20^{\circ} \mathrm{C}$. Como o gás é um mau condutor de calor, espera-se que o resfriamento se dê mais lentamente que o esperado por têmperas direta em água ou óleo. Como a base está sendo constantemente refrigerada, espera-se que haja, portanto, um gradiente de velocidades de resfriamento e, portanto, de tensões, ao longo da amostra. Esta diferença, aliada à geometria da carga de Mo utilizada para a produção da amostra UA1, levaram à formação das estruturas observadas no difratograma apresentado na Figura 19.

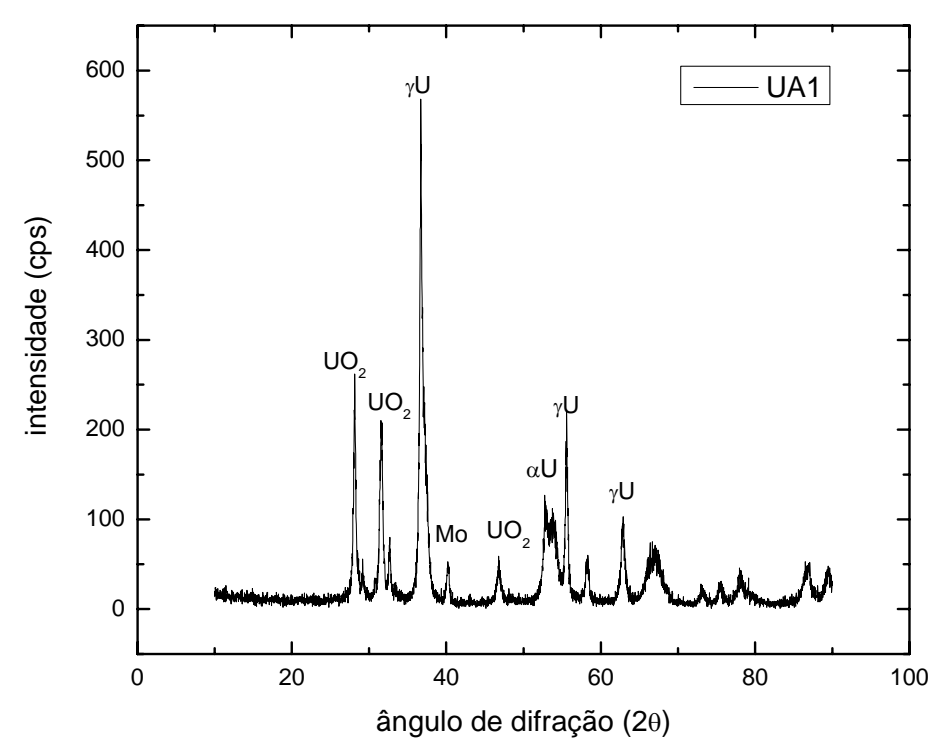

FIGURA 19 - Espectro de difração de raios-X, amostra UA1. 
Esta liga apresentou problemas de homogeneidade muito grandes. Em aumento de 400X observou-se a presença de 3 regiões distintas na amostra, o que indica que, mesmo com a aplicação de 3 refusões, não se conseguiu homogeneizar as cargas de urânio e de molibdênio. A primeira das regiões tem a estrutura comumente apresentada por todas as ligas aqui desenvolvidas, sendo mais clara, rica em urânio, e onde, em aumento de $600 \mathrm{X}$, podem ser identificadas fases dendríticas. A fase pobre em urânio, portanto rica em Mo, apresenta-se com coloração escura e contém algumas dendritas, embora em muito menor número. Finalmente, uma fase intermediária, com coloração acinzentada, indicando que o processo de interdifusão Mo-U se deu nesta interface, mas não se completou. Inferese então que esta tenha composição intermediária entre as apresentadas pelas fases ricas e pobres em urânio. Por problemas técnicos não foram tomadas imagens destas estruturas.

Outra observação importante é a de que a fase rica em urânio concentrou-se na parte inferior da amostra. Isto indica que, numa primeira fusão, a temperatura foi tal que todo o urânio tornou-se líquido, depositando-se no fundo da coquilha, enquanto o molibdênio fundiu-se apenas parcialmente, cobrindo após o resfriamento a camada de urânio. Após o primeiro tombamento da amostra e nova fusão, o arco em contato direto com o urânio o fundiu rapidamente. Entretanto, creio que novamente a temperatura ou o tempo de aplicação do arco não tenha sido suficiente para a fusão completa e mistura de ambos os materiais, o fenômeno novamente se repetiu. Após mais 3 refusões, o calor produzido foi suficiente somente para aumentar o tamanho da região de interação entre as amostras, mas não para a produção de uma liga homogênea. Daí a obtenção de um valor de densidade baixo e de um espectro de difração mostrando a presença de picos extras acentuados, analisados no parágrafo seguinte, diferentes de gama-U.

Observa-se na Figura 19 que, juntamente com os picos de gama-U mais intensos, aparecem os picos das fases alfa, próximos aos de gama mais intenso, a 36, $6^{\circ}$, mas também picos de Mo, mais intenso a $40^{\circ}$, e os de óxidos de urânio $\mathrm{UO}_{2.34}$, com picos a $28^{\circ}, 33^{\circ}$ e $47^{\circ}$ mais intensos. Picos de $\mathrm{U}_{2}$ Mo podem também estar presentes, pois há contagens em ângulos de $27^{\circ}, 38^{\circ}$ e $53^{\circ}$, mais intensos para esta fase. De qualquer forma, a difração de raios-X mostrou que mesmo com 3 refusões, o tipo de carga utilizada não permitiu a homogeneização correta do material. Além disso, alguma formação de óxido foi favorecida, dada a exposição repetida da amostra ao ar entre as refusões. Entretanto, fase gama foi formada em boa quantidade, como mostra a elevada intensidade na contagem de seu pico máximo, mas a presença de outras fases indica que mais algumas refusões seriam necessárias para que toda a amostra se homogeneizasse por completo. 
Como por meio desta liga teve-se o primeiro contato com a técnica de fusão por forno a arco, algumas de suas limitações, como o aquecimento da câmara externa quando se expõe a liga a tempos longos sob o arco. Tempos curtos e cargas em forma não convenientes, levam à má qualidade do produto. Assim, o tipo de carga de soluto mostra-se importante, pois evita tempos longos, a amostra homogeneíza-se mais facilmente.

Mesmo com a aplicação de várias refusões, não se conseguiu uma boa qualidade para a amostra. Assim, a realização de tratamentos térmicos de homogeneização, neste caso, é inócua, pois a amostra encontrou-se muito segregada, embora picos de gama$\mathrm{U}$ estejam presentes.

\subsubsection{2 liga código UA6}

Produzida com 4,5\% em peso de molibdênio, carga de molibdênio em pó, apresentou maior facilidade na dispersão pelo urânio metálico fundido. Não necessariamente isto indica que a solubilização seja mais fácil, dado que pequenas camadas de óxido podem envolver as partículas de molibdênio, dificultando a fusão.

Para esta quantidade de Mo, Van Thyne ${ }^{7}$ observa decomposição significativa de gama em alfa mais gama rica em Mo somente após 0,25 horas a $500^{\circ} \mathrm{C}$, principalmente intergranular, indicando nucleação heterogênea, resfriamento rápido. Somente após 5 horas toda a matriz está tomada, gama sendo identificada apenas por difração de raios-X.

Como foi pequena a quantidade de amostra enviada para a análise (aproximadamente 1,5g), o número de contagens foi baixo. Uma análise do espectro indica a presença de regiões com grande concentração de alfa-U, a presença de picos de gama-U em quantidade razoável, seguida de uma muito pequena quantidade de picos de molibdênio livre e óxido de urânio. De maneira geral, o espectro indica a óbvia necessidade de homogeneização na composição.

Os picos da fase alfa ortorrômbica são bem evidentes (Figura 20), especialmente os mais intensos a $35^{\circ}, 35,6^{\circ}, 36,9^{\circ}, 39,5^{\circ}, 51^{\circ}$ e $60,3^{\circ}$. O pico a $65^{\circ}$ indica a presença da fase gama-U, posto que os demais, mais intensos, de $36,6^{\circ}$ e $52,6^{\circ}$ podem estar misturados com os da fase alfa. Esta grande quantidade de fase alfa pode ser explicada se se levar em conta que houve grande perda de molibdênio quando da aplicação do arco sobre a amostra. Com pouco molibdênio fica mais difícil reter a fase gama sob resfriamento, o que leva à decomposição em alfa, proeutetóide, e delta. Ainda, deve-se levar em conta que, se após a perda de material se obtiver quantidade menor que 3\% em peso de molibdênio, durante o resfriamento a partir da região de gama puro a amostra 
deve, antes de passar pelo campo de alfa mais gama, passar pelo de beta mais gama. Há assim dois estágios na decomposição da liga, a saber: $\gamma \rightarrow \beta+\gamma$, e $\beta \rightarrow \alpha+\gamma$.

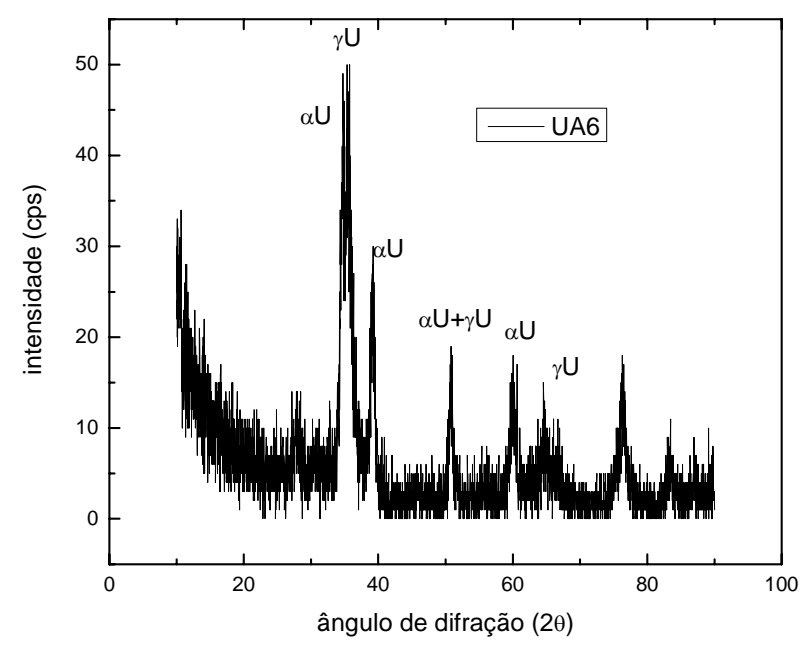

FIGURA 20 - Espectro de difração de raios-X, amostra UA6.

Num exame ao microscópio óptico simples, conforme Figura 21, a amostra UA6 apresentou-se bem homogênea, havendo a presença de estruturas semelhantes a dendritas, mas em número reduzido. Em aumento de $20 \mathrm{X}$, verifica-se a presença de fases em forma de cruz, que podem ser associadas à reação de decomposição da fase gama na intersecção entre 4 contornos de grão, formação de fase primária ou proeutetóide alfa. Um exame mais detalhado mostra que é na confluência de 3 ou mais grãos a formação de fases de decomposição é preferencial.
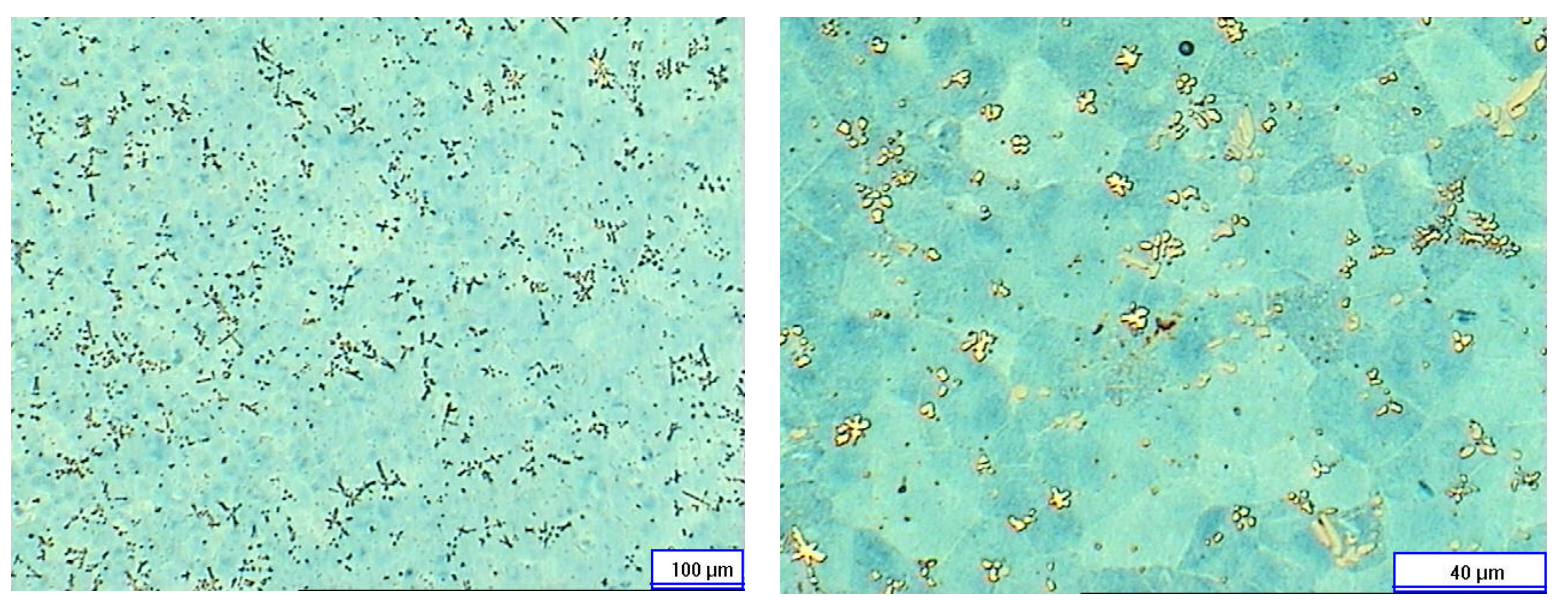

FIGURA 21 - Micrografias, liga UA6, esquerda (400X), direita (800X). 
Em aumento de 100X, observa-se presença de muitos pontos pequenos recobrindo toda a matriz, indicando haver nucleação de fase alfa intragranular, confirmando alguns resultados Saller et al. ${ }^{5}$. O baixo teor de Mo implica na presença da grande quantidade de fase alfa, conforme indicado pelo espectro de difração de raios-X, pois quanto menor o teor, menor a capacidade de se reter gama-U.

Assim, a aplicação de um número elevado de refusões não implica na obtenção de fase gama-U pura. Além disso, a presença de grande quantidade de alfa intragranular implica em velocidade de resfriamento não compatível com teor de molibdênio presente. Sugere-se assim que em teores de Mo mais baixos a liga deva ser resfriada mais rapidamente, para que fases de decomposição, de interesse no processo de obtenção de pós por meio da hidretação, sejam nucleadas apenas nos contornos de grão.

\subsubsection{3 liga código UA9}

Produzida com $9 \%$ de molibdênio em tabletes, a densidade de $15,24 \mathrm{~g} / \mathrm{cm}^{3}$ obtida após 5 refusões foi compatível com os valores apresentados pelas ligas produzidas via forno de indução, com a mesma porcentagem.

Observação em microscópio óptico comum (Figura 22) revelou a presença de dendritas na parte superior da amostra, homogeneidade aumentando com a proximidade da amostra à base, novamente indicando diferenças consideráveis para a velocidade de resfriamento ao longo da amostra. Mesmo assim, face às demais, a homogeneidade pode ser considerada boa, e o que contribui para isto foi o elevado número de refusões. Identificou-se também a presença de uma porosidade grande em sua parte superior, e que certamente contribuiu para a diminuição em sua densidade, pois é uma estrutura fechada (porosidade fechada).

Houve também dificuldade na diferenciação dos contornos de grão, fenômeno este comum em amostras contendo de 9 a 10\% de Mo. Conforme será visto adiante, somente em condições especiais esta diferenciação é conseguida, principalmente após tratamentos térmicos.

No espectro de difração de raios-X verificou-se a presença de fase gama preferencialmente, e alguns picos referentes a óxido em $28^{\circ}$ e $33^{\circ}$, associados à oxidação de fase alfa durante o processo de preparo das amostras. Observo que neste caso a fusão produziu fase gama estável, amostra homogênea quanto à composição, picos de gama foram bem evidentes em relação aos demais, comparáveis aos das ligas de indução. 


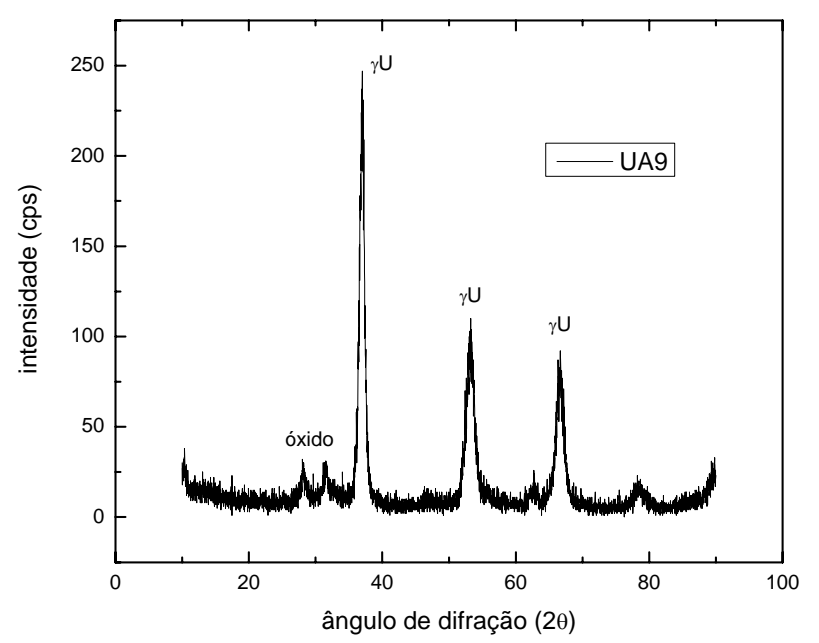

FIGURA 22 - Espectro de difração de raios-X, amostra UA9.
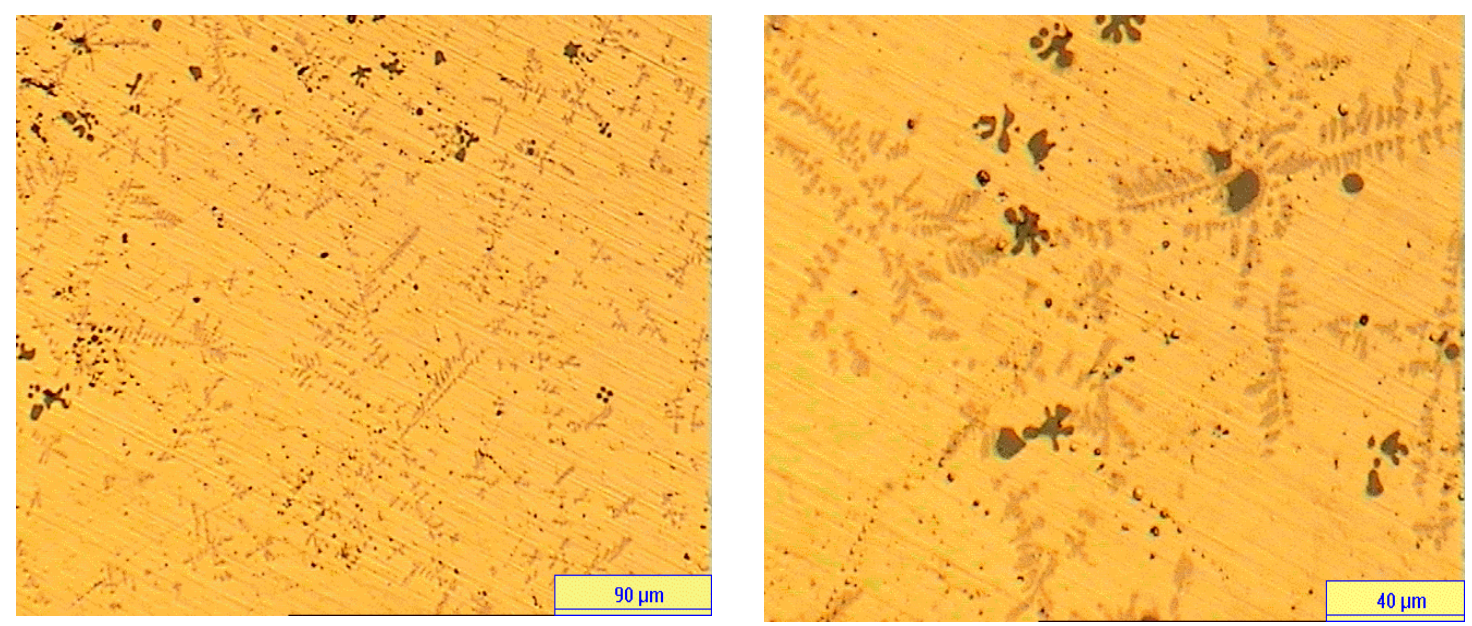

FIGURA 23 - Micrografias, liga UA9 400X (esquerda) e 800X (direita).

\subsubsection{4 liga código UA8}

Submetida a 2 refusões, contendo $8 \%$ em peso de molibdênio, forma de tabletes, valor de densidade semelhante ao das amostras de indução. Em microscópio óptico comum observa-se um aumento no número de dendritas na arte superior da amostra, parte em contato com o gás da câmara, material menos homogêneo, estruturas em forma de cruz e dendritas presentes. $\mathrm{Na}$ parte inferior, em contato com a base, material mais homogêneo. Pode ser identificada, de forma tênue, uma interface entre as duas regiões.

Observou-se a presença de uma miríade de dendritas, como as da amostra UA6. Em aumentos maiores verificou-se que estas estruturas apareceram bem concentradas nos contornos de grão, havendo ainda estruturas mais claras, provavelmente 
gama com pouco molibdênio, e os pontos pretos, distribuídos de maneira difusa por toda a amostra. Em aumentos maiores verificou-se a homogeneidade da distribuição de todas estas estruturas ao longo da peça que, ao contrário do observado na amostra UA6, possuíam estrutura dendrítica.
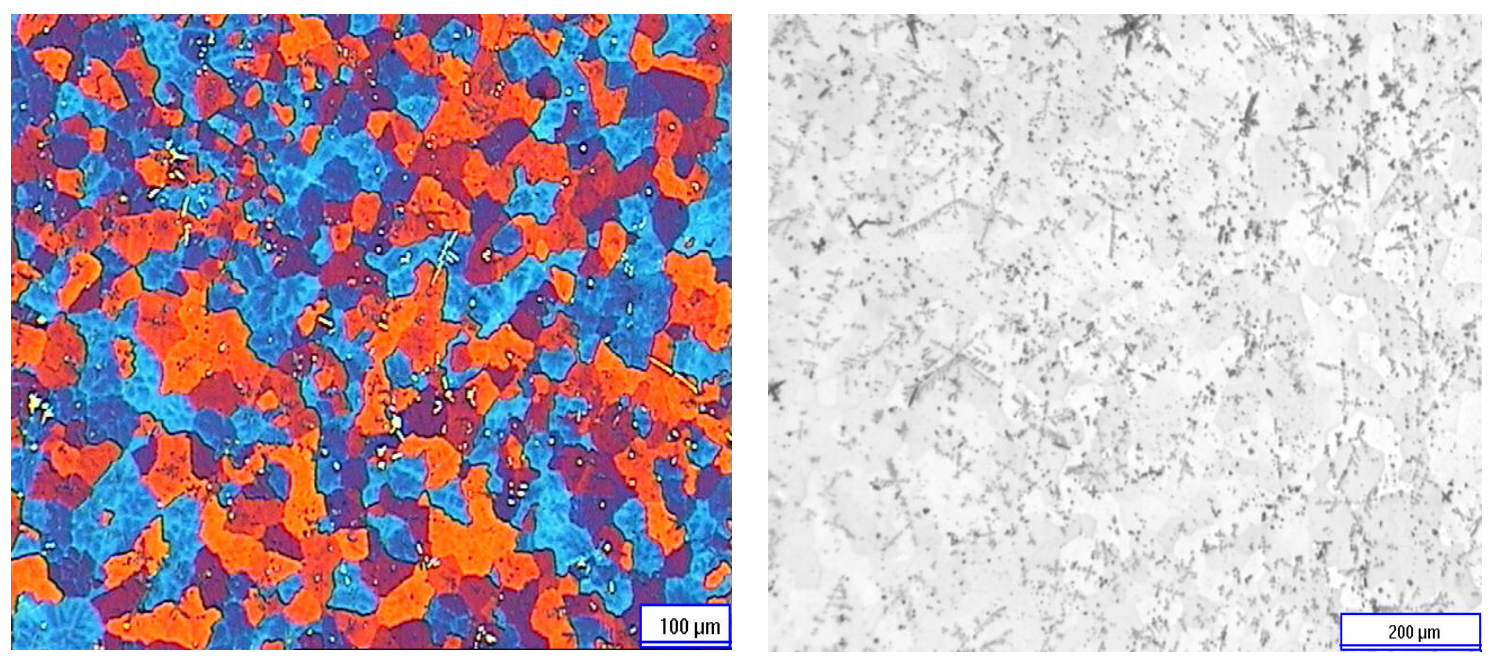

FIGURA 24 - Micrografias, liga UA8 (400X), esquerda: bruta de fusão, direita: tratada termicamente (100X).

Para fins de comparação, esta liga foi tratada termicamente por 72 horas a $1000^{\circ} \mathrm{C}$, e deixada resfriar sob vácuo, no interior da retorta, que foi retirada rapidamente do forno. Medidas de distribuição de tamanho de grão mostraram que o tratamento não foi efetivo na alteração do valor médio, nem tampouco na redução da fase alfa presente na amostra. Por problemas de difusão, conforme será discutido com mais detalhes adiante, esta fase alfa intergranular, uma vez precipitada no contorno de grão, não pode ser reconvertida a gama, a menos que se empregue um tratamento térmico em tempo superior ao aqui utilizado.

Considere neste caso a formação de um par de difusão $\gamma \mathrm{U} 8 \mathrm{Mo} / \alpha \mathrm{U} 8 \mathrm{Mo}$, neste caso uma liga contendo $8 \%$ de molibdênio. A solubilidade máxima de molibdênio na fase alfa é de $0,6 \%$ em peso. Portanto, supondo-se que seja esta a concentração de molibdênio, seria de se esperar que a realização de tratamento térmico promovesse a difusão de molibdênio para esta região, a $1000^{\circ} \mathrm{C}$, campo de gama, reconvertendo-a a gama. $\mathrm{O}$ que se mostrou aqui, na micrografia da direita, é que o tempo foi insuficiente para a homogeneização da estrutura, pois o nível de segregação promovido pelo processo de fusão a arco foi muito grande. 


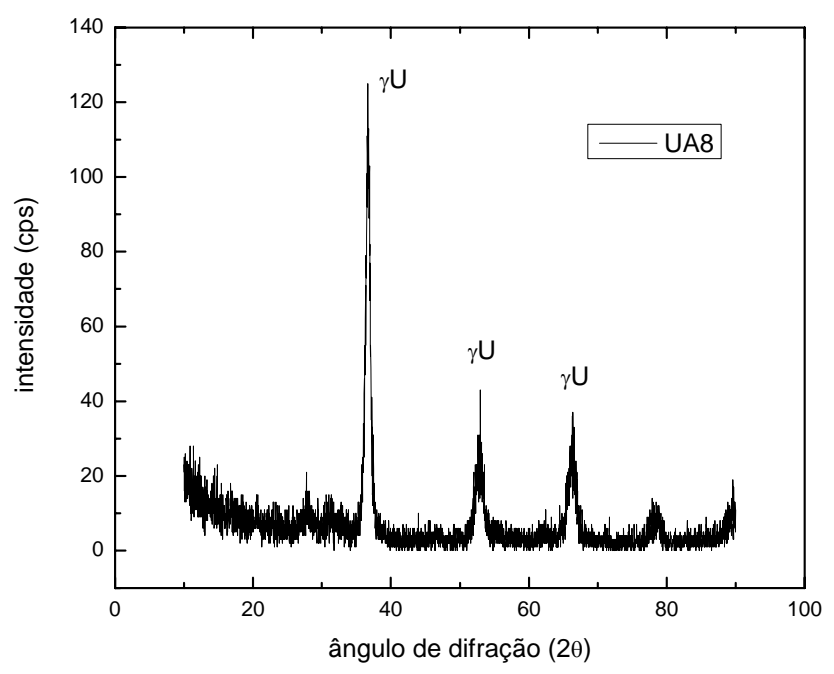

FIGURA 25 - Espectro de difração, amostra UA8.

No espectro da Figura 25 são observados predominantemente picos de fase gama, indicando boa estabilização mesmo a $8 \%$ e duas refusões. Picos de fase alfa também estão presentes, embora em menor intensidade. Novamente se obteve um bom resultado, entretanto, como a quantidade de alfa em menores porcentagens de molibdênio é maior, efetuou-se para esta liga tratamento térmico de homogeneização.

\subsubsection{5 liga código U7Mo (U7Mo2R)}

Preparada com 7\% em peso de molibdênio em tabletes, foi a que mais se aproximou do espectro teórico de difração de raios- $\mathrm{X}$ da estrutura gama- $\mathrm{U}$, conforme mostra a Figura 26, embora alguns picos de alfa contíguos aos de gama ainda possam ser vistos, dada a metaestabilidade da estrutura.

Esta afirmação se deve ao fato de que o pico de difração a $65.8^{\circ}$ nunca foi maior que a $52.7^{\circ}$, como nos espectros teóricos, refletindo a possibilidade de soma dos picos de alfa, gama e delta-U, entre $52^{\circ}$ e $53^{\circ}$. Picos de óxido aparecem, mas são devidos a exposição da amostra ao ar, durante preparo, manuseio, etc.. Indica-se com isso que a estabilização da fase gama, preparada nas mesmas condições dos dois experimentos anteriores, se deu de maneira a formar uma fase mais cristalina e, portanto, espera-se quantidade de molibdênio em toda a amostra mais bem homogeneizada. Como a quantidade de molibdênio foi menor, mais fácil foi a homogeneização, mesmo com duas refusões. 


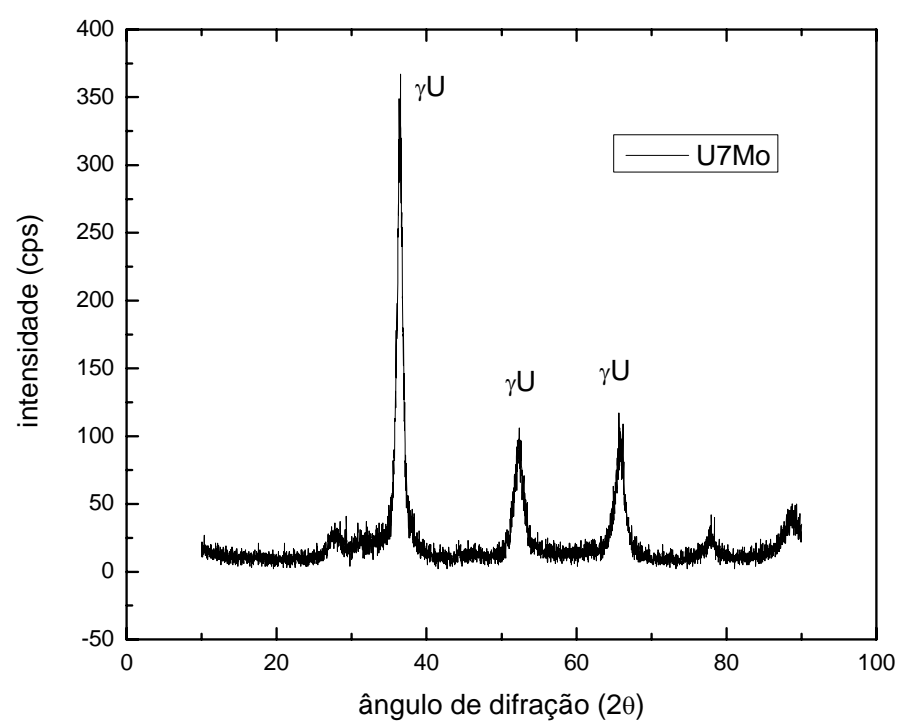

FIGURA 26 - Espectro de difração de raios-X, amostra U7Mo2R.

Sua densidade, estimada em $17,5 \mathrm{~g} / \mathrm{cm}^{3}$, está em plena conformidade com os valores teóricos e os obtidos por indução, para ligas com esta porcentagem. Isto indica que o trabalho com tabletes de molibdênio produz bons resultados, mesmo com poucas refusões, quando da utilização de porcentagens de molibdênio desta ordem. Isto se confirma pelo exame da Figura 27. O primeiro grupo de imagens foi tomado ao longo do eixo horizontal da amostra, da borda ao centro, com a intenção de se verificar a sua homogeneidade e a presença de estruturas ao longo destas direções.

Nas Figuras 27 a, b e c, observa-se que o número e o tamanho das estruturas dendríticas, típica da solidificação em moldes, diminui com a distância ao centro, o que seria de se esperar, pois o gradiente de temperatura se dá nesta mesma direção. Pelo fato de estarmos trabalhando com sistemas binários, além do mecanismo térmico de solidificação (resfriamento), devemos considerar o super-resfriamento constitucional, que ocorre quando o líquido apresenta composição diferente da do sólido que se solidifica ${ }^{53}$. Regiões dendríticas mais escuras podem representar a presença de oxidação superficial na amostra, detectada em pequenas quantidades pelo difratômetro de raios-X.

Um padrão semelhante, embora menos pronunciado, é apresentado pelas imagens das partes da amostra em contato com a base, Figura 27 d, que apresentaram um número de dendritas muito maior, pois esta é uma região sempre resfriada. Como estamos examinando estruturas de solidificação de ligas binárias, é de se esperar que estas dendritas sejam regiões de urânio alfa puro. 

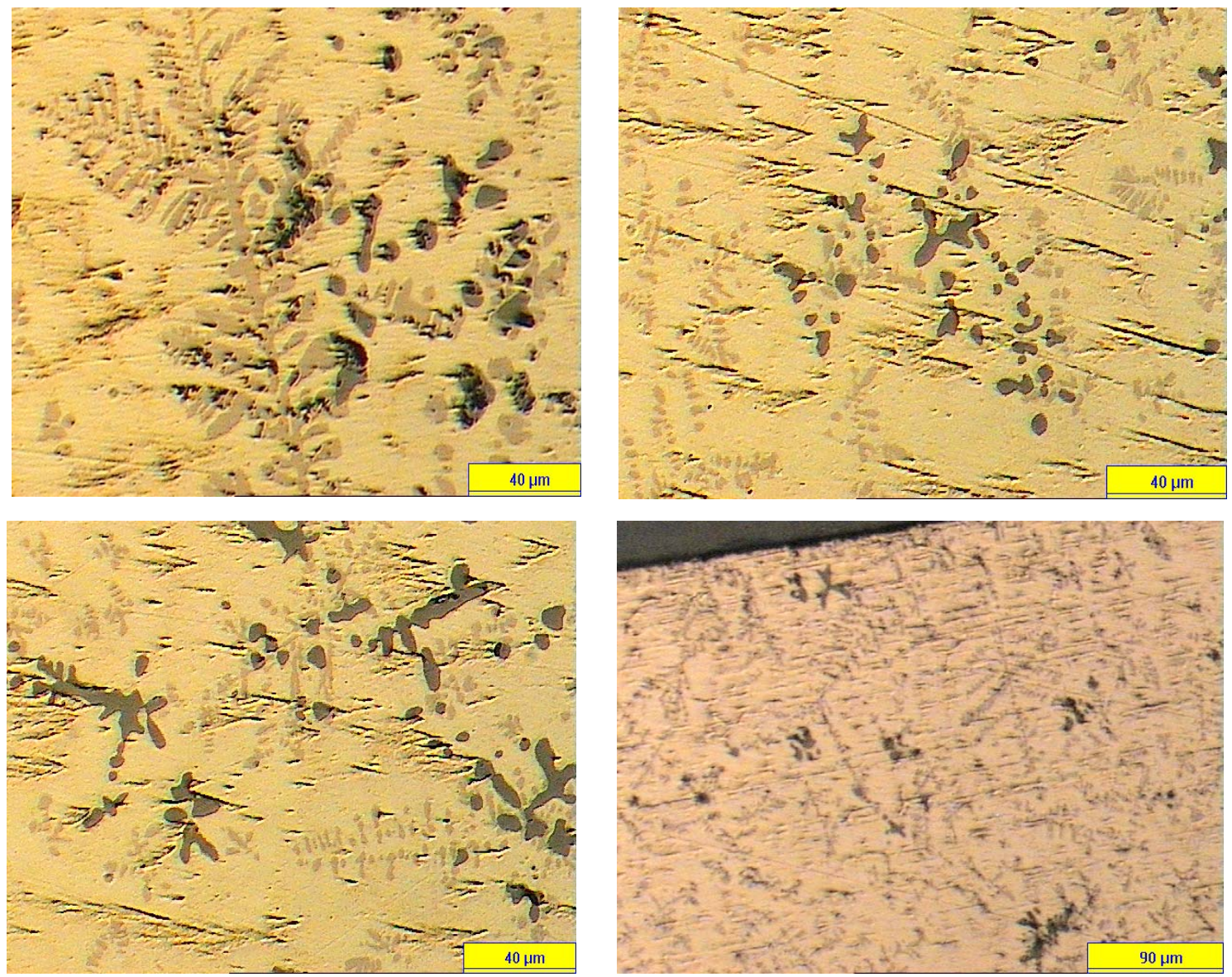

FIGURA 27 - Amostra U7Mo2R, superior esquerda: borda (800X), superior direita: entre borda e centro (800X), inferior esquerda: centro (800X), inferior direita: topo(400X).

A presença deste grande número de dendritas indica que, mesmo a amostra apresentando elevado grau de homogeneidade como atestam os difratogramas de raios-X, tratamento térmico ainda é necessário para que estas estruturas sejam removidas. $\mathrm{O}$ importante foi o fato de que, mesmo com baixo número de refusões e carga não muito adequada, um excelente resultado em termos de estabilização da fase gama foi obtido, indicando a possibilidade de se produzir ligas de boa qualidade nestas condições.

\subsubsection{6. liga código UA10}

Preparada com 7\% em peso de mistura $1 \mathrm{Mo}: 1 \mathrm{Si}$, molibdênio em tabletes, com pedaços de silício metálico, duas refusões, apresentou numa primeira análise ao microscópio óptico características peculiares. A idéia aqui foi verificar se o silício poderia ter efeito superior ao molibdênio na estabilização de fase gama, assim como o apresentado pela platina. Esta, quando adicionada em porcentagens de $2 \%$, tem poder de estabilização equivalente ao dobro da quantidade de Mo adicionada. Verificar-se-á-se inicialmente os 
resultados dos exames qualitativos obtidos em microscópio óptico e em seguida, os de difração de raios-X, Figura 28.

Após primeiro lixamento, verificou-se a presença de matriz contendo padrões observados em compostos U-Si, conforme visto nas Figuras 29 e 30, relativas a alfa-U e dendritas, obviamente tornando-a uma estrutura não homogênea. No sentido de seu comprimento, a segregação em contornos de alfa-U é a mesma que a apresentada em amostras contendo teor de Mo semelhante, mas aqui estas estruturas aparecem também depositadas nos contornos da fase U-Si, alfa precipitado em contornos de subgrãos. Pelo fato de ter realizado duas refusões, no centro da amostra há mais quantidade de U-Si, e nas bordas as estruturas são semelhantes às das ligas anteriores, alfa em contornos de matriz gama-U. Em aumento maior, identificou-se a presença de 3 fases, uma clara, a matriz, outra rósea e uma acinzentada, sendo interessante que esta acentua os contornos da fase USi. Poros também se fazem presentes em quantidade razoável.

Observando o diagrama binário UMo, com 3,5\% Mo durante o resfriamento a amostra ainda passa pelo campo de alfa mais gama, embora flutuações na composição possam levá-la ao campo de beta mais gama. Se se levar em conta que se adotou o mesmo procedimento para homogeneização utilizado anteriormente, admite-se que a amostra esteja bem homogênea, o resfriamento tendo sido conforme a isopleta que passa pelos campos de gama, alfa mais gama e alfa mais delta.

No diagrama binário U-Si, entretanto, a 3,5\% $\mathrm{Si}$ em peso tem-se a passagem da liga pela região de líquido mais épsilon, com ponto de fusão de aproximadamente $1500^{\circ} \mathrm{C}$. A $985^{\circ} \mathrm{C}$ estamos no campo de gama mais épsilon, e a $930^{\circ} \mathrm{C}$ há a formação do composto $\mathrm{U}_{3} \mathrm{Si}$ ou a fase delta U-Si, de estrutura tetragonal de corpo centrado e densidade de 15,58 $\mathrm{g} / \mathrm{cm}^{3}$. Um primeiro exame leva a conclusão de que não houve a formação de composto ternário U-Mo-Si, mas sim a formação de uma mistura contendo o composto $\mathrm{U}_{3} \mathrm{Si}$ e as fases alfa e gama-U.

Em aumentos maiores, as dendritas parecem estar sobrepostas à matriz, destacando-se. Neste aumento fica claro que há uma matriz clara, sulcada por pontos cinzas bem claros, e fase possivelmente referente a alfa-U. Mais para o centro estas fases encontram-se em menor número. Ao fundo, a matriz de siliceto permanece intacta, com os mesmos padrões geométricos apresentados nas micrografias de siliceto de urânio. Imagens típicas são as das Figuras 29, 30, 64, 68 e 71. 


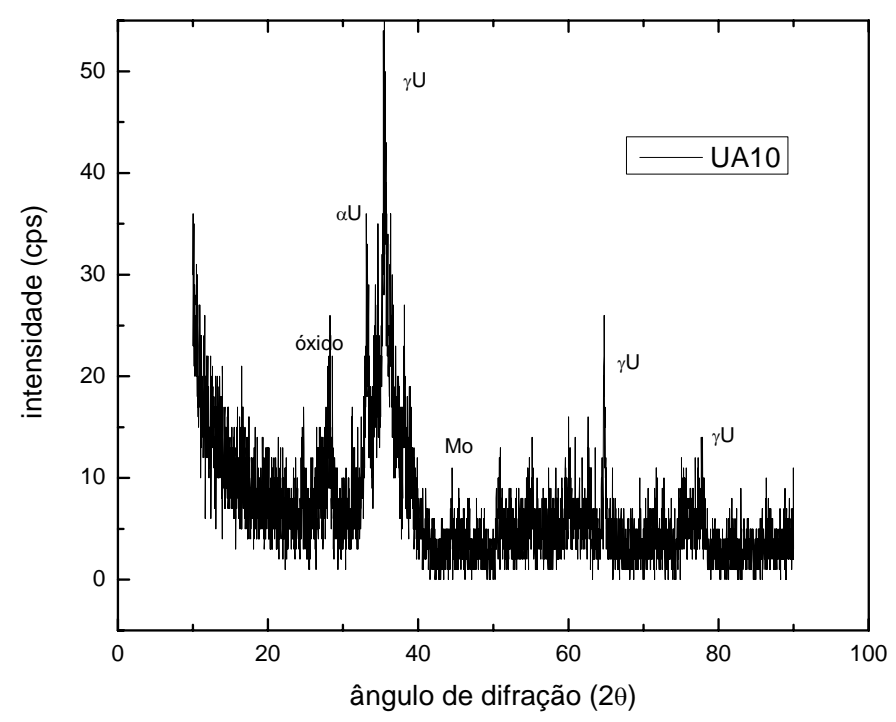

FIGURA 28 - Espectro de difração de raios-X, amostra UA10.

Vejamos os resultados de difração de raios-X, mostrados no espectro da Figura 28. Os picos mais intensos correspondem às fases alfa e gama-U. Isto seria de se esperar, visto que a pouca quantidade de molibdênio tem pouco efeito sobre a estabilidade da fase gama. Há a presença de picos de fase U-Si, indicando que, ao invés de estabilizar, a grande tendência à formação de compostos de siliceto de urânio prejudica este processo. A adição de silício deverá, então, ser realizada em quantidades mínimas, abaixo de 3\% em peso, se se quiser observar algum efeito adicional em termos de retenção da fase gama-U. Nesta região do diagrama de fases U-Si, não há compostos estáveis. Acima de $3 \%$ encontramos 6 compostos, com densidades em geral decrescendo quanto maior a porcentagem de siliceto adicionada. Abaixo, pelo diagrama de fases U-Si, a solubilidade de Si em $\gamma$-U máxima é de $2,0 \%$.

As estruturas identificadas como pertencentes à de alguma fase do sistema USi são apresentadas na Figura 29. Esta foi uma das estruturas características apresentadas por esta amostra. 


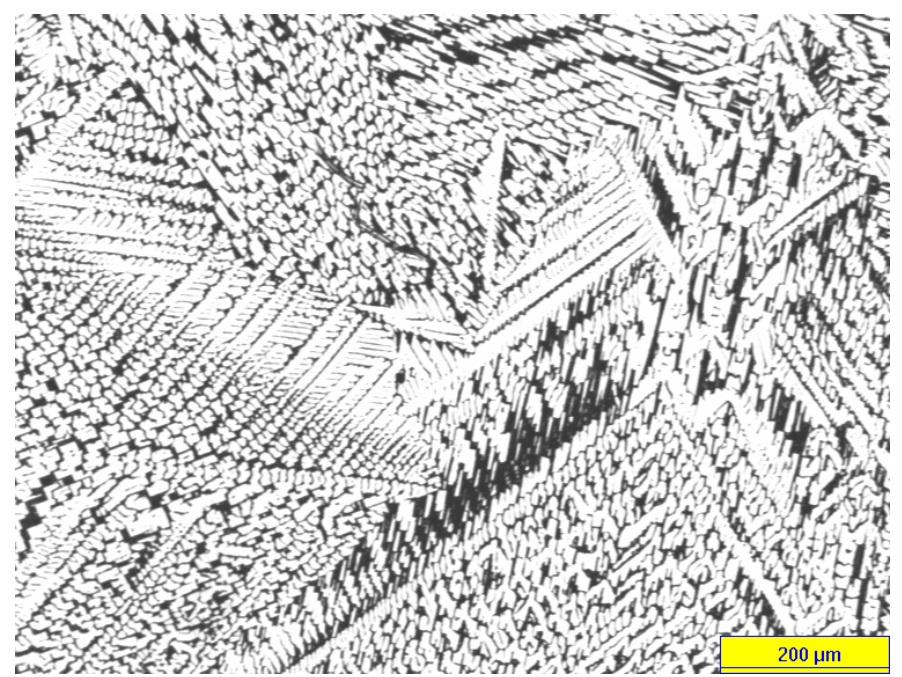

FIGURA 29 - Estrutura típica de fases dendríticas do composto $\mathrm{U}_{3} \mathrm{Si}_{2}(200 \mathrm{X})$.

Em amostras tratadas por 48 horas a $1038^{\circ} \mathrm{C}$, por comparação, temos as seguintes estruturas, dadas na Figura 30. Uma análise visual das fases presentes mostrou que não houve alteração substancial nas proporções relativas entre as fases, indicando também, neste caso, que os tratamentos térmicos devem ser realizados por um tempo maior. Ainda, como é clara a presença de uma mistura de fases, dada a baixa solubilidade do silício em urânio, poderia se esperar uma densificação das ligas.
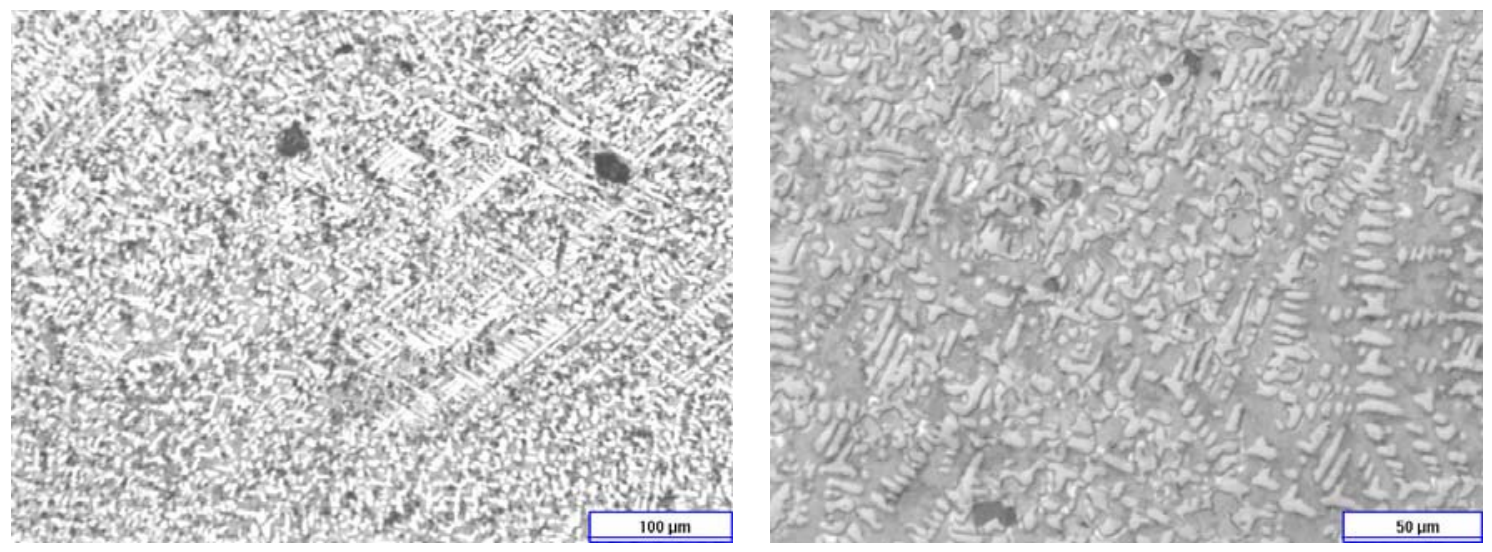

FIGURA 30 - Micrografias liga UA10, esquerda: bruta de fusão (400X), direita: tratada termicamente $(800 \mathrm{X})$.

\subsubsection{7 liga código UA7}

Esta liga foi preparada com 5\% em peso de molibdênio, na forma de tabletes. O baixo teor de molibdênio implicou em alto valor de densidade, condizente com a porcentagem adicionada. 
Um exame em microscópio óptico simples indicou a presença de duas regiões, uma clara, correspondendo à matriz gama permeada por alfa em contornos, e uma escura, mais acinzentada. Uma interface é formada entre ambas as regiões, indicando reação entre urânio e molibdênio incompleta. Não foram, por problemas técnicos, obtidas micrografias destas ligas.

Não há difratogramas referentes a esta amostra embora, por meio do exame ao microscópio, apesar da presença da interface, a liga pode ser considerada razoavelmente bem homogeneizada. Amostras foram retiradas para análises químicas e de variação de massa.

\subsubsection{8. liga código UMo3A}

Liga produzida via arco, com carga de molibdênio composta pelos pequenos cilindros $3 \mathrm{~mm} \times 3 \mathrm{~mm}$. Como foi verificado, mesmo sem o uso de refusões e com quantidade de $7 \%$ em peso de Mo, a liga apresentou-se bem homogênea, com densidade de $99,7 \%$ em relação a da fase gama-U teórica.
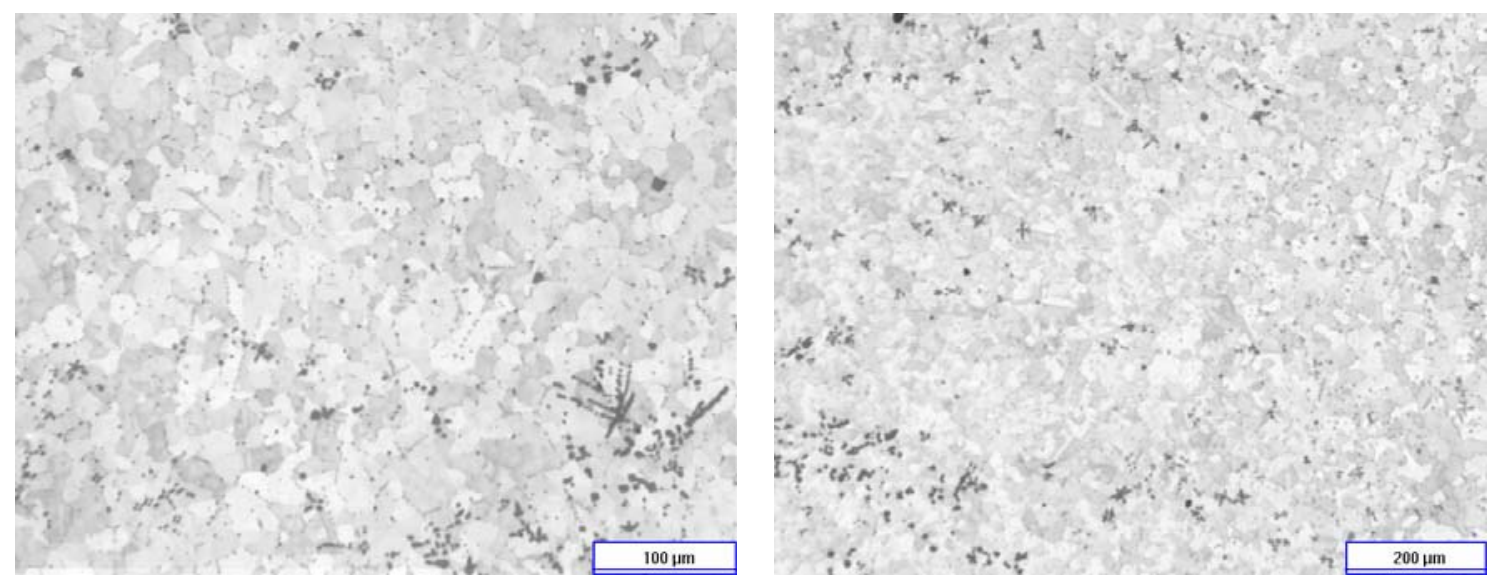

FIGURA 31 - Micrografias liga UMo3A, esquerda: detalhes dos grãos (400X), direita (200X).

Um exame ao microscópio óptico (Figura 31) mostra os contornos bem definidos, estruturas em forma de cruz mais concentradas na região superior, e ao fundo, onde a amostra entrou em contato com a base, são maiores, mas em menor número. Estas estruturas, após lixamento em lixa 2400, ficaram bem evidentes.

O difratograma da liga UMo3A é apresentado na Figura 32. Nele podemos observar a presença de gama-U como principal, senão único, constituinte, além da 
presença do pico de óxido, em muito mais baixa intensidade, oriunda dos processos de lixamento, polimento e exposição da amostra ao ambiente.

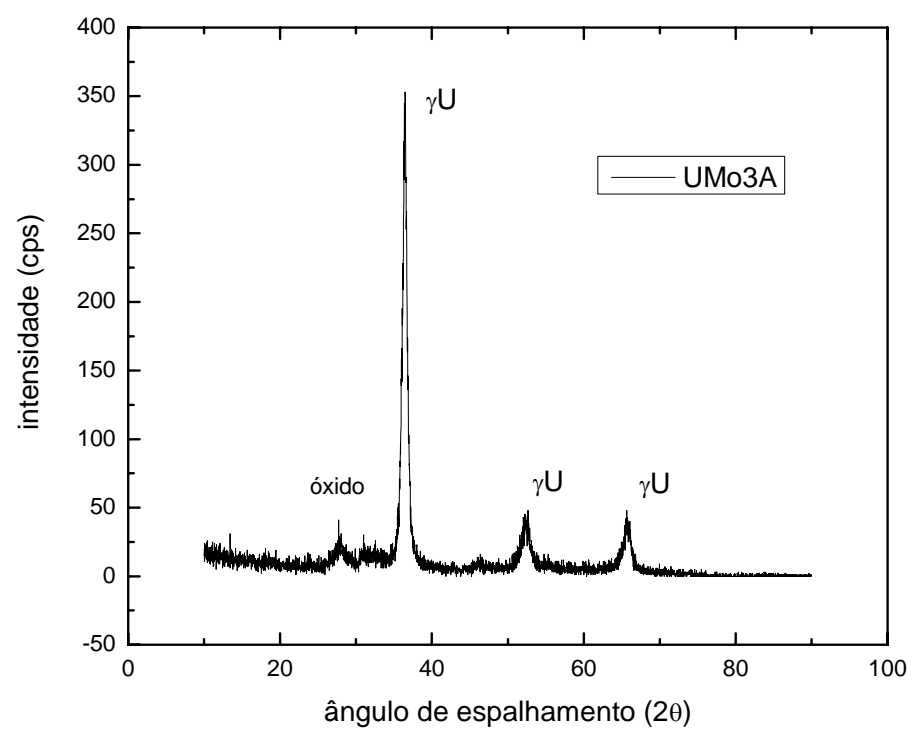

FIGURA 32 - Espectro de difração de raios-X, amostra UMo3A.

Novamente, assim como na amostra U7Mo, o segundo e terceiro picos mais intensos aparecem na proporção correta, ao menos o terceiro sendo mais intenso que o segundo. A concordância de ambos os espectros face ao teórico pode indicar que um valor ótimo estrutural para a substituição de átomos de urânio gama pelos de molibdênio esteja ao redor desta porcentagem.

Também importante é o fato de que as cargas cilíndricas de molibdênio $3 \mathrm{~mm} \times 3 \mathrm{~mm}$ permitiram melhores resultados em termos de fusão, indicando ser esta a geometria mais afeita ao processo de fuso destas ligas binárias.

\subsubsection{9 liga código UMo4}

Esta liga apresentou grande aderência de óxido em sua superfície externa. Entretanto, não houve detecção de picos de óxido nos espectros de difração de raios-X, nem de $\mathrm{UO}_{2}$ e tampouco de $\mathrm{U}_{3} \mathrm{O}_{8}$, provavelmente presentes abaixo dos limites de detecção.

Um exame por microscopia óptica mostra em baixo aumento a presença de 2 fases distintas. A mais externa, rica em molibdênio, obviamente por estar em contato mais direto com a base. A segunda, composta por urânio, com as características também encontradas nas demais amostras, com muitas dendritas presentes. O difratograma de raios-X da liga é o da Figura 33. Não há imagem disponível para esta liga. 


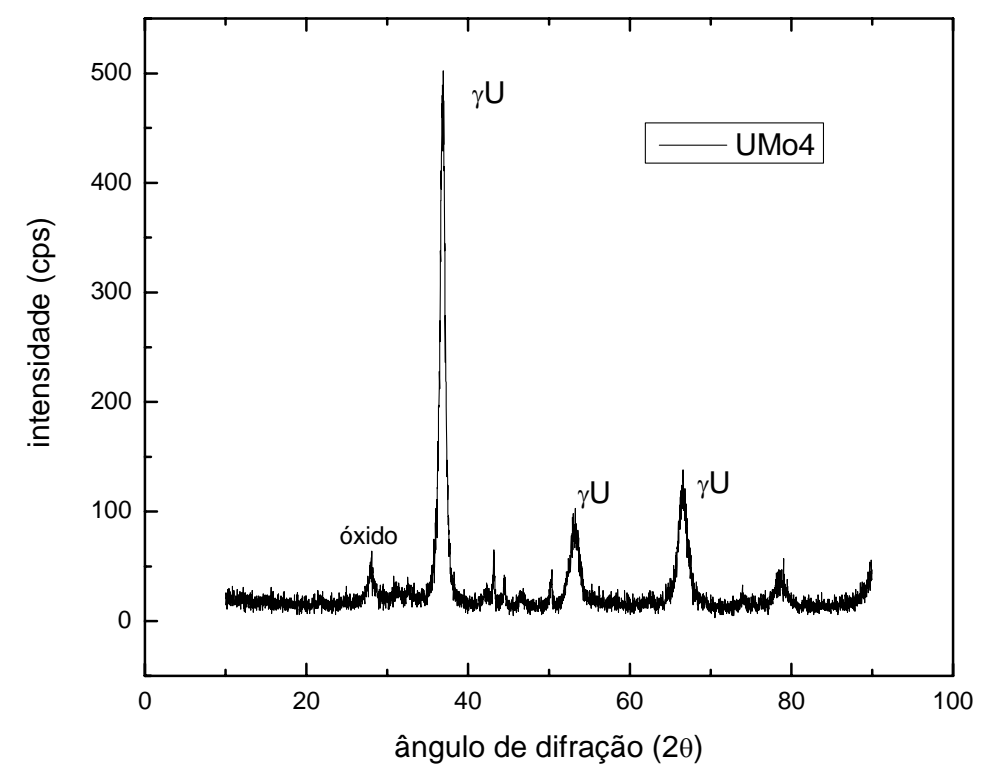

FIGURA 33 - Espectro de difração de raios-X, amostra UMo4.

Observa-se que há ainda a presença dos pequenos picos a $28^{\circ}$ e $33^{\circ}$, referentes ao óxido de urânio. Entretanto, a amostra é totalmente composta por gama, o que seria de se esperar dado que foi produzida com carga de $10 \%$ em peso de molibdênio, na forma dos cilindros de $3 \mathrm{mmx} 3 \mathrm{~mm}$. Outro bom resultado em termos de densidades foi obtido com este tipo de carga, adicionado ao fato de se ter efetuado sobre ela duas refusões.

Os picos relacionados ao cobre encontram-se em $43,1^{\circ}, 44,6^{\circ}$ e $50,3^{\circ}$. Como o ponto de fusão do cobre é de $1083^{\circ} \mathrm{C}$, baixo face ao do urânio, molibdênio e da composição U-10Mo, e pelo fato de, nesta amostra, se ter aplicado o arco por mais tempo, daí a sua alta irregularidade quanto à forma, algum cobre da coquilha foi por ela incorporado. Picos de óxido de urânio também estão presentes.

Observa-se também que, a menos destes dois materiais, a fase majoritária foi a gama-U, assim como na liga UMo3A. Isto indica novamente que a utilização deste tipo de carga de molibdênio, mesmo em mais altas porcentagens, com os quais seria de se esperar maior dificuldade na homogeneização, produziu bons resultados.

\subsubsection{0 liga código UA5}

Contendo 4\% em peso de molibdênio na forma de tabletes, apresentou valor de densidade de $17,39 \mathrm{~g} / \mathrm{cm}^{3}$, alto se se considerar que não foram feitas refusões, mas 
coerente com a pouca quantidade de Mo. Exames em microscópio óptico comum, figura 34, mostraram que há fase alfa, predominantemente nos contornos de grão. A presença de dendritas não é homogênea, estas se concentrando na parte da amostra que ficou em contato direto com o arco, enquanto que na parte inferior, em contato com a base e, portanto, mais refrigerada, praticamente não há. Entretanto, verificou-se maior homogeneidade da amostra na parte superior que na inferior.

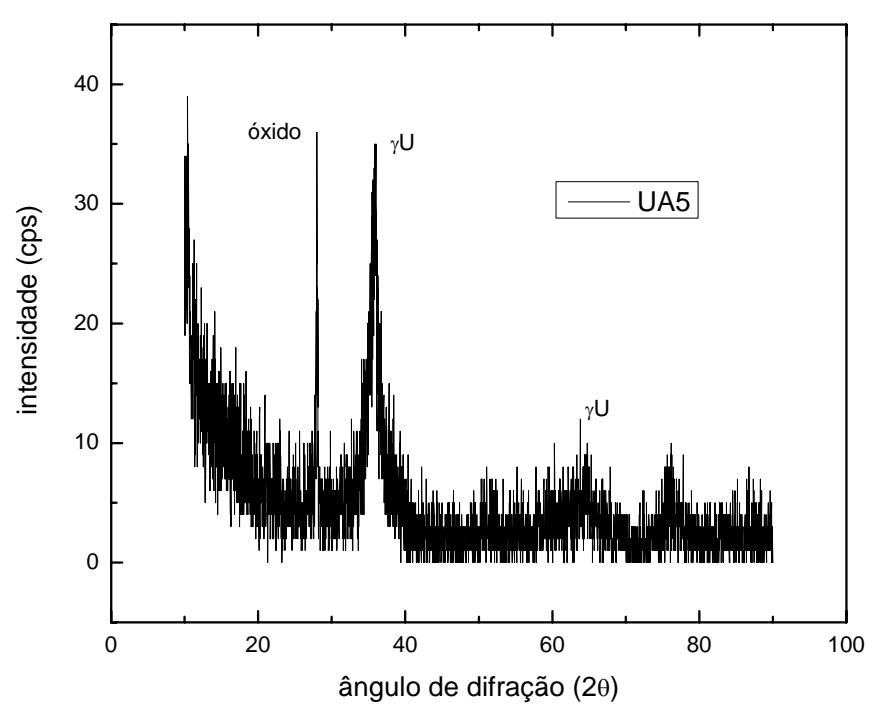

FIGURA 34 - Espectro de difração de raios-X, liga UA5.

Observou-se que as estruturas identificadas como dendritas são, na verdade, linhas de precipitados esféricos, perto das extremidades da amostra. Em aumentos maiores estas estruturas foram identificadas em concentração menor no centro da amostra. Após lixamento mais fino, verificou-se a presença de muita fase alfa, e após polimento, os contornos e fases presentes ficam bem mais evidentes.

As micrografias da Figura 35, juntamente com o espectro de difração de raiosX, Figura 34, indicam baixo grau de cristalização, a velocidade de solidificação de amostras em forno a arco com baixo teor de Mo não permite a retenção de estrutura gama.

Assim, necessariamente, recomenda-se a utilização de tratamentos térmicos ou, caso se necessite de liga altamente estabilizada em maior quantidade, a utilização de porcentagens de molibdênio maiores do que $4 \%$ em peso. 

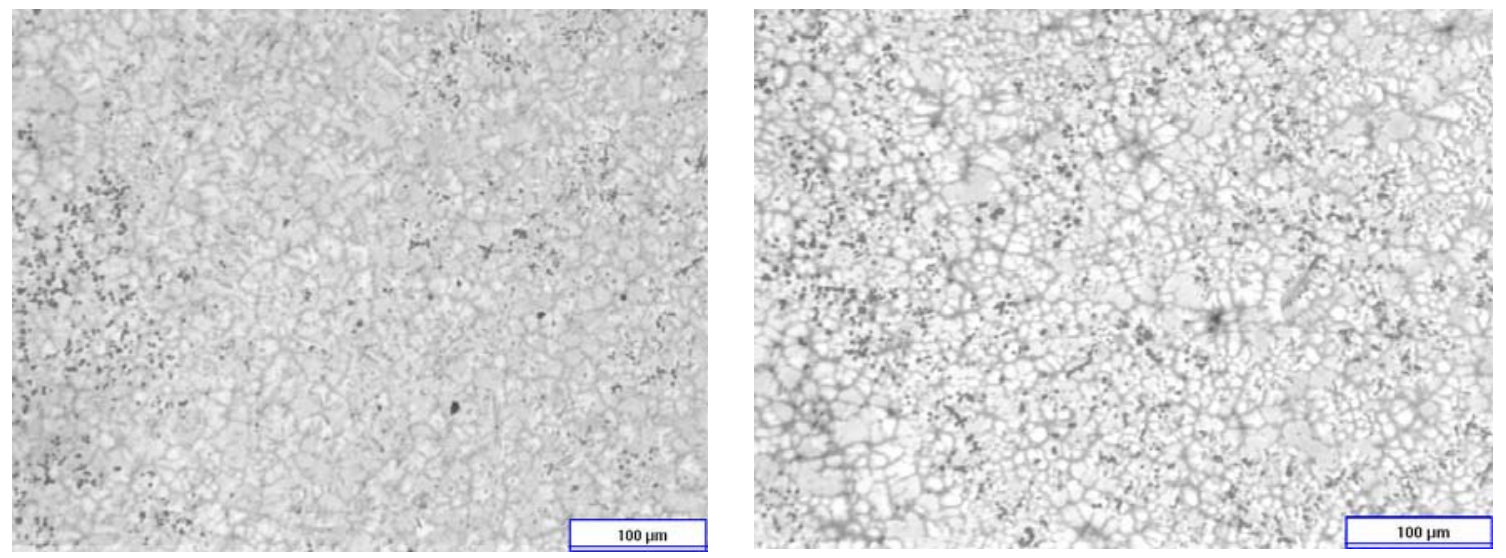

FIGURA 35 - Regiões distintas da liga UA5, aumento (200X), borda (esquerda) e centro (direita).

Observo que os picos de gama não estão tão destacados, embora presentes e compondo majoritariamente a estrutura da liga. Este é um espectro, pelo que estamos vendo aqui neste trabalho, característico de substituições com baixo molibdênio. O pico intenso a $28^{\circ}$ refere-se novamente à oxidação da amostra. Muito alfa também se faz presente, embora os picos estejam mascarados.

\subsubsection{1 liga código UA3}

Amostra quando vista ao microscópio apresentou região superior com estruturas características de substituição gama, matriz de gama e contornos contendo alfa, região inferior muito sulcada, daí o valor baixo de densidade, 63,5\% do valor teórico. Como não foi efetuada nenhuma refusão e a carga em forma de pó de molibdênio, isto pode ter prejudicado a qualidade final do material. Duas regiões se apresentam como distintas: uma mais clara, contendo muitas dendritas, e outra escura, com menor quantidade. Entretanto, ambas são bem parecidas estruturalmente, e devem diferir apenas quanto à quantidade de molibdênio presente. $\mathrm{O}$ interessante é que não se observa interface entre estas duas regiões, o que poderia indicar boa homogeneização.

Entretanto, em aumentos maiores, observa-se que as duas fases são bem distintas, fase escura rica em urânio, e a fase clara contendo mais molibdênio. Outro fato interessante: a presença de dendritas é quase nula, e as que existem estão muito "saltadas", creio que por serem muito mais duras que a fase matriz. Um resultado semelhante foi obtido nas primeiras amostras fundidas a arco, U6Mo e U10Mo, como será visto em seguida. Também por problemas técnicos as imagens da liga UA3 foram perdidas. 
O espectro de difração desta liga, Figura 36, mostra a presença de praticamente todas as fases que poderiam ser encontradas em uma amostra pouco homogênea. Observam-se picos de óxido, e das fases alfa, em grande quantidade, gama e também, e pela primeira vez, picos de molibdênio (mais intenso a $40^{\circ}$ ). Isto reflete o fato de que o trabalho com cargas de molibdênio em pó precisa ser cuidadoso, um número maior de refusões ou um tempo maior sob a ação do arco deveria ter sido aplicado.

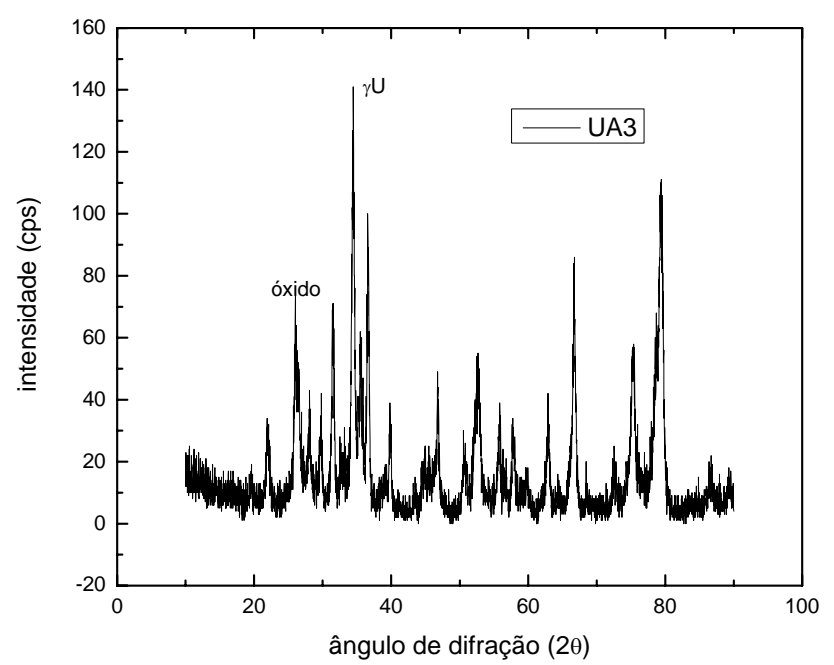

FIGURA 36 - Espectro de difração de raios-X, liga UA3.

\subsubsection{2 liga código U6Mo}

Como a anterior, foi uma das primeiras produzidas no IPEN por meio de forno a arco. Portanto, utilizou-se de carga de molibdênio em pó, e os resultados não foram muito bons.

Com um valor de densidade estimado em $16 \mathrm{~g} / \mathrm{cm}^{3}$, apresentou como característica a presença de um grande número de dendritas, Figuras 37 a 39, identificadas em microscópio com analisador de imagens. Esta amostra foi totalmente colocada à disposição para os ensaios de hidretação, e a dificuldade durante este processo indicou que muito da estrutura, que antes era composta por grande parte de alfa-U, na verdade se revelou ser uma rica fonte de estudo de processos de solidificação. Conforme será visto nas micrografias, a solidificação da amostra foi congelada em um estágio onde as dendritas eram a fase dominante. 


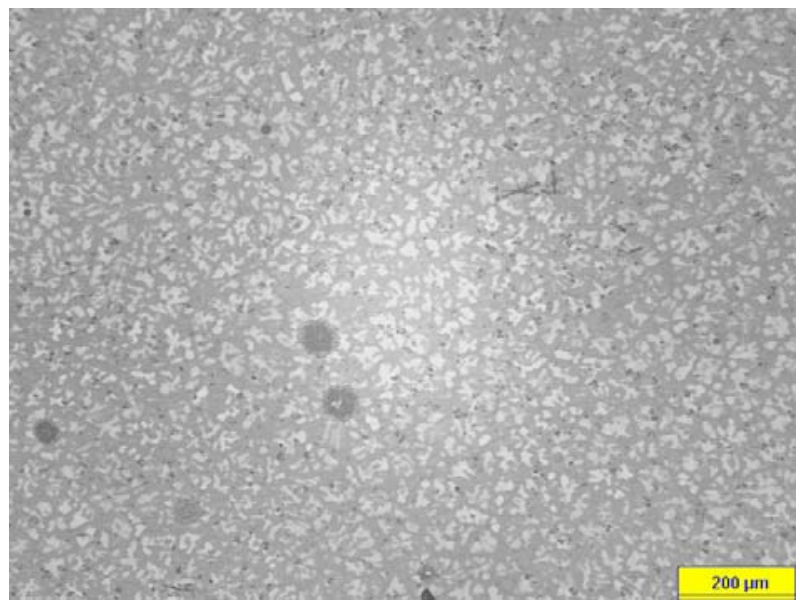

FIGURA 37 - Micrografia liga U6Mo (200X).

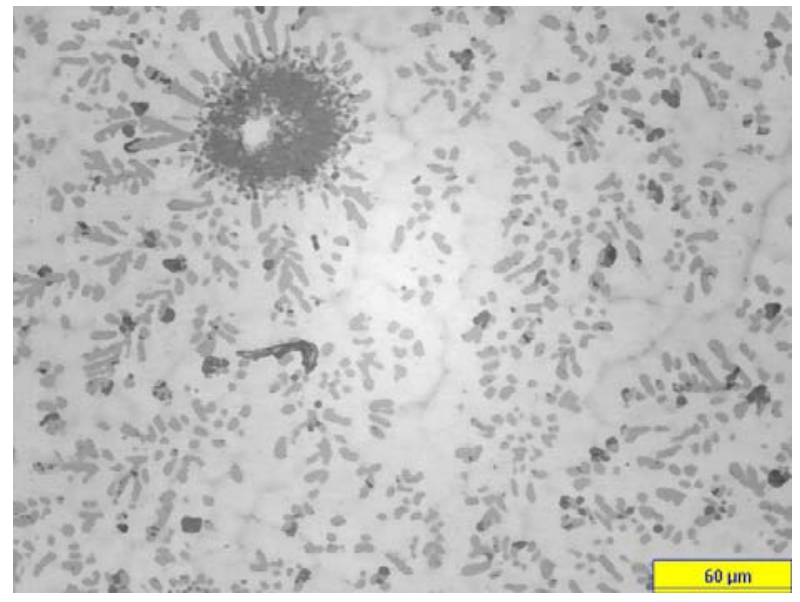

FIGURA 38 - Micrografia com detalhe, solidificação eutetóide, liga U6Mo (800X).

Verifica-se, ao fundo, a presença de contornos de grão bem tênues, mas a característica marcante é a rica quantidade de dendritas ao longo da matriz. Observa-se que em cada um dos grãos os ramos principais e secundários das dendritas se orientam de maneira diferenciada, realçando a pouca cristalinidade do material, e fornecendo condições para determinarmos a direção de crescimento de cada um dos grãos.

Possuindo gama-U uma estrutura cúbica de corpo centrado, cujas dendritas crescem preferencialmente numa dada direção, fica fácil estabelecer, a partir da adoção de uma delas na imagem como padrão, a direção relativa das demais. Fica claro, pelo exame da estrutura esférica, que dela se originam ramos de crescimento dendrítico. Conforme mencionado, em um material bruto de fusão com composição entre a do metal puro e a do eutetóide, ambas as estruturas de solidificação podem estar presentes. As estruturas esféricas representam o eutetóide, lamelas de composição $\alpha \mathrm{U}$ e $\mathrm{U}_{2} \mathrm{Mo}$. 
As dendritas, referentes ao metal puro alfa-urânio, as esferas, referentes ao eutetóide, mistura com características lamelares contendo alfa e, no caso, o composto $\mathrm{U}_{2} \mathrm{Mo}$, sendo esta então uma região, face à matriz, com a mesma composição em molibdênio, ao contrário das dendritas que são pobres em molibdênio.

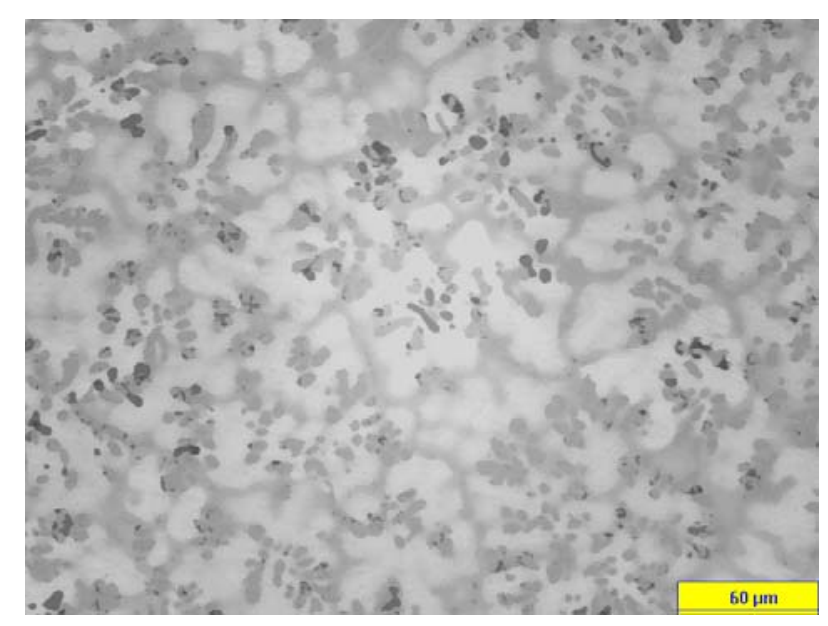

FIGURA 39 - Detalhe das dendritas e início de formação de contornos de grão, liga U6Mo (800X).

As Figuras 38 e 39 foram tomadas em regiões distintas da liga, e pode-se observar que as velocidades de resfriamento, que podem ser comparadas pelo exame da forma das dendritas, foram diferentes. Isto seria de se esperar, mesmo com um grande número de refusões, dada a geometria do sistema de fusão a arco. Regiões da liga em contato maior com a superfície da base refrigerada irão refrigerar-se mais rapidamente, as demais mais lentamente. Há um claro gradiente térmico ao longo da amostra, o que leva a obtenção de uma estrutura heterogênea.

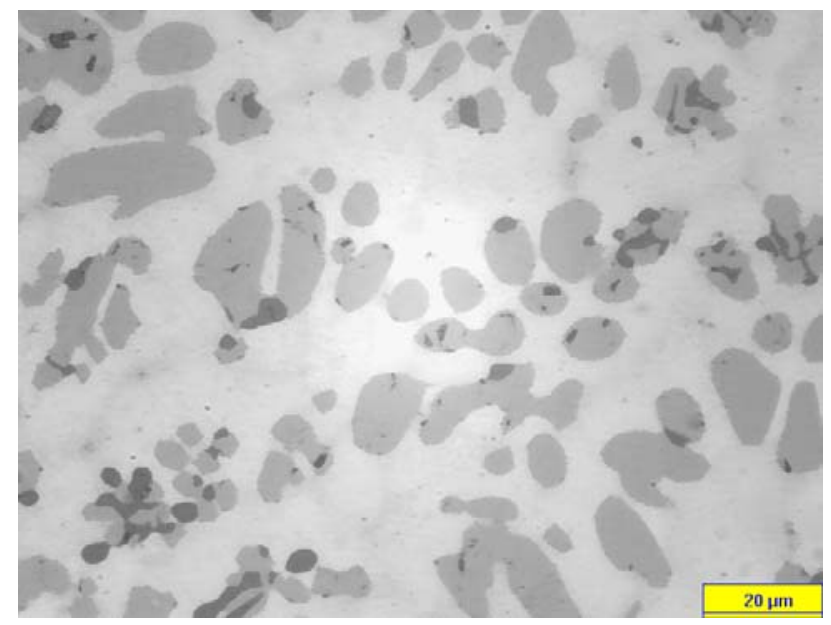

FIGURA 40 - Detalhe das dendritas da liga U6Mo (1200X). 
Assim, com imagens como estas, posso determinar a maneira como se processa a solidificação em ligas de urânio-molibdênio, via forno a arco. Em algumas das amostras foram identificadas estruturas semelhantes, que podem nos revelar mais sobre a natureza da solidificação destas ligas. Infelizmente, imagens de dendritas de amostras produzidas em forno de indução não foram obtidas, dado que os processos de homogeneização química e térmica são melhores.

A seguir, serão vistas quais as diferenças quando se aumentam a composição da liga para $10 \%$ em peso de molibdênio produzida via forno a arco, com a mesma carga de molibdênio. A liga seguinte, código U10Mo, foi a primeira a ser produzida nas instalações do Centro do Combustível Nuclear do IPEN.

\subsubsection{3 liga código U10Mo}

Produzida também com carga de molibdênio em pó, fundida somente uma vez, foi posteriormente tratada termicamente a uma temperatura média de $980^{\circ} \mathrm{C}$ por 72 horas, sob pressão de $10^{-1}$ torr. Para fins de comparação, difratogramas (Figura 41 e Figura 42) foram tomados após a fusão e tratamento térmico, bem como as micrografias. Análises de imagens e da composição foram efetuadas, respectivamente, em microscópio com analisador de imagens e em microscópio eletrônico de varredura, tanto para as estruturas brutas de fusão como para as de tratamento térmico.

Um grande número de dendritas foi observado, Figuras 43 e 44, sobrepondo-se a uma matriz com contornos de grão fracamente delineados, mas predominante, nas estruturas brutas de fusão. Após tratamento térmico observa-se a crescente solubilização das dendritas na matriz, conforme indicado por suas imagens, um tanto quanto mais fracas. Os difratograma da amostra bruta de fusão e da tratada termicamente são apresentados nas figuras 41 e 42, respectivamente.

Assim como na amostra U6Mo, esta liga apresentou muitas estruturas dendríticas, e também várias estruturas esféricas contendo possíveis lamelas de composição eutetóide também, neste caso em maior número. Isto se explica porque, em média, a amostra encontra-se mais próxima em termos de composição do valor da composição do eutetóide, de 10,6 a 10,8\% em peso de molibdênio.

Comparando os difratogramas apresentados nas Figuras 41 e 42, fica claro que há uma crescente diminuição de concentração de uma das fases e aumento da concentração de gama, evidenciando-se assim que o tratamento na região de gama do diagrama de fases homogeneíza a estrutura. A temperatura e tempo utilizado de tratamento térmico foram 
tomados com base em diversos trabalhos, realizados com o intuito de se determinar valores destes parâmetros necessários à melhor homogeneização das ligas. Devo levar em conta, entretanto, que como cada uma das ligas possui um teor de molibdênio diferente, a obtenção de predominância em fase gama dependerá fortemente da composição da liga.

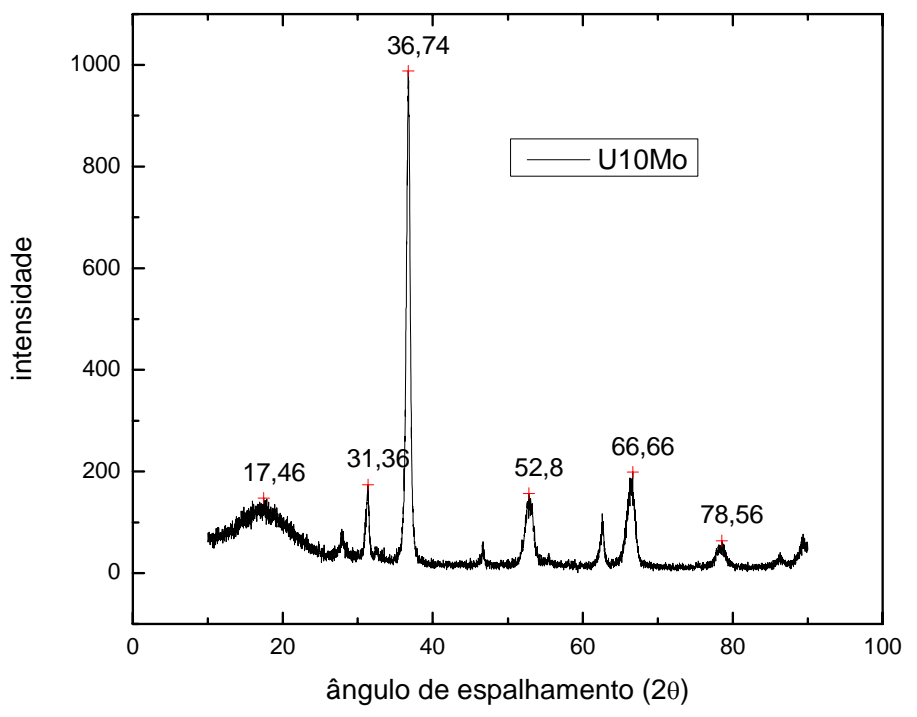

FIGURA 41 - Espectro de difração de raios-X, liga U10Mo, bruta de fusão.

Observa-se que com o tratamento térmico os picos de gama deslocaram-se para a direita $\left(36,74^{\circ}\right.$ para $\left.36,92^{\circ}\right)$ em relação aos picos da amostra bruta de fusão, que por sua vez aproximou-se mais do espectro teórico, que mesmo assim apresenta-se um pouco deslocado para a esquerda. Este desvio em relação ao teórico significa que uma maior quantidade de molibdênio foi utilizada como substituto na rede de urânio após o tratamento, daí o mesmo ser denominado tratamento térmico de homogeneização.

Picos próximos a $26^{\circ}, 47^{\circ}$ e $63^{\circ}$ tiveram intensidade reduzida, indicando que os mesmos referem-se a uma fase que provavelmente poderia conter algum molibdênio. Com o tratamento, esta fase foi se solubilizando na matriz, devido a perda deste elemento, seus picos caindo de intensidade. Daí a vantagem, especialmente em ligas produzidas via arco, da utilização de tratamento térmico. 


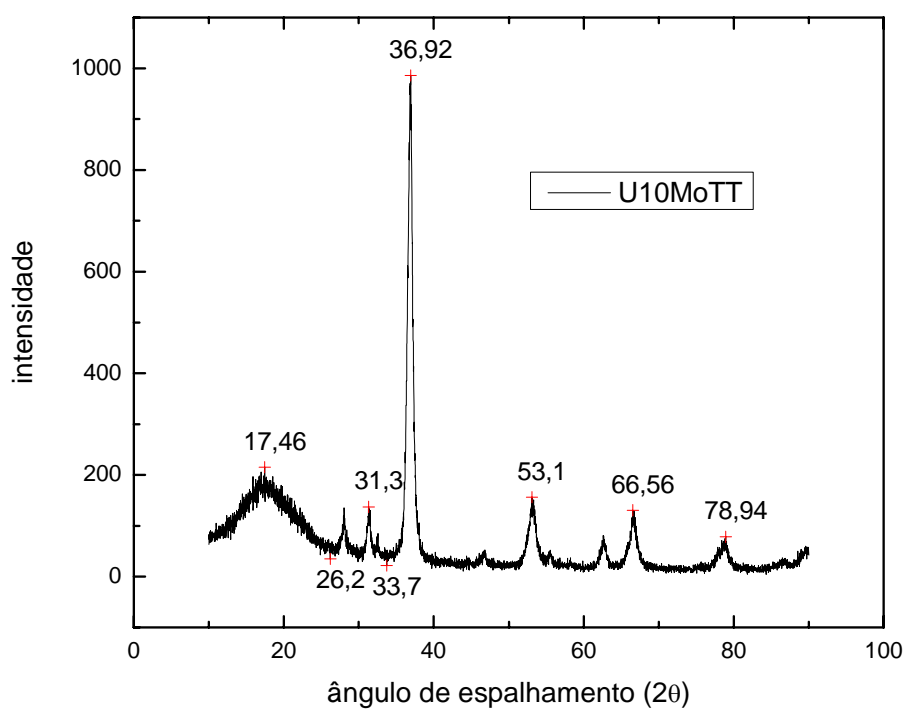

FIGURA 42- Espectro de difração de raios-X, liga U10Mo, tratada termicamente.

Nas micrografias das amostras brutas de fusão, Figura 43, observamos a presença de estruturas de fusão de ligas hipoeutetóides, que com o tratamento tenderam a deixar sobre a amostra a presença de uma sombra, indicando o seu desaparecimento, Figura 44.

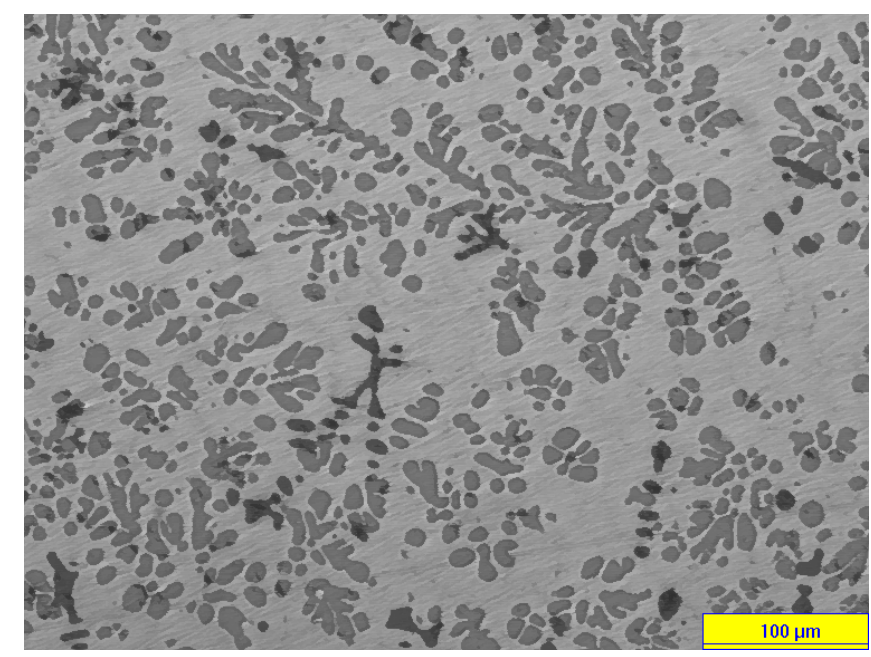

FIGURA 43 - Micrografia de liga bruta de fusão, microscópio óptico com analisador de imagens (400X).

$\mathrm{Na}$ imagem em aumento maior fica evidente a progressiva dissolução das dendritas na matriz, que se torna, entretanto, cada vez menos definida em termos de contornos de grão. Para que se examinasse a distribuição dos elementos pelas diversas 
fases observadas no microscópio, procedeu-se a uma análise por microscopia óptica de varredura da liga bruta de fusão, Figuras 45 e 46. Cinco foram as regiões da amostra escolhidas, correspondentes ao interior do grão e aos contornos, e a 3 regiões dendríticas distintas, principalmente quanto à coloração.

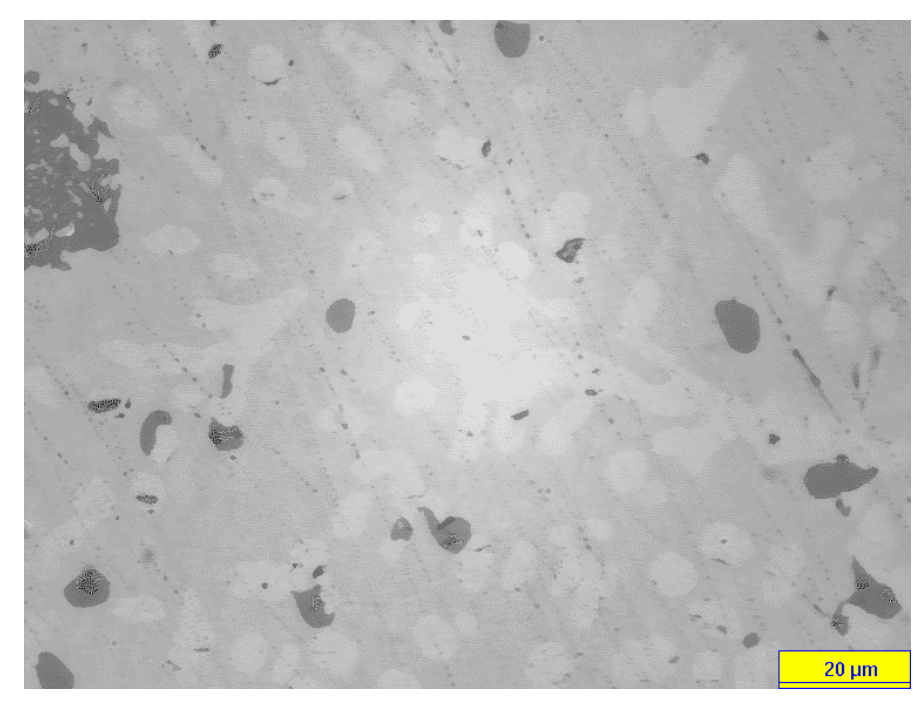

FIGURA 44 - Micrografia da liga tratada termicamente, microscópio óptico com analisador de imagens (1200X).

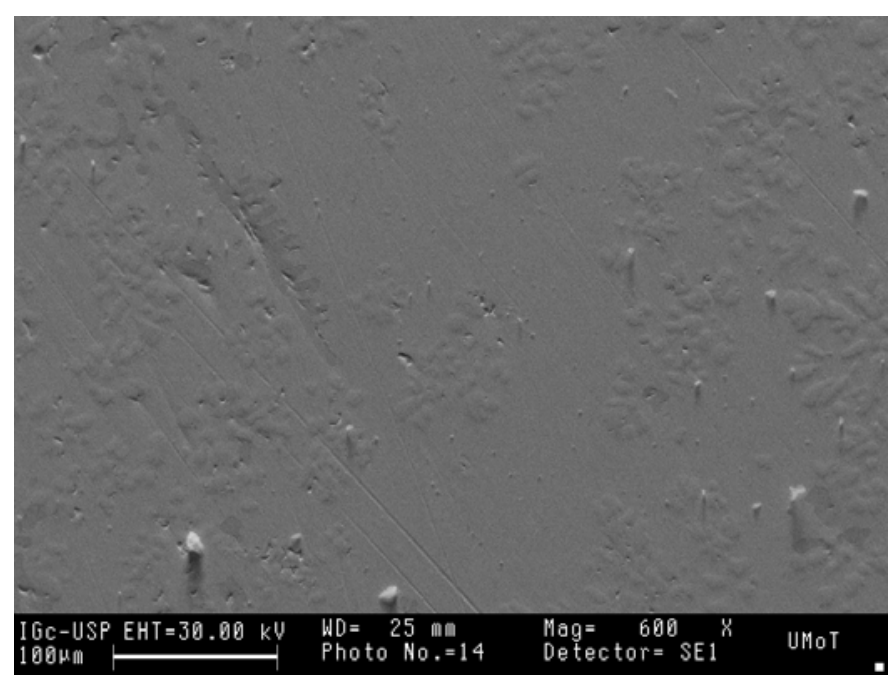

FIGURA 45 - Imagem de varredura de superfície da liga U10Mo (600X).

Na Figura 46, as regiões 1, 2 e 3, como seria de se esperar em solidificações de ligas binárias, mostraram composição da substância pura, dendritas compostas totalmente por urânio. Isto pode explicar a presença dos pouco intensos picos de difração de raios-X da estrutura alfa. Entretanto, o escurecimento maior das dendritas 1 e 2 provou-se ser 
devido à oxidação superficial (ver os picos de óxido também à figura 41, difratograma), dado o grande intervalo de tempo entre o preparo das amostras e a análise.

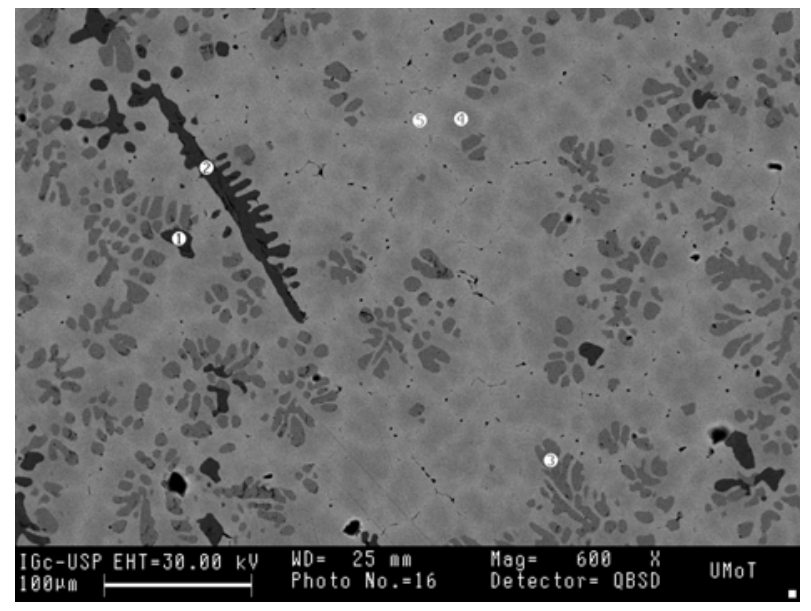

FIGURA 46 - Mesma imagem, por elétrons retro-espalhados (600X).

Na região 4, identificada como a matriz, a composição da liga aproximou-se da composição nominal em termos de molibdênio. Por esta técnica obteve-se uma quantidade de 10,74 (37) \% em peso de molibdênio (o número entre parênteses indica o erro padrão dos resultados), o que a torna uma liga muito próxima da composição eutetóide, e indicando também que a homogeneização da liga foi boa. Nas regiões intergranulares, Figura 47, mediu-se um teor de molibdênio ao redor de 6,48 (32) \%. Pela micrografia, observa-se que grãos já formados apresentam-se, muitos deles, definidos por estruturas que podem ser identificadas como poros. Em regiões onde o número de dendritas é grande os contornos não estão bem definidos, estas estruturas encontram-se ausentes.

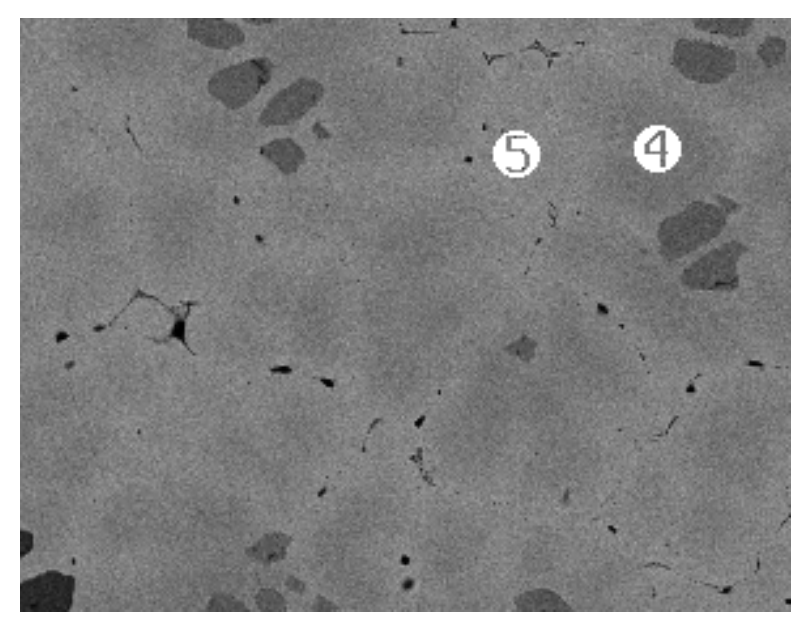

FIGURA 47 - Delineamento dos grãos por poros, liga U10Mo, micrografia anterior. 
Assim, estamos examinando uma micrografia relativa ao momento em que os grãos de gama-U estão sendo formados, daí a diferença na composição entre as regiões 4 e 5.

Para uma avaliação do progresso da solidificação, foram feitas análises de imagens na liga U10Mo. Considerou-se para tanto a diferença de coloração entre fase e matriz, composta pelas regiões 4 e 5 enumeradas na Figura 47, e nas dendritas, compostas pelas regiões 1,2 e 3, Figura 46, e alguma oxidação considerada mais evidente. Todas as três fases foram assinaladas com cores diferentes, conforme imagem seguinte.

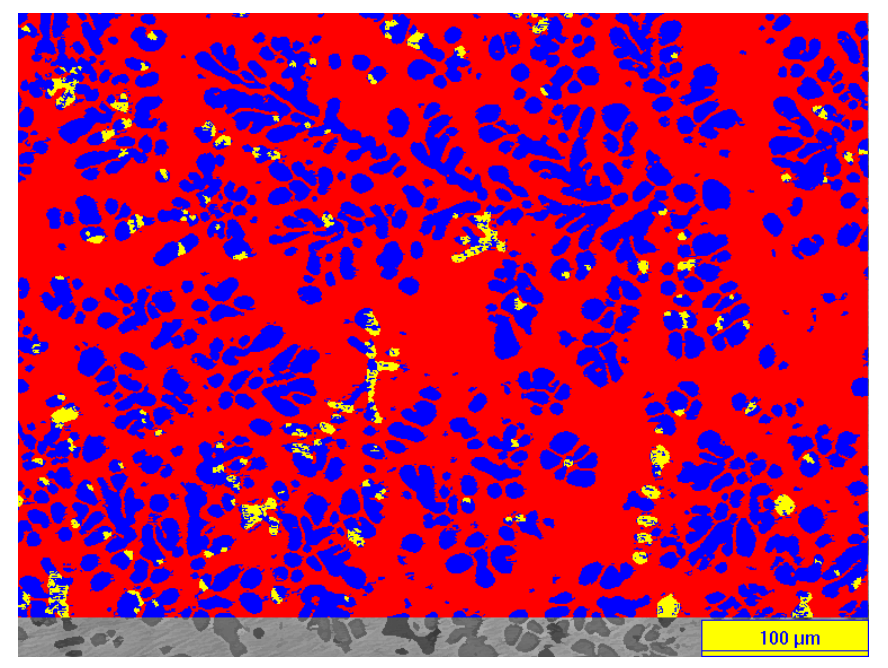

FIGURA 48 - Análise de imagens realizada sobre superfície da amostra U10Mo.

Os resultados em termos de fração de área ocupada pelas dendritas, matriz e oxidação foram os seguintes:

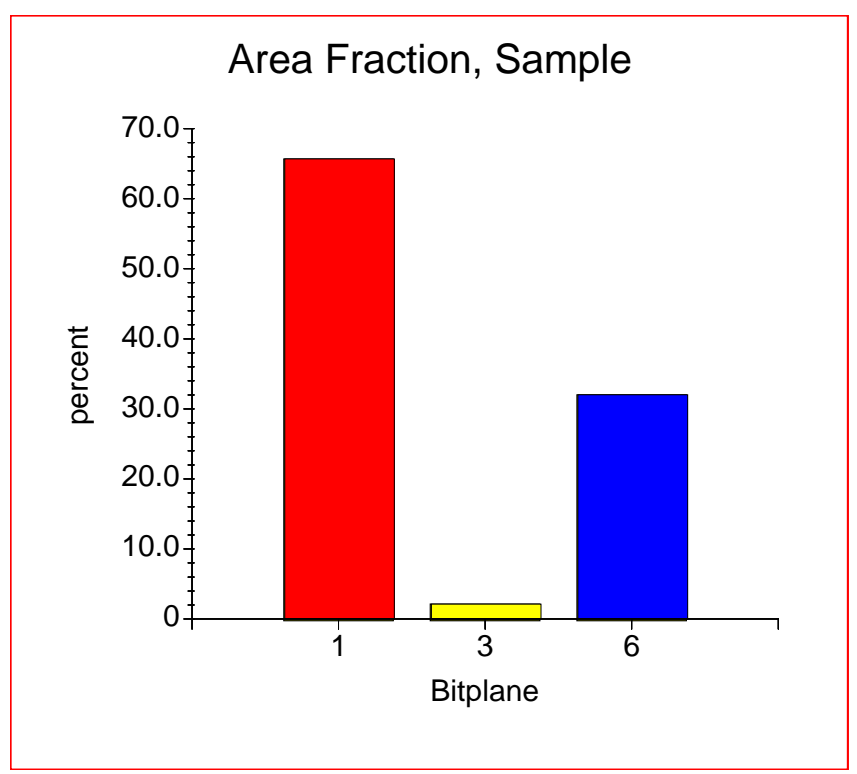

Field Summary

1: Bitplane1 $\quad 65.6825 \%$

3: Bitplane3 $\quad 2.12365 \%$

6: Bitplane6 $\quad 32.0073 \%$

Fld Area: $\quad 192476 \mu \mathrm{m}^{2}$

Tot Area: $\quad 192476 \mu \mathrm{m}^{2}$

Fld Count: 1

FIGURA 49 - Resultados de área de superfície por fase, Figura 48. 
indicando que $65,7 \%$ da área total da figura corresponde à matriz, considerada como formada pelos grãos mais contornos, $34,3 \%$ correspondendo às dendritas.

Quais ações poderiam ter sido tomadas, neste caso, para que a microestrutura desejada fosse obtida na primeira fusão? Perda de molibdênio pela aplicação do arco não ocorreu, dada a concentração de molibdênio na matriz. As estruturas dendríticas, mesmo após o tratamento térmico, ainda persistiram, mas muitas delas desapareceram, indicando a solubilização progressiva de alfa na matriz ou, melhor ainda, a progressiva dissolução do molibdênio nas fases dendríticas, homogeneizando-o pela amostra, conforme resultados dos difratogramas. Assim, um melhor controle da solidificação ou a realização de uma solidificação mais rápida, aliada ao uso de uma carga conveniente e também à aplicação de tratamento térmico, que aqui deveria ter sido realizado por mais tempo, poderia melhorar a qualidade do produto final.

Observa-se nesta primeira visão do processo de fusão das amostras via forno a arco que, em geral, o fator carregamento de molibdênio foi o determinante na obtenção das microestruturas observadas. Como as condições de solidificação das ligas foram as mesmas, conclui-se então que a facilidade com a qual as cargas cilíndricas pequenas homogeneízam-se ao longo do urânio líquido minimiza a necessidade de se elaborarem dispositivos para melhor controle do resfriamento.

$\mathrm{O}$ aumento no número de refusões aumenta a homogeneidade do molibdênio na matriz, mas não tem influência sobre a microestrutura final. Cargas outras que não a mencionada no parágrafo anterior levam a passos adicionais de fusão no processo, para que se atinja uma homogeneidade aceitável, mas o grande número de dendritas indica a necessidade de posterior tratamento térmico ou a utilização de acessórios para um melhor controle da solidificação, que deve ser efetuada em maior velocidade que as permitidas pelo equipamento. Pelo fato do equipamento ser tanto em termos de projeto e operação um tanto quanto mais simples, resultados encorajadores foram obtidos com ligas UMo3A, UMo4A, U7Mo2R, indicando-se assim um caminho para a obtenção de produtos de qualidade também via fusão a arco no IPEN.

Conforme veremos no item seguinte, esta inomogeneidade microestrutural é em muito minimizada pelo uso da técnica de fusão por indução, onde são obtidos materiais mais homogêneos. Entretanto, a indução também apresenta seus problemas, que serão discutidos a seguir. 


\subsection{Ligas produzidas por fusão via indução}

Neste item serão apresentados e discutidos os resultados de produção de ligas via fusão por indução. Conforme será visto, em termos de homogeneidade de composições e resultados dos tratamentos térmicos, esta técnica apresentou-se mais vantajosa. Entretanto, dado o menor nível de produção de alfa intergranular, menor segregação, para a produção de pós via hidretação, um novo tipo de tratamento térmico, o de conversão, deve ser aplicado às amostras. Isto será discutido no capítulo sobre hidrogenação.

\subsubsection{Densidades}

O método utilizado para a determinação das densidades foi o hidrostático, dada a forma das peças, semi-esférica. De maneira geral o comportamento das amostras obedeceu ao esperado, concordando com os previamente relacionados em literatura ${ }^{3,4}$. Na Figura 50 são mostrados os resultados, tomados como os valores médios sobre 5 determinações, efetuados após imersão de toda a liga em água.

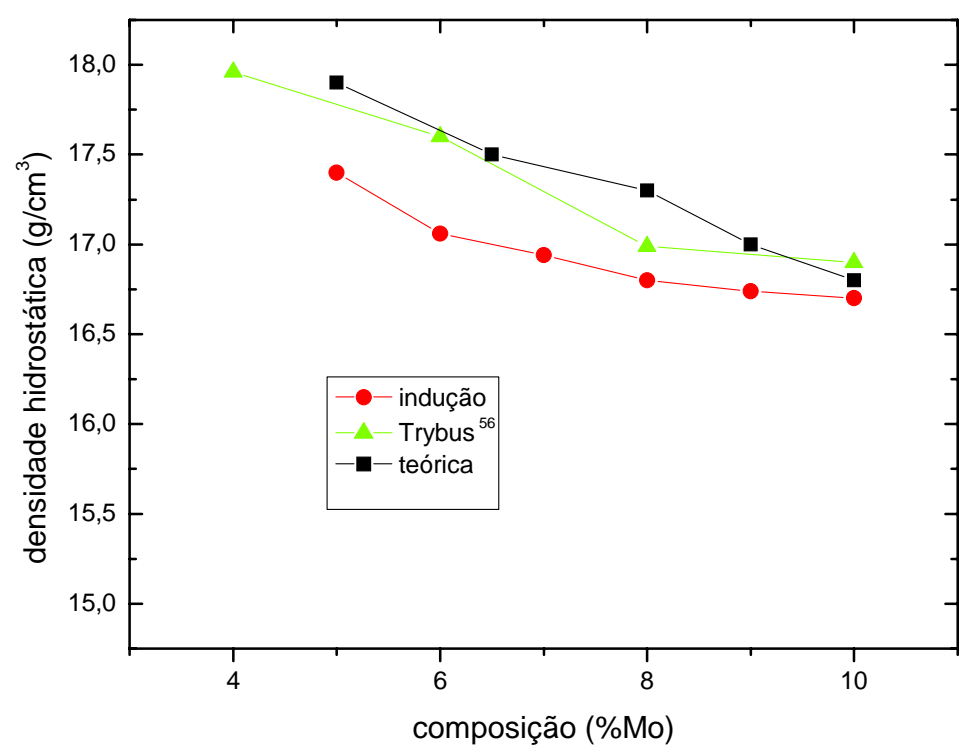

FIGURA 50 - Densidades das ligas produzidas por indução.

As ligas ternárias UMoSi apresentaram densidades menores que a das ligas $\gamma \mathrm{UMo}$, ao redor de 14,8 e $12,4 \mathrm{~g} / \mathrm{cm}^{3}$, mas maiores que a do siliceto de urânio. É de se esperar, então, a formação de fases diferentes da fase gama, como componentes da estrutura desta liga. É o que será verificado nos capítulos seguintes, especialmente após a caracterização via difração de raios-X. 


\subsubsection{Caracterização Microestrutural}

Serão apresentados inicialmente os resultados de microscopia óptica seguidos dos de difração de raios-X e análises químicas, para as amostras brutas de fusão e tratadas termicamente.

\subsubsection{1 liga Base $\gamma \mathrm{U} 5 \mathrm{Mo}$}

Observe-se a estrutura dos grãos desta liga. Contendo menor teor de molibdênio, é de se esperar uma maior visualização de fases pobres em molibdênio, no caso alfa-urânio, em contornos de grão e intragranularmente.

À primeira vista, observa-se que a estrutura de grãos é mais definida, identificando, ao contrário das amostras de forno a arco, boa homogeneidade, Figura 51. Os grãos em geral apresentam dimensões maiores que as ligas de forno a arco, o que vem a confirmar o fato de que o resfriamento em forno de indução é mais lento que em forno a arco, como seria de se esperar, pois neste caso estamos trabalhando com molde cerâmico, portanto um isolante térmico. Outra característica interessante é a presença de dendritas, principalmente nos contornos de grão, embora em pequena quantidade, reforçando o fato de que a presença de molibdênio atua como estabilizador da matriz de gama, minimizando a formação de precipitados. Um bom número de inclusões intragranulares pode ser também observado, provavelmente oriundas do processo de fabricação do urânio metálico.

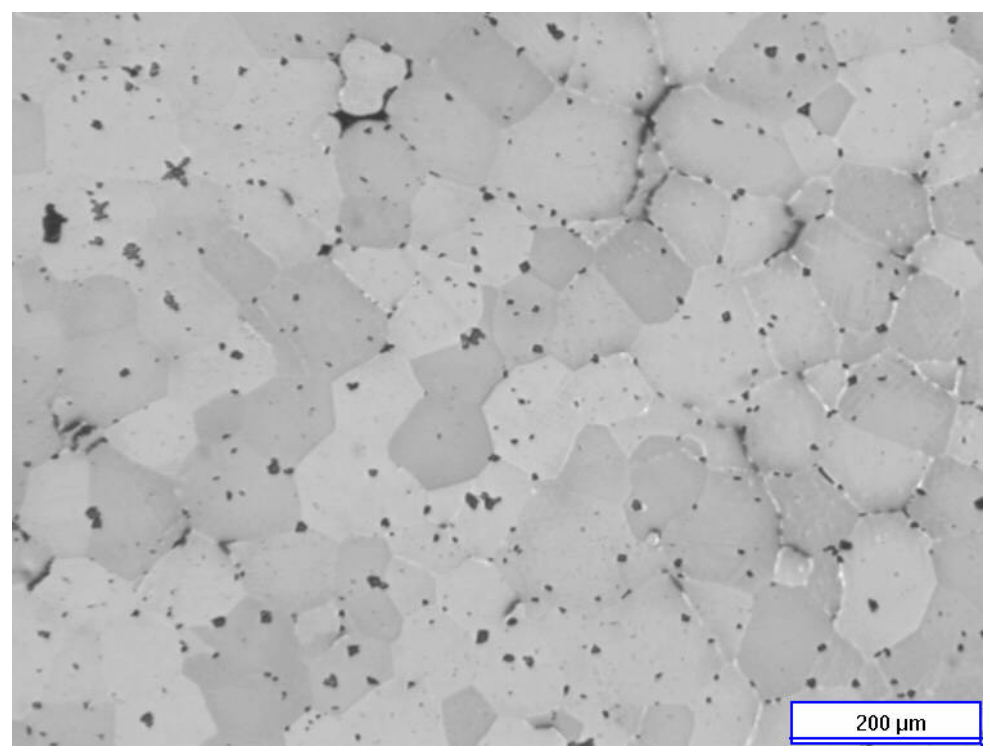

FIGURA 51 - Micrografia de liga $\gamma U 5$ Mo, 200X, bruta de fusão. 
Após tratamento térmico de homogeneização por 24 horas à temperatura média de $1038^{\circ} \mathrm{C}$, a estrutura de grãos da liga apresentou-se conforme mostrado na Figura 52.

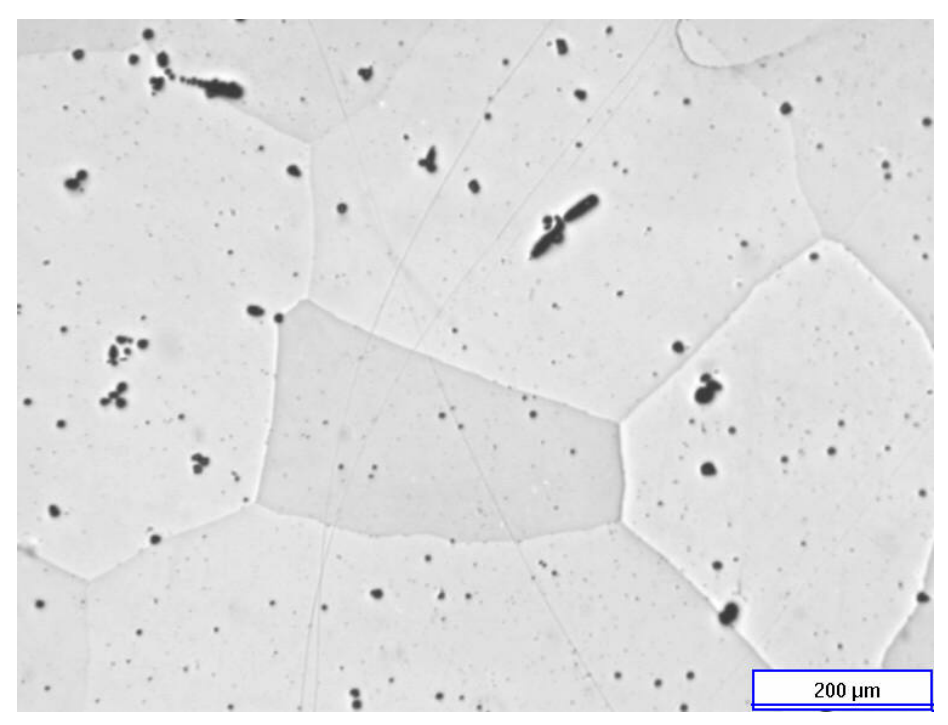

FIGURA 52 - Micrografia de liga $\gamma U 5 \mathrm{Mo}, 200 \mathrm{X}$, tratada termicamente, $1038^{\circ} \mathrm{C} / 24$ horas.

Aqui observou-se um crescimento no tamanho dos grãos bem acentuado, a presença das dendritas, agora intragranulares, aparecendo como poros, arrancadas as fases durante o processo de preparo das superfícies. Para verificar se 24 horas é um tempo suficiente para o limite no crescimento do tamanho dos grãos, efetuou-se tratamento térmico por 72 horas à temperatura média de $1000^{\circ} \mathrm{C}$. Na Figura 53 observa-se diminuição na porosidade das amostras, mas não foi observado aumento do tamanho dos grãos.

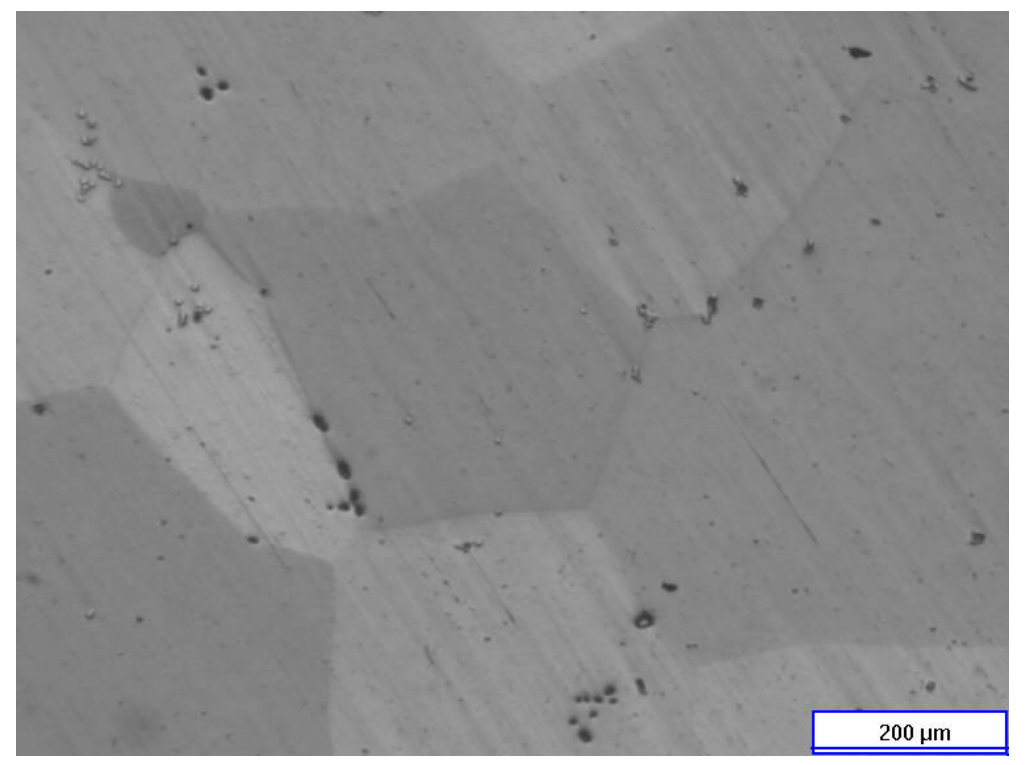

FIGURA 53 - Micrografia liga $\gamma \mathrm{U} 5 \mathrm{Mo}, 200 \mathrm{X}$, tratada termicamente, 72 horas, $1000^{\circ} \mathrm{C}$. 
Assim, o tratamento térmico inicialmente promove o aumento do tamanho dos grãos, que atinge um limite, em nosso caso, próximo a 24 horas. A solubilização da fase alfa, intragranular, continua a se processar, atingindo um nível satisfatório após as 72 horas de tratamento, tempo tradicionalmente utilizado para a homogeneização de ligas $\gamma \mathrm{UMo}$.

Portanto, se se desejar obter pó a partir destas estruturas, dever-se-á controlar o tempo para a obtenção do tamanho de grão correto. Nas especificações para os combustíveis do IPEN, o tamanho médio de grãos deve estar entre 44 e $53 \mu \mathrm{m}$. Assim, um tempo não superior a 24 horas deverá ser utilizado, caso se trabalhe nesta porcentagem de adição, utilizando a técnica de indução. Ou ainda, se se quiser tamanhos de grão menores, dever-se-á utilizar temperaturas menores, na região monofásica de gama.

Outro fenômeno importante, e que pode ser inferido a partir do exame destas micrografias, é a densificação das amostras com o progresso do tempo de tratamento térmico. Observa-se a redução, ao menos, na porosidade fechada, o que obviamente leva a uma maior contração em volume e, portanto, maior densidade.

\subsubsection{2 ligas Base $\gamma \mathrm{U} 6 \mathrm{Mo}$ e $\gamma \mathrm{U} 7 \mathrm{Mo}$}

Inicialmente apresenta-se uma micrografia da amostra bruta de fusão, figuras 54 e 56, e também as de tratamento térmico para a liga $\gamma \mathrm{U} 6 \mathrm{Mo}$, Figura 55. O efeito observado sobre o crescimento dos grãos e sobre a solubilização e desaparecimento das dendritas foi o mesmo, ou seja, aumento no tamanho de grãos acentuado entre o tempo zero e as primeiras 24 horas de tratamento térmico, seguido de estabilização, após 48 horas, no tamanho médio dos grãos.

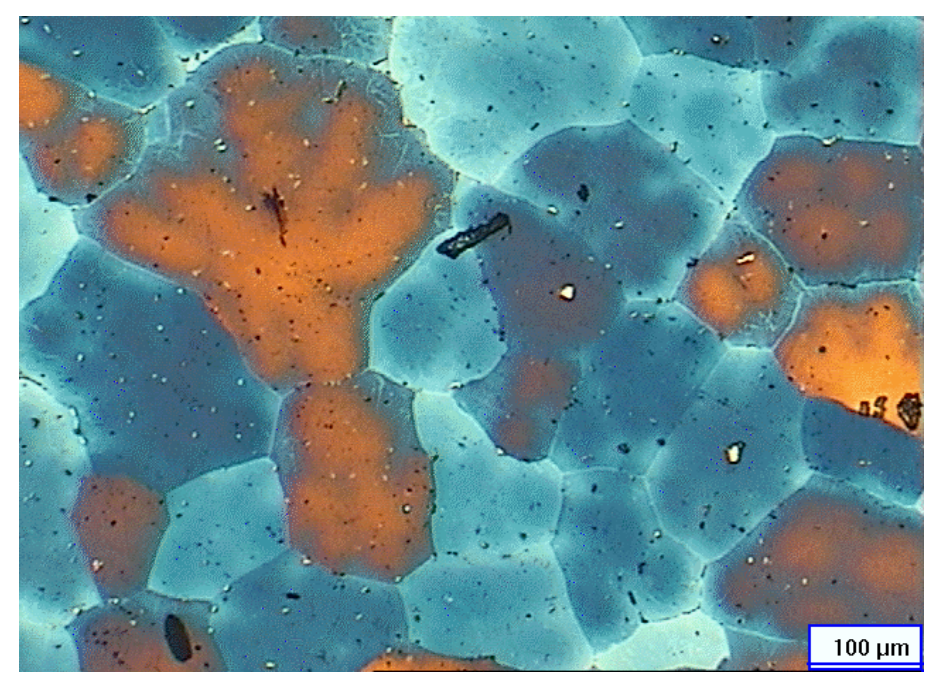

FIGURA 54 - Micrografia da liga $\gamma U 6 \mathrm{Mo}, 400 \mathrm{X}$, bruta de fusão. 
A liga base $\gamma \mathrm{U} 7 \mathrm{Mo}$ é a tradicionalmente utilizada na fabricação de pós via hidretação-dehidretação. Assim, é importante se saber o seu comportamento sob os diversos tratamentos térmicos, cuja evolução é mostrada a seguir. Novamente observa-se um elevado crescimento no tamanho dos grãos, por comparação entre as Figuras 54 e 55, após 24 horas de tratamento térmico, indicando-se a necessidade de se controlar o tamanho dos grãos em tempo anterior a este período.

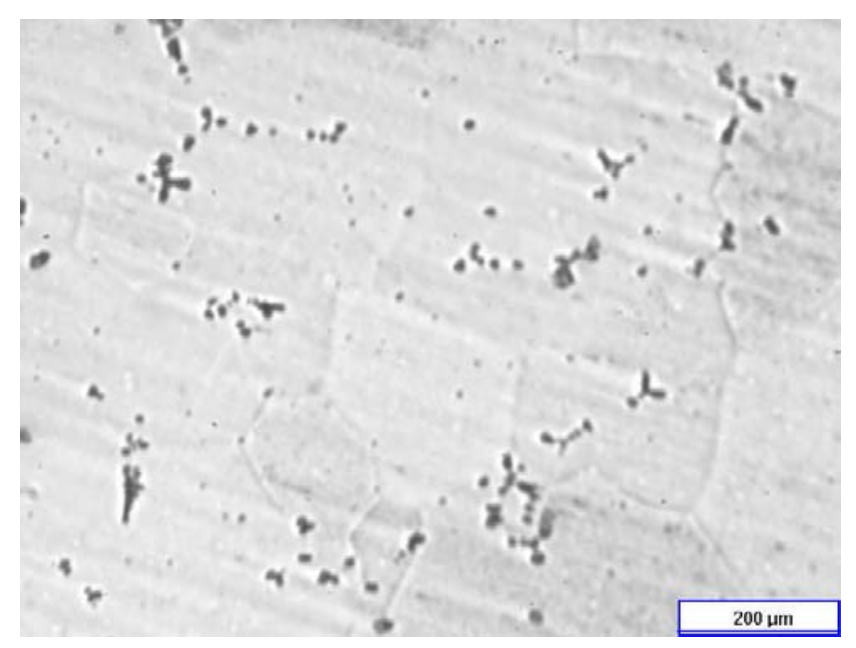

FIGURA 55 - Micrografia da liga $\gamma U 6 \mathrm{Mo}, 200 \mathrm{X}$, tratada termicamente, $1038^{\circ} \mathrm{C} / 24$ horas.

Na Figura 56 está apresentada a micrografia correspondente à liga $\gamma \mathrm{U} 7 \mathrm{Mo}$. Observo, face às duas anteriores, a ausência de fase alfa intergranular, responsável pelo sucesso na hidretação e obtenção de pós. Daí a necessidade da aplicação de tratamentos térmicos de conversão parcial da estrutura gama em alfa para a produção dos pós.

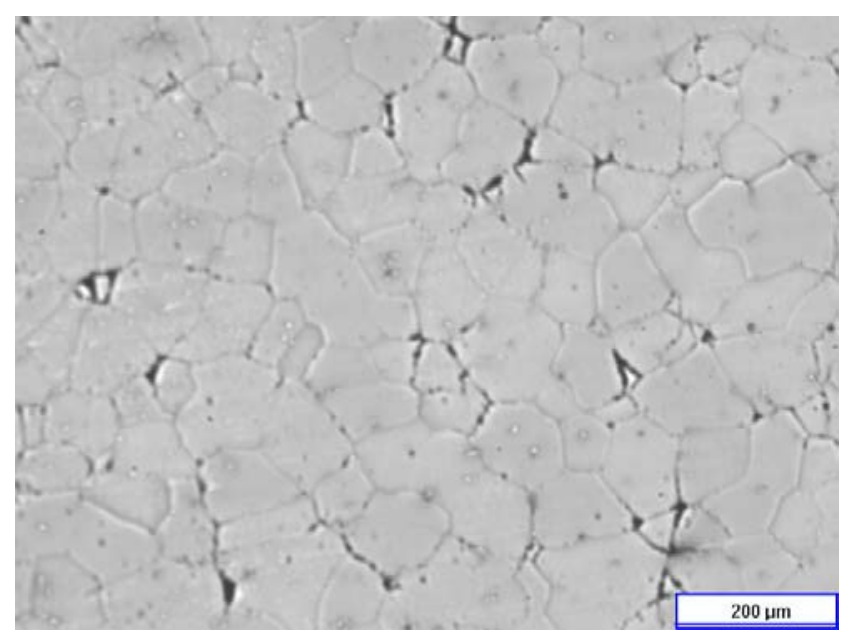

FIGURA 56 - Micrografia da liga $\gamma \mathrm{U} 7 \mathrm{Mo}, 200 \mathrm{X}$, bruta de fusão. 
Esta imagem foi propositalmente desfocada, para a melhor visualização dos contornos de grão. Observa-se a presença de porosidade intra e intergranular, e algumas inclusões. Conforme os resultados destas ligas, estas estruturas foram desaparecendo com o aumento nos tempos de tratamento térmico.

\subsubsection{Liga Base $\gamma \mathrm{U} 8 \mathrm{Mo}$}

A partir desta porcentagem, é possível que haja uma alteração nos mecanismos de precipitação de fase alfa e fragilização das ligas, conforme será discutido no capítulo 13, sobre hidrogenação e fabricação dos pós.

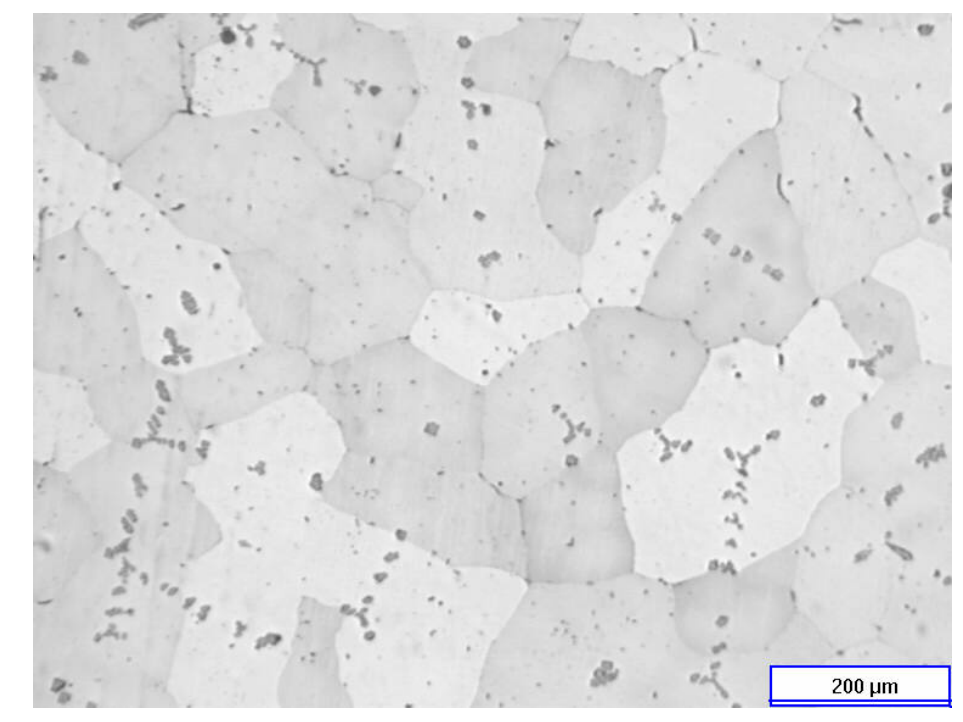

FIGURA 57 - Micrografia da liga $\gamma U 8 \mathrm{Mo}, 200 \mathrm{X}$, bruta de fusão.

Na Figura 57 observa-se a presença de dendritas, uma estrutura de grãos bem definida, ausência de fase alfa e porosidade intergranular, e presença de algumas inclusões. A ausência de alfa deve-se à estabilização da estrutura, pela quantidade de molibdênio adicionada. Novamente o crescimento dos grãos, nestas condições de tratamento térmico, foi muito elevado, conforme Figura 58. Algumas estruturas relacionadas à fase alfa e dendritas permaneceram, entretanto o padrão dos grãos alterou-se completamente.

Assim como nas ligas anteriores, houve boa visualização dos contornos de grão. Entretanto, após tratamentos térmicos, esta visualização tornou-se mais difícil, devido ao seu crescimento. Por este motivo as medidas de diâmetros dos grãos para estas ligas foram feitas sobre uma amostra de tamanho menor, relativamente à das ligas brutas de fusão. 


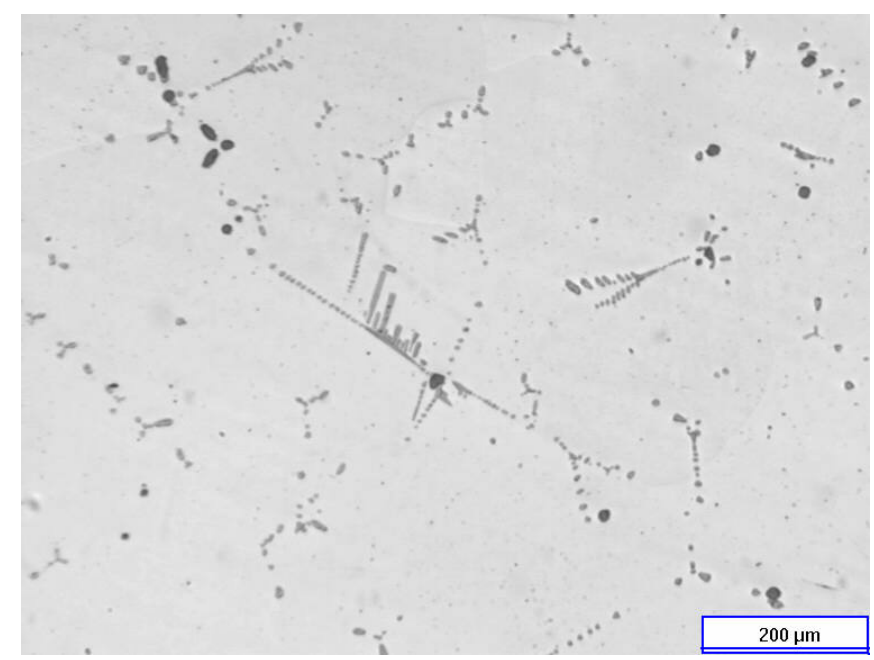

FIGURA 58 - Micrografia da liga $\gamma \mathrm{U} 8 \mathrm{Mo}, 200 \mathrm{X}$, tratada termicamente, $1038^{\circ} \mathrm{C} / 24$ horas.

\subsubsection{5 ligas Base $\gamma \mathrm{U} 9 \mathrm{Mo}$ e $\gamma \mathrm{U} 10 \mathrm{Mo}$}

Examine-se as diferenças principias entre estas ligas e a anterior, por meio das Figuras 59, 60, 61 e 62. A estrutura bruta de fusão foi semelhante à da liga $\gamma U 8 M o$, entretanto apresentaram um maior número de poros intergranulares. Esta maior presença de porosidade explica a queda brusca nas densidades das ligas a partir deste teor de molibdênio, conforme será visto adiante, à p. 202.

Após os tratamentos térmicos, os grãos crescem, Figuras 60 e 62, e ficam mais grosseiros, indicando a coalescência de muitos deles (recristalização), após 72 horas. Observa-se na Figura 60 que uma boa visualização dos grãos é possível pela existência dos poros. Ainda, em algumas regiões, os grãos apresentaram dimensões maiores que a do campo visual do microscópio óptico, não sendo possível a medida de seu diâmetro.

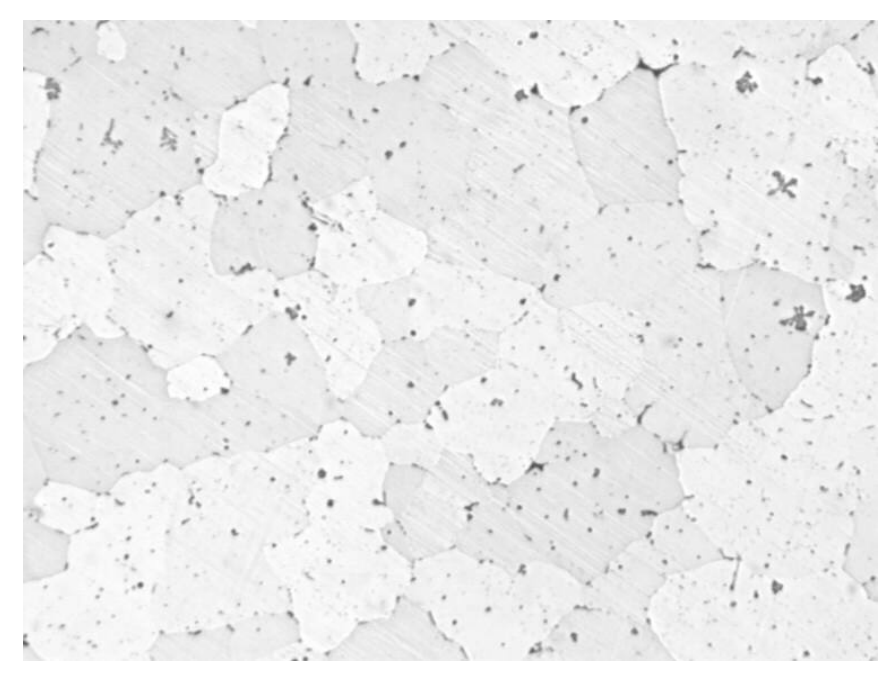

FIGURA 59 - Micrografia da liga $\gamma U 9 M o, 200 X$, bruta de fusão. 


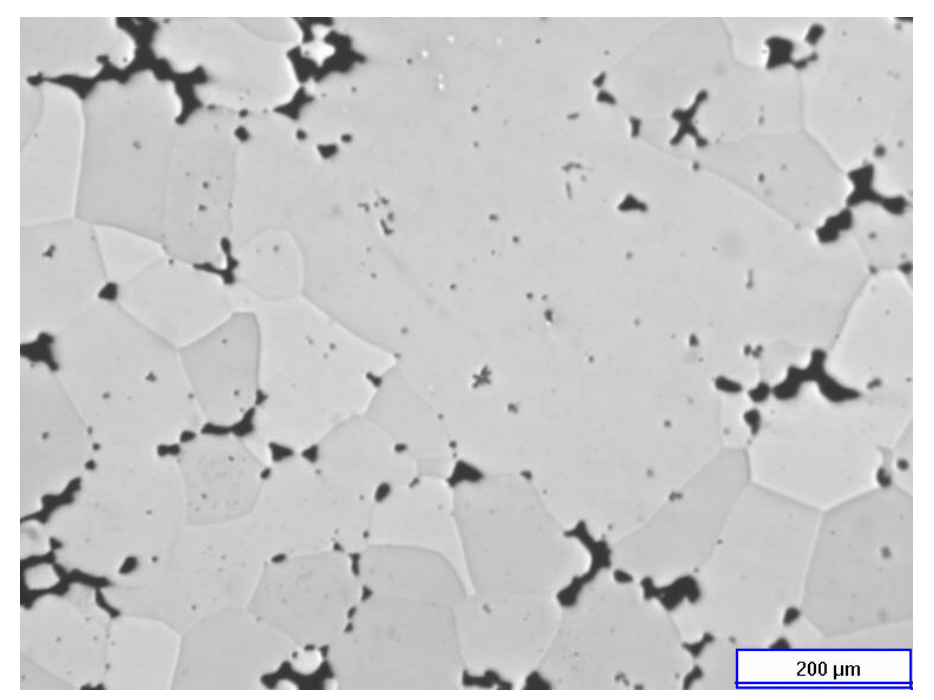

FIGURA 60 - Micrografia da liga $\gamma \mathrm{U} 9 \mathrm{Mo}, 200 \mathrm{X}$, tratada termicamente, $1038^{\circ} \mathrm{C} / 72$ horas.

A mais estável de todas elas, a liga base $\gamma \mathrm{U} 10 \mathrm{Mo}$, possui estrutura muito semelhante à da liga $\gamma \mathrm{U} 9 \mathrm{Mo}$, Figura 61. Observa-se que nenhuma alteração nas dimensões dos grãos foi observada. Podemos concluir, pelo formato dos grãos das amostras tratadas por 48 horas, que este tempo não foi suficiente para o crescimento dos grãos da liga. Outra conclusão possível é obtida a partir do difratograma de raios-X, à p. 195. Como há um pico intenso a $27^{\circ}$ (ver Figura 83, p.195), provavelmente relativo à fase delta, conclui-se então que a presença de alguma quantidade de fase delta iniba o crescimento dos grãos.

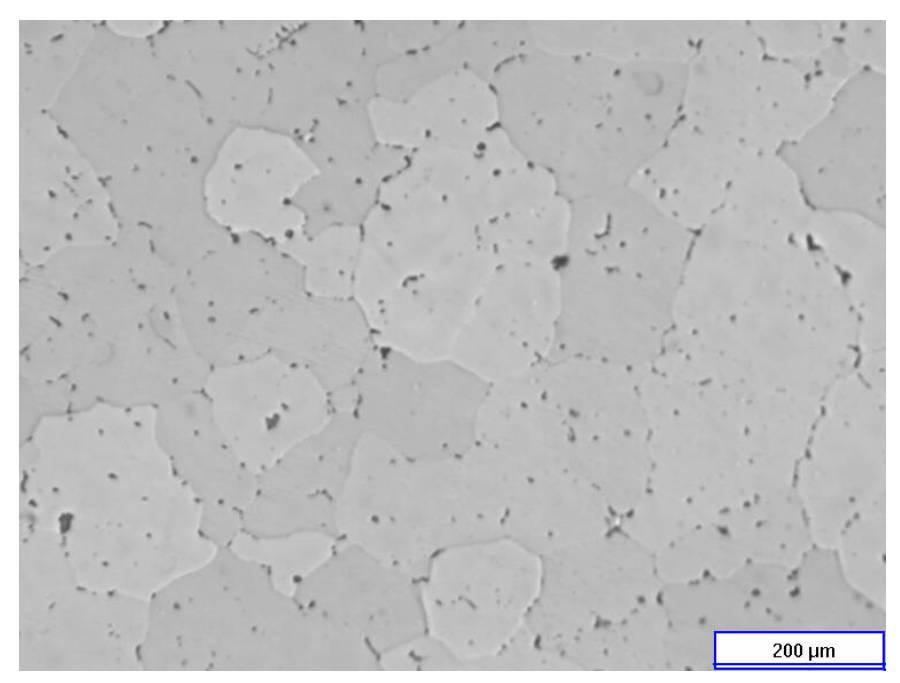

FIGURA 61 - Micrografia liga $\gamma U 10 \mathrm{Mo}, 200 \mathrm{X}$, bruta de fusão.

A fase delta é o único composto do sistema U-Mo. Por ter composição definida, não pode, por difusão, ser solubilizado na matriz, devendo ser considerado, para 
fins de produção de pós, como perda de processo. Entretanto, o trabalho mecânico sobre a liga a frio, conforme mencionado do trabalho de Bar-Or e Goldstein ${ }^{08}$ e Van Thyne e McPherson ${ }^{16}$, pode reverter delta a gama.

Estes autores observaram, durante a fabricação de pós mecanizados de ligas $\gamma \mathrm{U} 10 \mathrm{Mo}$, que a possível fase delta presente nas amostras pode ser convertida a gama por sucessivos ciclos de operação em equipamento de limagem e cominuição.

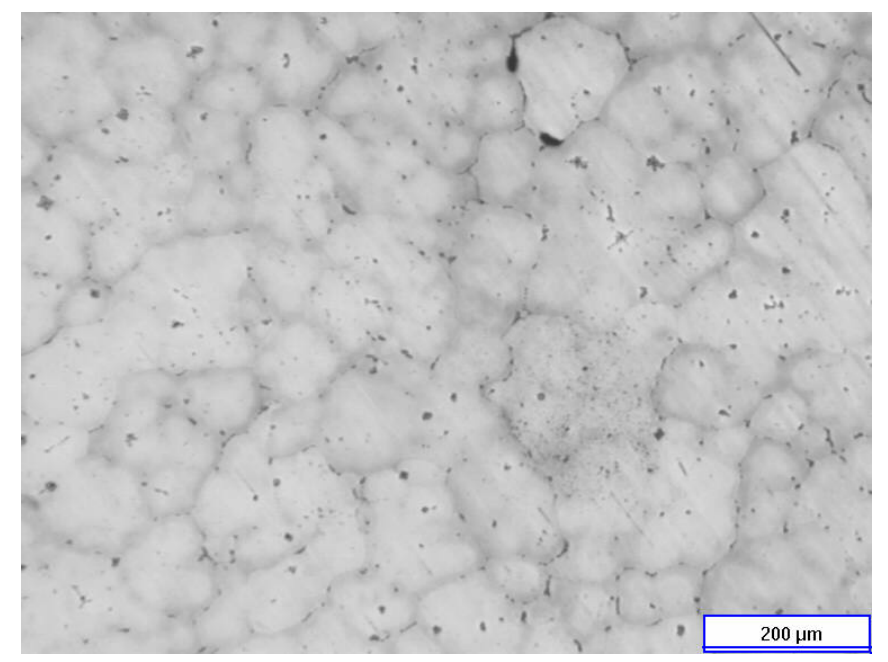

FIGURA 62- Micrografia da liga $\gamma \mathrm{U} 10 \mathrm{Mo}, 200 \mathrm{X}$, tratada termicamente, $1000^{\circ} \mathrm{C}, 48$ horas.

\subsubsection{7 ligas $\gamma \mathrm{UMOSi}$}

Como nas micrografias de fusão a arco, as amostras apresentaram-se compostas por uma matriz contínua, rica na fase gama-UMo, com formações dendríticas típicas das estruturas correspondentes à dos compostos de urânio e silício, figuras 63 e 64 . Assim, mesmo após os tratamentos térmicos, realizados a temperaturas entre 900 e $950^{\circ} \mathrm{C}$ por tempos de 2 a 8 horas, visto que foi observada reação neste sistema em temperaturas próximas a $1000^{\circ} \mathrm{C}$, pouca alteração foi observada. Ou seja, a amostra é composta por 2 fases, imiscíveis mesmo sob tratamento térmico de homogeneização.

O estudo destas adições ternárias tomou por base o já exposto no capítulo 3 sobre os melhores resultados quando das adições de silício tanto à matriz de alumínio quanto à matriz de combustível UMo, ou ainda em ação combinada, adições simultâneas de até $2 \%$ à matriz e de $0,5 \%$ na fase combustível.

O limite de solubilidade do silício em urânio gama está ao redor de $0,6 \%$, conforme diagrama de fases binário $\mathrm{U}_{-} \mathrm{Si}^{04}$. Conforme foi verificado nas fusões de amostras semelhantes de fusão a arco, descritas no item 10.1.2.6 (p.154) para a liga UA10, 
uma grande quantidade de excesso de silício na liga produz fases bem distintas. A mais destacada delas, aparecendo em relevo nas Figuras 63 e 64, composta principalmente por urânio e quantidades iguais de silício e molibdênio, mas este em menor quantidade que a nominal, e a matriz, composta de várias regiões, contendo urânio metálico somente, regiões com pouco molibdênio, e ainda regiões ricas em Mo e $\mathrm{Si}$, e a formação de compostos U-Si. Isto indica que este excesso promove reações do silício com Mo e U, o que retira Mo da fase em relevo, tornado-a menos estabilizada.

Como foi constatada a existência deste tipo de estrutura de segregação, partiuse daí para a resolução de um problema tecnológico relacionado à fabricação dos pós das ligas $\gamma \mathrm{UM}$.

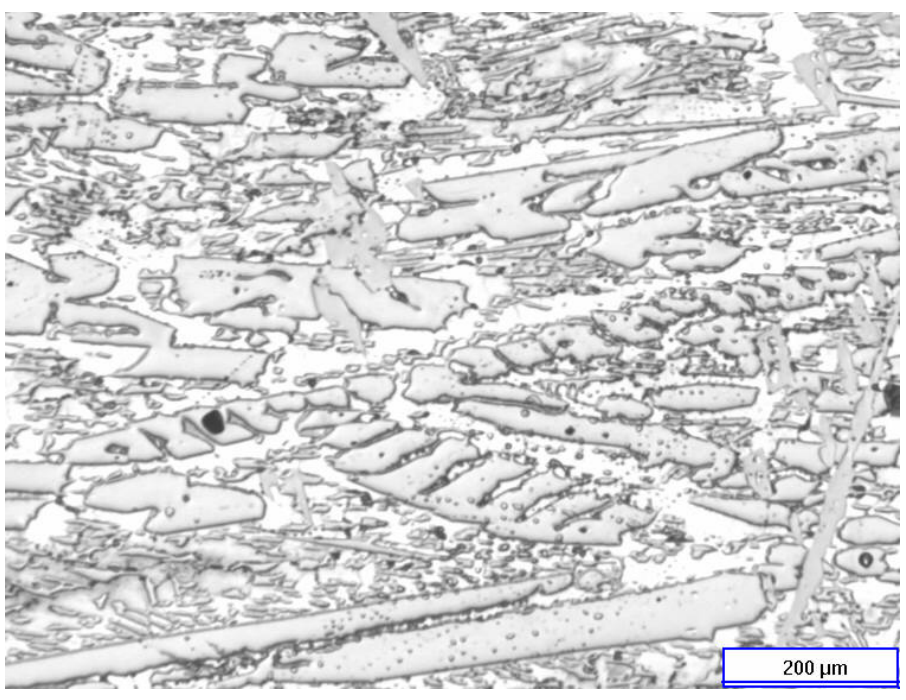

FIGURA 63 - Liga ternária código $\gamma \mathrm{UMo11,} \mathrm{(200X),} \mathrm{centro} \mathrm{da} \mathrm{amostra,} \mathrm{bruta} \mathrm{de} \mathrm{fusão.}$

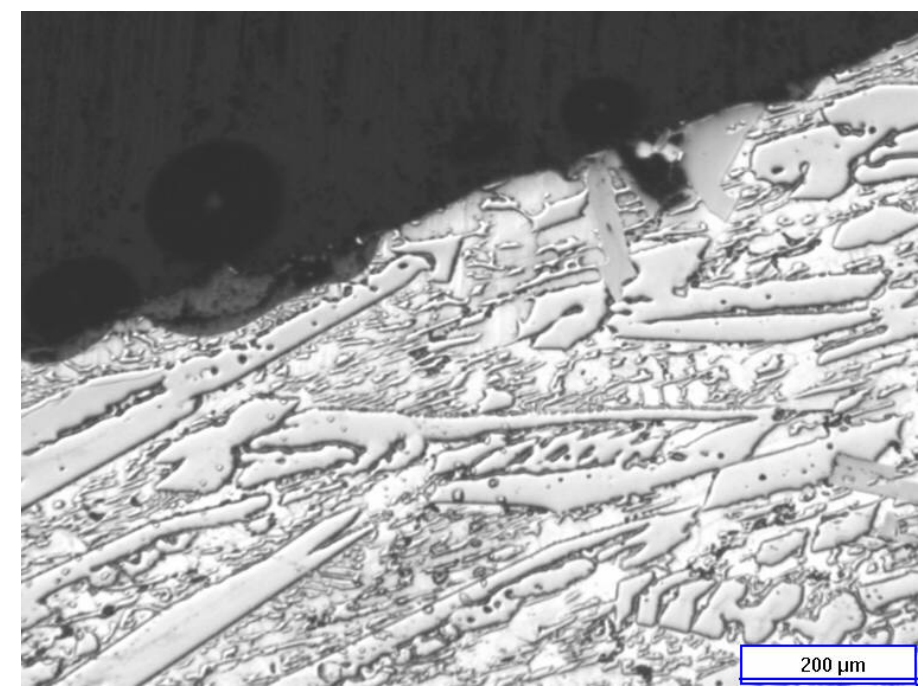

FIGURA 64 - Liga ternária código $\gamma U$ Mo11, (200X), borda, bruta de fusão. 
Sabendo que a ductilidade das ligas de urânio molibdênio é alta (como seria de se esperar para uma liga metálica, e como mostraram os resultados dos ensaios de dureza, a serem discutidos adiante), a técnica de HMDH para obtenção de pós parte do princípio de que a promoção de uma reação de decomposição da matriz de gama em alfa, após tratamentos térmicos sob hidrogênio, fragilize a liga, tornando-a mais susceptível à fragmentação.

Esta reação de decomposição apresenta algumas desvantagens, pois não é possível a reversão da fase alfa formada nos contornos de grão, o que leva a perda de material, e ainda, constitui-se em mais uma etapa a ser inserida no processo de fabricação das ligas. Entretanto, técnicas como esta estão mais relacionadas ao que se chama de "engenharia de materiais" do que as outras, as tradicionais de mecanização e as de atomização.

Assim, a idéia aqui foi a da escolha de um elemento que, além de estabilizar a fase gama satisfatoriamente, fosse capaz também de atuar como um formador de precipitados, em contornos de grão, como os obtidos por tratamento na técnica de HDH. Dados os bons resultados em termos de estabilização da fase gama com adição ternária mostradas nos trabalhos RERTR, e observados os resultados desta tese em termos de formação de precipitados, foi escolhido o silício como base para os estudos de adições ternárias. Este elemento, quando adicionado em porcentagem conveniente, mostrou-se completamente solúvel na matriz, pois predomina a estrutura gama nos espectros de difração de raios-X e, ainda, promove a formação de fases intergranulares, compostas principalmente por combinações MoSi e USi, mais frágeis que a matriz gama.

Portanto, em uma só etapa do processamento, são resolvidos três problemas de interesse na tecnologia de fabricação de combustíveis de alta densidade. O primeiro é o do aumento na estabilidade da fase gama, mesmo com adições de Mo inferiores a 9\%. O segundo, oriundo do primeiro e conforme mostrado no capítulo 3 como resultados dos testes RERTR, é o da inibição do crescimento da camada de reação, o que minimiza problemas de variação de temperatura e gradientes térmicos ao longo das placas, especialmente em ciclos de queima mais longos, e também problemas de inchamento. $\mathrm{O}$ terceiro é o da fabricação dos pós, por meio da precipitação de fase frágil, durante a solidificação das ligas, em contornos de grão, o que pode eliminar a necessidade de novas etapas no processo de fabricação de combustíveis à base de dispersões.

As imagens de microscopia eletrônica de varredura acompanhadas das análises de EDS são mostradas a seguir, para as ligas UMo11 e UMo12, Figuras 65 a $77 . \mathrm{Na}$ 
primeira delas, como a extensão das fases pobres em Mo foi maior, efetuaram-se dois tratamentos térmicos de homogeneização, nas condições mencionadas ao início deste item, para verificar seus efeitos sobre esta região. Para a segunda, dados os resultados dos tratamentos da primeira, efetuaram-se medidas somente sobre a liga bruta de fusão.

Os espectros de EDS foram tomados em diversas regiões das ligas, especialmente onde foi verificada a possibilidade de apresentarem concentrações dos principais elementos, $\mathrm{U}$, Mo e Si, diferentes, indicando a existência de fases diferentes.
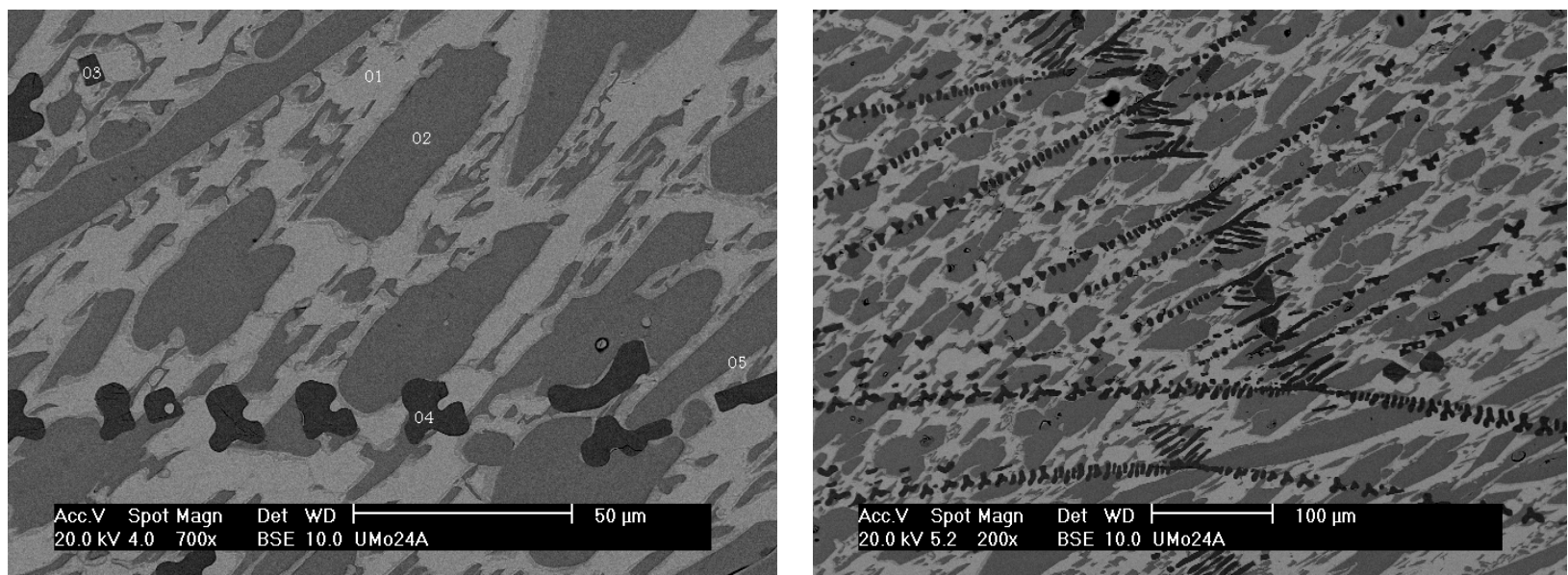

FIGURA 65 - Liga ternária UMo11, bruta de fusão, esquerda 700X, direita 200X.

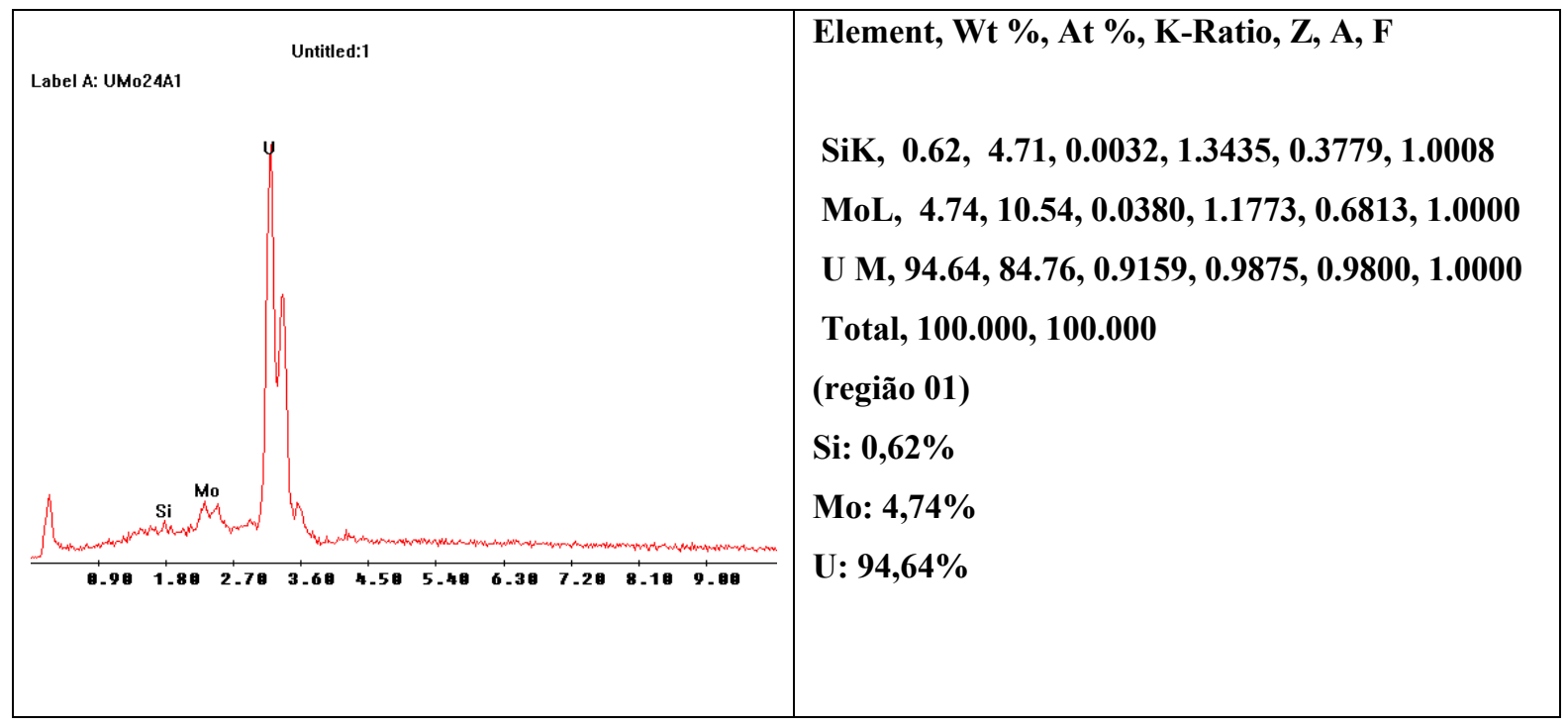

FIGURA 66 - EDS, liga ternária UMo11, bruta de fusão, concentrações na região 01 da amostra. 


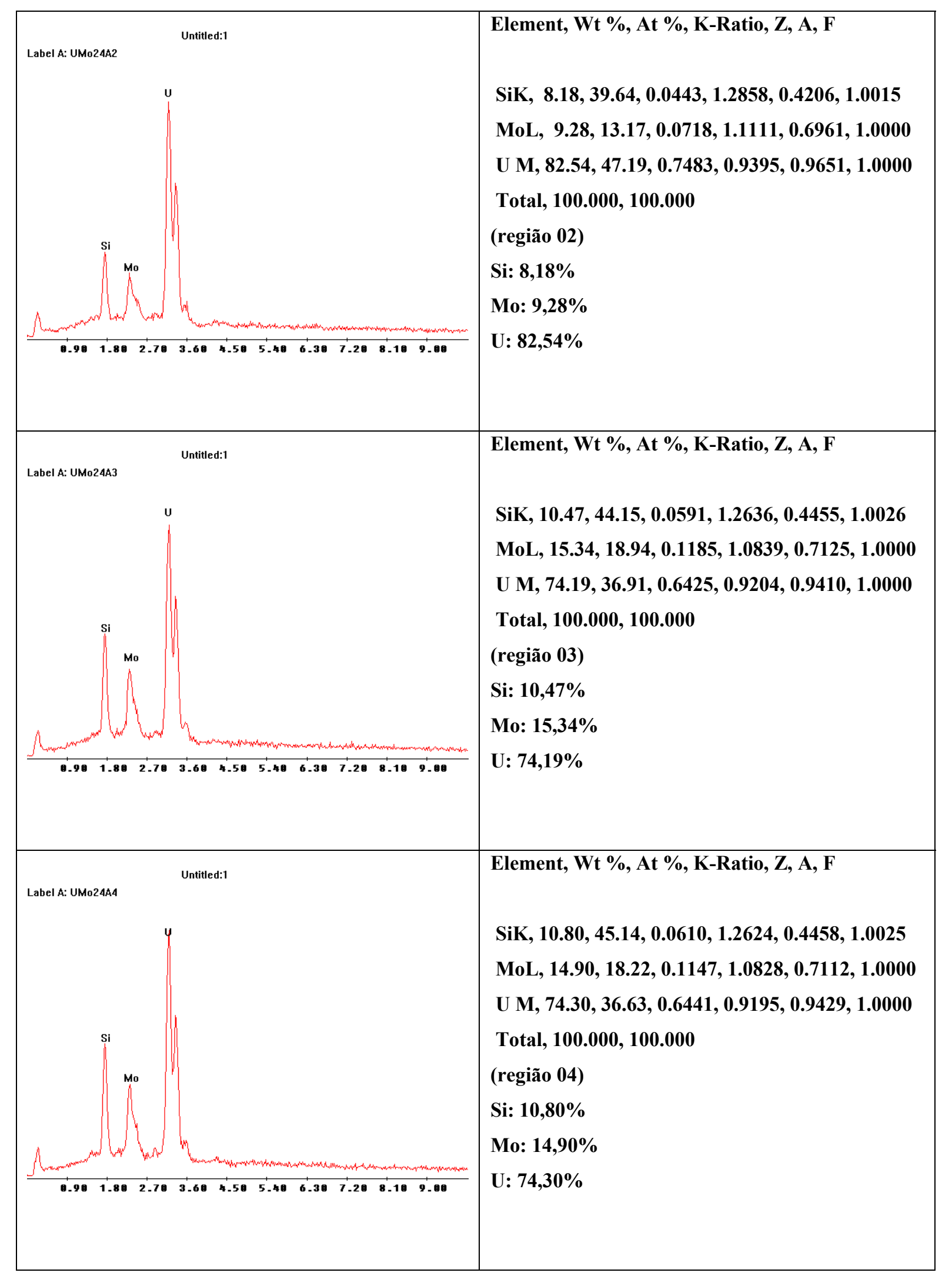

FIGURA 67 - EDS, liga ternária UMo11, bruta de fusão, concentrações nas regiões 02 a 04 da amostra. 


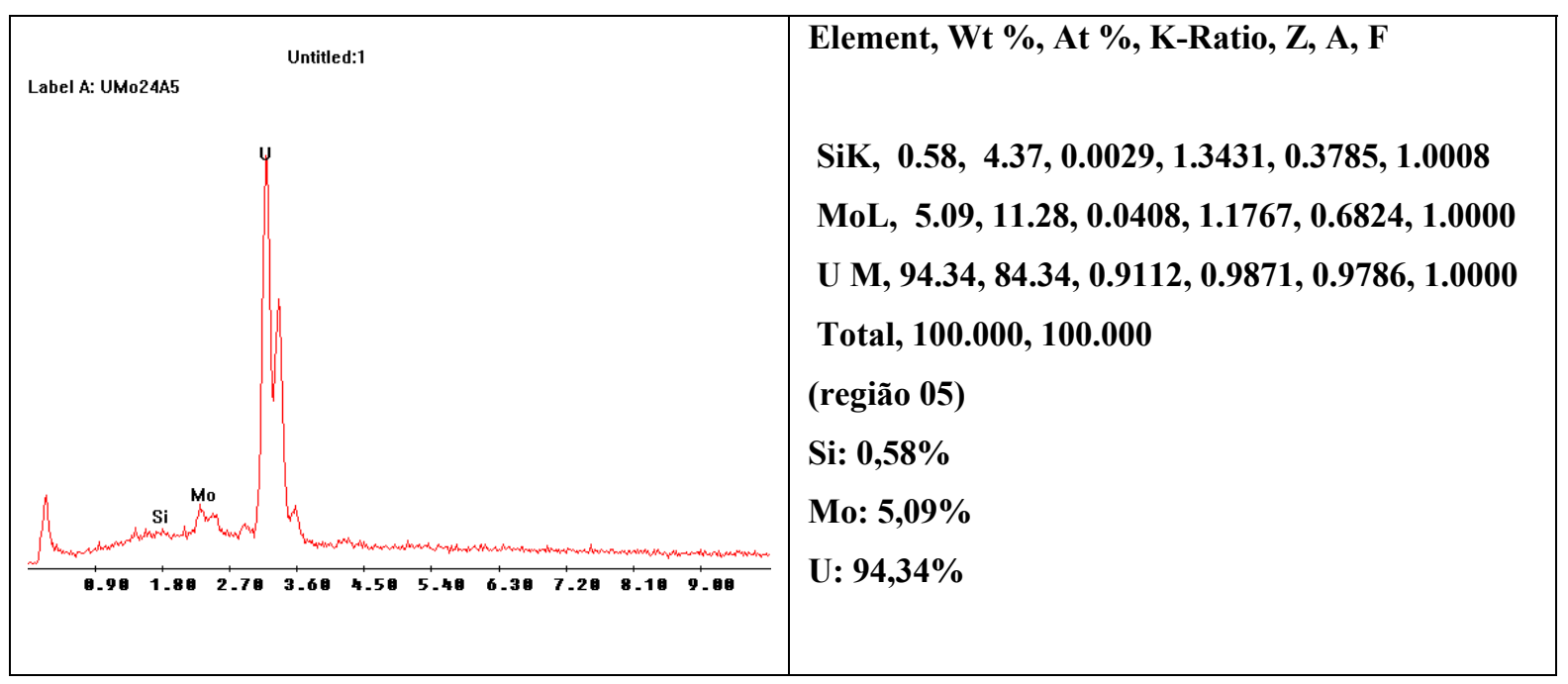

FIGURA 68 - EDS, liga ternária UMo11, bruta de fusão, concentrações na região 05 da amostra.
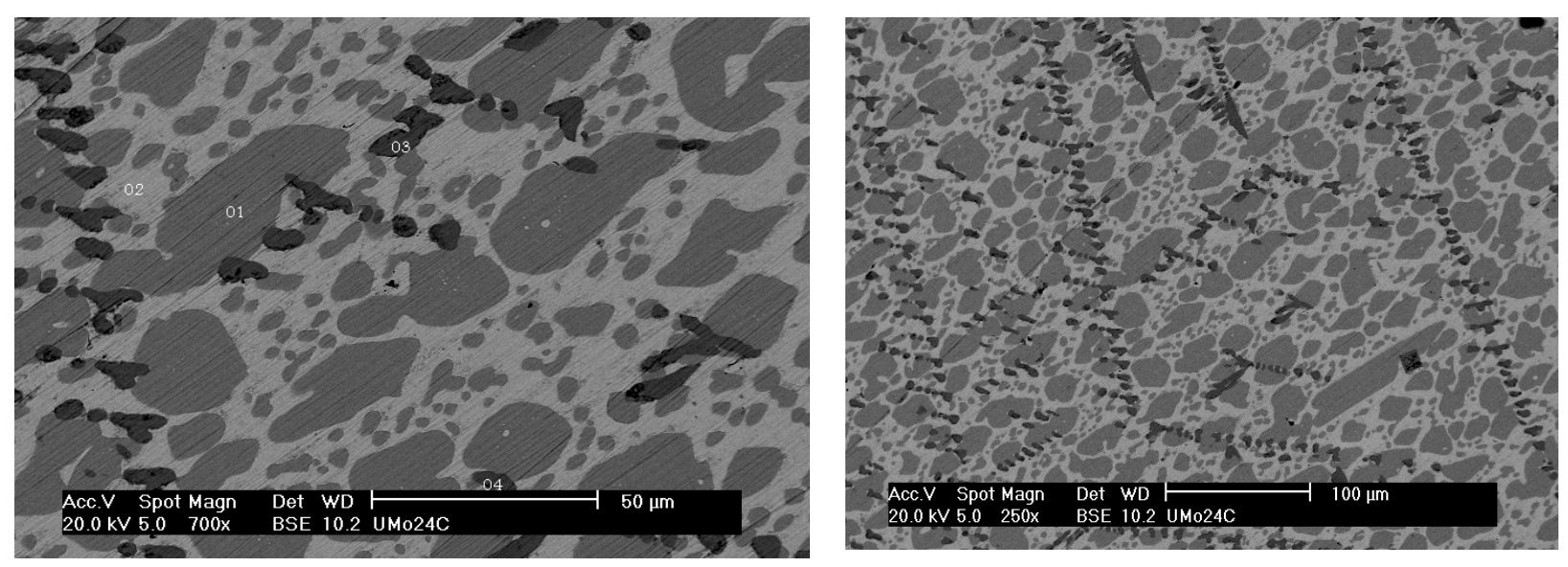

FIGURA 69 - Liga ternária UMo11, $900^{\circ} \mathrm{C}$ / 8horas, esquerda $700 \mathrm{X}$, direita $250 \mathrm{X}$.

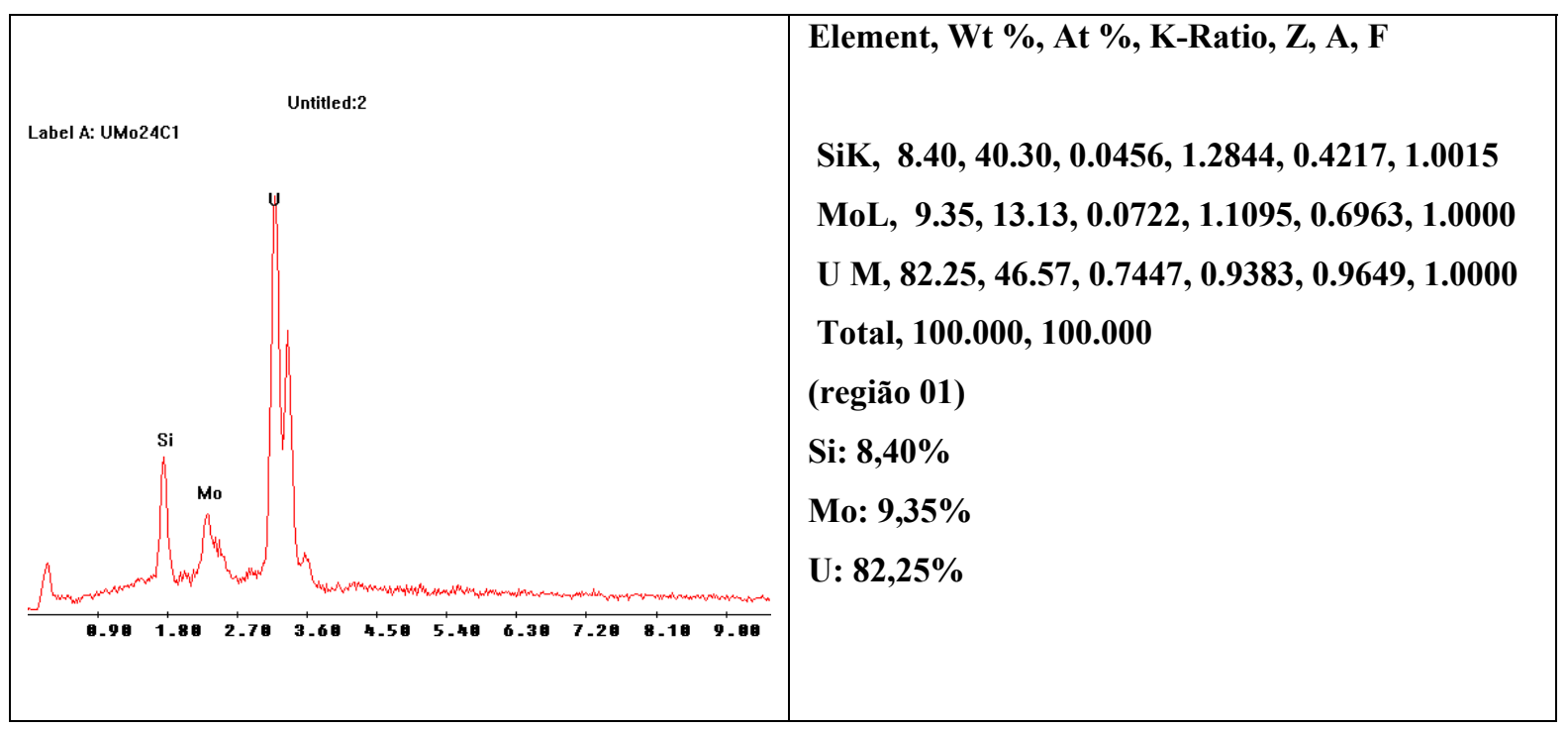

FIGURA 70 - EDS, liga ternária UMo11, $900^{\circ} \mathrm{C} / 8$ horas, concentrações na região 01 da amostra. 


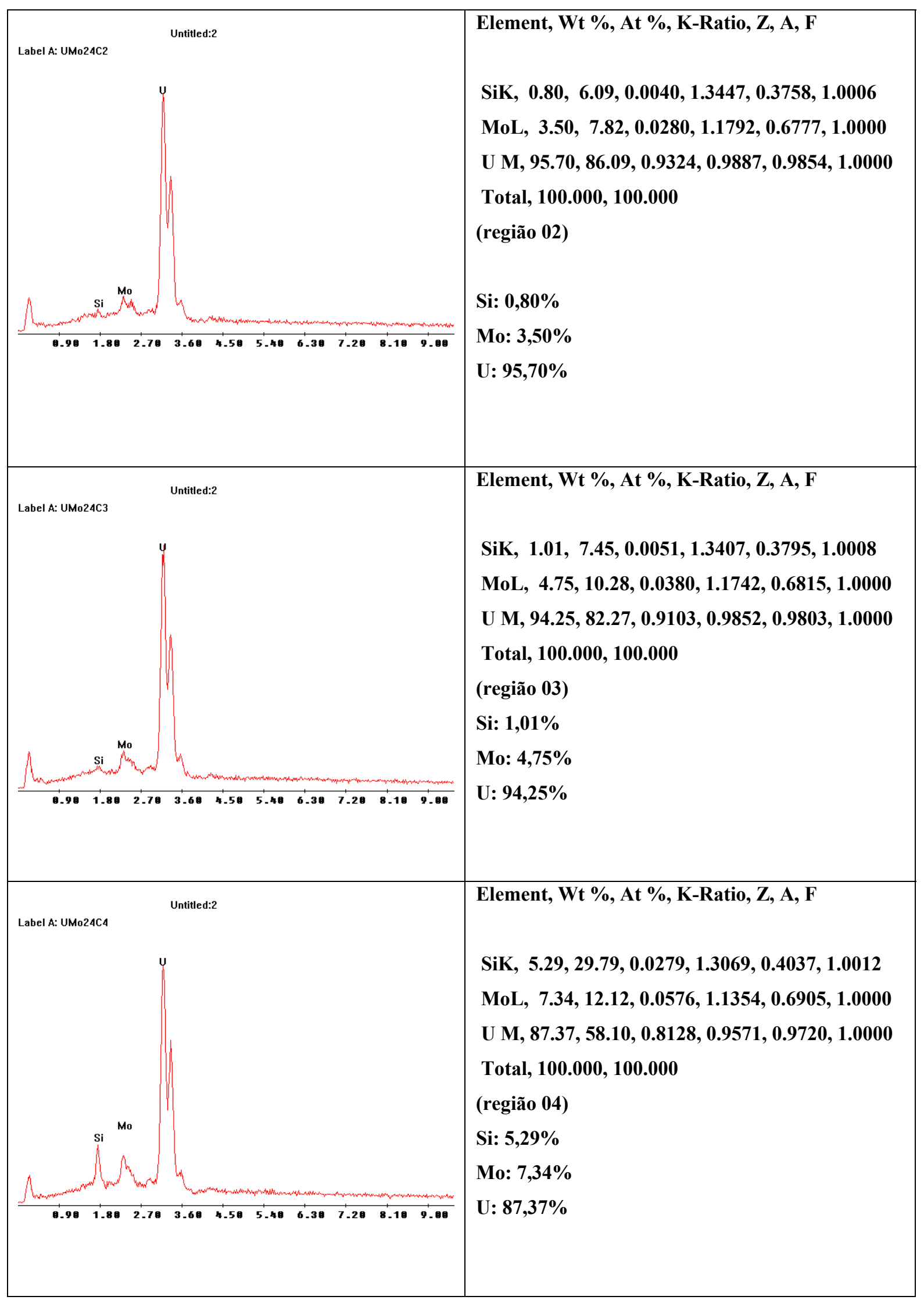

FIGURA 71 - EDS, liga ternária UMo11, $900^{\circ} \mathrm{C} / 8$ horas, regiões 02 a 04 da amostra. 

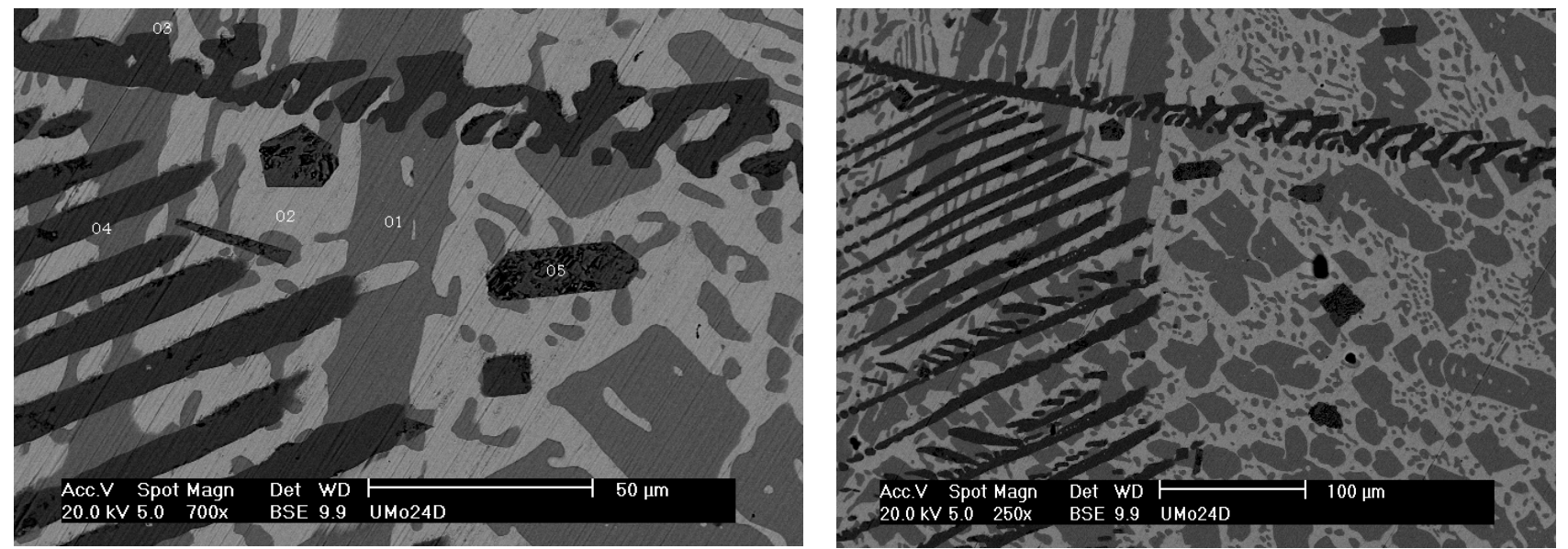

FIGURA 72 - Liga ternária UMo11, $950^{\circ} \mathrm{C} / 8$ horas, esquerda $700 \mathrm{X}$, direita $250 \mathrm{X}$.

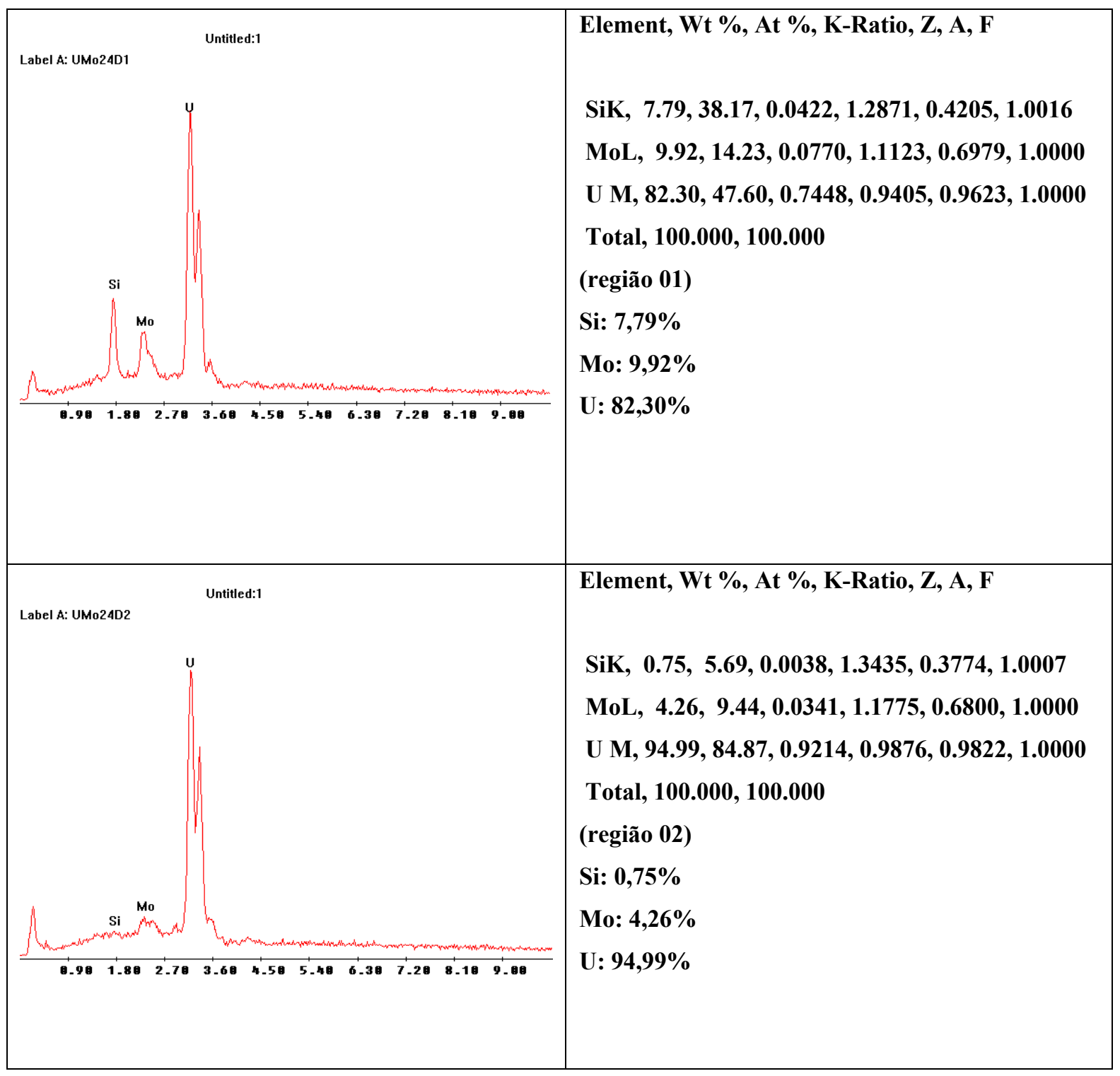

FIGURA 73 - EDS, liga ternária UMo $11,950^{\circ} \mathrm{C} / 8$ horas, concentrações nas regiões $01 \mathrm{e}$ 02 da amostra. 


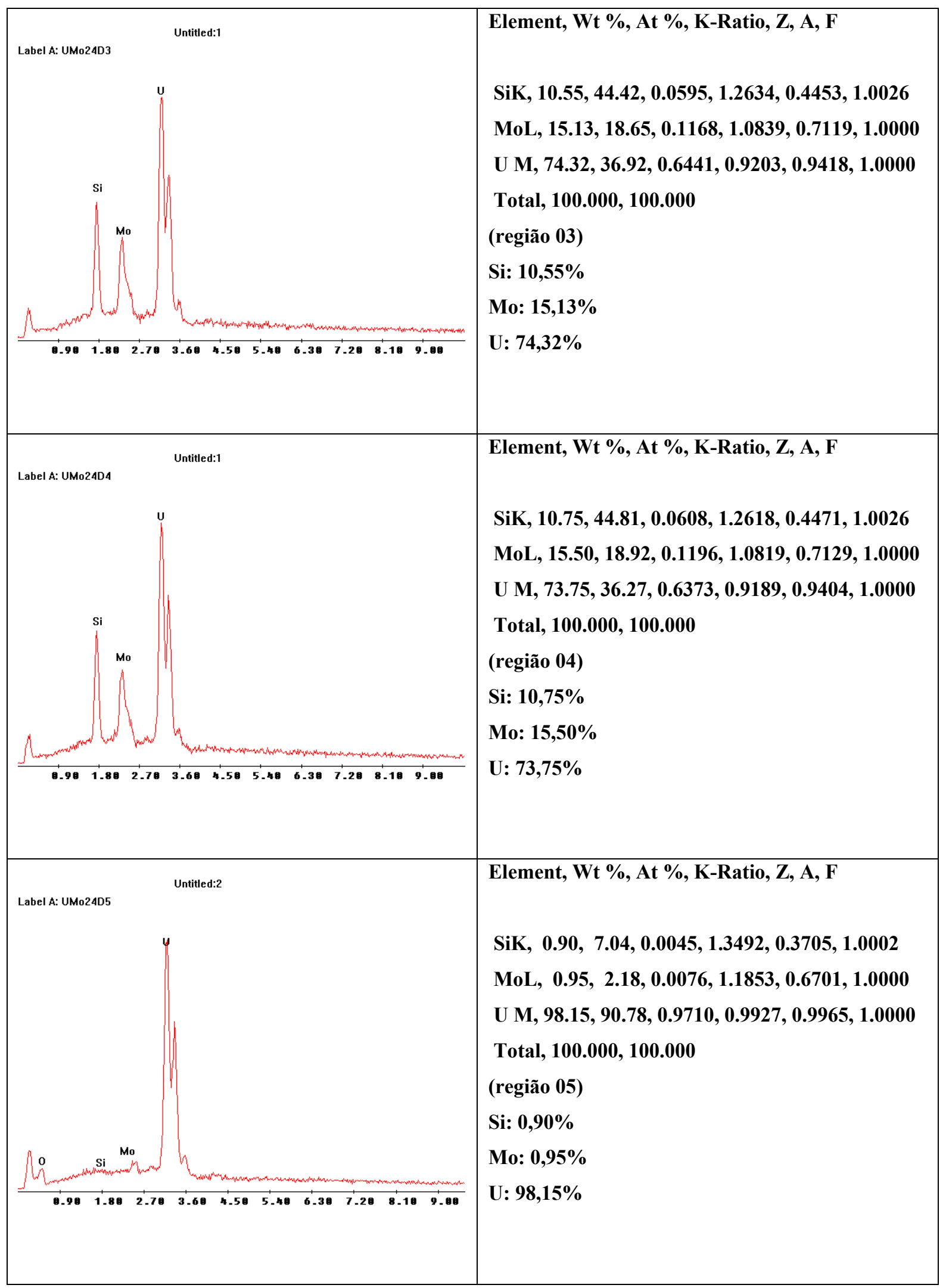

FIGURA 74 - EDS, liga ternária UMo $11,950^{\circ} \mathrm{C} / 8$ horas, concentrações nas regiões 03 e 05 da amostra. 

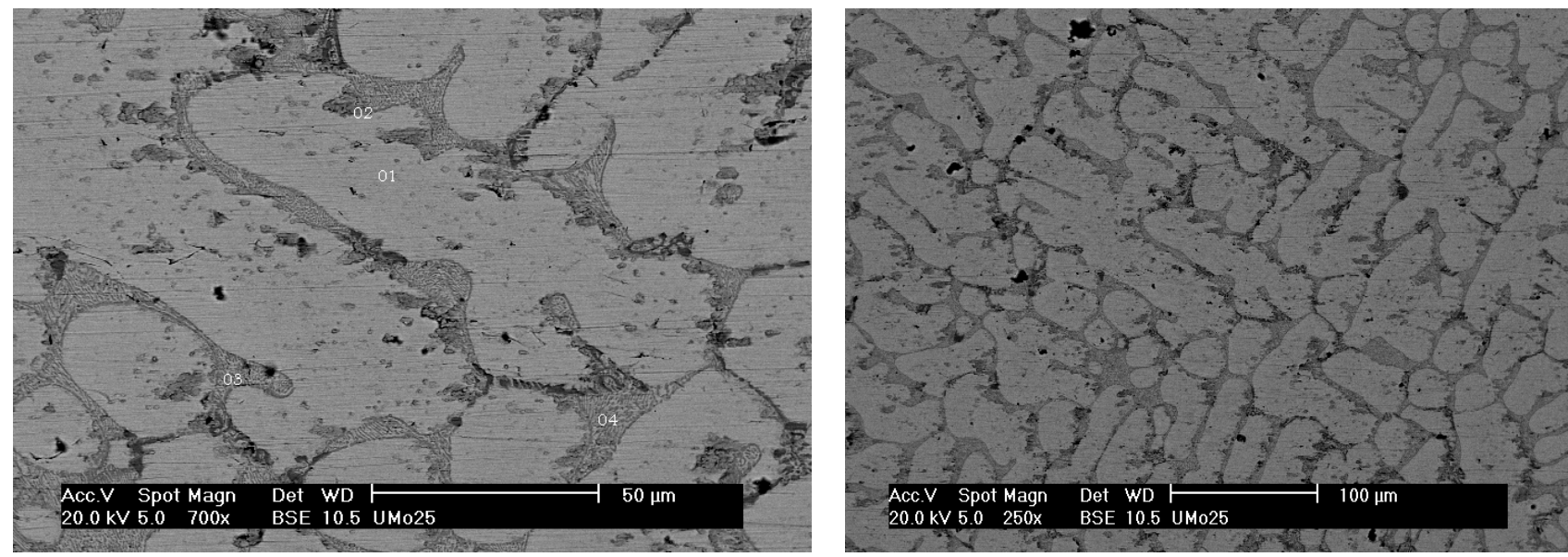

FIGURA 75 - Liga ternária UMo12, bruta de fusão, esquerda 700X, direita 250X.

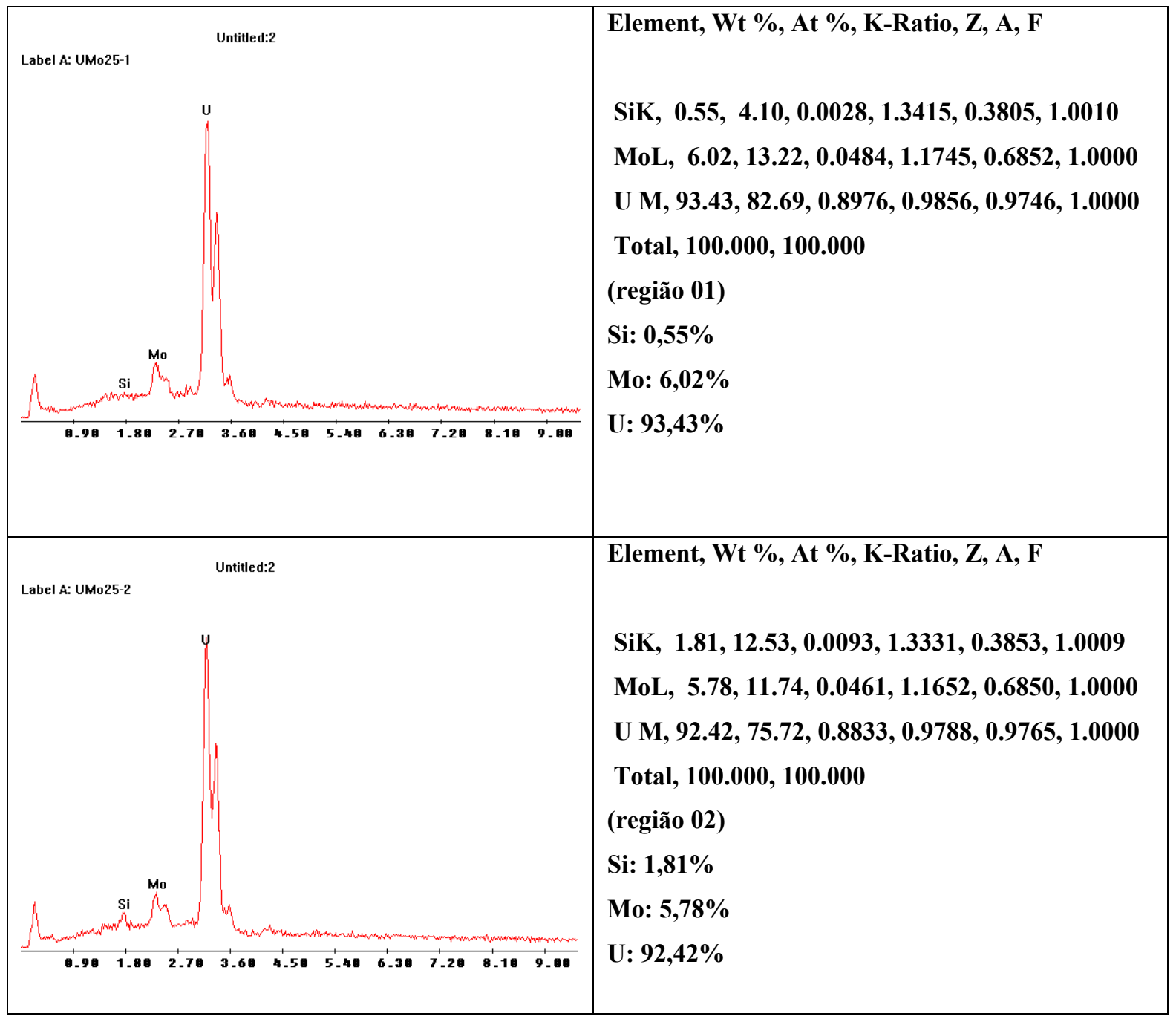

FIGURA 76 - EDS, liga ternária UMo12, bruta de fusão, concentrações nas regiões $01 \mathrm{e}$ 02 da amostra. 


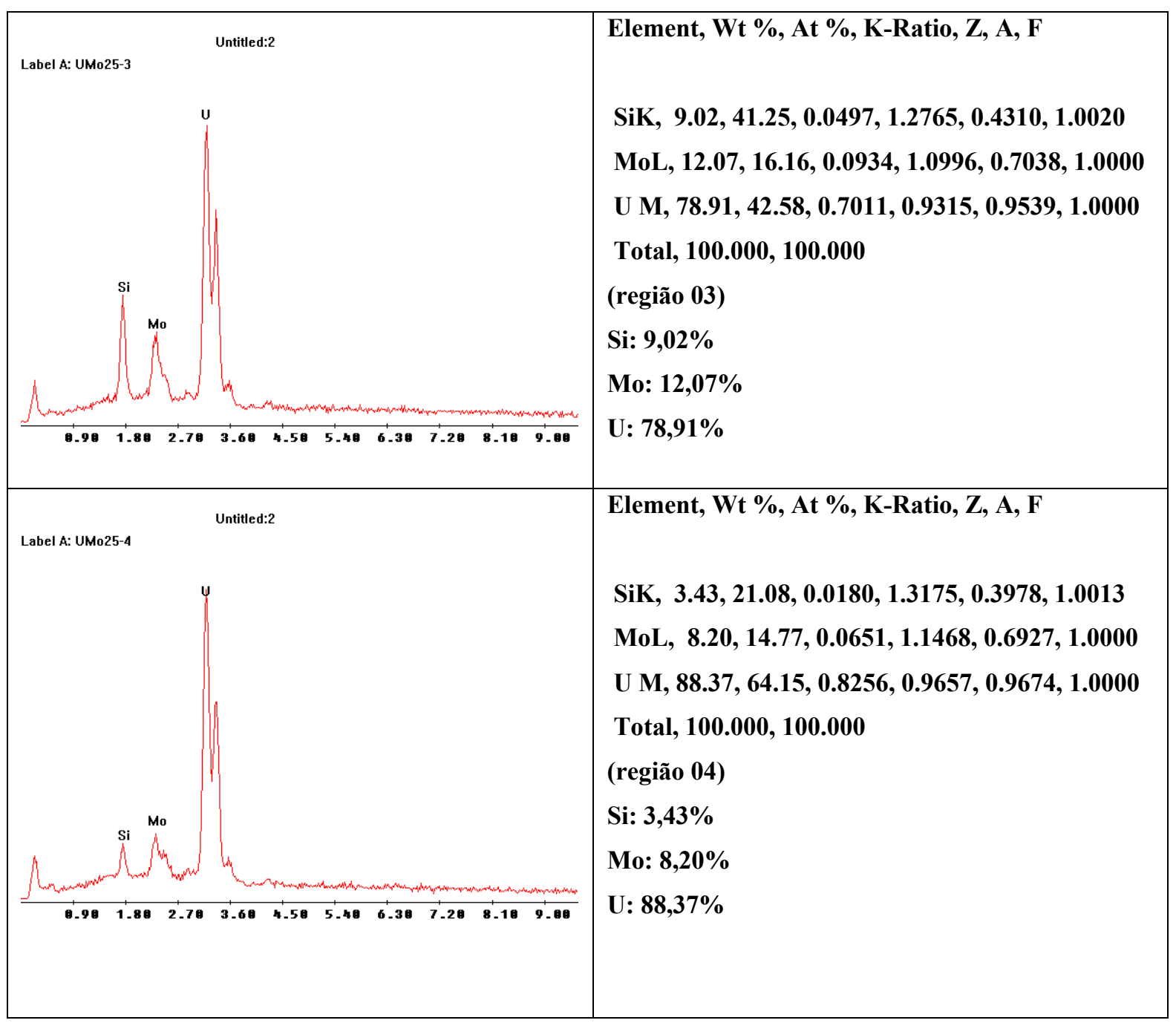

FIGURA 77 - EDS, liga ternária UMo12, bruta de fusão, concentrações nas regiões 03 e 04 da amostra.

Observa-se nas amostras $\gamma \mathrm{UMo11}$, independentemente da realização dos tratamentos térmicos, que nas regiões acinzentadas houve mistura, praticamente 1:1, dos elementos de adição, e nas regiões mais escuras, pretas, a concentração de urânio foi muito baixa, sempre abaixo de $90 \%$. Composições mais próximas às nominais foram obtidas sempre nas regiões mais claras. Entretanto, como a segregação nestas ligas foi muito grande, o desvio do valor nominal chegou a um máximo de até 4\%, na amostra UMo11, mas manteve-se em torno de $2 \%$ nas demais. Estes resultados indicaram, obviamente, que o excesso de silício não deve se afastar muito de seu limite de solubillidade, na estrutura gama.

Com base nisto a liga UMo12 foi fabricada, e os resultados preliminares mostraram que as fases claras dissolveram Mo e Si em quantidades próximas às nominais. 
Isto indica provável manutenção da estrutura gama, bem como do limite de solubilidade do silício nesta estrutura. Os resultados de análise de difração de raios-X desta amostra ainda não foram fornecidos.

Nas regiões que contornam estas fases, foram observadas variações de concentração de $1,8 \%$ de $\mathrm{Si}$ em regiões próximas à fronteira entre as fases, a até $9 \%$ de $\mathrm{Si}$, nas regiões mais centrais. Conforme será visto adiante, a presença desta fase diminuiu a dureza destas ligas, fato este verificado preliminarmente pela facilidade com a qual as mesmas foram cortadas, quando da preparação de amostras para análise.

Este foi um dos principais resultados deste trabalho, e por meio dele sugere-se que a mecanização ou hidretação para a obtenção dos pós possa ser feita, sem as dificuldades reportadas em literatura, com menor gasto de energia e tempo, visto que a formação de fases frágeis é feita previamente aos tratamentos térmicos ou mecânicos.

\subsubsection{Difratogramas de Raios-X.}

Todas as ligas obtidas por indução apresentaram espectros de difração muito semelhantes, picos de gama mais intensos, picos de alfa, muito próximos aos de gama, em menor intensidade ou inexistentes, indicando elevada homogeneidade, mesmo sem a aplicação dos tratamentos térmicos, conforme Figuras 78 a 84.

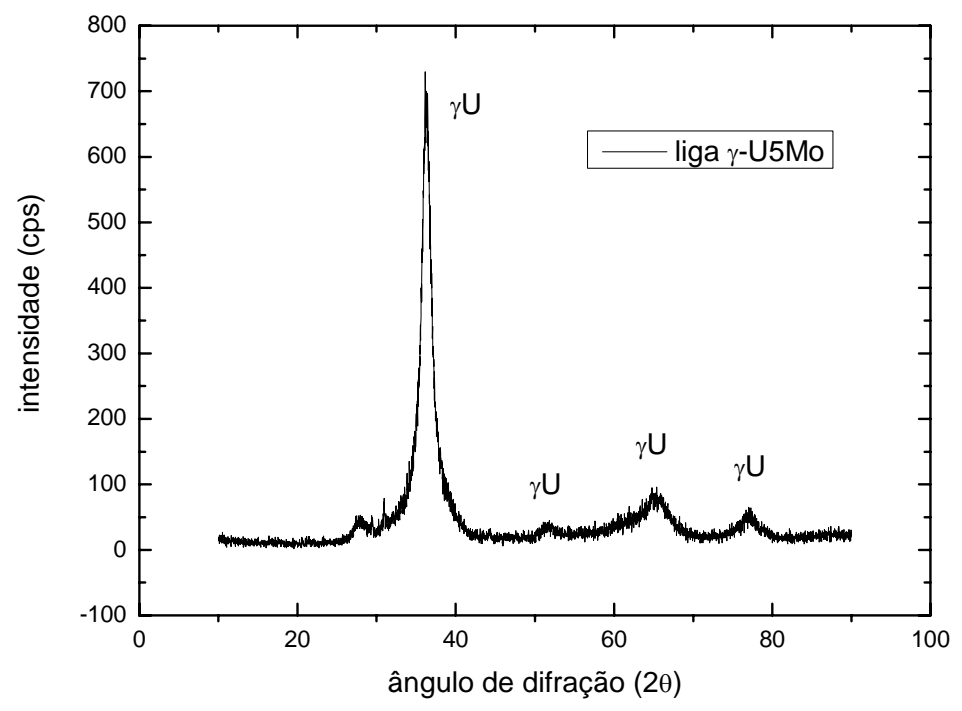

FIGURA 78- Difratograma de raios-X, liga base $\gamma \mathrm{U} 5 \mathrm{Mo}$. 


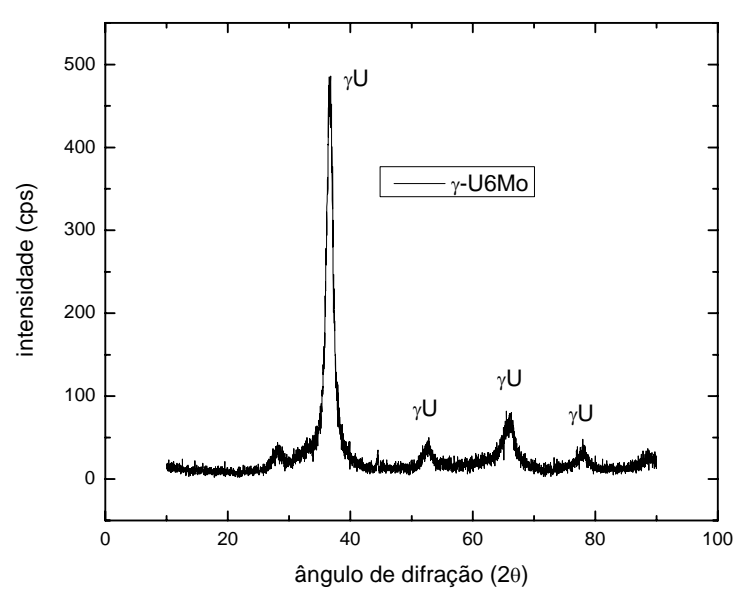

FIGURA 79- Difratograma de raios-X, liga base $\gamma \mathrm{U} 6 \mathrm{Mo}$.
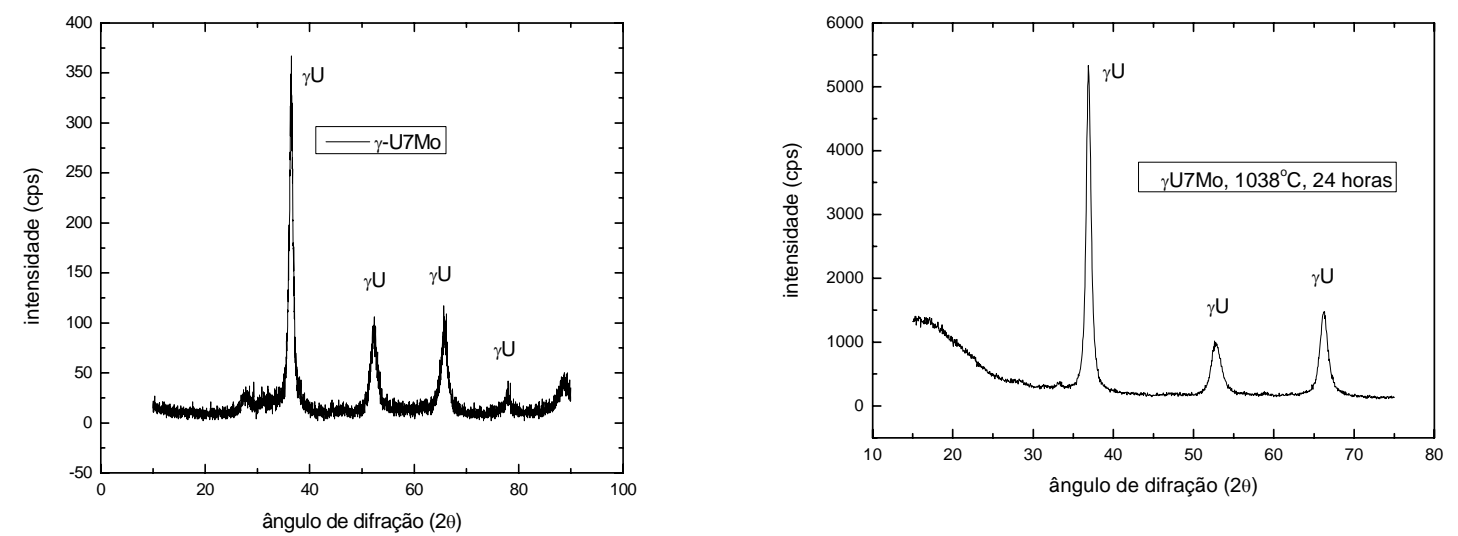

FIGURA 80- Difratograma de raios-X, liga base $\gamma U 7$ Mo bruta de fusão (esquerda) e após tratamento térmico (direita).
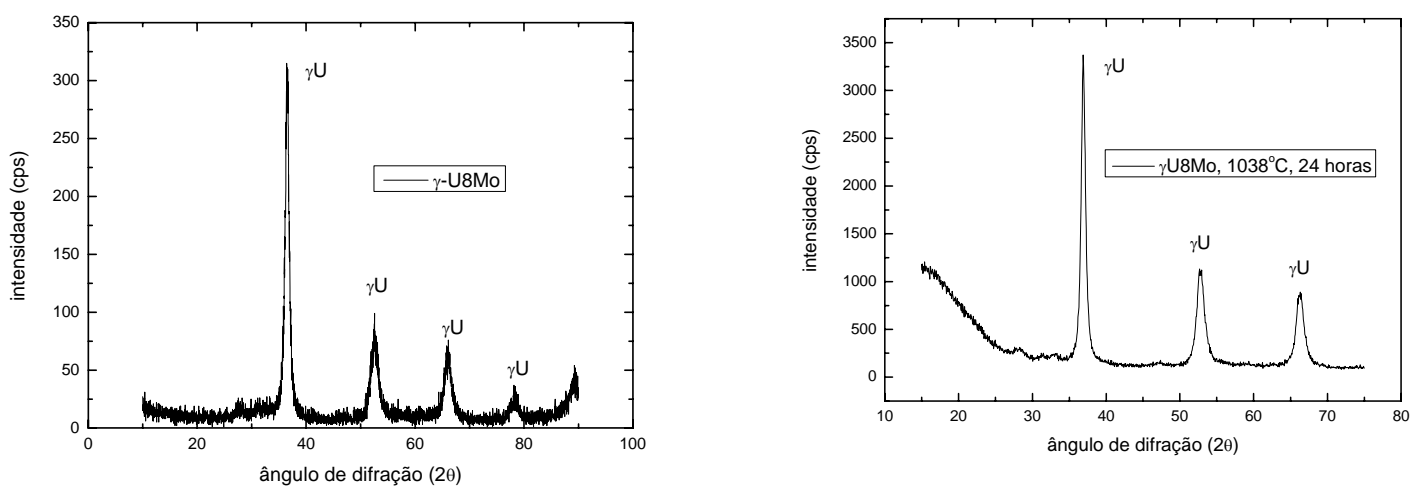

FIGURA 81- Difratograma de raios-X, liga base $\gamma$ U8Mo bruta de fusão (esquerda) e após tratamento térmico (direita). 


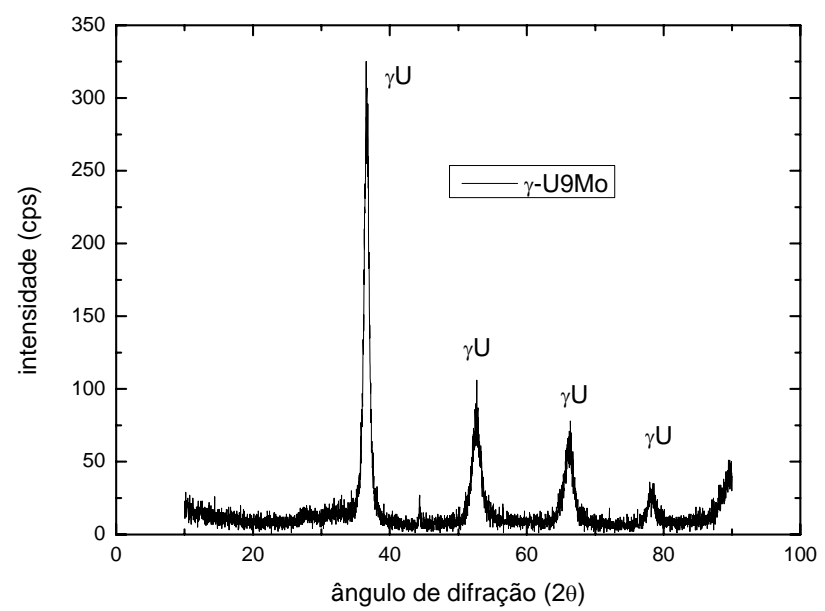

FIGURA 82- Difratograma de raios-X, liga base $\gamma$ U9Mo.

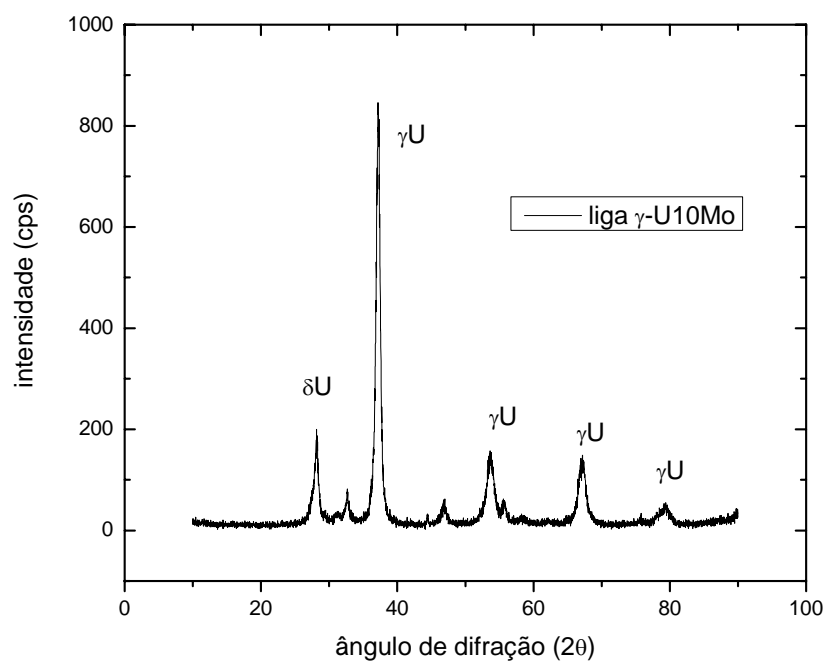

FIGURA 83- Difratograma de raios-X, liga base $\gamma \mathrm{U} 10 \mathrm{Mo}$.

De maneira geral, observa-se a evolução dos picos da fase gama, não muito definidos na liga a $5 \%$ de Mo, progressivamente mais definidos com o aumento na concentração de Mo. Isto indica, novamente, o poder do molibdênio na estabilização da fase gama do urânio. Intensidades maiores estão relacionadas à maior quantidade de amostra utilizada na análise.

O estreitamento dos picos de gama é função da quantidade de Mo, mas em $10 \%$ de adição, picos da fase delta $\mathrm{U}_{2}$ Mo também estão presentes, indicando que está-se trabalhando com uma composição acima da eutetóide. Os tratamentos térmicos, quando 
aplicados às amostras, resolveram estes problemas, estreitando os picos, ou seja, aumentando a concentração de fase gama, homogeneizando melhor as amostras.

Mostra-se também, pelo exame das Figuras 80 e 81, qual o resultado da realização dos tratamentos térmicos sobre as amostras, mesmo em tempos considerados menores do que os tradicionalmente utilizados. A intensidade dos picos de difração aumenta em ambos os casos, diminuindo-se também o ruído de fundo, indicando que a difusão de molibdênio nestas condições já foi suficiente para a eliminação de eventuais segregações. Entretanto, como as amostras apresentaram tamanhos de grão muito maiores do que os das amostras brutas de fusão, considerou-se conveniente, para os estudos de hidrogenação, trabalhar com as amostras no estado bruto. Ver-se-á em seguida que os tratamentos aumentam a dureza das amostras, o que pode ser vantajoso em termos da obtenção de pós pelos métodos mecânicos tradicionais.

Na Figura 84 está apresentado o difratograma para a liga UMo11, bruta de fusão. Observa-se a presença de pequenos picos de silicetos a $25^{\circ}$ e $27^{\circ}$, aproximadamente, e pico bem intenso da fase gama, a 37,25 . Ao menos estruturalmente, a liga apresentou-se bem homogênea. Como a intensidade do pico principal de difração da fase gama é maior quando comparado ao das demais amostras, conclui-se que o silício tem a propriedade de homogeneizar a amostra em termos estruturais, embora, conforme visto nas micrografias do item anterior (p. 184 a 191), grande quantidade de segregação tenha sido formada.

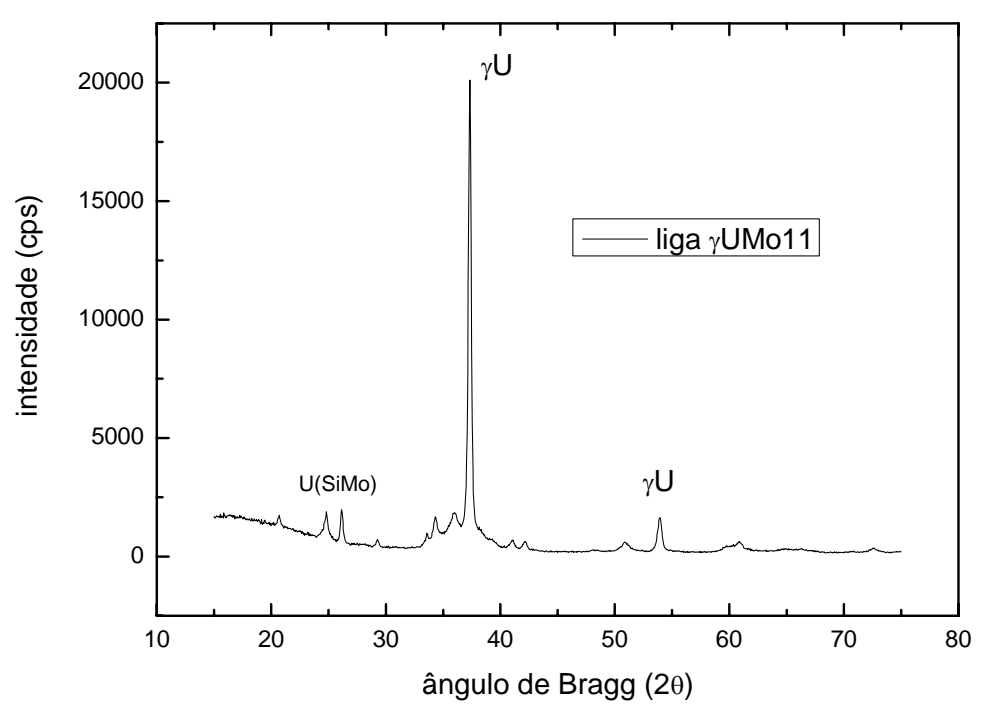

FIGURA 84- Difratograma de raios-X, liga base $\gamma \mathrm{UMo} 11$. 
Pode-se concluir, com base nestes resultados e nos de dureza apresentados no item seguinte, novamente a favor das adições de silício à liga UMo para a resolução dos problemas da estabilidade e da obtenção dos pós.

\subsection{Microdureza Vickers}

Os resultados dos ensaios de dureza para as ligas obtidas por fusão a arco e por indução são mostrados nas Tabelas 10 a 15. Escolheu-se este tipo de ensaios mecânico pela facilidade na tomada das medidas, que pode ser feita sobre as próprias amostras de embutimento, não havendo a necessidade de confecção de amostras em geometrias especiais. Nestas tabelas, Hv é o valor médio da dureza, Vickers, de $\mathrm{N}$ medidas ao longo da amostra, Sd e Se são os desvios e erros padrão, respectivamente.

TABELA 10 - Microdureza Vickers, ligas brutas de fusão, indução.

\begin{tabular}{c|c|c|c|c}
\hline Liga & Hv & Sd & Se & N \\
\hline \hline$\gamma$ U5Mo & 238 & 23 & 7 & 10 \\
\hline$\gamma \mathrm{U} 6 \mathrm{Mo}$ & 225 & 20 & 7 & 8 \\
\hline$\gamma \mathrm{U} 7 \mathrm{Mo}$ & 243 & 37 & 12 & 10 \\
\hline$\gamma \mathrm{U} 8 \mathrm{Mo}$ & 239 & 38 & 12 & 10 \\
\hline$\gamma \mathrm{U} 9 \mathrm{Mo}$ & 282 & 11 & 4 & 10 \\
\hline$\gamma \mathrm{U} 10 \mathrm{Mo}$ & 291 & 42 & 13 & 10 \\
\hline$\gamma \mathrm{UMo12}$ & 272 & 11 & 3 & 14 \\
\hline$\gamma \mathrm{UMo11}$ & 367 & 85 & 23 & \\
\hline
\end{tabular}

TABELA 11 - Microdureza Vickers, ligas de indução, tratadas termicamente, $1038^{\circ} \mathrm{C}, 24$ horas.

\begin{tabular}{c|c|c|c|c}
\hline Liga & Hv & Sd & Se & N \\
\hline \hline$\gamma$ U5Mo & 248 & 25 & 8 & 10 \\
\hline$\gamma$ U6Mo & 264 & 5 & 2 & 10 \\
\hline$\gamma \mathrm{U} 7 \mathrm{Mo}$ & 259 & 12 & 4 & 10 \\
\hline$\gamma \mathrm{U} 8 \mathrm{Mo}$ & 229 & 73 & 23 & 10 \\
\hline$\gamma \mathrm{U} 9 \mathrm{Mo}$ & 247 & 16 & 5 & 10 \\
\hline$\gamma \mathrm{U} 10 \mathrm{Mo}$ & 273 & 25 & 8 & 10 \\
\hline
\end{tabular}


TABELA 12 - Microdureza Vickers, ligas de indução, tratadas termicamente, $1038^{\circ} \mathrm{C}, 48$ horas.

\begin{tabular}{c|c|c|c|c}
\hline Liga & Hv & Sd & Se & N \\
\hline \hline$\gamma \mathrm{U} 10 \mathrm{Mo}$ & 404 & 29 & 9 & 10 \\
\hline$\gamma \mathrm{U} 6 \mathrm{Mo}$ & 297 & 38 & 12 & 10 \\
\hline
\end{tabular}

TABELA 13 - Microdureza Vickers, ligasde indução ternárias tratadas termicamente, $900^{\circ} \mathrm{C} / 6$ horas (C) e $920^{\circ} \mathrm{C} / 3$ horas (D).

\begin{tabular}{c|c|c|c|c}
\hline Liga & Hv & Sd & Se & N \\
\hline \hline$\gamma \mathrm{UMo11C}$ & 468 & 75 & 24 & 10 \\
\hline$\gamma \mathrm{UMo11D}$ & 386 & 130 & 41 & 10 \\
\hline
\end{tabular}

TABELA 14 - Microdureza Vickers, ligas brutas de fusão, arco.

\begin{tabular}{c|c|c|c|c}
\hline Liga & Hv & Sd & Se & N \\
\hline \hline$\gamma \mathrm{U} 3 \mathrm{Mo}$ & 446 & 49 & 15 & 10 \\
\hline$\gamma \mathrm{U} 4 \mathrm{Mo}$ & 162 & 52 & 15 & 12 \\
\hline$\gamma \mathrm{U} 6 \mathrm{Mo}$ & 276 & 27 & 9 & 8 \\
\hline$\gamma \mathrm{U} 8 \mathrm{Mo}$ & 205 & 73 & 23 & 10 \\
\hline$\gamma \mathrm{U} 9 \mathrm{Mo}$ & 219 & 85 & 27 & 4 \\
\hline$\gamma \mathrm{U} 10 \mathrm{Mo}$ & 354 & 57 & 29 & 10 \\
\hline
\end{tabular}

TABELA 15 - Microdureza Vickers, ligas de arco, tratadas termicamente, $1038^{\circ} \mathrm{C}, 48$ horas.

\begin{tabular}{c|c|c|c|c}
\hline Liga & Hv & Sd & Se & N \\
\hline \hline$\gamma$ U8Mo & 235 & 52 & 17 & 10 \\
\hline$\gamma \mathrm{U} 9 \mathrm{Mo}$ & 333 & 18 & 6 & 10 \\
\hline$\gamma \mathrm{U} 7(\mathrm{MoSi})$ & 558 & 97 & 31 & 10 \\
\hline
\end{tabular}

Ligas com adição de silício apresentaram dureza bem maior que a das demais, confirmando a hipótese de que possam conter agentes de fragmentação, na fabricação dos pós. Uma tendência a um aumento e, também, à uniformidade nos valores para as ligas de indução foi observada após os tratamentos térmicos a $1038^{\circ} \mathrm{C}$ em 24 horas, ao contrário do ligeiro crescimento observado, dentro da precisão dos resultados, para as ligas brutas de 
fusão em adições de 9 e 10\% de Mo. Isto confirma que há um aumento na estabilidade da estrutura gama com o aumento nas adições de Mo, pois tenho uma maior quantidade de soluto disponível para a substituição na rede do urânio, e aumento assim a cristalinidade da fase gama da amostra. Um aumento na cristalinidade implica em picos de difração mais definidos, e também em uma maior dureza das amostras.

Com o aumento do tempo de tratamento para 48 horas, houve em geral novo aumento na dureza para as ligas $\gamma \mathrm{U} 6 \mathrm{Mo}$ e $\gamma \mathrm{U} 10 \mathrm{Mo}$. Assim, o que se está observando, juntamente com as micrografias do item anterior, é um aumento na cristalinidade das amostras, evidenciado também pelo aumento no tamanho de seus grãos. Este fenômeno pode ser utilizado favoravelmente nas etapas do processo de fabricação de pós, embora aqui o controle das dimensões das partículas seja necessário, pois os grãos apresentam dimensões bem maiores que as exigidas pelas especificações.

As adições de silício aumentaram em muito a dureza das ligas, embora os valores sejam médios, tomados sobre fases com composição diferente, conforme as micrografias do item anterior revelam. Entretanto, a diferença na dureza entre elas, que chegou a 33\% nas amostras brutas de fusão e a 12\% nas tratadas termicamente, principalmente nas ligas com alto excesso de silício, pode ser utilizada como promotora da fragmentação das amostras, pois estas apresentaram quantidade de fase intergranular muito elevada. Nas ligas com pequeno excesso, esta diferença não ultrapassou a 5\%. Fases intergranulares apareceram em menor quantidade, pois o silício concentrou-se principalmente na matriz de urânio gama.

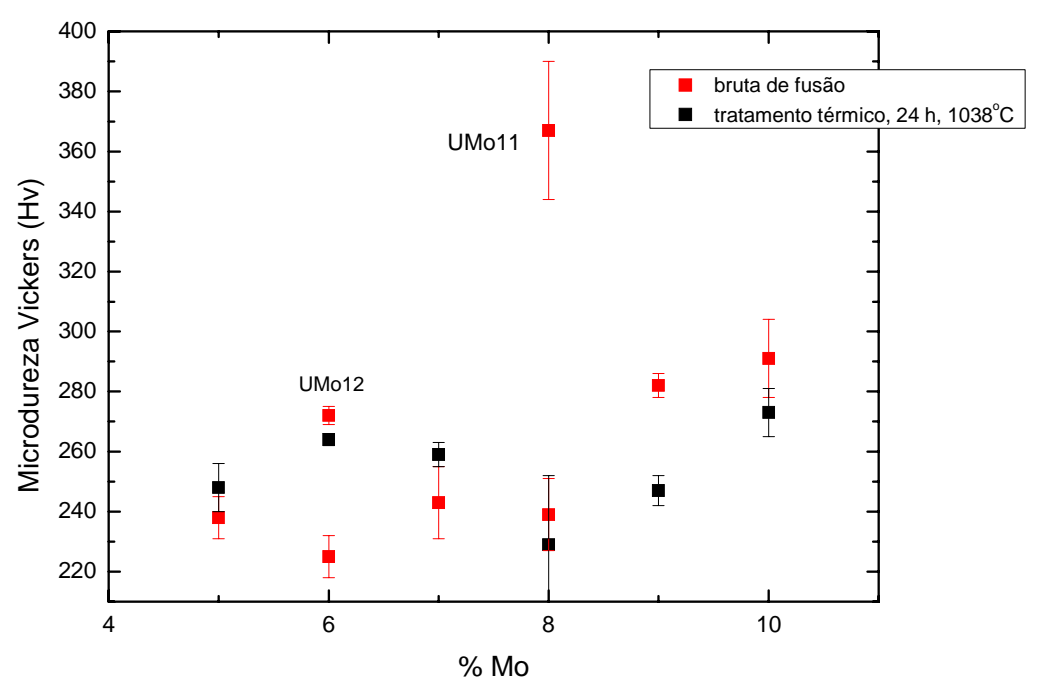

FIGURA 85- Microdureza Vickers, ligas de indução. 


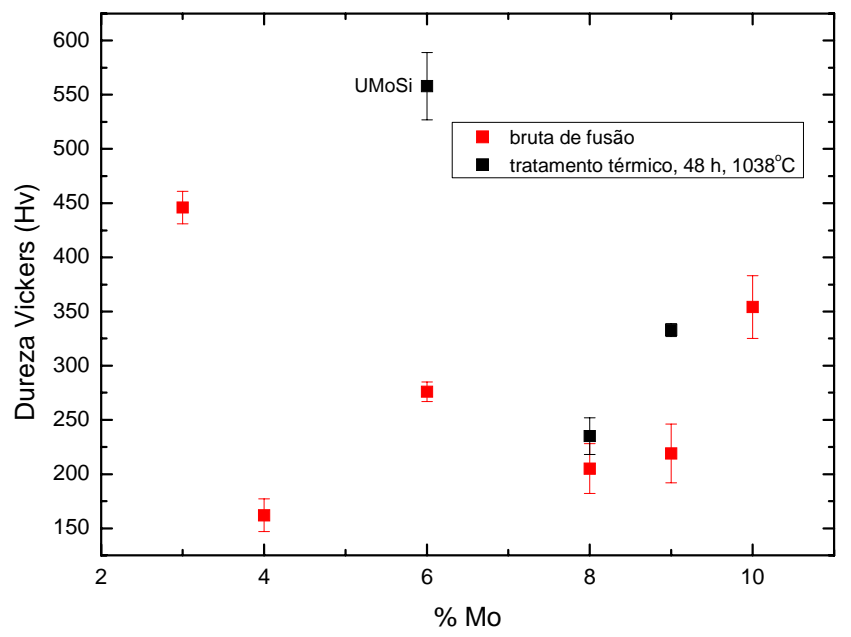

FIGURA 86- Microdureza Vickers, ligas produzidas via de arco.

Valores irregulares na dureza das amostras de fusão a arco indicam e confirmam a baixa cristalinidade, elevado número de estruturas dendríticas presentes, mesmo com a aplicação dos tratamentos térmicos. Novamente há uma pequena tendência a um aumento na dureza com o aumento na porcentagem de Mo e com as adições de silício, devido ao óbvio aumento na cristalinidade das ligas.

As Figuras 85, 86 e 87 ilustram o exposto. Um padrão semelhante a este será encontrado nos capítulos 11 e 12, relativos à estabilidade da liga frente ao alumínio e ao oxigênio. Podemos então, associar diretamente aqueles resultados aos de dureza.

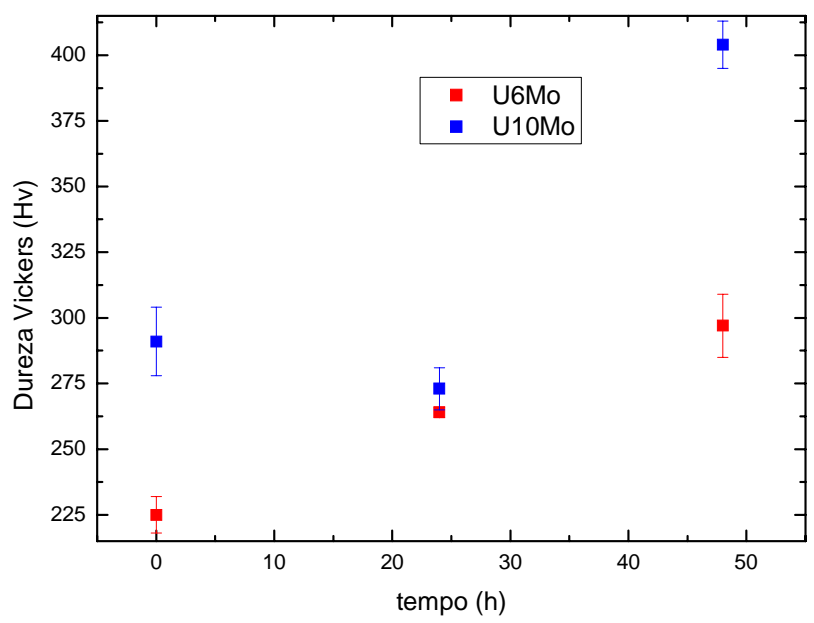

FIGURA 87- Microdureza Vickers, tratamento a $1038^{\circ} \mathrm{C}$, ligas $\gamma \mathrm{U} 6 \mathrm{Mo}$ e $\gamma \mathrm{U} 10 \mathrm{Mo}$, ligas produzidas via forno de indução. 
Aumentos na dureza com os tratamentos térmicos, como os mostrados nas Figuras 85 a 87, foram acompanhados de aumento nas dimensões dos grãos das ligas, conforme pode ser observado nas micrografias do item 10.2. No item seguinte será analisada a evolução da cristalinidade das ligas $\gamma \mathrm{UMo}$, em função dos tratamentos térmicos.

Na tabela 9 de Beghi ${ }^{10}$ encontram-se os valores de dureza para as ligas $\gamma \mathrm{U} 8 \mathrm{Mo}$, $\gamma \mathrm{U} 10 \mathrm{Mo}, \gamma \mathrm{U}(10,9) \mathrm{Mo}$, em função da temperatura e dos tratamentos de estabilização da fase gama, conforme trabalho de Waldron, Burnett e Pough ${ }^{67}$. Na temperatura ambiente os valores de microdureza Vickers foram, respectivamente, 297, 316 e 348. Todos eles pouco maiores do que os obtidos para as mesmas adições, pois os autores utilizaram tratamentos térmicos mais prolongados. Enquanto o tempo máximo a $1000^{\circ} \mathrm{C}$ aqui foi de 48 horas, suficiente para a elevação da dureza de uma liga $\gamma \mathrm{U} 10 \mathrm{Mo}$ a 404, após $900^{\circ} \mathrm{C}$ por 7 dias, os autores chegaram a 348. Isto indica, novamente, que o efeito da temperatura na dureza supera o efeito do tempo. Além disso, mostra que os valores para as ligas aqui estudadas não se afastam dos previamente reportados em literatura.

Com os resultados do item 10.2 e os de dureza, conclui-se que se deve ficar atento à porcentagem de adição de silício. Como a estabilidade é mantida até o limite de excesso superior em concentração aqui utilizado, no caso de pequenos excessos, embora a segregação seja menor, a dureza das amostras é comparável à de uma liga U7Mo, indicando que o processo de hidretação, empregado aqui com sucesso, pode promover o mesmo resultado. Em excessos próximos a 3\%, havendo maior segregação, a dureza da fase que contorna a matriz é maior. Evidencia-se esta fragilidade pela facilidade com a qual as amostras se rompem quando do preparo para as análises.

Assim, um compromisso entre dureza e segregação deve ser obedecido, de modo a se evitar as perdas de composição e a facilitar o processo de obtenção dos pós.

\subsection{Comparação Arco x Indução}

Na Figura 88 encontram-se os dados de densidade das ligas aqui produzidas via forno a arco e indução, os teóricos e os obtidos experimentalmente para as adições de 5 a $10 \%$ de molibdênio, conforme publicação de Trybus ${ }^{56}$.

Pode-se verificar que, em termos de densidades, ligas preparadas pelos dois métodos comportam-se da mesma maneira até $8 \%$ de adição, a queda nas densidades ocorrendo à mesma razão. Acima de $8 \%$, a queda na densidade é substancial, devido à 
formação de alguma porosidade fechada, o que não é um problema sério em termos de fabricação de pós. Foi observado que o "paralelismo" das curvas de densidade das amostras de arco e indução foi possível somente após aplicação de, no mínimo, duas refusões às amostras de arco. No caso das ligas de indução, não foi necessário rebatimento, mesmo trabalhando-se com cargas 30 vezes mais pesadas, o que foi possível dado o elevado nível de agitação do processo, proporcional à freqüência de operação do sistema de indução. A agitação nas amostras de forno a arco é feita manualmente, e ainda tem-se o agravante de que a remoção de calor é muito mais rápida, pois estamos trabalhando com molde metálico refrigerado.

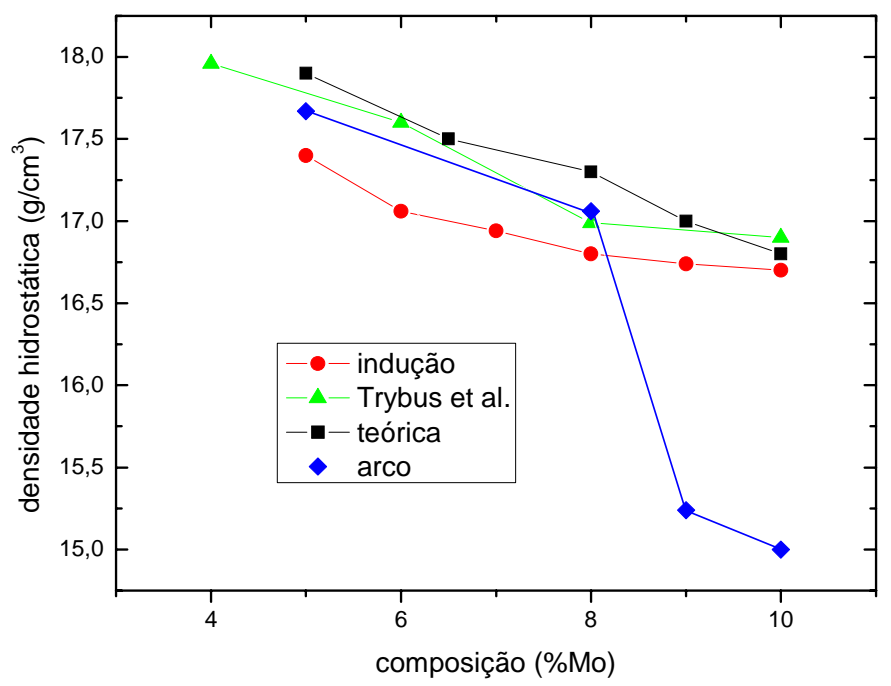

FIGURA 88 - Densidades de $\gamma \mathrm{UM}$ Mo em função da porcentagem de soluto.

Entretanto, a diferença mais importante e óbvia quando do exame de todas as micrografias aqui exibidas, é a microestrutural. Foi observado que as estruturas das ligas de indução são principalmente constituídas por uma matriz $\gamma$-UMo homogênea, com alguma porosidade, como se pode ver nas imagens de microscopia eletrônica de varredura seguintes. No caso das ligas com baixo poder de estabilização ( 5 a 7\% em peso de Mo), algum alfa-U está também presente nos contornos de grão, conforme revelaram as figuras de microscopia óptica. Nas amostras de fusão a arco, um grande número de estruturas dendríticas e algumas regiões intragranulares contendo alfa- $U$, mesmo após refusões, foi observado, o que indica alguma incompatibilidade entre as velocidades de resfriamento e de difusão do molibdênio pelo urânio nas amostras, a primeira delas maior que a segunda. 
Outra propriedade que atesta a maior homogeneidade das amostras de indução em comparação com as de forno a arco é a dureza. Observa-se nas tabelas do item anterior que a magnitude dos erros (Se) é maior nas amostras de arco, indicando maior heterogeneidade, pois a penetração do indentador se faz em vários grãos, com composição variável. No caso das amostras de indução, a uniformidade na composição reflete-se também na menor variação dos resultados de dureza. Com os tratamentos térmicos, tanto os valores médios quanto os desvios tendem a se uniformizar, dada a facilidade com a qual a difusão térmica se processa pela amostra, devido ao pequeno gradiente de concentrações ao longo dos grãos.

Fatores que afetam a solidificação das ligas são principalmente os relacionados ao projeto de construção dos fornos, como a geometria de fusão (cadinhos) e cargas (como dispor-se a carga no interior dos cadinhos), possíveis impurezas introduzidas nas cargas pelos cadinhos e demais materiais do sistema, e ainda, principalmente, pelo seu sistema de resfriamento.

Em termos de fabricação de pós por $\mathrm{HDH}$, estruturas contendo altas quantidades de alfa urânio são as maiores responsáveis pela facilidade nas operações do processo, mas também relacionadas a um baixo grau de homogeneização dos principais constituintes das amostras. Portanto, é de se esperar que na hidretação de amostras de fusão a arco, as velocidades de absorção de hidrogênio sejam maiores que as de indução. Mas se estivermos procurando por pós homogêneos em termos de composição, e manutenção da integridade da estrutura $\gamma \mathrm{UMo}$, há a necessidade de se trabalhar com as amostras de indução, e tentar encontrar-se métodos para aumentar a taxa de incorporação de hidrogênio por estas ligas.

Como exemplos, espectros de difração de raios-X e imagens de microscopia eletrônica de varredura de liga $\gamma$-U8Mo são mostrados nas Figuras 89 e 90, nas quais se observa um alto grau de homogeneização apresentado pelas amostras de indução. Dendritas são regiões de baixo teor de molibdênio e, portanto, as mais convenientes para promover altas velocidades de absorção de hidrogênio, devido à alta afinidade entre hidrogênio e alfa-U. Eles formam, por reação química, tri-hidreto de urânio, que leva, por dehidretação, à formação de pós. Entretanto, a fase alfa remanescente constitui-se numa perda de material, pois não há a possibilidade de reconvertê-la a gama, visto que a sua segregação processa-se usualmente em contornos de grão, fora da matriz de gama. 

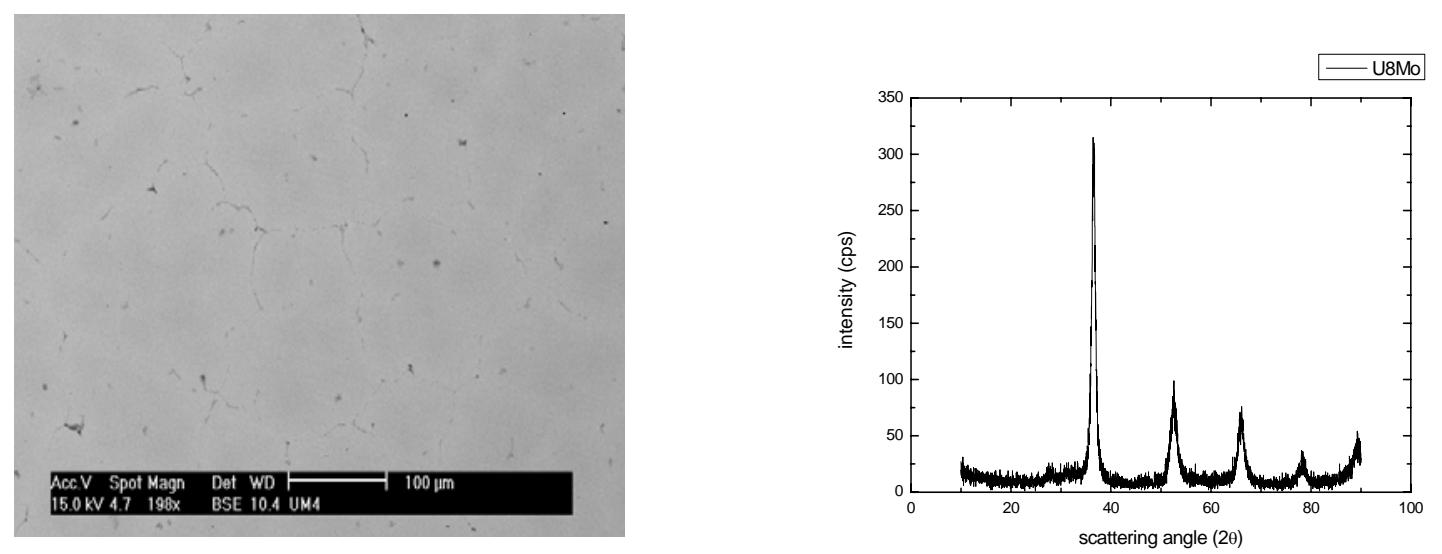

FIGURA 89 - Imagem de MEV e espectro de difração de raios-X de uma liga $\gamma$-U8Mo alloy, fundida via indução.
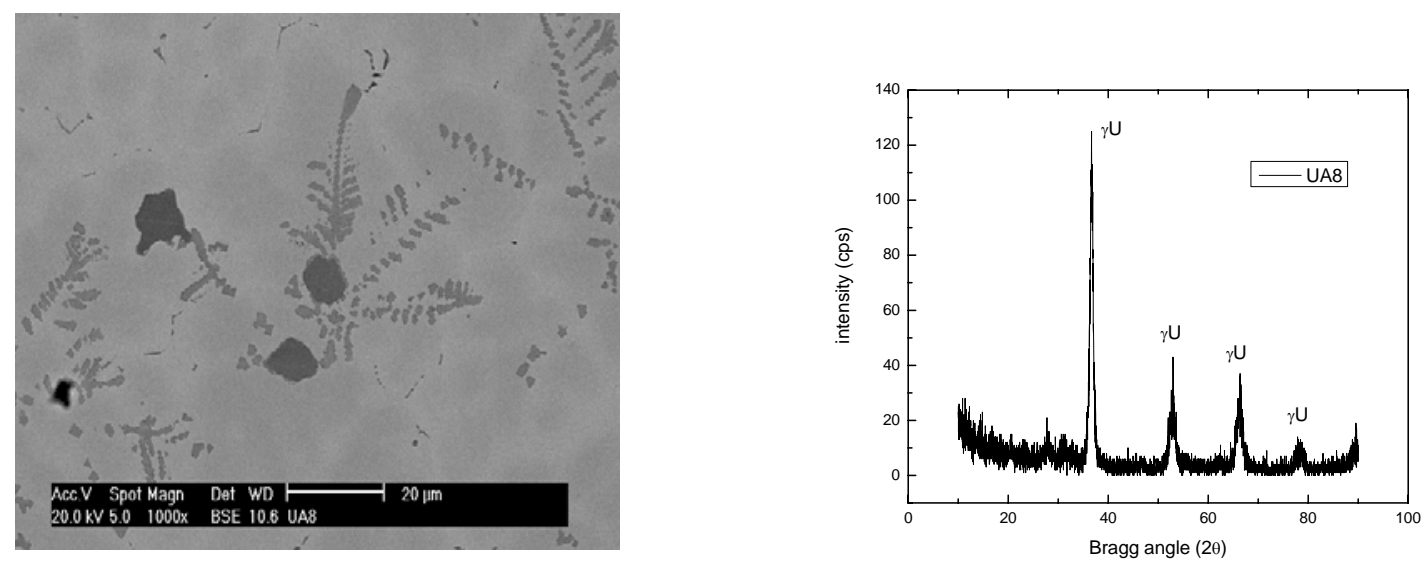

FIGURA 90 - Imagem de MEV e espectro de difração de raios-X de liga $\gamma$-U8Mo, fundida via arco, tratada termicamente, mesma composição que a amostra de indução.

Experimentos de absorção de hidrogênio foram realizados exatamente nas mesmas condições de fluxo de gás, massas e forma das amostras. Como exemplo, pode-se ver na Figura 91 que a taxa de absorção foi maior para as ligas produzidas via arco do que a absorção das ligas de indução.

Dessa figura pode-se concluir que as amostras de arco têm mais capacidade de absorver hidrogênio que as de indução, visto que a taxa de absorção de hidrogênio foi aproximadamente 4,5 vezes maior. Mas, como mostrado nas respectivas micrografias, inomogeneidades na composição são as principais responsáveis por esta velocidade maior. Se gama é considerada como a fase mais recomendável para aplicações como combustíveis de alta densidade, estas anomalias são indesejáveis, e devem ser tratadas como perdas de processo. De fato, em Pasqualini ${ }^{51}$, fase alfa indesejada, após dehidretação, é eliminada do lote de fabricação de pós via HDH por peneiramento. 


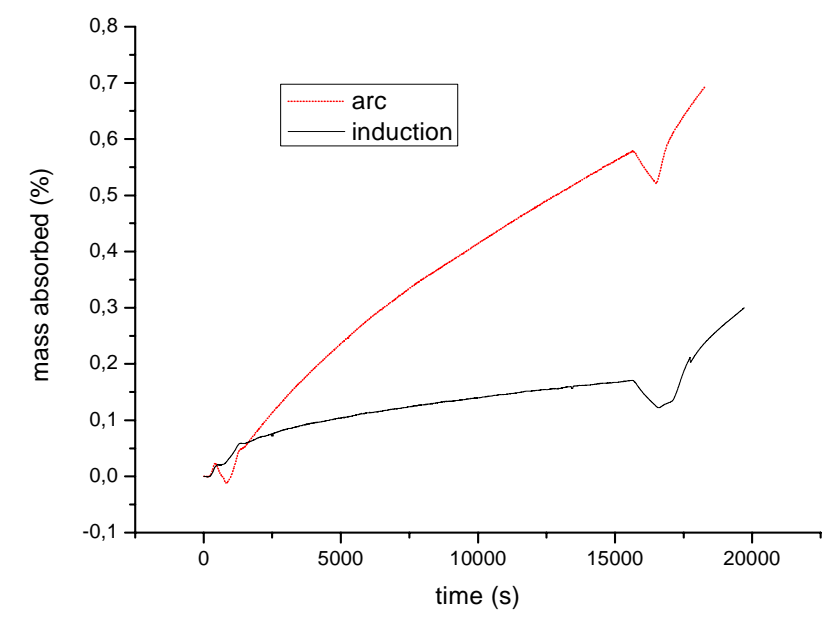

FIGURA 91 - Comparação entre as adsorções de hidrogênio entre as amostras de arco e indução, mesmas condições de análise.

Como exemplo, na Figura 92 apresenta-se uma micrografia de partículas de pó produzidas após tratamento térmico sob hidrogênio de uma liga $\gamma \mathrm{U} 8 \mathrm{Mo}$, produzida por indução.

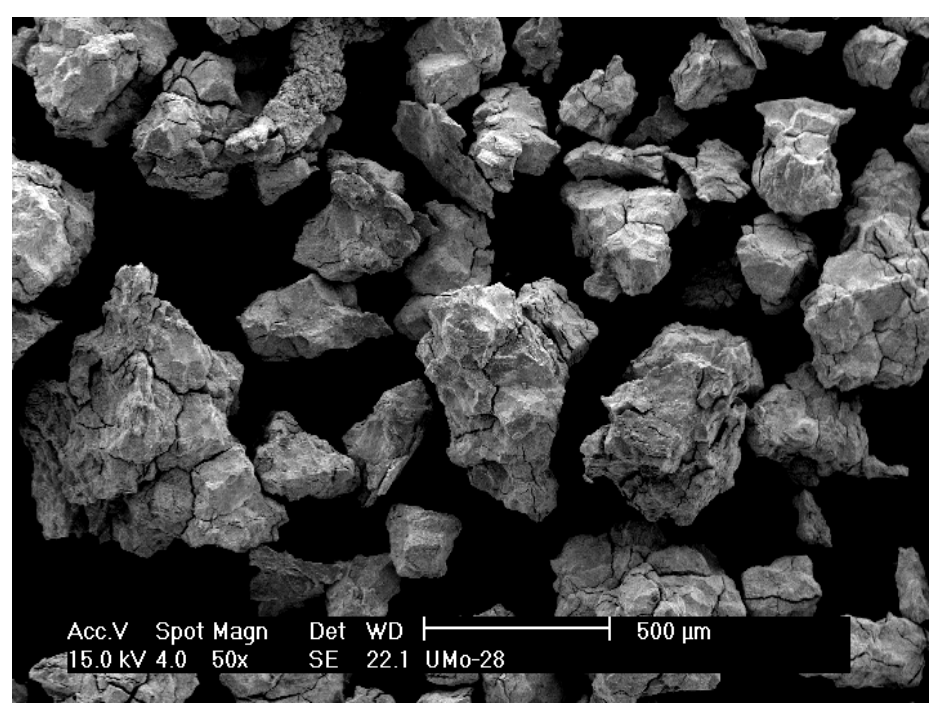

FIGURA 92 - Partículas de liga $\gamma$-U8Mo.

Assim, a dificuldade na obtenção, em uma única etapa, de uma liga microestruturalmente homogênea pelo método da fusão a arco, sua abrupta redução na densidade em composições maiores que $8 \%$ de adição, leva-nos a concluir que, para a obtenção da mesma qualidade apresentada pelas ligas preparadas por indução, algumas das características do processo de fusão a arco devem ser alteradas. Geometria de fusão e de 
carga, número de rebatimentos, e principalmente o sistema de refrigeração e as condições de tratamento térmico. O parâmetro que se pode alterar nesta tese foi o número de refusões, para minimizar os problemas de falta de homogeneidade. Entretanto, conforme observação no item 10.1., a elevação no número de refusões pode levar à incorporação de material da matriz pela liga e também à formação de óxidos, introduzindo impurezas no produto final.

Outro fator importante relacionado ao processo de fabricação é o da cristalinidade. Conforme pode ser observado nas micrografias do item 10.2, grãos das ligas de indução, brutas de fusão e tratadas termicamente, apresentaram-se maiores e mais homogêneos quanto à composição. Grãos de ligas de forno a arco apresentaram-se bem menores, e em algumas das ligas pouco definidos, indicando baixa cristalinidade, mesmo após tratamentos térmicos. Novamente por isso indica-se o uso de indução para a produção das ligas binárias e ternárias a base de $\gamma \mathrm{UM}$.

Por estas considerações, o uso de indução para a produção de ligas $\gamma$-UMo foi o método escolhido no IPEN-CNEN / Brasil. É sobre elas que os ensaios de hidrogenação para a produção de pós serão conduzidos. 


\section{INFLUÊNCIA DO OXIGÊNIO NA ESTABILIDADE DAS LIGAS}

\subsection{Comportamento das Ligas Frente ao Oxigênio}

Os resultados dos ensaios de análise térmica diferencial para as ligas-base $\gamma \mathrm{UMo}$ e os ternários UMoSi são dados a seguir. Para cada uma das ligas foram determinadas as temperaturas em que ocorreu a oxidação, bem como o ganho de massa ao final dos experimentos.

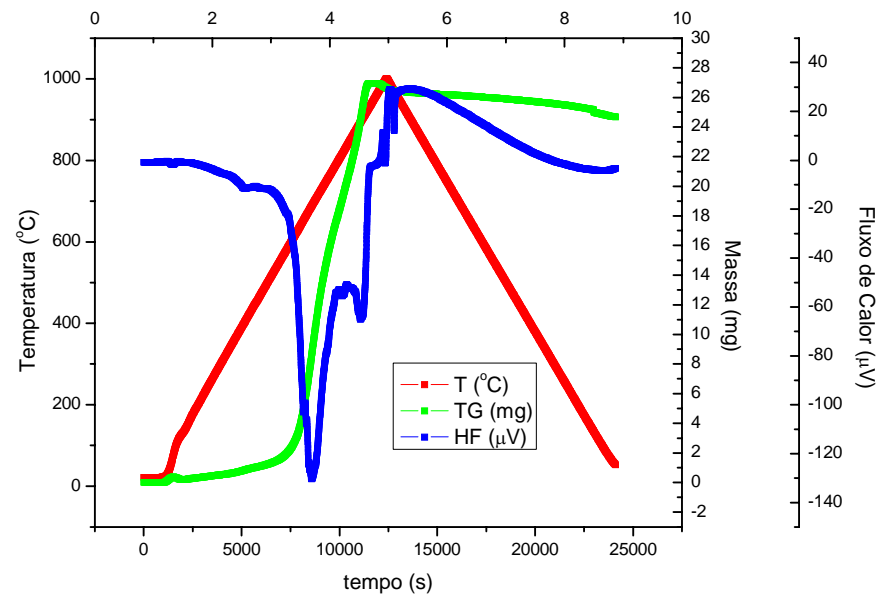

FIGURA 93 - Liga-base $\gamma \mathrm{U} 5 \mathrm{Mo}$, tratada termicamente, enfatizando TG.

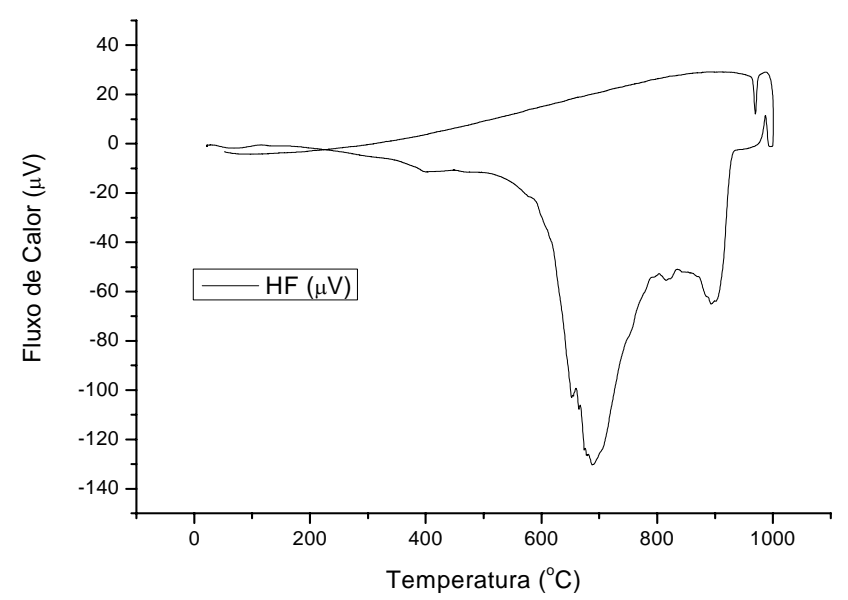

FIGURA 94 - Liga-base $\gamma \mathrm{U} 5 \mathrm{Mo}$, tratada termicamente, temperaturas de oxidação. 


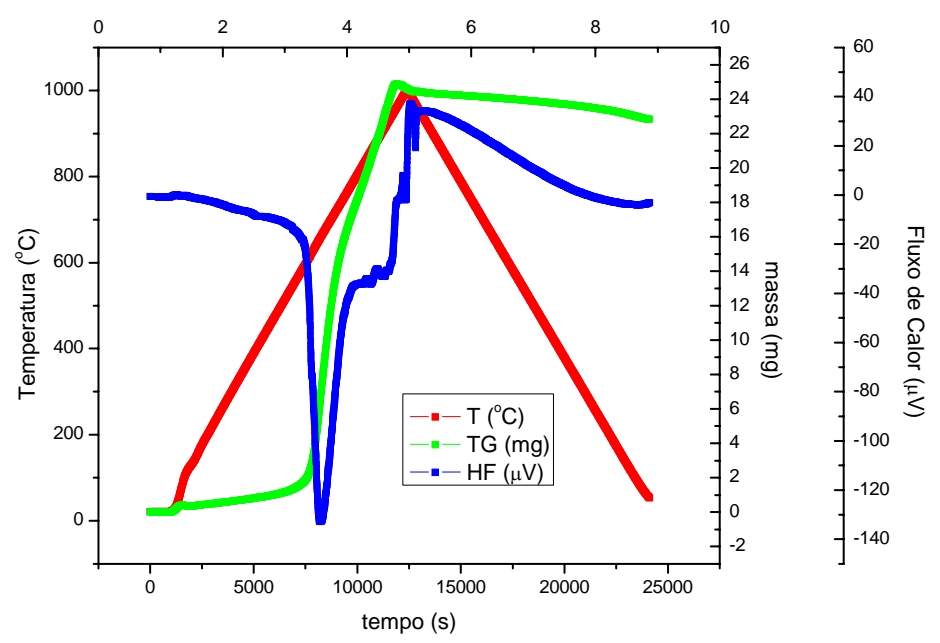

FIGURA 95 - Liga-base $\gamma$ U5Mo, bruta de fusão, enfatizando TG.

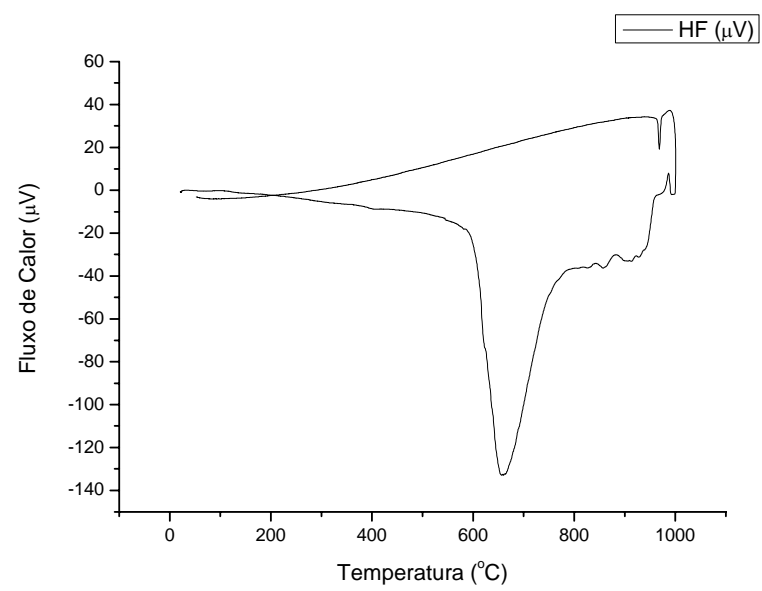

FIGURA 96 - Liga-base $\gamma U 5 \mathrm{Mo}$, bruta de fusão, temperaturas de oxidação.

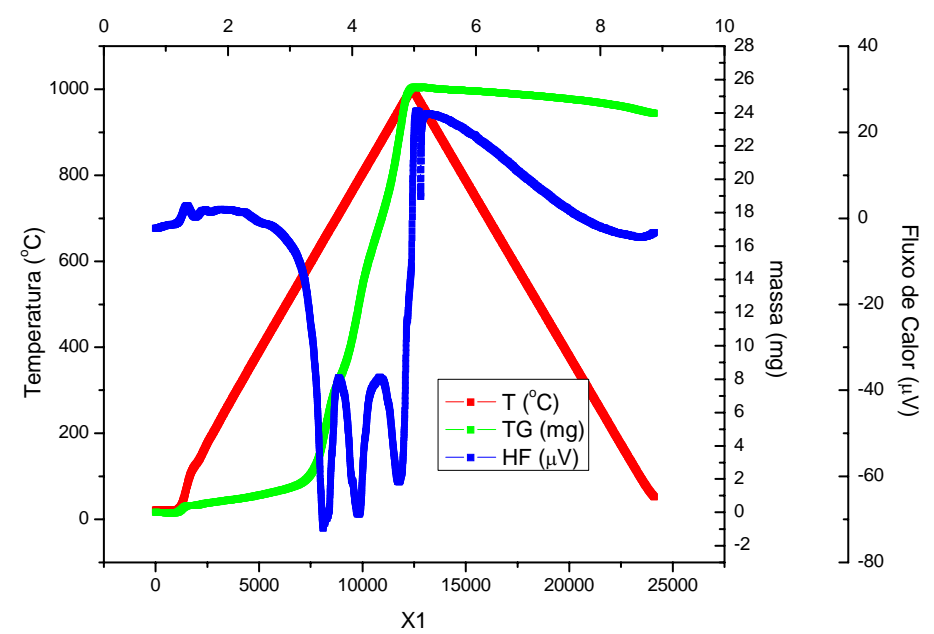

FIGURA 97 - Liga-base $\gamma \mathrm{U} 6 \mathrm{Mo}$, tratada termicamente, enfatizando TG. 


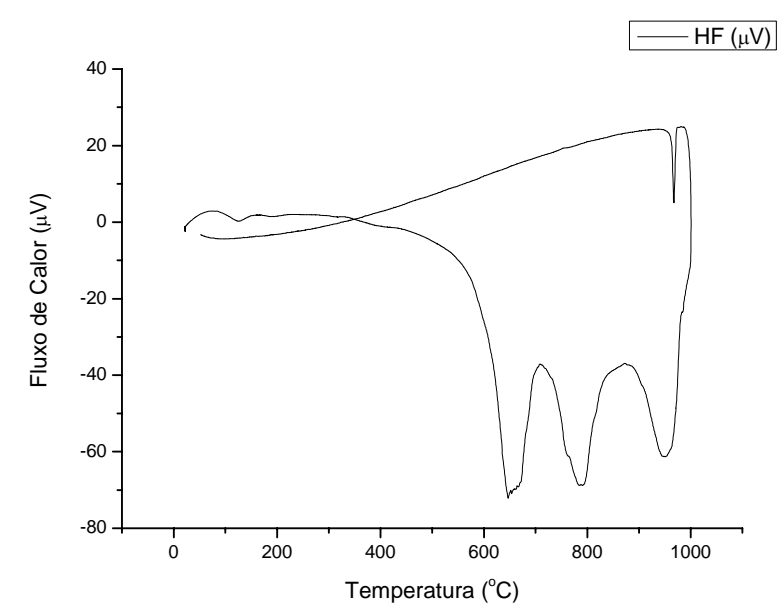

FIGURA 98 - Liga-base $\gamma \mathrm{U} 6 \mathrm{Mo}$, tratada termicamente, temperaturas de oxidação.

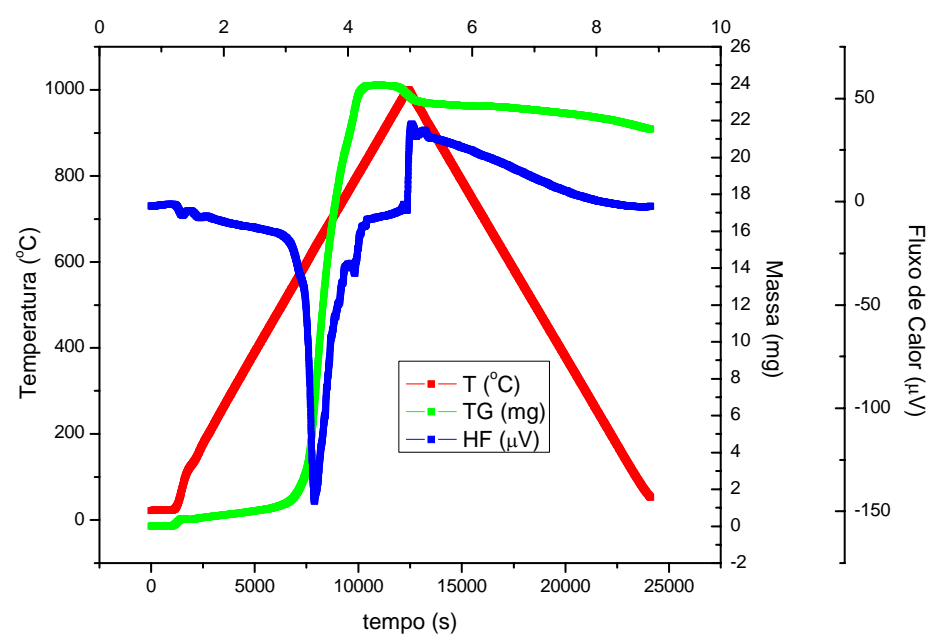

FIGURA 99 - Liga-base $\gamma$ U6Mo, bruta de fusão, enfatizando TG.

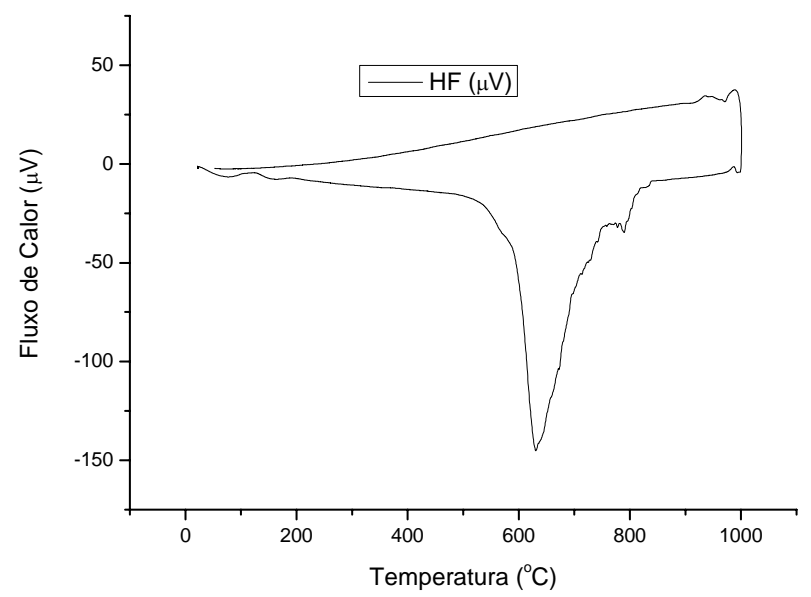

FIGURA 100 - Liga-base $\gamma U 6 \mathrm{Mo}$, bruta de fusão, temperaturas de oxidação. 


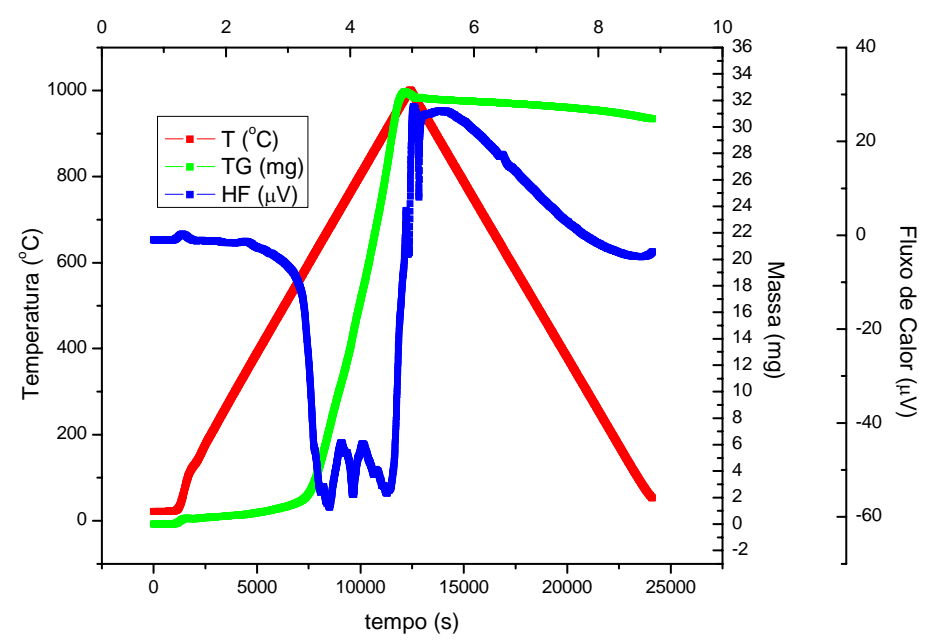

FIGURA 101 - Liga-base $\gamma \mathrm{U} 7 \mathrm{Mo}$, tratada termicamente, enfatizando TG.

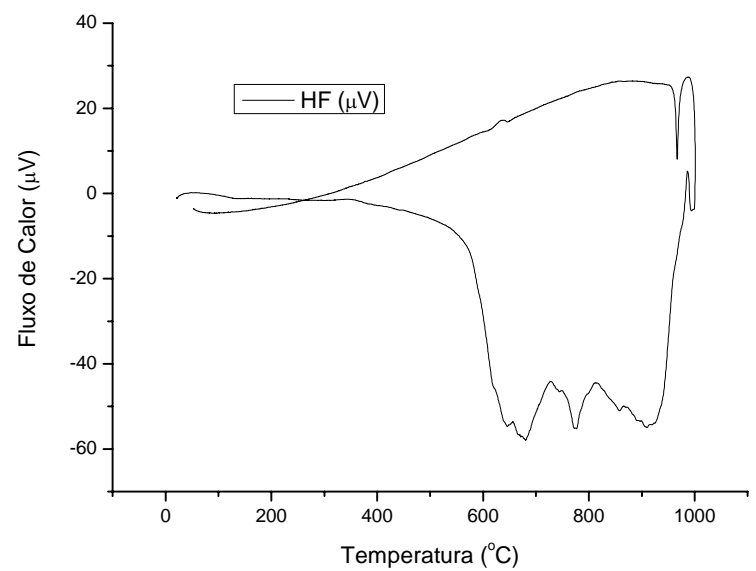

FIGURA 102 - Liga-base $\gamma \mathrm{U} 7 \mathrm{Mo}$, tratada termicamente, temperaturas de oxidação.

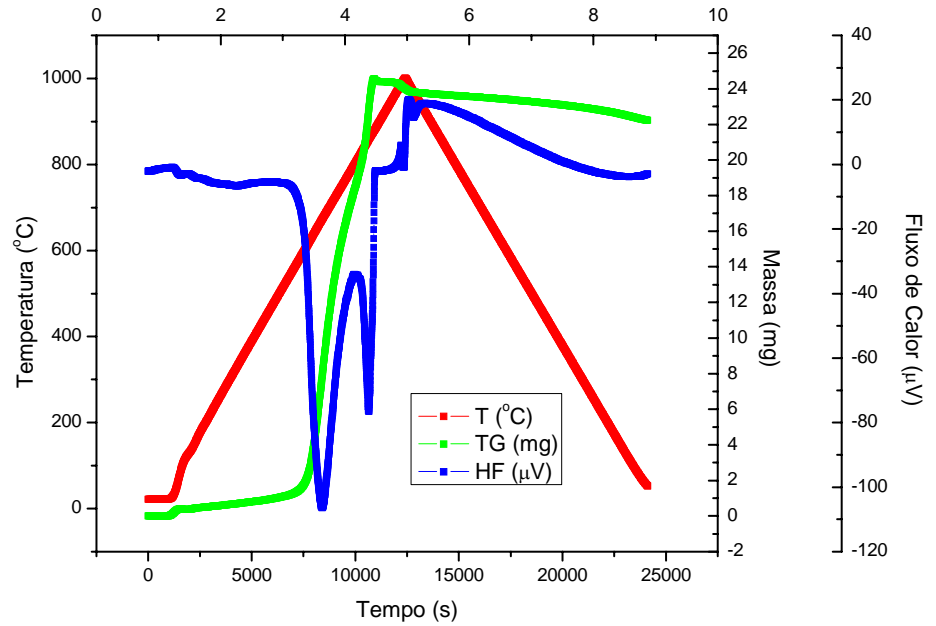

FIGURA 103 - Liga-base $\gamma \mathrm{U} 7 \mathrm{Mo}$, bruta de fusão, enfatizando TG. 


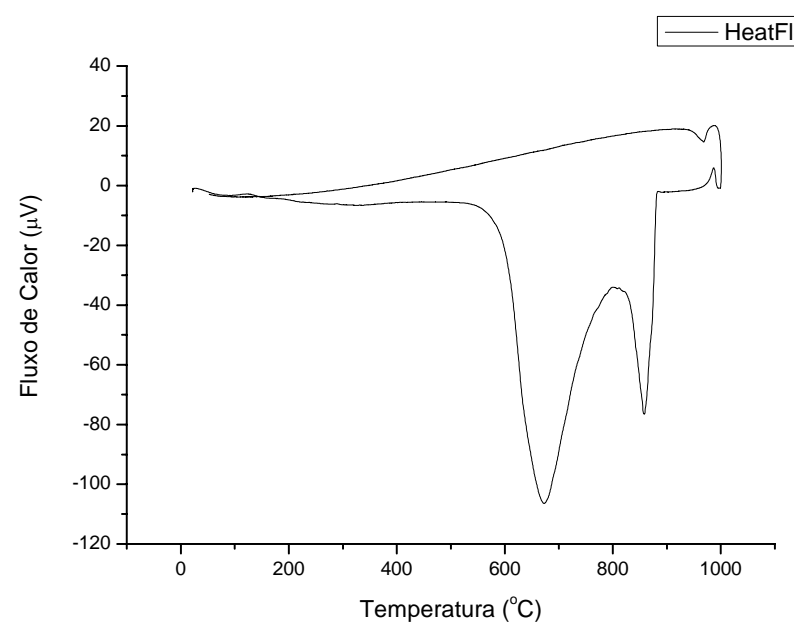

FIGURA 104 - Liga-base $\gamma U$ UMo, bruta de fusão, temperaturas de oxidação.

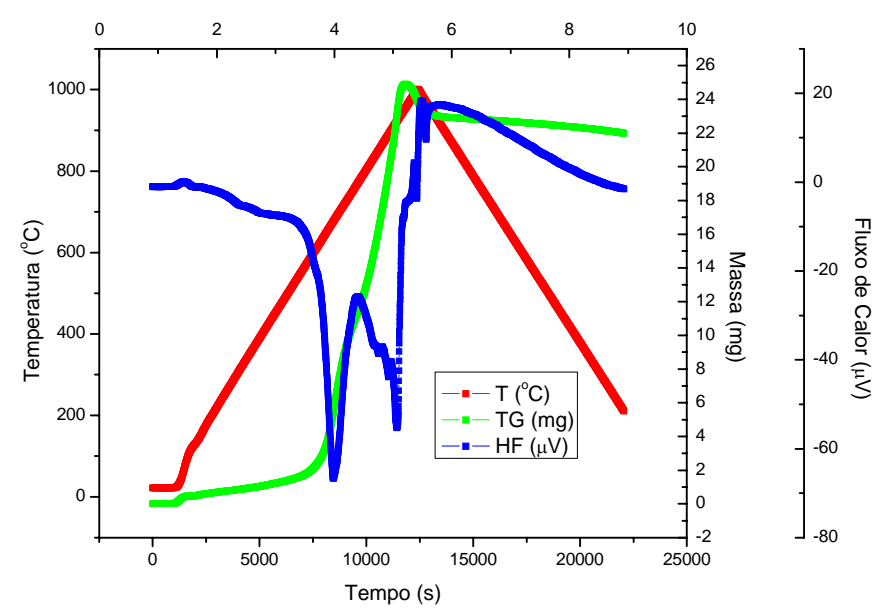

FIGURA 105 - Liga-base $\gamma \mathrm{U} 8 \mathrm{Mo}$, tratada termicamente, enfatizando TG.

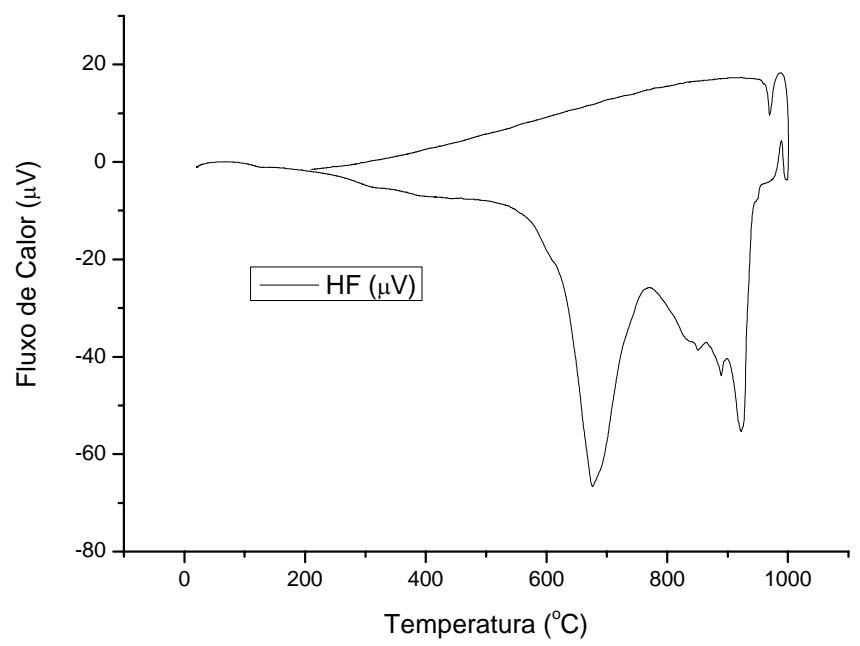

FIGURA 106 - Liga-base $\gamma \mathrm{U} 8 \mathrm{Mo}$, tratada termicamente, temperaturas de oxidação. 


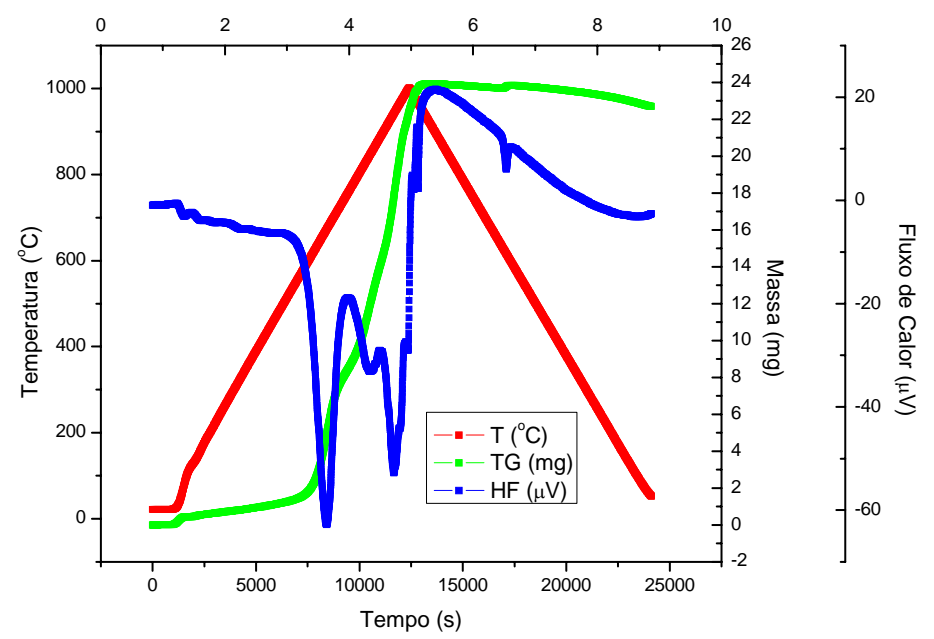

FIGURA 107 - Liga-base $\gamma \mathrm{U} 8 \mathrm{Mo}$, bruta de fusão, enfatizando TG.

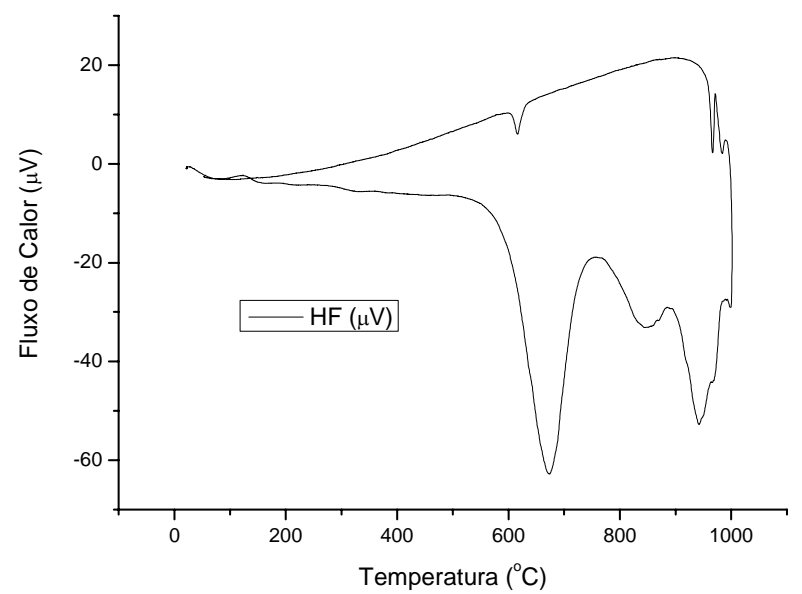

FIGURA 108 - Liga-base $\gamma U 8 \mathrm{Mo}$, bruta de fusão, temperaturas de oxidação.

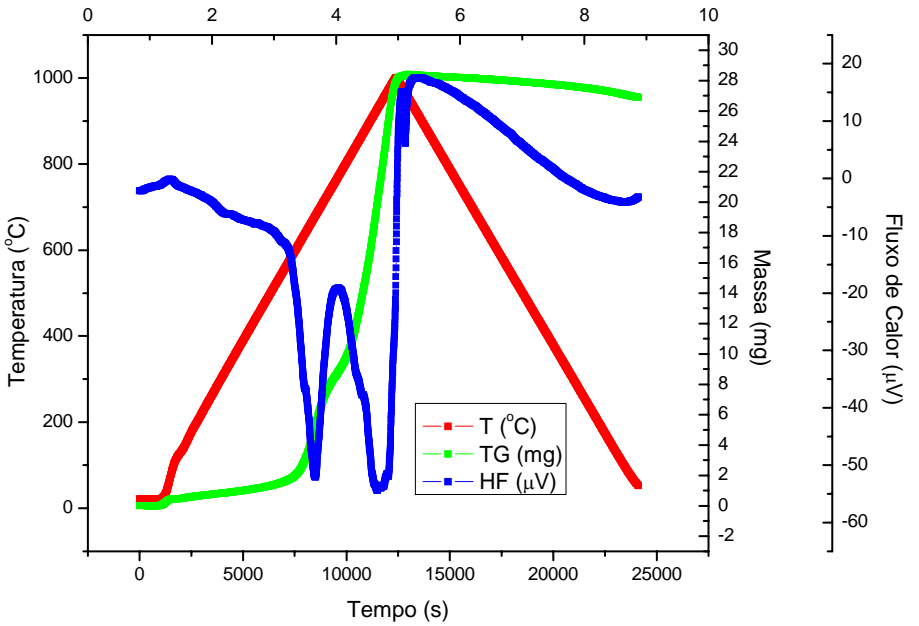

FIGURA 109 - Liga-base $\gamma$ U9Mo, tratada termicamente, enfatizando TG. 


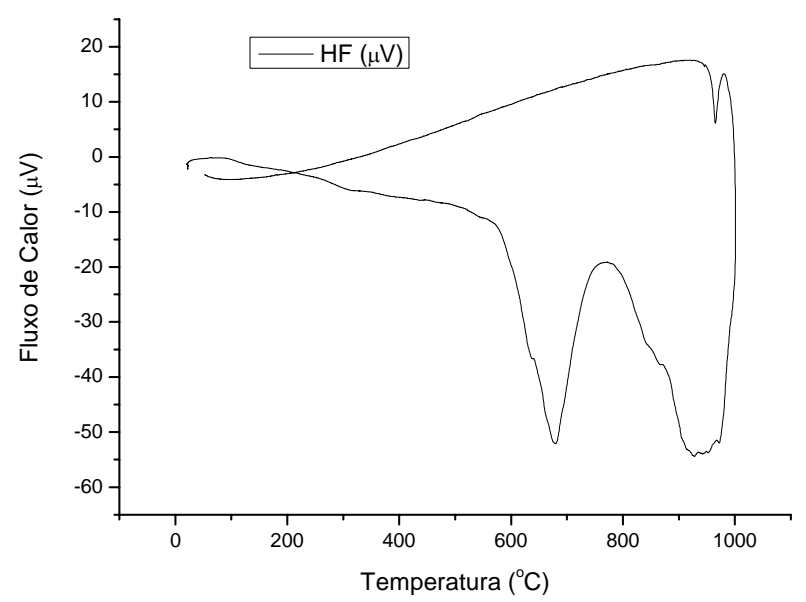

FIGURA 110 - Liga-base $\gamma \mathrm{U} 9 \mathrm{Mo}$, tratada termicamente, temperaturas de oxidação.

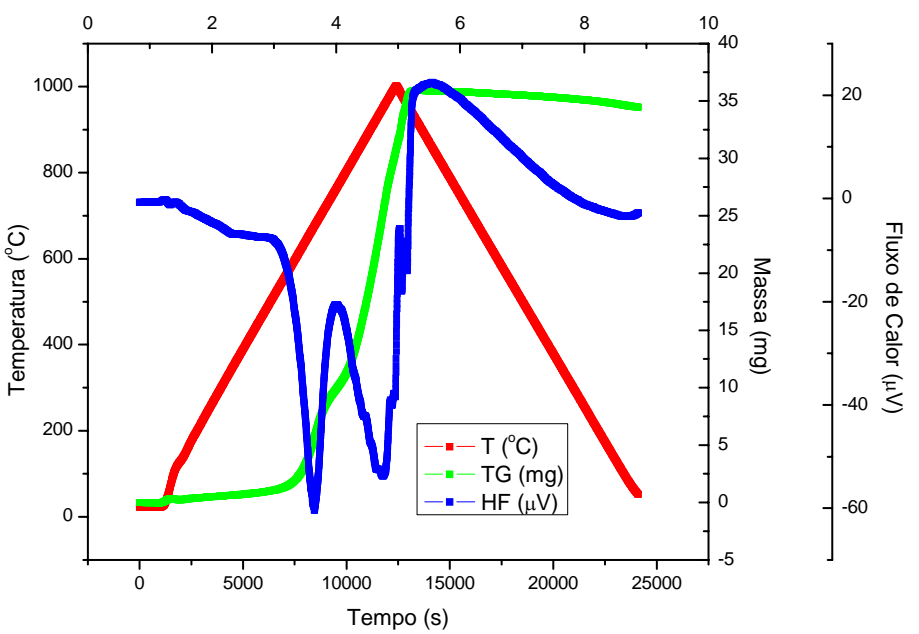

FIGURA 111 - Liga-base $\gamma \mathrm{U} 9 \mathrm{Mo}$, bruta de fusão, enfatizando TG.

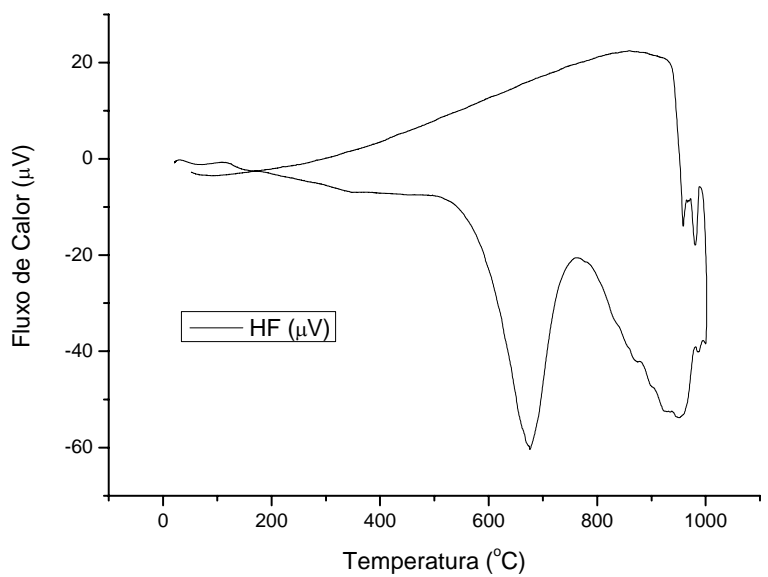

FIGURA 112 - Liga-base $\gamma U 9$ Mo, bruta de fusão, temperaturas de oxidação. 


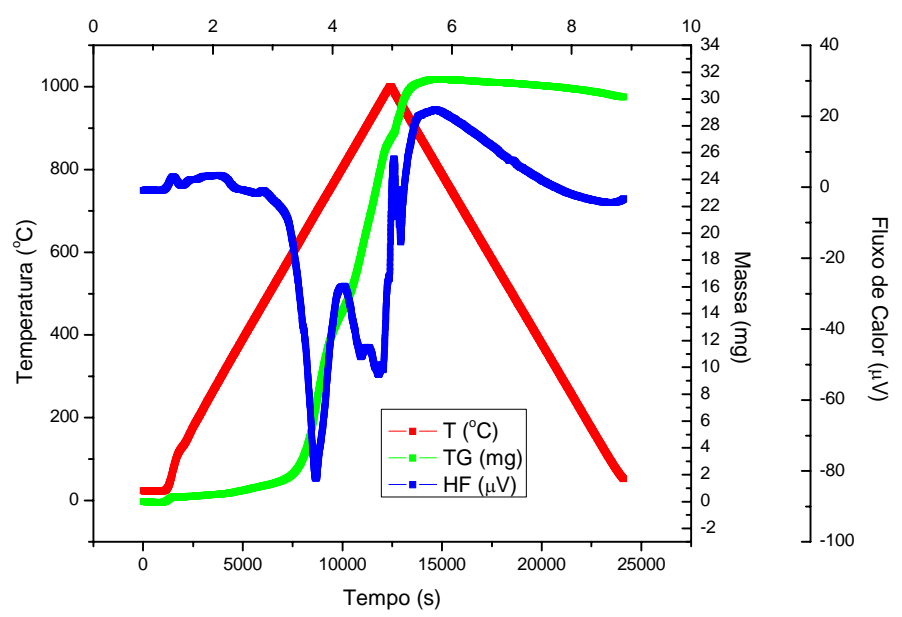

FIGURA 113- Liga-base $\gamma \mathrm{U} 10 \mathrm{Mo}$, tratada termicamente, enfatizando TG.

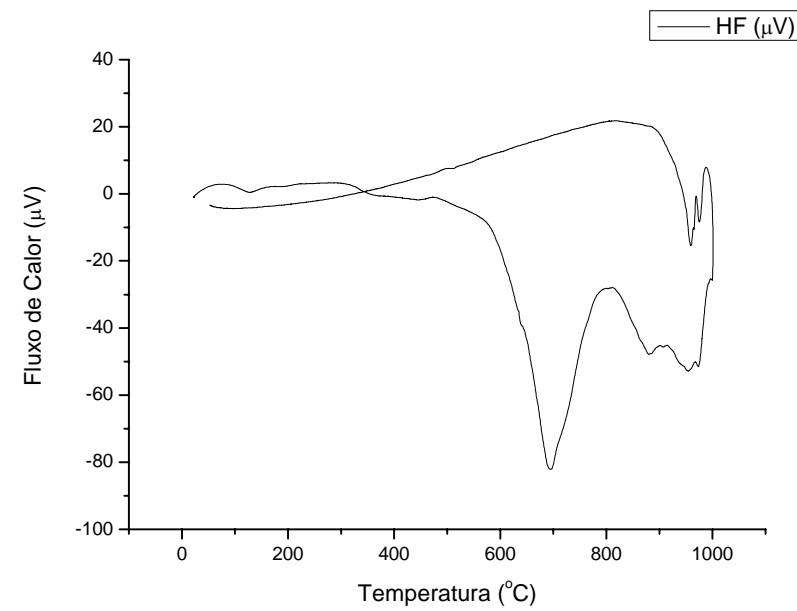

FIGURA 114 - Liga-base $\gamma \mathrm{U} 10 \mathrm{Mo}$, tratada termicamente, temperaturas de oxidação.

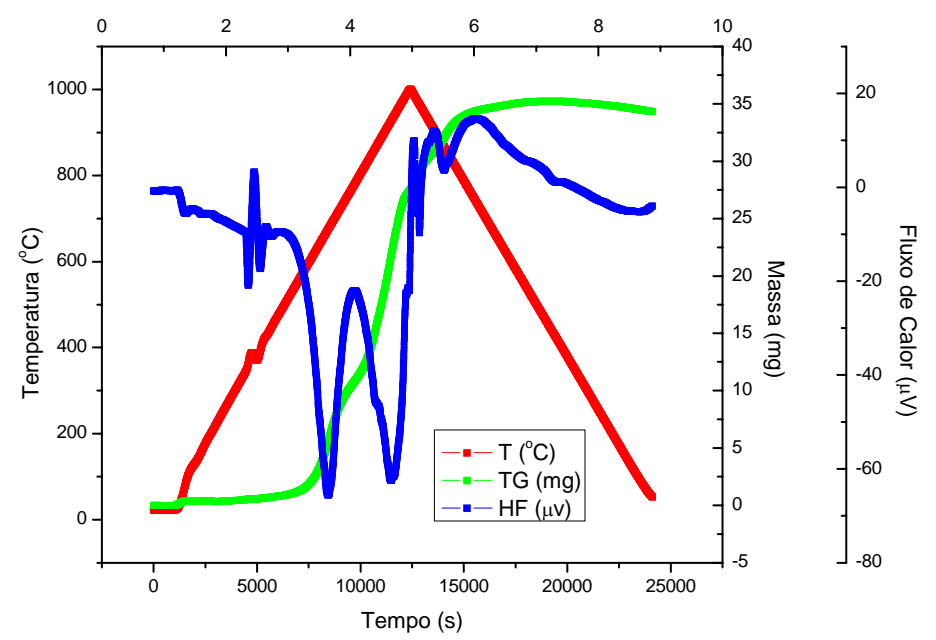

FIGURA 115 - Liga-base $\gamma U 10 \mathrm{Mo}$, bruta de fusão, enfatizando TG. 


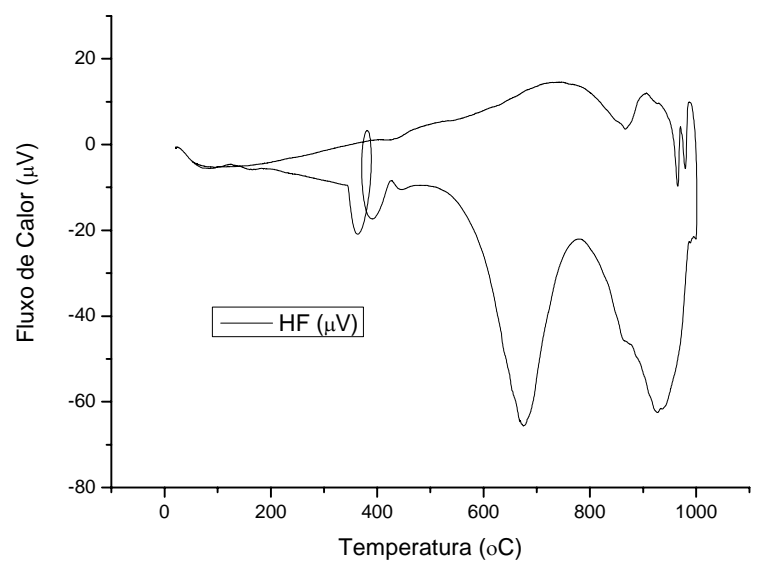

FIGURA 116 - Liga-base $\gamma \mathrm{U} 10 \mathrm{Mo}$, bruta de fusão, temperaturas de oxidação.

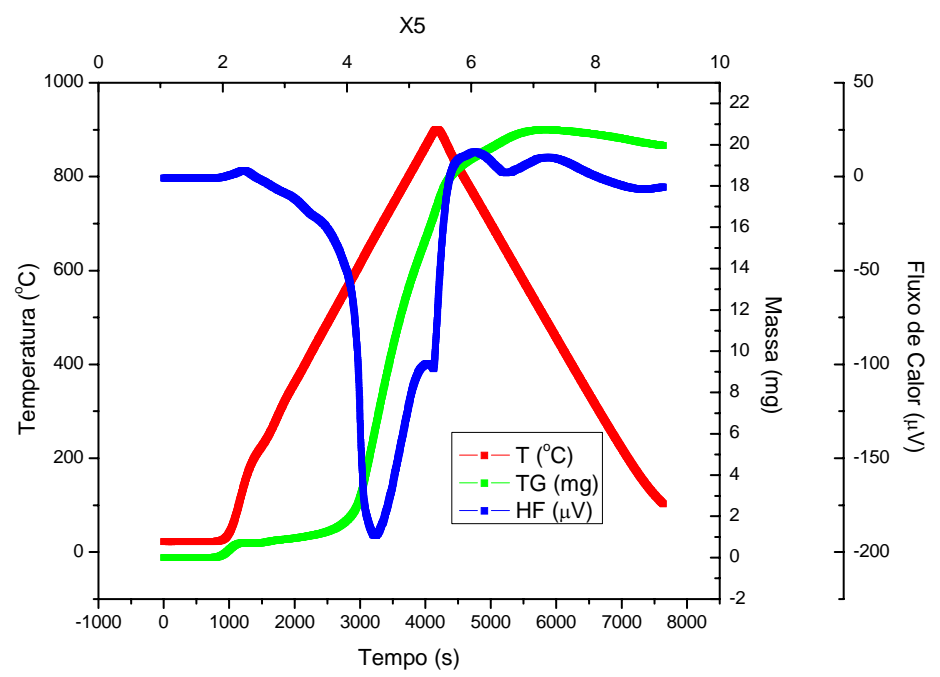

FIGURA 117 - Liga-base $\gamma \mathrm{UMoSi}$, bruta de fusão, enfatizando TG.

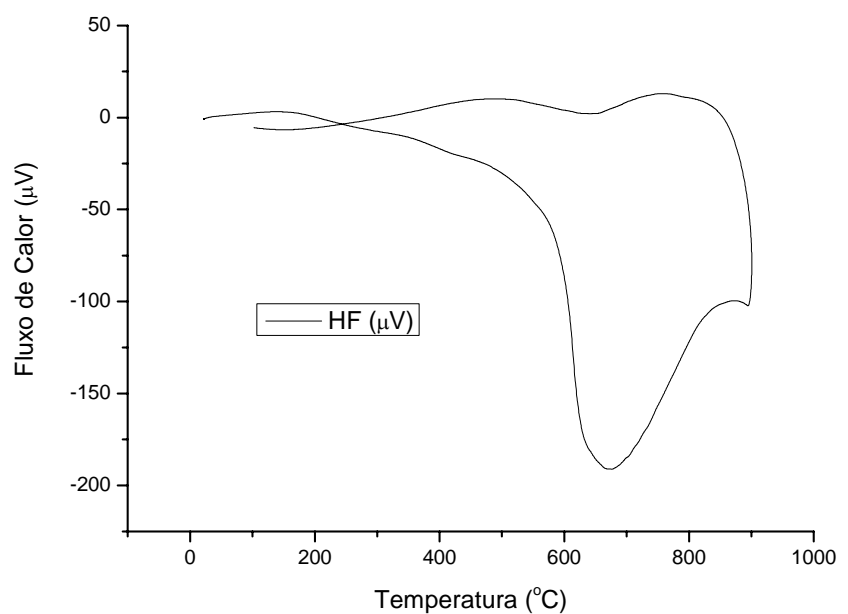

FIGURA 118 - Liga-base $\gamma \mathrm{UMoSi}$, bruta de fusão, temperaturas de oxidação. 


\subsection{Análise}

A partir das curvas de temperaturas onde há reação de oxidação e ganho de massa das ligas-base ou da liga ternária com o ar sintético, pode ser montada a tabela 16, com valores importantes para os parâmetros experimentais.

TABELA 16 - Valores de ganho de massa, ligas-base e ternária.

\begin{tabular}{|c|c|c|}
\hline liga & ganho de massa (mg) & $\%$ \\
\hline үU5Mo & 22,828 & 19,160 \\
\hline$\gamma \mathrm{U} 5 \mathrm{Mo} \mathrm{tt}$ & 24,675 & 18,886 \\
\hline$\gamma \mathrm{U} 6 \mathrm{Mo}$ & 21,537 & 19,015 \\
\hline$\gamma$ U6Mo tt & 23,972 & 19,564 \\
\hline$\gamma \mathrm{U} 7 \mathrm{Mo}$ & 22,234 & 19,290 \\
\hline$\gamma \mathrm{U} 7 \mathrm{Mo} \mathrm{tt}$ & 30,615 & 19,676 \\
\hline$\gamma \mathrm{U} 8 \mathrm{Mo}$ & 22,697 & 20,242 \\
\hline$\gamma \mathrm{U} 8 \mathrm{Mo} \mathrm{tt}$ & 21,989 & 19,433 \\
\hline$\gamma$ U9Mo & 34,450 & 20,187 \\
\hline$\gamma \mathrm{U} 9 \mathrm{Mo} \mathrm{tt}$ & 26,894 & 20,302 \\
\hline$\gamma \mathrm{U10Mo}$ & 34,324 & 20,229 \\
\hline$\gamma \mathrm{U} 10 \mathrm{Mo} \mathrm{tt}$ & 30,142 & 20,603 \\
\hline$\gamma \mathrm{UMoSi}$ & 19,955 & 15,184 \\
\hline
\end{tabular}

na qual \% refere-se à porcentagem relativa à massa inicial de amostra, e tt refere-se às amostras tratadas termicamente. Observa-se que a precisão nas medidas recai na casa dos microgramas. Os ganhos de massa foram obtidos ao final de cada experimento, temperatura da amostra próxima à ambiente, à exceção da liga-base $\gamma \mathrm{U} 8 \mathrm{Mott}$, que foi obtido a $210^{\circ} \mathrm{C}$, e da liga $\gamma \mathrm{UMoSi}$, a $102^{\circ} \mathrm{C}$, ambas por problemas operacionais. Entretanto, é de se esperar que em temperaturas mais baixas, os respectivos valores de ganho de massa sejam menores.

Com base nestes resultados, pode-s traçar as curvas apresentadas na Figura 119: 


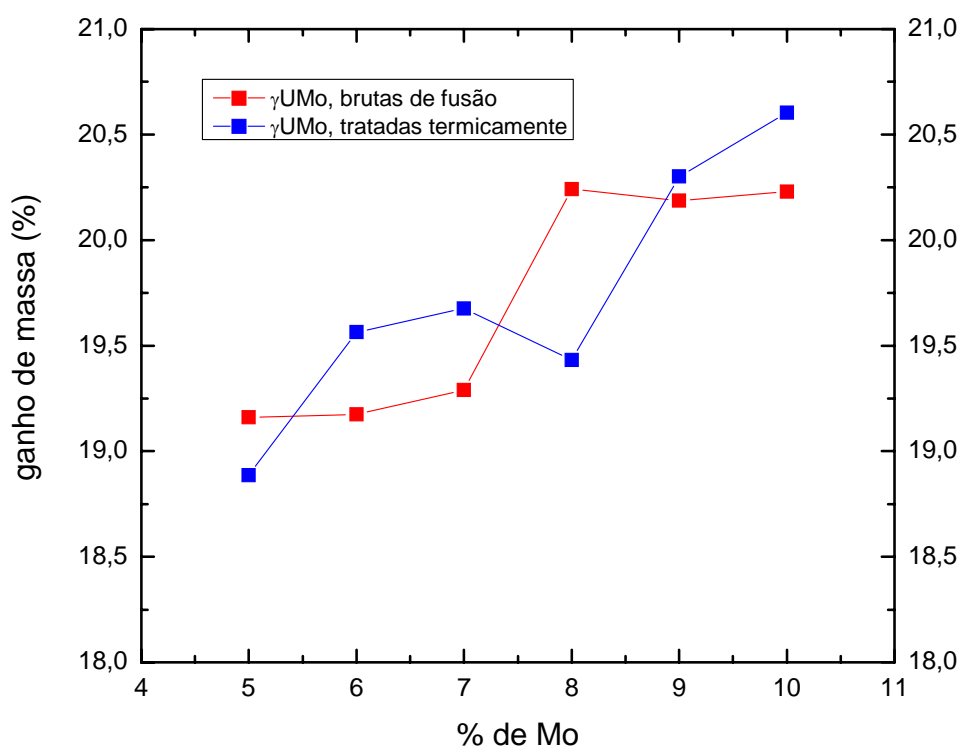

FIGURA 119 - Curvas de ganho de massa absoluta, ligas-base $\gamma$ UMo.

na qual se observa que há aumento na massa de oxigênio incorporado à liga, em todos os casos, com o aumento na quantidade de molibdênio adicionado. Como se sabe que a solubilidade do oxigênio em urânio no estado líquido é pequena, aproximadamente igual a $0,05 \mathrm{a} / \mathrm{o}$ de oxigênio no ponto de fusão do urânio $\left(1138^{\circ} \mathrm{C}\right)^{04}$, é de se esperar que seja ainda menor em urânio no estado sólido.

Supondo-se ainda que toda a quantidade de material incorporado pela liga se deva ao oxigênio, pela terceira coluna e sabendo-se que os óxidos de urânio $\mathrm{UO}_{2}, \mathrm{U}_{3} \mathrm{O}_{8} \mathrm{e}$ $\mathrm{UO}_{3}$ possuem razão mássica $\mathrm{O} / \mathrm{U}$ iguais a $0,1345,0,1793$ e 0,2017 , é de se supor que a oxidação foi completa, levando o material, ao final, ao $\mathrm{UO}_{3}$, com urânio em seu mais alto estado de oxidação.

Assim, como as observações das micrografias do capítulo $\mathrm{X}$ indicam um aumento na porosidade intergranular com o aumento na porcentagem de molibdênio, e ainda, como os valores de densidade decrescem também com o aumento na porcentagem de molibdênio, supõe-se então que a difusão do oxigênio pelo interior da liga seja mais fácil quando o teor de molibdênio for maior. Esta é a explicação para a tendência no aumento no ganho de massa com o aumento na porcentagem de adição, até a estabilização a $10 \%$ Mo.

A aplicação dos tratamentos térmicos de homogeneização leva à menor produção de alfa intergranular, dada a diminuição nas diferenças de concentração de 
molibdênio no interior dos grãos. Portanto, como alfa é potencialmente mais reativa ao oxigênio que a fase gama, seria de se esperar uma diminuição no ganho de massa com os tratamentos. Entretanto, não foi isso o que ocorreu, evidenciando outro aspecto da difusão de gases por metais, apresentado a seguir.

Sabe-se que os metais, quando expostos ao ar, imediatamente sofrem a ação do oxigênio, havendo então a formação de uma camada de óxido sobre a sua superfície mais externa. Como foi observado no capítulo 10, o tamanho médio dos grãos das amostras brutas de fusão é menor que o das amostras tratadas termicamente. Isto significa que, no primeiro caso, tem-se maior área superficial, portanto mais reativa quando em contato com o oxigênio. A formação de camada de óxido se faz à velocidade mais rápida e de maneira mais uniforme, e acaba por preencher toda a sua superfície. Entretanto, como no segundo caso se tem grãos maiores, a formação de camada de óxido é mais lenta e pouco uniforme, havendo regiões no metal onde são formadas as chamadas ilhas de óxidos, deixando superfície livre. Assim, a incorporação de oxigênio pelo metal é maior, pois não há barreiras de óxidos superficiais que impeçam a difusão do gás ao interior da estrutura da liga. Isto, portanto, promove a sua maior absorção de oxigênio com conseqüente reação, e aumento nos ganhos de massa relativamente aos materiais brutos de fusão.

Está-se aqui falando de diferenças entre 0,4 e 0,8\% em ganhos de massa, obviamente que muito pequenos. Se se levar em conta que se trabalhou com as mesmas vazões e, portanto, quantidades de oxigênio, em todos os ensaios, mesma forma para as amostras e, portanto, aproximadamente a mesma área de superfície exposta ao oxigênio, os resultados podem ser considerados confiáveis. Entretanto, condições de preparo das superfícies das amostras podem ter levado ao cruzamento das curvas, indicando a necessidade de um melhor preparo das superfícies. De qualquer maneira, a tendência geral é para o aumento no ganho de massa com o aumento na porcentagem de adição, o que indica que o papel da porosidade e do aumento em área de grãos prepondera sobre a quantidade de fase alfa, mais reativa, presente nos contornos de grão.

De qualquer forma, independentemente dos estados das superfícies das ligasbase, o que foi observado é que a adição de silício à liga diminui, em muito, a incorporação do oxigênio. Quantitativamente, ao se levar em conta que a porcentagem de adição foi igual a $10 \%$ em $(\mathrm{Mo}+\mathrm{Si})$, houve uma redução em incorporação de aproximadamente 5\%, quando comparada à mesma adição de Mo. Isto mostra que a reatividade da liga proposta, ao menos frente ao oxigênio, é menor que a das ligas-base, o que pode ser um indício de que seja também mais estável frente ao alumínio. 
Ao se corrigir os valores relacionando-os somente à quantidade de U nas ligas, obtém-se as seguintes curvas, supondo ganho de massa totalmente devido ao oxigênio presente no ar sintético.

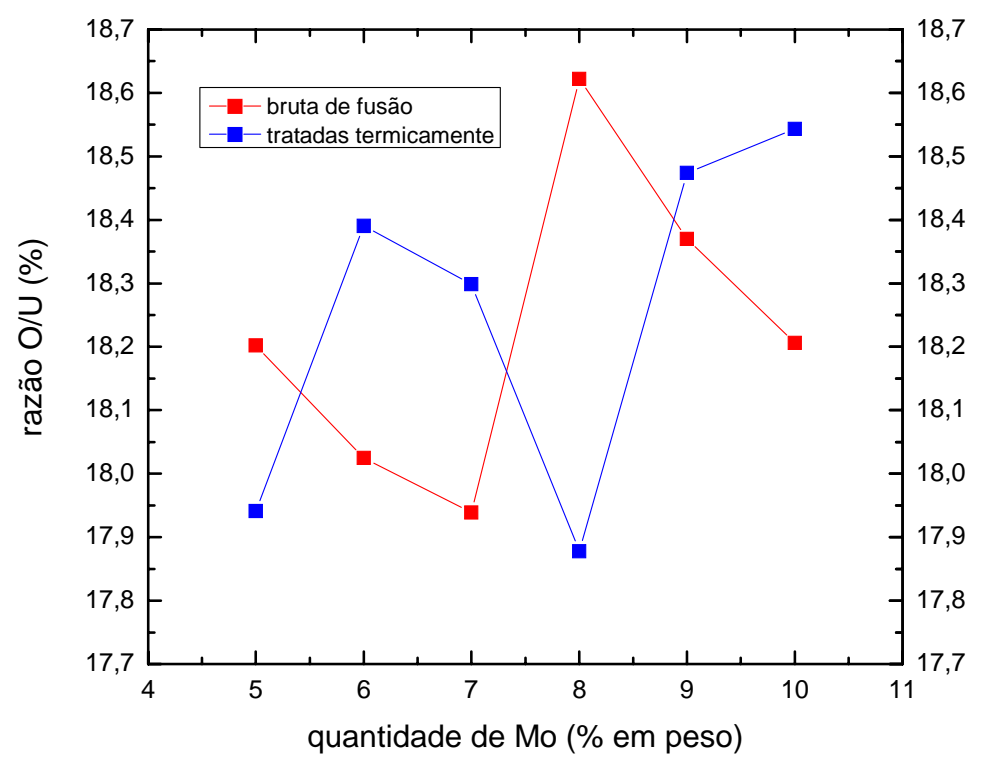

FIGURA 120 - Razão O/U, ligas-base.

O interessante é se observar, em adição ao exposto no segundo parágrafo da página anterior, que uma mistura de óxidos pode ter sido obtida. Nas curvas de fluxo de calor em função da temperatura, os primeiros picos referem-se à formação de óxido com urânio em estado de oxidação mais baixo, no caso $\mathrm{UO}_{2}$, o segundo referente ao estado seguinte de oxidação, $\mathrm{U}_{3} \mathrm{O}_{8}$, e o terceiro no estado de oxidação mais alto, $\mathrm{UO}_{3}$. Como os valores estão entre $[\mathrm{O} / \mathrm{U}]$ do $\mathrm{U}_{3} \mathrm{O}_{8}$ e do $\mathrm{UO}_{3}$, presume-se então que a formação de mistura de óxidos se dê nesta faixa.

Outro fato importante em termos de incorporação de oxigênio e que se deve levar em conta é o de que foram utilizadas massas de amostra progressivamente maiores no sentido do aumento da quantidade de Mo. Como, neste sentido, as densidades das ligasbase decrescem, está-se então com volumes maiores de material nos cadinhos, portanto com maior área superficial para a incorporação. Independentemente, observa-se ainda assim o melhor desempenho da liga UMoSi face à absorção.

Entretanto, em termos de massa os resultados podem não ser conclusivos, e deve-se, portanto, analisar a estabilidade das ligas-base utilizando outro critério, o da obtenção das temperaturas de oxidação. 
Nas tabelas e nos gráficos seguintes encontram-se os resultados da análise térmica diferencial para as ligas-base e a proposta. Considerar-se-ão para esta análise apenas os valores de temperatura na qual houve o início da reação de oxidação, correspondentes aos primeiros picos nas curvas. Como estamos falando em estabilidade, o ponto onde ocorre a primeira grande transformação é sempre o mais importante, pois indica o limite superior de temperaturas para o qual se pode trabalhar com o combustível, em atmosfera ou ambiente oxidante.

TABELA 17 - Resultados de temperatura de oxidação, ligas-base e ternária, indução.

\begin{tabular}{|c|c|c|c|}
\hline Liga & $\begin{array}{c}\text { Temperatura } \\
\text { de Oxidação } \\
\left({ }^{\circ} \mathrm{C}\right)\end{array}$ & $\begin{array}{c}\text { Fluxo de } \\
\text { calor } \\
(\mu \mathrm{V})\end{array}$ & $\begin{array}{c}\text { Tempo } \\
(\mathrm{s})\end{array}$ \\
\hline \hline$\gamma \mathrm{U} 5 \mathrm{Mo}$ & 660,31 & $-132,09$ & 8247 \\
\hline$\gamma \mathrm{U} 5 \mathrm{Mo} t \mathrm{tt}$ & 687,55 & $-130,37$ & 8580 \\
\hline$\gamma \mathrm{U} 6 \mathrm{Mo}$ & 630,67 & $-145,17$ & 7884 \\
\hline$\gamma \mathrm{U} 6 \mathrm{Mo} t \mathrm{tt}$ & 646,75 & $-72,11$ & 8100 \\
\hline$\gamma \mathrm{U} 7 \mathrm{Mo}$ & 672,36 & $-106,42$ & 8399 \\
\hline$\gamma \mathrm{U} 7 \mathrm{Mo} \mathrm{tt}$ & 680,34 & $-57,95$ & 8506 \\
\hline$\gamma \mathrm{U} 8 \mathrm{Mo}$ & 672,57 & $-62,80$ & 8413 \\
\hline$\gamma \mathrm{U} 8 \mathrm{Mo} \mathrm{tt}$ & 676,30 & $-66,69$ & 8457 \\
\hline$\gamma \mathrm{U} 9 \mathrm{Mo}$ & 675,82 & $-60,43$ & 8453 \\
\hline$\gamma \mathrm{U} 9 \mathrm{Mo} \mathrm{tt}$ & 679,73 & $-52,10$ & 8502 \\
\hline$\gamma \mathrm{U} 10 \mathrm{Mo}$ & 675,03 & $-65,63$ & 8443 \\
\hline$\gamma \mathrm{U} 10 \mathrm{Mo} \mathrm{tt}$ & 694,16 & $-82,109$ & 8668 \\
\hline$\gamma \mathrm{UMoSi}$ & 670,78 & $-191,08$ & $3224 *$ \\
\hline
\end{tabular}




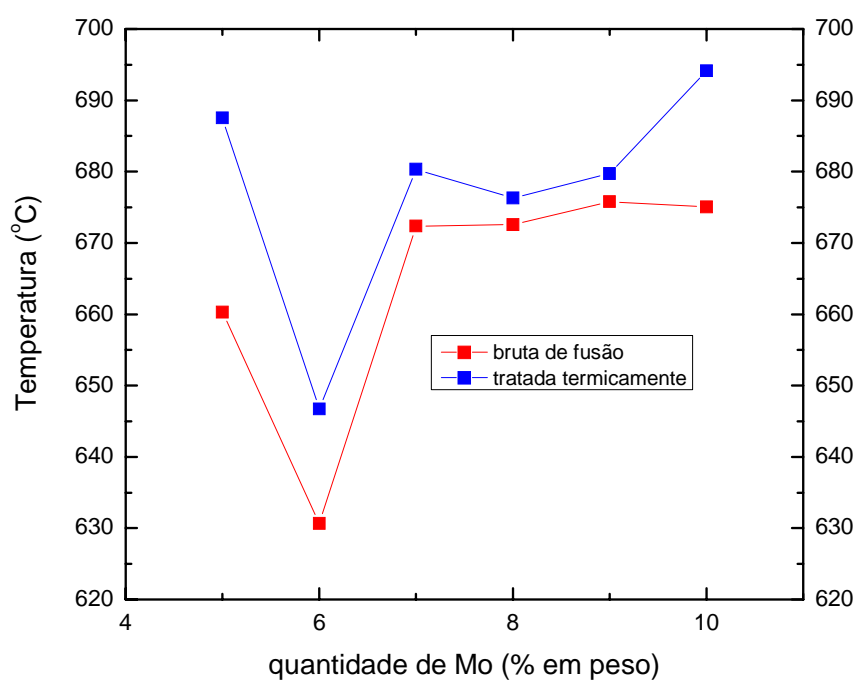

FIGURA 121 - Temperaturas de oxidação, primeiros picos ATD, ligas base $\gamma$-UMo.

Aqui é nitidamente maior a resistência à oxidação apresentada pelas ligas tratadas termicamente com relação às brutas de fusão, pois há, em todas as adições, aumento na temperatura de oxidação. A tendência geral é a de crescimento nas temperaturas de oxidação, o que evidencia o aumento na estabilidade química das ligas com o aumento na adição de molibdênio. Nas ligas brutas de fusão, observa-se a estabilização a partir de $8 \%$ de adição, e nas tratadas termicamente, há grande aumento nos extremos de composição. Conforme comentado na introdução, um dos motivos pelos quais se utiliza a fase gama é a sua maior estabilidade química, quando comparada à da fase alfa, além de sua isotropia.

A menor resistência química da liga $\gamma$ U6Mo pode ser devida a vários fatores, como por exemplo, a presença de uma estrutura de grãos mais fina, devida provavelmente à presença de alguma impureza que pode ter funcionado como inoculante, ou ainda, a maior segregação de Mo. Ou seja, embora a composição esteja correta, maior quantidade de material pode ter sido segregada, o que, mesmo após tratamento térmico de homogeneização, dificultou a melhoria em sua distribuição. As análises químicas, que ainda estão por vir, poderão elucidar este problema. Este comportamento aparentemente anômalo das ligas $\gamma \mathrm{U} 6 \mathrm{Mo}$ foi observado também quanto à irradiação, formação de bolhas, nos primeiros testes RERTR ${ }^{25,27}$, os autores sugerindo que, nesta porcentagem, há alguma transição entre os mecanismos de precipitação da fase alfa. Isto será visto adiante, no capítulo 13 , sobre hidrogenação das ligas. 
Outro comportamento interessante é o parabólico, apresentado pelas diferenças nas temperaturas de oxidação entre as amostras tratadas termicamente e brutas de fusão, para cada uma das porcentagens de adição, conforme curva abaixo.

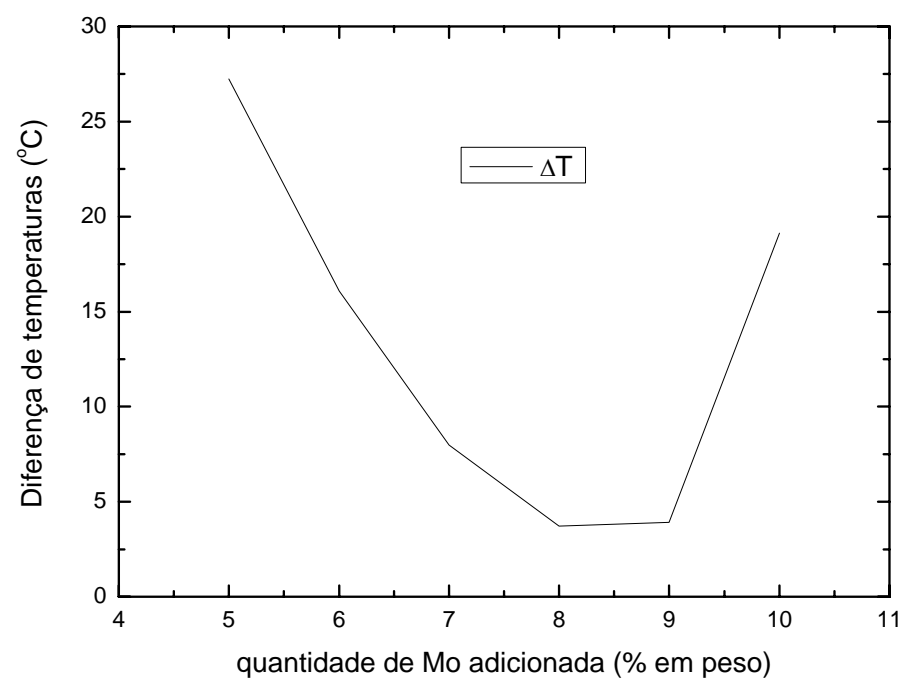

FIGURA 122 - Diferenças de temperatura de oxidação, ligas-base, diferentes condições.

Pode-se explicá-lo por meio dos seguintes argumentos. A 5\% e 10\% de adição, está-se em extremos de comportamento. No limite inferior, há grande quantidade de fase alfa inter e intragranulares, conforme exame das micrografias do capítulo X, e no limite superior, está-se muito próximo da composição eutetóide. Assim, desvios pequenos da composição levam à formação de fase delta ou $\mathrm{U}_{2} \mathrm{Mo}$, neste caso, e para $5 \%$, muita fase alfa proeutetóide está presente, inter e intragranularmente. Os tratamentos térmicos produzem, então, maior efeito na homogeneização das ligas, nestas composições, e menor efeito onde as concentrações de possíveis produtos de reação de decomposição gama são intermediárias.

Assim, em termos tecnológicos, permitir-se-ía o trabalho em condições um pouco mais severas de temperatura, sem que haja a possibilidade de oxidação dos combustíveis. Por exemplo, a 5\% de Mo numa amostra tratada termicamente, a oxidação da liga começaria a uma temperatura $27^{\circ} \mathrm{C}$ maior que a da correspondente bruta de fusão. A mínima diferença de compatibilidades se dá a $8 \%$ de Mo, onde este aumento não chega a $4^{\circ} \mathrm{C}$. Em seguida, há novo crescimento na diferença de temperaturas em $10 \%$ de $\mathrm{Mo}$, chegando-se a aproximadamente $19^{\circ} \mathrm{C}$. 
Portanto, haverá menor diferença de propriedades quando do trabalho com ligas entre 7 e $8 \%$ de adição, ou seja, os tratamentos térmicos aplicados a estas ligas, em termos de favorecimento da estabilidade química, não produzirão efeito acentuado. Nos extremos, as diferenças são maiores, portanto deve ser maior a preocupação com a homogeneização das ligas.

O desempenho da liga ternária, bruta de fusão, foi semelhante ou bem próximo ao da liga $\gamma$ U7Mo. Como se utilizou uma velocidade de aquecimento 3 vezes maior neste experimento em relação aos demais, o tempo de 3224s, assinalado com * na Tabela 17 , para a oxidação da liga que ocorreu a $670,78^{\circ} \mathrm{C}$, seria dado por $\left[(3224-600)^{*} 3+600\right]=$ 8472 s, onde 600s é o tempo de estabilização do equipamento, antes do aquecimento. Mantém-se então a liga nos mesmos níveis de estabilidade, quanto à temperatura, das ligas-base.

Um dos principais motivos para a determinação das temperaturas de oxidação das ligas-base foi o de dar apoio à realização dos ensaios nas demais atmosferas, especialmente os de hidrogenação. Em temperaturas superiores às aqui estabelecidas a oxidação das ligas vai ocorrer, o que pode influenciar os resultados de ganho de massa. $\mathrm{O}$ trabalho com gases, mesmo de alta pureza, sempre carrega consigo um pouco de oxigênio ou ar, e o seu efeito deve ser minimizado, trabalhando-se sempre abaixo destes valores, que serão considerados como limites superiores. No capítulo sobre hidrogenação será apresentado um possível efeito da presença de oxigênio em gases com a denominação 5.0 nos resultados, dadas as suas concentrações, constante em certificado de análises, e a precisão do equipamento de análise térmica, que recai na casa dos microgramas. 


\section{ESTABILIDADE DAS LIGAS FRENTE AO ALUMÍNIO}

\subsection{Comportamento das ligas frente ao alumínio}

Os resultados dos ensaios de análise térmica diferencial para as ligas-base $\gamma$ UMo e os ternários são dados a seguir. Para cada uma das ligas foram determinadas as temperaturas nas quais ocorreram os eventos do sistema, fusão do alumínio, reação com as ligas-base e ternárias, solidificação do alumínio, etc. Foram também determinadas as curvas características para os pontos de fusão e solidificação do alumínio, bem como o ganho de massa ao final dos experimentos.

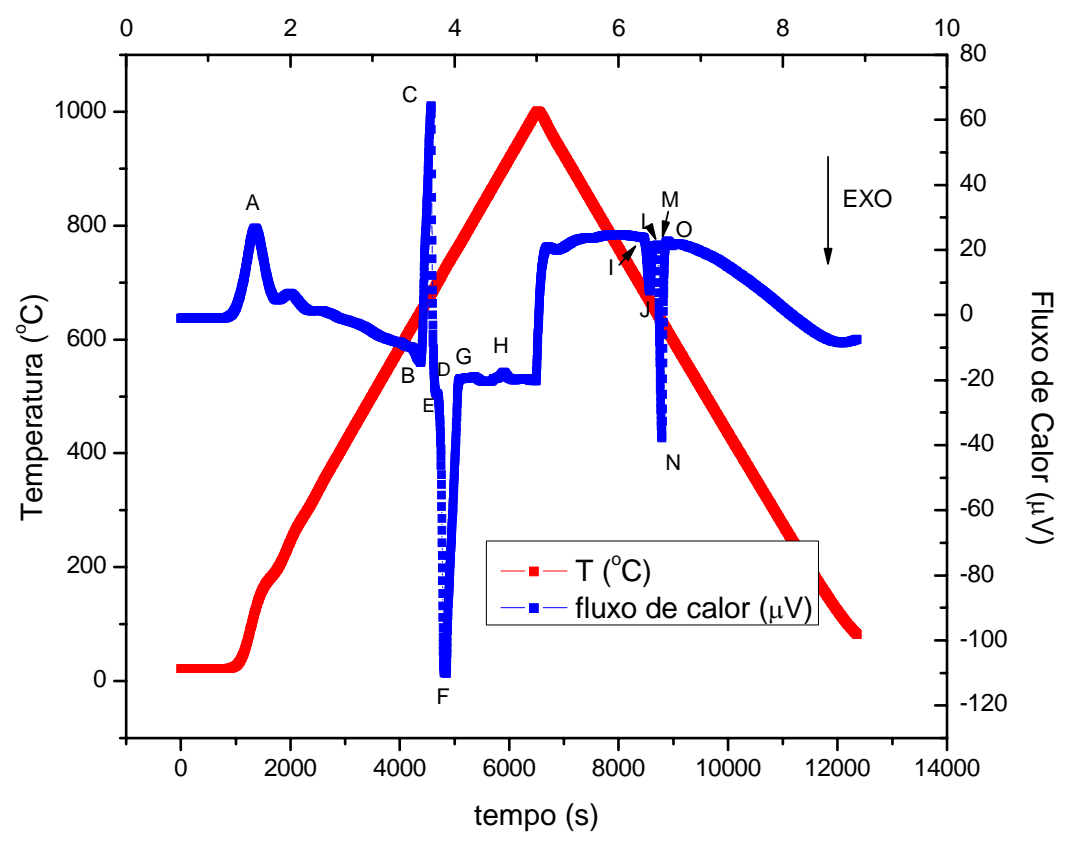

FIGURA 123 - Liga-base $\gamma \mathrm{U} 5 \mathrm{Mo}$, tratada termicamente. 


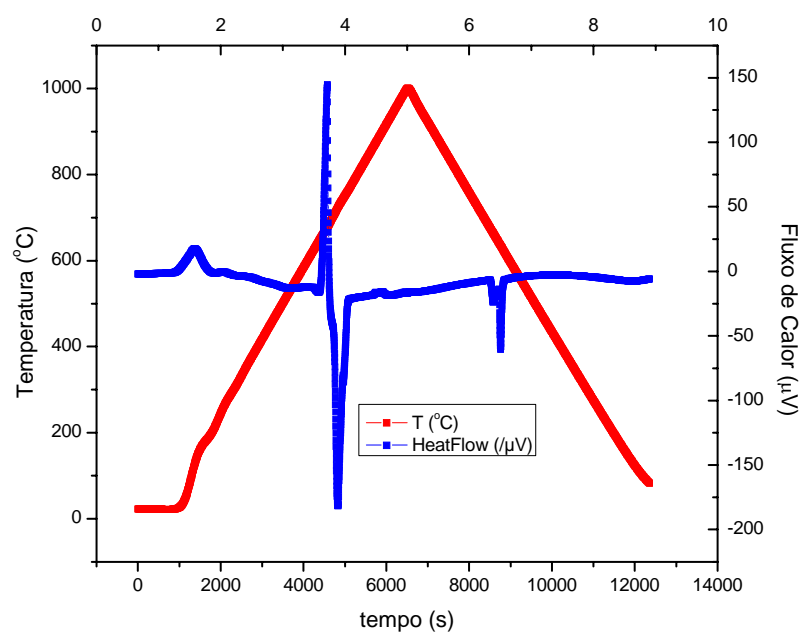

FIGURA 124 - Liga-base $\gamma \mathrm{U} 6 \mathrm{Mo}$, tratada termicamente.

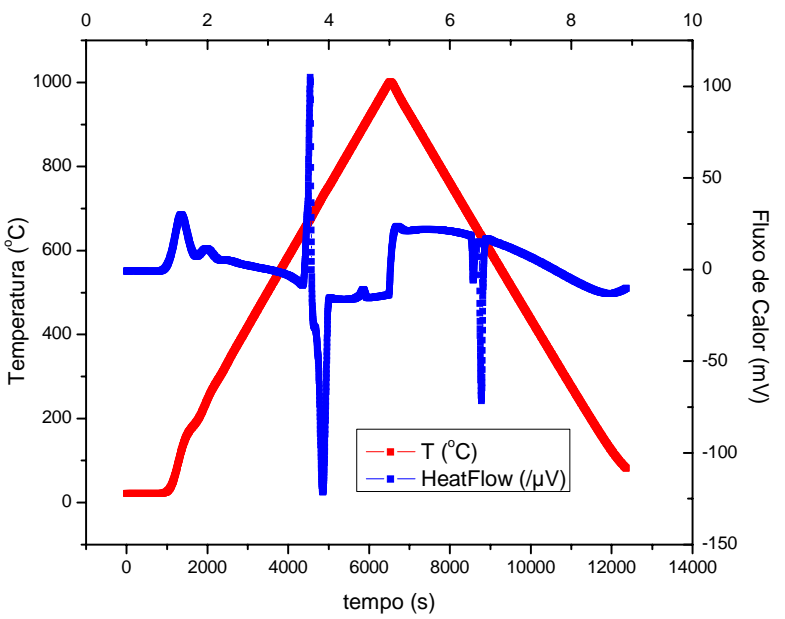

FIGURA 125 - Liga-base $\gamma \mathrm{U} 6 \mathrm{Mo}$, bruta de fusão.

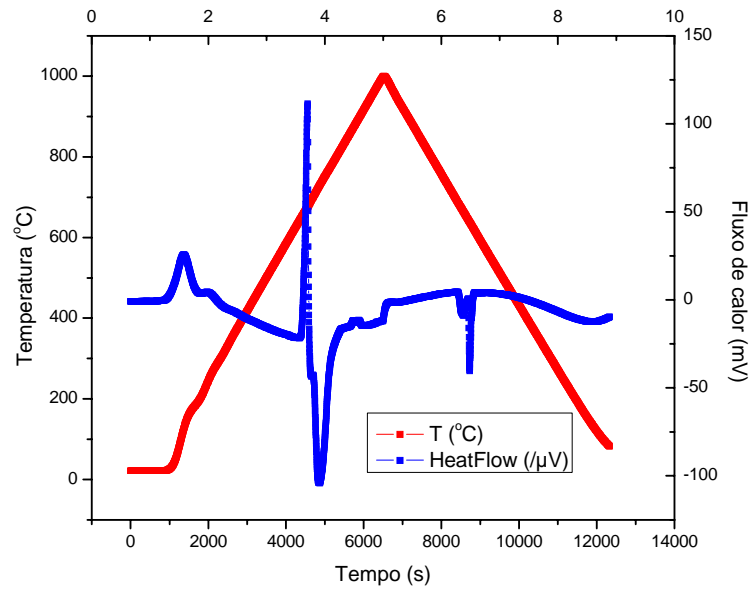

FIGURA 126 - Liga-base $\gamma \mathrm{U} 7 \mathrm{Mo}$, tratada termicamente. 


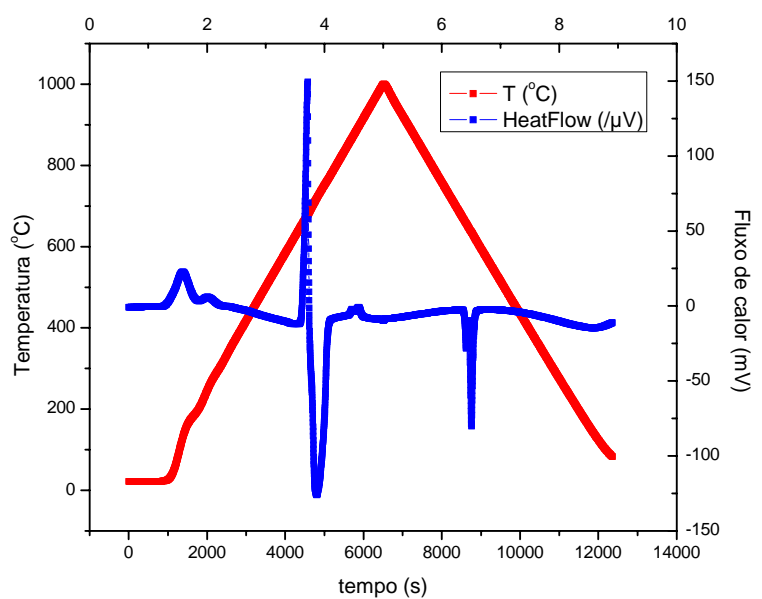

FIGURA 127 - Liga-base $\gamma \mathrm{U} 8 \mathrm{Mo}$, tratada termicamente.

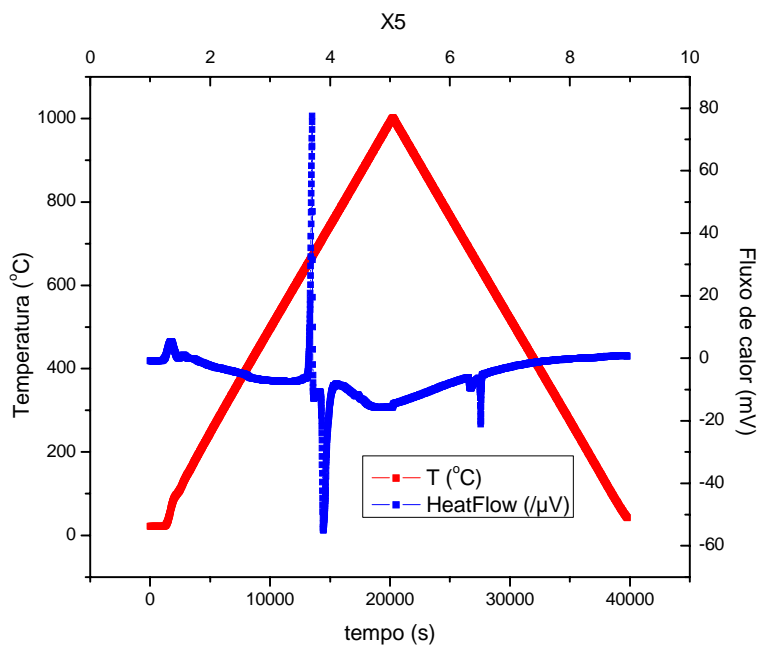

FIGURA 128 - Liga-base $\gamma$ U9Mo, tratada termicamente.

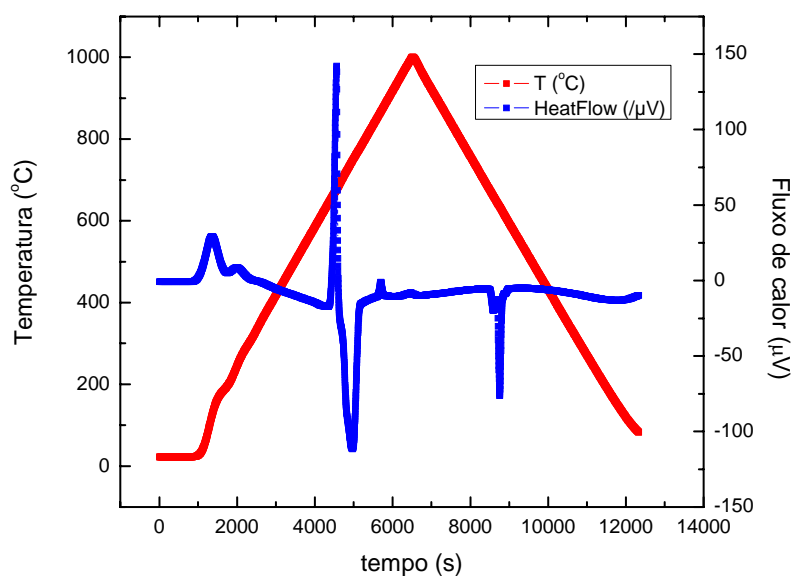

FIGURA 129 - Liga-base $\gamma \mathrm{U} 10 \mathrm{Mo}$, tratada termicamente. 


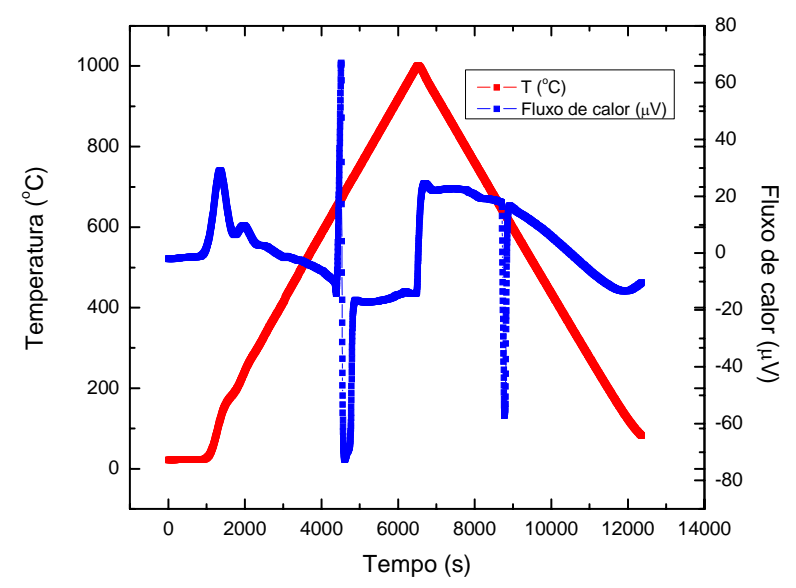

FIGURA 130 - Liga-base $\gamma \mathrm{UMoSi}$, bruta de fusão, amostra 111.

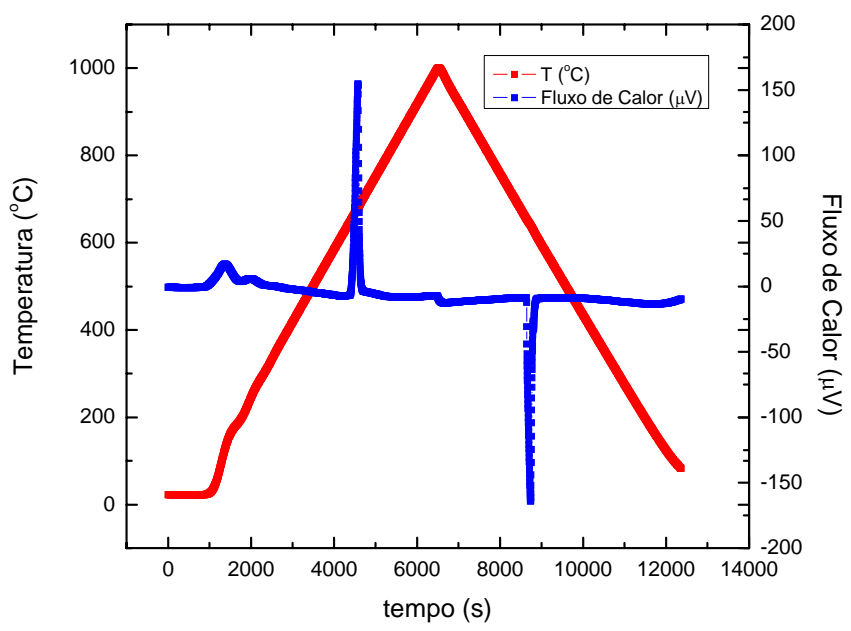

FIGURA 131 - Pontos de fusão e solidificação do alumínio.

\subsection{Análise}

Nas Tabelas 18 e 21 relaciona-se os principais eventos, para cada uma das ligas estudadas. Como a sensibilidade da análise térmica diferencial não foi adequada para a verificação destes eventos, os mesmos foram evidenciados pelo traçado da primeira derivada das curvas de fluxo de calor em função da temperatura.

Como se está tratando do sistema $\gamma$-UMo / Al, a idéia para a verificação da ocorrência das reações, bem como de seu andamento, foi a de se comparar os picos de fluxo de calor quando da fusão e solidificação do alumínio, nas regiões de aquecimento e resfriamento das curvas, respectivamente. Tomando como padrão a Figura 129, na qual se efetuou o mesmo ciclo de aquecimento e resfriamento para o alumínio 6061 puro, observa- 
se que as intensidades apresentam, em módulo, praticamente o mesmo valor. Ou seja, para a dada quantidade de alumínio, podemos dizer que toda a massa disponível para a fusão, na região de aquecimento, solidificou-se, na região de resfriamento.

Ao se analisar as demais curvas, observamos a presença de alguns picos menores, quando do aquecimento, além do referente à fusão do alumínio. Na região de resfriamento, o pico correspondente à solidificação do alumínio apresenta-se menos intenso. Depreende-se daqui que as quantidades de alumínio disponíveis para a solidificação são menores, por reação com a liga $\gamma$ UMo. Pode-se então calcular a quantidade de alumínio livre no sistema, sabendo-se a massa inicial dos reagentes. Por diferença, determina-se a quantidade reagida. Análises de difração de raios-X serão realizadas para a identificação dos produtos, com provável composição média dada nos diversos trabalhos publicados no RERTR ${ }^{21,22,23,35}$. De maneira geral, e conforme observado por $\mathrm{Kim}^{23}$, reações das ligas $\gamma \mathrm{UMo}$ com o alumínio ocorrem a $645^{\circ} \mathrm{C}$. Como o início da fusão se dá, conforme Figura 129, a aproximadamente $641^{\circ} \mathrm{C}$, então a reação ocorre logo após a fusão do alumínio, sendo portanto favorecida em fase líquida.

Observa-se em todos os casos os picos logo após a fusão do alumínio, confirmando os resultados mencionados $\mathrm{em} \mathrm{Kim}^{23}$. Temos aí a formação de composto, com alumínio ligado à estrutura $\gamma \mathrm{UMo}$.

TABELA 18 - Eventos principais nas curvas de análise térmica diferencial.

\begin{tabular}{|c|l|l|l|l|l|l|l|l|l|}
\hline Evento & $\gamma \mathrm{U} 5 \mathrm{Mo}$ & $\gamma \mathrm{U}^{\mathrm{M}}{ }^{*}$ & $\gamma \mathrm{U} 6 \mathrm{Mo}$ & $\gamma \mathrm{U} 7 \mathrm{Mo}$ & $\gamma \mathrm{U} 8 \mathrm{Mo}$ & $\gamma \mathrm{U} 9 \mathrm{Mo}$ & $\gamma \mathrm{U} 10 \mathrm{Mo}$ & $\gamma \mathrm{UMoSi}^{\circ}$ & $\mathrm{Al}^{\circ}$ \\
\hline \hline $\mathrm{A}$ & 1358 & 1343 & 1365 & 1370 & 1385 & 1768 & 1358 & 1355 & 1370 \\
\hline $\mathrm{B}$ & 4380 & 4355 & 4365 & 4350 & 4428 & 13360 & 4353 & 4388 & 4429 \\
\hline $\mathrm{C}$ & 4570 & 4548 & 4575 & 4558 & 4573 & 13512 & 4565 & 4518 & 4580 \\
\hline $\mathrm{D}$ & não há & não há & não há & 4665 & não há & 13656 & não há & não há & 4663 \\
\hline E & 4690 & 4653 & 4690 & 4695 & 4613 & 14096 & 4653 & não há & não há \\
\hline F & 4848 & 4858 & 4833 & 4868 & 4808 & 14448 & 4970 & 4610 & não há \\
\hline G & 5074 & 5040 & 5075 & 5438 & 5125 & 15528 & 5158 & 4895 & não há \\
\hline $\mathrm{H}$ & 5903 & 5855 & 5895 & 5735 & 5873 & 17320 & 5700 & não há & não há \\
\hline $\mathrm{I}$ & 8498 & 8525 & 8493 & 8405 & 8525 & 26528 & 8470 & não há & não há \\
\hline J & 8570 & 8578 & 8583 & 8568 & 8625 & 26744 & 8590 & não há & não há \\
\hline L & 8700 & 8725 & 8658 & 8695 & 8705 & 27440 & 8703 & não há & não há \\
\hline M & 8700 & 8725 & 8658 & 8695 & 8705 & 27440 & 8703 & 8483 & 8638 \\
\hline N & 8790 & 8778 & 8763 & 8730 & 8760 & 27576 & 8758 & 8778 & 8738 \\
\hline O & 8871 & 8918 & 8853 & 8870 & 8918 & 27680 & 8835 & 8913 & 8898 \\
\hline
\end{tabular}


Nas tabelas, o símbolo * refere-se à liga bruta de fusão, as demais, todas, tratadas termicamente. Os eventos estão indicados por pontos nas curvas de análise térmica em função do tempo, Figura 123, e são eles: $\mathrm{A}=$ primeiro pico, antes dos eventos relacionados às possíveis reações no sistema, $\mathrm{B}=$ início fusão alumínio, $\mathrm{C}=$ máximo na fusão do alumínio, $\mathrm{D}$ = mínimo na fusão do alumínio, $\mathrm{E}$ = possível início de reação exotérmica, $F$ = pico reação endotérmica, $G$ = final reação endotérmica, $H=$ pico de indício de transformação, $\mathrm{I}$ = início solidificação ou reação reversa de transformação, $\mathrm{J}=$ pico da reação reversa, $\mathrm{L}$ = fim reação reversa, $\mathrm{M}=$ início solidificação do alumínio, $\mathrm{N}=$ máximo na solidificação do alumínio, $\mathrm{O}$ = final da solidificação do alumínio.

Os números da Tabela 18 referem-se aos tempos t de ocorrência dos eventos, e os da Tabela 19 à temperatura $\mathrm{T}$ correspondente, formando-se portanto um par $(\mathrm{t} ; \mathrm{T})$, que define o evento. A cada um deles está associada uma temperatura, Tabela 19, e um fluxo de calor, Tabela 20. Os picos D e E poderiam ser coincidentes, se não houvesse a reação exotérmica, denotada pelos picos F. Assim, D fica particularizado ao alumínio puro, não ocorrendo nas demais ligas, e $\mathrm{E}$ aos sistemas binários.

TABELA 19 - Temperaturas $\left({ }^{\circ} \mathrm{C}\right)$ associadas aos eventos da Tabela 18.

\begin{tabular}{|c|l|l|l|l|l|l|l|l|l|}
\hline Evento & $\gamma$ U5Mo & $\gamma$ U6Mo* $^{*}$ & $\gamma$ U6Mo & $\gamma \mathrm{U}$ Mo & $\gamma$ U8Mo & $\gamma$ U9Mo & $\gamma$ U10Mo & $\gamma$ UMoSi & $\mathrm{Al}^{\circ}$ \\
\hline \hline A & 123,32 & 117,6 & 124,31 & 125,88 & 130,64 & 67,29 & 123,31 & 121,12 & 126,24 \\
\hline B & 647,54 & 643,77 & 644,14 & 643,22 & 654,69 & 660,95 & 643,19 & 648,85 & 654,54 \\
\hline C & 678,15 & 674,42 & 678,86 & 674,5 & 676,85 & 667,57 & 676,48 & 669,7 & 678,87 \\
\hline D & não há & não há & não há & 694,12 & não há & 676,02 & não há & não há & 694,12 \\
\hline E & 699,35 & 693,2 & 697,85 & 699,13 & 684,16 & 697,62 & 692,71 & não há & não há \\
\hline F & 726,92 & 728,75 & 723,76 & 729,2 & 719,69 & 715,81 & 747,24 & 686,59 & não há \\
\hline G & 762,68 & 757,62 & 762,38 & 822,39 & 720,77 & 768,4 & 777,12 & 733,36 & não há \\
\hline H & 901,02 & 893,09 & 898,95 & 871,4 & 894,95 & 857,34 & 866,97 & não há & não há \\
\hline I & 678,93 & 674,78 & 678,22 & 690,58 & 672,98 & 690,83 & 680,48 & não há & não há \\
\hline J & 667,3 & 666,39 & 663,75 & 664,36 & 656,88 & 680,25 & 661,06 & não há & não há \\
\hline L & 646,0 & 642,24 & 651,53 & 643,49 & 643,76 & 645,97 & 642,79 & não há & não há \\
\hline M & 646,0 & 642,24 & 651,53 & 643,49 & 643,76 & 645,97 & 642,79 & 681,73 & 654,62 \\
\hline N & 631,96 & 634,48 & 634,48 & 638,15 & 635,48 & 639,57 & 634,52 & 634,44 & 612,32 \\
\hline O & 615,99 & 611,08 & 619,74 & 615,07 & 609,19 & 634,28 & 621,53 & 612,0 & 640,27 \\
\hline
\end{tabular}


TABELA 20 - Fluxos de calor $(\mu \mathrm{V})$ asssociados aos eventos da Tabela 18.

\begin{tabular}{|c|l|l|l|l|l|l|l|l|l|}
\hline Evento & $\gamma \mathrm{U} 5 \mathrm{Mo}$ & $\gamma \mathrm{U} 6 \mathrm{Mo}^{*}$ & $\gamma \mathrm{U} 6 \mathrm{Mo}$ & $\gamma \mathrm{U} 7 \mathrm{Mo}$ & $\gamma \mathrm{U} 8 \mathrm{Mo}$ & $\gamma \mathrm{U} 9 \mathrm{Mo}$ & $\gamma \mathrm{U} 10 \mathrm{Mo}$ & $\gamma \mathrm{UMoSi}$ & $\mathrm{Al}^{\mathrm{o}}$ \\
\hline $\mathrm{A}$ & 26,71 & 29,92 & 17,41 & 25,55 & 22,71 & 5,44 & 29,19 & 29,02 & 16,86 \\
\hline $\mathrm{B}$ & $-14,56$ & $-8,59$ & $-16,31$ & $-21,6$ & $-0,04$ & 20,8 & $-17,31$ & $-14,31$ & 0,38 \\
\hline $\mathrm{C}$ & 64,31 & 104,87 & 144,76 & 111,51 & 149,6 & 77,44 & 142,04 & 66,92 & 154,78 \\
\hline $\mathrm{D}$ & não há & não há & não há & $-43,44$ & não há & $-12,95$ & não há & não há & $-0,21$ \\
\hline E & $-24,28$ & $-31,35$ & $-39,38$ & $-42,68$ & $-1,24$ & $-10,67$ & $-27,23$ & não há & não há \\
\hline F & $-110,15$ & $-121,39$ & $-181,82$ & $-103,98$ & $-126,05$ & $-55,14$ & $-111,52$ & $-72,67$ & não há \\
\hline G & $-21,14$ & $-15,42$ & $-24,06$ & $-16,48$ & $-11,01$ & $-8,24$ & $-17,14$ & $-14,31$ & não há \\
\hline H & $-17,64$ & $-10,9$ & $-15,78$ & $-11,8$ & $-0,9$ & $-11,64$ & $-1,19$ & não há & não há \\
\hline I & 20,65 & 17,98 & $-6,66$ & 4,4 & $-2,66$ & $-6,17$ & $-5,68$ & não há & não há \\
\hline J & 7,34 & $-5,76$ & $-23,96$ & $-8,86$ & $-28,34$ & $-9,62$ & -20 & não há & não há \\
\hline L & 21,46 & 15,08 & $-14,8$ & 0,64 & $-9,65$ & $-6,35$ & $-12,58$ & não há & não há \\
\hline M & 21,46 & 15,08 & $-14,8$ & 0,64 & $-9,65$ & $-6,35$ & $-12,58$ & 18,81 & $-8,63$ \\
\hline N & $-37,81$ & $-71,68$ & $-60,61$ & $-40,36$ & $-80,25$ & $-21,03$ & $-76,43$ & $-57,32$ & $-164,28$ \\
\hline O & 22,78 & 16,99 & $-6,72$ & 4,31 & $-3,08$ & $-5,62$ & $-10,48$ & 16,69 & $-9,42$ \\
\hline
\end{tabular}

Para a liga $\gamma \mathrm{U} 8 \mathrm{Mo}$, um pequeno pico antes de $\mathrm{H}$ surgiu, com coordenadas $(\mathrm{t}$; $\mathrm{T}$; $\Phi)=($ tempo do evento, Temperatura, fluxo de calor $)=(5710 ; 867,87 ;-2,18)$, nas unidades acima especificadas. Para a liga $\gamma \mathrm{U} 9 \mathrm{Mo}$, os pontos D e E estão bem distintos, indicando final de fusão do alumínio e início de reação da liga, respectivamente.

A partir dos dados apresentados nas tabelas proceder-se-á à análise das reações. $\mathrm{Na}$ Tabela 21 estão apresentados as denominações dos eventos, os valores numéricos referindo-se à integração das curvas limitadas pelos pontos referentes a cada evento. $\mathrm{O}$ evento A não será detalhado, pois refere-se à perda de umidade das amostras. A integração foi feita, obviamente, tomando-se por base o tempo.

Aqui, a seqüência de letras indica o "triângulo" sobre o qual a área foi calculada, o primeiro valor, em módulo, abaixo do evento, representa a "base" do triângulo, com unidades de tempo, e o segundo valor representa a sua altura, com unidades de fluxo de calor. Para o material UMoSi, foi considerado como ponto D o valor médio entre os pontos $\mathrm{C}$ e $\mathrm{E}$, com coordenadas iguais a $(4564 ; 678,19 ;-61,93)$.

Portanto, os valores das bases representam os tempos de duração dos eventos, em segundos, e os valores das alturas representam seus fluxos de calor máximos. Obviamente que sinais negativos de área não possuem significado físico. Entretanto, foram mantidos para enfatizar a natureza dos picos, endotérmicos ou exotérmicos. 
TABELA 21 - Resultados de Integração (mV.s).

\begin{tabular}{|c|c|c|c|c|c|c|c|c|c|}
\hline Evento & $\gamma$ U5Mo & $\gamma \mathrm{U}^{2} \mathrm{Mo}^{*}$ & $\gamma \mathrm{U} 6 \mathrm{Mo}$ & $\gamma \mathrm{U} 7 \mathrm{Mo}$ & $\gamma$ U8Mo & $\gamma \mathrm{U} 9 \mathrm{Mo}$ & $\gamma$ U10Mo & $\gamma \mathrm{UMoSi}$ & $\mathrm{Al}^{\circ}$ \\
\hline \multicolumn{10}{|l|}{$\overline{\mathrm{BCD}(\mathrm{E})}$} \\
\hline$|\mathrm{B}-\mathrm{D}(\mathrm{E})|$ & 310 & 298 & 325 & 315 & 185 & 296 & 300 & 176 & 234 \\
\hline $\mathrm{C}-(\mathrm{D}+\mathrm{B}) / 2$ & 83,73 & 124,84 & 172,61 & 143,65 & 150,24 & 72,37 & 164,31 & 105,04 & 154,87 \\
\hline Área & 25,9 & 37,2 & 56,1 & 45,3 & 27,8 & 21,4 & 49,3 & 18,5 & 36,2 \\
\hline \multicolumn{10}{|l|}{$\overline{\mathrm{D}(\mathrm{E}) \mathrm{FG}}$} \\
\hline$|\mathrm{D}(\mathrm{E})-\mathrm{G}|$ & 384 & 387 & 385 & 743 & 512 & 1432 & 505 & 331 & não há \\
\hline $\mathrm{F}-(\mathrm{D}+\mathrm{G}) / 2$ & $-87,44$ & $-98,01$ & $-150,1$ & $-74,4$ & $-119,93$ & $-45,68$ & $-89,34$ & $-34,55$ & não há \\
\hline Área & $-33,6$ & $-37,9$ & $-57,8$ & $-55,3$ & $-61,4$ & $-65,4$ & $-45,1$ & $-11,4$ & --- \\
\hline \multicolumn{10}{|l|}{$\mathbf{H}$} \\
\hline Posição & $-17,64$ & $-10,9$ & $-15,78$ & $-11,8$ & $-0,9$ & $-11,64$ & $-1,19$ & --- & --- \\
\hline \multicolumn{10}{|l|}{ IJJ(M) } \\
\hline$|\mathrm{I}-\mathrm{L}(\mathrm{M})|$ & 202 & 200 & 165 & 290 & 180 & 912 & 233 & não há & não há \\
\hline $\mathrm{J}-(\mathrm{I}+\mathrm{L}) / 2$ & $-13,72$ & $-22,49$ & $-13,59$ & $-11,38$ & $-22,19$ & $-3,36$ & $-10,87$ & não há & não há \\
\hline Área & $-2,7$ & $-4,5$ & $-2,2$ & $-3,3$ & $-3,9$ & $-3,1$ & $-2,5$ & --- & --- \\
\hline \multicolumn{10}{|l|}{ L(M)NO } \\
\hline$|\mathrm{L}(\mathrm{M})-\mathrm{O}|$ & 171 & 193 & 195 & 175 & 213 & 240 & 132 & 430 & 260 \\
\hline $\mathrm{N}-(\mathrm{L}+\mathrm{O}) / 2$ & $-59,93$ & $-87,72$ & $-49,85$ & $-42,83$ & $-73,88$ & $-15,05$ & $-64,09$ & $-75,07$ & $-155,3$ \\
\hline Área & $-10,3$ & $-16,9$ & $-9,7$ & $-7,5$ & $-15,7$ & $-3,6$ & $-8,5$ & $-32,3$ & $-40,4$ \\
\hline
\end{tabular}

Para os eventos H, com exceção das ligas $\gamma \mathrm{U} 8 \mathrm{Mo}$ e $\gamma \mathrm{U} 10 \mathrm{Mo}$, os picos não ficaram muito claros. Ambos são os mais intensos (menos negativas) e mais definidos, indicando, pelos valores de massa de alumínio utilizado, que a verificação de possíveis reações deve ser feita com maior quantidade de alumínio. As quantidades de alumínio utilizadas, em termos absolutos, foram maiores nestes dois ensaios, embora a relação entre as massas de liga e alumínio tenham sido, aproximadamente, as mesmas em todos eles.

Para se eliminar dúvidas quanto à possibilidade de interferência nos resultados pela variação das massas de liga UMoSi utilizada em cada experimento, foram realizados mais dois ensaios, com relação entre as massas de liga e alumínio menor do que 1. As figuras seguintes mostram que, mesmo com 10 e $20 \mathrm{mg}$ de excesso de alumínio, e mesmo com o aumento da massa total de reagentes, os resultados foram praticamente os mesmos. Isto indica que a melhor definição dos picos deve ser obtida por meio de maiores massas e razões entre as massas de alumínio e liga. 


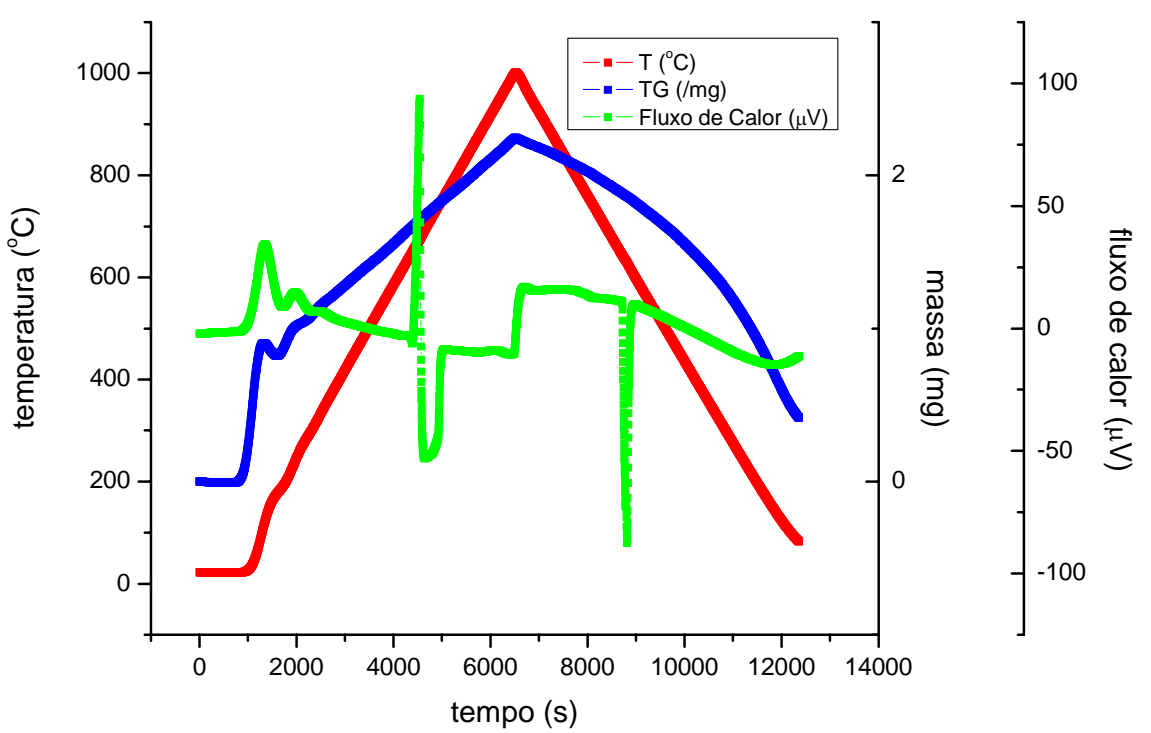

FIGURA 132 - Liga-base $\gamma \mathrm{UMoSi}$, bruta de fusão, amostra 113.

A curva de variação no fluxo de calor tem praticamente a mesma forma que a da Figura 130, com picos intensos de fusão e solidificação do alumínio. Neste ensaio um excesso de $10 \mathrm{mg}$ de alumínio foi utilizado. No ensaio seguinte, um excesso de $20 \mathrm{mg}$, e a curva não se alterou. Isto não indica necessariamente a ausência de reação. Sabe-se que um dos principais problemas de combustíveis desta classe é a alta taxa de reação entre a fase combustível e a matriz de alumínio, responsável pela maioria dos trabalhos existentes nesta área, conforme mencionado no capítulo 3.

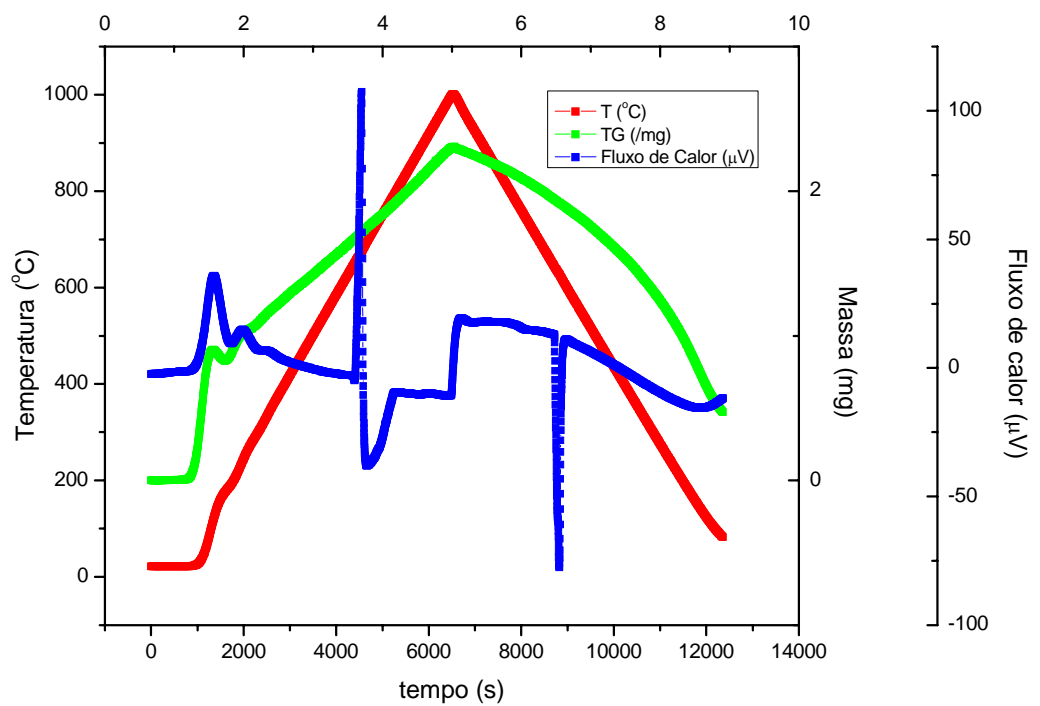

FIGURA 133 - Liga-base $\gamma \mathrm{UMoSi}$, bruta de fusão, amostra 115. 
Esta reação permite a formação de uma camada isolante ao redor da partícula de combustível, com composição ternária entre ( $\mathrm{UMo}) \mathrm{Al}_{3}$ e $(\mathrm{UMo}) \mathrm{Al}_{4}$, conforme trabalhos citados no referido capítulo. Uma análise de estabilidade como a que está sendo desenvolvida aqui deve levar em conta que este problema pode ser solucionado de duas maneiras. A primeira delas é evitar a formação da camada, pela adição de elementos que retardem a difusão do alumínio ao interior das partículas de combustível, minimizando o seu crescimento. A outra, visto que alumínio e urânio apresentam a tendência para a reação e que, pelos vários trabalhos apresentados no capítulo 3, conclui-se que evitar a reação é impossível, é utilizar a adição de elementos ou a elaboração de um combustível no qual a camada de reação, mesmo formada, mantenha-se estável.

A análise dos resultados deste capítulo mostra que é grande a tendência da reação ocorrer, para todas as porcentagens de adição de molibdênio, visto que os picos de solidificação do alumínio diminuem consideravelmente em cada ensaio. Isto indica que menos alumínio está disponível no sistema, não reagido, e que, portanto, a intensidade dos picos de solidificação deve diminuir, conforme observado nos eventos N. Ao convertermos intensidade em energia, como foi feito na Tabela 20, observamos em todas as ligas binárias que houve uma redução na energia para a solidificação, em valores absolutos, quando comparada com a energia absorvida para a fusão.

Foi obtido experimentalmente que a razão entre as energias para a solidificação e a fusão do alumínio puro é de aproximadamente 1,1. Espera-se, portanto, que em um sistema onde haja pouca interação entre fase combustível e alumínio, esta relação seja mantida, e que, a menos das transformações alotrópicas, a curva de fluxo de calor em função do tempo seja semelhante à do alumínio.

Para as ligas testadas UMoSi, isto não ocorreu. Como a porcentagem de silício utilizada foi superior ao seu limite de solubilidade na fase gama do urânio, é de se esperar então a formação de uma mistura de componentes. A solubilização do silício se dá no máximo a $0,5 \%$ em peso na estrutura gama, portanto os $1,5 \%$ restantes estão livres para reagir com $\mathrm{U}$, formando fases pobres em silício, compostas principalmente pelo siliceto $\mathrm{U}_{3} \mathrm{Si}$. As fases foram caracterizadas por MEV com EDS, mas ainda deverão ser caracterizadas por difração de raios-X. Espera-se então um comportamento em termos de compatibilidade intermediário relativamente aos silicetos e às ligas $\gamma$ U8Mo. Ao compararmos as intensidades dos eventos $\mathrm{F}$ nos 3 experimentos, verificamos que a proximidade com relação a curva de alumínio puro se dá com o aumento no excesso de alumino, o que seria de se esperar. Entretanto, houve concomitantemente à adição de 
alumínio, um aumento na massa de reagentes, sendo razoável supor que, caso houvesse reação, os picos seriam mais intensos. Não foi este o caso, aumentou-se a relação alumínio / combustível, a curva não apresentou novos picos.

Os resultados da Tabela 20 são mais bem interpretados quando são normalizados com relação às massas, como apresentado na Tabela 22. As energias são dadas em função das massas de reagentes totais e individuais. Nela, MT é a massa total dos reagentes, mc a massa da fase combustível e mAl a do alumínio, todas em mg.

TABELA 22 - Resultados de Integração (mV.s), normalizados (mV.s/g).

\begin{tabular}{|c|c|c|c|c|c|c|c|c|c|}
\hline Evento & $\gamma \mathrm{U} 5 \mathrm{Mo}$ & $\gamma$ U6Mo* $^{*}$ & $\gamma \mathrm{U6Mo}$ & $\gamma \mathrm{U} 7 \mathrm{Mo}$ & $\gamma \mathrm{U} 8 \mathrm{Mo}$ & $\gamma$ U9Mo & $\gamma \mathrm{U} 10 \mathrm{Mo}$ & $\gamma \mathrm{UMoSi}$ & $\mathrm{Al}^{\circ}$ \\
\hline mt & 149,144 & 148,909 & 168,991 & 173,298 & 175,507 & 148,447 & 155,642 & 133,136 & \\
\hline me & 75,836 & 73,94 & 89,5 & 97,437 & 91,654 & 74,127 & 77,095 & 65,468 & \\
\hline mAl & 73,308 & 74,692 & 79,491 & 75,86 & 83,853 & 74,320 & 78,546 & 67,668 & 82,010 \\
\hline \multicolumn{10}{|l|}{$\overline{\mathrm{BCD}(\mathrm{E})}$} \\
\hline mt & 174,04 & 249,83 & 331,96 & 261,11 & 158,37 & 144,30 & 316,71 & 138,86 & \\
\hline me & 342,27 & 503,14 & 626,79 & 464,40 & 303,25 & 288,98 & 639,38 & 282,38 & \\
\hline $\mathbf{m A I}$ & 354,07 & 498,07 & 701,75 & 596,49 & 331,47 & 288,23 & 627,57 & 273,20 & 441,89 \\
\hline Área & 25,9 & 37,2 & 56,1 & 45,3 & 27,8 & 21,4 & 49,3 & 18,5 & 36,2 \\
\hline \multicolumn{10}{|l|}{$\mathrm{D}$ (E)FG } \\
\hline mt & 225,13 & 254,72 & 341,96 & 318,98 & 349,87 & 440,65 & 289,87 & 85,89 & \\
\hline mc & 442,76 & 512,98 & 645,68 & 567,33 & 669,96 & 882,45 & 585,21 & 174,68 & \\
\hline mAI & 458,03 & 507,82 & 722,89 & 728,70 & 732,28 & 880,16 & 574,39 & 169,00 & \\
\hline Área & $-33,6$ & $-37,9$ & $-57,8$ & $-55,3$ & $-61,4$ & $-65,4$ & $-45,1$ & $-11,4$ & --- \\
\hline \multicolumn{10}{|l|}{ 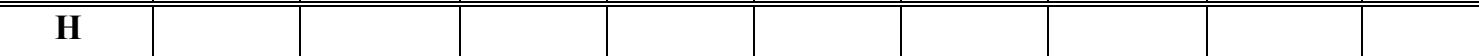 } \\
\hline Posição & $-17,64$ & $-10,9$ & $-15,78$ & $-11,8$ & $-0,9$ & $-11,64$ & $-1,19$ & --- & --- \\
\hline \multicolumn{10}{|l|}{ IJL(M) } \\
\hline mt & 18,58 & 30,21 & 13,27 & 19,04 & 22,76 & 20,64 & 16,27 & & \\
\hline mc & 36,55 & 60,83 & 25,05 & 33,87 & 43,58 & 41,33 & 32,85 & & \\
\hline mAl & 37,80 & 60,22 & 28,05 & 43,50 & 47,63 & 41,23 & 32,25 & & \\
\hline Area & $-2,7$ & $-4,5$ & $-2,2$ & $-3,3$ & $-3,9$ & $-3,1$ & $-2,5$ & --- & --- \\
\hline \multicolumn{10}{|l|}{$\bar{L}$ L(M)NO } \\
\hline mt & 68,71 & 113,69 & 57,52 & 42,79 & 89,66 & 24,33 & 54,35 & 242,46 & \\
\hline mc & 135,13 & 228,97 & 108,61 & 76,12 & 171,69 & 48,73 & 109,73 & 493,06 & \\
\hline mAl & 139,79 & 226,66 & 121,60 & 97,77 & 187,67 & 48,60 & 107,71 & 477,04 & 492,35 \\
\hline Área & $-10,3$ & $-16,9$ & $-9,7$ & $-7,5$ & $-15,7$ & $-3,6$ & $-8,5$ & $-32,3$ & $-40,4$ \\
\hline
\end{tabular}


O pico de provável reação com alumínio é o $\mathrm{F}$, reação imediata logo após a fusão. Os picos que se pode chamar de controle são os de fusão do alumínio, cuja energia é de 441,89 mV.s/g, e o de sua solidificação, 492,35 mV.s/g. Suponho que na solidificação imediata após a fusão do alumínio sejam liberados $492,35 \mathrm{mVs} / \mathrm{g}$ de energia, então a reação do alumínio com as ligas tem energia dada pela diferença entre este valor e os dos picos N de cada reação. Observa-se que o ponto de ebulição do alumínio é de $2792 \mathrm{~K}$, muito acima de $1000^{\circ} \mathrm{C}$.

O indício favorável à estabilidade da liga UMoSi foi apresentado nesta tabela. Ao lado do valor de solidificação do alumínio, temos um valor aproximadamente igual para a fusão do alumínio remanescente após tratamento da liga. A diferença, pequena, de $15,31 \mathrm{mVs} / \mathrm{g}$, corresponde à fração de alumínio inicial que reagiu com UMoSi. Comparando com os demais, este valor é bem menor.

Fazendo o gráfico das energias do evento $\mathrm{F}$ em função da porcentagem de Mo, novamente verificamos a menor energia desprendida pelo sistema UMoSi / Al, indicando que, se há reação, o produto formado é mais estável. Isto vem de encontro ao problema de estabilização da camada de reação, no caso de combustíveis de alta densidade. Infere-se assim a possibilidade do uso deste material como estabilizante da camada, em altas temperaturas.

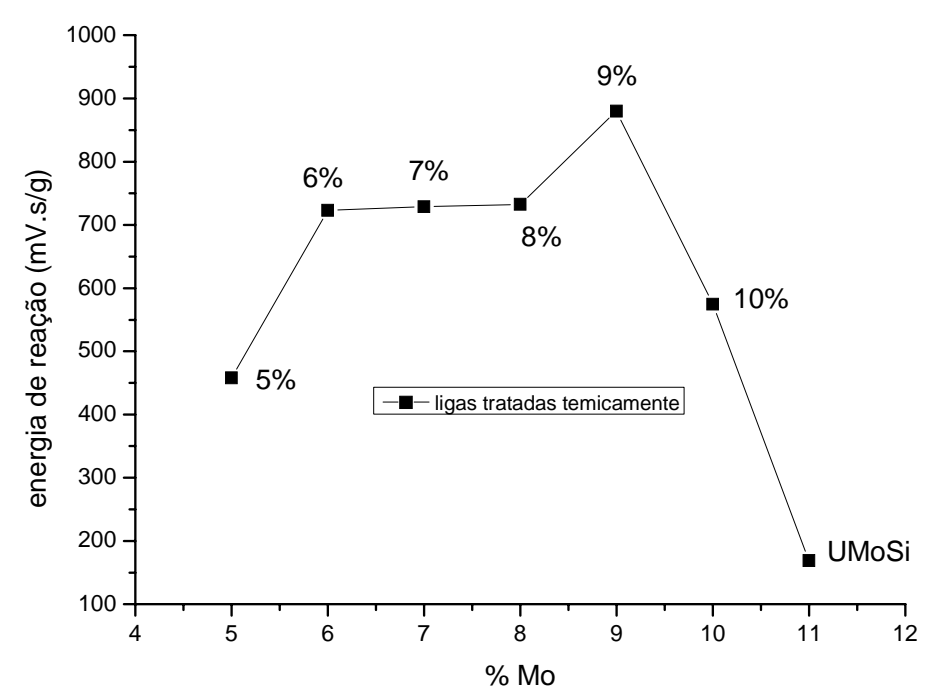

FIGURA 134 - Energia de reação x \% Mo, comparada a UMoSi. 


\section{HIDROGENAÇÃO E EQUILÍBRIO $\gamma \rightarrow \alpha$}

Neste capítulo serão apresentados os principais resultados dos experimentos de hidrogenação. Sob um ponto de vista tecnológico, utilizou-se os dados dos vários experimentos para a elaboração de um procedimento para a produção de pós de liga $\gamma \mathrm{UMo}$ de alta densidade, oferecendo-o ao IPEN-CNE/SP como alternativo aos tradicionais, mas em pouco uso, métodos de transformação mecânica.

Sob um ponto de vista acadêmico, utilizou-se destes mesmos resultados no estudo da estabilidade da fase gama do urânio, nas condições de tratamento empregadas. A idéia foi a de se estabelecer os instantes em que os primeiros núcleos da fase alfa são formados, qual a velocidade de crescimento, e sua influência na ruptura da estrutura da fase gama.

Nesta apresentação, chamar-se-á T1 a temperatura do primeiro tratamento térmico de hidrogenação e, quando for o caso, de T2 a temperatura do segundo tratamento térmico, realizado no mesmo ensaio, após T1. Aqui T2 foi usualmente próxima à temperatura de dehidretação utilizada tradicionalmente. Entretanto, por fazer parte de um ciclo de tratamento das amostras sob hidrogênio, não foi levada em conta como uma dehidretação.

A escolha das isotermas para a obtenção dos dados de adsorção de hidrogênio tomou por base o fato de que os ensaios à taxa constante de elevação de temperatura não produziram resultados visíveis, mesmo com a aplicação de velocidades de aquecimento pequenas, de $3{ }^{\circ} \mathrm{C} /$ min.. Também, como na produção de pós via hidretação-dehidretação trabalha-se a temperatura constante, procurou-se simular os efeitos do hidrogênio em operações HDH por meio dos ensaios em analisador termogravimétrico.

Como se estudou a fragilização das ligas $\gamma$ UMo via hidretação e dehidretação da fase alfa, presente em contornos de grão, primeiramente verificou-se a ação do hidrogênio sobre esta fase, pura, em urânio metálico produzido no IPEN. Em seguida, dada a peculiaridade nos resultados, uma análise das curvas de adsorção de hidrogênio da liga $\gamma \mathrm{U} 6 \mathrm{Mo}$ foi realizada, pois elas foram semelhantes aos resultados de hidrogenação de ligas apresentados na literatura ${ }^{46-50}$. Para este caso em particular, pôde-se observar claramente a saturação nas curvas, algo que não foi possível para as demais ligas. 
Em seguida, apresentam-se as evidências da relação entre hidrogenação e equilíbrio gama / alfa, pelo exame dos ensaios do primeiro ciclo e pelos resultados de hidrogenação das ligas $\gamma \mathrm{U} 8 \mathrm{Mo}$, do segundo ciclo. Após estes resultados, a análise minuciosa da perda e ganho de massa nas curvas de resfriamento dos tratamentos térmicos de hidrogenação, para todas as ligas, foi efetuada, e uma relação foi estabelecida entre o poder de estabilização, função da quantidade de molibdênio na liga, e fragilização.

Finalmente, as partículas produzidas tipicamente em cada um dos ensaios foram caracterizadas, os resultados apresentados em função da quantidade de molibdênio. Análises dos pós quanto à pureza, dimensões e estrutura foram realizadas em difração de raios-X e microscópio eletrônico de varredura. Estas análises forneceram os parâmetros de saída do processo HDH proposto e que fecha o capítulo, estabelecido com base em todos os resultados aqui discutidos.

\subsection{Hidretação da Fase $\alpha-U$}

Para verificação da velocidade e da quantidade de hidrogênio absorvido pelo urânio alfa, foram realizados ensaios de TG / DTA simultaneamente. A partir da massa inicial da peça metálica, de $80,656 \mathrm{mg}$, os resultados de hidretação e dehidretação foram os seguintes:

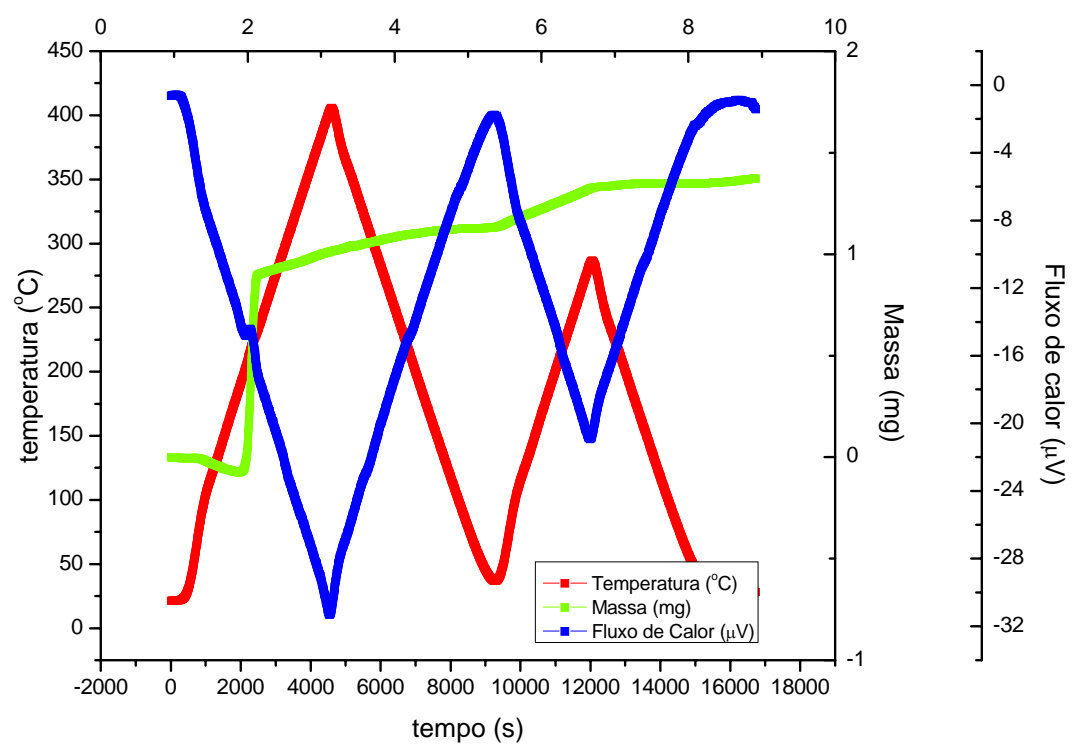

FIGURA 135 - Hidretação de urânio metálico. 


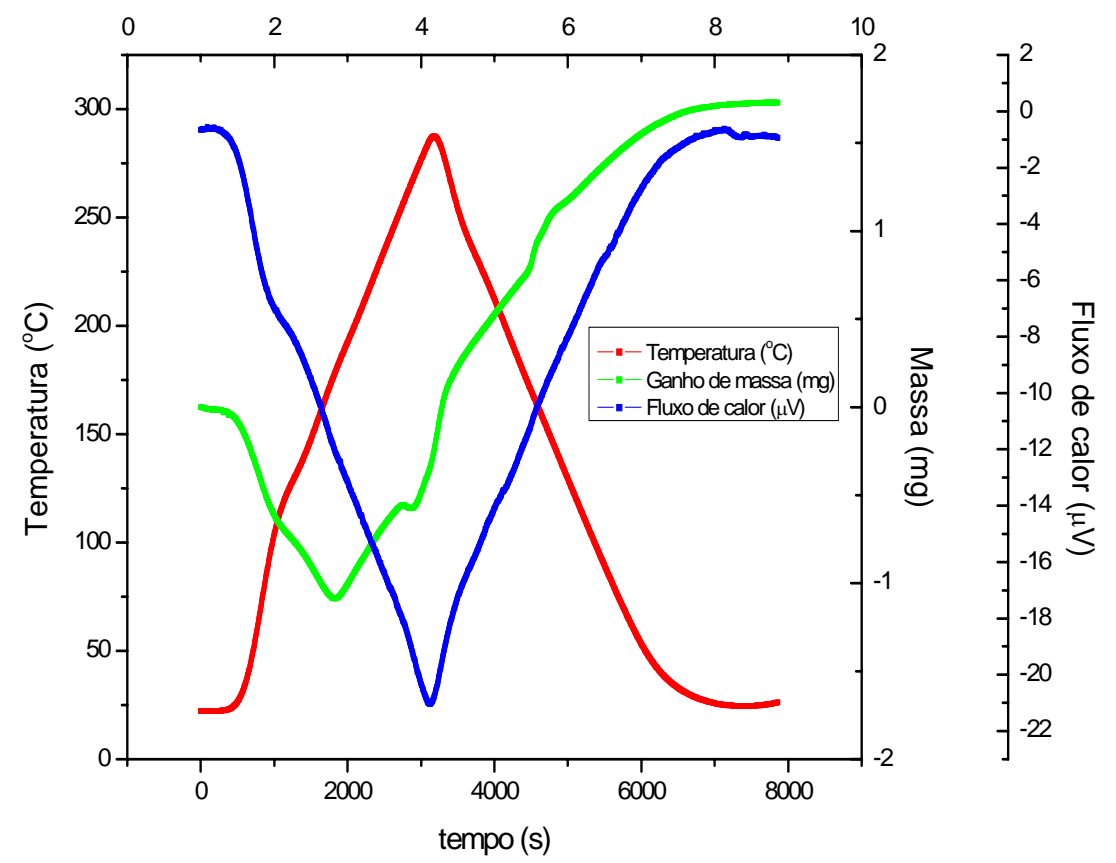

FIGURA 136 - Dehidretação de urânio metálico.

No primeiro ensaio foi utilizado o procedimento de aquecimento e resfriamento mostrado em vermelho na Figura 135, para a verificação da sensibilidade da liga ao hidrogênio nas temperaturas de $400^{\circ} \mathrm{C}$ e $300^{\circ} \mathrm{C}$. Pretendeu-se com isso verificar se, mesmo sob hidrogênio, um abaixamento da temperatura após rampa de aquecimento promoveria a eliminação de hidrogênio. Como se trabalhou com fluxo contínuo sobre a amostra, não houve dehidretação, mas sim adsorção contínua até o final do experimento, com tendência clara à estabilização.

Defino aqui um sistema de coordenadas de eventos (t; T; m; HF), onde t é o tempo, em segundos, $\mathrm{T}$ a temperatura, em ${ }^{\circ} \mathrm{C}, \mathrm{m}$ a massa da amostra, em $\mathrm{mg}$, e HF o fluxo de calor, em $\mu \mathrm{V}$. Para a definição mais precisa e correta dos eventos, utilizou-se a derivação da curva de ganho de massa em relação ao tempo, apresentada na figura 137.

As coordenadas dos eventos A, B e C, início de estabilização no valor de ganho de massa, máxima massa incorporada (ambos nos experimentos de hidretação, figura 135) e de início de hidretação (Figura 136) são dados na Tabela 23. O evento mais importante, entretanto, o de início da hidretação do urânio, ocorre nas coordenadas (t; T; m; HF) iguais a $(1999 ; 190,2 ;-0,074 ;-14,08)$. O valor de massa negativo corresponde à perda de massa 
da amostra, antes da hidretação, pela presença prévia de umidade e outros materiais voláteis adsorvidos na superfície do metal.

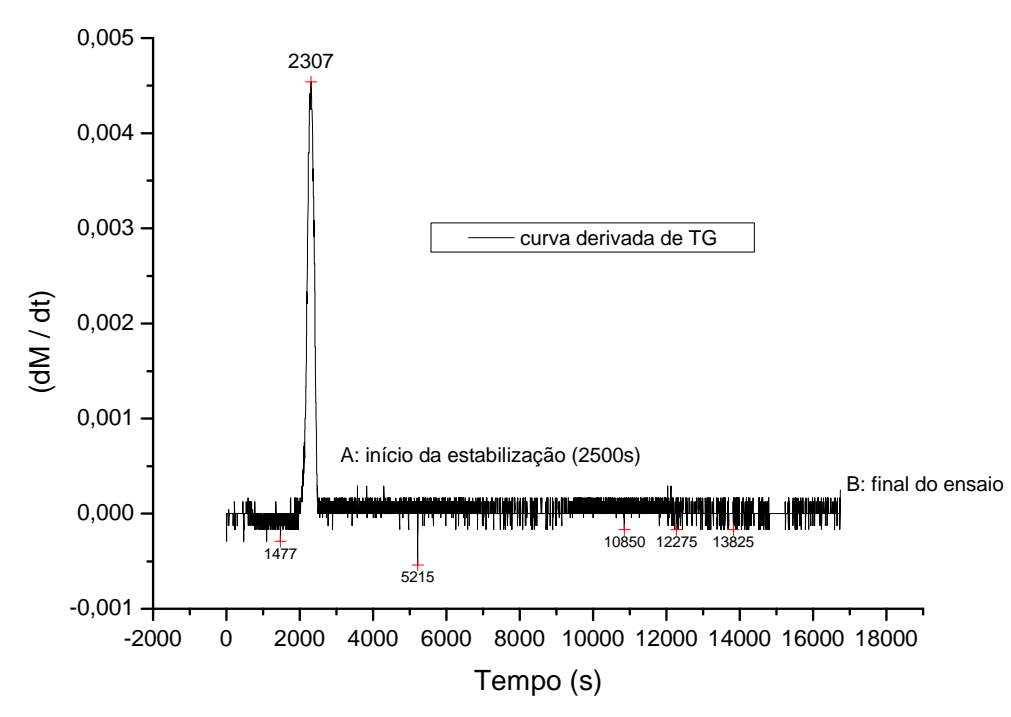

FIGURA 137- Taxa de variação da massa com relação ao tempo, hidretação.

Valores existentes em literatura indicam faixa de temperatura de hidretação para o urânio metálico de $200^{\circ} \mathrm{C}$ a $350^{\circ} \mathrm{C}^{66}$, a variação devida a fatores como pureza, cristalinidade, etc. Para a amostra ensaiada, o valor pode ser obtido da curva apresentada na figura 135. Observa-se que o início da hidretação se dá em um ponto onde há transição no regime de incorporação de massa, da perda de materiais voláteis ao ganho de hidrogênio. O máximo na hidretação se dá no ponto onde a derivada assume o valor máximo, o que ocorre nas coordenadas $(2307 ; 218,96 ; 0,446 ;-14,58)$. Assim, chega-se a um máximo em $218,96^{\circ} \mathrm{C}$, próximo ao limite inferior especificado em literatura, e que deve ser levado em conta nos experimentos de simulação computacional de hidretação das ligas $\gamma \mathrm{UMo}$.

TABELA 23 - Coordenadas dos eventos A e B, hidretação, e DH, dehidretação.

\begin{tabular}{|c|c|c|c|}
\hline Variável & Evento A & Evento B & Evento C \\
\hline \hline Tempo & $2503 \mathrm{~s}$ & $16741 \mathrm{~s}$ & $1831 \mathrm{~s}$ \\
\hline Temperatura & $233,13{ }^{\circ} \mathrm{C}$ & $28,2{ }^{\circ} \mathrm{C}$ & $178,53{ }^{\circ} \mathrm{C}$ \\
\hline Ganho de massa & $0,898 \mathrm{mg}$ & $1,372 \mathrm{mg}$ & $-1,087 \mathrm{mg}$ \\
\hline Fluxo de calor & $-17,21 \mu \mathrm{V}$ & $-1,45 \mu \mathrm{V}$ & $-12,1 \mu \mathrm{V}$ \\
\hline
\end{tabular}


Para estimativa do valor teórico ou estequiométrico de quantidade de hidrogênio necessária para reação de hidretação total da massa de urânio metálico utilizada nestes experimentos, faz-se alguns cálculos simples. Para U na fase alfa, tem-se:

$$
2 \alpha \mathrm{U}+3 \mathrm{H}_{2} \rightarrow 2 \alpha \mathrm{UH}_{3}
$$

e como se está trabalhando com uma massa inicial de amostra de 80,656mg, ter-se-ía uma quantidade $\mathrm{x}$ de hidrogênio absorvida pela amostra, teórica, igual a:

$$
\mathrm{x}=(80,656 \times 6) / 476=1,004 \mathrm{mg}
$$

que corresponde a 1,24\% da massa de urânio alfa. Assim, pode-se aceitar os resultados de hidretação como satisfatórios. Esta é a massa teórica que deverá ser liberada pelo urânio na fase de dehidretação. O valor da massa mínima (Tabela 23), foi igual a 1,087mg, 7,3\% acima do valor teórico, e entre os valores dos eventos A e B. Assim, prova-se que o ciclo de dehidretação proposto funciona, e também, que as quantidades de hidrogênio absorvidas pelas ligas $\gamma \mathrm{UMo}$, se maiores do que este valor, estão em desacordo com o estequiométrico. Em cada um dos ensaios de hidrogenação das ligas $\gamma \mathrm{UMo}$, a quantidade de hidrogênio absorvida foi inferior a $0,3 \%$, caindo com o aumento da porcentagem de Mo.

Outras propriedades da fase alfa determinada por este grupo de ensaios foi a sua temperatura de dehidretação, igual a $178,53^{\circ} \mathrm{C}$. Assim, nos ensaios de dehidretação das ligas $\gamma \mathrm{UMo}$, dever-se-á obter valores de máximo próximos a este. Obviamente que, em cada caso, deve ser analisada a quantidade de urânio alfa presente na estrutura. Quando pequena, pode estar abaixo da sensibilidade do equipamento, que é de microgramas. Observa-se que estes valores são diferentes dos encontrados em publicações como a de Blackledge e Libowitz ${ }^{66}$, que reportam temperaturas de hidretação entre $250^{\circ} \mathrm{C}$ e $350^{\circ} \mathrm{C}$, e de dehidretação ao redor de $200^{\circ} \mathrm{C}$. Obviamente que estamos tratando de amostras com pureza e origem diferentes, daí a discrepância.

\subsection{Tratamentos de sensibilização das ligas ao hidrogênio}

Este é um comportamento das ligas $\gamma \mathrm{UMo}$ previsto em literatura, nos trabalhos

de Balart ${ }^{46,51}$ e Pasqualini ${ }^{48,49}$, que afirmam que um tratamento prévio das amostras em temperaturas entre $120^{\circ} \mathrm{C}$ e $250^{\circ} \mathrm{C}$ torna as ligas de $\gamma \mathrm{UMo}$ mais susceptíveis à ação do hidrogênio. Infelizmente este fenômeno foi observado somente com as amostras da liga 
$\gamma$ U6Mo. Observe-se os ensaios nos quais foram realizados tratamentos prévios em temperaturas desta ordem, e analise-se os resultados.

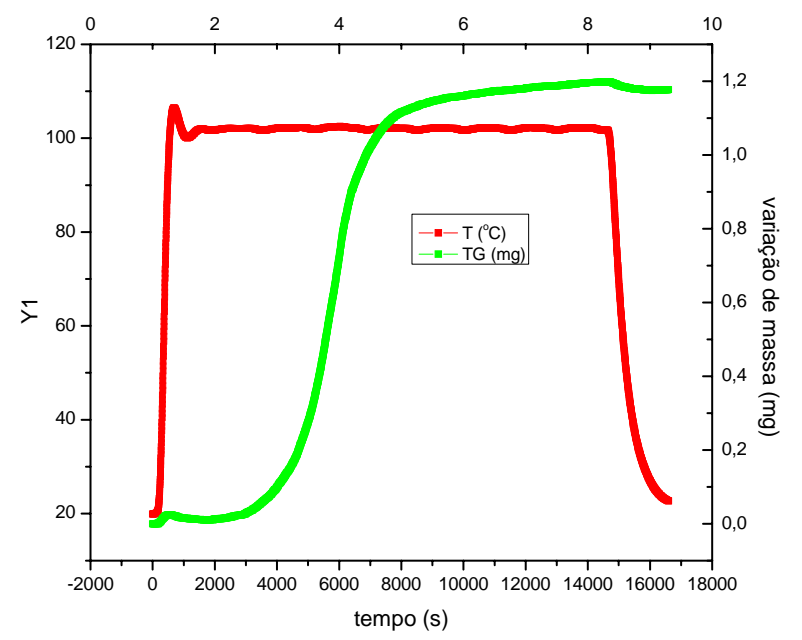

FIGURA 138 - Taxa de variação da massa com relação ao tempo, hidretação a $100^{\circ} \mathrm{C}$ por 4 horas, liga $\gamma \mathrm{U} 6 \mathrm{Mo}$.

Observa-se na Figura 138 que a absorção de massa atingiu um valor limite, que se manteve constante mesmo após o resfriamento, indicando reação total do hidrogênio com a liga para a formação do hidreto. O ganho de massa foi igual a 1,177mg, correspondendo a $1,34 \%$ da massa inicial da amostra, próximo ao valor teórico de 1,24\% para a hidretação completa.

Na publicação de Balart et al. ${ }^{46}$ é apresentado um gráfico de variação de pressão em função do tempo na hidretação de uma liga $\gamma$ U7Mo. Neste trabalho, monitoraram o andamento da reação de hidretação por meio de um indicador de pressão. Conforme suas condições experimentais, observaram os autores que, a partir de um determinado ponto, a pressão começou a cair, indicando o consumo de hidrogênio, presente na atmosfera do sistema de hidretação, pelas ligas. Assim, levando-se em conta que trabalharam com sistema fechado e pressão inicial de hidrogênio constante, o progresso da hidretação se dá com a redução na pressão. Ao final da reação, a curva de queda de pressão tende a um patamar, indicando a reação completa.

Nesta tese monitorou-se, ao invés da pressão, a variação de massa da amostra. Assim, com o andamento da reação, esperou-se por um progressivo aumento da massa com o tempo, e também que, ao final do processo, um valor fixo seria obtido, indicando reação de hidretação completa. Isto foi o que ocorreu neste caso. Dentro dos limites da precisão na determinação do valor de massa inicial, dadas as pequenas e constantes oscilações na 
balança, o valor de massa absorvida foi praticamente igual ao valor teórico, indicando reação total de hidretação, após um tempo de 4 horas de experimento. A fragmentação da amostra foi total, mesmo sem a dehidretação. $\mathrm{O}$ valor do tempo foi importante, pois indica que nas condições do experimento a reação se completou após 4 horas.

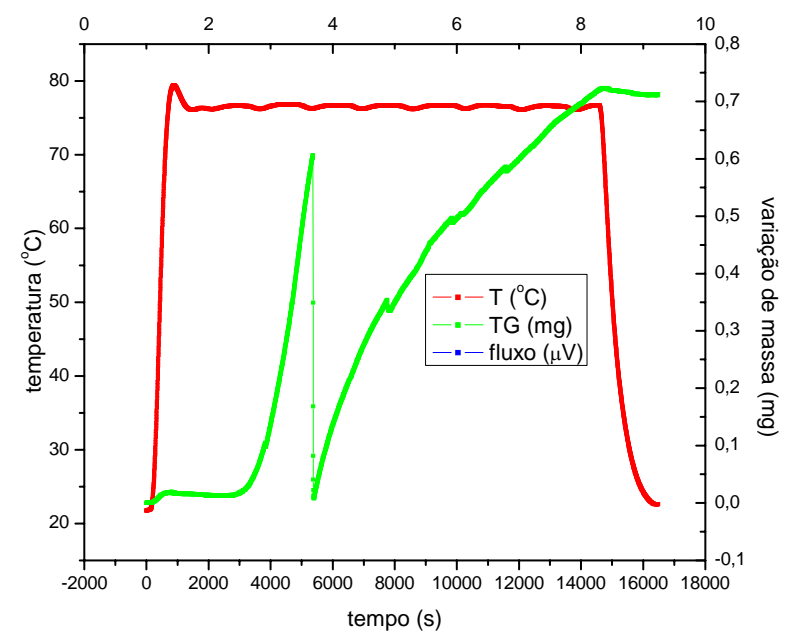

FIGURA 139 - Taxa de variação da massa com relação ao tempo, hidretação a $75^{\circ} \mathrm{C}$ por 4 horas, liga $\gamma \mathrm{U} 6 \mathrm{Mo}$.

Para a mesma liga a $75^{\circ} \mathrm{C}$, observou-se a ruptura da estrutura em uma temperatura bem abaixo da prevista em literatura para a sensibilização da liga ao hidrogênio, igual a $120^{\circ} \mathrm{C}$. Isto não indica necessariamente uma reação de hidretação completa, visto que nas hipóteses assumidas neste trabalho, a fragmentação não precisa ocorrer após a finalização da reação. Neste experimento percebe-se facilmente que quase toda a massa absorvida foi perdida no intervalo $(5363 ; 76,26 ; 0,601)$ a $(5399 ; 76,27$; 0,008). A massa final de $0,008 \mathrm{mg}$ corresponde à quantidade de hidrogênio retida na liga, antes da nova absorção. Esta liberação de hidrogênio foi feita a uma velocidade de $16,472 \mu \mathrm{g} / \mathrm{s}$, considerando-a linear.

Após a fase de queda de massa, na qual todo o hidrogênio absorvido pela estrutura e que não reagiu com o urânio desprendeu-se da liga, os fragmentos formados foram responsáveis pelo novo acréscimo na massa do sistema, até o final do experimento. Após a fase de temperatura constante, e como no caso anterior, a massa permaneceu constante, alcançando valor máximo nas coordenadas (14744; 67,53; 0,723). Observa-se neste caso que se está trabalhando a uma temperatura bem próxima à do ambiente, e mesmo assim a quantidade de hidrogênio retida foi de $0,54 \%$ da massa inicial. Verificarse-á no item 13.7 todos os valores de massa relativa, para fins de modelagem matemática. 
Para verificar qual a temperatura limite para a qual podemos ter a sensibilização pelo hidrogênio, mais um ensaio foi realizado, agora a $50^{\circ} \mathrm{C}$, mesma liga. $\mathrm{O}$ resultado é apresentado na figura seguinte.

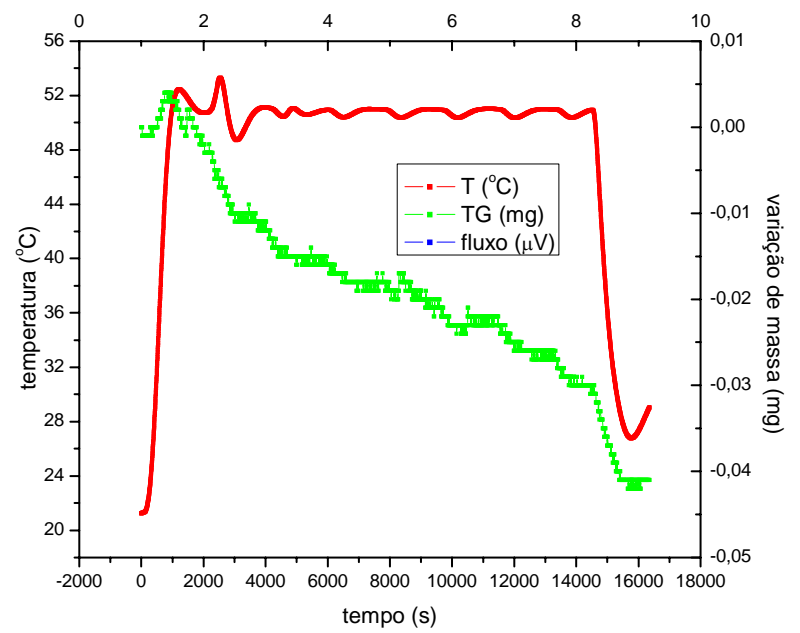

FIGURA 140 - Taxa de variação da massa com relação ao tempo, hidretação a $50^{\circ} \mathrm{C}$ por 4 horas, liga $\gamma \mathrm{U} 6 \mathrm{Mo}$.

Assim como veremos adiante, esta temperatura não foi suficiente para sensibilizar a liga, o único evento relacionado ao comportamento de perda de massa do sistema, devido à presença de umidade ou algum outro produto volátil, nesta temperatura. Observou-se também a dificuldade do equipamento em manter o valor de temperatura constante. De qualquer forma, nenhum evento marcante, como nas curvas anteriores, foi relatado.

Podemos então concluir que, para a liga $\gamma \mathrm{U} 6 \mathrm{Mo}$, um pré-tratamento sob atmosfera de hidrogênio pode ser realizado a $75^{\circ} \mathrm{C}$, condição suficiente para que, após $5363 \mathrm{~s}$, toda a massa inicial de 133,882mg entre em colapso e se fragmente, e abaixo do valor encontrado em literatura, igual a $120^{\circ} \mathrm{C}$. É óbvio que se se trabalhasse nas condições de Balart ${ }^{46}$ e Pasqualini ${ }^{48}$, com quantidades da ordem de 1,0 kg de material, um maior tempo a $75^{\circ} \mathrm{C}$ seria necessário. Entretanto, foi mostrado aqui que se pode reduzir a temperatura, e obter bons resultados em termos de fragmentação. Ainda, poder-se-ía ter testado a hipótese de que maiores tempos seriam necessários para o colapso da estrutura em temperaturas menores, mas isto não foi feito nesta tese de doutoramento.

A partir dos resultados acima para a liga $\gamma \mathrm{U} 6 \mathrm{Mo}$, observe-se outros relacionados às outras ligas, em experimentos conduzidos em condições similares. Para a 
liga $\gamma \mathrm{U} 5 \mathrm{Mo}$, um ensaio foi realizado a $120^{\circ} \mathrm{C}$ por 2 horas, e o resultado é apresentado na Figura 141.

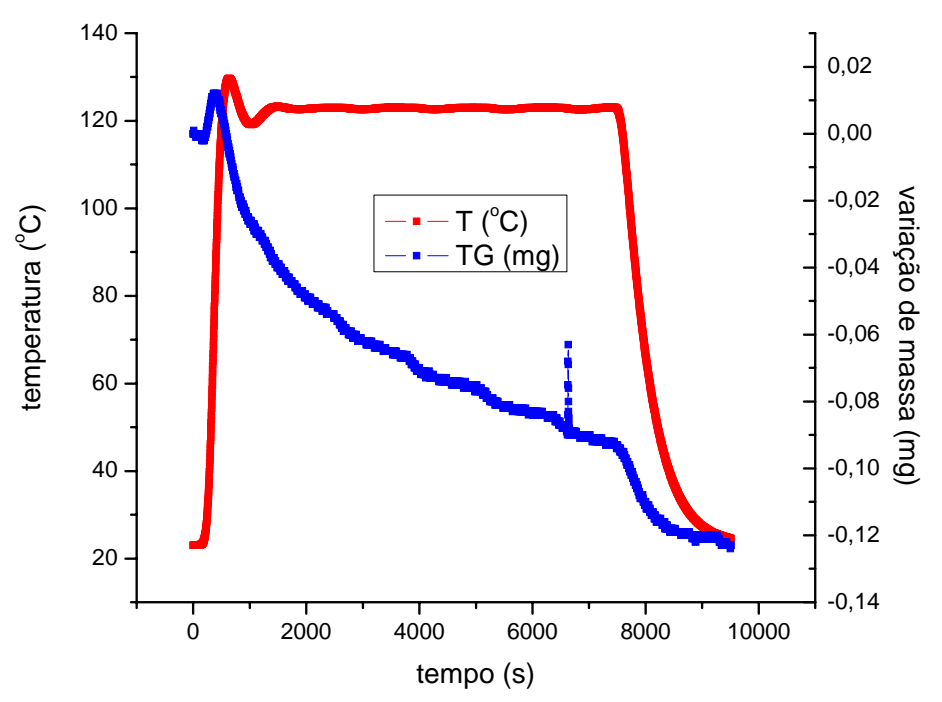

FIGURA 141 - Taxa de variação da massa com relação ao tempo, hidretação a $120^{\circ} \mathrm{C}$ por 2 horas, liga $\gamma \mathrm{U} 5 \mathrm{Mo}$.

O comportamento desta curva foi semelhante ao do experimento conduzido com a liga $\gamma \mathrm{U} 6 \mathrm{Mo}$ a $50^{\circ} \mathrm{C}$, a menos do evento a $(6630 ; 122,78 ; 0,063)$, um máximo na absorção de massa, que logo caiu sobre a curva original. Como não houve nenhum evento relacionado a esta coordenada, como variação de temperatura e fluxo de calor, a alguma vibração provocada durante o experimento, podemos relacioná-lo a algum impacto sobre o equipamento. Assim, como acidentes deste tipo afetam somente a coleta de dados relativos à massa, é fácil verificar que após esta vibração acidental, a curva de variação de massa com o tempo voltaria a acompanhar a curva original, que foi o que ocorreu.

Não houve, portanto, nenhum evento digno de registro, nas condições deste ensaio, novamente indicando que a temperatura de sensibilização da liga ao hidrogênio é diferente do valor encontrado em literatura, ou o tempo necessário para a sensibilização da liga não foi suficiente. Entretanto, pode-se argumentar contra esta hipótese, ao se verificar o comportamento das curvas das ligas sensibilizadas $\gamma \mathrm{U} 6 \mathrm{Mo}$ a $100^{\circ} \mathrm{C}$ e $75^{\circ} \mathrm{C}$, com grande incorporação de massa logo ao início, seguida de estabilização, indicando reação completa e saturação.

Para a liga $\gamma \mathrm{U} 7 \mathrm{Mo}$, o mesmo tipo de ensaio, e com o mesmo resultado, foi conduzido a $130^{\circ} \mathrm{C}$ por 1 hora. Vejamos o comportamento das curvas, apresentadas na Figura 142. 


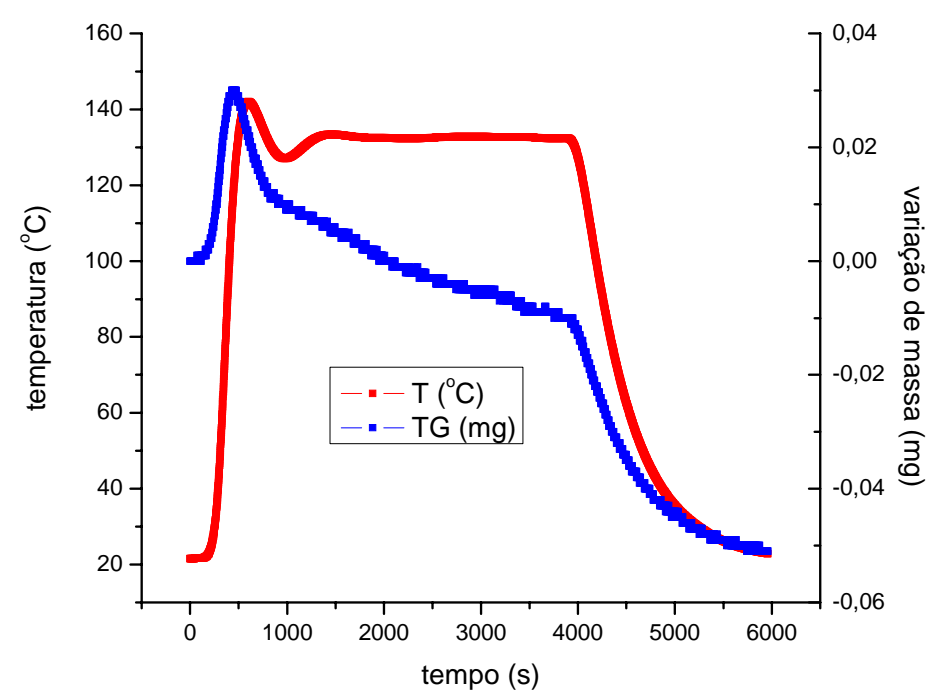

FIGURA 142- Taxa de variação da massa com relação ao tempo, hidretação a $130^{\circ} \mathrm{C}$ por 1 hora, liga $\gamma \mathrm{U} 7 \mathrm{Mo}$.

Novamente, nenhum evento marcante foi observado, indicando discordância com o valor de literatura, ao menos para as ligas aqui produzidas. Para a liga $\gamma \mathrm{U} 10 \mathrm{Mo}$, duas experiências a $100^{\circ} \mathrm{C}$ por 4 horas foram conduzidas, para a verificação da influência da massa nos resultados de sensibilização. Os resultados são apresentados nas Figuras 143 e 144.

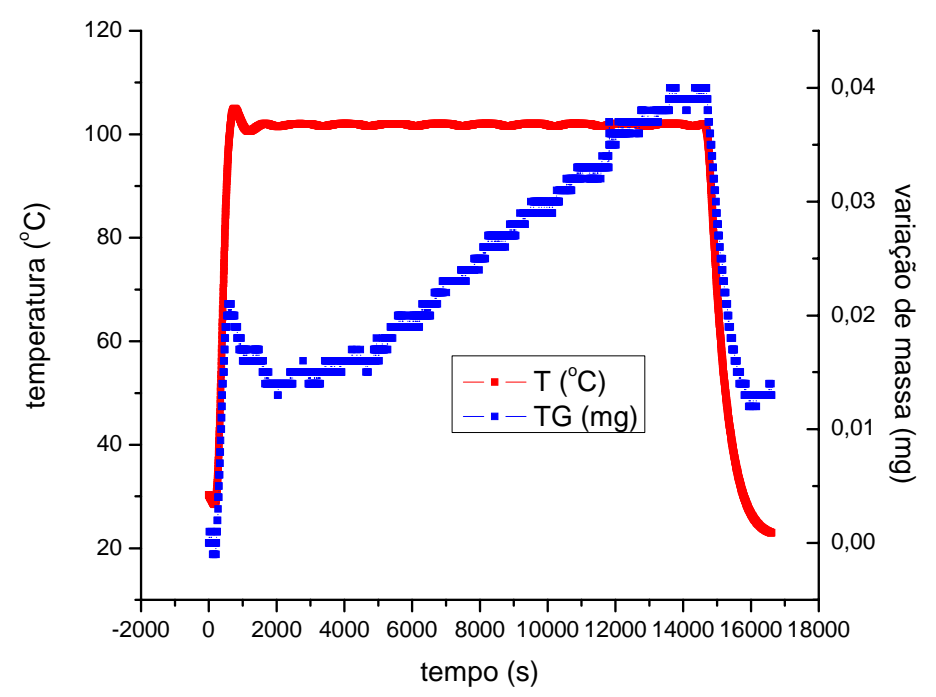

FIGURA 143 - Taxa de variação da massa com relação ao tempo, hidretação a $100^{\circ} \mathrm{C}$ por 4 horas, liga $\gamma \mathrm{U} 10 \mathrm{Mo}$, massa igual a $106 \mathrm{mg}$. 


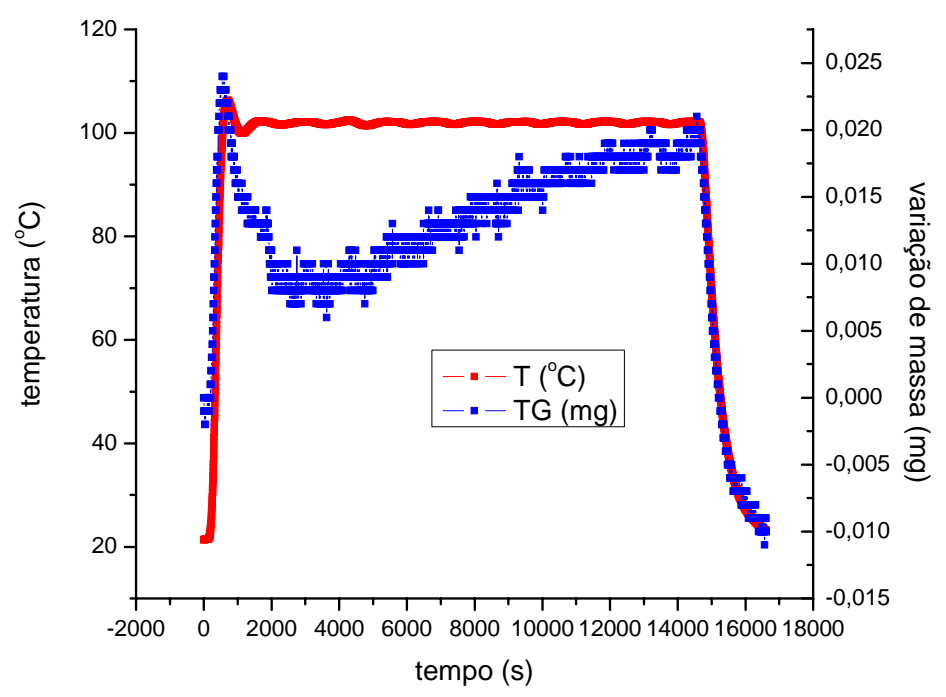

FIGURA 144 - Taxa de variação da massa com relação ao tempo, hidretação a $100^{\circ} \mathrm{C}$ por 4 horas, liga $\gamma \mathrm{U} 10 \mathrm{Mo}$, massa igual a $77 \mathrm{mg}$.

E aqui, neste conjunto de experimentos, e associando-os aos resultados de microestrutura das ligas $\gamma \mathrm{U} 10 \mathrm{Mo}$, observa-se que houve um acréscimo na massa absorvida em ambos os casos, maior para a liga de maior massa. Ao se verificar a sua microestrutura, constatou-se que ligas produzidas com 10\% de molibdênio apresentaram maior porosidade. Assim, eles funcionam como locais de armazenamento de hidrogênio no interior da estrutura do metal, a despeito de também possuírem menor quantidade de fase alfa presente. A queda de massa, que acompanha a queda de temperatura, indica que nenhum hidrogênio ficou retido no interior das amostras, nestes experimentos.

Por fim, considere-se o estudo das ligas $\gamma \mathrm{U} 9 \mathrm{Mo}$, nos quais os pré-tratamentos a temperaturas de $250^{\circ} \mathrm{C}$ foram realizados, para observar se há influência no rendimento na produção de pós. O procedimento adotado foi o de se variar os tempos nos patamares a $250^{\circ} \mathrm{C}$, seguido dos tratamentos de conversão tradicionais, na temperatura escolhida de $562^{\circ} \mathrm{C}$, em tempos de 4 horas, Figuras 145 a 148 . Novamente, no ensaio a $250^{\circ} \mathrm{C}$ por 1 hora, Figura 143, observou-se somente a perda de massa da amostra, indicando baixa sensibilização ao hidrogênio. Assim, provavelmente, para a sensibilização da liga $\gamma \mathrm{U} 9 \mathrm{Mo}$, tempos maiores nesta temperatura seriam necessários para a produção de suficiente sensibilização, ou ainda, seria necessária a utilização de temperaturas maiores do que esta. Adiante será apresentado o comportamento das mesmas nas temperaturas de $250^{\circ} \mathrm{C}$ e $300^{\circ} \mathrm{C}$, escolhida por ser baixa frente à dos tratamentos tradicionais de reconversão, mas tida como a mínima para a transformação detectável destas ligas. 


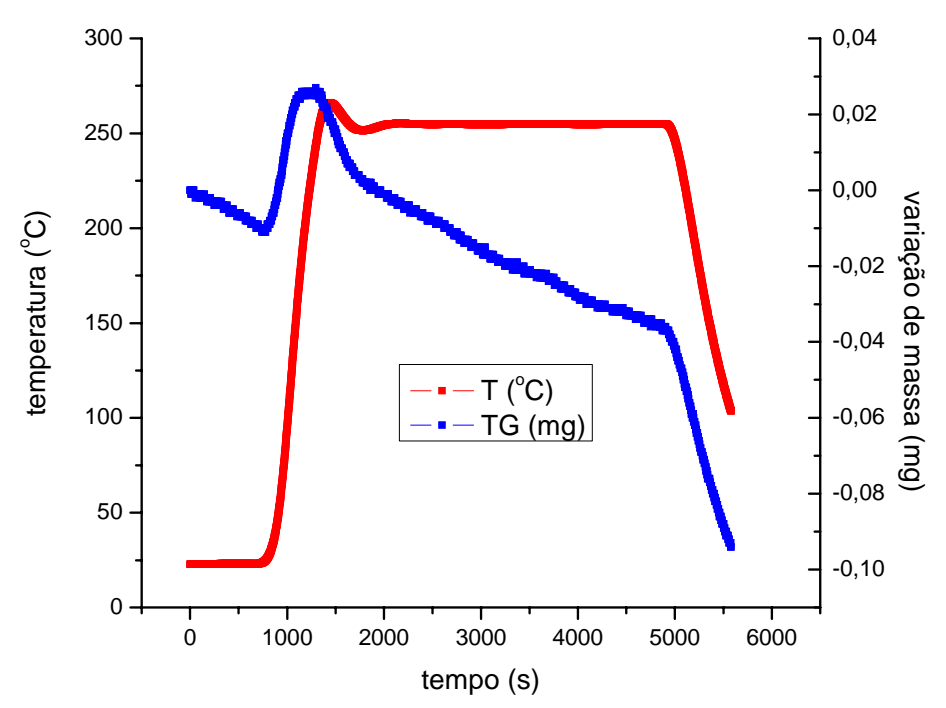

FIGURA 145 - Taxa de variação da massa com relação ao tempo, hidretação a $250^{\circ} \mathrm{C}$ por 1 hora, liga $\gamma \mathrm{U} 9 \mathrm{Mo}$.

A massa de amostra utilizada neste ensaio foi igual a 163,901mg. Como não houve produção de pós, rendimento foi nulo, e procedeu-se à verificação seguinte. Se efetuar este tratamento seguido de conversão a $562^{\circ} \mathrm{C}$, o resultado foi o apresentado na Figura 146.

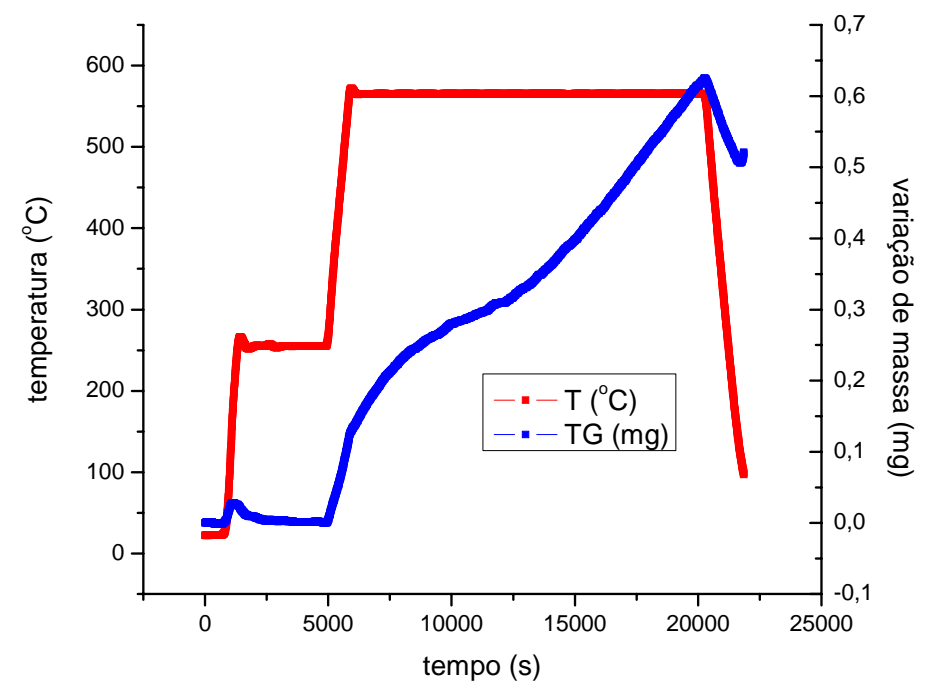

FIGURA 146 - Taxa de variação da massa com relação ao tempo, hidretação a $250^{\circ} \mathrm{C} / 1 \mathrm{~h}+562^{\circ} \mathrm{C} / 4 \mathrm{~h}$, liga $\gamma \mathrm{U} 9 \mathrm{Mo}$.

Ao final do experimento, obteve-se um aumento no rendimento para 34,5\%, maior quando comparado ao obtido sem o tratamento, igual a 5,5\%, Figura 147, relativa ao 
experimento sem o pré-tratamento a $250^{\circ} \mathrm{C}$. Houve também a presença do ponto de mudança de mecanismo de absorção, na região de resfriamento. $\mathrm{O}$ mesmo ocorreu para as demais curvas, mostradas abaixo, com aumento progressivo de 1 hora nos tempos de tratamento a $250^{\circ} \mathrm{C}$.

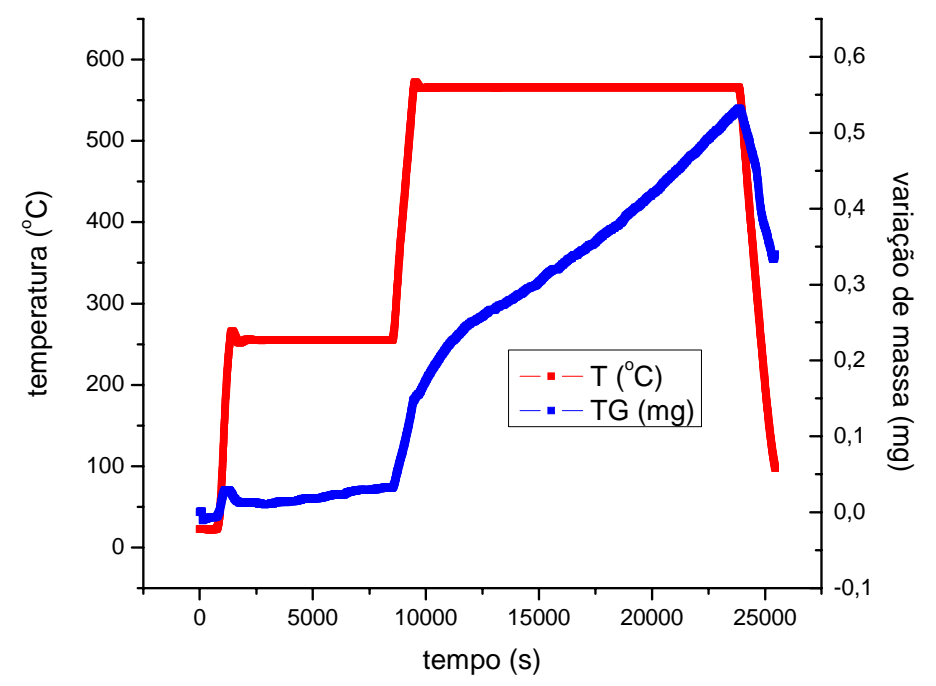

FIGURA 147 - Taxa de variação da massa com relação ao tempo, hidretação a $250^{\circ} \mathrm{C} / 2 \mathrm{~h}+562^{\circ} \mathrm{C} / 4 \mathrm{~h}$, liga $\gamma \mathrm{U} 9 \mathrm{Mo}$.

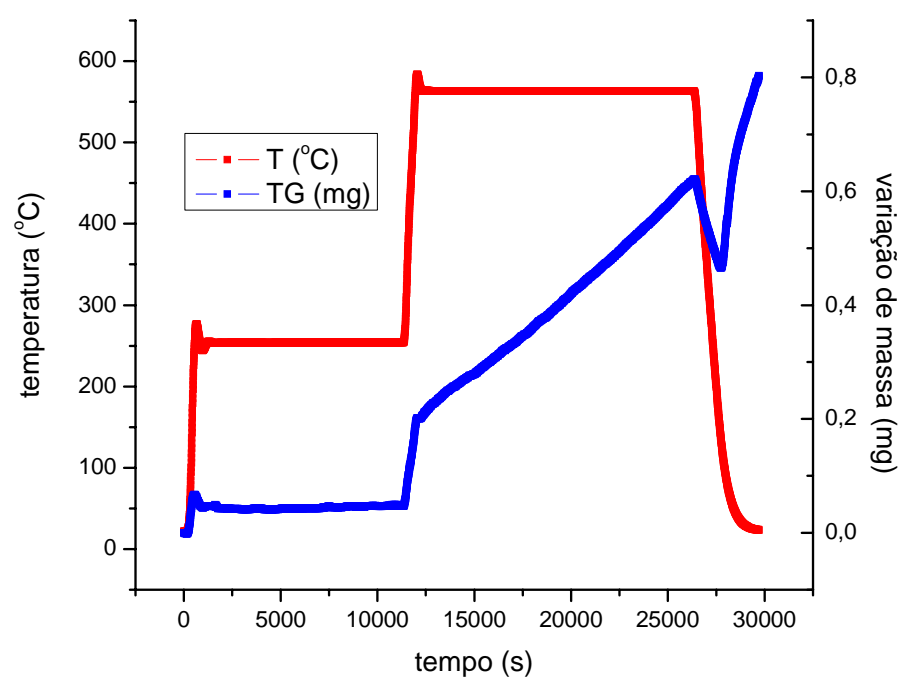

FIGURA 148 - Taxa de variação da massa com relação ao tempo, hidretação a $250^{\circ} \mathrm{C} / 3 \mathrm{~h}+562^{\circ} \mathrm{C} / 4 \mathrm{~h}$, liga $\gamma \mathrm{U} 9 \mathrm{Mo}$.

À exceção do primeiro, em todos os experimentos foi observado o ponto de mudança na variação de massa. Em termos de fragmentação, obteve-se um rendimento de $62,7 \%$ no experimento a $250^{\circ} \mathrm{C}$ por 2 horas, mas que caiu para $40 \%$ quando do tratamento 
por 3 horas. Até o tempo de 2 horas trabalhou-se com massas da ordem de 170mg, e neste último, a massa foi igual a 274,398mg. Explica-se a queda pela utilização de maior massa. As amostras, apresentando a mesma densidade, ocupam maior volume no interior do cadinho, disponibilizando menos espaço para a interação do gás. Este efeito será levado em conta quando da correção dos dados para o estudo de equilíbrio, pois serão adotados como base de cálculo os volumes, e não as massas, das amostras.

O resultado de variação de massa em função do tempo para a amostra da liga $\gamma \mathrm{U} 9 \mathrm{Mo}$ a $562^{\circ} \mathrm{C}$ por 4 horas está apresentado na Figura 149.

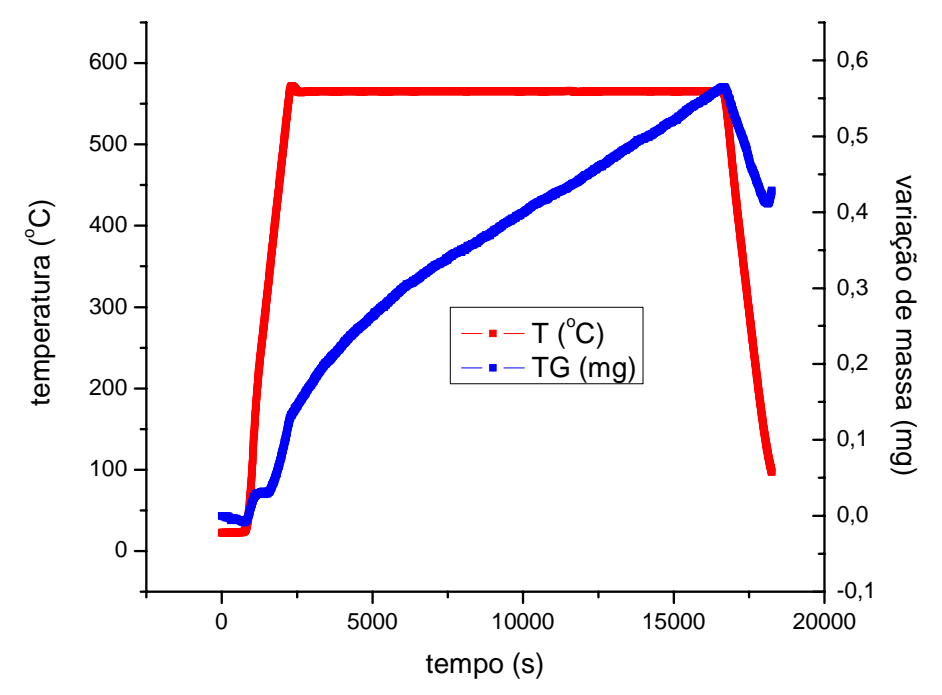

FIGURA 149 - Taxa de variação da massa com relação ao tempo, hidretação a $562^{\circ} \mathrm{C} / 4 \mathrm{~h}$, liga $\gamma \mathrm{U} 9 \mathrm{Mo}$.

Assim, houve um aumento no rendimento em relação ao da amostra não previamente tratada a $250^{\circ} \mathrm{C}$, indicando a possibilidade da utilização destes dois patamares de temperatura para a produção de pós de ligas altamente estabilizadas.

Outros experimentos foram conduzidos a $250^{\circ} \mathrm{C}$ com a liga $\gamma \mathrm{U} 6 \mathrm{Mo}$, obtendo-se um rendimento de $70 \%$, após 1 hora de tratamento. Houve grande semelhança entre as curvas na região do patamar de temperatura, mas a diferença marcante, novamente, foi obtida na região de resfriamento. Mesmo com massas maiores, o ganho de hidrogênio, após o ponto da mudança, pela liga menos estabilizada $\gamma \mathrm{U} 6 \mathrm{Mo}$ foi muito maior, indicando que a sensibilidade ao hidrogênio é tanto maior quanto menos estabilizada for a liga. Podese concluir daí que o teor de fase alfa presente ao início dos experimentos exerce influência sobre a fragmentação das ligas. Observa-se que, ao se tratar 370mg da liga $\gamma \mathrm{U} 6 \mathrm{Mo}$, com volume maior no interior do cadinho do que o das demais amostras, obteve-se rendimento 
total, inclusive com transbordamento de massa para fora dos cadinhos. Ambos os experimentos são apresentados a seguir.

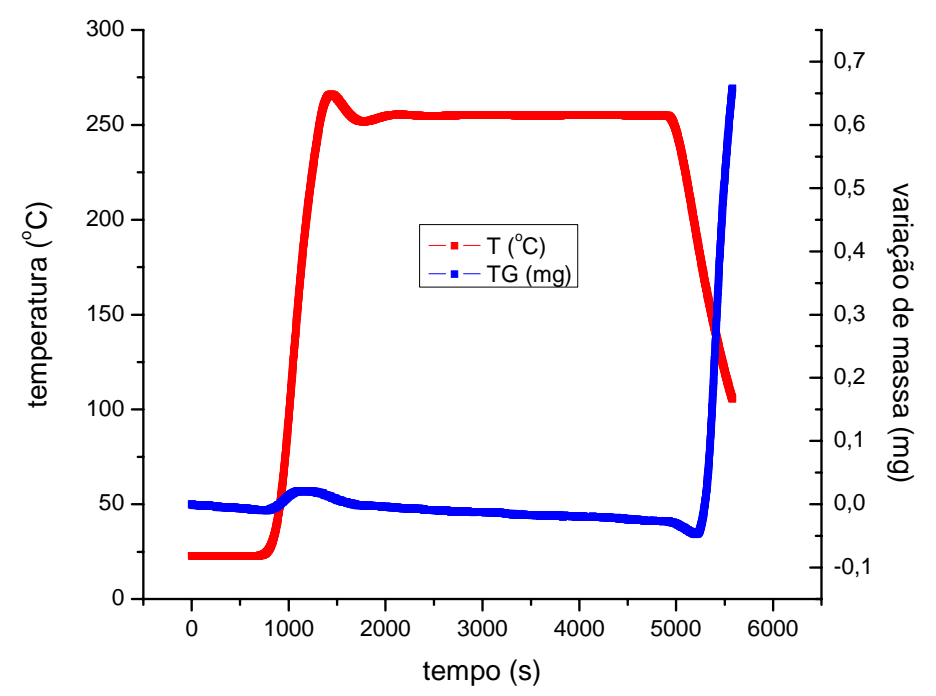

FIGURA 150 - Taxa de variação da massa com relação ao tempo, hidretação a $250^{\circ} \mathrm{C} / 1 \mathrm{~h}$, liga $\gamma \mathrm{U} 6 \mathrm{Mo}$.

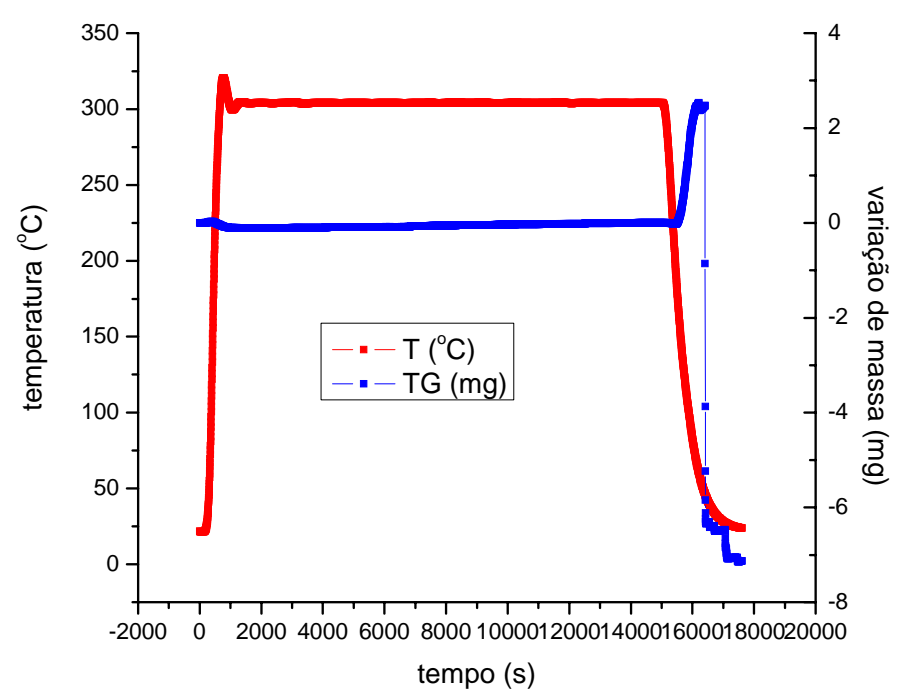

FIGURA 151 - Taxa de variação da massa com relação ao tempo, hidretação a $300^{\circ} \mathrm{C} / 4 \mathrm{~h}$, liga $\gamma \mathrm{U} 6 \mathrm{Mo}$.

Quando se compara as micrografias das ligas a $6 \%$ e a $9 \%$ de molibdênio, notamos no primeiro caso a presença de fase alfa em quantidade maior do que no segundo caso. Portanto, mostrou-se que é mais fácil a obtenção de pós de ligas fracamente 
estabilizadas, mas que também é possível, ao contrário do que dizem alguns trabalhos em literatura, a obtenção de pós de ligas altamente estabilizadas via hidrogenação.

Feitas estas verificações preliminares, estude-se agora a relação entre os resultados de hidrogenação, obtidos na região de resfriamento dos experimentos, e o poder de estabilização do molibdênio sobre a fase gama do urânio. Conforme mencionado anteriormente, várias simulações de operações de hidrogenação foram conduzidas, e algumas evidências diretas foram obtidas. A apresentação dos resultados e a sua discussão serão realizadas no item 13.3 .

\subsection{Evidências da relação entre hidrogenação e decomposição $\gamma \rightarrow \alpha$}

\subsubsection{Ensaios do primeiro ciclo}

A primeira evidência da relação entre a quantidade de hidrogênio absorvida pelas ligas $\gamma$ UMo e suas propriedades de estabilidade foi através da determinação dos rendimentos na produção de pós, nos ensaios do primeiro ciclo, efetuados sobre amostras brutas de fusão provenientes de arco e indução. Ficou claro, à primeira vista, e independentemente da qualidade dos pós, que maiores rendimentos foram obtidos quando se trabalhou em temperaturas próximas à da transformação eutetóide teórica, de $575^{\circ} \mathrm{C}$. Outra constatação importante foi a de que há alguma fragmentação por ação do hidrogênio mesmo em amostras com composição de $10 \%$ em peso de Mo, altamente estabilizadas.

Apesar dos ensaios do capítulo 10 indicarem que a oxidação das ligas se dê entre $630^{\circ} \mathrm{C}$ e $675^{\circ} \mathrm{C}$, nesta primeira bateria de testes a hipótese da ação do oxigênio, existente como impureza do gás, não foi considerada. Os motivos: vácuo de até $1 \mu$ bar (aproximadamente $10^{-6} \mathrm{~atm}$ ) foi realizado previamente à inserção de gás na câmara interna do forno, teor de oxigênio no hidrogênio utilizado, 5.0 analítico (denominação do fabricante) menor do que 1 ppm (partes por milhão), teor de água ou umidade também menor do que 1ppm, possibilidades de vazamento somente para fora do sistema, pois a pressão na câmara interna foi estabelecida para se igualar à externa, além do que o sistema foi checado regularmente quanto à estanqueidade. Além disso, fluxo contínuo de hidrogênio sobre a amostra garante a constante alimentação da câmara com o gás. Entretanto, nos ensaios dos demais ciclos, não se trabalhou em temperaturas acima destes valores.

A definição da porcentagem de produção de partículas como parâmetro de 
controle foi algo subjetivo, pois não se definiu qual o tamanho de partícula se tomaria como referência. Assim, considerou-se a formação de dois conjuntos distintos de sólidos, um deles totalmente particulado, e o outro, aqui chamado de núcleo total ou parcialmente não reagido, sem fragmentos. Um rendimento nulo significa que o material de entrada não sofreu qualquer ação do hidrogênio no sentido de fragmentá-lo, portanto está intacto. Um rendimento de $100 \%$ indica que todo o material foi fragmentado, não importando qual o tamanho os fragmentos. Para fins, entretanto, de um controle simples, considerou-se fragmentos menores do que 1,0mm, por inspeção visual. Um núcleo remanescente com 2,0mm não foi considerado como partícula, o que levou a rendimentos próximos mas não iguais a $100 \%$.

Tempos foram utilizados para a obtenção das curvas de transformação das ligas. De antemão, dos resultados de equilíbrio dados no capítulo II, menores teores de molibdênio correspondem a ligas menos estabilizadas, maiores teores a maior estabilização. Assim, em ensaios próximos à temperatura teórica de transformação eutetóide, em ligas com baixo Mo, foram realizados, em sua maioria, ensaios em tempos não superiores a 4 horas. Em ligas altamente estabilizadas, 8 e 16 horas de ensaio foram comuns, embora os resultados em termos de rendimento não tenham sido satisfatórios.

Outro fato importante foi o relacionado à aparência das partículas das ligas, por inspeção visual. Apesar de baixo rendimento ser obtido com ligas de alta estabilidade, o brilho apresentado pelas poucas partículas formadas foi maior que o das provenientes de ligas menos estabilizadas, mais escuros. Conforme os trabalhos de Balart et al. ${ }^{50}$, Solonin et al. ${ }^{47}$, e Pasqualini et al. ${ }^{49}$, como resultado da ação do hidreto ou da formação de alguma camada de passivação. Obviamente que se sabe que os pós de HDH ou HMDH, sendo muito finos, são muito reativos e até mesmo pirofóricos, o que torna a passivação quase que obrigatória. Entretanto, para fins de caracterização, a passivação altera os espectros de difração de raios-X, interferido na análise, um problema que será discutido adiante.

Desta análise preliminar pode-se inferir que os mecanismos de fragilização das ligas podem variar, conforme o teor de molibdênio. Em Powell ${ }^{68}$, que estuda a fragilização de ligas urânio-molibdênio, sugerem-se os já tradicionais mecanismos de fragilização, o de formação de precipitado intergranular, no caso constituído pela fase alfa, e o intragranular, responsável pela formação de partículas com dimensões menores que a dos grãos. Nas figuras a serem apresentadas adiante, observa-se que as partículas de ligas com teor em molibdênio menor ou igual a 7\% apresentam-se mais inchadas, semelhantes às de Pasqualini ${ }^{51}$ e Balart ${ }^{50}$, e as contendo $8 \%$ ou mais se apresentam mais planas, facetadas. 
Analise-se agora os resultados de fragmentação em função da temperatura, dados nos gráficos da Figura 152. Para cada uma das porcentagens de adição, temos limites entre os campos binários alfa mais delta, gama mais alfa e gama puro diferentes, conforme os limites dados pelo traçado das retas na montagem abaixo.

A liga a 5\% de molibdênio foi produzida a arco, por possuir teor de molibdênio baixo e por apresentar, conforme apresentado no capítulo 10, maior quantidade de fase alfa presente que as de uma amostra de indução. Pretende-se com esta amostra visualizar melhor os efeitos dos tratamentos térmicos sob hidrogênio no rendimento e, principalmente, na verificação de como se processa o equilíbrio. Os números acima de cada ponto são os referentes aos códigos utilizados nas experiências. Assim, como nos gráficos está sendo dada ênfase às temperaturas, para as demais condições, as tabelas do capítulo 6 devem ser consultadas.
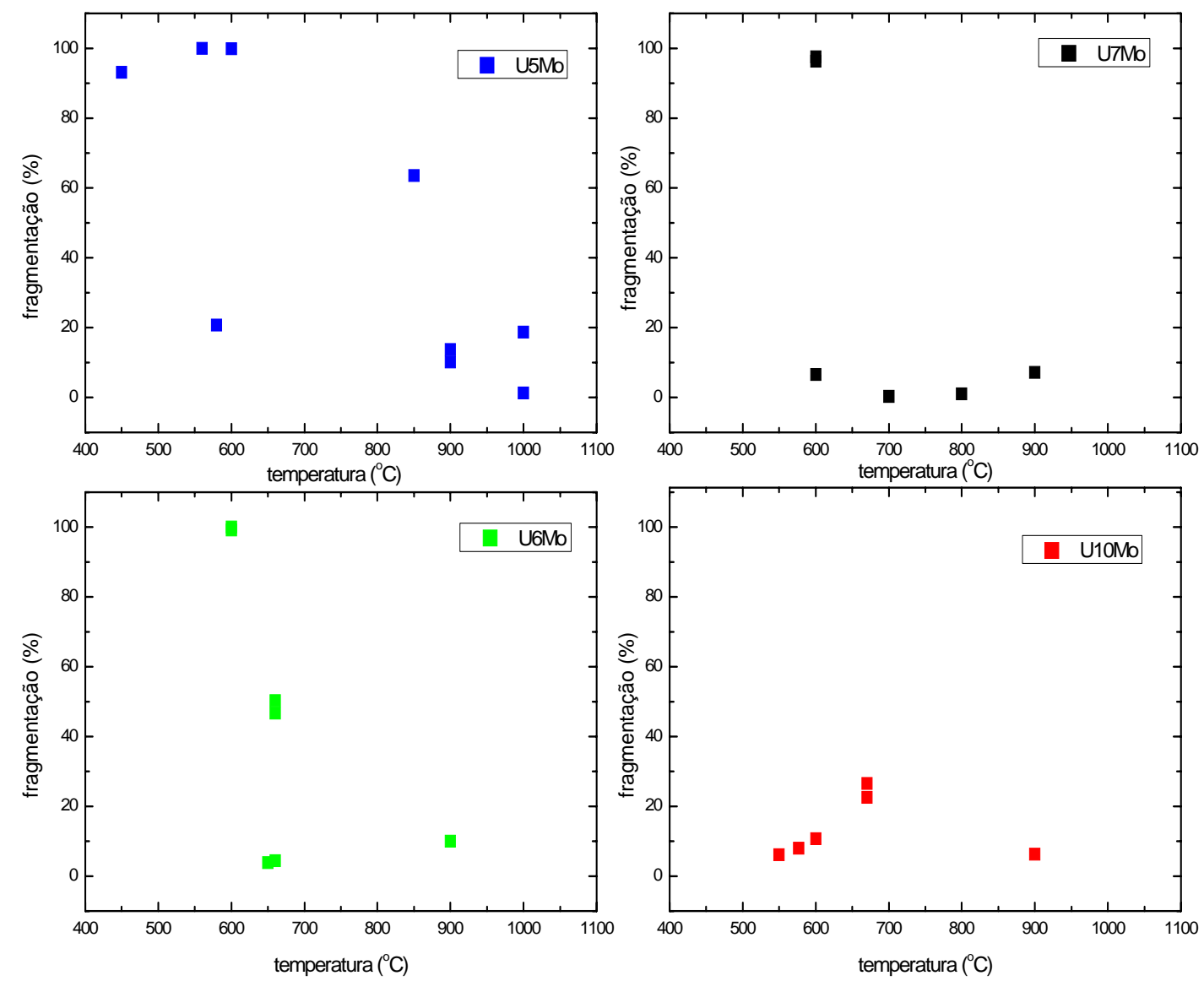

FIGURA 152 - Rendimentos na produção dos pós em função da temperatura, ensaios TG/DTA. 
Uma primeira análise mostra que a produção de fragmentos cai com o distanciamento dos campos de gama mais alfa, ou ainda, cai com o aumento na diferença entre as temperaturas de tratamento e de transformação eutetóide teórica. Rendimentos próximos a $100 \%$ foram obtidos para as ligas fracamente estabilizadas até temperaturas próximas a $600^{\circ} \mathrm{C}$, caindo bruscamente nas ligas de indução e suavemente na liga de forno a arco. Para $10 \%$ de adição, há um aumento no rendimento já no campo de gama puro, decrescendo em temperatura próxima à $1000^{\circ} \mathrm{C}$.

Para explicar de maneira qualitativa estes resultados, observa-se que, em geral, já se dispõe de quantidades maiores de fase $\alpha$-UMo nos contornos de grão de amostras com baixo teor de Mo. Assim, como esta fase tem grande afinidade pelo hidrogênio, a incorporação é favorecida, sendo, portanto, maior e mais rápida. Com o aumento no teor de Mo, mais estabilizada torna-se a liga, menos alfa está disponível nos contornos, portanto há menos quantidade de hidreto formada, e maior é a dificuldade de fragilização da estrutura. Além disso, o tempo atua favoravelmente na decomposição da matriz de $\gamma$ em $\alpha$, que é tanto mais rápida quanto menor o teor de Mo, conforme mostram alguns dos diagramas TTT encontrados em literatura ${ }^{7-10,13,14,16,17}$, quando se está trabalhando nos campos binários.

Ao se tratar a liga em temperaturas entre $900^{\circ} \mathrm{C}$ e $1000^{\circ} \mathrm{C}$, o aumento excessivo no tamanho dos grãos, com conseqüente melhor distribuição de Mo na matriz, deveria levar rendimentos progressivamente menores, especialmente quando do trabalho com ligas fracamente estabilizadas. Entretanto, uma inferência preliminar, condições de resfriamento poderiam atuar, juntamente com o aumento excessivo no tamanho dos grãos, por um mecanismo de fragilização térmica, a um aumento nos rendimentos. Isto será verificado adiante, p. 262, item relativo ao choque térmico.

Assim, a fragilização por formação de hidreto intergranular tem maior efetividade na formação dos pós que o mecanismo da saturação e surgimento de fontes de tensão, conforme reportado em Powell ${ }^{68}$, e dada a pequena quantidade de alfa intergranular, este ocorre isoladamente em temperaturas da região monofásica $\gamma$-UMo. Como houve ligeiro aumento no rendimento em temperaturas elevadas, este mecanismo tem maior efetividade quanto maior for a temperatura e estabilidade das ligas, pois atua conjuntamente à fragilização da estrutura por aumento nas dimensões dos grãos.

A análise específica dos resultados da liga $\gamma$-U5Mo mostrou que melhores resultados foram obtidos quando do tratamento das amostras nos campos bifásicos, 
especialmente no campo $\alpha+\gamma$, na faixa de temperaturas entre 560 e $600^{\circ} \mathrm{C}$, ensaios 711 e 707 respectivamente, o que pode explicar a utilização de tratamentos pré-hidretação nesta faixa de temperaturas, utilizados tradicionalmente na hidretação de ligas após tratamento térmico de homogeneização ${ }^{48,49,50,51,68}$. Rendimento um pouco menor obteve-se no campo $\alpha+\delta$, ensaio 702, embora toda a amostra tenha se fragmentado, mas em partículas com dimensões superiores ao nosso limite. Acima de $650^{\circ} \mathrm{C}$, região do campo monofásico $\gamma$, os rendimentos são ainda bons, mas a tendência à queda pode ser explicada pela conversão progressiva da fase $\alpha \rightarrow \gamma$, mesmo em tempos de tratamento térmico de 1 hora. A progressiva estabilização da fase $\gamma$ observada justifica o uso dos tratamentos de reconversão após obtenção dos pós nesta faixa de temperaturas.

Assim, pode-se por meio desta curva determinar a velocidade de reconversão da estrutura alfa em gama, como função das temperaturas de tratamento, para cada um dos tempos estudados. Aqui deve-se supor como hipótese que a absorção de hidrogênio se dá somente por reação com alfa-U dos contornos. Portanto, a progressiva menor quantidade de hidrogênio absorvido pela liga relaciona-se à menor quantidade de alfa produzida, quanto maior a temperatura. No caso dos tratamentos em campo de gama puro, a absorção deve se relacionar com a reconversão progressiva de alfa a gama, que por sua vez é maior com a temperatura.

Ao se levar em conta os experimentos realizados somente no campo monofásico, em temperaturas bem acima da linha limite entre os campos de $\gamma$ e $\gamma+\alpha$, ensaios 701, 703, 704, 705 e 709, notou-se que, quando houve tratamento T2 (701, 705 e 709), conseguiu-se progressivamente maior quantidade de pó, resultado também obtido para as ligas de indução. Este foi um resultado interessante, pois como se está preocupado com a integridade estrutural e homogeneidade das ligas em termos de composição e fases, obviamente que a fragmentação em temperaturas desta ordem é mais vantajosa, pois assegura a presença inteiramente da fase gama na liga, e evita as etapas de pré-tratamento da liga e reconversão ou têmpera do pó. Portanto, pelos experimentos deste ciclo, inferiuse que a aplicação de tratamento térmico em temperaturas dos campos $\gamma$ e $\gamma+\alpha$, seguido de novo a temperaturas de $\alpha+\delta$, aumenta o rendimento. Veremos nos experimentos do segundo e terceiro ciclos que este tratamento subseqüente, na maioria da vezes, não é necessário.

A título de curiosidade, inverteu-se a magnitude das temperaturas em um dos ensaios, realizados com 2 patamares, ensaio 710, quando a temperatura do primeiro 
tratamento foi menor que a do segundo. Como seria de se esperar, a fragmentação da amostra foi pequena, com rendimento aproximado de $22 \%$, pois tratamento subseqüente em T2>T1 converte parte da estrutura alfa, ainda presente na liga, em gama.

Para as ligas de indução, comportamento semelhante foi observado, embora rendimentos menores tenham sido obtidos pelo fato de serem ligas mais homogêneas, mesmo brutas de fusão, que as ligas de arco. Assim, para a composição de 6\% de Mo, os melhores rendimentos ocorreram novamente quando do trabalho próximo à temperatura de transformação eutetóide, experimentos 601 e 602, onde se mostrou também que tempo de 2 horas já foi suficiente para uma boa fragmentação. Os rendimentos caem quando se vai para o campo de $\gamma$, sendo cada vez mais dependentes, para que haja algum rendimento, do tratamento em T2 e do tempo. Assim, em ensaios à mesma T1 mas em T2 diferentes, ensaios 604 e 606, praticamente o mesmo rendimento foi obtido. Quando se diminui o tempo em T1 e se manteve T1 e T2, o rendimento foi menor. No experimento 607, observou-se que mesmo após 7 horas em T1, praticamente nada ocorreu, pois não houve tratamento subseqüente em $\mathrm{T} 2$.

Para as amostras de liga contendo $7 \%$ de Mo, a sensibilidade ao parâmetro tempo foi evidenciada quando se compara os resultados dos experimentos 207 e 203 / 204. Mesmo tratando as amostras em campos bifásicos, o aumento na quantidade de Mo aumenta o tempo para que se produza fragmentação na amostra. Assim como nas amostras de arco, melhores resultados foram obtidos, independentemente do uso de T2, em temperaturas próximas à da transformação eutetóide.

Para as ligas $\gamma$-U10Mo, observou-se rendimento maior em temperaturas próximas à da linha limite entre os campos de $\gamma$ e $\gamma+\alpha$, conforme resultados dos experimentos 1002 e 1001, semelhante ao comportamento geral das outras ligas, embora os rendimentos tenham sido muito pequenos. $\mathrm{O}$ tratamento prolongado, 7 horas, dado a amostra do ensaio 1005, evidenciou que a temperatura tem maior influência do que o tempo na produção de fragmentação, conforme comparação com os resultados dos experimentos 1004 e 1003.

Assim, no primeiro ciclo foi determinada uma faixa de condições na qual a fragmentação das ligas é possível, analisando-se inicialmente os extremos de composição e, portanto, de estabilidade. Entretanto, alguns dados interessantes podem ser retirados das curvas dos ensaios, como a da Figura 153, supondo absorção devida somente à fase alfa intergranular. 


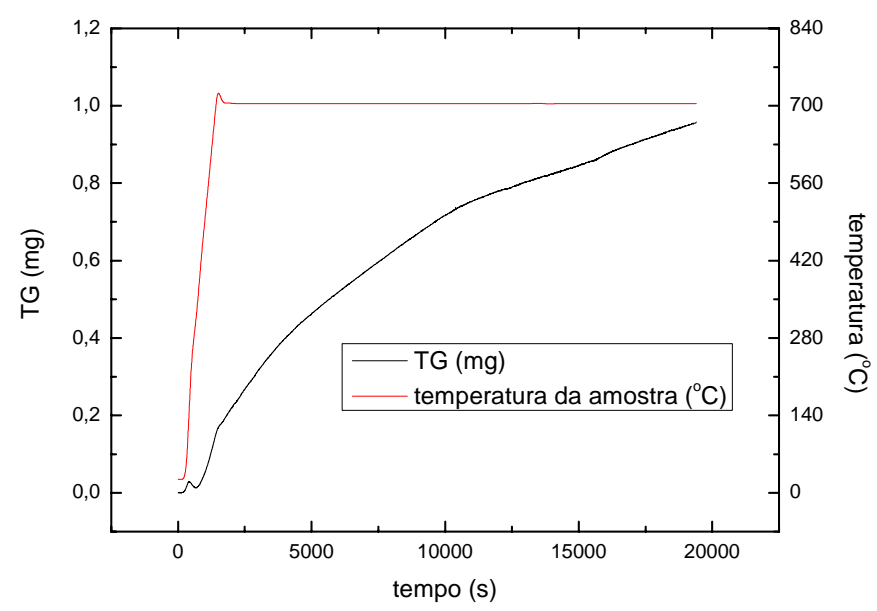

FIGURA 153 - Curva típica de um ensaio termogravimétrico, amostra 201 (U7Mo).

Exemplifique-se com os ensaios de ganho de massa em função do tempo para a composição $\gamma \mathrm{U} 5 \mathrm{Mo}$, produzida em forno a arco. Como as massas das amostras e vazões de gás apresentaram-se um pouco diferentes de ensaios para ensaio (diferenças em massa da ordem de $10 \%$ e vazões da ordem de $5 \%$ por amostra, devidos às imprecisões no corte das amostras e na regulagem da vazão do hidrogênio), houve a necessidade de normalização. Os gráficos, após correções estão apresentados na Figura 154.

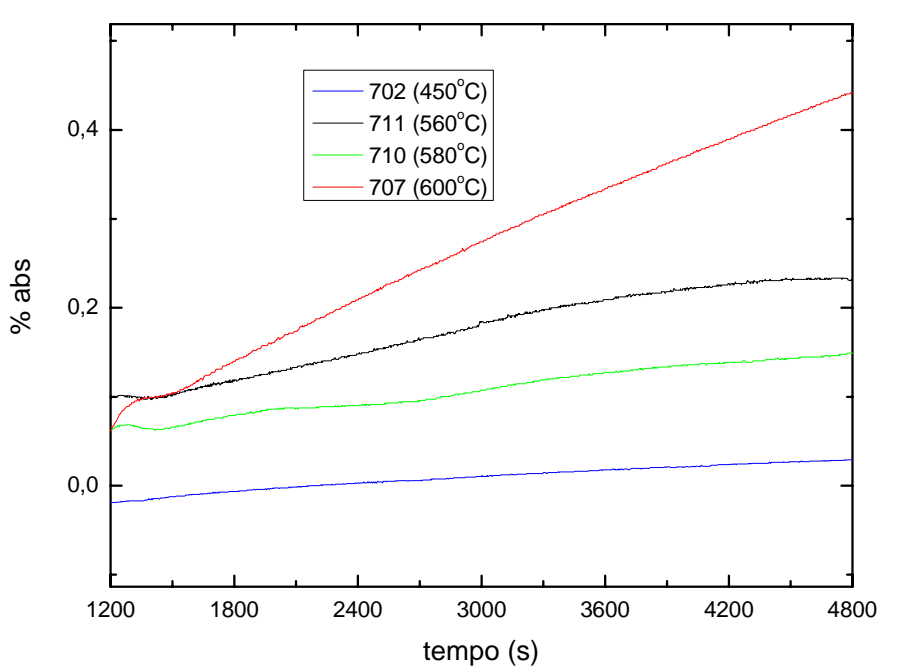

FIGURA 154 - Curvas dos ensaios de termogravimetria, liga $\gamma \mathrm{U} 5 \mathrm{Mo}, \mathrm{T} \leq 600^{\circ} \mathrm{C}$. 


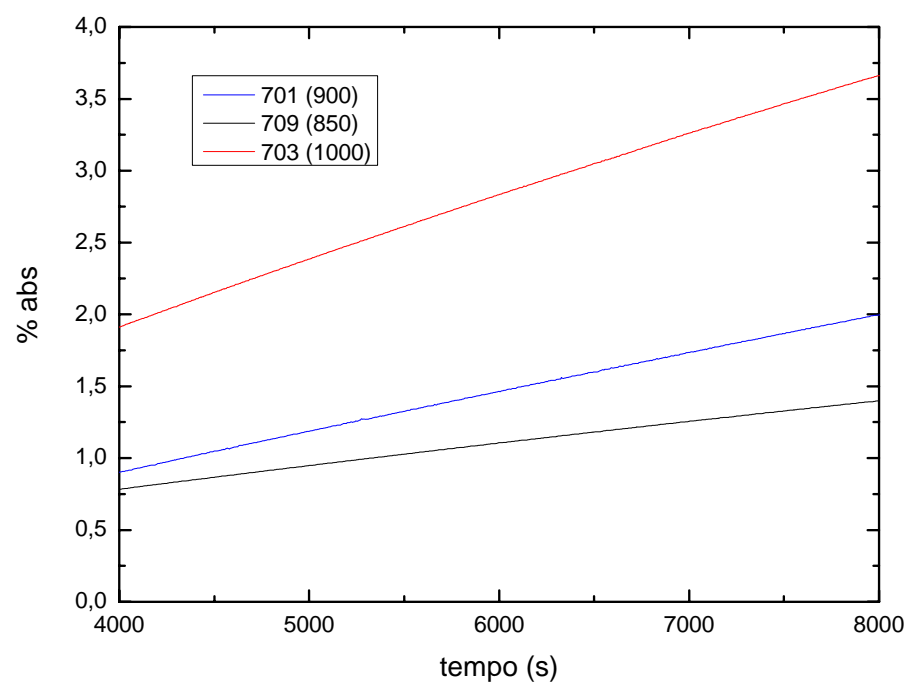

FIGURA 155 - Curvas dos ensaios de termogravimetria, liga $\gamma \mathrm{U} 5 \mathrm{Mo}, \mathrm{T} \geq 850^{\circ} \mathrm{C}$.

Aqui estão mostradas somente as partes das curvas estáveis quanto ao regime de absorção, Figura 155. Por meio delas, pode-se obter taxas instantâneas de incorporação de massa, e analisar os efeitos da temperatura na absorção de hidrogênio pela liga. Tomese como exemplo os dados de absorção para o tempo de $5400 \mathrm{~s}$ ou $1,5 \mathrm{~h}$. O resultado está apresentado no gráfico da Figura 156. O tempo é referente à adsorção de uma unidade de massa.

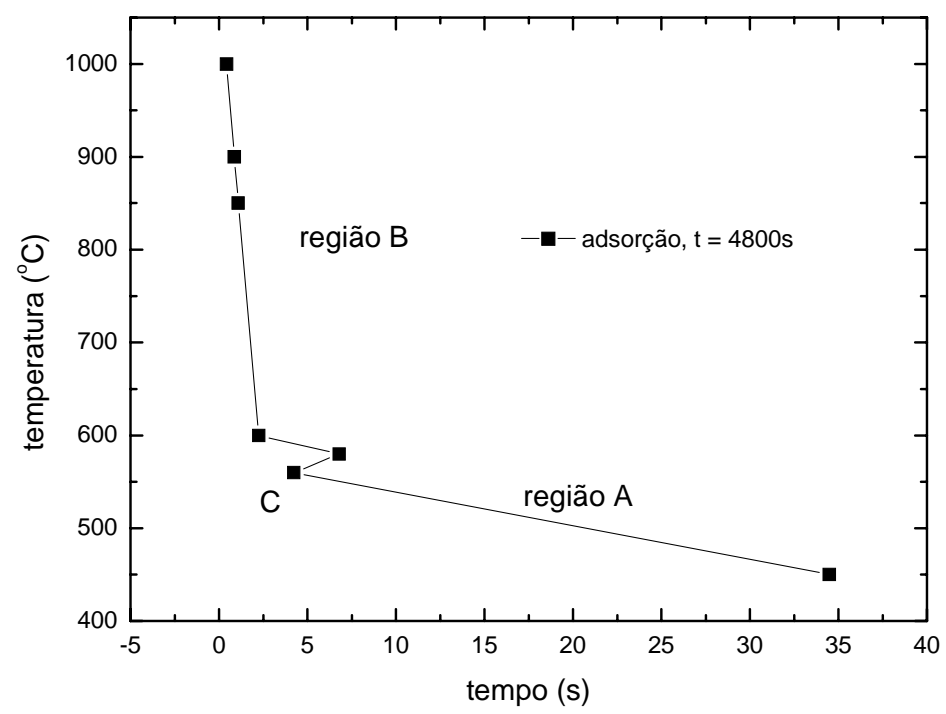

FIGURA 156 - Mudança nos mecanismos de incorporação de $\mathrm{H}_{2}$. 
Esta curva foi construída da seguinte maneira. A partir das curvas de ganho de massa, fixou-se um instante de tempo, no caso 4800s, e determinou-se, após as normalizações, qual a massa absorvida pela liga. Assim, tem-se um valor médio, de ganho de massa pelo tempo, uma velocidade instantânea de absorção, em (mg/mg amostra)/(s), ou em fração de massa absorvida relativa à massa da amostra, em porcentagem, por unidade de tempo. Se se inverter os valores, ter-se-á então o tempo necessário para a absorção de uma unidade de massa de hidrogênio pela amostra. Pela hipótese considerada, pode-se relacionar esta unidade de massa à quantidade de fase alfa produzida, durante o processo de tratamento térmico sob hidrogênio. Supondo que a fase alfa é nucleada homogeneamente, conforme equações do capítulo 7 tem-se condições de inferir o quanto da fase alfa foi produzida, até um instante de tempo escolhido.

Para o tempo de 1,5 hora, nota-se claramente uma mudança brusca no regime de incorporação de hidrogênio pela amostra, em temperatura de $560^{\circ} \mathrm{C}$, ponto $\mathrm{C}$, dado pela mudança nas inclinações das curvas prolongadas das regiões A e B. A temperatura de $560^{\circ} \mathrm{C}$ é muito próxima à da transformação eutetóide, na qual há máxima precipitação da fase alfa em contornos de grão e, portanto, na qual se espera a maior absorção de hidrogênio. Acima deste valor, a nucleação de alfa é menor, conforme diversos diagramas TTT para o sistema UMo, e então, daí em diante, após a linha que delimita os campos de gama e alfa mais gama, há homogeneização do material, o regime de incorporação de hidrogênio se dá por aumento de solubilidade com a temperatura.

Assim, por meio das equações de taxa de nucleação como as apresentadas no desenvolvimento teórico, pode-se inferir qual o papel da formação de fase alfa na incorporação do hidrogênio pela amostra. Entretanto, é interessante determinar a razão entre a quantidade de hidrogênio absorvida pela amostra e a desprendida, em ensaios subseqüentes de dehidretação. Isto foi conduzido para as ligas a $6 \%$ de molibdênio, dehidretação das amostras dos ensaios 606 e 602, materiais processados a (m; T1, t1; T2, t2) iguais a $(172,196 ; 660,4 ; 250,0,5)$ e $(255,252 ; 600,2 ; 300,0,5), \mathrm{T}$ em ${ }^{\circ} \mathrm{C}, \mathrm{t}$ em horas, massas em mg.

Utilizou-se para a dehidretação de ambas as amostras uma mistura contendo núcleos não reagidos e partículas. Os resultados são apresentados nas Figuras 157 a 159. 


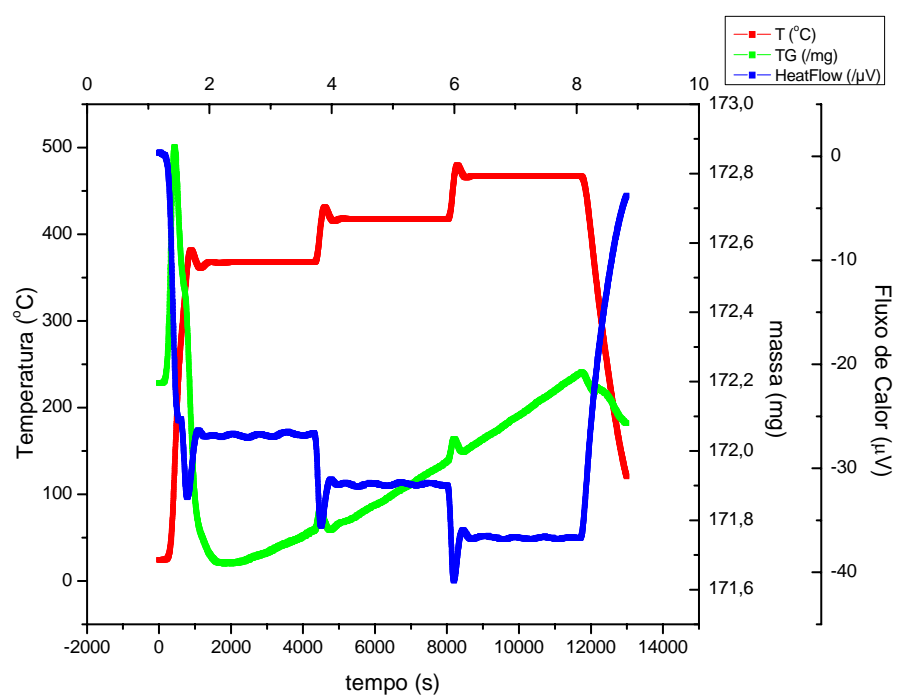

FIGURA 157 - Dehidretação, ensaio 606.

Para esta amostra foi observada uma perda de massa total, diferença entre os pontos de máximo e mínimo na curva de ganho de massa em função do tempo, igual a $1,202 \mathrm{mg}$, o que corresponde a $0,698 \%$ da massa da amostra ao início do ensaio. Ou seja, pode-se relacionar esta perda de massa com a quantidade absorvida de hidrogênio pela fase alfa, presente na liga ao início e durante o processo de tratamento térmico. Pelo ensaio de hidretação correspondente, dado na Figura 158, pode-se estimar a quantidade de hidrogênio solubilizada na amostra, a diferença entre o total adsorvido e o adsorvido por hidretação, conforme análise seguinte.

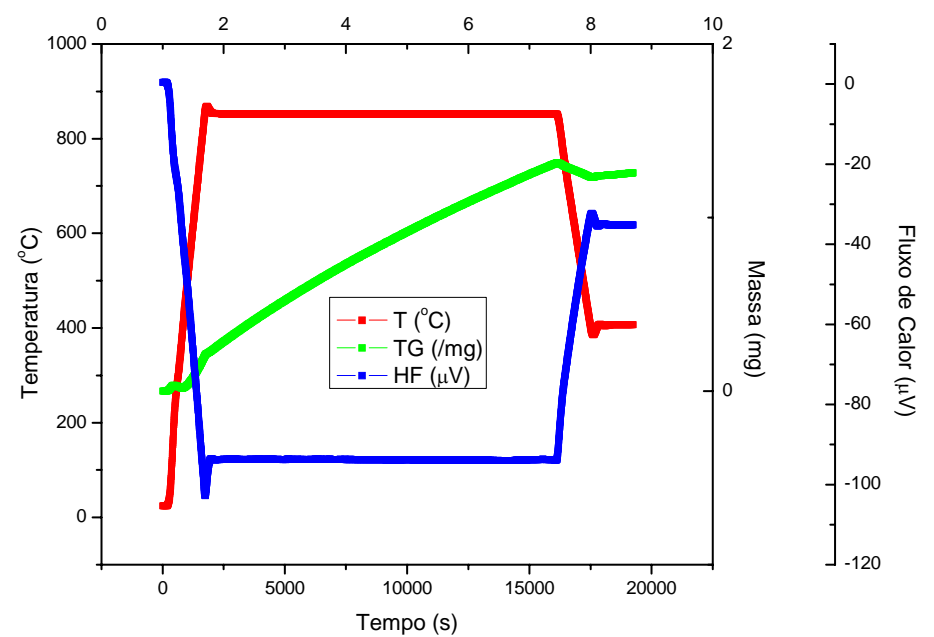

FIGURA 158 - Hidretação, ensaio 606. 


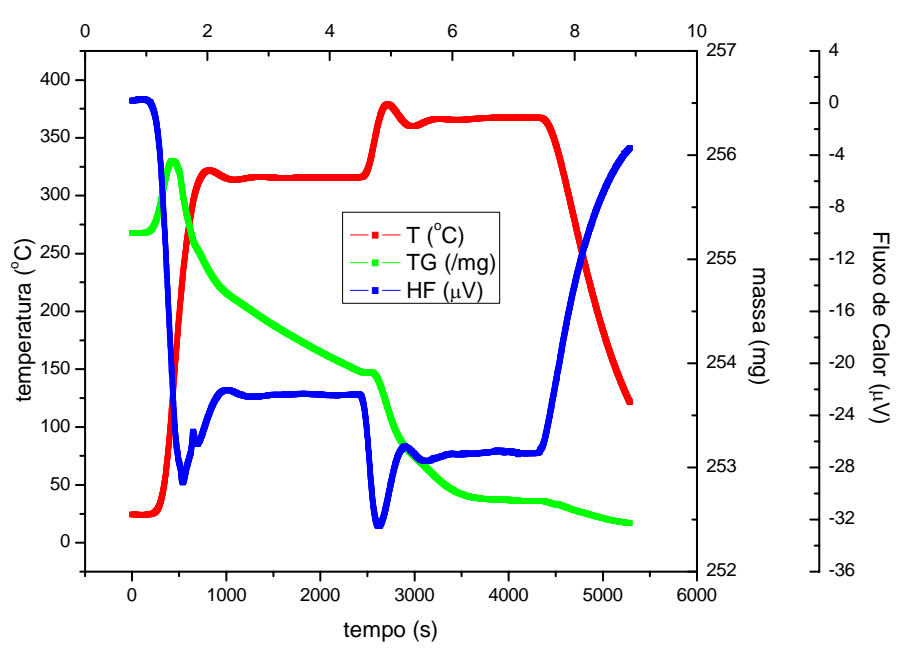

FIGURA 159 - Dehidretação, ensaio 602.

Para o ensaio 602, Figura 159, é de se esperar, dada a proximidade da temperatura da transformação eutetóide, que uma maior quantidade de massa seja absorvida no ensaio de hidretação e, portanto, uma maior quantidade seja dessorvida no de hidretação. Apesar de se utilizar massa maior, as condições de hidrogenação foram as mesmas.

Assim, analisando a curva de perda de massa na dehidretação e utilizando o mesmo critério do experimento anterior, calcula-se uma porcentagem de 1,36\% em relação à massa inicial, no experimento. Observa-se ainda que, trabalhando-se na metade do tempo do ensaio anterior, a absorção por hidretação, mesmo assim, foi maior. Isto indica que a temperatura é o fator preponderante na hidrogenação das amostras.

Outro fato importante ocorrido neste experimento, Figura 160, deriva da observação de que, pela primeira vez neste primeiro ciclo de experimentos, a velocidade de incorporação de hidrogênio pelas amostras na região de resfriamento cresceu de maneira violenta, indicando que grande quantidade de pó deve ter se formado, e que permitiu uma maior exposição da liga ao hidrogênio. Pela determinação das coordenadas (m; TM; tM), onde $\mathrm{M}$ indica o ponto de mudança nos mecanismos de incorporação de massa na região do resfriamento, pode-se também determinar propriedades de equilíbrio importantes no sistema $\gamma$ UMo. Isto será visto no próximo item, nos experimentos com as ligas estabilizadas $\gamma \mathrm{U} 8 \mathrm{Mo}$, produzidas via indução. 


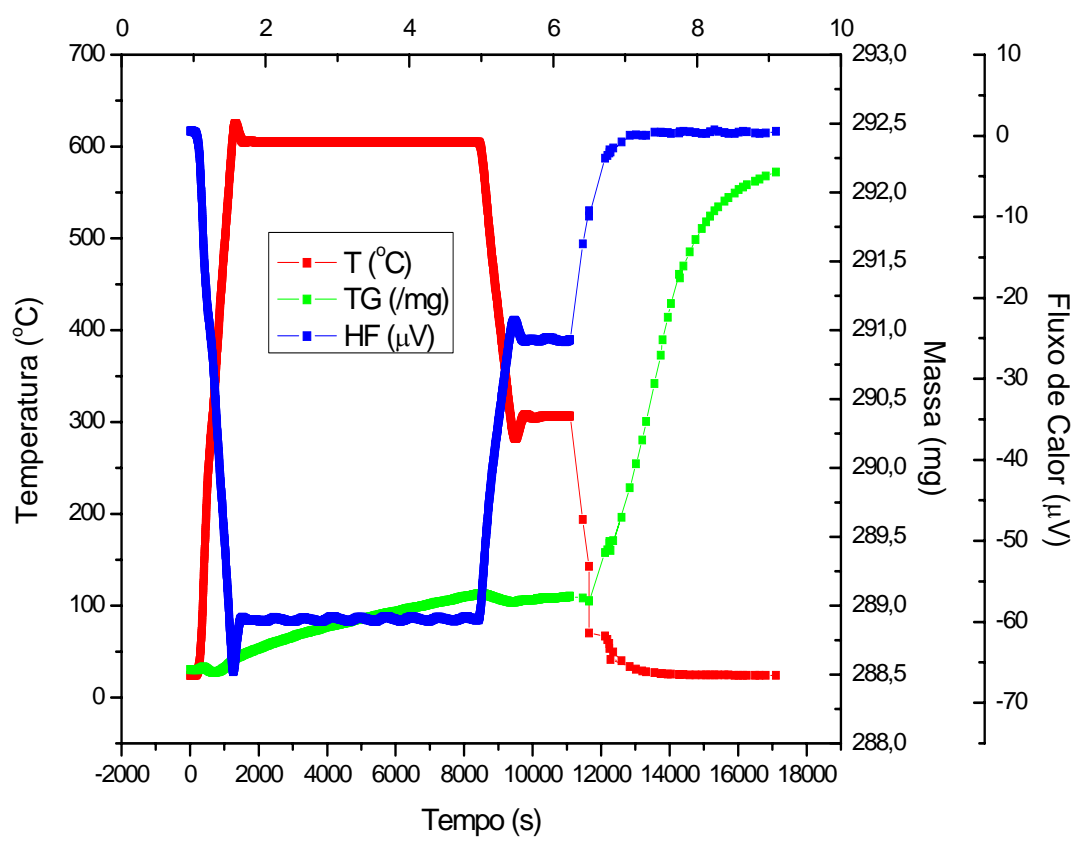

FIGURA 160 - Hidretação, ensaio 602, liga $\gamma U 6 \mathrm{Mo.}$

\subsubsection{Choque térmico e equilíbrio em ligas $\gamma \mathrm{U} 8 \mathrm{M}$ o}

Para verificação do papel do choque térmico no rendimento em produção de partículas, faça-se uma análise preliminar de alguns dos ensaios de hidretação de ligas $\gamma$ U8Mo. As condições experimentais são dadas a seguir, pertencentes ao conjunto de experimentos do segundo ciclo, com os respectivos resultados de rendimento.

A preocupação aqui foi a da determinação das temperaturas e tempos para os quais a formação de pós é possível já nos tratamentos térmicos em hidretação ou T1. Assim, não foram realizados ensaios de dehidretação para todas as amostras. Mostra-se a seguir, e como mencionado anteriormente, que o resfriamento das mesmas apresenta papel importante na fragmentação das ligas, e pode fornecer indícios sobre parâmetros de estabilidade da fase gama.

Na Figura 161 são mostradas as respectivas curvas de ganho de massa, contendo as regiões de aquecimento, estabilidade e resfriamento. Nesta última, observamos pontos de inversão no comportamento da interação hidrogênio amostra, passando de um regime de liberação para um de brusca inversão e aumento na incorporação de massa. 
TABELA 24 - Tratamentos Isotérmicos de Ligas $\gamma$-U8Mo e Respectivos Rendimentos.

\begin{tabular}{|c|c|c|c|}
\hline $\begin{array}{c}\text { Temperatura } \\
\left({ }^{\circ} \mathrm{C}\right)\end{array}$ & $\begin{array}{c}\text { Tempo } \\
(\mathrm{h})\end{array}$ & $\begin{array}{c}\text { Rendimento } \\
(\%)\end{array}$ & $\begin{array}{c}\text { Massas } \\
(\mathrm{mg})\end{array}$ \\
\hline \hline 504,26 & 4 & 1,84 & 175,019 \\
\hline 525,66 & 3 & 4,67 & 186,397 \\
\hline 563,56 & 2 & 75,23 & 166,752 \\
\hline 565,40 & 4 & 100 & 189,401 \\
\hline 568,39 & 4 & 100 & 178,915 \\
\hline 573,53 & 4 & 12,58 & 162,289 \\
\hline 602,33 & 2 & 3,30 & 179,083 \\
\hline 600,38 & 4 & 4,38 & 297,263 \\
\hline
\end{tabular}

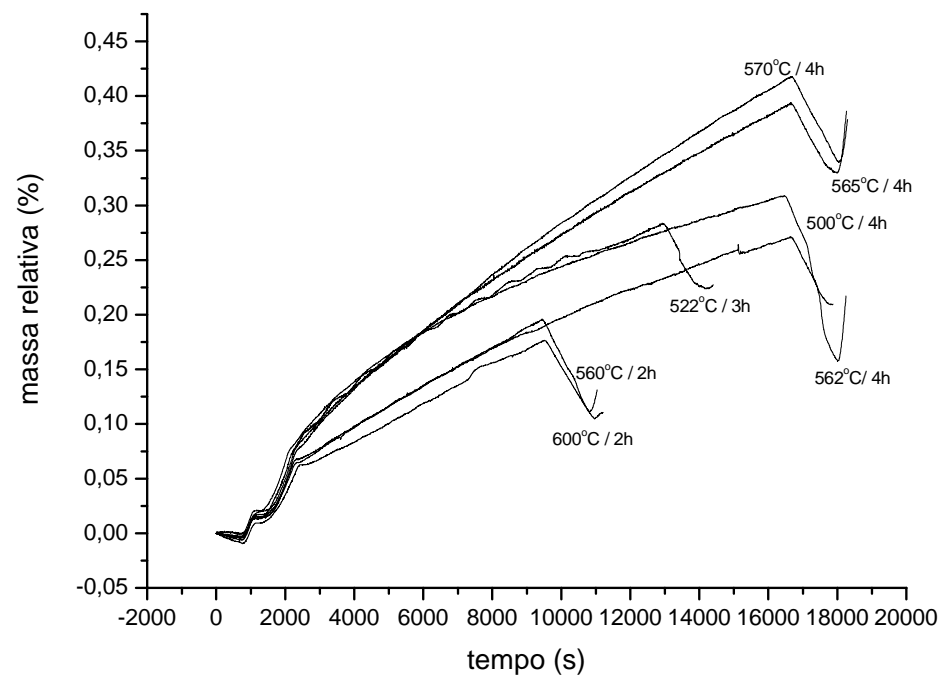

FIGURA 161 - Curvas de ganho de hidrogênio para as amostras das ligas $\gamma$-U8Mo.

Para cada experimento individual é possível obter, a partir das curvas de resfriamento, temperaturas e tempos onde a mudança no regime de interação entre $\mathrm{H} / \gamma$ U8Mo ocorre. As temperaturas efetivas nos patamares, como indicadas pelo programa do analisador térmico, são apresentadas na Tabela 24, ao invés das nominais ou programadas. $\mathrm{Na}$ Tabela 25 são apresentadas as diferenças $\Delta \mathrm{T}$ entre as temperaturas de mudança e as de 
tratamento térmico dos ensaios, denominadas respectivamente TM e TT, e também com relação à temperatura de transformação eutetóide, TE. As diferenças foram calculadas conforme as relações simples:

$$
\Delta \mathrm{Tt}=|\mathrm{TT}-\mathrm{TM}|
$$

e

$$
\Delta \mathrm{Te}=|\mathrm{TE}-\mathrm{TM}|
$$

nas quais $\Delta \mathrm{Tt}$ e $\Delta \mathrm{Te}$ são tomados em valor absoluto. Pode-se observar que há correlação entre $\mathrm{TM}$ e $\Delta \mathrm{Te}$ com os rendimentos na tabela anterior, quando se toma os mesmos intervalos de tempo. No caso, isto é melhor visualizado quando se trabalha com as ligas ensaiadas por 4 horas.

Tabela 25 - Dados Térmicos a Partir das Curvas de Resfriamento.

\begin{tabular}{|c|c|c|c|}
\hline $\mathrm{TT}\left({ }^{\circ} \mathrm{C}\right)$ & $\mathrm{TM}\left({ }^{\circ} \mathrm{C}\right)$ & $\Delta \mathrm{Tt}\left({ }^{\circ} \mathrm{C}\right)$ & $\Delta \mathrm{Te}\left({ }^{\circ} \mathrm{C}\right)$ \\
\hline \hline 504,26 & 99,93 & 404,33 & 465,07 \\
\hline 525,66 & 139,21 & 386,45 & 425,79 \\
\hline 563,56 & 139,02 & 424,54 & 425,98 \\
\hline 565,40 & 145,41 & 419,63 & 419,59 \\
\hline 568,39 & 150,87 & 417,52 & 414,13 \\
\hline 573,53 & 145,82 & 427,21 & 419,18 \\
\hline 602,33 & 145,66 & 456,67 & 419,34 \\
\hline 600,38 & 25,73 & 634,65 & 539,27 \\
\hline
\end{tabular}

Como os rendimentos, conforme experimentos do primeiro ciclo, são influenciados pela distância à temperatura de transformação eutetóide, considerada aqui igual a $565^{\circ} \mathrm{C}$, torna-se interessante determinar as relações mássicas, obtidas nos pontos de final de isoterma e na virada. Na Tabela 26 encontram-se estes dados, resumidos, além dos resultados de ganho e massa para este conjunto de experimentos do ciclo 02. Nela, a quantidade de hidrogênio retida foi calculada como a diferença entre o máximo absorvido, 
ao final das isotermas, e a quantidade de hidrogênio no ponto de virada.

Tabela 26 - Dados de Absorção de Hidrogênio, Isotermas

\begin{tabular}{|c|c|c|c|c|c|c|}
\hline TT $\left({ }^{\circ} \mathrm{C}\right)$ & TM $\left({ }^{\circ} \mathrm{C}\right)$ & $\begin{array}{c}\text { M em TM } \\
(\%)\end{array}$ & $\begin{array}{c}\text { t em TM } \\
(\mathrm{s})\end{array}$ & $\begin{array}{c}\text { TMAX } \\
\left({ }^{\circ} \mathrm{C}\right)\end{array}$ & $\begin{array}{c}\text { MMAX } \\
(\mu \mathrm{g})\end{array}$ & $\begin{array}{c}\mathrm{t} \mathrm{em} \\
\text { TMAX }(\mathrm{s})\end{array}$ \\
\hline \hline 504,26 & 99,93 & 0,20912 & 17856 & 503,94 & 0,30911 & 16463 \\
\hline 525,66 & 139,21 & 0,22372 & 14193 & 525,22 & 0,28380 & 12931 \\
\hline 563,56 & 139,02 & 0,11154 & 10819 & 563,02 & 0,19611 & 9446 \\
\hline 565,40 & 145,41 & 0,15734 & 18004 & 564,94 & 0,27138 & 16650 \\
\hline 568,39 & 150,87 & 0,32977 & 18001 & 568,37 & 0,39404 & 16643 \\
\hline 573,53 & 144,93 & 0,33952 & 18056 & 573,52 & 0,41777 & 16654 \\
\hline 602,33 & 145,66 & 0,10422 & 10971 & 602,35 & 0,17645 & 9515 \\
\hline 600,38 & 25,73 & 0,74345 & 18724 & 593,83 & 0,82015 & 15698 \\
\hline
\end{tabular}

Aqui, TT é a temperatura média de tratamento isotérmico, TM é a temperatura no ponto de mudança da inclinação da curva de resfriamento, M em TM é a massa neste ponto, $\mathrm{t}$ em TM é o tempo neste ponto, TMAX é a temperatura onde ocorreu a máxima absorção, em geral próxima ao final da isoterma, MMAX é o valor de massa de hidrogênio incorporado máximo pela amostra, $t$ em TMAX o tempo neste ponto.

Por meio destes dados pode-se construir as curvas seguintes. Para os tratamentos a 4 horas nas temperaturas de $504^{\circ} \mathrm{C}, 565^{\circ} \mathrm{C}, 568^{\circ} \mathrm{C}, 573^{\circ} \mathrm{C}$ e $600^{\circ} \mathrm{C}$, observase que a curva de ganho de massa relativa se assemelham, em muito, às curvas dos diagramas tempo-temperatura-transformação. É de se esperar então que as curvas de rendimento apresentem, também, o mesmo comportamento. Veja-se a confirmação experimental destas hipóteses na Figura 162.

A partir destes gráficos, alguns fatos importantes devem ser considerados na formação de pós e em sua relação com o equilíbrio da fase metaestável gama. Primeiramente, se certa quantidade de fase alfa estiver presente inicialmente, e pela reação de incorporação de hidrogênio, dada na introdução, sabe-se que ela tem a tendência a reagir com hidrogênio, esperar-se-á que a absorção de hidrogênio pela liga $\gamma$-U8Mo deva ser influenciada pela taxa na qual alfa for formada. Sabe-se do trabalho de Hofman et al. ${ }^{14}$ e de alguns diagramas TTT do binário UMo que a taxa de decomposição de gama a alfa em uma liga homogênea é fortemente dependente da temperatura de tratamento isotérmico, 
sendo mais pronunciada quando o sistema estiver próximo à temperatura de transformação eutetóide. Portanto, a facilidade no processo $\mathrm{HDH}$ na produção de pós de $\gamma$-UMo e, portanto, na fragmentação das ligas, é causada primariamente pela quantidade inicial de fase alfa, continuamente formada por reação de decomposição celular da matriz, levando à sua precipitação nos contornos de grão. Assim, é lógica a suposição de que se o conteúdo de molibdênio for alto, mais difícil a fragmentação das amostras e, portanto, o primeiro ponto a ser examinado será a quantidade total de hidrogênio absorvido pela amostra.

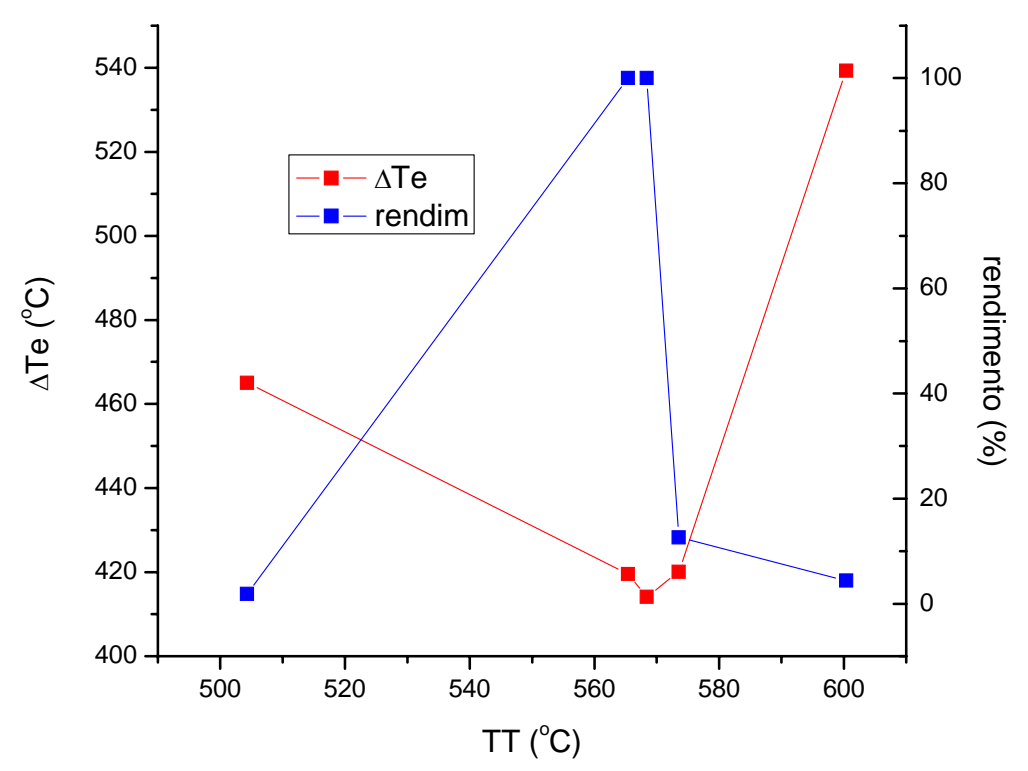

FIGURA 162 - Correlação entre rendimento e $\Delta$ Te.

Tem-se também, dos trabalhos de Van Thyne e McPherson ${ }^{07,16}$ e McGeary $^{69}$, a posição do nariz ou cotovelo da curva TTT varia fortemente, conforme o método de análise utilizado. Segundo $\mathrm{McGeary}^{68}$ a temperatura na qual há máxima decomposição para a liga $\gamma$-U8Mo é de $525^{\circ} \mathrm{C}$, pela técnica de difração de raios-X acompanhada de metalografia. De acordo com Repas ${ }^{17}$, métodos de medida de resistividade indicam um valor de $500^{\circ} \mathrm{C}$, e pela técnica de dureza, $570^{\circ} \mathrm{C}$. Como esta tese lida com fragmentação de pós, é razoável supor-se que seja confirmado que o valor para o qual $\gamma$-U8Mo sofre uma mais pronunciada produção de fase alfa seja próximo ou igual ao observado por esta última técnica. Pelos valores da Tabela 26 e dos gráficos da Figura 162, este valor estaria entre $568,39^{\circ} \mathrm{C}$ e $573,53^{\circ} \mathrm{C}$.

Para esta última condição, foi obtido o maior valor de absorção de hidrogênio, 
mas produziu-se apenas $12 \%$ de fragmentação. Como a temperatura de transição entre os campos de gama e gama mais alfa para esta composição é de aproximadamente $619^{\circ} \mathrm{C}$, afastada da temperatura de transformação eutetóide, observa-se então que o afastamento de apenas alguns graus da condição de equilíbrio, embora haja maior absorção de massa, leva a menor produção de pós. Portanto, a posição do cotovelo, ou seja, do ponto de máxima decomposição, é alcançado quando se está mais perto de $568,39^{\circ} \mathrm{C}$, ao invés de $573,53^{\circ} \mathrm{C}$.

Um outro argumento favorável à escolha deste valor é a posição da temperatura de mudança na região de resfriamento. A $568,39^{\circ} \mathrm{C}$ tem-se o valor mais alto, e que corresponde a um mínimo de energia necessária para a quebra da liga durante o resfriamento, por choque térmico. Isto significa que, considerando que foi utilizada a mesma velocidade de resfriamento em todos os experimentos, é possível concluir que com menores diferenças o rendimento é maior. Portanto, o valor de $568,39^{\circ} \mathrm{C}$ é o mais próximo da verdadeira temperatura de máxima velocidade de decomposição, o "nariz" dos diagramas TTT's para esta composição.

A despeito de a absorção ser menor quando comparada com as das temperaturas de 504, 573 e $602^{\circ} \mathrm{C}$ (neste caso específico, se o tempo for duplicado e, considerando a mesma velocidade de absorção, será possível obter aproximadamente o dobro de massa absorvida em 2 horas: o mesmo é válido para os outros experimentos, quando o tempo foi menor do que 4 horas), as seguintes conclusões surgem. Absorção de hidrogênio ocorre por 2 mecanismos, descritos em Powell ${ }^{68}$, um relacionado ao preenchimento das posições intersticiais e outro relacionado à precipitação intergranular da fase alfa. Se $\Delta$ Te aumenta, o sistema está longe das condições que o levam a uma maior precipitação de alfa e, portanto, o primeiro mecanismo, relacionado à ocupação de posições intersticiais e chamado de fragilização por criação de fontes de tensão pela saturação da liga em hidrogênio, não é suficiente para quebrar a amostra produzindo, nas condições experimentais aqui utilizadas, bom rendimento. Isto explica a boa absorção, mas o baixo rendimento, apresentado pelas amostras tratadas nestas temperaturas.

Assim, foi demonstrado aqui que, ao menos para esta composição, um bom rendimento é possível em temperaturas próximas a $568^{\circ} \mathrm{C}$, que provavelmente deve ser a sua real temperatura de máxima velocidade na decomposição.

Outro aspecto é a característica do pó formado, que pode ser inferida pelo elevado aumento nas taxas de absorção, principalmente na região de resfriamento das curvas de variação de massa em função do tempo. Em todos os experimentos nos quais houve rendimento elevado, foi observado que em algum momento na rampa de 
resfriamento houve uma mudança no mecanismo de incorporação de massa. Considerando que a absorção é um fenômeno dependente da quantidade de área livre existente no sistema, espera-se que uma maior superfície do material exposta ao gás leva a uma maior absorção e, portanto, podemos estimar parâmetros dimensionais dos pós, como por exemplo, seu diâmetro médio de partícula.

A forte mudança na taxa de absorção que segue um breve período de perda de massa pode ser explicada por meio das seguintes considerações. Hidrogênio difunde-se através da amostra a uma velocidade determinada, e reage com urânio alfa, enquanto o mesmo é formado por decomposição da matriz e precipita-se nos contornos de grão, durante o tratamento isotérmico. Com o progresso da reação, a absorção aumenta, aumentando também a quantidade de hidrogênio absorvida pelo reticulado da liga. Em um ponto específico, no qual o tratamento isotérmico cessa e o resfriamento inicia, as diferenças na estrutura cristalina da matriz e do hidreto de urânio, que possuem diferentes propriedades de expansão ou contração térmicas, fazem com que a amostra colapse. Isto leva a um aumento na velocidade de absorção, devido ao aumento na quantidade de pó formado. Partículas são partes da amostra inicial da liga, mas com alta área superficial exposta à ação do hidrogênio. Como foi observado, e conforme esperado, a absorção cresceu com o tempo na região de resfriamento.

Assim, há uma criação de um número de sítios pelas partículas “destacadas” da liga original, que podem ser capazes de absorver mais hidrogênio até a saturação. Esta criação de novos sítios de absorção está relacionada com as diferenças entre a quantidade total de hidrogênio máxima absorvida no tratamento isotérmico e o ponto de mínimo na região de resfriamento, após o qual o sistema ganha um novo aumento na velocidade de absorção. Este aumento permite a estimativa da área de superfície criada, e, portanto, dos parâmetros dimensionais das partículas produzidas em cada experimento.

Portanto, a fragmentação das amostras pode ser obtida diretamente do tratamento de hidrogenação, sem a necessidade de moagem, o ajuste do tamanho de partículas pode ser feito após a dehidretação. Demonstra-se assim que se pode proceder a uma redução em duas etapas nos processos tradicionais de hidretação das ligas. A primeira delas é o tratamento de conversão, e a outra é a moagem, após a hidretação. Ambas podem, portanto, ser unidas em uma única etapa. 


\subsection{Características dos pós}

Outra evidência interessante para a predominância de mecanismos de fragmentação das amostras foi obtida pelo exame das micrografias eletrônicas de varredura de amostras de pós das ligas aqui estudadas. Observou-se que, a partir de $8 \%$ a $9 \%$ de adição, as características das partículas são bem diferentes daquelas obtidas com menor quantidade de Mo.

Partículas de ligas com teores de Mo menores ou iguais a 7\% em peso apresentaram-se em conformidade com as obtidas por Pasqualini ${ }^{51}$ e Balart ${ }^{50}$, por exame das micrografias por eles apresentadas em suas publicações. Obtiveram maiores rendimentos, mas pouco se fala sobre a obtenção de partículas de ligas altamente estabilizadas. Ver-se-á a seguir algumas de suas características.

\subsubsection{Ligas $\gamma$-U5Mo e $\gamma$-U6Mo}

Fragmentação das amostras foi possível em praticamente todas as condições de tempo e temperatura. Para tempos da ordem de 1 hora, fragmentação total $(100 \%$ de rendimento) foi possível em temperaturas próximas à temperatura teórica de transformação eutetóide, ao redor de $565^{\circ} \mathrm{C}$, até à temperatura máxima de teste de $583,37^{\circ} \mathrm{C}\left(580^{\circ} \mathrm{C}\right.$ nominal). A temperatura de teste mínima foi de $543,77^{\circ} \mathrm{C}\left(540^{\circ} \mathrm{C}\right.$ nominal $)$, na qual a fragmentação foi de $24 \%$.

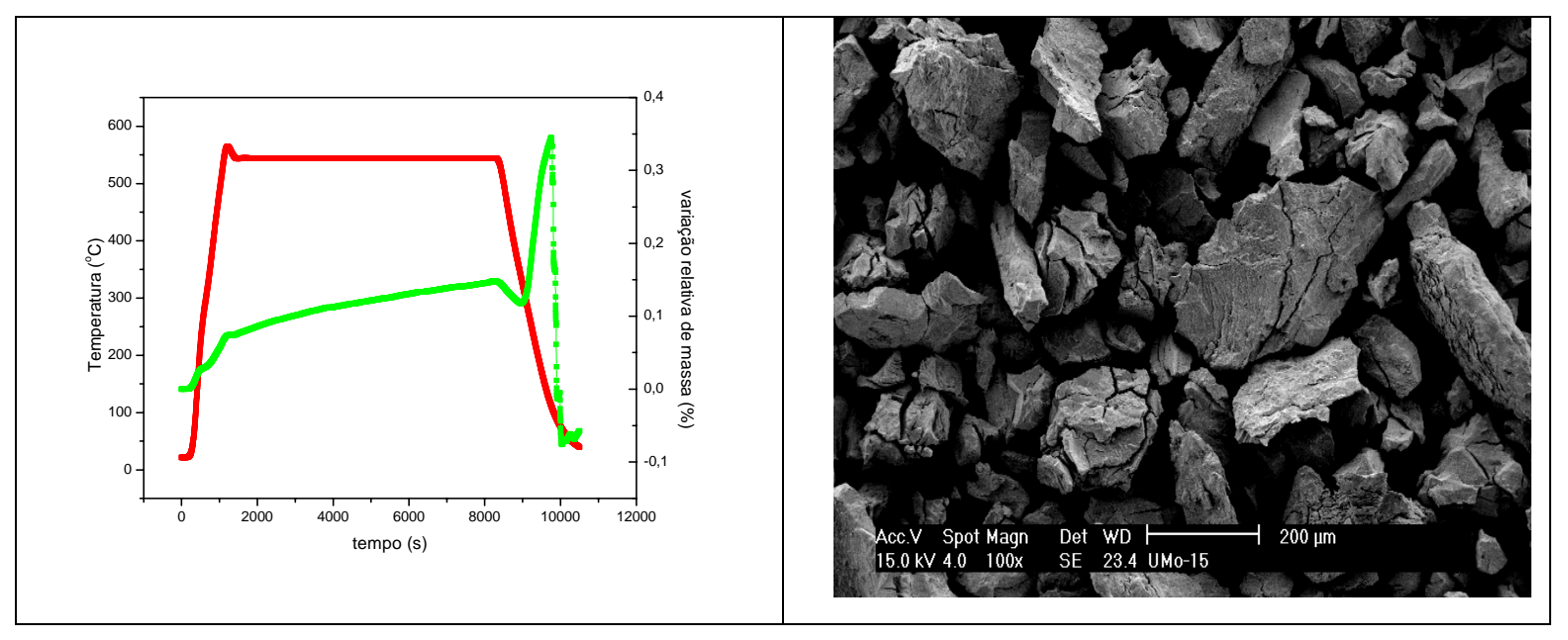

FIGURA 163 - Curvas típicas de variação de massa (esquerda) e respectiva estrutura do pó (direita), liga $\gamma$-U5Mo.

Para duas horas de tratamento, fragmentação total foi possível na faixa de $533,44^{\circ} \mathrm{C} \quad\left(530^{\circ} \mathrm{C}\right.$ nominal $)$ a $591,08^{\circ} \mathrm{C}\left(590^{\circ} \mathrm{C}\right.$ nominal $)$, caindo os rendimentos 
drasticamente a $600,95^{\circ} \mathrm{C}\left(600^{\circ} \mathrm{C}\right.$ nominal), na qual não houve praticamente formação de pós.

Na Figura 163 são dados exemplos de curvas de ganho de massa de uma liga $\gamma$ U5Mo, durante um ciclo de tratamento isotérmico típico, juntamente com características típicas dos pós após etapa de hidretação. Na seqüência, Figura 164, por comparação, são mostradas suas curvas de dehidretação, juntamente com o pó resultante.

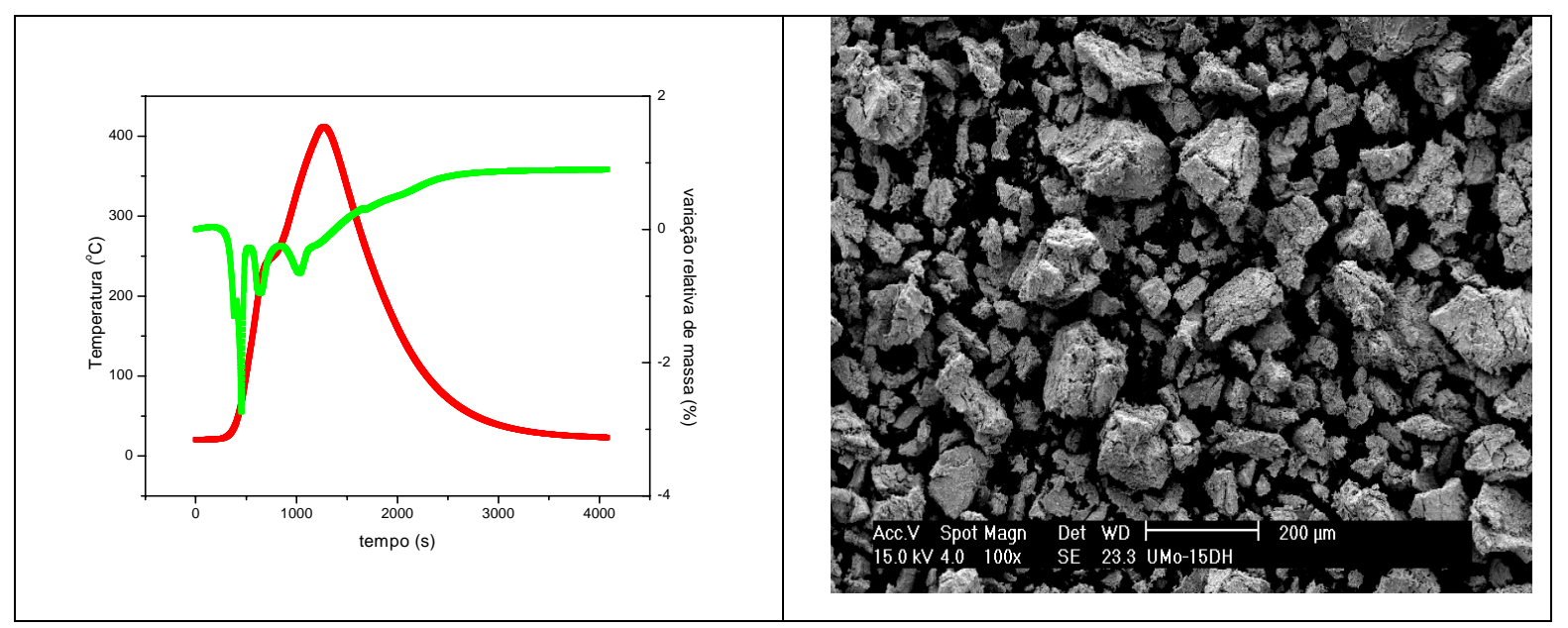

FIGURA 164 - Curvas típicas de dehidretação (esquerda) e respectiva estrutura do pó formado (direita), liga $\gamma$-U5Mo.

\subsubsection{Liga $\gamma$-U7Mo}

Para 1 hora de tratamento, não foi possível a obtenção de $100 \%$ de rendimento. Para duas horas, somente em temperaturas próximas à da transformação eutetóide. Para 4 horas, na temperatura de $482,77^{\circ} \mathrm{C}\left(480^{\circ} \mathrm{C}\right.$ nominal), foi obtido $11,4 \%$ de fragmentação. $\mathrm{O}$ rendimento cresceu a $100 \%$ na faixa de $502,53^{\circ} \mathrm{C}\left(500^{\circ} \mathrm{C}\right.$ nominal $)$ a $573,22^{\circ} \mathrm{C}\left(570^{\circ} \mathrm{C}\right.$ nominal), caindo drasticamente até $600^{\circ} \mathrm{C}$.

A Figura 165 apresenta curvas típicas para esta liga, bem como a forma de suas partículas, muito similares à das ligas anteriores. Entretanto, nota-se uma pequena diferença na forma das partículas. No caso das ligas a 7\% Mo, dada a maior dificuldade na precipitação do hidreto, conforme as energias de ativação para a nucleação da fase alfa a partir da matriz de gama apresentadas no trabalho de Hofman et al. ${ }^{14}$ são menores, a quantidade de hidreto formada é menor, por reação com hidrogênio, conforme equação (40) do capítulo 7.

Como este material é formado principalmente nos contornos de grão, na reação chamada de decomposição celular, quando dos tratamentos a estas temperaturas, presume- 
se que os campos de tensão criados internamente na matriz de gama sejam devidos não somente ao crescimento e expansão da fase alfa ao seu redor. Deve haver, portanto, grande contribuição devida ao hidrogênio dissolvido na rede, que torna-se responsável pela aparente maior esfericidade das partículas, nesta porcentagem.

Outro fator que afeta a forma das partículas é, obviamente, o tempo de exposição à atmosfera de hidrogênio. Quanto maior o tempo de exposição, maior a absorção de hidrogênio pela liga, e portanto é maior a contribuição exercida pelas tensões internas à matriz na fragmentação.

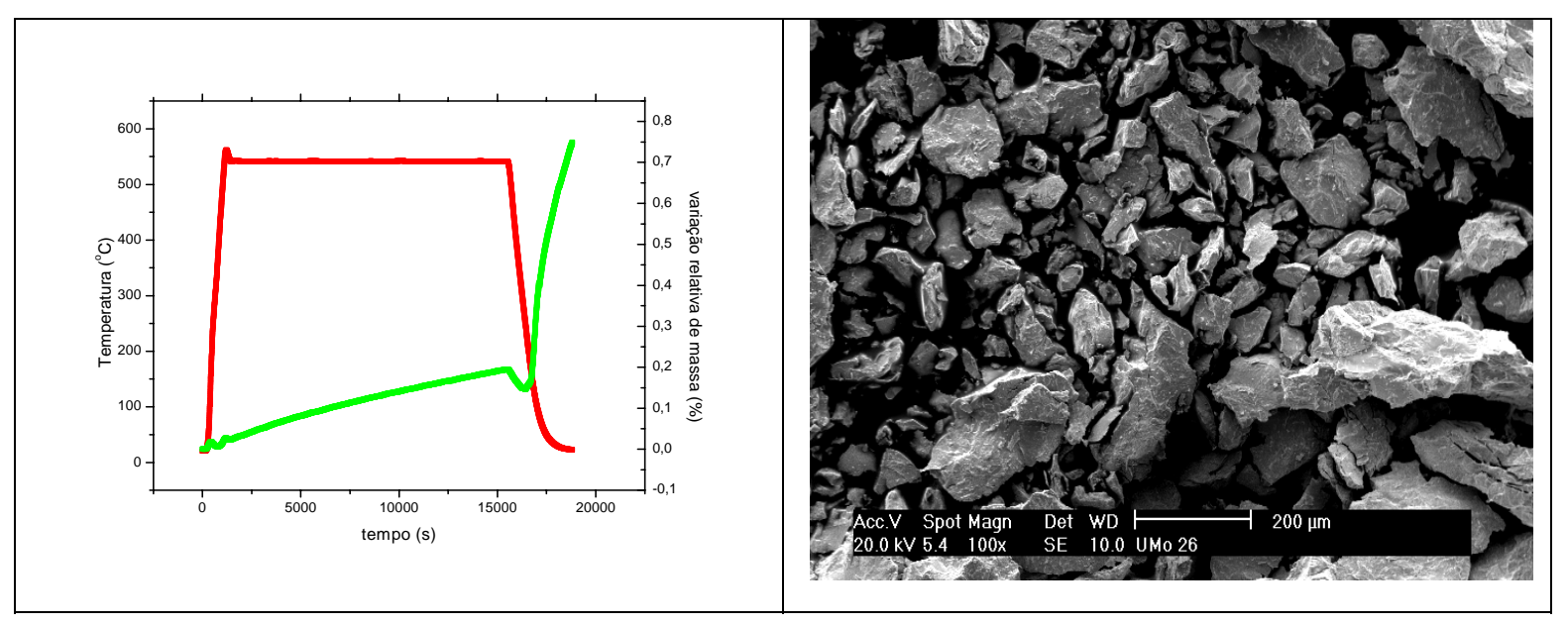

FIGURA 165 - Curvas típicas de variação de massa (esquerda) e respectiva estrutura do pó (direita), liga $\gamma$-U7Mo.

\subsubsection{Liga $\gamma$-U8Mo}

Total fragmentação foi possível somente após 4 horas de tratamento, numa faixa estreita de temperaturas entre $565,4^{\circ} \mathrm{C}\left(562^{\circ} \mathrm{C}\right.$ nominal $)$ e $568,39^{\circ} \mathrm{C}\left(565^{\circ} \mathrm{C}\right.$ nominal $)$, caindo drasticamente a $560^{\circ} \mathrm{C}$ e, num outro extremo, a $570^{\circ} \mathrm{C}$, ambos nominais. Nas temperaturas utilizadas onde não houve fragmentação total da liga $\gamma$-U7Mo, não foi produzido nenhum pó até $504,26^{\circ} \mathrm{C}\left(500^{\circ} \mathrm{C}\right.$ nominal $)$.

Este fato foi importante na definição das condições de tratamento térmico de hidretação, evidenciando que a decomposição intergranular é um mais eficiente mecanismo para a promoção de fragilização das amostras que o de criação de fontes de tensão intragranulares, dominante nas adições superiores ou iguais a $8 \%$ em peso. $\mathrm{O}$ decréscimo progressivo na quantidade de fase alfa é o principal responsável por este fenômeno. 
Outra importante diferença está na região de resfriamento das curvas de variação de massa. Neste exemplo e em todos os casos estudados, os pontos de mudança ou inversão nos mecanismos de absorção de massa se dão usualmente abaixo de $151^{\circ} \mathrm{C}$. Comparando com os anteriores, é necessário maior tempo para a quebra das ligas, que em teores de adição menores, ocorre prontamente às temperaturas de $250^{\circ} \mathrm{C}$ ou superiores.
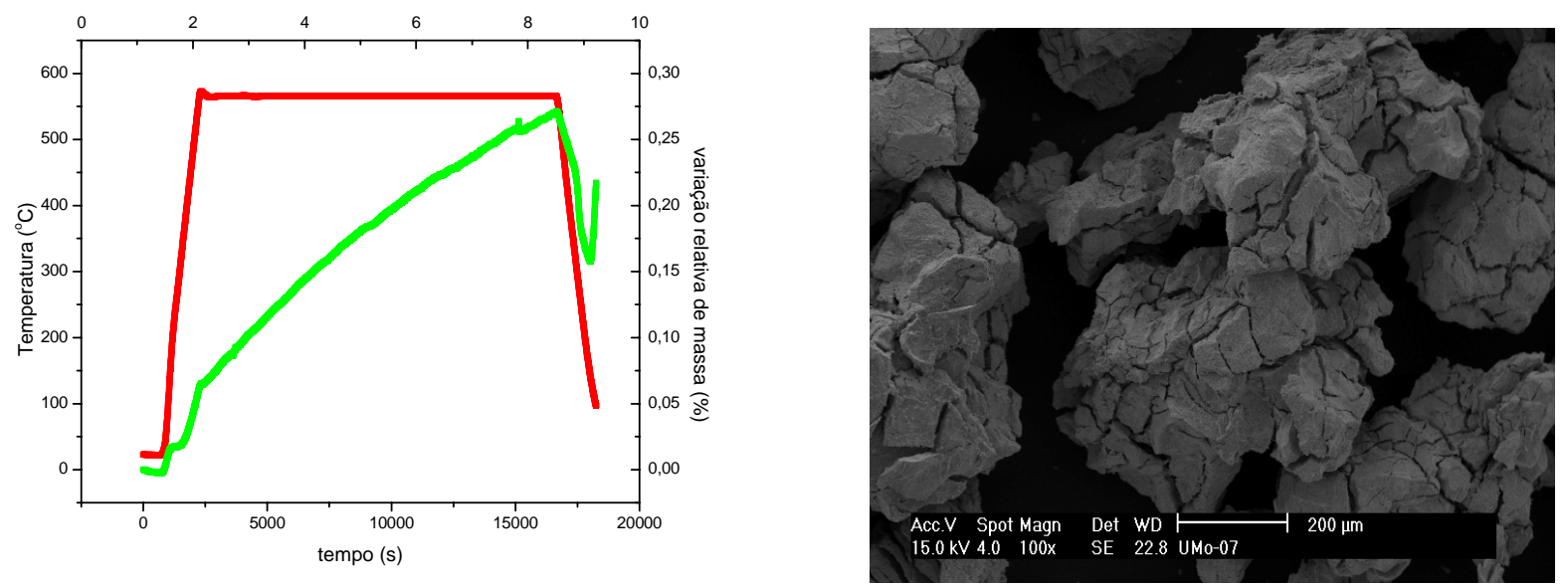

FIGURA 166 - Curvas típicas de variação de massa (esquerda) e respectiva estrutura do pó (direita), liga $\gamma$-U8Mo.

\subsubsection{Ligas $\gamma$-U9Mo e $\gamma$-U10Mo}

Para os tempos utilizados, não foi possível fragmentação total em nenhuma das temperaturas. Formação dos pós é dada por um mecanismo superficial, não volumétrico, como o que ocorre nas outras composições. As formas das partículas são muito diferentes das anteriores, Figura 167(direita), e o que se sugere aqui é que 9\% seja uma fronteira bem definida, na qual a contribuição da fragilização intergranular caia abruptamente. Isto se deve ao fato de que a estabilização das ligas atinge um máximo em termos de decomposição $\gamma \rightarrow \alpha$ nesta porcentagem.

Assim, as partículas, que em adições menores apresentam aparência de flocos, com 9 e 10\% de adição apresentam-se mais facetadas. Também é importante observar que, embora com menores rendimentos, pós nestas adições apresentam brilho mais metálico, indicando que a ação do hidrogênio não se dá por reação com alfa urânio. O hidreto normalmente é escuro, e mesmo após dehidretação, pode tornar a partícula sensível à reação com oxigênio, o que a torna mais escura. 

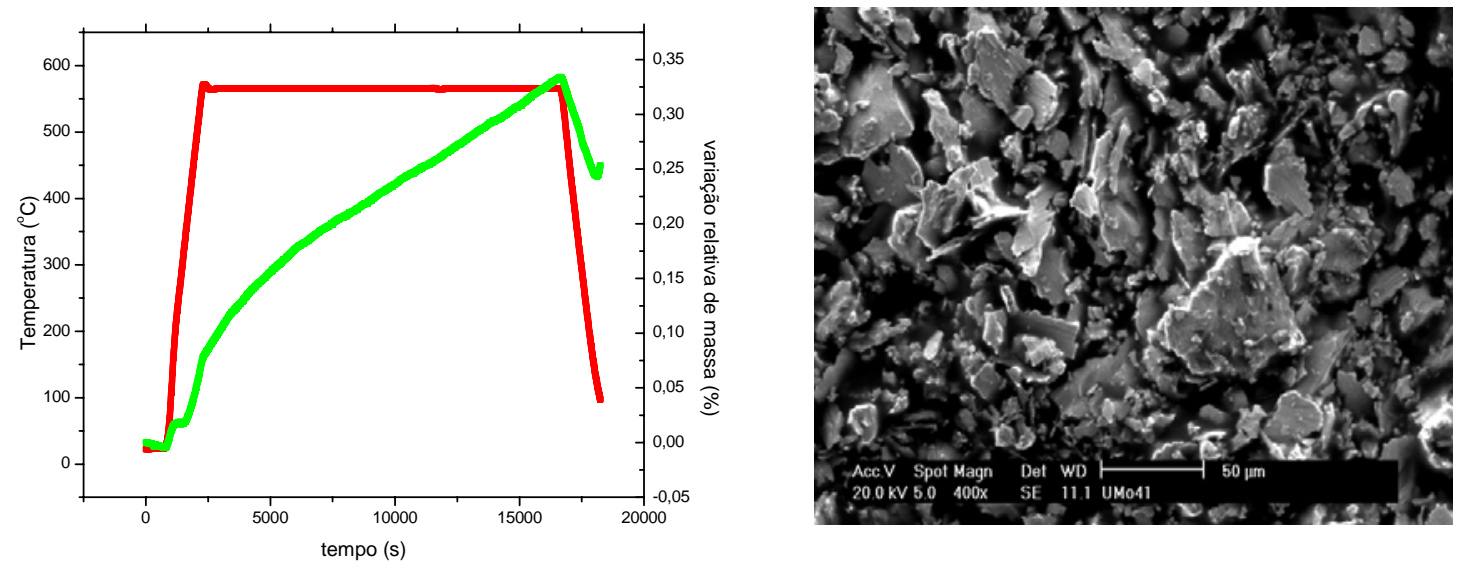

FIGURA 167 - Curvas típicas de variação de massa (esquerda) e respectiva estrutura do pó (direita), liga $\gamma$-U9Mo.

\subsection{Processo sugerido para a obtenção de pós via hidretação-dehidretação}

Com base no exposto até aqui, sugere-se então um processo para a obtenção de partículas. Assim, para a obtenção de pós de ligas metálicas $\gamma U$ Mo ou de ligas com características semelhantes às do sistema UMo, como urânio-zircônio, urânio-nióbio, ferrocarbono, etc., que apresentem decomposições eutetóides, os pós são obtidos por meio inicialmente de exposição da amostra a tratamentos térmicos de decomposição da liga sob atmosfera de hidrogênio. Durante o seu resfriamento, a uma dada temperatura, foi demonstrado que há grande quantidade de pó formado, pela brusca elevação da taxa de absorção de hidrogênio. O pó assim formado é tratado termicamente sob vácuo para eliminação de hidrogênio na forma de hidreto, nos tratamentos de dehidretação, e posteriormente homogeneiza-se a fase original da liga por meio de tratamento térmico para homogeneização da composição das partículas do pó.

Assim, deve-se expor a liga a uma série de tratamentos térmicos, concomitantes à ação de uma atmosfera de hidrogênio. Isto favorece inicialmente a absorção de hidrogênio pela fase proeutetóide, à medida que se forma. Posteriormente, por meio de novo tratamento térmico para a liberação do hidrogênio solubilizado e resfriamento rápido ou choque térmico, fragiliza-se a liga de tal maneira que a estrutura colapsa, havendo a formação de partículas, com dimensões da ordem de grandeza das dimensões dos grãos da liga original.

Conforme mencionado na introdução, tradicionalmente, três são os tipos de processos para a fabricação de pós de ligas metálicas dúcteis. Os mecânicos, que incluem a 
moagem (criogênica ou não) e a mecanização, a atomização e hidretação-dehidretação, cada um produzindo partículas com características diferentes. Cada um dos processos produz pós com diferentes características, avaliadas por meio de parâmetros como, por exemplo, valor médio e distribuição do tamanho de partícula, forma, resistência mecânica, fluidez. A primeira delas refere-se à capacidade do pó em ser prensado para a obtenção de altas densidades. A forma afeta a resistência do material verde e o grau de segregação, e a ductilidade indica a facilidade ou não em se conformar o pó.

Os processos de mecanização são os mais simples dos métodos e os mais utilizados devido aos baixos custos operacionais envolvidos e à fácil disponibilidade de equipamentos. Estão em desuso na área nuclear porque a grande taxa de deformação introduzida no pó resultante o torna pouco resistente, sua conformação mecânica por prensagem e outras técnicas torna-se complicada, dada a pequena escoabilidade e grande heterogeneidade quanto à forma. Em aplicações nucleares, por exemplo, pelo fato da partícula sofrer muitas deformações durante o processo, a densidade de discordâncias é alta, aumentando o número de regiões em potencial para a nucleação e crescimento de bolhas de gás durante a irradiação.

A linha estabelecida para obtenção de pós a partir de ligas $\gamma-\mathrm{U} \leq 7 \mathrm{Mo}$, via hidrogênio, e que tradicionalmente é utilizada para a fabricação de pós de ligas que sofrem decomposição eutetóide com produção de fase com alta afinidade pelo hidrogênio, compreende o seguinte grupo de operações, a partir da etapa inicial de fabricação das ligas: fusão a arco da carga de molibdênio mais $\alpha U$, tratamento térmico de homogeneização, hidretação, seguida de moagem, dehidretação, novo tratamento térmico para recuperação de parte da estrutura da matriz. Entretanto, como esta é uma linha desenvolvida para adições de até $7 \%$ de Mo, e como os melhores resultados em termos de estabilidade da estrutura $\gamma \mathrm{UMo}$ foram obtidos com a ligas contendo porcentagens maiores do que $9 \% \mathrm{e}$ menores do que a referente à decomposição eutetóide, sugere-se aqui, por meio deste invento, um processo para a obtenção de pós de ligas metálicas hipoeutetóides em geral.

$\mathrm{O}$ teor de soluto relaciona-se à quantidade de fase proeutetóide inicialmente presente, usualmente a fase alfa nos diagramas de fases binários aqui referidos. Como esta reage facilmente com hidrogênio, é de se prever que um menor teor de soluto, que leva a uma menor quantidade de fase gama estável e precipitação de alfa em contornos de grão ou intragranularmente, produza uma absorção de massa / redução na pressão acentuadas no sistema. Os tratamentos térmicos de conversão gama-alfa mostram que é possível se 
produzir fase alfa em boa quantidade, preparando a amostra para ser hidretada. Entretanto, deve-se levar em conta que a transformação gama-alfa leva a perda de material, posto que não se reverte a fase alfa em gama novamente, dado que agora pertencem a regiões desconexas no espaço e, portanto, a difusão de molibdênio entre ambas é impossível.

É de se notar, entretanto, que a maioria dos casos de produção de pós, especialmente os das ligas de urânio, existentes em literatura, referem-se a ligas com porcentagens de adição de soluto muito abaixo daquela em que ocorre a decomposição eutetóide, com a formação de grande quantidade de fase proeutetóide. Para certas aplicações, no entanto, é importante obter-se materiais com composição próxima a eutetóide, muitas vezes por se desejar maior dureza, resistência mecânica, resistência química, por exemplo.

Sendo assim, o que se oferece nesta tese é uma solução simples para este problema, um método alternativo para a melhoria dos processos de hidrogenação de ligas metálicas com alta ductilidade ou com características similares às do binário $\gamma \mathrm{UMo}$, conforme menção anterior. Toma-se por base o fato de que, sob determinadas condições de processamento, ligas previamente submetidas a tratamentos isotérmicos sob atmosfera de hidrogênio próximas à temperatura de decomposição eutetóide apresentam, em alguma temperatura durante a etapa de resfriamento prévio à etapa de hidretação, um ganho de massa uma ordem de grandeza maior que a obtida durante o período isotérmico.

Isto indica, conforme mencionado nos itens anteriores, que ao período de liberação do hidrogênio pela liga, ainda no estado sólido, trecho decrescente da curva de ganho de massa em função do tempo, segue-se o colapso do material, já previamente fragilizado pelo hidrogênio, havendo a formação de fragmentos ou pó.

Etapa adicional, verificada ser benéfica em porcentagens de adição de 6 e 7\%, e já mencionada no item 13.2, é o da sensibilização das ligas por tratamento térmico em temperaturas da ordem de 100 a $200^{\circ} \mathrm{C}$. A ação conjunta dos tratamentos de sensibilização e hidretação-dehidretação pode levar a melhores rendimentos, conforme será verificado no item seguinte. Utilizando-se a unidade semi-piloto existente no Laboratório de Materiais Magnéticos do IPEN, partiu-se para a validação dos resultados de hidretação em TG/DTA de aproximadamente $70 \mathrm{~g}$ de uma liga a $7 \%$ de Mo. 
(a)

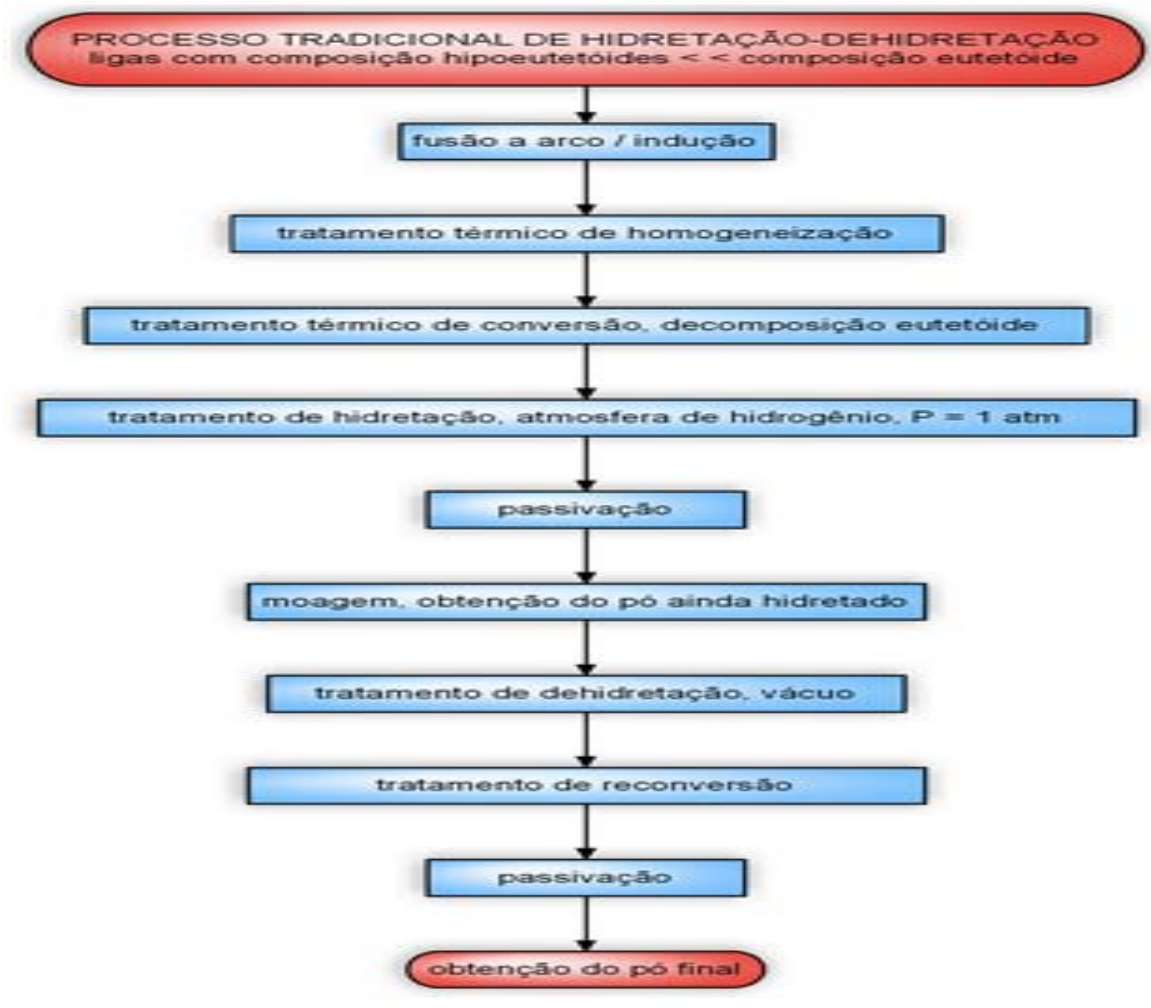

(b)

PROCESSO OFERECIDO DE HIDROGENACĀOA-CHOQUE TERMICO-DEHIDRETACĀO ligas de composiçăo hipoeutetóides até composiçăo eutetóide

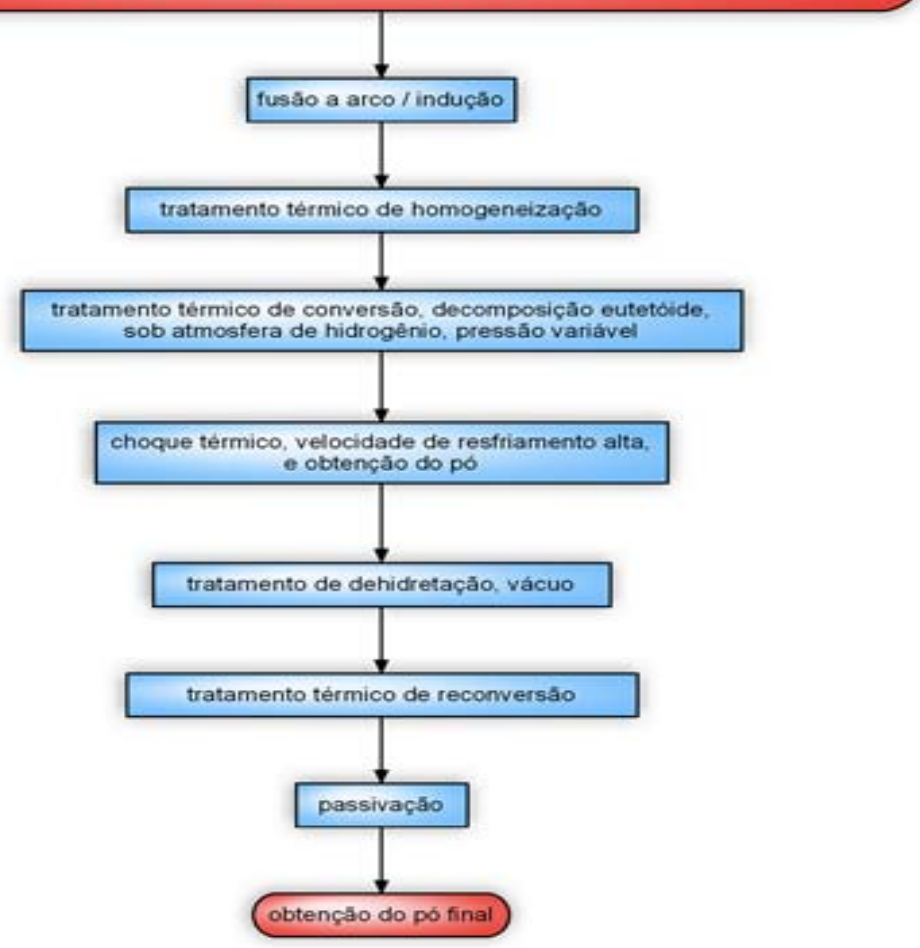

FIGURA 168 - Processos comparados, (a) tradicional, (b) o oferecido por esta tese. 
Com a constante passagem do fluxo de hidrogênio sobre o material e com maior área disponível para absorção, tanto em posições intersticiais quanto na fase proeutetóide, hidrogênio é capturado pela liga, o que leva a um aumento na taxa de absorção de massa pela liga. Subseqüentes colapsos e novos incrementos foram também observados, indicando que a fragmentação ocorre em estágios, encerrando-se quando a curva de ganho de massa em função do tempo permanece num valor constante.

Indo mais além, oferece-se aqui a possibilidade de se tratar simultaneamente a liga no sentido da conversão $\gamma \rightarrow \alpha$, e da hidretação. O processo sugerido pela tese está apresentado na Figura 168 b, onde ele é comparado ao convencional ou tradicional.

\subsection{Validação}

Neste item será apresentado o resultado de hidretação de uma liga $\gamma \mathrm{U} 7 \mathrm{Mo}$, em quantidade 5 ordens de grandeza maior que a utilizada nos experimentos do analisador térmico, em unidade semi-piloto. O procedimento operacional adotado, dadas as características do equipamento, foi um pouco diferente quando comparado aos experimentos realizados no analisador térmico.

Aqui, o material a ser hidretado foi colocado sobre uma "barquinha" de alumina, inserido no interior de uma retorta horizontal, e este conjunto introduzido no interior de um forno tubular. Entretanto, não foi utilizado um fluxo de gás hidrogênio sobre a amostra. Portanto, a preocupação em se remover toda a umidade ou ar do sistema foi maior, apesar de se saber que, pelo fato do gás hidrogênio ser redutor, em operações a fluxo contínuo ele remove estes elementos do sistema.

Após a realização de um ciclo de 3 purgas, inseriu-se hidrogênio até à pressão desejada, anotando-se os valores de sua redução ao passo de sua absorção pela amostra, ao longo do tempo. Sabendo-se o volume da retorta, pode-se converter a redução na pressão em massa absorvida pela liga, a partir do valor de pressão máximo atingido quando da fase de manutenção da liga nos patamares de temperatura.

Um ciclo típico de operação é dado na Figura 169, onde os valores de pressão são mostrados. Mais adiante, a respectiva imagem típica de microscópio eletrônico de varredura do pó resultante, é apresentada na Figura 173. As imagens apresentadas, obviamente, são a dos pós após o processo, portanto, um ajuste da granulometria ainda é necessário. Além destes testes, atestou-se a qualidade dos pós formados por inspeção visual. A coloração acinzentada é típica de materiais produzidos via hidretaçãodehidretação. 
Os primeiros gráficos mostram os resultados de hidretação-dehidretação, na fase de preparo da liga. Reduções na pressão são pequenas, conforme visto na figura 169, indicando que a hidretação da liga, cujo gráfico é mostrado na figura 168, não foi suficiente, pela pouca quantidade de hidrogênio no sistema. Entretanto, esta exposição da amostra é importante, no preparo de sua superfície para as exposições seguintes.

Nesta fase do processo, os pós apresentaram coloração escura, indicando que a penetração do gás na liga, foi prejudicada pela presença de camada de óxido superficial, mesmo após polimento, presente em alguma quantidade.

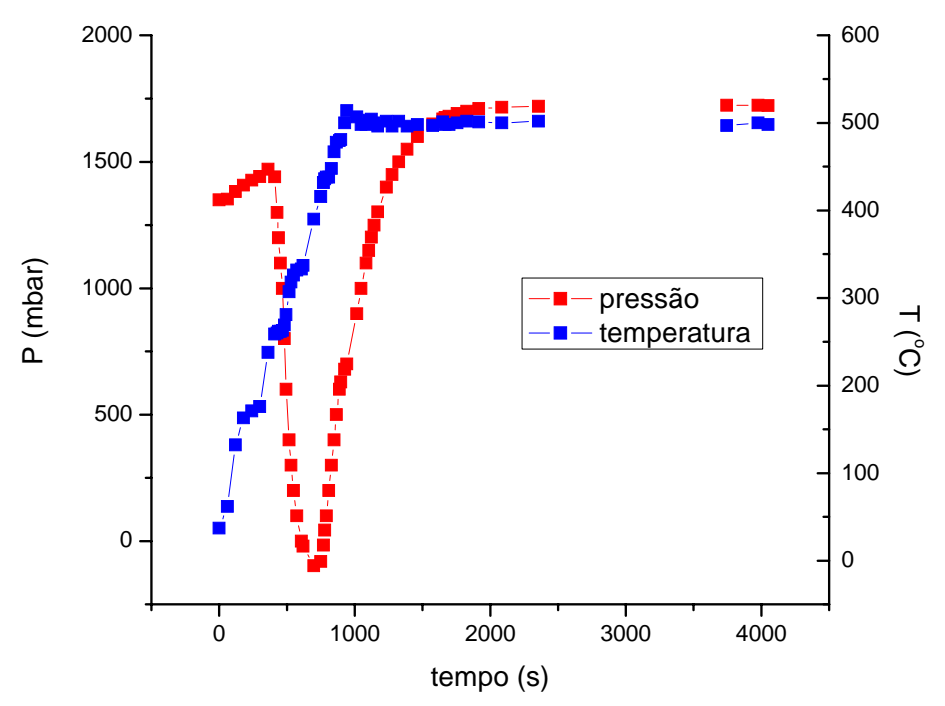

FIGURA 169 - Hidretação liga $\gamma U 7 \mathrm{Mo}$, pré-tratamento.

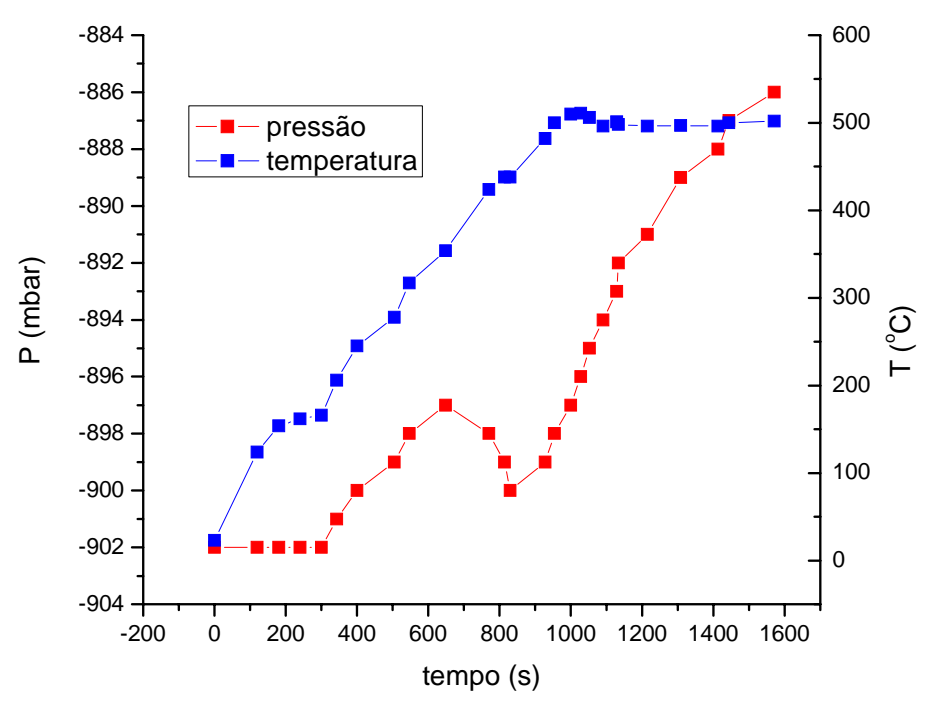

FIGURA 170 - Dehidretação liga $\gamma \mathrm{U} 7 \mathrm{Mo}$, pré-tratamento. 
Após a exposição da amostra a novos ciclos, os resultados foram bem melhores, a liga passou a absorver o hidrogênio espontaneamente, conforme mostrado nas Figuras 171 e 172. Permitiu-se assim a inserção de hidrogênio em quantidades equivalentes à pressão de 4000 mbar, com velocidades de absorção e dehidretação muito mais elevadas.

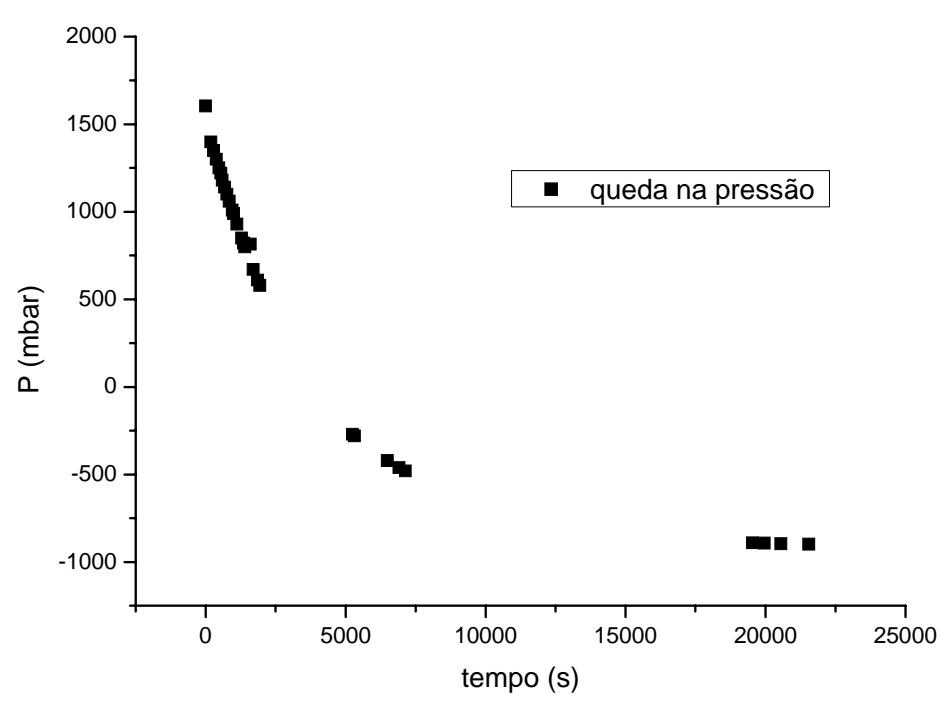

FIGURA 171 - Absorção de hidrogênio, liga $\gamma U 7 \mathrm{Mo}$.

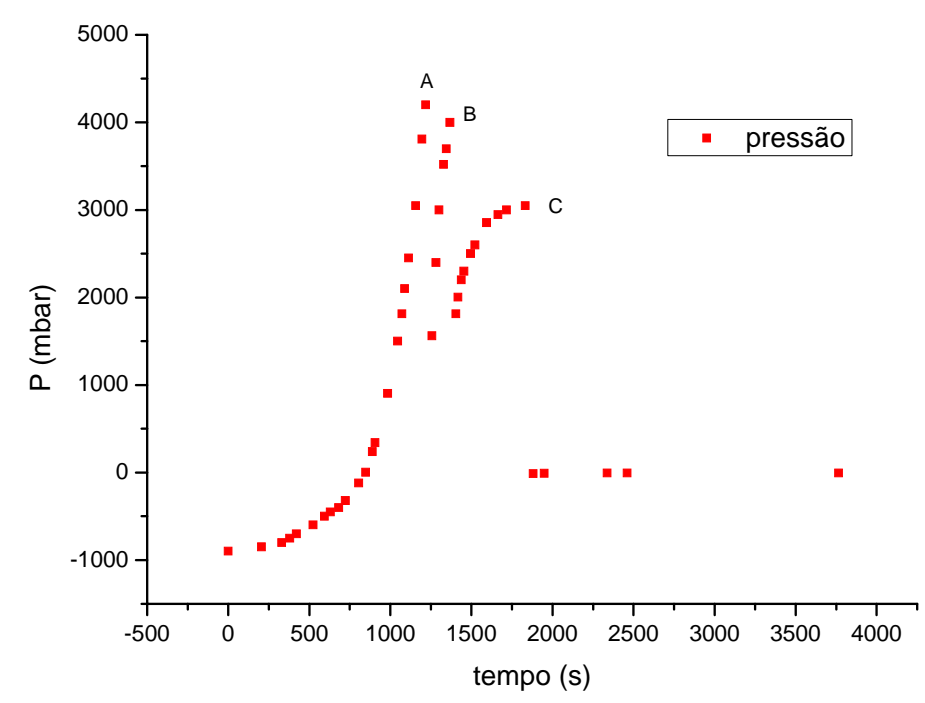

FIGURA 172 - Dessorção de hidrogênio, liga $\gamma \mathrm{U} 7 \mathrm{Mo.}$

Neste experimento, a introdução de 1604 mbar de hidrogênio em um sistema pré-evacuado a -902 mbar produziu absorção instantânea, indicando superfície da liga bem 
preparada. Ao final do experimento após aproximadamente 6 horas, todo o gás inserido foi absorvido, a pressão no sistema voltou ao valor de -902 mbar. Esta liga já havia passado por uma etapa de hidretação anterior. A curva de aumento de pressão no sistema devida à sua desidrogenação foi mostrada na figura anterior, onde observamos a grande capacidade de retenção do hidrogênio apresentada pelo material.

Nos pontos A, B e C a pressão do sistema foi reduzida, pois superou a capacidade de registro do indicador, e também por motivos de segurança.

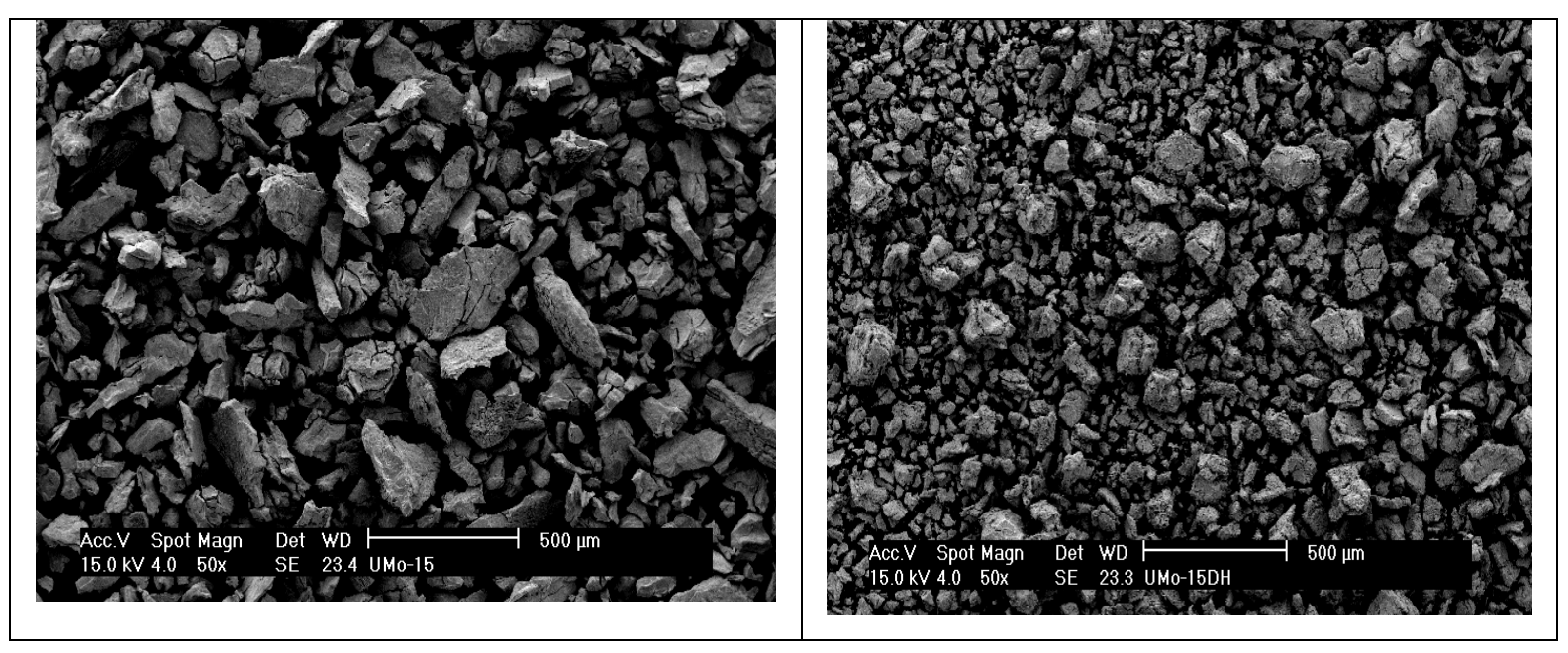

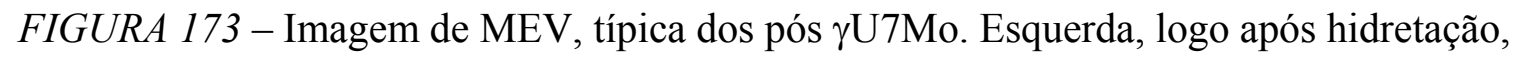
direita, após dehidretação.

\subsection{Modelagem matemática}

Neste item serão apresentadas as equações utilizadas para a elaboração do modelo, servindo para posterior reprodução dos resultados experimentais. Todo este desenvolvimento tomou por base o exposto no capítulo 9, a equação final para o tempo de nucleação apresentada no capítulo 7, dados importantes de propriedades térmicas, constantes no capítulo 8 e no livro de Beghi ${ }^{10}$, e em algumas equações mais fundamentais, relacionadas principalmente ao crescimento de defeitos, apresentadas no capítulo 3, mas que, por ora, não serão acrescentadas no modelo. Serão listadas as equações utilizadas no modelo simplificado, face ao apresentado no capítulo 9, e portanto na simulação, cujos parâmetros de interesse serão apresentados nas tabelas. O objetivo deste item é apresentar somente o modelo, que servirá de orientação para a realização de simulações.

A primeira das equações será utilizada para a previsão do tempo para a formação de núcleos de fase alfa em função da temperatura, para uma dada porcentagem de Mo. Para cada porcentagem de adição, ter-se-á um valor de energia para a 
decomposição da fase gama em alfa, que será tanto menor quanto menor for a \% Mo, pois menos estável será a liga, mais fácil se decompõe em alfa. As equações sugeridas são a (45):

$$
I=\frac{N}{V} A \exp \left[-\left(\frac{U i+U^{*} m}{R T}\right)\right]
$$

e a (53):

$$
\frac{d \ln t i}{d(1 / T)}=-\frac{U i}{R}
$$

A partir da primeira equação, pode-se obter a quantidade de hidrogênio absorvida por reação com a fase alfa, precipitada nos contornos de grão, e que leva à formação do hidreto, responsável pela fragilização e ruptura das ligas. Identificando o tempo com a taxa de nucleação, pode-se determinar alternativamente a quantidade de hidrogênio absorvida por reação, a partir da segunda.

Precisa-se também saber os dados de difusão do hidrogênio pela peça de gamaU, e daí obter um perfil de concentrações do mesmo em seu interior. As equações a serem utilizadas são:

$$
\frac{c(x, t)-c o}{c s-c o}=1-\frac{4}{\pi} \sum_{n=0}^{\infty} \frac{(-1)^{n}}{(2 n+1)} \exp \left[-(2 n+1)^{2} \frac{\pi^{2}}{4} \frac{D t}{h^{2}}\right] \cos \left[\frac{(2 n+1)}{2}\left(\pi \frac{x}{h}\right)\right]
$$

e para a concentração média $\mathrm{cm}$ na placa, temos:

$$
\frac{c m(t)-c o}{c s-c o}=1-\frac{8}{\pi^{2}} \sum_{n=0}^{\infty} \frac{(1)}{(2 n+1)^{2}} \exp \left[-(2 n+1)^{2} \frac{\pi^{2}}{4} \frac{D t}{h^{2}}\right]
$$

nas quais $D$ é o coeficiente de difusão do hidrogênio pelo urânio gama e pela fase alfa, dados também no capítulo 8. Estas duas equações fornecem o perfil de concentrações do gás hidrogênio em diversas seções transversais da liga, posicionadas segundo as coordenadas $\mathrm{x}$.

Para as condições de problema deste estudo, $c o=0$, pois não há hidrogênio presente no material ao início do experimento. A concentração de hidrogênio na superfície, $c s$, pode ser estimada partindo-se das seguintes hipóteses. Como se está trabalhando com 
fluxo constante de gás, a superfície externa da liga, de coordenadas $(-\mathrm{x}, 0)$ e $(\mathrm{x}, 0), \mathrm{x}$ representando a sua meia espessura, é suprida continuamente com quantidade uniforme de hidrogênio. Assim, pode-se supor que a velocidade com a qual hidrogênio é adsorvido na superfície do metal não interfere nos resultados.

Sabendo que a $c s$ é diretamente proporcional à área da superfície externa da liga, e que sobre esta área uma determinada fração pode estar disponível para adsorção, com base na equação:

$$
\chi \mathrm{Hs}=\mathrm{N}_{\mathrm{Hs}} /\left(\mathrm{N}_{\mathrm{Hs}}+\mathrm{N}_{\mathrm{Ms}}\right)
$$

na qual, desta vez, se está referindo somente aos átomos da superfície. Pode-se supor, para uma dada quantidade de átomos de metal, supondo uma camada superficial monocristalina de fase gama, portanto com estrutura cúbica de corpo centrado, que o número de posições intersticiais tetraédricas por ela compreendida é igual a 6 (considerando somente os centros das faces), e nos interstícios tetraédricos igual a 3, por átomo de metal. Considerando difusão de hidrogênio por estas 9 posições, pode-se dizer então que $c s$ é igual a 9 vezes a quantidade de átomos na superfície do metal. Supondo metal homogeneamente denso, temos então que:

$$
c s=9 \cdot \rho_{x} \cdot a
$$

onde $\rho_{x}$ é a densidade da liga $\gamma \mathrm{U}_{\mathrm{x}} \mathrm{Mo}$, e $a$ é a espessura da camada superficial monocristalina, igual ao parâmetro de rede da liga $\gamma \mathrm{U}_{\mathrm{x}}$ Mo. Aqui, $c s$ é dada em unidades de massa por unidade de área, e 9 pode ser identificado com $Z$, da equação (64), pois temos $Z$ posições intersticiais disponíveis por átomo, na estrutura cúbica. Aqui, está-se considerando para estimativa de $c s$ que todos os interstícios estejam ocupados, ou seja, que $\theta=1$, na equação (64).

Pelos espectros de difração de raios-X, $a$ pode ser encontrado, em função da quantidade de Mo presente na liga, na Tabela 27. Para as ligas estudadas, considerando apenas os picos de difração mais intensos das ligas sem tratamento térmico e produzidas via indução, obtém-se os seguintes valores para $a$. Observa-se ainda que os valores são diferentes do parâmetro de rede de uma estrutura gama-U pura, pois aqui tem-se adições de Mo. Em Rough e Bauer ${ }^{4}$ o valor do parâmetro fornecido é 3,524A. 
Os valores de $c s$ foram estimados por meio da equação (95), com o auxílio dos valores de densidade das ligas de indução, e os $a$ pela lei de Bragg:

$$
\mathrm{n} \lambda=2 \mathrm{~d}_{\mathrm{hkl}} \operatorname{sen}(\theta)
$$

na qual $\mathrm{n}=1, \lambda=1,54 \mathrm{~A}$. Aqui está-se levando em conta o cálculo através do plano com menor índice de Miller de uma estrutura cúbica de corpo centrado, índices $(1,1,0)$.

TABELA 27 - Parâmetros de rede médios das ligas $\gamma \mathrm{U}_{\mathrm{x}}$ Mo e estimativas de $c s$.

\begin{tabular}{c|c|c|c|c}
\hline$\gamma \mathrm{UxMo}, x$ & $\theta\left(^{\circ}\right)$ & $a(\mathrm{~A})$ & $\rho\left(\mathrm{g} / \mathrm{cm}^{3}\right)$ & $c s\left(\mu \mathrm{g} / \mathrm{cm}^{2}\right)$ \\
\hline \hline 5 & 18,07 & 3,5107 & 17,46 & 5,5167 \\
\hline 6 & 18,39 & 3,4517 & 17,10 & 5,3121 \\
\hline 7 & 18,25 & 3,4772 & 17,00 & 5,3202 \\
\hline 8 & 18,22 & 3,4828 & 16,80 & 5,2659 \\
\hline 9 & 18,26 & 3,4754 & 16,74 & 5,2360 \\
\hline 10 & 18,59 & 3,4158 & 16,71 & 5,1370 \\
\hline
\end{tabular}

Basta então saber-se a área de superfície da amostra exposta ao hidrogênio, para se obter o valor de $c s$.

Passe-se agora à estimativa de parâmetros termomecânicos das ligas $\gamma \mathrm{U}_{\mathrm{x}} \mathrm{Mo}$. Deve-se estudar as propriedades das fases alfa, gama e do hidreto de urânio. Como já se tem de antemão as densidades de alfa e das ligas $\gamma \mathrm{U}_{\mathrm{x}} \mathrm{Mo}$, procure-se a densidade da fase hidreto. O objetivo é a determinação das variações de volume que possam ocorrer durante a reação de decomposição $\gamma \rightarrow \alpha$, e também durante a reação de formação do hidreto. De antemão, por exemplo, utilizar-se-á, para o coeficiente de expansão linear do hidreto de urânio, o valor de $1,631 \times 10^{-5} /{ }^{\circ} \mathrm{C}^{66}$.

Do trabalho de Waldron et al. ${ }^{67}$ pode-se obter uma correlação entre dados de dureza e as propriedades mecânicas das ligas $\gamma \mathrm{U}_{\mathrm{x}}$ Mo. Como os únicos resultados de propriedades mecânicas que foram obtidos a partir de dados de dureza, e como tratar-se-á de propriedades como tensão de ruptura e elongação, optou-se por obter uma correlação entre estas propriedades, com base nos resultados destes autores, e aplicá-las aos materiais.

Os resultados das correlações estão apresentados na Tabela 28, para ajuste por polinômio de segundo grau, para as temperaturas estudadas por Waldron et al. ${ }^{67}$. Não se 
teve condições de obter valores de dureza e propriedades mecânicas a quente, portanto os resultados utilizados nesta tese tomarão por base os destes autores.

TABELA 28 - Coeficientes da equação de correlação de segundo grau $\mathrm{Y}=\mathrm{A}+\mathrm{B} . \mathrm{HV}+\mathrm{C}$. $\mathrm{HV}^{2}$, tensão de ruptura $\mathrm{Y}$ e dureza $\mathrm{HV}$, segundo Waldron et al. ${ }^{67}$.

\begin{tabular}{c|c|c|c}
\hline $\mathrm{T}\left({ }^{\circ} \mathrm{C}\right)$ & $\mathrm{A}$ & $\mathrm{B}$ & $\mathrm{C}$ \\
\hline \hline 20 & 688,92 & $-3,84$ & $5,95 \times 10^{-3}$ \\
\hline 200 & 314,13 & $-1,56$ & $2,39 \times 10^{-3}$ \\
\hline 400 & $-432,27$ & 3,93 & $-7,68 \times 10^{-3}$ \\
\hline 800 & $-278,18$ & 1,86 & $-3,03 \times 10^{-3}$ \\
\hline \hline $\mathrm{E}_{20}$ & 22,61 & $-9,15 \times 10^{-1}$ & $8,49 \times 10^{-3}$ \\
\hline
\end{tabular}

Para correlação entre a elongação porcentual na ruptura e a tensão de ruptura, utilizou-se como valores os obtidos à temperatura ambiente, $\mathrm{E}_{20}$, dados na última linha da Tabela 28 , na qual os coeficientes correspondem ao mesmo ajuste polinomial, embora com relação à tensão de ruptura. Visto que os dados, para as demais temperaturas, não apresentam boa correlação tanto linear quanto polinomial, adotou-se este para a determinação dos valores de elongação das ligas nas demais temperaturas.

Assim, pode-se estimar, para as ligas $\gamma \mathrm{U}_{\mathrm{x}} \mathrm{Mo}$, os valores da tensão de ruptura e da elongação porcentual na ruptura, conforme Tabela 29, para as ligas de indução.

TABELA 29 - Tensões de ruptura e elongação na ruptura, ligas de indução, brutas de fusão.

\begin{tabular}{c|c|c|c|c|c|c}
\hline $\begin{array}{c}\text { Liga } \\
\gamma \mathrm{U}_{\mathrm{x}} \text { Mo }\end{array}$ & $\begin{array}{c}\mu \text { Dureza } \\
\text { Vickers }\end{array}$ & $\begin{array}{c}\mathrm{Y}_{20} \\
\left(\mathrm{kgf} / \mathrm{mm}^{2}\right)\end{array}$ & $\mathrm{E}_{20}(\%)$ & $\begin{array}{c}\mathrm{Y}_{200} \\
\left(\mathrm{kgf} / \mathrm{mm}^{2}\right)\end{array}$ & $\begin{array}{c}\mathrm{Y}_{400} \\
\left(\mathrm{kgf} / \mathrm{mm}^{2}\right)\end{array}$ & $\begin{array}{c}\mathrm{Y}_{800} \\
\left(\mathrm{kgf} / \mathrm{mm}^{2}\right)\end{array}$ \\
\hline$\gamma \mathrm{U} 5 \mathrm{Mo}$ & 238 & 110,89 & 25,55 & 78,23 & 68,04 & - \\
\hline$\gamma \mathrm{U} 6 \mathrm{Mo}$ & 225 & 125,13 & 41,04 & 84,12 & 63,18 & - \\
\hline$\gamma \mathrm{U} 7 \mathrm{Mo}$ & 243 & 105,96 & 20,98 & 76,18 & 69,22 & - \\
\hline$\gamma \mathrm{U} 8 \mathrm{M} 0$ & 239 & 109,89 & 24,58 & 77,81 & 68,31 & - \\
\hline$\gamma \mathrm{U} 9 \mathrm{Mo}$ & 282 & 77,62 & 2,74 & 64,27 & 65,25 & 5,38 \\
\hline$\gamma \mathrm{U} 10 \mathrm{Mo}$ & 291 & 73,64 & 1,27 & 62,56 & 61,01 & 6,49 \\
\hline$\gamma \mathrm{UMo12}$ & 272 & 83,17 & 5,24 & 66,63 & 68,49 & 3,57 \\
\hline$\gamma \mathrm{UMo11}$ & 291 & 73,64 & 1,27 & 62,56 & 61,01 & 6,49 \\
\hline
\end{tabular}


Aqui, os índices das tensões Y referem-se às temperaturas, em graus Celsius. Valores não indicados de tensão e elongação estão fora dos limites dos dados da correlação, portanto são imprecisos.

TABELA 30 - Tensões de ruptura e elongação na ruptura, ligas de indução, tratadas termicamente: $1038^{\circ} \mathrm{C}, 24$ horas (binários). Liga C conforme cap. 10.

\begin{tabular}{c|c|c|c|c|c|c}
\hline $\begin{array}{c}\text { Liga } \\
\gamma \mathrm{U}_{\mathrm{x}} \mathrm{Mo}\end{array}$ & $\begin{array}{c}\mu \text { Dureza } \\
\text { Vickers }\end{array}$ & $\begin{array}{c}\mathrm{Y}_{20} \\
\left(\mathrm{kgf} / \mathrm{mm}^{2}\right)\end{array}$ & $\mathrm{E}_{20}(\%)$ & $\begin{array}{c}\mathrm{Y}_{200} \\
\left(\mathrm{kgf} / \mathrm{mm}^{2}\right)\end{array}$ & $\begin{array}{c}\mathrm{Y}_{400} \\
\left(\mathrm{kgf} / \mathrm{mm}^{2}\right)\end{array}$ & $\begin{array}{c}\mathrm{Y}_{800} \\
\left(\mathrm{kgf} / \mathrm{mm}^{2}\right)\end{array}$ \\
\hline$\gamma \mathrm{U} 5 \mathrm{Mo}$ & 248 & 101,32 & 17,06 & 74,24 & 70,02 & 17,06 \\
\hline$\gamma \mathrm{U} 6 \mathrm{Mo}$ & 264 & 88,46 & 8,10 & 68,86 & 69,99 & 8,10 \\
\hline$\gamma \mathrm{U} 7 \mathrm{Mo}$ & 259 & 92,15 & 10,39 & 70,41 & 70,42 & 10,39 \\
\hline$\gamma \mathrm{U} 8 \mathrm{Mo}$ & 229 & 120,54 & 35,67 & 82,22 & 64,95 & 35,67 \\
\hline$\gamma \mathrm{U} 9 \mathrm{Mo}$ & 247 & 102,22 & 17,79 & 74,62 & 69,89 & 17,79 \\
\hline$\gamma \mathrm{U} 10 \mathrm{Mo}$ & 293 & 72,88 & 1,02 & 62,23 & 59,90 & 1,02 \\
\hline$\gamma \mathrm{UMo11C}$ & 386 & 90,23 & 9,17 & 68,07 & & 9,17 \\
\hline
\end{tabular}

Assim, pode-se estimar o tempo para o rompimento da liga, com base nos valores de elongação, sabendo-se os coeficientes de expansão térmica das ligas. Como se dispõe dos dados de dilatação para as ligas com 8, 9 e 10\% de adição, apresentados no trabalho de Saller et al. ${ }^{70}$, Konobeevski et al. ${ }^{11}$ e Repas et al. ${ }^{17}$, serão eles os considerados para as estimativas. Segundo Konobeevski et al. ${ }^{11}$, o coeficiente de expansão térmica de uma liga a $9 \%$ Mo pode ser dado pela equação, na faixa de 20 a $500^{\circ} \mathrm{C}$ :

$$
\alpha=11,6 \cdot 10^{-6}+0,28 \cdot 10^{-8} \mathrm{~T}
$$

e segundo Repas et al. ${ }^{17}$, tem-se, para a liga $\gamma \mathrm{U} 8 \mathrm{Mo}, 18,8.10^{-6} /{ }^{\circ} \mathrm{C}$ de 500 a $575^{\circ} \mathrm{C}$, e $20,7.10^{-6} /{ }^{\circ} \mathrm{C}$ na região de gama, e para a liga $\gamma \mathrm{U} 10 \mathrm{Mo}$, respectivamente, os valores médios são $18,7.10^{-6} /{ }^{\circ} \mathrm{C}$ e $22,0.10^{-6} /{ }^{\circ} \mathrm{C}$.

Em Saller et al. ${ }^{70}$ são dados os valores médios para a liga $\gamma \mathrm{U} 9 \mathrm{Mo}$, obtidos em várias faixas de temperatura, a partir da ambiente. Para uma liga tratada termicamente na região de gama, nas temperaturas entre 20 e $700^{\circ} \mathrm{C}$, nas quais a maioria das análises foi realizada, o valor médio para o coeficiente é de $16,07.10^{-6} /{ }^{\circ} \mathrm{C}$, quando do aquecimento das ligas, e de $15,04.10^{-6} /{ }^{\circ} \mathrm{C}$, quando de seu resfriamento. Esta diferença de $6,5 \%$ pode explicar 
o rompimento das ligas, quando do resfriamento, nos ensaios de hidrogenação.

Vejamos agora as variações de volume produzidas em um grão de fase gama, quando o mesmo se decompõe em fase alfa, com posterior reação de formação de hidreto. Para os valores de densidade média das ligas estudadas, e sabendo-se que a densidade da fase alfa é de $19,12 \mathrm{~g} / \mathrm{cm}^{3}$, e a da fase hidreto é $11,1 \mathrm{~g} / \mathrm{cm}^{3}$ conforme Rough e Bauer ${ }^{04}$. Assim, tomando como exemplo a decomposição de uma liga $\gamma \mathrm{U} 7 \mathrm{Mo}$, cuja densidade é de $17,0 \mathrm{~g} / \mathrm{cm}^{3}$, em alfa, levaria, para cada $\mathrm{cm}^{3}$ de matriz, a um volume de $0,8868 \mathrm{~cm}^{3}$, ou seja, uma diminuição de $11,32 \%$. Uma subseqüente reação de alfa com o hidreto leva agora a um aumento, para cada $\mathrm{cm}^{3}$ de fase alfa, a um aumento em volume de $1,727 \mathrm{~cm}^{3}$, ou seja, 72,7\%. Assim, em termos globais, cada $\mathrm{cm}^{3}$ de fase $\gamma \mathrm{U} 7 \mathrm{Mo}$ matriz ao se decompor de maneira celular aumenta em $61,38 \%$ o seu volume. Os cálculos são válidos para quaisquer unidades de volume, tomou-se esta apenas como exemplo.

É aqui que se faz importante a determinação das velocidades de decomposição da fase gama em alfa, e da reação de formação do hidreto de urânio. Por meio de seu conhecimento, define-se a velocidade limitante, dado que são reações em série na hidretação e, portanto, a quantidade de hidrogênio absorvida pela amostra em função do tempo. Da Figura 137, a máxima velocidade de absorção de hidrogênio no processo de hidretação da fase alfa é de $4,5 \times 10^{-3} \mathrm{mg} / \mathrm{s}$. Sabendo que a massa inicial de urânio alfa foi de $80,606 \mathrm{mg}$, então, por unidade de massa, teremos $\mathrm{v}_{\mathrm{H} \alpha}=55,83\left(\mu \mathrm{gH}_{2} / \mathrm{g}\right) / \mathrm{s}$. Esta deve ser a velocidade adotada para as simulações.

Obviamente que o fator limitante, dado que a velocidade acima foi suposta como constante, será a velocidade de decomposição da matriz. O uso das equações (45) e (53) permite a obtenção destas velocidades, em função da temperatura e da quantidade de Mo presente na liga. Sabe-se que ela assume o valor máximo no "nariz" da curva TTT. Os gráficos do artigo de Hofman et $\mathrm{al}^{14}$ que permitem a obtenção dos valores de energia para início da decomposição da fase gama em alfa em função da quantidade de Mo e em função da temperatura são apresentados na Figura 174. Estes valores de energia devem ser utilizados na equação (45), tomando-se o cuidado para escolhê-los conforme a região da curva TTT em que se realizou o tratamento. Assim, na Figura 175, observa-se que há uma mudança na inclinação, para as adições de 8 e 10\%, a partir de uma determinada temperatura. Esta temperatura é definida pelo "nariz" ou ponto de inflexão da curva TTT, e que, para cada porcentagem de adição, pode ser determinado com o auxílio também das curva da Figura 09 do capítulo 7. 
Assim, a evolução da quantidade de fase alfa produzida pode ser determinada e, portanto, o consumo de hidrogênio por hidretação. Variações de volume da matriz podem então ser determinadas, e por conseguinte o tempo para que a estrutura se rompa, durante aquecimento ou resfriamento, também.

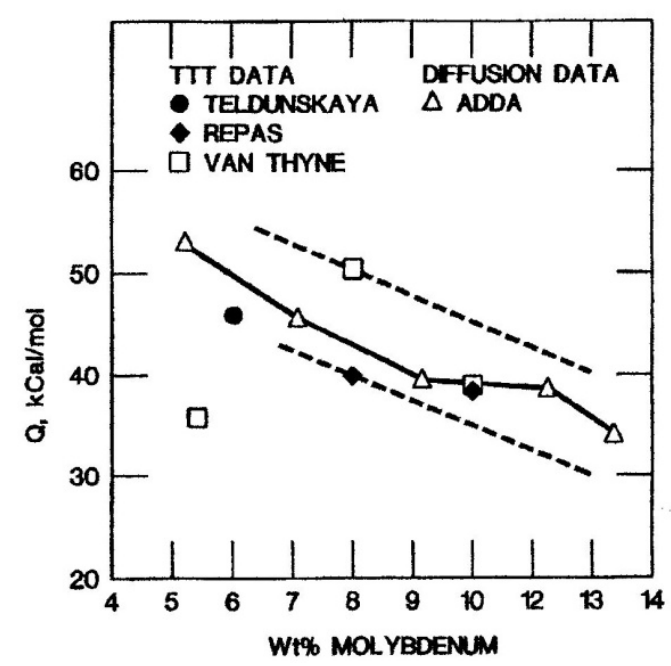

FIGURA 174 - Comparação das energias de ativação obtidas para o início da decomposição e interdifusão, ligas $\gamma \mathrm{UMo}^{14}$.

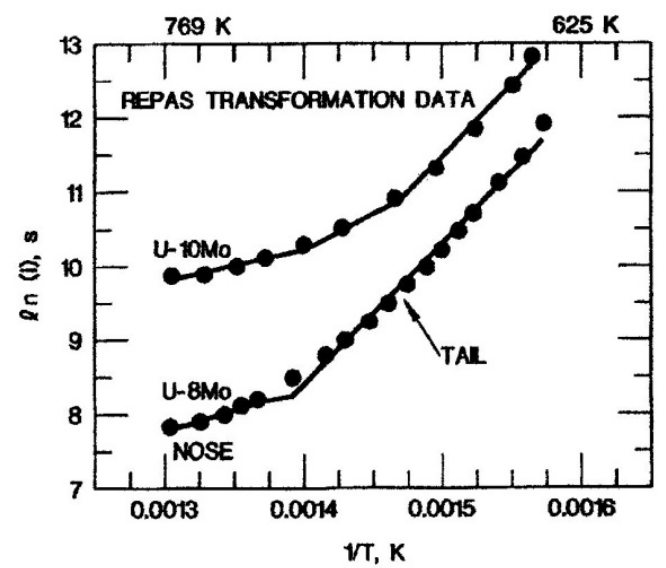

FIGURA 175 - Início da decomposição da fase $\gamma$-UMo como função da temperatura ${ }^{14}$.

Nas Tabelas 31 e 32 são fornecidos os dados das curvas de ganho de massa em função do tempo, necessários para a realização das comparações com as simulações. Exemplificar-se-á com os resultados da liga $\gamma \mathrm{U} 8 \mathrm{Mo}$. Concentrar-se-á a atenção na região de resfriamento das curvas, que se inicia usualmente a partir do ponto de máximo em absorção ao final da região de tratamento isotérmico. Aqui, $\mathrm{V}_{\mathrm{H} 2}$ refere-se à vazão de hidrogênio, indicada em mm no tubo de Brooks do analisador térmico, mas aqui corrigida 
conforme tabela do fabricante do equipamento para $\mathrm{L} / \mathrm{h}, \mathrm{p}_{\mathrm{H} 2}$ é a pressão do gás no interior da câmara, dada em bar, $\mathrm{t}_{\text {máx }}, \mathrm{T}_{\text {máx }}$ e $\mathrm{m}_{\text {máx }}$ são, respectivamente, o tempo em segundos, a temperatura em graus Celsius e variação de massa em $\mathrm{mg}$ ao final do tratamento isotérmico, $\mathrm{t}_{\mathrm{m}}, \mathrm{T}_{\mathrm{m}}$ e $\mathrm{m}_{\mathrm{m}}$ são os mesmos parâmetros, tomados nos pontos de mudança de inclinação da curva na região de resfriamento, e $m_{a m}, T_{a m}$ e $t_{a m}$ foram tomados em pontos de inclinação máxima após o ponto de mudança, também na região de resfriamento.

TABELA 31 - Parâmetros das curvas de resfriamento, liga $\gamma \mathrm{U} 8 \mathrm{Mo}$, liberação até mudança.

\begin{tabular}{|c|c|c|c|c|c|c|c|c|c|c|}
\hline liga & exp. & $\mathbf{m}_{\mathbf{i}}$ & $\mathbf{V}_{\mathbf{H} 2}$ & $\mathbf{P}_{\mathbf{H} 2}$ & $\mathbf{m}_{\text {máx }}$ & $\mathbf{t}_{\text {máx }}$ & $\mathbf{T}_{\text {máx }}$ & $\mathbf{m}_{\mathbf{m}}$ & $\mathbf{t}_{\mathbf{m}}$ & $\mathbf{T}_{\mathbf{m}}$ \\
\hline \hline $\boldsymbol{\gamma} \mathbf{U 8 M 0}$ & & & & & & & & & & \\
\hline $560 / 1$ & 0436 & 347,120 & 90 & 1,8 & 0,618 & 4775 & 560,08 & 0,443 & 6232 & 115,82 \\
\hline $570 / 2$ & 0437 & 282,738 & 90 & 1,7 & 0,924 & 8390 & 570,12 & 0,774 & 9782 & 136,93 \\
\hline $565 / 2$ & 0438 & 311,209 & 88 & 1,7 & 0,913 & 8381 & 565,23 & 0,72 & 9780 & 131,54 \\
\hline $565 / 1$ & 0439 & 304,433 & 92 & 1,7 & 0,675 & 4782 & 565,01 & 0,547 & 6203 & 126,49 \\
\hline $600 / 4$ & 0440 & 297,263 & 95 & 1,7 & 2,4378 & 15698 & 593,83 & 2,210 & 18724 & 25,73 \\
\hline $500 / 4$ & 0203 & 175,019 & 85 & 1,2 & 0,5410 & 16463 & 503,94 & 0,3660 & 17856 & 99,93 \\
\hline $560 / 2$ & 0204 & 166,752 & 77 & 1,2 & 0,3270 & 9446 & 563,02 & 0,1860 & 10819 & 139,02 \\
\hline $570 / 4$ & 0205 & 162,289 & 75 & 1,2 & 0,6779 & 16654 & 573,52 & 0,5510 & 18056 & 144,93 \\
\hline $565 / 4$ & 0206 & 178,915 & 78 & 1,25 & 0,7049 & 16643 & 568,37 & 0,5900 & 18001 & 150,87 \\
\hline $562 / 4$ & 0207 & 189,401 & 78 & 1,24 & 0,5139 & 16650 & 564,94 & 0,2980 & 18004 & 145,41 \\
\hline $1000 / 4$ & 0208 & 138,140 & 0 & 1,2 & & & & & & \\
\hline $522 / 3$ & 0209 & 186,397 & 80 & 1,28 & 0,5289 & 12931 & 525,22 & 0,4170 & 14193 & 139,21 \\
\hline $600 / 2$ & 0210 & 179,083 & 78 & 1,25 & 0,3159 & 9515 & 602,35 & 0,1869 & 10971 & 145,66 \\
\hline
\end{tabular}

TABELA 32 - Parâmetros das curvas de resfriamento, liga $\gamma U$ 8Mo, após mudança.

\begin{tabular}{|c|c|c|c|c|c|c|c|c|c|c|}
\hline liga & $\mathbf{e x p}$ & $\mathbf{m}_{\mathbf{i}}$ & $\mathbf{m}_{\mathbf{a m}}$ & $\mathbf{t}_{\mathbf{a m}}$ & $\mathbf{T}_{\mathbf{a m}}$ & $\boldsymbol{\eta ( \% )}$ & $\Delta \mathrm{m}_{1}$ & $-\Delta \mathbf{m}_{\mathbf{r}}$ & $-\Delta \mathrm{t}_{1}$ & $-\Delta \mathrm{t}_{\mathbf{r}}$ \\
\hline \hline$\gamma \mathbf{U 8 M o}$ & & & & & & & & & & \\
\hline \hline $560 / 1$ & 0436 & 347,120 & 0,471 & 6797 & 49,43 & & 0,175 & 0,028 & 1457 & 565 \\
\hline $570 / 2$ & 0437 & 282,738 & 0,895 & 10212 & 68,43 & & 0,15 & 0,121 & 1392 & 430 \\
\hline $565 / 2$ & 0438 & 311,209 & 0,891 & 10605 & 40,50 & & 0,193 & 0,171 & 1399 & 825 \\
\hline $565 / 1$ & 0439 & 304,433 & 0,615 & 6838 & 49,01 & & 0,128 & 0,068 & 1421 & 635 \\
\hline $600 / 4$ & 0440 & 297,263 & 2,210 & 19110 & 23,26 & & 0,2278 & & 3026 & 386 \\
\hline $500 / 4$ & 0203 & 175,019 & & & & 1,84 & 0,175 & & 1393 & \\
\hline $560 / 2$ & 0204 & 166,752 & 0,219 & 11040 & 96,35 & $?$ & 0,141 & 0,033 & 1373 & 221 \\
\hline $570 / 4$ & 0205 & 162,289 & 0,614 & 18297 & 97,07 & 99 & 0,1269 & 0,063 & 1402 & 241 \\
\hline $565 / 4$ & 0206 & 178,915 & 0,691 & 18267 & 96,86 & 100 & 0,1149 & 0,101 & 1358 & 266 \\
\hline $562 / 4$ & 0207 & 189,401 & 0,411 & 18252 & 96,55 & $?$ & 0,2159 & 0,113 & 1354 & 248 \\
\hline $1000 / 4$ & 0208 & 138,140 & & & & & & & & \\
\hline $522 / 3$ & 0209 & 186,397 & 0,424 & 14410 & 97,37 & 4,67 & 0,1119 & 0,007 & 1262 & 217 \\
\hline $600 / 2$ & 0210 & 179,083 & 0,198 & 11215 & 97,23 & 3,3 & 0,129 & $-0,0111$ & 1456 & 244 \\
\hline \hline
\end{tabular}

A partir das velocidades médias de liberação e reabsorção de hidrogênio, calculadas por meio das expressões:

$$
\mathrm{v}_{\mathrm{l}}=\left[\left(\mathrm{m}_{\text {máx }}-\mathrm{m}_{\mathrm{m}}\right) /\left(\mathrm{t}_{\text {máx }}-\mathrm{t}_{\mathrm{m}}\right)\right]=\Delta \mathrm{m}_{\mathrm{l}} / \Delta \mathrm{t}_{1}
$$




$$
\mathrm{v}_{\mathrm{r}}=\left[\left(\mathrm{m}_{\mathrm{m}}-\mathrm{m}_{\mathrm{am}}\right) /\left(\mathrm{t}_{\mathrm{m}}-\mathrm{t}_{\mathrm{am}}\right)\right]=\Delta \mathrm{m}_{\mathrm{r}} / \Delta \mathrm{t}_{\mathrm{r}}
$$

e mostrados nas colunas finais das Tabelas 30 e 31, é que se iniciou, de fato, a análise do equilíbrio entre as fases gama e alfa do urânio. Nestas tabelas também é apresentado o rendimento $\eta$, as diferenças de massa liberada $\Delta \mathrm{m}_{1}$ e reabsorvida $\Delta \mathrm{m}_{\mathrm{r}}$, e os intervalos de tempo entre os eventos de perda $\Delta \mathrm{t}_{1}$ e reabsorção de massa, $\Delta \mathrm{t}_{\mathrm{r}}$.

Torna-se óbvio, então, que se a reação de decomposição em função da temperatura toma a forma da curva em C dos diagramas TTT, a absorção de hidrogênio pelas ligas, via hidretação da fase alfa intergranular, também deve acompanhar este perfil. Sabendo-se então que tanto maior é a quantidade de fase alfa quanto mais próximas à temperatura de máxima decomposição forem realizados os tratamentos, mais facilmente a liga torna-se frágil, pelo mecanismo de precipitação intergranular, resistindo menos ao choque térmico, que a leva a romper-se em temperaturas mais próximas à do tratamento, quando de seu resfriamento.

Explica-se assim a forma das curvas em C, apresentadas na Figura 162, em termos de $\Delta$ Te em função das temperaturas de tratamento. 
CONCLUSÕES 
Conforme os objetivos propostos, as conclusões principais desta tese estão apresentadas abaixo.

\section{C.0 Fusão a Arco x Indução}

Conforme mencionado, conclui-se favoravelmente ao uso de indução como método de fabricação das ligas urânio-molibdênio, para uso como combustível nuclear. Entretanto, foi ressaltado que para ligas contendo baixa concentração de molibdênio, nas quais o problema de homogeneidade não é tão sério, a fusão a arco pode ser utilizada, condicionada à aplicação de um número adequado de refusões. Deve-se salientar que estamos trabalhando com forno a arco de eletrodo não consumível, mais restritivo quanto à obtenção de produtos homogêneos. A utilização de eletrodo consumível pode minimizar o problema.

Esta tese evidenciou um fato importante relativo ás técnicas de fabricação das ligas $\gamma$ UMo. As ligas de arco mostraram, em todas as composições, várias estruturas dendríticas, que são regiões de baixa concentração de molibdênio, constituídas principalmente pela fase alfa. Isto conduz, necessariamente, aos tratamentos térmicos de homogeneização. Contudo, estes em alguns casos não foram suficientes para eliminar totalmente as estruturas de segregação ou dendríticas, conduzindo a diferenças de composição no interior dos grãos, atestada pelas variações nas medidas de dureza das amostras. Esta pode ser uma vantagem sob o ponto de vista da produção dos pós, mas a um custo da perda de homogeneidade.

Para preservar a homogeneidade estrutural das peças fundidas, o processo de fusão por indução é considerado aqui o candidato mais satisfatório par a produção do combustível, fornecendo matéria-prima homogênea para o próximo passo de hidretaçãodehidretação na obtenção de pós com alta concentração da fase gama.

\section{C.1. Adsorção de hidrogênio e estabilidade $\gamma \rightarrow \alpha$}

Não se levando em consideração os tratamentos de dehidretação aplicados por vários autores sobre a HDH de ligas $\gamma$-UMo para a produção de pós, principalmente nas composições de 5 a 7\% em peso de Mo, a ênfase aqui foi dada aos tratamentos isotérmicos sob hidrogênio. Sem sombra de dúvidas, a dehidretação é muito importante de modo a recuperar a composição da matriz, que pode estar livre de hidrogênio, mas não é essencial para a fragmentação das ligas, como foi aqui demonstrado. 
A conversão da estrutura gama em alfa é mencionada na literatura como prérequisito para a obtenção de bons rendimentos em ligas contendo $7 \%$ ou menos de Mo. O que foi demonstrado aqui é que, utilizando um conjunto conveniente de parâmetros, a fragmentação pode ser obtida mesmo em ligas com teor maior do que $8 \%$ em peso de Mo, embora em condições mais restritas de temperatura, principalmente nas próximas ou logo acima da temperatura de transformação eutetóide, Te. Tratamentos isotérmicos em temperaturas bem acima da Te foram também aplicados, levando a baixos rendimentos, mas oferecendo a possibilidade de obtenção de pós com alto conteúdo em gama.

Como alfa é formada na liga bruta de fusão, como precipitados intergranulares, o que se espera com os tratamentos isotérmicos no campo de alfa mais gama é que uma maior quantidade de fase alfa se precipite. Como o tempo atua favoravelmente à difusão, que tende a homogeneizar a composição reduzindo a microssegregação e superfícies internas, e a precipitação é um fenômeno que é favorecido por estes defeitos superficiais, chega-se à conclusão de que pré-tratamentos a $150^{\circ} \mathrm{C}$ ou $250^{\circ} \mathrm{C}$ são questionáveis, na faixa de adições de molibdênio menores do que $8 \%$, devido aos bons rendimentos obtidos nesta tese.

Assim, em termos do equilíbrio entre as fases gama e alfa, foi determinado que os maiores rendimentos e, portanto, a maior proximidade da temperatura de decomposição máxima da liga $\gamma \mathrm{U} 8 \mathrm{M}$ Mo pode ser obtida quando do tratamento a $568,39^{\circ} \mathrm{C}$, sendo também fácil a produção de fragmentos nesta temperatura. Como este é um ponto de máxima decomposição, é também onde ocorre o maior rendimento, dada a maior quantidade de fase alfa produzida.

Ao se inverter os eixos das curvas da figura 160, obtém-se gráfico muito semelhante a um TTT, o que demonstra a sua relação com as propriedades de equilíbrio das ligas $\gamma \mathrm{UMo}$. Assim, pode-se associá-la teoricamente às equações apresentadas no capítulo 7 para a nucleação da fase alfa, que apresentam também o mesmo aspecto.

Considerando-se a absorção como devida à presença de alfa urânio somente, por partir-se da hipótese de que a absorção devida a solubilização do hidrogênio na estrutura da liga seja linear, pode ser feita uma correlação direta entre a produção de alfa e a incorporação de hidrogênio.

\section{C.2 Processo Alternativo Hidretação-Dehidretação}

O processo aqui desenvolvido pode ser descrito resumidamente como segue. Após a produção da liga e realização dos tratamentos térmicos de homogeneização, 
procede-se a um tratamento térmico conveniente, já sob atmosfera de hidrogênio, para a precipitação de fase proeutetóide, que se deposita usualmente em contornos de grão, e que reage com o hidrogênio à medida que vai sendo formada, por decomposição eutetóide. As temperaturas utilizadas estão associadas aos diagramas de tempo-temperaturatransformação, onde é máxima a taxa de decomposição eutetóide, e variam para cada sistema metálico em particular. Os tempos de exposição são definidos pelas quantidades de liga a serem hidretadas. Assim, tem-se, ao contrário das publicações existentes, produção de proeutetóide e reação de hidretação, simultâneas, além da solubilização de hidrogênio na rede do próprio metal ou liga. A este processo dá-se o nome de hidrogenação, pois o segundo não se refere à reação química de hidretação.

Ao final da hidrogenação, a liga é resfriada a uma velocidade conveniente, de modo a se produzir, em um determinado instante, a fragmentação inicial da liga. Diz-se fragmentação inicial pois foi observado, em alguns casos, que a fragmentação ocorre em vários estágios de adsorção e dessorção de hidrogênio. Observa-se assim, pela posição dos picos de inversão, na região de resfriamento, entre dessorção e reabsorção de hidrogênio, que a quantidade de hidrogênio absorvida pela liga foi suficiente para a quebra total da estrutura. Recomenda-se, especialmente para ligas contendo pouca quantidade de fase proeutetóide com alta afinidade pelo hidrogênio, que este ciclo se repita algumas vezes, até que se produza a quantidade necessária de pó. No caso de ligas UMo, isto é recomendado em porcentagens de 9 a $10 \%$ em peso de soluto.

Para que se recupere a homogeneidade da liga original, agora prejudicada pelos tratamentos térmicos efetuados durante as etapas de hidrogenação-deshidrogenação e dehidretração, um novo tratamento térmico é necessário, agora sob atmosfera inerte, nos campos onde a fase que se deseja estabilizar é a preponderante. Como exemplo, em ligas de U-Mo, $850^{\circ} \mathrm{C}$ a $900^{\circ} \mathrm{C}$ são as temperaturas usuais de tratamento de recuperação ou reconversão. Os tempos de exposição são usualmente calculados em função da quantidade de liga a ser tratada, perfis térmicos dos fornos, e outros parâmetros.

O pó assim formado deve ser retirado do forno. Para se evitar a sua oxidação, passiva-se os mesmos expondo-os a pequeno fluxo de ar. Como a fase proeutetóide formada tem dimensões muito menores que a da fase matriz ou desejada, procede-se então a um peneiramento para a sua separação. O pó assim obtido está pronto para uso.

Em adição, notou-se a importância do preparo prévio da superfície, para obtenção de maiores rendimentos em escalas maiores. Embora de espessura muito fina, e levando-se em conta que o hidrogênio é um redutor, reações de hidrogênio com óxido 
podem levar à formação de água, que por sua vez, caso as temperaturas de processo assim o permitam, pode passivar novamente a superfície da liga.

\section{C.3. Combustível Alternativo de Alta Densidade}

A liga de urânio-molibdênio silício aqui estudada comportou-se melhor que os binários $\gamma \mathrm{UMo}$ frente ao oxigênio, incorporando menos massa, e oxidando-se à temperatura semelhante. Isto pode ser explicado pela maior presença de fase intermetálica UMoSi ou de composto $\mathrm{U}_{3} \mathrm{Si}$ ou $\mathrm{U}_{3} \mathrm{Si}_{2}$, presentes na mistura. O estudo de oxidação é importante, pois nos dá uma noção sobre a estabilidade química da liga, que será utilizada em condições nas quais, possivelmente e em caso de falhas, poderá interagir com o oxigênio.

A estabilidade frente ao alumínio é comparável à de uma liga a 7\% de Mo, há a formação instantânea de camada de reação assim como em todas as outras composições, a aproximadamente $720^{\circ} \mathrm{C}$, valor médio. A reação para o material UMoSi ocorre a $680^{\circ} \mathrm{C}$, indicando que a adição de silício promove a reação com o alumínio. Entretanto um novo produto entre 860 e $890^{\circ} \mathrm{C}$ não foi observado em UMoSi. Como estas condições estão bem acima das que se utilizam em reatores nucleares, poder-se-ía não se preocupar, caso haja a presença de produtos. Mas em termos de estabilização observa-se, entretanto, que a reação de formação deste produto, provavelmente devida ao siliceto ali presente, cessa a formação de mais produtos.

Deve-se levar em conta que um dos maiores problemas do RERTR está relacionado não somente à formação da camada de reação, mas também com a sua estabilidade. Assim, o fato de que não há formação posterior de produtos, ao contrário das demais ligas binárias $\gamma \mathrm{UMo}$, indica que a camada ou produto formado após esta primeira reação é estável, não sofrendo a ação subseqüente do Al. O fato importante a ser aqui mencionado é que os trabalhos RERTR que tratam da adição de silício não fazem referência a espectros de difração ou outras estruturas encontradas neste sistema. Sabendose que a solubilidade de silício em urânio gama máxima é de $0,5 \%$, trabalhos que se referem a UMoSi, com adições superiores a este valor, como ligas, tornam-se um tanto quanto duvidosos. Este não é o caso, por exemplo, quando alguns autores referem-se aos sistemas UMoZr, UMoTi, UMoNb, dada a elevada solubilidade dos elementos ternários em gama urânio, conforme se conclui do exame dos diagramas de fases binários.

Assim, conforme os ensaios de caracterização, espera-se que a estabilização se dê pela combinação de propriedades destes dois sistemas de urânio, USi e UMo. Em 
termos de processos de fabricação de pós, dadas as diferenças de dureza das fases presentes nas ligas ternárias frente às binárias, espera-se que os métodos tradicionais de mecanização e também o processo de hidretação possam ser utilizados com rendimentos elevados, sem tanto consumo de energia. Caso haja a necessidade do controle do tamanho de partículas da fase UMo, pode-se proceder a um tratamento de hidretação, nos moldes aqui desenvolvidos.

É importante ter-se em mente que as adições de silício devem ser feitas de maneira a estabilizar a estrutura gama, conforme comparação da Figura $82 \mathrm{com}$ as demais, e a permitir quantidade suficiente de fase intergranular na amostra de modo a facilitar processos de obtenção dos pós.

Resumindo, temos:

- C.0 Fusão a Arco x Indução ligas $\gamma$ UMo

- Para preservar a homogeneidade estrutural das peças fundidas, o processo de fusão por indução é considerado aqui o candidato mais satisfatório par a produção do combustível, fornecendo matéria-prima homogênea para o próximo passo de hidretação-dehidretação na obtenção de pós com alta concentração da fase gama.

- Entretanto, para ligas contendo baixa concentração de molibdênio, onde o problema de homogeneidade não é tão sério, a fusão a arco pode ser utilizada, condicionada à aplicação de um número adequado de refusões.

- C.1. Absorção de hidrogênio e estabilidade $\gamma$ UMo

- Foi determinado que os maiores rendimentos são obtidos em temperaturas próximas à da máxima decomposição. Para a liga $\gamma \mathrm{U} 8 \mathrm{Mo}$, esta temperatura é igual a $568,39^{\circ} \mathrm{C} \rightarrow$ maior quantidade de fase alfa produzida.

- Curvas de absorção são muito semelhante a um TTT, o que demonstra a sua relação com as propriedades de equilíbrio das ligas $\gamma \mathrm{UMo}$. 
- C.2 Processo Alternativo Hidretação-Dehidretação $\gamma$ UMo

- Hidrogenação já é, na maioria das composições estudadas, suficiente para a produção de fragmentos.

- $\mathrm{DH}$, choque térmico e tratamentos de sensibilização facilitam a produção de pós.

- C.3. Compatibilidade x Combustíveis $\gamma$ UMo e $\gamma$ UMoxSi

- Evidenciou-se que Mo promove a reação com Al, Si a inibe. Oxidação ocorre a porcentagens menores de Mo, evidenciando o papel da fase alfa presente no sistema.

- Problemas de processamento, especialmente quando utilizamos as técnicas de mecanização e HDH para a fabricação dos pós, podem ser resolvidos por meio do estudo do papel das adições ternárias. Elementos como o Si podem atuar tanto como estabilizadores da fase gama, formadores de fase frágil nos contornos de grão, facilitando a quebra e produção dos pós.

- Resolve-se assim vários problemas de fabricação, com a elaboração de ligas adequadas $\rightarrow$ engenharia de materiais $\rightarrow$ combustíveis inteligentes. 


\section{REFERÊNCIAS BIBLIOGRÁFICAS}

01 OLIVEIRA, F.B.V., Development of High Density Fuel Based on LEU U-Mo Alloys, Projeto de Cooperação Técnica e em Pesquisa entre Brasil e Agência Internacional de Energia Atômica AIEA, n ${ }^{\circ}$ BRA 4053, Abril de 2002.

HOFMAN, G.L., et al., US Patent no. 7100670, 5 de setembro de 2006.

03 HOFMAN G.L., A Short Note on High Density Fuels, ANL Bulletin, Argonne, Illinois, June 1996. Alloys, Addison-Wesley Publishing Company, Inc., Massachussets, USA, 1951.

05 SALLER, H.A., ROUGH, F.A., VAUGHAN, D.A., The Constitution Diagram of. Uranium-Rich Uranium-Molybdenum Alloys, BMI-72, Battelle Memorial Institute, june $1,1951$.

06 AHMAN, D., SNOW, A.I., WILSON, A.S., The Uranium-Molybdenum Binary System, CT-2946, July, 1945. Molybdenum Alloys, Transactions of the ASM, v.49, 1957, pp.598-621.

08 GOSLDSTEIN, Y., BAR-OR, A., Decomposition of Gamma-Phase in Uranium Alloys Containing 8, 10.8 and $14.3 \mathrm{wt} \%$ Molybdenum, Journal of the Institute of Metals, v.95, 1967, pp.17-21.

09 LEHMANN, J., Processus des Transformations dans les Alliages UraniumMolybdene de Faibles Teneurs en Molybdene, Journal of Nuclear Materials, v.2, $\mathrm{n}^{\mathrm{o}} .2,1960, \mathrm{pp} .152-168$.

10 BEGHI, G., Gamma Phase Uranium-Molybdenum Alloys, Euratom Document EUR $4053 e, 1968$.

11 KONOBEVSKY, S.T., Décima Segunda Conferência de Genebra, 1958.

12 LEHMAN, J., Phases Monocliniques dans les Alliages Uranium-Molybdene, Journal of Nuclear Materials, v.4, $\mathrm{n}^{\circ} .2,1961, \mathrm{pp} .218-225$.

13 CABANÉ, G., DONZÉ, G., Stabilisation de la Phase $\gamma$ dans les Alliages Ternaires a Base d'Uranium Molybdene, Journal of Nuclear Materials, v.4, 1959, pp.364-373. 
14 HOFMAN, G.L., MEYER, M.K., RAY, A., Design of High Density Gamma-Phase Uranium Alloys for LEU Dispersion Fuel Applications, Proceedings of the RERTR Meeting, São Paulo, October 1998.

15 PARK, J.M., et al., Interdiffusion Behaviors of. U-Mo-Zr / Al-Si, Proceedings of the XXVIII RERTR Meeting, Cape Town, South Africa, 2006.

16 VAN THYNE, R.J., McPHERSON, D.J., Transformation Kinetics of UraniumNiobium and Ternary Uranium-Molybdenum Base Alloys, Transactions of the $\boldsymbol{A S M}$, v.49, 1957, pp.576-597.

17 REPAS, P.E., et al., Transformation Characteristics of U-Mo and U-Mo-Ti Alloys, Transactions of the ASM, v.57, 1964, pp.150-163.

18 PARK, J.M., et al., Interdiffusion Behaviors of. U-Mo-Ti / Al-Si, Proceedings of the XXIX RERTR Meeting, Prague, Czech Republic, 2007.

19 PASQUALINI, E.E., Advances and Perspectives in U-Mo Monolithic and Dispersed Fuels, Proceedings of the XXVIII International Meeting on Reduced Enrichment of Research and Test Reactors, Cape Town, South Africa, 2006.

20 DUBOIS, H., et al., Development of UMo/Al Dispersion Fuel: an Oxide Layer as a Protective Barrier Around the UMo Particles, Proceedings of the XXVIII International Meeting on Reduced Enrichment of Research and Test Reactors, Cape Town, South Africa, 2006.

21 VARELA, C. L. K., et al., Identification of. Phases in the Interaction Layer Between U-Mo-Zr / Al and U-Mo-Zr / Al-Si, Proceedings of the XXIX RERTR Meeting, Prague, Czech Republic, 2007.

22 KIM, Y.S., et al., Interaction-Layer Growth Correlation for (U-Mo) / Al and Si added (U-Mo) / al Dispersion Fuels, Proceedings of the XXVIII RERTR Meeting, Cape Town, South Africa, 2006.

23 KIM, K.-H. et al., An Investigation on the Fuel-Matrix Reaction Behavior of U$\mathrm{Mo} / \mathrm{Al}$ Dispersion Fuels Prepared with Centrifugal Atomization, Proceedings of the RERTR Meeting, Las Vegas, Nevada, March 2000.

24 LEE, S.-H. et al., An Investigation of the Thermophysical Properties of U-Mo Dispersion Fuel Meats, Proceedings of the RERTR Meeting, Las Vegas, Nevada, March 2000. 
Fuel: Fuel Performance Data from RERTR-1 and RERTR-2, Proceedings of the XXII RERTR Meeting, Budapest, Hungary, 1999.

26 KIM, K-H., et al., Stable in-Reactor Performances at Low Temperature of U-10\%wt Mo Dispersion Fuel Containing Centrifugally Atomized Powder, Proceedings of the XXII RERTR Meeting, Budapest, Hungria, 1999.

27 HOFMAN, G.L., et al., Initial Assessment of Radiation Behavior of Very-High Density Low-Enriched-Uranium Fuels, Proceedings of the XXII RERTR Meeting, Budapest, Hungria, 1999.

28 MEYER, M.K., et al., Metallographic Analysis of Irradiated RERTR-3 Fuel Test Specimens, Proceedings of the XXIII RERTR Meeting, Las Vegas, Nevada, 2000.

29 HOFMAN, G.L., et al, Observations on the Irradiation Behavior of U-Mo Alloys Dispersion Fuel, Proceedings of the XXIII RERTR Meeting, Las Vegas, Nevada, 2000.

30 LEE, S.-H. et al., An Investigation of the Thermophysical Properties of U-Mo Dispersion Fuel Meats, Proceedings of the XXIII RERTR Meeting, Las Vegas, Nevada, March 2000.

31 HOFMAN, G.L., MEYER, M.K., Progress in Irradiation Performance of Experimental Uranium-Molybdenum Dispersion Fuel, Proceedings of the XXIV RERTR Meeting, San Carlos de Bariloche, Argentina, Novembro 2002.

32 WACHS, D.M., et al., Design and Status of RERTR Irradiation Tests in the Advanced Test Reactor, XXVIII International Meeting on Reduced Enrichment for research and Test reactors, Cape Town, South Africa, November 2006.

33 FINLAY, M.R., et al., Post Irradiation Examination of Monolithic Mini Fuel Plates from RERTR-6, XXVIII International Meeting on Reduced Enrichment for Research and Test Reactors, Cape Town, South Africa, November 2006.

34 HOFMAN, G.L., et al., Results of Low Enriched U-Mo Dispersion Fuel Miniplates from Irradiation Test, RERTR-6, XXVIII International Meeting on Reduced Enrichment for Research and Test Reactors, Cape Town, South Africa, November 2006.

35 RYU, H.J., et al., Characterization of the Interaction products in U-Mo / Al Dispersion Fuel from in-pile and Out-of-pile Tests, XXVIII International Meeting on Reduced Enrichment for Research and Test Reactors, Cape Town, South Africa, November 2006.

36 KEYSER et al., op.cit. em RYU, H.J., et al, Characterization of the Interaction 
products in U-Mo / Al Dispersion Fuel from in-pile and Out-of-pile Tests, $\boldsymbol{X X \boldsymbol { V I I I }}$ International Meeting on Reduced Enrichment for Research and Test Reactors, Cape Town, South Africa, November 2006.

REST, J., HOFMAN, G.L., KONOVALOV, I., MASLOV, A., Experimental and Calculated Swelling Behavior of U-10Mo wt \% under Low Irradiation Temperatures, Proceedings of the RERTR Meeting, São Paulo, Brazil, October 1998.

38 SZIMANN, R., The Effect of Radiation upon Diffusion in Metals, Journal of Nuclear Materials, v.69 (1970), pp. 386-412.

39 BLAISLFORD, A.D., BULLOUGH, R., Void Growth and its Relation to Intrinsic Point Defect Properties, Journal of Nuclear Materials, v.69(1978), pp.434-450.

REST, J., HOFMAN, G.L., DART Model for Irradiation-Induced Swelling of Uranium Silicide Dispersion Fuel Elements, Nuclear Technology, v.126, 1999, pp. 88-101.

41 KONOVALOV, I., Basic Properties of Fuels Determining its Behavior Under Irradiation, Proceedings of the RERTR Meeting, Las Vegas, Nevada, March 2000. U Alloys, Proceedings of the RERTR Meeting, São Paulo, Brazil, March 2000.

43 REST, J., The DART Dispersion Analysis Research Tool: A Mechanistic Model for Predicting Fission-Product-Induced Swelling of Aluminum Dispersion Fuels, Argonne National Laboratory Report no. ANL-95/36, August, 1995.

44 CLARK, C.R., MEYER, M.K., STRAUSS, J.T., Fuel Powder Production from Ductile Uranium Alloys, Proceedings of the RERTR Meeting, São Paulo, Brazil, October 1998.

WIENCEK, T., PROKOFIEV, L.G., Low-Enriched Uranium-Molibdenum Fuel Plate Development, Proceedings of the RERTR Meeting, Las Vegas, Nevada, March 2000.

46 BALART, S. et al., U-Mo Alloy Powder Obtained by a Hydride-Dehydride Process, Proceedings of the RERTR Meeting, Las Vegas, Nevada, March 2000. Chicago, USA, October 2004. 
PASQUALINI, E.E., LÓPEZ, M., GARCÍA, L. J. H., ECHENIQUE, P., ADELFANG, P., Scaling up the Production Capacity of U-Mo Powder by HMD Process, Proceedings of the XXIVRERTR Meeting, San Carlos de Bariloche, Argentina, Novembro 2002.

BALART, S., Proceedings of the RERTR Meeting, 2004.

51 BALART, S., BRUZZONI, P., GRANOVSKY, M.S., U-Mo Alloy Powder Obtained Through Selective Hydriding, Particle Size Control, Proceedings of the XXIV RERTR Meeting, San Carlos de Bariloche, Argentina, Novembro 2002.

OLIVEIRA, F.B.V., RIELLA, H.G., Transactions of the European Nuclear Conference ENC 2007, Brussels, Belgium, 2007, pp. 99-104.

53 MARTORANO, M.A., CAPOCCHI, J.D.T., Microssegregação em Ligas Metálicas Binárias, Boletim Técnico da Escola Politécnica da USP / Departamento de Engenharia Metalúrgica e de Materiais, BT/PMP/003, 2000.

54 OLIVEIRA, F.B.V., et al., Powder Formation of $\gamma$ UMo Alloys Via HydrationDehydration, Proceedings of the XXIX International Meeting on the Reduced Enrichment of Research and Test Reactors, Prague, Czech Republic, September 2007.

55 PERRY, R., GREEN, D.W., Chemical Engineer's Handbook, McGraw-Hill, 7.ed., 1997.

56 TRYBUS, C.L., et al., Design and Fabrication of High Density Uranium Dispersion Fuels, Proceedings of the RERTR Meeting, São Paulo, October 1998.

58 MIEDEMA, A.R., The Electronegativity Parameter for Transition Metals: Heat of Formation and Charge Transfer in Alloys, Journal of The Less-Common Metals, v.32(1973), pp.117-136.

59 MIEDEMA, A.R., BOOM, R., DE BOER, F.R., On the Heat of Formation of Solid Alloys, Journal of The Less-Common Metals, v.41 (1975), pp.283-298.

60 HAFNER, J., et al., The Structure of Binary Compounds, North Holland, Inc., Amsterdan, 1.ed., 1989.

61 HOFMAN, G.L., comunicação pessoal. 
62 RODRIGUES, J.A., Fundamentos da Reação Metal-Gás, em MIRANDA, P.E.V, RODRIGUES, J.A., Gases em Metais e Ligas, editado pelo Núcleo de Publicações da COPPE, Rio de Janeiro, 1994, pp.3-73.

63 LEVENSPIEL, O., Engenharia das Reações Químicas, vol.2, São Paulo, Edgard Blucher, 1984.

64 FAST, J.D., Gases in Metals, MacMillan Press, Londres, 1971.

65 FUKAI, Y., The Metal-Hydrogen System, vol. 21 em Springer Series in Materials Science, Springer-Verlag, 1993.

66 BLACKLEDGE, LIBOWITZ, Metal Hydrides, Pergamon - Press, Nova Yorque, 2 ed., 1965.

67 WALDRON, M.B., BURNETT, R.C., POUGH, S.F., The Mechanical Properties of Uranium-Molybdenum Alloys, AERE-M/R Report 2554, 1958.

68 POWELL, Internal Hydrogen Embrittlement of Gamma Stabilized Uranium Alloys, Corrosion, v.32 (1), novembro 1956, pp.442-456.

69 McGEARY, USAEC report WAPD-127-I, 1955.

70 SALLER, H.A., DICKERSON, R.F., HURR, W.E., Uranium Alloys for High Temperature Applications, relatório BMI-1098, 1956. 